RUBENS TADASHI FURUSAWA

\title{
CONTRIBUIÇÃO AO DIMENSIONAMENTO DE REDE DE DISTRIBUIÇÃO DE ÁGUA POR CRITÉRIO DE CUSTO GLOBAL
}


RUBENS TADASHI FURUSAWA

\section{CONTRIBUIÇÃO AO DIMENSIONAMENTO DE REDE DE DISTRIBUIÇÃO DE ÁGUA POR CRITÉRIO DE CUSTO GLOBAL}

Dissertação apresentada à Escola Politécnica da Universidade de São Paulo para obtenção do título de mestre em Engenharia Civil

Área de Concentração:

Engenharia Hidráulica

Orientador:

Prof. Dr. José Rodolfo Scarati Martins 
Este exemplar foi revisado e alterado em relação à versão original, sob responsabilidade única do autor e com a anuência de seu orientador.

São Paulo, 04 de julho de 2011.

Assinatura do autor

Assinatura do orientador

FICHA CATALOGRÁFICA

Furusawa, Rubens Tadashi

Contribuição ao dimensionamento de rede de distribuição de água por critério de custo global /Ferreira / R.T. Furusawa. -ed.rev. -- São Paulo, 2011.

$207 \mathrm{p}$.

Dissertação (Mestrado) - Escola Politécnica da Universidade de São Paulo. Departamento de Engenharia Hidráulica e Sanitária.

1. Redes de distribuição de água 2. Otimização global I. Universidade de São Paulo. Escola Politécnica. Departamento de Engenharia Hidráulica e Sanitária II. t. 


\section{DEDICATÓRIA}

Ao meu pai, Toshio Furusawa (em memória), a minha mãe, Hiromi Furusawa e a minha esposa, Isabel Cristina Furusawa. 


\section{AGRADECIMENTOS}

Ao bom Deus que me deu a oportunidade de chegar até aqui e por colocar as pessoas certas na minha vida.

Ao meu orientador Prof. Dr. José Rodolfo Scarati Martins pela forma de me conduzir durante o desenvolvimento desse trabalho, pelos ensinamentos transmitidos, pela sua paciência e por acreditar no meu potencial até nos momentos mais difíceis, além da oportunidade em complementar o seu trabalho na área do dimensionamento econômico.

A Escola Politécnica da Universidade de São Paulo, grande responsável no meu desenvolvimento acadêmico. Em especial a todos os integrantes do Departamento de Hidráulica e Ambiental (PHD).

A Beatriz Vilella Benitez Codas, José Orlando Paludetto Silva e Ricardo Lazzari Mendes, pelo incentivo e por compartilhar conhecimentos técnicos e profissionais.

A todas as pessoas que colaboraram ao longo deste trabalho e da minha vida. 


\section{RESUMO}

Este trabalho apresenta o dimensionamento otimizado de redes pressurizadas de distribuição de água em regime permanente para áreas de topografia relativamente plana. Além dos critérios tradicionais de dimensionamento hidráulico, o resultado ótimo é aquele com menor custo global, ou seja, onde a soma dos custos de implantação e de operação é mínimo. Para a determinação dos resultados, as equações que envolvem a perda de carga nos circuitos e vazões em cada nó foram solucionadas através da programação não linear com emprego de métodos matriciais. As principais variáveis analisadas foram os diferentes materiais das tubulações (PEAD, PVC e Ferro Fundido), tipos de superfície (terra, concreto, paralelepípedo e asfalto), locação da rede (passeio, viário pavimentado e sem pavimentação), tarifas de energia elétrica para concessionárias de água, vida útil usuais para o sistema de bombeamento e taxa de juros ao longo da operação do sistema. Os resultados obtidos através da metodologia proposta demonstraram que as principais variáveis em relação ao custo referencial unitário foram o custo da pressurização inicial, custo da tubulação, além do custo de remoção e recomposição de viário em pavimento asfáltico.

Palavras-chave: Redes de distribuição de água. Otimização Global. 


\begin{abstract}
This work presents the optimal design of pressurized networks of water distribution in steady state flow to areas of relatively flat topography. In addition to the traditional hydraulic criteria for design, the optimal outcome is that with lower overall cost, in other words, where the sum of the costs of implementation and operation is minimal. To obtain the results, the equations that involving headloss in the circuits and flows at each node were solved by nonlinear programming with the use of matrix methods. The main variables studied were the different materials of pipes (HDPE, PVC and Cast Iron), surface types (clay, concrete and asphalt paving), network location (walk, paved and unpaved road), electricity tariffs for water utilities, normal life for the pumping system and interest rates along the system operation. The results obtained by the proposed methodology showed that the main variables in relation to the unit cost were the cost of initial pressurization, cost of the pipe, besides the cost of removal and restoration of roads in asphalt pavement.
\end{abstract}

Key words: Water distribution networks. Global Optimization. 


\section{LISTA DE FIGURAS}

Figura 4.1 - Mapa do índice de atendimento total de água dos participantes do SNIS em 2008. .7

Figura 4.2 - Esquema de rede de distribuição do ramificada. 13

Figura 4.3 - Esquema de rede de distribuição em malha. 14

Figura 4.4 - Variação do perfil de consumo em função do dia da semana para o setor Itaim Paulista, predominantemente residencial. 15

Figura 4.5 - Variação do perfil de consumo em função do dia da semana para o setor Avenida, com ocupação comercial significativa.

Figura 4.6 - Curvas de Frequência de Excedência de $K_{1}$ para o SAM de São Paulo.

Figura 4.7 - Curvas de Frequência de Excedência de $K_{2}$ para o SAM de São Paulo. .22

Figura 4.8 - Perfis de Consumo para os 22 setores da RMSP. 24

Figura 4.9 - Limites de Vazões conforme NBR 12118. 27

Figura 4.10 - Comparação das Vazões Máximas por Porto, Martins e NBR 12218.28

Figura 4.11 - Diagrama de Rouse .36

Figura 4.12 - Diagrama de Moody 37

Figura 4.13 - Diagrama obtido com a Equação 4.12 38

Figura 5.1 - Faixa a recapear devido à abertura de vala contínua conforme IR-001 da SIURB .58

Figura 5.2 - Seção do Tipo 1 para tráfego leve conforme IR-001 da SIURB. 59

Figura 5.3 - Seção do Tipo 2 para tráfego médio conforme IR-001 da SIURB... .59

Figura 5.4 - Seção do Tipo 4 para tráfego pesado conforme IR-001 da SIURB...... 59

Figura 5.5 - Gráfico do custo de assentamento de tubulação de PVC em função do diâmetro 62

Figura 5.6 - Gráfico do custo de assentamento de tubulação de PEAD em função do diâmetro 
Figura 5.7 - Gráfico do custo de assentamento de tubulação de Ferro Fundido em função do diâmetro.

Figura 5.8 - Gráfico do custo da tubulação de PVC em relação ao diâmetro 67

Figura 5.9 - Gráfico do custo da tubulação de PEAD em relação ao diâmetro.

Figura 5.10 - Gráfico do custo da tubulação de Ferro Fundido em relação ao diâmetro 68

Figura 6.1 - Características da área de estudo no litoral de São Paulo. .78

Figura 6.2 - Esquema Hidráulico da área de estudo no litoral de São Paulo 78

Figura 6.3 - Composição de Custos de Rede Otimizada por Tipo de Pavimento PVC

Figura 6.4 - Composição de Custos de Rede Otimizada por Tipo de Pavimento PEAD 83

Figura 6.5 - Composição de Custos de Rede Otimizada por Tipo de Pavimento FoFo

Figura 6.6 - Comparação de Custo Referencial Unitário de Rede Otimizada por Tipo de Pavimento

Figura 6.7 - Composição de Custos de Rede Otimizada por Tarifa de Energia para Viário em Paralelepípedo - PVC.

Figura 6.8 - Composição de Custos de Rede Otimizada por Tarifa de Energia para Viário em Paralelepípedo - FoFo 88

Figura 6.9 - Comparação de Custo Referencial Unitário de Rede Otimizada por Tarifa de Energia para Viário em Paralelepípedo. .89

Figura 6.10 - Composição de Custos de Rede Otimizada por Taxa de Juros Anual para Viário em Paralelepípedo - PVC

Figura 6.11 - Composição de Custos de Rede Otimizada por Taxa de Juros Anual para Viário em Paralelepípedo - FoFo .92

Figura 6.12 - Comparação Comparação de Custo Referencial Unitário de Rede Otimizada por Juros para Viário em Paralelepípedo..... .93 
Figura 6.13 - Composição de Custos de Rede Otimizada pela Vida Útil para Viário em Paralelepípedo - PVC

Figura 6.14 - Composição de Custos de Rede Otimizada por Taxa de Juros Anual para Viário em Paralelepípedo - FoFo .96

Figura 6.15 - Comparação de Custo Referencial Unitário de Rede Otimizada pela Vida Útil para Viário em Paralelepípedo.

Figura 6.16 - Composição de Custos de Rede Otimizada por Aumento do Custo da Tubulação para Viário em Paralelepípedo - PVC 100

Figura 6.17 - Comparação de Custo Referencial Unitário de Rede Otimizada pelo Aumento de Custo da Tubulação de PVC para Viário em Paralelepípedo 101 


\section{LISTA DE TABELAS}

Tabela 4.1 - Caracterização global dos sistemas de água dos prestadores de serviços participantes do SNIS em 2008.

Tabela 4.2 - Níveis de atendimento de água dos prestadores de serviços participantes do SNIS em 2008, segundo região geográfica

Tabela 4.3 - Indicadores de Custo do sistema convencional de abastecimento de água - SABESP - 1998

Tabela 4.4 - Informações gerais sobre tipo de tubulações 11

Tabela 4.5 - Valores do consumo médio per capita de água no Brasil - SNIS - 2008

Tabela 4.6 - Valores recomendados para o coeficiente $\mathrm{K}_{1}$

Tabela 4.7 - Análise de risco na utilização dos valores de $\mathrm{K}_{1}$ de 1,2 para a RMSP .21

Tabela 4.8 - Valores recomendados para o coeficiente $\mathrm{K}_{2}$.

Tabela 4.9 - Análise de risco na utilização dos valores de $K_{2}$ de 1,5 para a RMSP.23

Tabela 4.10 - Velocidades Máximas Usuais. .26

Tabela 4.11 - Vazões Mínimas e Máximas conforme NBR 12118 27

Tabela 4.12 - Vazões Máximas conforme Martins (1976) …………………........28

Tabela 5.1 - Recobrimento das Tubulações ......................................................57

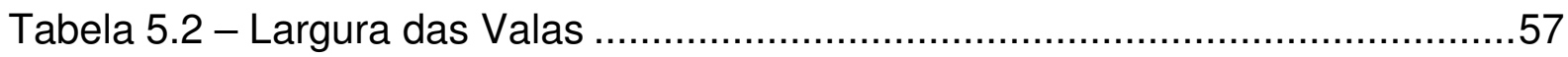

Tabela 5.3 - Espessuras das camadas de reposição de pavimento conforme tipo de tráfego 59

Tabela 5.4 - Larguras Adotadas para Reposição de Pavimento conforme tipo de camada .60

Tabela 5.5 - Preços Unitário de Movimento de Terra .60

Tabela 5.7 - Preços Unitário de Assentamento de Tubulação de Ferro Fundido .....61

Tabela 5.8 - Preços Unitário de Remoção de Pavimentação

Tabela 5.9 - Preços Unitário de Transporte de Material de Pavimentação .61 
Tabela 5.10 - Preços Unitário de Transporte de Concreto .....................................61

Tabela 5.11 - Preços Unitário de Execução de Pavimentação..................................62

Tabela 5.12 - Preços Unitário de Recomposição de Pavimentação.........................62

Tabela 5.13 - Características do Tubos de PVC ...................................................64

Tabela 5.14 - Características do Tubos de PEAD ...................................................65

Tabela 5.15 - Características do Tubos de Ferro Fundido ......................................65

Tabela 5.16 - Custo dos Tubos de PVC por diâmetro …….....................................66

Tabela 5.17 - Custo dos Tubos de PEAD por diâmetro...........................................66

Tabela 5.18 - Custo dos Tubos de Ferro Fundido por diâmetro ...............................66

Tabela 5.19 - Características do Sistema de Pressurização Inicial ..........................69

Tabela 5.20 - Tarifas de Energia para Subgrupo A4 - AES Eletropaulo a partir de

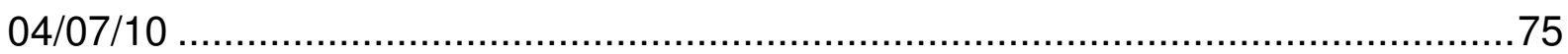

Tabela 6.1 - Cota de cada nó da rede de água ……………………………......79

Tabela 6.2 - Extensões de cada trecho de rede de água ......................................79

Tabela 6.3 - Demandas pontuais por nó para o dimensionamento da rede de água 


\section{SUMÁRIO}

1 INTRODUÇÃO .................................................................... 1

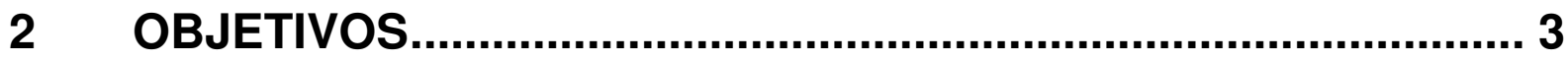

3 MÉTODO DE TRABALHO..................................................... 4

4 REVISÃO BIBLIOGRÁFICA ....................................................... 5

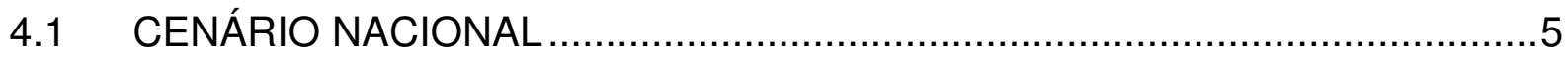

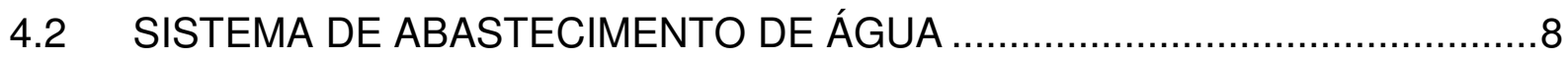

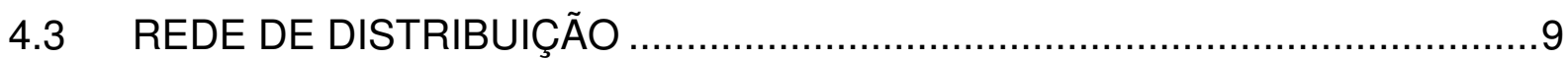

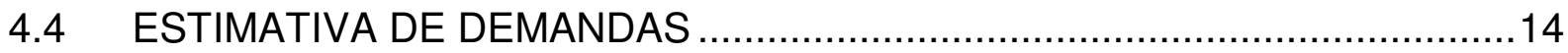

4.5 CRITÉRIOS DE DIMENSIONAMENTO HIDRÁULICO.................................25

4.6 MÉTODOS DE DIMENSIONAMENTO DE REDES ......................................30

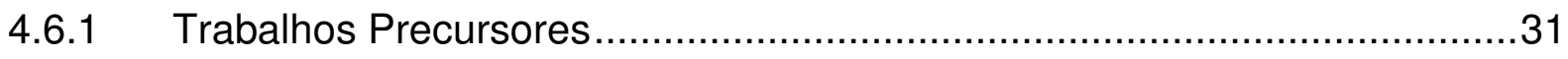

4.6.2 Entropia Máxima na modelação do Coeficiente de Atrito $f \ldots \ldots \ldots \ldots \ldots \ldots \ldots \ldots . . . . .38$

4.7 MÉTODOS TRADICIONAIS DE DIMENSIONAMENTO...............................40

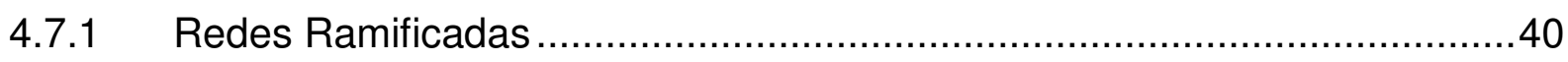

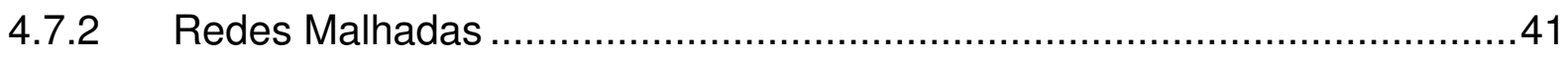

4.7.2.1 Método do Seccionamento Fictício ......................................................41

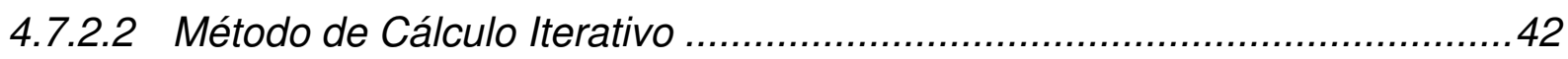

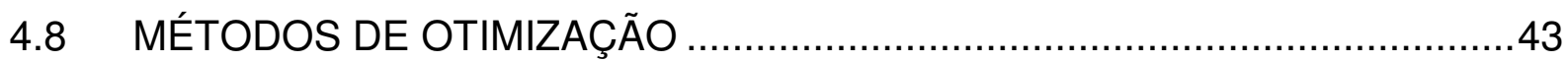

5 PROPOSIÇÃO DE MÉTODO DE OTIMIZAÇÃO GLOBAL ..........51

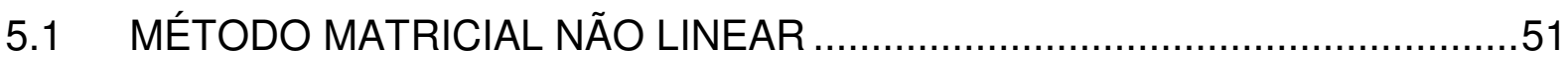

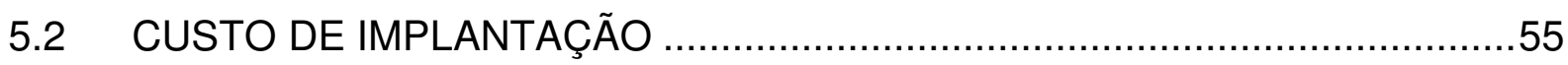

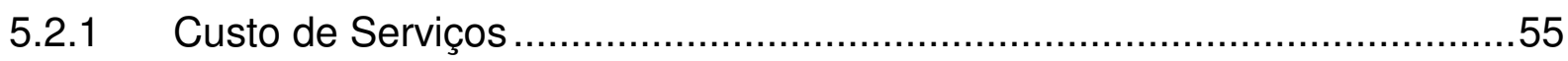

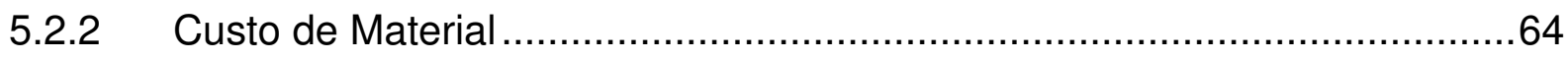

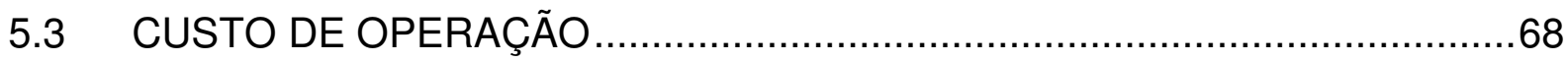




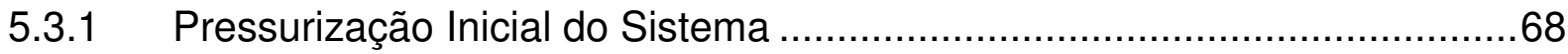

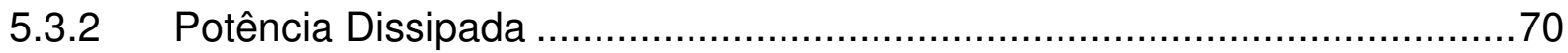

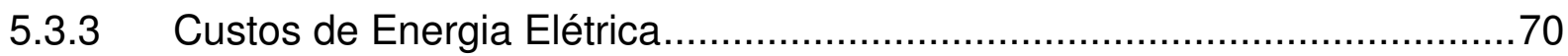

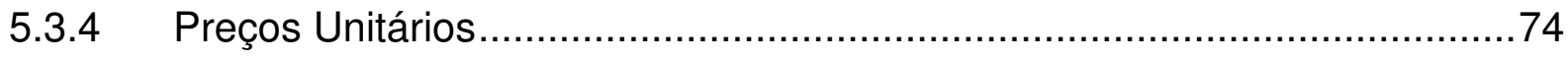

5.3.5 Custo de Operação em Valor Presente ……………………………....75

$6 \quad$ ESTUDO DE CASO ...............................................................77

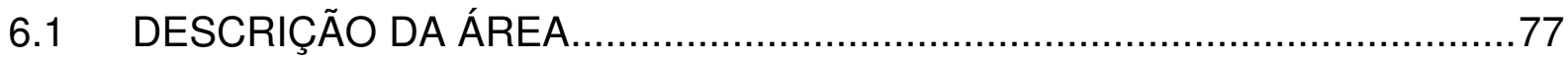

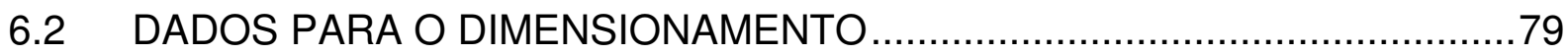

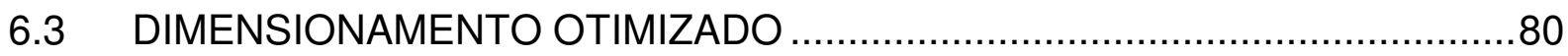

6.3.1 Dimensionamento Otimizado por Tipo de Pavimento …............................81

6.3.2 Dimensionamento Otimizado com Variação da Tarifa de Energia Elétrica.86

6.3.3 Dimensionamento Otimizado com Variação na Taxa de Juros....................90

6.3.4 Dimensionamento Otimizado com Variação na Vida Útil .............................94

6.3.5 Dimensionamento Otimizado com Aumento do Custo da Tubulação de PVC .98

7 DISCUSSÃO .....................................................................102

8 CONCLUSÕES .....................................................................106

9 REFERÊNCIAS................................................................109

APÊNDICE A1 - PLANILHA DE DIMENSIONAMENTO PARA VIÁRIO EM TERRA - PVC ........................................................................116

APÊNDICE A2 - PLANILHA DE DIMENSIONAMENTO PARA PASSEIO EM CONCRETO - PVC .................................................. 118 APÊNDICE A3 - PLANILHA DE DIMENSIONAMENTO PARA VIÁRIO EM PARALELEPÍPEDO - PVC ...................................................120 APÊNDICE A4 - PLANILHA DE DIMENSIONAMENTO PARA VIÁRIO
EM ASFALTO PARA TRÁFEGO LEVE - PVC .................................122 
APÊNDICE A5 - PLANILHA DE DIMENSIONAMENTO PARA VIÁRIO EM ASFALTO PARA TRÁFEGO MÉDIO - PVC .124 APÊNDICE A6 - PLANILHA DE DIMENSIONAMENTO PARA VIÁRIO EM ASFALTO PARA TRÁFEGO PESADO - PVC 126 APÊNDICE A7 - PLANILHA DE DIMENSIONAMENTO PARA VIÁRIO EM TERRA - PEAD. 128

APÊNDICE A8 - PLANILHA DE DIMENSIONAMENTO PARA PASSEIO EM CONCRETO - PEAD. 130 APÊNDICE A9 - PLANILHA DE DIMENSIONAMENTO PARA VIÁRIO EM PARALELEPÍPEDO - PEAD 132 APÊNDICE A10 - PLANILHA DE DIMENSIONAMENTO PARA VIÁRIO EM ASFALTO PARA TRÁFEGO LEVE - PEAD. 134 APÊNDICE A11 - PLANILHA DE DIMENSIONAMENTO PARA VIÁRIO EM ASFALTO PARA TRÁFEGO MÉDIO - PEAD 136 APÊNDICE A12 - PLANILHA DE DIMENSIONAMENTO PARA VIÁRIO EM ASFALTO PARA TRÁFEGO PESADO - PEAD ..........................138 APÊNDICE A13 - PLANILHA DE DIMENSIONAMENTO PARA VIÁRIO EM TERRA - FOFO. 140

APÊNDICE A14 - PLANILHA DE DIMENSIONAMENTO PARA PASSEIO EM CONCRETO - FOFO. 142

APÊNDICE A15 - PLANILHA DE DIMENSIONAMENTO PARA VIÁRIO EM PARALELEPÍPEDO - FOFO 144

APÊNDICE A16 - PLANILHA DE DIMENSIONAMENTO PARA VIÁRIO EM ASFALTO PARA TRÁFEGO LEVE - FOFO 146 APÊNDICE A17 - PLANILHA DE DIMENSIONAMENTO PARA VIÁRIO EM ASFALTO PARA TRÁFEGO MÉDIO - FOFO 148 
APÊNDICE A18 - PLANILHA DE DIMENSIONAMENTO PARA VIÁRIO EM ASFALTO PARA TRÁFEGO PESADO - FOFO 150 APÊNDICE B1 - PLANILHA DE DIMENSIONAMENTO PARA TARIFA VERDE - FORA DE PONTA ÚMIDA E VIÁRIO EM PARALELEPÍPEDO - PVC 152

APÊNDICE B2 - PLANILHA DE DIMENSIONAMENTO PARA TARIFA CONVENCIONAL E VIÁRIO EM PARALELEPÍPEDO - PVC. 154

APÊNDICE B3 - PLANILHA DE DIMENSIONAMENTO PARA TARIFA AZUL - PONTA SECA E VIÁRIO EM PARALELEPÍPEDO - PVC.....156 APÊNDICE B4 - PLANILHA DE DIMENSIONAMENTO PARA TARIFA VERDE - PONTA SECA E VIÁRIO EM PARALELEPÍPEDO - PVC..158 APÊNDICE B5 - PLANILHA DE DIMENSIONAMENTO PARA TARIFA VERDE - FORA DE PONTA ÚMIDA E VIÁRIO EM PARALELEPÍPEDO - FOFO 160

APÊNDICE B6 - PLANILHA DE DIMENSIONAMENTO PARA TARIFA CONVENCIONAL E VIÁRIO EM PARALELEPÍPEDO - FOFO 162 APÊNDICE B7 - PLANILHA DE DIMENSIONAMENTO PARA TARIFA AZUL - PONTA SECA E VIÁRIO EM PARALELEPÍPEDO - FOFO ..164 APÊNDICE B8 - PLANILHA DE DIMENSIONAMENTO PARA TARIFA VERDE - PONTA SECA E VIÁRIO EM PARALELEPÍPEDO - FOFO166 APÊNDICE C1 - PLANILHA DE DIMENSIONAMENTO PARA JUROS DE 4\%AA E VIÁRIO EM PARALELEPÍPEDO - PVC 168 APÊNDICE C2 - PLANILHA DE DIMENSIONAMENTO PARA JUROS DE 6\%AA E VIÁRIO EM PARALELEPÍPEDO - PVC 170 APÊNDICE C3 - PLANILHA DE DIMENSIONAMENTO PARA JUROS DE 8\%AA E VIÁRIO EM PARALELEPÍPEDO - PVC 172 
APÊNDICE C4 - PLANILHA DE DIMENSIONAMENTO PARA JUROS DE 10\%AA E VIÁRIO EM PARALELEPÍPEDO - PVC .174 APÊNDICE C5 - PLANILHA DE DIMENSIONAMENTO PARA JUROS DE 4\%AA E VIÁRIO EM PARALELEPÍPEDO - FOFO. 176 APÊNDICE C6 - PLANILHA DE DIMENSIONAMENTO PARA JUROS DE 6\%AA E VIÁRIO EM PARALELEPÍPEDO - FOFO. 178 APÊNDICE C7 - PLANILHA DE DIMENSIONAMENTO PARA JUROS DE 8\%AA E VIÁRIO EM PARALELEPÍPEDO - FOFO. 180 APÊNDICE C8 - PLANILHA DE DIMENSIONAMENTO PARA JUROS DE 10\%AA E VIÁRIO EM PARALELEPÍPEDO - FOFO 182 APÊNDICE D1 - PLANILHA DE DIMENSIONAMENTO PARA VIDA ÚTIL DE 10 ANOS E VIÁRIO EM PARALELEPÍPEDO - PVC.......... 184 APÊNDICE D2 - PLANILHA DE DIMENSIONAMENTO PARA VIDA ÚTIL DE 20 ANOS E VIÁRIO EM PARALELEPÍPEDO - PVC.......... 186 APÊNDICE D3 - PLANILHA DE DIMENSIONAMENTO PARA VIDA ÚTIL DE 30 ANOS E VIÁRIO EM PARALELEPÍPEDO - PVC........... 188 APÊNDICE D4 - PLANILHA DE DIMENSIONAMENTO PARA VIDA ÚTIL DE 40 ANOS E VIÁRIO EM PARALELEPÍPEDO - PVC.......... 190 APÊNDICE D5 - PLANILHA DE DIMENSIONAMENTO PARA VIDA ÚTIL DE 10 ANOS E VIÁRIO EM PARALELEPÍPEDO - FOFO ....... 192 APÊNDICE D6 - PLANILHA DE DIMENSIONAMENTO PARA VIDA ÚTIL DE 20 ANOS E VIÁRIO EM PARALELEPÍPEDO - FOFO ....... 194 APÊNDICE D7 - PLANILHA DE DIMENSIONAMENTO PARA VIDA ÚTIL DE 30 ANOS E VIÁRIO EM PARALELEPÍPEDO - FOFO ....... 196 APÊNDICE D8 - PLANILHA DE DIMENSIONAMENTO PARA VIDA ÚTIL DE 40 ANOS E VIÁRIO EM PARALELEPÍPEDO - FOFO 198 
APÊNDICE E1 - PLANILHA DE DIMENSIONAMENTO PARA AUMENTO DE $100 \%$ NA TUBULAÇÃO DE PVC E VIÁRIO EM

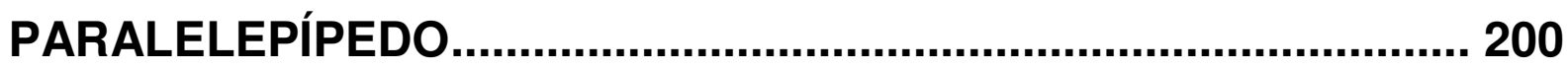
APÊNDICE E2 - PLANILHA DE DIMENSIONAMENTO PARA AUMENTO DE $125 \%$ NA TUBULAÇÃO DE PVC E VIÁRIO EM PARALELEPÍPEDO.................................................................. 202 APÊNDICE E3 - PLANILHA DE DIMENSIONAMENTO PARA AUMENTO DE $150 \%$ NA TUBULAÇÃO DE PVC E VIÁRIO EM

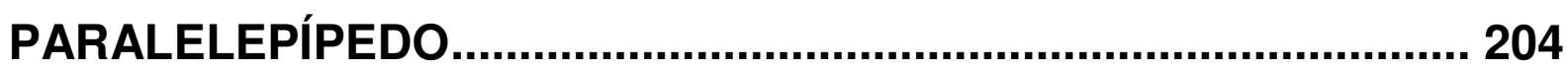
APÊNDICE E4 - PLANILHA DE DIMENSIONAMENTO PARA AUMENTO DE 175\% NA TUBULAÇÃO DE PVC E VIÁRIO EM PARALELEPÍPEDO 206 


\section{INTRODUÇÃO}

Água é um dos elementos fundamentais ao desenvolvimento da vida. Entre os seus vários usos destacam-se aqueles fundamentais a vida, como o preparo de alimentos, higiene e o saneamento, assim como no transporte, no lazer geração de energia e nos serviços de forma geral.

Para que a água chegue até cada usuário em quantidade, qualidade e pressão adequadas, é necessária a implantação de infra-estrutura de distribuição, ou seja, um sistema de abastecimento de água, composto por unidades localizadas (captação, estação de tratamento, estações elevatórias, booster e reservatórios) e lineares (adutoras e redes de distribuição de água).

Diferente das unidades localizadas, as redes de distribuição de água são compostas por tubulações, conexões, válvulas e hidrantes, que abrangem toda a área do sistema de abastecimento, e funcionam como elemento logístico do sistema, encarregado da distribuição em escala ininterrupta.

Sua função é a distribuição de água potável para cada usuário do sistema, geralmente por conduto forçado, ou seja, onde a água é conduzida a seção plena e sob pressão maior que a atmosférica.

Todos os seus componentes devem ter resistência suficiente para suportar as pressões internas estáticas, dinâmicas e ocasionadas por transitórios hidráulicos operacionais, além dos esforços externos devido ao peso do solo sobre a tubulação e carga de veículos na superfície.

Para Tsutiya (2006), em geral, a implantação das redes de distribuição é o componente que necessita de maior investimento do total de obras do sistema (cerca de 50 a $75 \%$ do custo total).

Para que a água possa escoar através da tubulação, é necessária certa quantidade de energia, que pode ser traduzida pela perda de carga por atrito.

Conforme a topografia de cada sistema, a energia disponível pode ser menor que a perda de carga para o escoamento, necessitando o aumento na altura de reservatórios ou implantação de pressurização no sistema. 
Durante muito tempo o dimensionamento de redes pressurizadas para a distribuição de água potável foi baseado em formulações empíricas tais como a equação de Hazen-Williams, associadas a algum critério empírico que permitisse a especificação do melhor diâmetro, tal como a vazão e perda de carga no escoamento. Porém a aplicação de tais critérios não é genérica e varia localmente, sendo satisfatória apenas para casos específicos

Ainda, no dimensionamento de redes de distribuição de água, adotam-se perdas de carga correspondentes a o regime de escoamento turbulento rugoso para a população de final de plano e com aplicação dos fatores do maior dia e da hora de maior consumo na vazão de projeto. Na prática, as condições de escoamento numa rede de distribuição podem variar de laminar a turbulento, o que resulta em valores incorretos da perda de carga e, finalmente, no dimensionamento hidráulico.

Com o desenvolvimento de formulações com fundamentos conceituais, tais como a Fórmula Universal ou de Darcy-Weissbach, estes problemas tendem a ser reduzidos, possibilitando-se uma maior precisão na obtenção do valor da perda de carga.

A partir do valor mais preciso da perda de carga e com os avanços tecnológicos das ferramentas para a análise e de modelagem nos últimos 30 anos, foi possível incluir no dimensionamento hidráulico de redes de distribuição de água o princípio da otimização econômica global, isto é, o dimensionamento otimizado considerando tanto os valores relativos ao projeto e obra propriamente ditos, como aqueles relacionados a vida útil da tubulação, como a energia para pressurização, os custos de manutenção e etc.

Como se verá ao longo deste trabalho, estes conceitos podem ser aplicáveis hoje em dia, e resultam em redes diferentes daquelas obtidas pelos processos convencionais. 


\section{OBJETIVOS}

O objetivo deste trabalho é apresentar um método de fácil aplicação, baseado em processo de otimização, para avaliação de redes de distribuição de água, com o emprego do conceito de menor custo global. Este método deve atender os critérios hidráulicos e convergir para uma solução ótima do ponto de vista dos custos totais, incluindo a implantação e de operação do sistema.

Para a aplicação deste método, o sistema estudado foi ser restrito a certas características de topografia, tipo de pavimento existente no sistema viário onde será implantada a rede, da característica do sistema de bombeamento, além de configuração, do regime de escoamento e do tipo de material utilizado na tubulação.

Através dos resultados do dimensionamento otimizado em um estudo de caso hipotético, foi analisado o comportamento do modelo para variações do material da rede, do tipo de pavimento para implantação da rede, da tarifa de energia elétrica, da taxa de juros vigente, vida útil do sistema de pressurização e ainda com variações no custo de um tipo específico de tubulação, no caso o PVC, como forma de verificar o comportamento deste parâmetro específico nas escolhas finais de projeto.

Após análise, foram determinadas as relações de causa e efeito adotadas pelo modelo. 


\section{MÉTODO DE TRABALHO}

Neste trabalho apresenta-se inicialmente uma revisão dos conceitos e métodos empregados no dimensionamento de sistemas de distribuição de água por conduto forçado, seja o aspecto de cálculo das perdas de carga como as aplicações mais recentes, envolvendo algoritmos evolucionários e métodos de otimização não lineares para determinação dos diâmetros.

Na sequência, um método de dimensionamento pelo critério do mínimo custo global é proposto e em seguida testado, para verificação da sensibilidade do mesmo aos diferentes parâmetros intervenientes. Para que tal método pudesse ser transformado em uma ferramenta pronta para aplicação, foi necessário o levantamento e atualização de custos dos diversos itens componentes do processo de implantação e operação de um sistema urbano de água, limitando-se o mesmo aos custos diretos de implantação, como as obras propriamente ditas, e os custos de operação, restritos aos custos de pressurização e energia dissipada no sistema resultante.

Para tal, empreendeu-se uma pesquisa bibliográfica para levantamento das últimas propostas ligadas ao dimensionamento de sistemas de distribuição pressurizada de água, bem como as técnicas de dimensionamento econômico em prática.

Após a construção de um aplicativo em planilha eletrônica foi possível o dimensionamento considerando as múltiplas variáveis intervenientes de um sistema piloto hipotético e a avaliação do método proposto através do estudo de seus diferentes componentes. 


\section{REVISÃO BIBLIOGRÁFICA}

O sistema de abastecimento de água é responsável pelo fornecimento ao usuário de água de boa qualidade para seu uso, quantidade suficiente e pressão adequada.

\subsection{CENÁRIO NACIONAL}

Diagnóstico dos Serviços de Água e Esgotos do Sistema Nacional de Informações sobre Saneamento (SNIS) da Secretaria Nacional de Saneamento Ambiental do Ministério das Cidades foi publicado em março de 2010 (ano de referência de 2008), com as informações enviadas pelos prestadores de serviços e os indicadores calculados com base nessas informações (SECRETARIA NACIONAL DE SANEAMENTO AMBIENTAL, 2010).

No ano de referência 2008 a amostra correspondeu à totalização de dados de 4.627 municípios atendidos com os serviços de água e de $1.468 \mathrm{com}$ os serviços de esgotos (respectivamente 83,1 e $26,4 \%$ do total dos municípios brasileiros).

Algumas informações apresentadas na tabela abaixo permitem uma caracterização global dos sistemas de água no Brasil, conforme diagnóstico da SNIS em 2008.

Tabela 4.1 - Caracterização global dos sistemas de água dos prestadores de serviços participantes do SNIS em 2008

\begin{tabular}{ccc}
\hline Informação & Unidade & Quantidade \\
\hline Quantidade de ligações de água & Unid. & 41.055 .764 \\
\hline Extensão da rede de água & $\mathrm{km}$ & 469.581 \\
\hline Volume de água produzido & Mil m & 14.303 .079 \\
\hline Volume de água consumido & Mil m$^{3}$ & 8.364 .361 \\
\hline
\end{tabular}

Fonte: Diagnóstico dos Serviços de Água e Esgotos 2008 do SNIS

No ano de 2008, observou-se uma evolução dos sistemas de água quando os dados são comparados aos de 2007, onde:

- Os sistemas de abastecimento de água passaram a atender 1,3 milhão de novas ligações (acréscimo de 3,3\%);

- As redes de água cresceram cerca de 12,1 mil quilômetros (acréscimo de $2,6 \%)$

- A produção de água manteve-se sem acréscimo, com volume total no mesmo patamar de 2007; enquanto que o volume de água consumido teve um acréscimo de $2,7 \%$. 
A partir desses resultados, o diagnóstico concluiu que em 2008 houve um crescimento físico dos sistemas e do volume de água consumido, com o volume de água produzido mantendo-se no mesmo patamar, sem crescimento, indicando uma melhor eficiência dos sistemas sob a ótica do aproveitamento dos recursos hídricos.

A Tabela 4.2 apresenta os valores médios dos índices de atendimento para todo o conjunto de prestadores de serviços participantes do SNIS em 2008 de acordo com as regiões geográficas brasileiras.

Tabela 4.2 - Níveis de atendimento de água dos prestadores de serviços participantes do SNIS em 2008, segundo região geográfica

\begin{tabular}{ccc}
\hline \multirow{2}{*}{ Região } & \multicolumn{2}{c}{ Índice de Atendimento de Água (\%) } \\
\cline { 2 - 3 } & Total & Urbano \\
\hline Norte & 57,6 & 72,0 \\
\hline Nordeste & 68,0 & 89,4 \\
\hline Sudeste & 90,3 & 97,6 \\
\hline Sul & 86,7 & 98,2 \\
\hline Centro-oeste & 89,5 & 95,6 \\
\hline Brasil & $\mathbf{8 1 , 2}$ & $\mathbf{9 4 , 7}$
\end{tabular}

Fonte: Diagnóstico dos Serviços de Água e Esgotos 2008 do SNIS

Os índices médios nacionais de atendimento da população total (urbana + rural) identificados pelo SNIS em 2008 foram de $81,2 \%$ para o abastecimento de água. Considerando somente a população urbana, os dados evidenciam um elevado atendimento pelos serviços de água, com índice médio nacional igual a 94,7\%.

Na comparação com os dados de 2007, observou-se uma oscilação para cima nos dois indicadores, sendo de 0,3 pontos percentuais no índice de atendimento com abastecimento de água relativamente à população total. No outro indicador relativo ao atendimento da população urbana, ocorreu oscilação positiva de 0,5 pontos percentuais no abastecimento de água.

Conforme conclusão do diagnóstico da SNIS, o menor crescimento do índice de atendimento dos serviços de água demonstrou a grande dificuldade de aumentar índices mesmo com os investimentos realizados. Os dados indicaram que, nessas condições, para se alcançar a universalização dos serviços faz se necessário focar prioritariamente as áreas não atendidas. Considerando o baixo impacto no crescimento do atendimento, é de se supor que os recursos estavam sendo investidos em maior intensidade na reposição da infra-estrutura existente ou na melhoria da qualidade do atendimento em áreas já servidas com os serviços. 
A visualização espacial do índice de atendimento total com abastecimento de água segundo diagnóstico do SNIS em 2008, distribuídos por faixas percentuais, segundo os estados brasileiros, é apresentada no mapa da Figura 4.1.

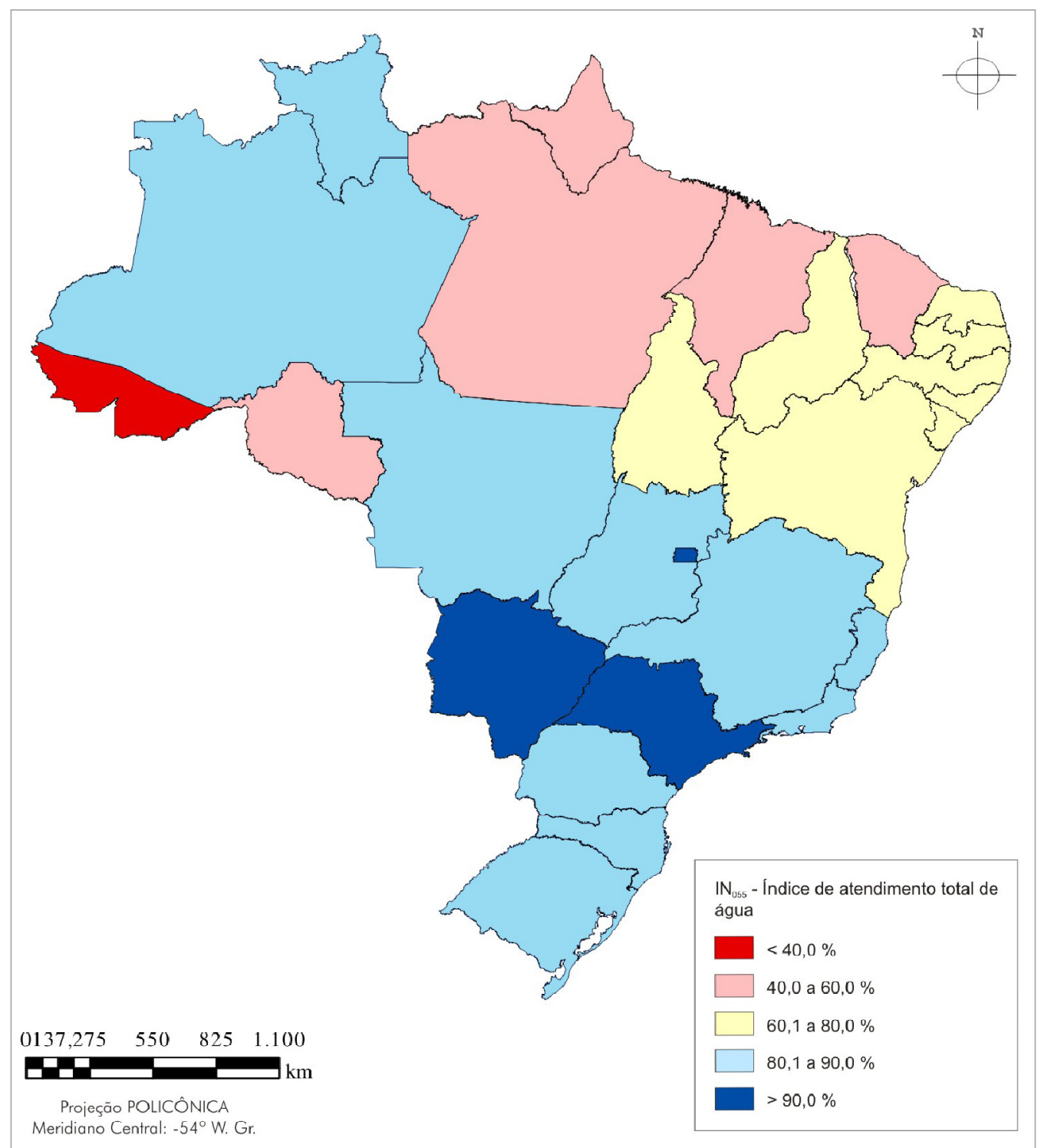

Figura 4.1 - Mapa do índice de atendimento total de água dos participantes do SNIS em 2008. Fonte: Diagnóstico dos Serviços de Água e Esgotos 2008 do SNIS

Em relação ao índice de atendimento total com abastecimento de água, dois estados, Mato Grosso do Sul e São Paulo, mais o Distrito Federal situaram-se na maior faixa (>90\%).

Na segunda faixa $(80,1 \%$ a $90,0 \%)$ houve uma maior quantidade de estados, num total de 10 , sendo que a única região ausente foi a Nordeste. 
$\mathrm{Na}$ terceira faixa $(60,1 \%$ a $80,0 \%)$ apareceram 8 estados, concentrados no Nordeste, à exceção de Tocantins, na região Norte.

Nos menores índices, observa-se 5 estados na faixa de 40,0 a $60,0 \%$ e apenas um estado, o Acre, na menor faixa $(<40 \%)$.

\subsection{SISTEMA DE ABASTECIMENTO DE ÁGUA}

Para Tsutiya (2006), de um modo geral os sistemas são constituídos das seguintes partes:

- Manancial: corpo de água superficial ou subterrâneo com quantidade e qualidade adequadas para captação de água para o abastecimento populacional;

- Captação: conjunto de estruturas e dispositivos, construídos ou montados junto ao manancial, para a retirada de água destinada ao sistema de abastecimento;

- Estação Elevatória: conjunto de obras e equipamentos destinados a recalcar a água para a unidade seguinte ou para pressurização em adutoras ou redes de distribuição;

- Adutora: canalizações que se destinam a conduzir água entre unidades que precedem a rede de distribuição;

- Estação de Tratamento de Água: conjunto de unidades destinado a tratar a água de modo a adequar as suas características aos padrões de potabilidade;

- Reservatório: é o elemento do sistema de distribuição de água destinado a regularizar as variações entre as vazões de adução e de distribuição e condicionar as pressões na rede de distribuição;

- Rede de Distribuição: parte do sistema de abastecimento de água formada de tubulações e acessórios destinada a colocar água potável à disposição dos consumidores de forma contínua em quantidade e pressão recomendada.

A porcentagem do custo das principais unidades do sistema de abastecimento de água, levantadas pela Companhia de Saneamento Básico de São Paulo apud Tsutiya (2006) varia com a população atendida, conforme pode ser observado na Tabela 4.3. 
Tabela 4.3 - Indicadores de Custo do sistema convencional de abastecimento de água SABESP - 1998

\begin{tabular}{ccccc}
\hline \multirow{2}{*}{$\begin{array}{c}\text { Unidade do } \\
\text { Sistema }\end{array}$} & $\begin{array}{c}\text { População } \mathbf{5} \\
\mathbf{1 0 . 0 0 0} \text { hab. }\end{array}$ & $\begin{array}{c}\text { População entre } \\
\mathbf{1 0 . 0 0 0} \text { a } \mathbf{4 0 . 0 0 0 ~ h a b . ~}\end{array}$ & $\begin{array}{c}\text { População entre } \\
\mathbf{4 0 . 0 0 0} \mathbf{~ 1 0 0 . 0 0 0} \\
\text { hab. }\end{array}$ & $\begin{array}{c}\text { População }> \\
\mathbf{1 0 0 . 0 0 0} \text { hab. }\end{array}$ \\
\hline Captação & 30 & 20 & 8 & 3 \\
\hline Adução & 8 & 9 & 11 & 11 \\
\hline Bombeamento & 6 & 5 & 5 & 1 \\
\hline Tratamento & 12 & 9 & 9 & 5 \\
\hline Reservação & 6 & 6 & 6 & 4 \\
\hline Distribuição & 38 & 51 & 61 & 76 \\
\hline Fonyyyyy
\end{tabular}

Fonte: Tsutiya (2004)

\subsection{REDE DE DISTRIBUIÇÃO}

Ao contrário de outras unidades do sistema tais como a captação, bombeamento, tratamento e reservação, a rede de distribuição de água constitui unidade descentralizada e dispersa, geralmente em toda a área de influência do sistema.

São unidades pouco visíveis, de difícil acesso, inspeção e manutenção, porque em grande parte dos casos se encontram enterradas sob vias públicas ou passeios, contendo, em linhas gerais, os seguintes componentes na forma de tubulações e órgãos acessórios, tais como: curvas, tês, reduções, válvulas, hidrantes e outros.

Todos esses componentes devem suportar as seguintes solicitações, tais como:

- Pressões internas estáticas e dinâmicas;

- Esforços externos (peso do material de reaterro sobre a tubulação e carregamento devido trânsito de veículo na superfície); e

- Variações de pressões e transitórios hidráulicos (abertura e fechamento rápido de válvulas, além de partida e parada de bombas).

As tubulações são condutos fechados tradicionalmente em seção circular, que são responsáveis pelo transporte de água potável até os consumidores. Funcionam como conduto forçado, ou seja, o fluído neles escoa em seção plena com pressão diferente da pressão atmosférica.

Os principais materiais utilizados nas tubulações da rede de distribuição são o ferro fundido dúctil, policloreto de vinila (PVC) e o polietileno (PE). Além desses materiais, também são utilizadas tubulações de aço com junta soldada ou elástica, PVC reforçado com fibra de vidro e poliéster reforçado com fibra de vidro. 
Na Tabela 4.4, são apresentadas as principais características de cada tipo de tubulação.

Segundo Kuroda e Pádua (2006) o assentamento de tubulações de ferro fundido é fácil, porém esse serviço é normalmente dificultado pelo peso do material e equipamentos envolvidos para a obra. A partir desse ponto de vista, é muito mais fácil a implantação de tubulações de polietileno do que ferro fundido, ao contrário que apresenta a tabela a seguir. 
Tabela 4.4 - Informações gerais sobre tipo de tubulações

\begin{tabular}{|c|c|c|c|c|c|c|c|c|c|}
\hline \multirow{3}{*}{ Características } & \multicolumn{9}{|c|}{ Material } \\
\hline & \multirow{2}{*}{ FoFo Dúctil } & \multirow{2}{*}{ Aço } & \multicolumn{2}{|c|}{ PVC } & \multicolumn{2}{|c|}{ Polietileno } & \multirow{2}{*}{ PP } & \multirow{2}{*}{ PRFV/JE } & \multirow{2}{*}{ RPVC/JE } \\
\hline & & & PBA & DEFoFo & PEMD & PEAD & & & \\
\hline $\begin{array}{l}\text { Coeficiente de } \\
\text { Rugosidade }\end{array}$ & 130 & 130 & 160 & 160 & 150 & 150 & 150 & $135-150$ & $135-150$ \\
\hline $\begin{array}{l}\text { Rugosidade Abs. } \\
\text { Equivalente }(\varepsilon) \mathrm{mm}\end{array}$ & 0,1 & - & - & - & 0,02 & 0,02 & 0,02 & $\begin{array}{c}0,06- \\
0,08\end{array}$ & $\begin{array}{c}0,009- \\
0,011\end{array}$ \\
\hline $\begin{array}{l}\text { Diâmetros Fabricados } \\
(\mathrm{mm})\end{array}$ & $80-1800$ & $170-2500$ & $\begin{array}{l}50- \\
180\end{array}$ & $\begin{array}{l}100- \\
500\end{array}$ & \multicolumn{2}{|c|}{$16-1600$} & $20-500$ & $50-2400$ & $25-700$ \\
\hline $\begin{array}{l}\text { Pressão de Serviço } \\
(\mathrm{MPa})\end{array}$ & $\leq 7,7$ & $\leq 12,15$ & $\begin{array}{c}0,6- \\
1,0\end{array}$ & 1,0 & \multicolumn{2}{|c|}{$0,2-2,0$} & $0,6-1,0$ & $0,2-3,2$ & $0,2-3,2$ \\
\hline Massa Específica $\left(\mathrm{g} / \mathrm{cm}^{3}\right)$ & - & - & \multicolumn{2}{|c|}{$1,4-1,45$} & 0,944 & 0,954 & 0,900 & $1,4-1,6$ & 1,7 \\
\hline Resistência ao Choque & Alta & Alta & \multicolumn{2}{|c|}{ Baixa } & \multicolumn{2}{|c|}{ Média } & Baixa & Média & Média \\
\hline $\begin{array}{l}\text { Módulo de Elasticidade à } \\
\text { Tração (GPa) }\end{array}$ & Alta & Alta & \multicolumn{2}{|c|}{ Baixa } & \multicolumn{2}{|c|}{ Baixa } & Baixa & - & - \\
\hline Coeficiente de Poisson & 0,27 & 0,30 & \multicolumn{2}{|c|}{0,46} & $\geq 600$ & $\geq 350$ & $\geq 50$ & 2,0 & 2,0 \\
\hline $\begin{array}{l}\text { Resistência a solos } \\
\text { ácidos }\end{array}$ & $\begin{array}{c}\text { Requer } \\
\text { revestimento }\end{array}$ & Baixa & \multicolumn{2}{|c|}{ Alta } & \multicolumn{2}{|c|}{ Alta } & Alta & \multicolumn{2}{|c|}{ Alta } \\
\hline $\begin{array}{c}\text { Resistência a cargas } \\
\text { externas }\end{array}$ & Alta & Alta & \multicolumn{2}{|c|}{ Baixa } & \multicolumn{2}{|c|}{ Baixa } & Baixa & \multicolumn{2}{|c|}{ Média } \\
\hline $\begin{array}{l}\text { Coeficiente de Dilatação } \\
\text { Linear }\left({ }^{\circ} \mathrm{m} / \mathrm{C}^{-1}\right)\end{array}$ & - & - & \multicolumn{2}{|c|}{$(5$ a 15$) \times 10^{-5}$} & $5,5 \times 10^{-2}$ & $4,7 \times 10^{-2}$ & $4,0 \times 10^{-2}$ & $35 \times 10^{-6}$ & $25 \times 10^{-6}$ \\
\hline Vazamentos & Tem & Pouco & \multirow{2}{*}{\multicolumn{2}{|c|}{ Tem }} & \multicolumn{2}{|c|}{ Pouco } & Pouco & \multicolumn{2}{|c|}{ Tem } \\
\hline Arrebentamentos & Pouco & Muito pouco & \multirow{2}{*}{\multicolumn{2}{|c|}{$\begin{array}{l}\text { Pouco } \\
\text { Alta }\end{array}$}} & \multirow{2}{*}{\multicolumn{2}{|c|}{$\frac{\text { Muito pouco }}{\text { Alta }}$}} & Muito pouco & & \\
\hline Resistência à corrosão & Alta & Baixa & & & & & Alta & \multicolumn{2}{|c|}{$\frac{\text { Pouco }}{\text { Alta }}$} \\
\hline Consertos & Médio & Médio & \multicolumn{2}{|c|}{ Fácil } & \multicolumn{2}{|c|}{ Relativamente fácil } & $\begin{array}{l}\text { Relativamente } \\
\text { fácil }\end{array}$ & \multicolumn{2}{|c|}{ Médio } \\
\hline $\begin{array}{l}\text { Assentamento e } \\
\text { Recobrimento }\end{array}$ & Fácil & $\begin{array}{l}\text { Relativamente } \\
\text { fácil }\end{array}$ & \multicolumn{2}{|c|}{$\begin{array}{l}\text { Cuidados } \\
\text { especiais }\end{array}$} & Cuidados & speciais & $\begin{array}{l}\text { Cuidados } \\
\text { especiais }\end{array}$ & Cuidado & especiais \\
\hline Montagem & Fácil & $\begin{array}{c}\text { Solda e } \\
\text { Revestimento }\end{array}$ & Relat & $\begin{array}{l}\text { amente } \\
\text { ácil }\end{array}$ & Solda relativ & nente fácil & $\begin{array}{l}\text { Solda } \\
\text { relativamente fácil }\end{array}$ & & cil \\
\hline
\end{tabular}

Fonte: Kuroda e Pádua (2006) 
A rede de distribuição de água é constituída por tubulações principais e secundárias, que são definidas da forma:

- Principal: Tubulação de maior diâmetro responsável pela distribuição de água para as tubulações secundárias. É também denominada como conduto tronco, tubulação mestra ou primária;

- Secundária: Tubulação de menor diâmetro responsável pelo abastecimento dos pontos de consumo do sistema.

Conforme a disposição da tubulação de distribuição principal e o sentido de escoamento das tubulações secundárias, as redes de distribuição de água são classificadas como:

- Ramificada;

- Malhada;

- Mista.

A rede do tipo ramificada é aquela onde a alimentação é feita através da tubulação principal, que é alimentada por um reservatório, adutora ou estação elevatória. A partir da tubulação principal, a distribuição é feita através das secundárias.

Nesse tipo de configuração tem-se que:

- O sentido de escoamento é único e conhecido em qualquer trecho;

- Apresenta várias pontas secas ou extremidades mortas com grande probabilidade de acúmulo de material da rede e estagnação da água;

- Requer instalação e operação periódica de dispositivos de descarga em pontos estratégicos para manter a qualidade da água distribuída;

- A interrupção no escoamento em uma tubulação compromete todo o abastecimento nas tubulações situadas à jusante da mesma, dificultando a execução de manutenção;

- É recomendada quando não existe a possibilidade de se utilizar a rede do tipo malhada.

Na figura a seguir, é apresentado esquema de uma rede de distribuição ramificada. 


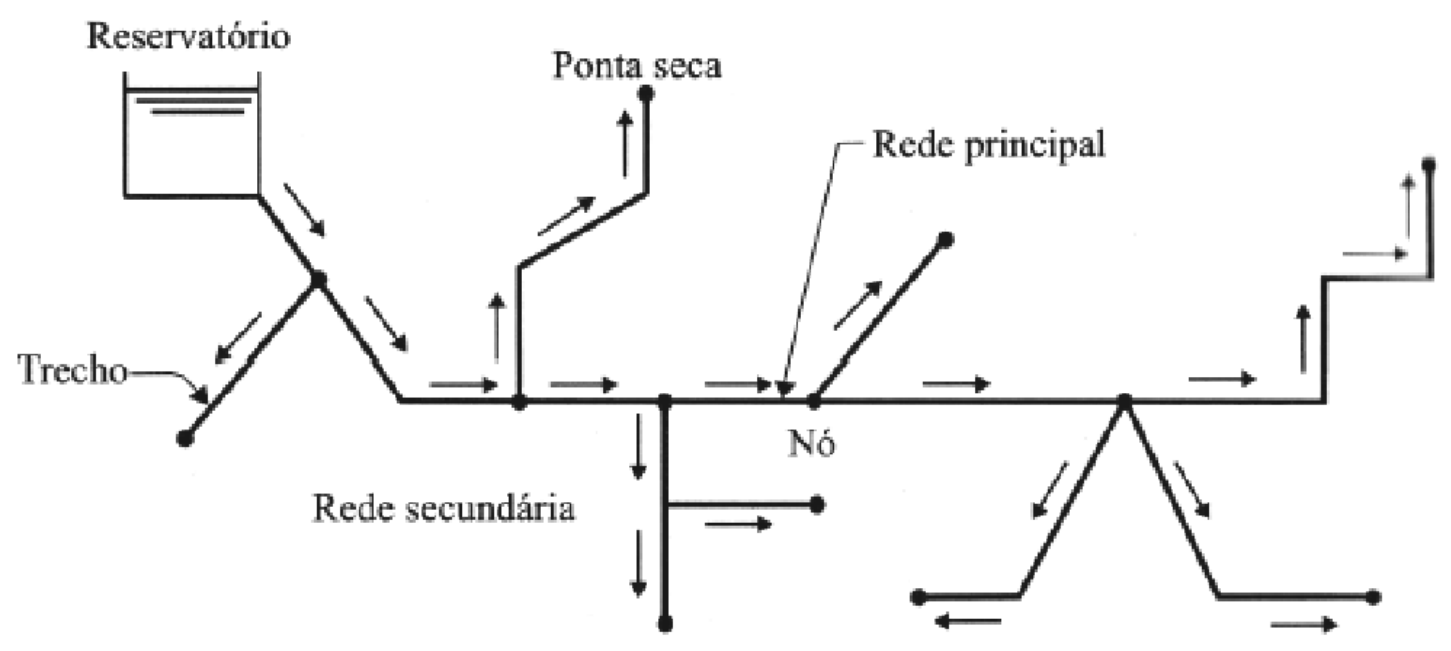

Figura 4.2 - Esquema de rede de distribuição do ramificada.

Fonte: Tsutiya (2006)

A rede do tipo malhada é composta por tubulações principais, que formam anéis ou blocos, onde o abastecimento de qualquer ponto pode ser feito por mais de um caminho.

Nesse tipo de configuração tem-se que:

- O sentido de escoamento é variável, garantindo um maior flexibilidade em satisfazer as demandas;

- A interrupção no escoamento em uma tubulação não compromete todo o abastecimento, pois o mesmo pode ser feito por mais de um caminho, facilitando a execução de manutenção;

- Não apresenta pontas secas ou extremidades mortas, menor probabilidade de acúmulo de material da rede e estagnação da água.

Na figura a seguir, é apresentado esquema de uma rede de distribuição em malha. 


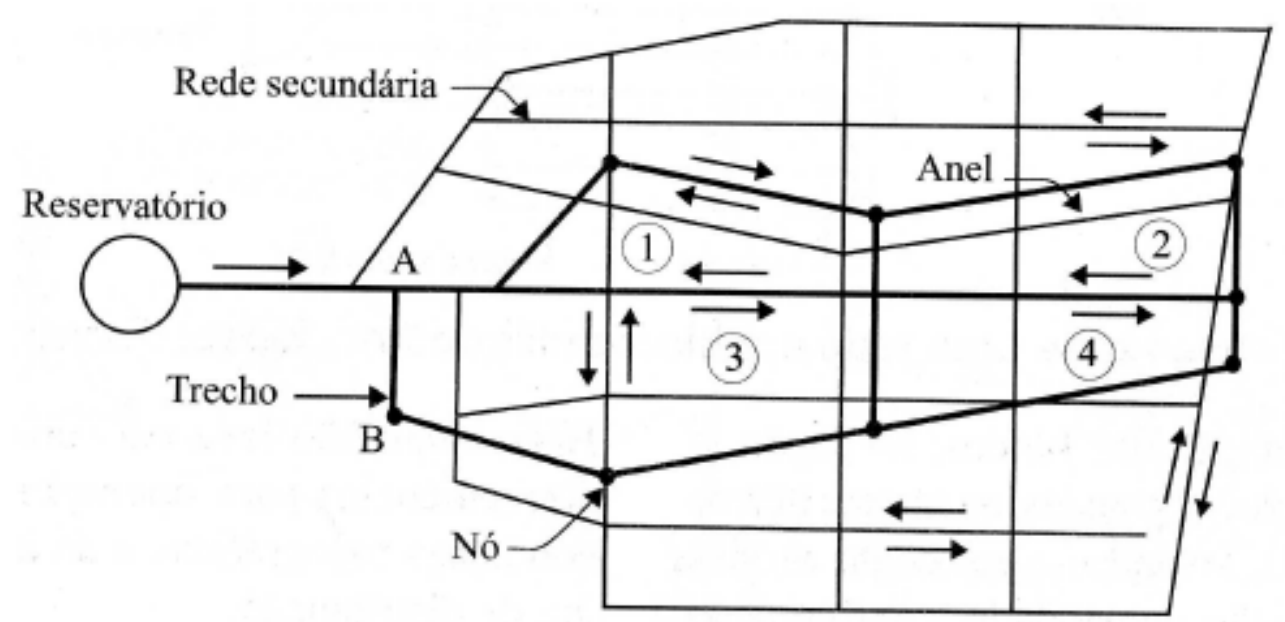

Figura 4.3 - Esquema de rede de distribuição em malha.

Fonte: Tsutiya (2006)

A rede do tipo mista é aquela que apresenta a associação de rede do tipo ramificada e malhada.

\subsection{ESTIMATIVA DE DEMANDAS}

O dimensionamento das redes de distribuição é feito em função das vazões de água, que dependem do consumo médio por habitante (per capita), da estimativa do número de habitantes, das variações de demanda e outros consumos que podem ocorrer na área de estudo.

Para a determinação da vazão de distribuição do dimensionamento, é necessário definir a classificação dos consumidores, o consumo per capita, a variação no consumo e estimativa populacional.

Tradicionalmente os consumidores são classificados em quatro grandes categorias, sendo:

- Doméstico;

- Comercial;

- Industrial;

- Público.

Essa divisão é facilmente identificável e serve para o estabelecimento de políticas tarifárias e de cobranças diferenciadas. 
A categoria de uso doméstico (residenciais) é a mais homogênea, onde a variabilidade de consumo diário de água é baixa e o perfil de consumo se mantem praticamente constante ao longo da semana.

A categoria comercial e industrial é mais heterogênea, podendo variar de pequenos consumidores (bares, padarias e outros) até grandes consumidores (shopping Center e indústrias de bebida), onde o consumo de água está diretamente relacionado com o seu uso e o perfil de consumo varia ao longo da semana.

O consumo per capita de água de um setor, cidade ou sistema pode ser obtido através de medições existentes (micromedições e macromedições) ou estimado a partir de setor, cidade ou sistema com características semelhantes.

Através da utilização de uma série histórica de 3,5 anos de dados de consumos horários de 22 setores de abastecimento da Região Metropolitana de São Paulo pertencentes ao Sistema Adutor Metropolitano (SAM) de São Paulo, Hasegawa; Filho e Ignácio (1999) analisaram os perfis típicos de curvas de consumo de água.

Quando analisam as curvas médias obtidas para cada dia da semana, observaram, em geral, que nos setores predominantemente residenciais, não há mudanças significativas da forma das curvas de consumo, tampouco da magnitude das vazões médias e extremas, conforme Figura 4.4. Nos setores com parcela de uso comercial significativo, observaram uma redução nas vazões máximas horárias da ordem de $15 \%$ nos finais de semana, conforme Figura 4.5.

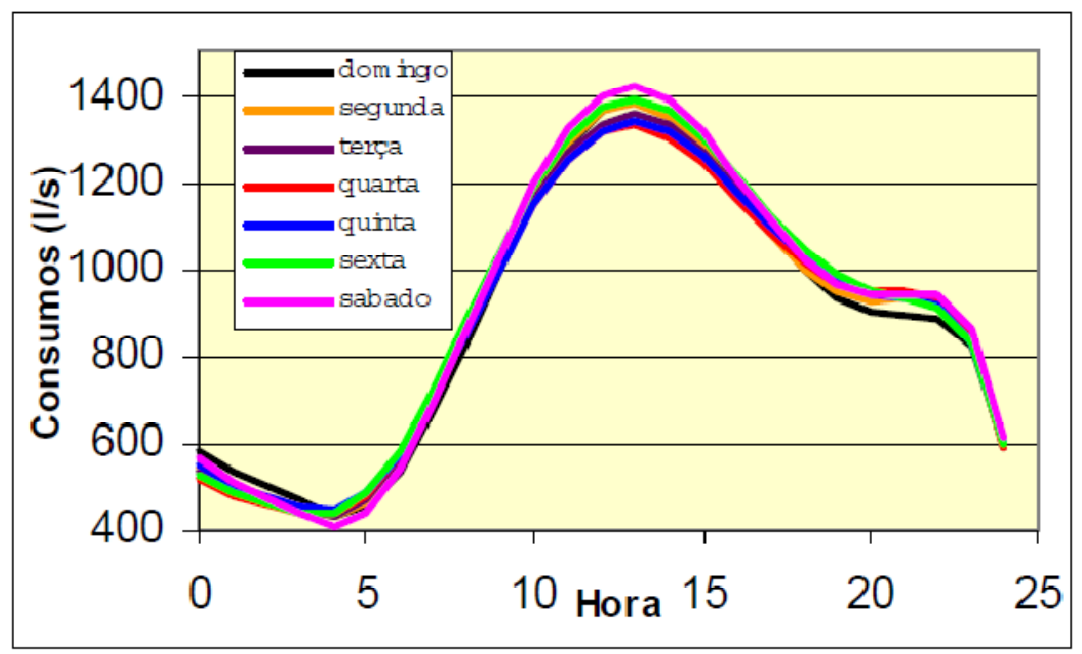

Figura 4.4 - Variação do perfil de consumo em função do dia da semana para o setor Itaim Paulista, predominantemente residencial.

Fonte: Hasegawa; Filho e Ignácio (1999) 


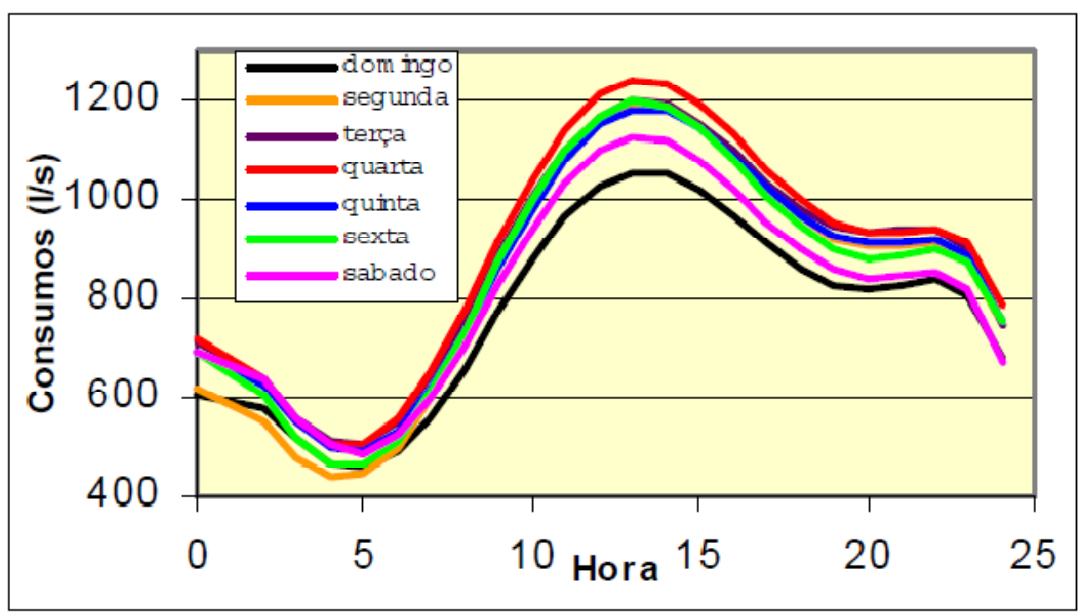

Figura 4.5 - Variação do perfil de consumo em função do dia da semana para o setor Avenida, com ocupação comercial significativa.

Fonte: Hasegawa; Filho e Ignácio (1999)

O Diagnóstico dos Serviços de Água e Esgotos do Sistema Nacional de Informações sobre Saneamento (SNIS) da Secretaria Nacional de Saneamento Ambiental do Ministério das Cidades foi publicado em março de 2010 (ano de referência de 2008), relacionou os consumos médios per capita de água no Brasil a partir de uma amostra altamente representativa (SECRETARIA NACIONAL DE SANEAMENTO AMBIENTAL, 2010).

A tabela a seguir mostra os valores médios per capita encontrados para a amostra total do SNIS em 2007 e 2008, segundo estado, região geográfica e Brasil. 
Tabela 4.5 - Valores do consumo médio per capita de água no Brasil - SNIS - 2008

Estados / Regiões Per Capita 2007 (L/hab*dia) Per Capita 2008 (L/hab*dia). Variação (\%)

\begin{tabular}{|c|c|c|c|}
\hline Acre & 118,7 & 143,7 & $21,1 \%$ \\
\hline Amazonas & 133,3 & 134,1 & $0,6 \%$ \\
\hline Amapá & 156,7 & 160,7 & $2,6 \%$ \\
\hline Pará & 151,4 & 147,4 & $-2,6 \%$ \\
\hline Rondônia & 94,0 & 107,3 & $14,1 \%$ \\
\hline Roraima & 154,7 & 134,1 & $-13,3 \%$ \\
\hline Tocantins & 118,2 & 123,1 & $4,1 \%$ \\
\hline Norte & 134,1 & 135,7 & $1,2 \%$ \\
\hline Alagoas & 89,7 & 89,2 & $-0,6 \%$ \\
\hline Bahia & 122,1 & 121,7 & $-0,3 \%$ \\
\hline Ceará & 151,8 & 131,0 & $-13,7 \%$ \\
\hline Maranhão & 115,4 & 103,8 & $-10,1 \%$ \\
\hline Paraíba & 98,0 & 92,0 & $-6,1 \%$ \\
\hline Pernambuco & 85,1 & 90,2 & $6,0 \%$ \\
\hline Piauí & 103,5 & 109,8 & $6,1 \%$ \\
\hline Rio Grande do Norte & 126,8 & 116,0 & $-8,5 \%$ \\
\hline Sergipe & 119,1 & 117,9 & $-1,0 \%$ \\
\hline Nordeste & 114,8 & 110,5 & $-3,7 \%$ \\
\hline Espírito Santo & 192,4 & 185,0 & $-3,8 \%$ \\
\hline Minas Gerais & 142,5 & 138,3 & $-2,9 \%$ \\
\hline Rio de Janeiro & 205,8 & 236,3 & $14,8 \%$ \\
\hline São Paulo & 175,0 & 176,0 & $0,6 \%$ \\
\hline Sudeste & 173,8 & 178,1 & $2,5 \%$ \\
\hline Paraná & 127,0 & 127,5 & $0,4 \%$ \\
\hline Rio Grande do Sul & 143,7 & 145,4 & $1,2 \%$ \\
\hline Santa Catarina & 134,0 & 141,0 & $5,2 \%$ \\
\hline Sul & 134,9 & 137,2 & $1,7 \%$ \\
\hline Distrito Federal & 182,9 & 175,6 & $-4,0 \%$ \\
\hline Goiás & 127,1 & 125,5 & $-1,3 \%$ \\
\hline Mato Grosso do Sul & 122,4 & 125,5 & $2,5 \%$ \\
\hline Mato Grosso & 165,4 & 166,1 & $0,4 \%$ \\
\hline Centro-Oeste & 145,2 & 143,8 & $-1,0 \%$ \\
\hline Brasil & 149,6 & 151,2 & $1,1 \%$ \\
\hline
\end{tabular}

Fonte: Diagnóstico dos Serviços de Água e Esgotos 2008 do SNIS

Observa-se pequena variação dos valores médios regionais e nacional, e também dos valores dos estados, uma vez que 21 dos 27 consumos médios tiveram variação menor que $10 \%$ e em apenas um caso houve variação superior a $20 \%$.

O consumo médio per capita do país em 2008 foi de 151,2 L/hab.dia. Observa-se que a região Sudeste, com o maior consumo médio regional, foi a única região com 
valor superior à média do país (18\% maior), enquanto que a região Nordeste, com menor valor regional, apresentou resultado $27 \%$ inferior à média de todo o conjunto do SNIS.

Segundo estudo do U.S. Geological Survey, a média de água para abastecimento público dos Estados Unidos da América em 1990 foi de 397 L/hab.dia.

A quantidade de água consumida em uma rede de abastecimento varia continuamente ao longo do dia e ao longo do ano em função das atividades e hábitos da população, condições climáticas e outros (TSUTIYA, 2006).

Normalmente, o consumo doméstico apresenta uma grande variação, enquanto que para o consumo industrial a variação é menor. Quanto ao consumo comercial e público, a variação de consumo situa-se numa posição intermediária.

Para o abastecimento de água, geralmente as variações no consumo podem ser:

- Variação Anual: Variação devido o aumento de consumo de água (aumento populacional e/ou aumento no consumo per capita);

- Variação Mensal: Variação mensal, conforme as estações do ano (verão e inverno);

- Variação Diária: Variação em relação ao consumo médio diário anual, sendo maior no verão e menor no inverno;

- Variação Horária: Variação em relação ao consumo médio diário do dia, sendo geralmente maior entre 10 às 12 horas;

- Variação Instantânea: Variação no atendimento de pontos de consumo desprovidos de reservatório domiciliar.

Para dimensionamento e operação de redes de distribuição de água, são adotados coeficientes apresentados a seguir.

O coeficiente do dia de maior consumo $\mathrm{K}_{1}$ é a relação entre o maior consumo diário verificado no período de um ano e o consumo médio diário neste mesmo período, sendo recomendado um período de observação consecutivo de cinco anos.

Para a determinação desse coeficiente, o ideal é a aferição do mesmo através de série de dados existentes, pois esse valor varia conforme a característica de cada local estudado. 
Na falta de dados existentes, é usual a adoção de valores recomendados, conforme apresentado na Tabela 4.6 abaixo.

Tabela 4.6 - Valores recomendados para o coeficiente $K_{1}$

\begin{tabular}{|c|c|c|c|c|}
\hline Autor / Entidade & Local & Ano & $\begin{array}{c}\text { Coeficiente } \\
\mathrm{K}_{1}\end{array}$ & $\begin{array}{c}\text { Condições de Obtenção do } \\
\text { Valor }\end{array}$ \\
\hline Azevedo Netto et al. & Brasil & 1998 & $1,1-1,4$ & Recomendação para projeto \\
\hline Tsutiya & RMSP - Setor Lapa & 1989 & $1,08-3,8$ & $\begin{array}{l}\text { Medição em sistema operando há } \\
\text { vários anos }\end{array}$ \\
\hline Saporta et al. & Barcelona - Espanha & 1993 & $1,10-1,25$ & $\begin{array}{l}\text { Medição em sistema operando há } \\
\text { vários anos }\end{array}$ \\
\hline Walski et al. & EUA & 2001 & $1,2-3,0$ & Recomendações para projeto \\
\hline Mays & EUA & 1999 & $1,5-3,5$ & $\begin{array}{l}\text { Medição em sistemas norte- } \\
\text { americanos }\end{array}$ \\
\hline Hammer & EUA & 1996 & $1,2-4,0$ & $\begin{array}{l}\text { Medição em sistemas norte- } \\
\text { americanos }\end{array}$ \\
\hline AEP & Canadá & 1996 & $1,5-2,5$ & Recomendações para projeto \\
\hline
\end{tabular}

Fonte: Tsutiya (2006) e Mays (1999)

No Brasil, é comum adotar o valor de 1,2 para $\mathrm{K}_{1}$ para o dimensionamento de sistemas de abastecimento de água.

Através da utilização de uma série histórica de 3,5 anos de dados de consumos horários de cerca de 120 setores pertencentes ao Sistema Adutor Metropolitano (SAM) de São Paulo, foram obtidos os valores do coeficiente associado às frequências de excedência de 1\%, 2.5\%,5\%,10\%, 15\% e 20\% (HASEGAWA; FILHO, IGNÁCIO,1999). Para cada um desses níveis de frequência, foi elaborada uma outra curva com os valores dos coeficientes de todos os setores, indicando os riscos admitidos ao se utilizar esses valores, conforme apresentado na Figura 4.6. 


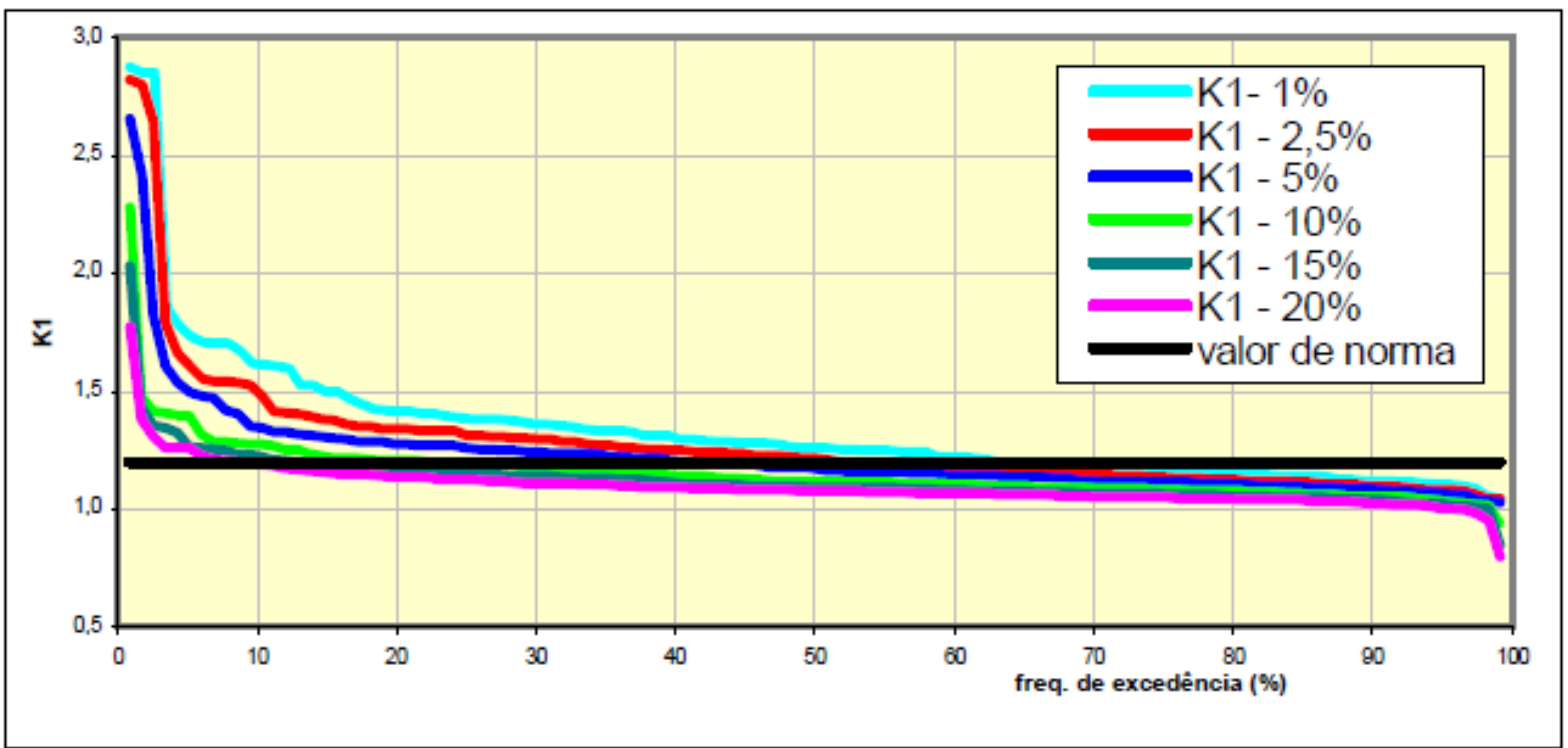

Figura 4.6 - Curvas de Frequência de Excedência de $K_{1}$ para o SAM de São Paulo.

Fonte: Hasegawa; Filho e Ignácio (1999)

Para os mencionados autores, a análise do gráfico da Figura 4.6 mostra que, ao se adotar o coeficiente $\mathrm{K}_{1}$ usualmente utilizado, resulta em uma confiabilidade razoável para uma frequência de excedência de 10, 15 e 20\%, mas ao admitir um risco menor (1, 2.5 e 5\%), a confiabilidade do valor utilizado também diminui. Para uma frequência de excedência de 10\%, pode-se encontrar no gráfico, os seguintes intervalos de variação de $\mathrm{K}_{1}$ :

- Maior que 1,5 em 3\% dos casos;

- Variando entre 1,2 e 1,5 em 20\% dos casos;

- Variando entre 1,1 e 1,2 em 40\% dos casos;

- Variando entre 1,0 e 1,1 em 37\% dos casos.

Para uma frequência de excedência de $10 \%$, observa-se que os valores de $K_{1}$ obtidos do SAM de São Paulo estão mais concentrados na faixa de 1,0 até 1,2. Os valores extremos obtidos de $\mathrm{K}_{1}$ estão em torno de 1,1 e 1,5.

Ainda conforme Hasegawa; Filho e Ignácio (1999), para a Região Metropolitana de São Paulo (RMSP), o uso do coeficiente $\mathrm{K}_{1}$ igual á 1,2 pode gerar riscos que variam com as frequências de excedência, como mostra a Tabela 4.7. 
Tabela 4.7 - Análise de risco na utilização dos valores de $\mathrm{K}_{1}$ de 1,2 para a RMSP

\begin{tabular}{cc}
\hline $\begin{array}{c}\text { Frequência de } \\
\text { excedência (\%) }\end{array}$ & $\begin{array}{c}\text { Risco (\%) admitido } \\
\text { para } \mathbf{K}_{\mathbf{1}}=\mathbf{1 , 2 0}\end{array}$ \\
\hline 1 & 63 \\
\hline 2,5 & 51 \\
\hline 5 & 41 \\
\hline 10 & 22 \\
\hline 15 & 12 \\
\hline 20 & 8 \\
\hline
\end{tabular}

Fonte: Hasegawa; Filho e Ignácio (1999)

Estes resultados, segundo os autores, podem ter discrepâncias, pois a série de dados utilizada engloba o período de transição de alguns setores entre o rodízio (período pré-obra) e a regularização do abastecimento (período pós-obra).

A partir do exposto acima, fica evidente, que estes parâmetros requerem uma avaliação cuidadosa para cada local estudado. A adoção de um valor comum recomendado para projeto pode gerar riscos, que variam com as freqüências de excedência.

O coeficiente da hora de maior consumo $\mathrm{K}_{2}$ é a relação entre a maior vazão horária observada num dia e a vazão média horária do mesmo dia.

Para a determinação desse coeficiente, o ideal é a aferição do mesmo através de série de dados existentes, pois esse valor varia conforme a característica de cada local estudado. Na falta de dados existentes, é usual a adoção de valores recomendados, conforme apresentado na Tabela 4.8 a seguir.

Tabela 4.8 - Valores recomendados para o coeficiente $K_{2}$

\begin{tabular}{|c|c|c|c|c|}
\hline Autor / Entidade & Local & Ano & $\begin{array}{c}\text { Coeficiente } \\
\mathrm{K}_{2}\end{array}$ & $\begin{array}{l}\text { Condições de Obtenção do } \\
\text { Valor }\end{array}$ \\
\hline Azevedo Netto et al. & Brasil & 1998 & $1,5-2,3$ & Recomendação para projeto \\
\hline Tsutiya & RMSP - Setor Lapa & 1989 & $1,5-4,3$ & $\begin{array}{l}\text { Medição em sistema operando há } \\
\text { vários anos }\end{array}$ \\
\hline Saporta et al. & Barcelona - Espanha & 1993 & $1,3-1,4$ & $\begin{array}{l}\text { Medição em sistema operando há } \\
\text { vários anos }\end{array}$ \\
\hline Walski et al. & EUA & 2001 & $3,0-6,0$ & Recomendações para projeto \\
\hline Mays & EUA & 1999 & $2,0-7,0$ & $\begin{array}{l}\text { Medição em sistemas norte- } \\
\text { americanos }\end{array}$ \\
\hline Hammer & EUA & 1996 & $1,5-10,0$ & $\begin{array}{c}\text { Medição em sistemas norte- } \\
\text { americanos }\end{array}$ \\
\hline AEP & Canadá & 1996 & $3,0-3,5$ & Recomendações para projeto \\
\hline
\end{tabular}

Fonte: Tsutiya (2004) e Mays (1999) 
Vale lembrar que em muitos locais nos Estados Unidos da América e no Canadá os sistemas de abastecimento de água não contam com reservatórios domiciliares.

No Brasil, é comum adotar o valor de 1,5 para $\mathrm{K}_{2}$ para o dimensionamento de sistemas de abastecimento de água.

De acordo com o já citado estudo de Hasegawa; Filho e Ignácio (1999), na avaliação do valor de $\mathrm{K}_{2}$ através de 3,5 anos de dados de consumos horários de cerca de 120 setores pertencentes ao Sistema Adutor Metropolitano (SAM) de São Paulo, associado às freqüências de excedência de 1\%, 2.5\%, 5\%, 10\%, 15\% e 20\% de forma similar ao valor de $\mathrm{K}_{1}$ é apresentada na Figura 4.7 .

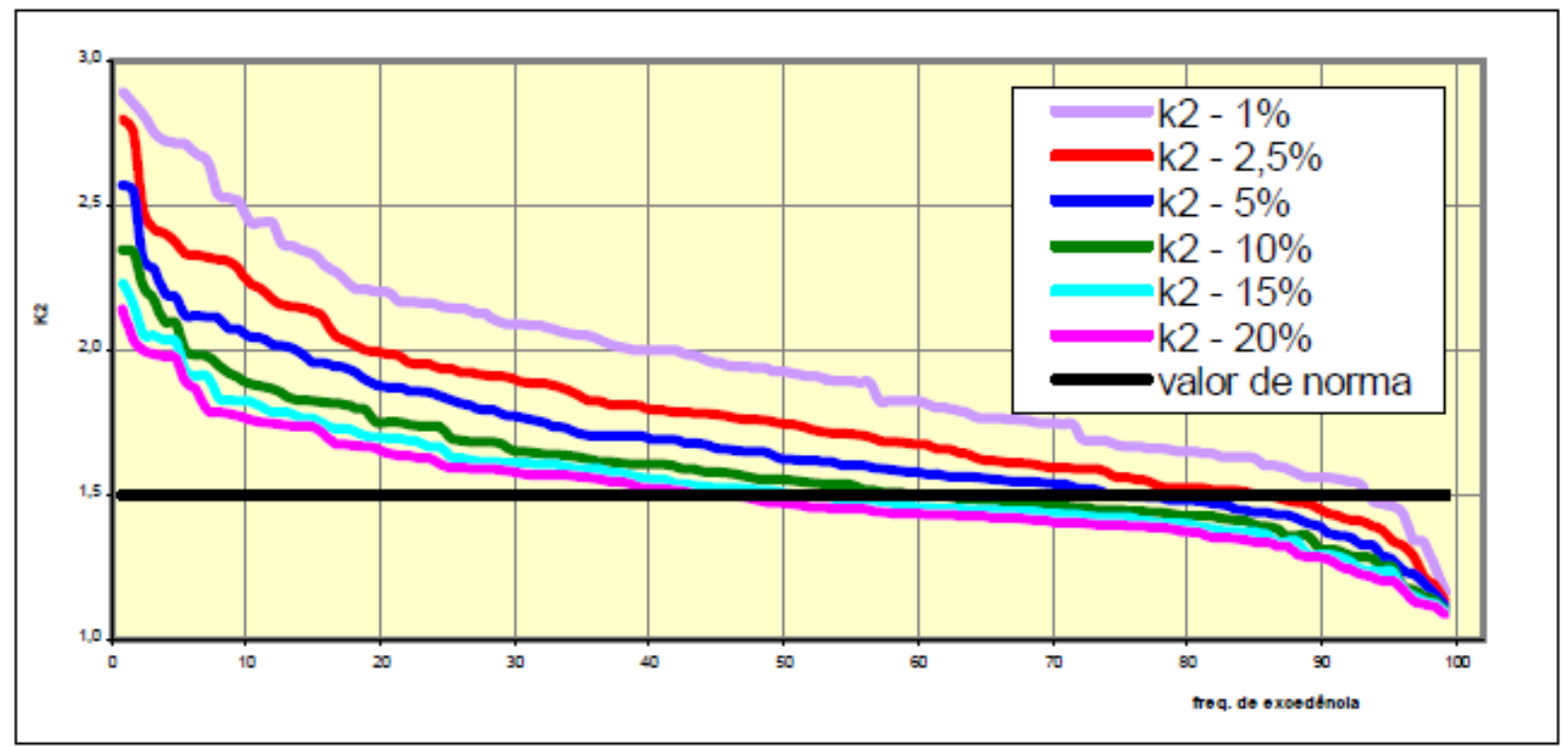

Figura 4.7 - Curvas de Frequência de Excedência de $K_{2}$ para o SAM de São Paulo.

Fonte: Hasegawa; Filho e Ignácio (1999)

Observou-se que ao se adotar o valor usual 1,5, induz-se ao "subdimensionando" do consumo dos setores, pois a confiabilidade que se obtém ao utilizar $K_{2}=1,5$ é muito pequena. Para uma freqüência de excedência de $10 \%$, encontra-se no gráfico os seguintes intervalos de variação de $\mathrm{K}_{2}$ :

- Maior que 2,0 em 5\% dos casos;

- Variando entre 1,5 e 2,0 em 55\% dos casos;

- Variando entre 1,2 e 1,5 em 35\% dos casos;

- Variando entre 1,1 e 1,2 em 5\% dos casos.

Para uma freqüência de excedência de 10\%, pode-se observar que os valores de $\mathrm{K}_{2}$ obtidos do SAM de São Paulo estão mais concentrados na faixa de 1,2 até 2,0. Os 
valores extremos obtidos de $K_{2}$ estão em torno de 1,2 e 2,0. Assim, o uso do coeficiente $K_{2}$ igual 1,50 pode gerar riscos que variam com as freqüências de excedência. Os riscos foram analisados e apresentados na Tabela $4.9 \mathrm{com}$ a ressalva de que os valores podem ter sido afetados pelos períodos de transição dos sistemas (pré e pós obra).

Tabela 4.9 - Análise de risco na utilização dos valores de $\mathrm{K}_{2}$ de 1,5 para a RMSP

\begin{tabular}{cc}
$\begin{array}{c}\text { Freqüencia de } \\
\text { excedência (\%) }\end{array}$ & $\begin{array}{c}\text { Risco }(\%) \text { admitido } \\
\text { para } \mathbf{K}_{\mathbf{2}} \mathbf{= 1 , 5 0}\end{array}$ \\
\hline 1 & 93 \\
\hline 2,5 & 85 \\
\hline 5 & 74 \\
\hline 10 & 61 \\
\hline 15 & 51 \\
\hline 20 & 46 \\
\hline
\end{tabular}

Fonte: Hasegawa; Filho e Ignácio (1999)

Hasegawa; Filho e Ignácio (1999) também analisaram os perfis típicos de curvas de consumo de 22 setores de abastecimento da Região Metropolitana de São Paulo, para o mesmo período utilizado para a obtenção dos coeficientes $\mathrm{K}_{1}$ e $\mathrm{K}_{2}$.

A Figura 4.8 apresenta as curvas médias adimensionais, obtidas dividindo-se a vazão média de consumo em cada hora pelo consumo médio do setor. A partir dessas curvas, pode-se observar um comportamento típico para a maioria dos setores, em que a vazão mínima ocorre por volta das $3 \mathrm{~h}$, a vazão máxima por volta das $12 \mathrm{~h}$ e a vazão média é coincidente com o consumo do período entre as 7 e $8 \mathrm{~h}$ e entre $18 \mathrm{~h}$ e $22 \mathrm{~h}$. 


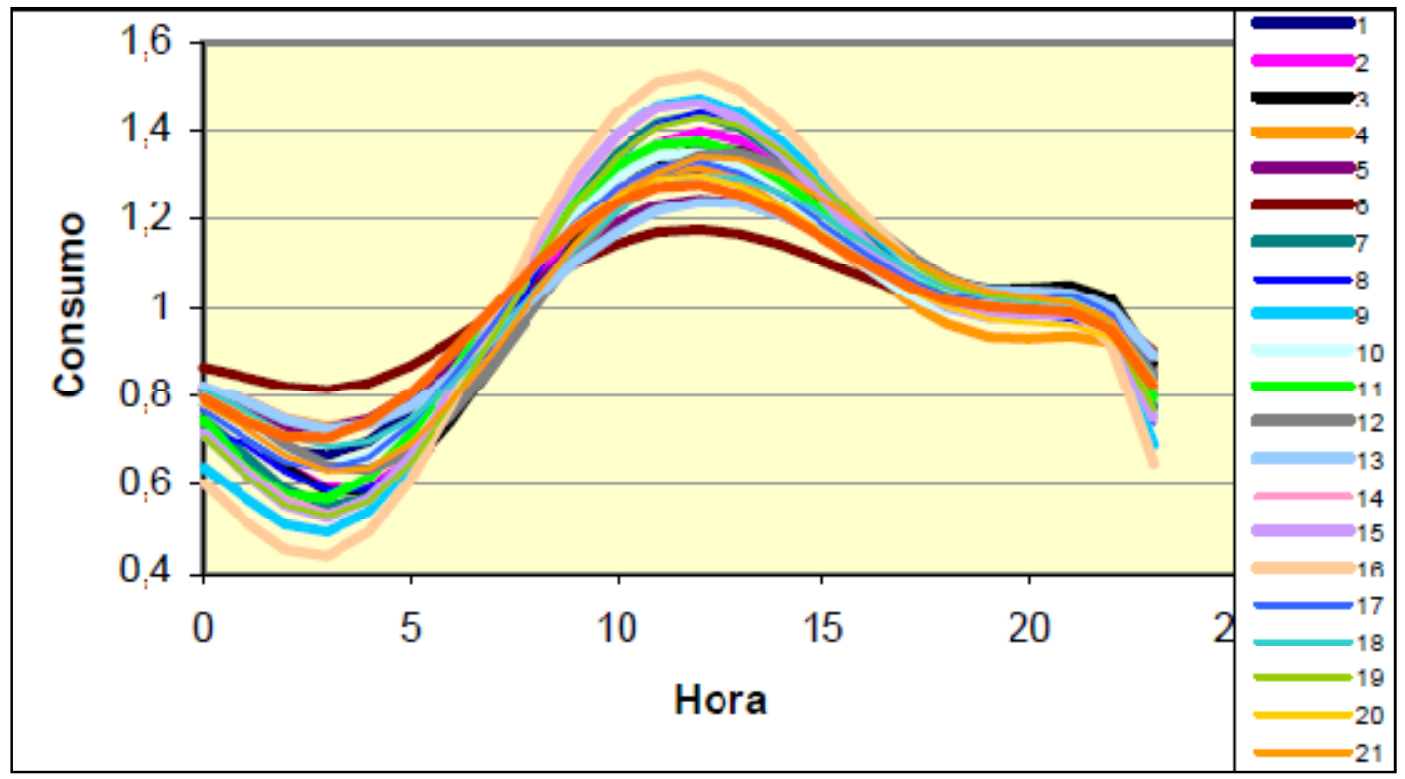

Figura 4.8 - Perfis de Consumo para os 22 setores da RMSP Fonte: Hasegawa; Filho e Ignácio (1999)

Segundo os autores, a análise da variação dos perfis de consumo dos setores Avenida e Itaim Paulista, setores respectivamente comercial e residencial, mostrou que, para diferentes dias da semana, não há uma tendência de alteração na forma do perfil de consumo, e tampouco no consumo propriamente dito quando se analisa o setor Itaim Paulista. Para o setor Avenida, há uma pequena diferença nos valores de consumo do sábado e domingo, porém não há alteração na forma dos perfis.

Hasegawa, Filho e Ignácio (1999) observaram que o comportamento da curva de consumo em um dia qualquer pode ser diferente da curva média do setor, em função de outros parâmetros intervenientes, sendo recomendada a aplicação de curvas de dias típicos de consumo do setor ao invés de uma curva média.

Os sistemas de abastecimento de água devem ser projetados para atender uma determinada população, em geral maior que a atual, que corresponde ao crescimento demográfico para um determinado número de anos. Esse período de tempo é denominado horizonte de projeto, que normalmente é adotado um período de 20 anos.

Para a estimativa populacional, devem ser considerados os seguintes fatores: as especificidades da área de projeto, suas características sócio-econômicas, urbanísticas e a dinâmica da ocupação do solo. 
A partir da estimativa populacional, a implantação do sistema de abastecimento de água pode ser avaliada e subdividida em etapas para evitar ociosidade do mesmo.

\subsection{CRITÉRIOS DE DIMENSIONAMENTO HIDRÁULICO}

A seguir são apresentados os critérios de dimensionamento adotados neste trabalho em relação aos limites de pressão, velocidade, vazão, diâmetro e perda de carga.

Para o dimensionamento de rede de distribuição, são estabelecidos limites de pressão mínima dinâmica e pressão máxima estática.

O limite de pressão mínima visa garantir o atendimento adequado nos pontos de consumo.

O limite de pressão máxima está relacionado à resistência das tubulações e às perdas físicas, sendo usualmente desconsiderado um fator muito importante que é o custo energético de bombeamento.

De acordo com a norma NBR 12118 da ABNT (1994), a pressão dinâmica mínima na rede deve ser 100 kPa e pressão estática máxima na rede deve ser $500 \mathrm{kPa}$.

Esta mesma norma estabelece que em trechos de condutos principais que não abastecem consumidores ou tubulações secundárias não estão sujeitos aos limites de pressão estabelecidos acima, mas devem ser verificados quanto à estabilidade estrutural e à segurança sanitária.

Segundo Mays (1999), nos Estados Unidos da América, onde as residências não possuem reservatórios domiciliares, é usual adotar que:

- A pressão mínima não deve ser menor que 30 psi (cerca de 210 kPa); e

- A pressão máxima não deve ser maior que 80 psi (cerca de 560 kPa).

O limite da velocidade mínima é recomendado para que haja uma permanente circulação de água na rede de forma a não prejudicar a qualidade da água fornecida ao consumidor, conforme menciona Gomes (2004).

Para Tsutiya (2006), o uso de baixas velocidades na rede de distribuição favorece a durabilidade, sob aspecto da abrasão das tubulações e peças especiais, além de minimizar os efeitos dos transientes hidráulicos ocasionados pelas variações de pressão. Já a utilização de velocidades altas na rede de distribuição propiciam a redução dos diâmetros das tubulações e consequentemente o custo de aquisição e 
assentamento das mesmas, entretanto, causam aumento da perda de carga e dos custos de energia elétrica nos bombeamentos ou na altura dos reservatórios, provocam ruídos nas tubulações, além de favorecer o desgaste por abrasão e a cavitação de peças e válvulas, aumentando os custos de manutenção.

Segundo a norma NBR 12118 da ABNT, a velocidade mínima deve ser de 0,6 m/s e a máxima de $3,5 \mathrm{~m} / \mathrm{s}$ para as demandas máximas diárias no início e no final da etapa de execução da rede. Observa-se que não são encontradas justificativas embasadas para estes valores.

Para as velocidades máximas admissíveis nos dimensionamentos, Porto (1998) recomenda adotar a equação empírica, onde a velocidade está limitada a 2,0 m/s.

$$
V_{\max }=0,60+1,5 \cdot D
$$

sendo: $\quad V_{\max }=$ velocidade máxima $(\mathrm{m} / \mathrm{s})$;

$D=$ diâmetro $(\mathrm{m})$.

Também é usual adotar os valores recomendados por Martins (1976). Estes valores são apresentados na Tabela 4.10.

Tabela 4.10 - Velocidades Máximas Usuais

\begin{tabular}{ccc}
\hline \multirow{2}{*}{ Diâmetro (mm) } & \multicolumn{2}{c}{ Velocidades Máximas (m/s) } \\
\cline { 2 - 3 } & Porto (1998) & Martins (1976) \\
\hline 50 & 0,68 & 0,50 \\
\hline 75 & 0,71 & 0,50 \\
\hline 100 & 0,75 & 0,60 \\
\hline 150 & 0,83 & 0,80 \\
\hline 200 & 0,90 & 0,90 \\
\hline 250 & 0,98 & 1,10 \\
\hline 300 & 1,05 & 1,20 \\
\hline 350 & 1,13 & 1,30 \\
\hline 400 & 1,20 & 1,40 \\
\hline 450 & 1,28 & 1,50 \\
\hline 500 & 1,35 & 1,60 \\
\hline 550 & 1,43 & 1,70 \\
\hline 600 & 1,50 & 1,80 \\
\hline
\end{tabular}

O limite de vazão máxima e mínima está relacionado com o limite das velocidades máximas e mínimas, sendo que as mesmas devem atender as demandas máximas diárias no início e no final da etapa de execução da rede. 
Obedecendo aos limites da norma NBR 12118 da ABNT, obtém-se as seguintes vazões mínimas e máximas admissíveis apresentadas na tabela abaixo.

Tabela 4.11 - Vazões Mínimas e Máximas conforme NBR 12118

\begin{tabular}{|c|c|c|c|c|}
\hline $\begin{array}{l}\text { Diâmetro } \\
\text { (mm) }\end{array}$ & $\begin{array}{l}\text { Velocidade Mínima } \\
(\mathrm{m} / \mathrm{s})\end{array}$ & $\begin{array}{l}\text { Velocidade Máxima } \\
\qquad(\mathrm{m} / \mathrm{s})\end{array}$ & $\begin{array}{c}\text { Vazão Mínima } \\
\text { (L/s) }\end{array}$ & $\begin{array}{c}\text { Vazão Máxima } \\
\text { (L/s) }\end{array}$ \\
\hline 50 & 0,6 & 3,5 & 1,2 & 6,9 \\
\hline 75 & 0,6 & 3,5 & 2,7 & 15,5 \\
\hline 100 & 0,6 & 3,5 & 4,7 & 27,5 \\
\hline 150 & 0,6 & 3,5 & 10,6 & 61,9 \\
\hline 200 & 0,6 & 3,5 & 18,8 & 110,0 \\
\hline 250 & 0,6 & 3,5 & 29,5 & 171,8 \\
\hline 300 & 0,6 & 3,5 & 42,4 & 247,4 \\
\hline 350 & 0,6 & 3,5 & 57,7 & 336,7 \\
\hline 400 & 0,6 & 3,5 & 75,4 & 439,8 \\
\hline 450 & 0,6 & 3,5 & 95,4 & 556,7 \\
\hline 500 & 0,6 & 3,5 & 117,8 & 687,2 \\
\hline 550 & 0,6 & 3,5 & 142,5 & 831,5 \\
\hline 600 & 0,6 & 3,5 & 169,6 & 989,6 \\
\hline
\end{tabular}

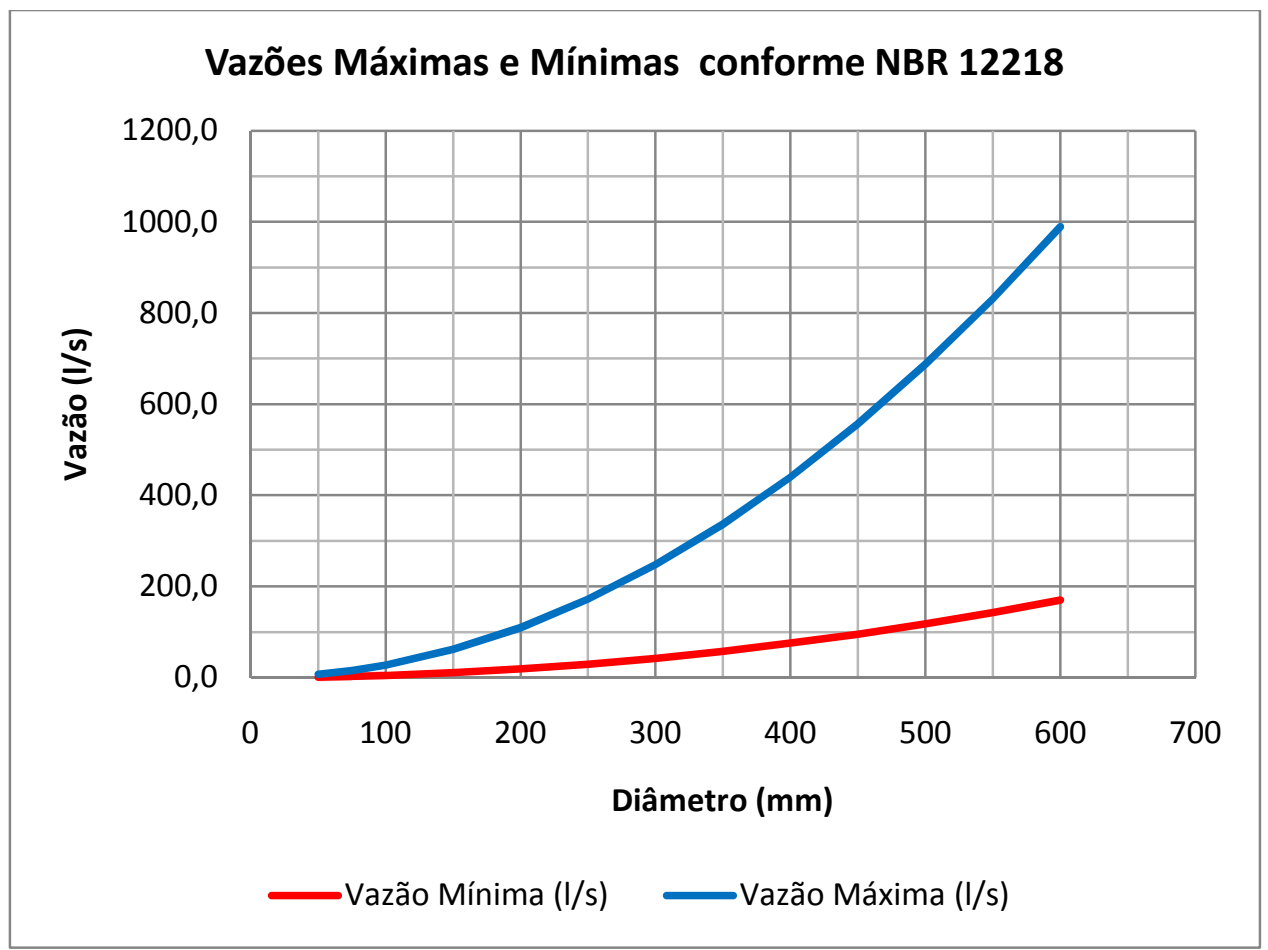

Figura 4.9 - Limites de Vazões conforme NBR 12118 
A partir das velocidades máximas recomendadas por Porto (1998), Martins (1976) e pela NBR 12218, resulta o seguinte gráfico comparativo entre as vazões máximas, conforme Figura 4.10.

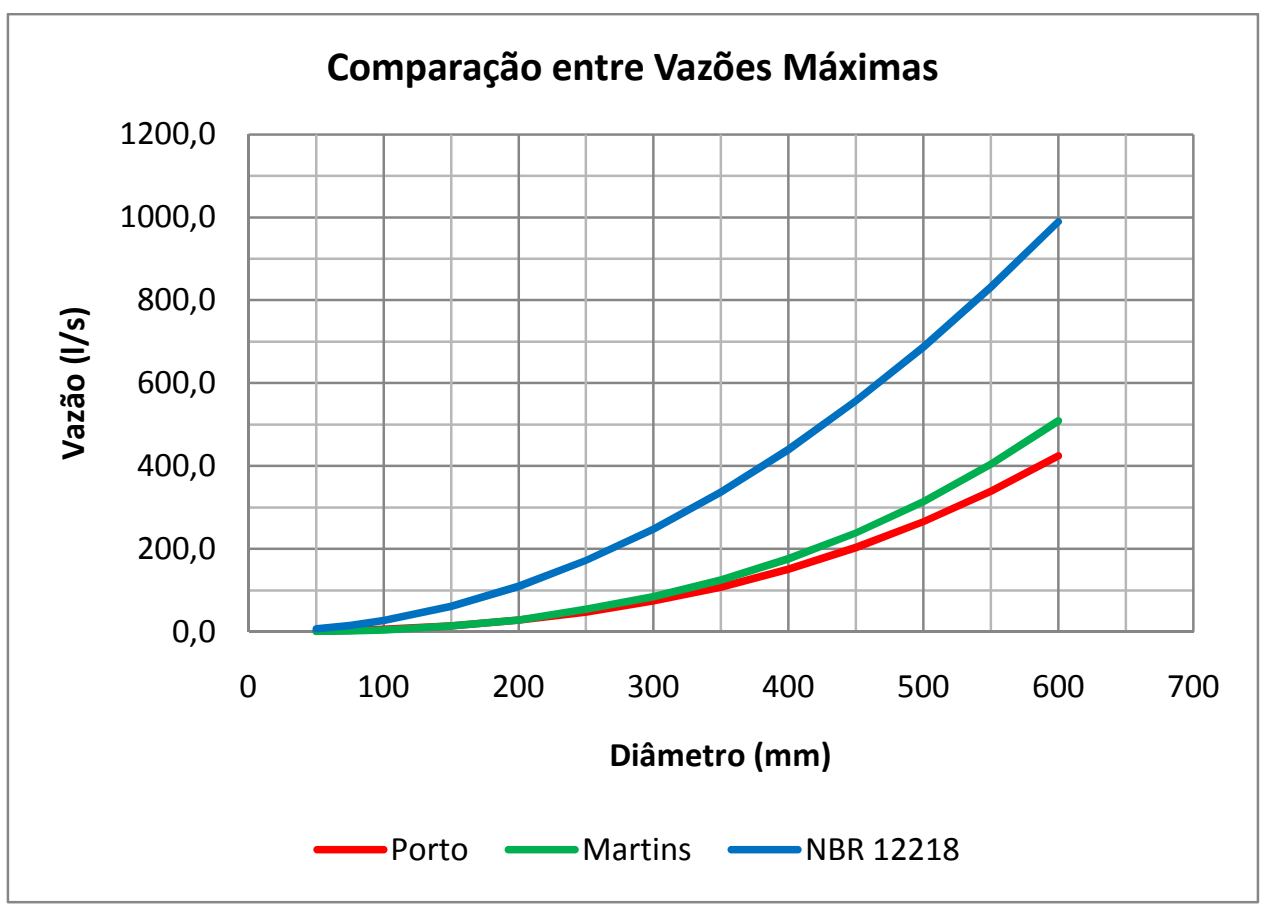

Figura 4.10 - Comparação das Vazões Máximas por Porto, Martins e NBR 12218 É usual ainda adotar os valores recomendados por Martins (1976) apresentadas na tabela abaixo.

Tabela 4.12 - Vazões Máximas conforme Martins (1976)

Diâmetro (mm)

\begin{tabular}{cc}
\hline 50 & 1,0 \\
\hline $\mathbf{7 5}$ & $\mathbf{2 , 2}$ \\
\hline 100 & 4,7 \\
\hline 150 & 14,1 \\
\hline 200 & 28,3 \\
\hline 250 & 53,9 \\
\hline 300 & 84,8 \\
\hline 350 & 125,0 \\
\hline 400 & 176,0 \\
\hline 450 & 238,0 \\
\hline 500 & 314,0 \\
\hline 550 & 403,0 \\
\hline 600 & 509,0 \\
\hline
\end{tabular}


A escolha do diâmetro mínimo a ser adotado para as redes de distribuição de água deve levar em conta as perdas de carga e as vazões requeridas.

Segundo o critério da norma NBR 12118 da ABNT, o diâmetro mínimo dos condutos secundários é de $50 \mathrm{~mm}$, porém não há nenhuma recomendação para as tubulações principais.

Na antiga norma PNB 594 da ABNT, a recomendação para os diâmetros mínimos das tubulações principais das redes malhadas era:

- Diâmetro igual a $150 \mathrm{~mm}$ quando abastecem zonas comerciais ou zonas residenciais com densidade igual ou superior a $150 \mathrm{hab} . / \mathrm{ha}$;

- Diâmetro igual a 100 mm quando abastecem as demais zonas de núcleos urbanos, cuja população de projeto é superior a 5.000 habitantes;

- Diâmetro igual a $75 \mathrm{~mm}$ para núcleos urbanos cuja população de projeto é igual ou inferior a 5.000 habitantes.

Ainda de acordo com a norma NBR 12118 da ABNT, não há nenhuma recomendação para o valor da perda de carga máxima.

Na antiga norma PNB 594 da ABNT, era recomendado o valor máximo de perda de carga de $8 \mathrm{~m} / \mathrm{km}$ para determinação do limite máximo de vazão das tubulações secundárias, conforme diâmetro e material da mesma.

A perda de carga máxima admissível deverá ser avaliada para cada situação. A princípio, em sistemas de distribuição de água com topografia acidentada, a perda de carga não é um fator limitante, pois existe energia suficiente. Isso não ocorre em sistemas de distribuição de água com topografia plana, onde a perda de carga tem que ser minimizada.

O cálculo da perda de carga distribuída deve ser feito preferencialmente pela fórmula universal (NBR 12218, 1994), considerando, também, o efeito do envelhecimento do material das tubulações da rede.

O sistema de distribuição não deve ser dimensionado com capacidade excessiva, pois resultarão em longos tempos de trânsito da água entre a unidade de tratamento e o consumidor. A capacidade excessiva somente é justificada para o atendimento do aumento da demanda futura já conhecida, porém existe a possibilidade de 
construção de unidades em etapas, que evita a ociosidade de instalações e aperfeiçoa a utilização de recursos financeiros.

Devem ser evitados situações de baixa vazão, zonas mortas e curtos-circuitos, pois podem causar problemas de longos tempos de residência e trechos nos quais pode ocorrer o acúmulo de sedimentos.

Os microrganismos fecais e vírus humanos podem estar presentes na água subterrânea próxima a tubulação e durante transientes de baixa ou negativa pressão poderão ser arrastados para dentro da rede. Os trechos que podem ocorrer pressões negativas podem ser identificados na modelagem matemática.

Tais situações podem ocorrer onde houver:

- Residências em áreas de topografia elevada;

- Propriedades remotas no fim de longos trechos de tubulações;

- Demandas que sejam maiores que as projetadas;

- Tubulações de capacidade inadequada (diâmetros pequenos);

- Tubulações rugosas (tubulações de ferro corroídas ou tubulações com excesso de sedimentos);

- Falha em equipamentos (bombas e válvulas).

\subsection{MÉTODOS DE DIMENSIONAMENTO DE REDES}

A maior parte dos sistemas de abastecimento de água no mundo foi construída muito antes da disponibilidade das ferramentas de modelagem desenvolvidas nas últimas décadas. Muito foi realizado com só gráficos, réguas de cálculo e bom senso.

Dentre esses vários colaboradores, pode-se citar alguns trabalhos precursores que contribuíram com o desenvolvimento de equações, gráficos e metodologias hidráulicas, que criaram condições para o desenvolvimento do dimensionamento hidráulico de sistema de abastecimento de água.

A partir desses trabalhos precursores e do avanço tecnológico, foi possível o aprimoramento dos dimensionamentos hidráulicos de sistema de abastecimento de água, através de novas metodologias e ferramentas de modelagem. 


\subsubsection{Trabalhos Precursores}

Em 97 a.C, Sexto Júlio Frontino, comissário de água de Roma, escreveu os primeiros livros de hidráulica, descrevendo a construção do sistema de abastecimento de água de Roma. A engenharia romana era baseada mais em regras gerais, em vez de princípios científicos. Os primeiros sistemas de água dependiam principalmente de escoamento em canal aberto, porém foram utilizados condutos fechados para o abastecimento de fontes e banheiros públicos.

No início do século XVII, Benedetto Castelli formulou a relação entre fluxo, velocidade e a área de conduto, através da seguinte equação (4.2).

$$
Q=A \cdot V
$$

Sendo:

$Q=\operatorname{Vazão}\left(\mathrm{m}^{3} / \mathrm{s}\right)$;

$A=$ Área da tubulação $\left(\mathrm{m}^{2}\right)$;

$V=$ Velocidade média $(\mathrm{m} / \mathrm{s})$.

Em meados do século XVIII, Daniel Bernoulli e o seu pai Johann aplicaram as primeiras descobertas de Isaac Newton e Leibniz no campo da física e da matemática para analisar o fluxo de fluídos. De Leibniz, utilizou um estudo sobre o princípio da energia, onde relacionava as parcelas de energia potencial e cinética. De Newton, usou a equação de impulso para avaliar separadamente o termo da pressão correspondente.

Daniel Bernoulli publicou o livro Hydrodynamica em 1738, que foi o livro de hidráulica mais completo em seu tempo. Os princípios contidos nesse livro foram à chave para os princípios da energia usados nos modelos hidráulicos e a base para vários dispositivos, tais como o medidor de Venturi e a asa de avião.

A equação atribuída a Bernoulli (equação 4.3) e muitas outras equações básicas na hidráulica foi de fato desenvolvida por Leonhard Euler em 1752.

$$
z_{1}+\frac{V_{1}^{2}}{2 g}+\frac{p_{1}}{\gamma}=\text { constante }
$$

Para o escoamento em tubulação entre dois pontos, a perda de carga pode ser inclusa, conforme equação 4.4 . 


$$
z_{1}+\frac{V_{1}^{2}}{2 g}+\frac{p_{1}}{\gamma}=z_{1}+\frac{V_{1}^{2}}{2 g}+\frac{p_{1}}{\gamma}+\Delta h
$$

Sendo:

$Z=$ Elevação $(\mathrm{m})$;

$V=$ Velocidade $(\mathrm{m} / \mathrm{s})$;

$g=$ Aceleração da gravidade $\left(\mathrm{m} / \mathrm{s}^{2}\right)$;

$p=$ Pressão $(\mathrm{Pa})$;

$\gamma=$ Peso especííco do fluído $\left(\mathrm{N} / \mathrm{m}^{3}\right)$;

$\Delta h=$ Perda de carga $(\mathrm{m})$.

Antoine Chézy foi o primeiro a estender a idéia que é necessária certa energia para o movimento de fluídos sob pressão numa tubulação, onde mostrou que a perda de carga é proporcional à velocidade ao quadrado, conforme equação 4.5.

$$
V=C \sqrt{R_{H} \cdot J}
$$

Sendo:

$V=$ Velocidade $(\mathrm{m} / \mathrm{s})$;

$C=$ Constante de Chézy;

$R_{H}=$ Raio hidráulico $(\mathrm{m})$;

$J=$ Perda de carga unitária $(\mathrm{m} / \mathrm{m})$.

Todas as equações posteriores de perda de carga em regime turbulento estão relacionadas ao seu trabalho.

Em 1839, Gotthilf Hagen e Jean Louis Poiseuille desenvolveram uma equação empírica para a determinação de perda de carga em regime laminar em tubulações pequenas, conforme equação 4.6 .

$$
V=\frac{\Delta p \cdot D^{2}}{32 \cdot \mu \cdot L}
$$

Sendo:

$V=$ Velocidade $(\mathrm{m} / \mathrm{s})$;

$\Delta p=$ Variação de pressão $(\mathrm{Pa})$;

$D=$ Diâmetro da tubulação $(\mathrm{m})$;

$\mu=$ viscosidade dinâmica do fluído (Pa's); 
$L=$ comprimento da tubulação $(\mathrm{m})$.

Nesse tipo de regime a resistência ao escoamento é devida inteiramente à viscosidade. Mesmo que o regime laminar não tenha a mesma importância na distribuição de água do que o regime turbulento, esta equação é útil para a compreensão global da perda de carga em tubulações.

O aspecto mais importante da equação de Poiseuille e Hagen foi de ser considerada a primeira equação de atrito de fluido com precisão moderna.

Em 1856, Franz Neuman and Eduard Hagenbach deduziram teoricamente a equação de Hagen-Poiseuille.

Em 1845, Júlio Weisbach e Henry Darcy desenvolveram uma fórmula mais geral sobre a perda de carga em tubulações, a qual é uma extensão do trabalho de Chézy.

A equação é apresentada a seguir e ainda é considerada a fórmula teoricamente mais correta para a perda de carga em tubulações, sendo conhecida como fórmula universal.

$$
h_{f}=f \frac{L \cdot V^{2}}{2 \cdot g \cdot D}
$$

Sendo:

$h_{f}=$ perda de carga $(\mathrm{m})$;

$f=$ coeficiente de atrito;

$L=$ comprimento da tubulação $(\mathrm{m})$;

$V=$ Velocidade $(\mathrm{m} / \mathrm{s})$;

$g=$ Aceleração da gravidade $\left(\mathrm{m} / \mathrm{s}^{2}\right)$;

$D=$ Diâmetro da tubulação $(\mathrm{m})$.

O coeficiente de atrito $f$ era expresso pela seguinte equação, onde o valores de $\alpha \mathrm{e}$ $\beta$ são coeficientes de atrito, que variam de acordo com o diâmetro e o material da tubulação.

$$
f=\alpha+\frac{\beta}{\sqrt{V}}
$$


A equação 4.8 foi baseada em um conjunto de dados relativamente pequeno. Weisbach relatou 11 de seus próprios experimentos, enquanto 51 medições foram tomadas a partir dos relatórios de Claude Couplet, Bossut Charles, Pierre Du Buat, Gaspard Riche de Prony e Eytelwein Johann.

Ao contrário das demais teorias, consideraram que o coeficiente de atrito da tubulação era uma função, tanto da rugosidade, como do diâmetro da tubulação. Portanto, é tradicional chamar $f$, o coeficiente $f$ de Darcy, embora ele nunca tenha proposto dessa forma.

Em 1883, Osborne Reynolds investigou os regimes de escoamento diferentes e foi a primeira pessoa capaz de definir claramente a distinção entre o regime laminar e o turbulento através de experimentos. Ele identificou o número adimensional para caracterizar qualquer tipo de escoamento existente, a partir da equação 4.9.

$$
R_{e}=\frac{V \cdot D}{v}
$$

Sendo:

$R_{e}=$ número de Reynolds;

$V=$ Velocidade $(\mathrm{m} / \mathrm{s})$;

$D=$ Diâmetro da tubulação $(\mathrm{m})$;

$\nu=$ Viscosidade cinemática do fluído $\left(\mathrm{m}^{2} / \mathrm{s}\right)$.

Para número de Reynolds abaixo de 2000, o regime de escoamento é laminar na tubulação. Para valores acima de 4000, o regime de escoamento é turbulento. Para valores entre 2000 a 4000, é considerada zona de transição.

Embora a equação de Darcy-Weisbach pudesse ser utilizada para determinação da perda de carga em tubulações, a grande dificuldade era a obtenção do coeficiente de atrito $(f)$.

Em 1906, Alan Hazen e G. S. Williams desenvolveram uma equação empírica para a perda de carga no regime de escoamento turbulento rugoso adotando um coeficiente $\mathrm{C}$ em vez do fator de atrito, conforme apresentado na equação 4.10.

$$
J=10,643 \cdot Q^{1,85} \cdot C^{-1,85} \cdot D^{-4,87}
$$

Sendo: 
$J=$ perda de carga unitária $(\mathrm{m} / \mathrm{m})$;

$Q=$ vazão $\left(\mathrm{m}^{3} / \mathrm{s}\right)$;

$C=$ coeficiente de rugosidade de Hazen-Williams;

$D=$ diâmetro $(\mathrm{m})$.

O coeficiente $C$ está relacionado ao material e a idade de uso da tubulação, sendo o seu valor obtido facilmente através de tabelas publicadas por Williams e Hazen. A facilidade na aplicação fez a equação Hazen-Williams ser amplamente utilizada na prática de engenharia até hoje.

Devido a sua natureza empírica, a equação Hazen-Williams possui uma faixa de aplicação muito restrita. Muitos livros didáticos e manuais de software estabelecem valores do coeficiente $C$ com base apenas no tipo de tubulação, da condição e da idade, porém não informam os seus limites de aplicação em relação ao regime de escoamento e a viscosidade do fluído.

O nível de erro é significativo, quando a equação de Hazen-Williams é usada fora dos limites de aplicação, o que não ocorre com a equação teórica de DarcyWeisbach.

No início do século XX, cientistas alemães liderados por Ludwig Prandtl e os seus estudantes Theodor von Karmen, Johan Nikuradse, Henrich Blasius e Thomas Stanton estudaram exaustivamente a relação entre corpos sólidos e fluidos móveis.

Como resultado das suas pesquisas, eles foram capazes de verificar que a natureza da camada limite do arrasto entre as paredes de tubulações e um fluído determina o arraste e a perda de carga. Esse trabalho identificou três tipos de camadas limite em tubulações: a laminar, transição e turbulento.

Johan Nikuradse desenvolveu um famoso experimento, onde simulou uma mesma rugosidade relativa através de grãos de areia uniformes colados dentro de tubos de diâmetros diferentes. Verificou que para um determinado valor do número de Reynolds, o coeficiente de atrito $f$ era o mesmo para todas as tubulações. Isso veio a comprovar que o coeficiente de atrito $f$ é função do número de Reynolds e da rugosidade relativa (relação da espessura ou altura da rugosidade com o diâmetro da tubulação). 
Ao contrário das tubulações utilizadas por Nikuradse em seus experimentos, as medições realizadas por Cyril Colebrook e Cedric White (1938) mostraram que os tubos industriais com rugosidade não-uniformes, não apresentavam as mesmas curvas de transição. Para toda a região de regime turbulento, propuseram à seguinte equação empírica, conforme apresentado na equação 4.11 .

$$
\frac{1}{\sqrt{f}}=-2 \cdot \log \left\lfloor\frac{\varepsilon}{3,7 D}+\frac{2,51}{R_{e} \sqrt{f}}\right\rfloor
$$

Sendo:

$f=$ coeficiente de atrito;

$\mathcal{E}=$ espessura ou altura da rugosidade da tubulação $(\mathrm{m})$;

$D=$ Diâmetro da tubulação (m);

$R_{e}=$ número de Reynolds.

A equação de Colebrook pode ser convenientemente representada num diagrama, conforme publicados por Hunter Rouse e Lewis Moody.

$\mathrm{Na}$ Figura 4.11, é apresentado o diagrama de Rouse e na Figura 4.12, é acrescentado o diagrama de Moody.

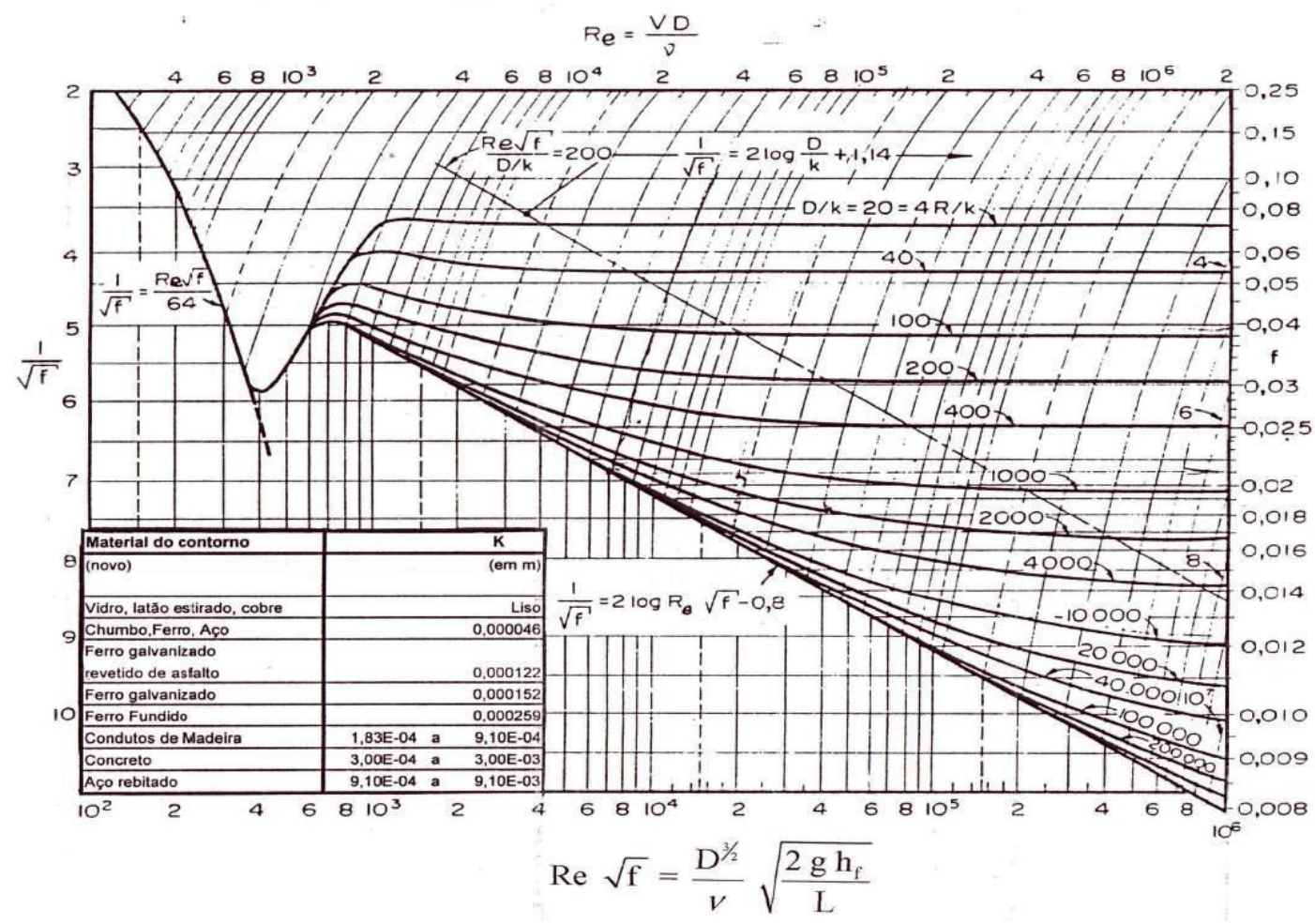

Figura 4.11 - Diagrama de Rouse 


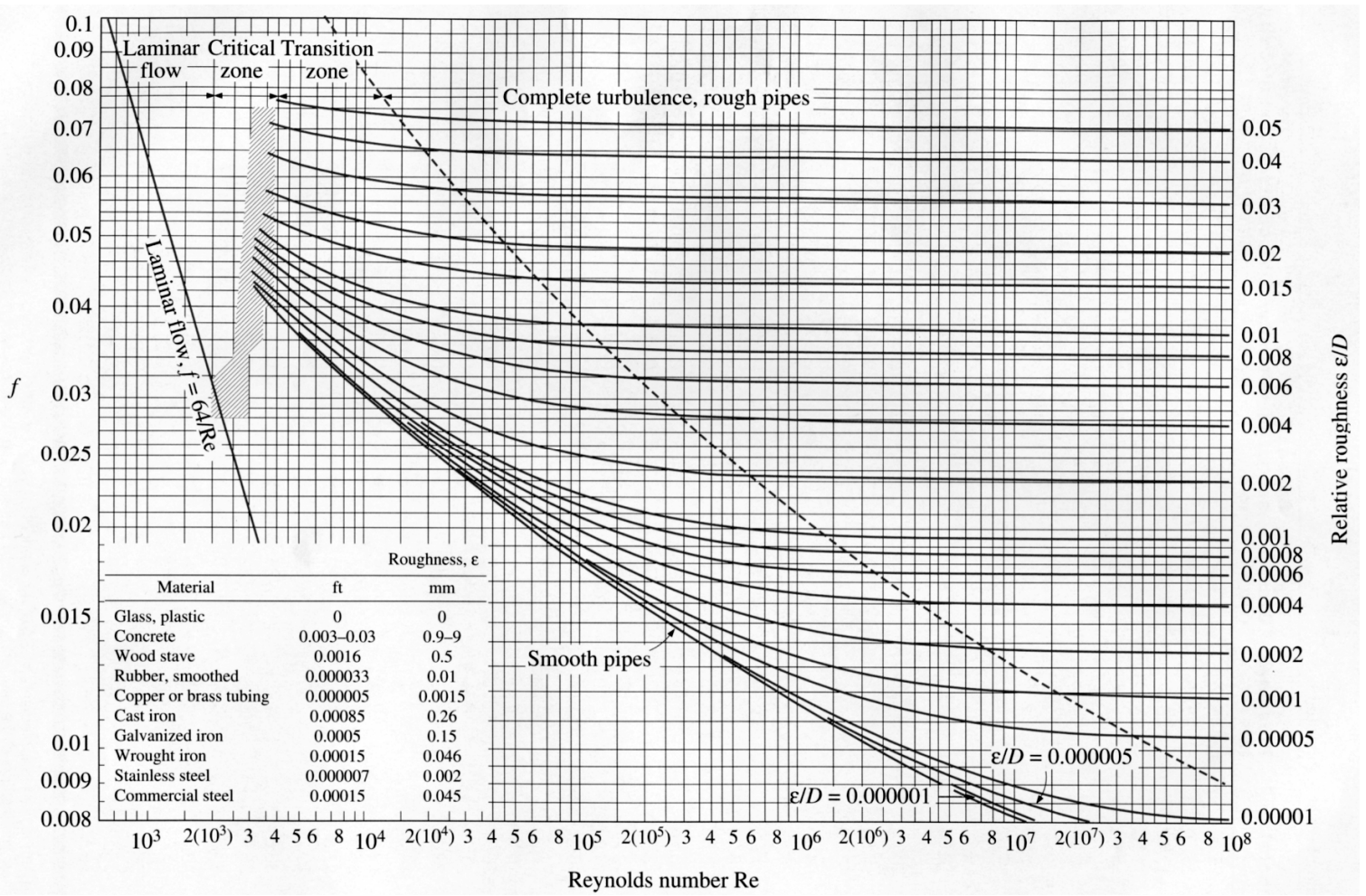

Figura 4.12 - Diagrama de Moody

Deve observar-se que o diagrama de Moody é mais conveniente usar para encontrar o valor de $\mathrm{h}$ conhecendo os valores de $\mathrm{Q}$ e D. Contudo, o diagrama de Rouse permite uma solução direta, não-iterativa do valor de $Q$ conhecendo os valores de $h$ e D. Assim, cada um tem as suas vantagens.

Também é prática e interessante a expressão combinada proposta por Swamee (1976) apud Porto (2006) para o cálculo explícito do fator f, que permite a obtenção do diagrama apresentado na Figura 4.13.

$$
f=\left\{\left(\frac{64}{R e}\right)^{8}+9,5\left[\ln \left(\frac{\varepsilon}{14,8 \cdot R h}+\frac{5,74}{R e^{0,9}}\right)-\left(\frac{2500}{R e}\right)^{6}\right]^{-16}\right\}^{0,125}
$$

Sendo:

$f=$ coeficiente de atrito;

$\mathcal{E}=$ espessura ou altura da rugosidade da tubulação $(\mathrm{m})$;

$R_{h}=$ Raio Hidráulico (m);

$R_{e}=$ número de Reynolds. 


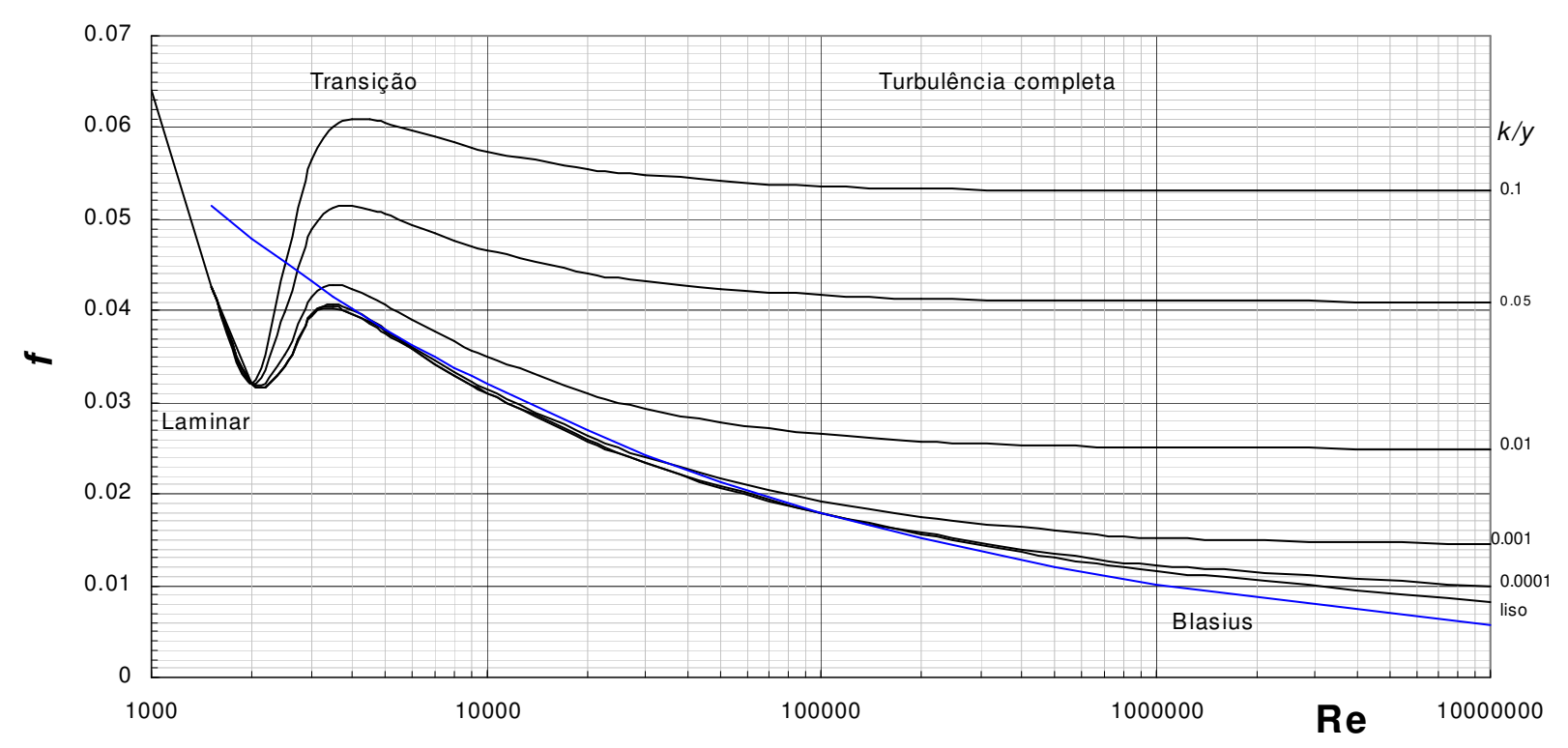

Figura 4.13 - Diagrama obtido com a Equação 4.12

Outra equação usual para o cálculo do fator f é a proposta por Halland (1983), conforme apresentado na equação 4.13 .

$$
\frac{1}{\sqrt{f}}=-1,8 \cdot \log _{10}\left[\left(\frac{\varepsilon}{3,7 D}\right)^{1,11}+\frac{6,9}{R e}\right]
$$

Sendo:

$f=$ coeficiente de atrito;

$\varepsilon=$ espessura ou altura da rugosidade da tubulação $(\mathrm{m})$;

$D=$ Diâmetro da tubulação $(\mathrm{m})$;

$R_{e}=$ número de Reynolds.

\subsubsection{ENTROPIA MÁXIMA NA MODELAÇÃO DO COEFICIENTE DE ATRITO $f$}

Moraes (2010) apresentou em seu trabalho o desenvolvimento do coeficiente de atrito $(f)$ para escoamentos incompressíveis, baseado no modelo clássico de Colebrook-White e no recente modelo de Entropia Máxima.

Chiu et al. (1993) desenvolveu um trabalho com o objetivo de aplicar seus conceitos desenvolvidos para escoamento em conduto forçado.

A partir da aplicação do conceito de entropia máxima foi possível modelar o perfil de velocidades para tubulações. O princípio da entropia pode ser utilizado para modelar 
a distribuição mais provável dos estados de um sistema. O comportamento do perfil de velocidades para os valores extremos de entropia, onde:

- Zero, representa a entropia elevada ao máximo; e

- Infinito, representa um escoamento livre de viscosidade.

Através de deução algébrica, Chiu et al. (1993) desenvolveu um equacionamento de perda de carga com base na tensão de cisalhamento do escoamento, da equação do perfil de velocidades e da fórmula universal. A parti de fórmula, foi possível isolar o coeficiente de atrito, conforme apresentado na equação 4.14.

$$
f=\frac{32}{R e_{a}}\left(\frac{\left(e^{M}-1\right)^{2}}{M \cdot e^{M}-e^{M}+1}\right)
$$

Sendo:

$f=$ coeficiente de atrito;

$e=$ Base neperiana;

$M=$ parâmetro de entropia;

$R e_{a}=$ Número de Reynolds Aparente.

Foi possível obter os valores correspondentes do parâmetro de entropia $(M)$ através da base de dados de fator de atrito e número de Reynolds, para regime turbulento liso, apresentados por McKeon et al. (2008).

Após ajustes, Moraes (2010) obteve a seguinte relação para regime turbulento liso, conforme equação 4.15 .

$$
M=\ln \left(\frac{R e_{a}}{435}\right)
$$

Observando os dado fornecidos por McKeon et al. (2008), foi verificado que o regime laminar abrange a faixa de valores de número de Reynolds de 0 a aproximadamente 3.000 , enquanto que a faixa do regime turbulento iniciava aproximadamente em 3.000 .

A equação geral do parâmetro entropia pode ser expressa pela seguinte equação 4.16.

$$
M=\alpha \cdot \ln \left(\frac{R e_{a}}{435}\right)
$$


Sendo:

$$
\alpha=\frac{1}{1+e^{3000-R e}}
$$

McKeon et al. (2004) relatou os experimentos realizados pelas universidades de Princeton e Oregon, utilizando sistemas de precisão de medição para observação do coeficiente de atrito em função do número de Reynolds. Tais experimentos utilizaram diferentes técnicas gerando resultados com grande precisão, que puderam ser comprovadas pela coincidência dos resultados em ambas as universidades.

\subsection{MÉTODOS TRADICIONAIS DE DIMENSIONAMENTO}

Os métodos de dimensionamento tradicionais levam em conta apenas o balanceamento hidráulico da rede, de forma a atender às condições impostas pelas equações da conservação de massa nos nós e conservação de energia nos anéis.

Os métodos tradicionais não possuem critérios de dimensionamento visando à minimização dos custos globais, embora algum critério de custo deve existir, desde que tubulação e velocidades são usualmente aceitos como elementos de otimização e devem ter sido inferidos a partir de redução de custos. No entanto, é indiscutível a importância destes métodos para a evolução da busca por um melhor dimensionamento dos sistemas de distribuição de água.

\subsubsection{Redes Ramificadas}

Em redes ramificadas, são conhecidos os sentidos de escoamento e o valor das vazões em cada trecho. Com essas informações, são determinados os diâmetros de cada trecho a partir das velocidades e vazões máximas admitidas para cada diâmetro. A partir das vazões, diâmetros, comprimentos, coeficientes de rugosidade em função do tipo de material de cada trecho, são calculadas as perdas de carga nos vários trechos e as pressões nos nós a partir de um ponto de pressão conhecido. Esse ponto geralmente é um reservatório com nível d'água (NA) conhecido ou uma adutora com a pressão estática e dinâmica conhecida.

Caso as pressões obtidas estejam adequadas conforme norma NBR 12218, o dimensionamento está completo. Caso não sejam, os diâmetros das redes são 
alterados e/ou a cota do NA do reservatório e os valores das pressões são recalculados até que atinjam valores satisfatórios segundo a norma NBR 12218.

\subsubsection{Redes Malhadas}

O dimensionamento de redes malhadas é um problema complexo, pois a princípio não são conhecidos o sentido de escoamento da água nas tubulações. Atualmente a tendência é a utilização cada vez maior de métodos de otimização econômica para dimensionamento dos sistemas de distribuição de água. Através desse método, o dimensionamento ótimo será aquele cujo os custo de implantação e operação do sistema seja mínimo.

Para o dimensionamento, são usadas soluções aproximadas através de tentativas.

Os métodos mais conhecidos são: método do seccionamento fictício e de cálculos iterativos.

\subsubsection{MÉTODO DO SECCIONAMENTO FICTÍCIO}

Nesse método a rede malhada e transformada em uma rede ramificada fictícia, onde os circuitos fechados são seccionados. Desse modo os sentidos de escoamento são fixados, sendo recomendado adotar o critério que a água deve percorrer o trajeto mais curto até cada ponto da rede.

O dimensionamento é feito de forma semelhante ao de redes ramificadas, porém é necessário verificar a hipótese dos seccionamentos adotados, onde as pressões resultantes nos pontos de seccionamento devem ser aproximadamente iguais, tais que as diferenças não excedam $5 \%$.

Caso as pressões obtidas não estejam adequadas ou a altura do reservatório esteja muito elevada, é necessário alterar o traçado da rede, o seccionamento adotado ou o diâmetro de alguns trechos. Feita a alteração, a rede é recalculada até chegar uma solução satisfatória.

Esse método é indicado para redes de abastecimento de cidades pequenas e para verificação de linhas secundárias das redes principais. 


\subsubsection{MÉTODO DE CÁLCULO ITERATIVO}

Segundo a norma NBR 12118 da ABNT, O dimensionamento dos circuitos fechados (rede malhada), formados de condutos principais, e a análise do funcionamento global da rede devem ser realizados por métodos de cálculo iterativos, que garantam resíduos máximos de vazão e de carga piezométrica de $0,1 \mathrm{~L} / \mathrm{s}$ e $0,5 \mathrm{kPa}$, respectivamente.

As leis da física que governam o escoamento em condutos sob pressão são a conservação de massa e a conservações de energia. De acordo com a lei de conservação de massa aplicada aos nós da rede, a demanda de um sistema representa a diferença entre a vazão aduzida (entrada) e a vazão requerida (saída) do sistema. Na lei da conservação de energia, a diferença de energia entre dois pontos é igual a soma de todas as perdas de carga (atrito e localizada) acrescida às energias adicionais (bombas) nos trechos. A partir dessas leis, é elaborado um conjunto de equações, onde a solução é obtida através do processo de iteração das mesmas.

Os métodos mais empregados são:

- Método de Hardy-Cross (correção das vazões); e

- Método da Linearização (matricial).

Gomes (2004), reporta que as redes pressurizadas de distribuição de água vêm, há muitos anos, sendo dimensionadas através das técnicas de determinação de fluxos e pressões desenvolvidas por Hardy Cross (1936). Esta metodologia é largamente usada no dimensionamento de redes malhadas; entretanto, ela não aborda a questão da otimização econômica e trata apenas da parte hidráulica da rede, calculando a sua distribuição de pressão e de vazão. Nesta metodologia as demandas nos nós são consideradas fixas, e cabe ao modelo determinar as vazões nas tubulações e pressões nos nós, hidraulicamente consistente com o atendimento pleno dessas demandas, considerando que os sistemas são fechados e o escoamento ocorre sob pressão.

Martins (2006) apresentou o dimensionamento de rede de distribuição de água em malha para regime permanente através do método da linearização. Nesse método as equações que envolvem a perda de carga nos circuitos são linearizadas para 
solução numérica com emprego de métodos matriciais. Para isso, todas as equações do sistema são resolvidas simultaneamente a cada iteração.

Pelo método, a perda de carga em cada iteração é aproximada como função linear da vazão, conforme apresentado na equação 4.18 e 4.19 .

$$
\begin{gathered}
\Delta H_{i, j}=f_{i} \frac{L \cdot\left|Q_{i, j}\right|}{D \cdot 2 g \cdot A_{i}^{2}} Q=k_{i} \cdot Q_{i, j} \\
k_{i}=f_{i} \frac{L \cdot\left|Q_{i, j}\right|}{D \cdot 2 g \cdot A_{i}^{2}}
\end{gathered}
$$

Sendo:

$\Delta H_{i, j}=$ perda de carga no trecho, onde i é o nó inicial e j o nó final (m);

$f_{i}=$ coeficiente de atrito do trecho;

$\mathrm{L}=$ comprimento do trecho $(\mathrm{m})$;

$D=$ diâmetro da tubulação do trecho $(\mathrm{m})$;

$Q_{i, j}=$ vazão no trecho $\left(\mathrm{m}^{3} / \mathrm{s}\right)$;

$g=$ aceleração da gravidade $\left(\mathrm{m} / \mathrm{s}^{2}\right)$;

$A_{i}=$ Área do tubo $\left(\mathrm{m}^{2}\right)$.

\subsection{MÉTODOS DE OTIMIZAÇÃO}

O dimensionamento das redes de distribuição de água pressurizadas é hidraulicamente indeterminado e admite inúmeras soluções, que atendem aos requerimentos de vazão e pressão nos pontos de consumo (Gomes, 2004). Os métodos de dimensionamento tradicionais de redes pressurizadas não levam em conta a busca da solução mais econômica. Atualmente, além dos critérios hidráulicos, estão sendo considerados os critérios de otimização econômica com objetivo de alcançar as soluções de mínimo custo dos sistemas de distribuição de água.

O custo de implantação de uma rede de distribuição pressurizada de água está relacionado ao seu diâmetro e pressões nominais, que são determinados em função dos requisitos hidráulicos (vazões e pressões requeridas nos pontos de consumo) e 
das características topológicas do sistema de abastecimento (traçado e topografia da rede).

Os custos de implantação e operação do sistema de distribuição de água para as condições definidas de projeto (demanda e traçado da rede) dependem da cota piezométrica do ponto de alimentação da rede, seja ela abastecida por um reservatório elevado ou por um sistema de bombeamento direto.

O custo de implantação da rede de distribuição está relacionado aos diâmetros necessários para a rede, além do tipo de material da tubulação. A princípio, quanto maior for à cota piezométrica do ponto de alimentação, menor o custo de implantação da rede, pois poderão ser selecionados tubos com diâmetros menores, uma vez que as cargas existentes serão suficientes para superar as perdas de cargas na distribuição.

Em contrapartida, o custo de operação de um sistema de bombeamento cresce em função da cota piezométrica de alimentação, pois os custos de energia aumentam.

De forma oposta, para uma menor altura de impulsão na alimentação da rede corresponderá um menor custo de operação da estação de bombeamento e um maior custo de implantação da rede, uma vez que serão necessárias tubulações com diâmetros maiores, pois provocam menos perdas de carga no sistema.

Portanto o dimensionamento otimizado será aquele onde o custo total (soma do custo de implantação e de operação do sistema) será o mínimo para cada sistema estudado.

Com base nesse critério de dimensionamento se desenvolveram os métodos de otimização econômica das redes pressurizadas de distribuição de água.

A preocupação com o dimensionamento econômico de sistemas de abastecimento de água foi intensificado, devido à aceleração no processo de urbanização. Antes desta época, muito pouco se conhecia sobre métodos para a otimização numérica de funções contendo muitas variáveis.

Com a evolução dos sistemas computacionais e as ferramentas matemáticas disponíveis atuais, torna-se possível a introdução de outros critérios e variáveis na formulação de novas metodologias de dimensionamento. 
Mas foi na década de 1940 que ocorreu o desenvolvimento de métodos de otimização, com destaque ao método Simplex, básico dentro da Programação Linear.

Os primeiros métodos de otimização não linear eram bastante restritos e tornaramse mais significativos no final da década de 1950 com a introdução de muitas variáveis em pequeno tempo.

Na década de 1960, com a consolidação do uso de computadores, nos centros de pesquisas e nas universidades, ocorreu o desenvolvimento e aplicações das técnicas de otimização matemática a problemas práticos como: alocação de recursos na indústria, planejamento de rotas de transportes, etc. Com isso, surgiram as primeiras idéias sobre a aplicação de técnicas de simulação e otimização no dimensionamento de redes de abastecimento de água.

Entretanto, foi no final da década de 1960, e início dos anos 1970, que ocorreu o surgimento de métodos mais elaborados para a otimização de redes de abastecimento. Esses métodos eram baseados em técnicas heurísticas de busca, ou no emprego da programação linear e da programação dinâmica (WALSKI, 1987).

Alperovits e Shamir (1977) aplicaram o método de gradiente de programação linear (GLP) para concepção de redes de abastecimento. Neste método o problema não linear foi convertido em linear, tomando os comprimentos de tubo como variáveis de decisão. A extensão entre os nós adjacentes foi dividido em segmentos diferentes e logo os comprimentos dos segmentos foram otimizados para minimizar o preço. Para superar limitações desta aproximação, muitos pesquisadores (QUINDRY et al, 1981; FEATHERSTONE; EL-JUMAILY, 1983; FUJIWARA; KHANG, 1987) desenvolveram aproximações em direção a otimização global.

A programação linear tem as suas limitações, como o problema do dimensionamento concepção da rede de distribuição, que não é linear por natureza. Um número de pesquisadores aplicaram a aproximação da otimização da programação não linear (PNL) a problemas da tubulação das redes (SHAMIR, 1974; EL-BAHRAWY; SMITH, 1987; SU et al, 1987; LANSEY; MAYS, 1989; DUAN et al, 1990). 
Como as aproximações de PNL confiam na solução inicial, eles não garantem identificação da ótima solução global. Além disso, o uso de variáveis discretas, tais como tamanhos de tubulações do mercado, reduz a qualidade da solução ótima.

Formiga (1999) aplicou o método de programação não linear em duas etapas para se obter uma solução ótima. Na primeira etapa as variáveis de decisão são as vazões e os diâmetros dos trechos. Na segunda etapa as variáveis de decisão são as vazões e comprimentos de tubos onde, para cada trecho foram selecionados dois diâmetros comerciais, um inferior e outro superior ao obtido na primeira etapa. A função objetivo é determinada pela variação do preço das tubulações em função do diâmetro e da classe de pressão, para suas variáveis de decisão.

Gomes e Formiga (2001) propuseram uma metodologia denominada PNL2000. Esta metodologia de dimensionamento utiliza o modelo matemático da Programação Não Linear e divide-se em duas etapas. Na primeira, faz-se um dimensionamento prévio do sistema, no qual os diâmetros e as vazões dos trechos, e a altura manométrica de cabeceira, são variáveis a serem determinadas no processo de otimização. Em seguida, com os resultados obtidos no pré-dimensionamento, executa-se uma segunda etapa, na qual se realiza um ajuste da solução inicialmente obtida. Este ajuste se faz necessário, porque os valores dos diâmetros encontrados na primeira etapa do processo (valores contínuos) não coincidem com as bitolas nominais disponíveis no mercado. O ajuste trata da substituição, em cada trecho, do diâmetro calculado inicialmente pelo comercial mais próximo. No processo de otimização, o PNL2000, utiliza o método do Gradiente Reduzido Generalizado (GRG2), desenvolvido por Lasdon et al. (1984). O modelo foi formulado e processado através da ferramenta Solver da planilha eletrônica Excel da Microsoft, também utilizado na parte prática deste trabalho. Este método aplica-se a redes malhadas para as seguintes situações de contorno: cota piezométrica de cabeceira fixa ou variável. $\mathrm{O}$ PNL2000 tem como objetivo a obtenção de solução que proporcione o custo mínimo de investimento mais operação de um sistema de distribuição de água. Nos custos envolvidos nessa metodologia não foram avaliadas as variações dos seguintes itens:

- Taxa de energia elétrica;

- Custo de diferentes materiais para diâmetros similares;

- Custo de implantação em função do tipo de pavimento (material e tráfego) e do material da tubulação (recobrimento); 
- Vida útil do sistema;

- Taxa de juros anual.

Essa método pode ser aplicado para redes em malha com cota de alimentação fixa ou variável, rede ramificada e rede abastecida por múltiplos reservatórios.

Santos (2002) utilizou o método PNL2000 em duas redes de distribuição de água existentes, uma malhada e outra ramificada: o Grande Anel da Rede de Distribuição de Água da cidade de Recife-PE e o Setor 11 do Perímetro Irrigado Senador Nilo Coelho em Petrolina-PE, respectivamente. Os resultados obtidos através da utilização do método PNL2000 na simulação mostraram-se eficazes, fornecendo ao final um conjunto de dados que condizem com a realidade das redes de abastecimento utilizadas como exemplos de aplicação.

Monbaliu et al. (1990) propuseram uma técnica de gradiente de pesquisa para alcançar um projeto eficiente, através da fixação inicial de um diâmetro mínimo para cada tubo e, em seguida, utilização de um pacote de simulação para determinação das pressões nos nós da rede. Se os limites mínimos de pressão não são satisfeitos, o tubo com a maior perda de carga unitária tem o seu diâmetro elevado para o imediatamente superior, em seguida é feita uma nova simulação. Este processo é repetido até que todos os limites de pressão sejam satisfeitos.

Leal e Gomes (2000) propõem uma metodologia semelhante, que ao invés de utilizar a maior perda de carga unitária como parâmetro para a escolha do diâmetro, utiliza o acréscimo de custos de um determinado trecho causado pela mudança de seu diâmetro consecutivo superior, relacionado com a diminuição da perda de carga correspondente, o que se chama de Gradiente de Câmbio (GRANADOS, 1986). Para se aplicar o método Granados no dimensionamento de redes malhadas, é necessário transformar essas redes em ramificadas, através de um seccionamento semelhante ao efetuado no método do Seccionamento Fictício (LEAL, 1995).

Bezerra (2005) propôs uma metodologia mais elaborada fundamentada no algoritmo de otimização de Granados, e que se divide em duas etapas. A primeira consiste na determinação da solução inicial, na qual a rede será composta pelos diâmetros das tubulações existentes submetidos às vazões do projeto de reabilitação. A segunda etapa compreende uma seqüência de interações, onde se diminui paulatinamente (a partir da solução inicial) a cota piezométrica de alimentação e, obtém-se, para cada 
decréscimo dessa cota, um novo custo de reabilitação para a rede de distribuição, decorrente de diversas opções de reabilitações (substituição das tubulações antigas por novas de maiores diâmetros, limpeza e reparo das tubulações antigas, etc.). $\mathrm{O}$ processo interativo termina quando o custo de intervenção numa determinada interação superar o custo energético. Esta interação apresentará os dados que resultam no custo ótimo do conjunto - investimento (intervenção física da rede) mais operação (custo atualizado da energia) do sistema de abastecimento/bombeamento. No seu processo interativo o método utiliza-se do conceito do Gradiente de Câmbio - "G” (Granados, 1990).

Originalmente, o "G" de um determinado trecho será definido como sendo o acréscimo de custo gerado pela substituição de uma tubulação específica por outra de maior diâmetro, relacionada com a diminuição da perda de carga correspondente. $\mathrm{Na}$ metodologia proposta por Bezerra (2005) este conceito foi ampliado, passando a sua definição a ser seu custo marginal da diminuição da perda de carga, alcançado num determinado trecho, mediante a aplicação de uma opção de reabilitação. Para a determinação do custo atualizado da energia de bombeamento, por metro de elevação, chamado de Gradiente Energético - Ge, que corresponde ao barateamento alcançado em termos de consumo de energia, para um metro na redução da cota piezométrica de alimentação. Desta forma, a cota piezométrica de alimentação que proporciona o custo ótimo da reabilitação da rede de distribuição mais a energia capitalizada consumida pelo bombeamento, é obtida quando o valor do gradiente energético é igualado ou superado pelo valor do Gradiente de Câmbio Ótimo - "G*", no processo interativo.

Costa et al. (2006) desenvolveram um software associado ao Epanet2 utilizando uma programação linear (método simplex) para minimizar os custos de uma rede de distribuição de água, obtendo uma economia de $12 \%$ em relação ao dimensionamento apresentado por Gomes (2004) utilizando o método PNL2000. O algoritmo analisa os nós, caso estes tenham uma pressão inferior a mínima ele substitui o trecho ligado ao nó por um diâmetro superior, do contrário o diâmetro é reduzido para pressões elevadas. O algoritmo finaliza quando não são solicitadas mudanças nos trechos.

Carvalho (2007) desenvolveu um software chamado EficienteE, que busca otimizar o dimensionamento de redes, através de um algoritmo iterativo, utilizando os conceitos 
de gradiente energético e gradiente de pressão, a metodologia apresentou ótimos resultados de dimensionamento, porém não existia um controle das variáveis de estado (pressão e velocidade da água) durante o processo iterativo.

Salvino (2009) utilizou um software associado ao Epanet2 chamado Lenhsnet, que utiliza um processo dinâmico e iterativo que parte de uma configuração inicial da rede, substituindo os diâmetros da rede pelos diâmetros mínimos. O algoritmo tem a possibilidade de se especificar as pressões máximas e mínimas para o dimensionamento, além das velocidades máximas e mínimas. Durante o dimensionamento, é realizado o balanceamento hidráulico da rede, através do simulador hidráulico, de forma a atender as condições impostas pelas equações de conservação de massas nos nós e de energia nos anéis.

Atualmente, a pesquisa está mais concentrada nos métodos de otimização estocásticos pelo uso de algoritmos evolucionários ( $\mathrm{AE})$, pois eles são eficientes no manejo de variáveis discretas, como os diâmetros comerciais. Na maioria destes métodos, a estratégia de pesquisa é a de fazer o valor da função objetivo convergir para a melhor solução (em iterações subseqüentes) em comparação com a maior parte de métodos de programação, que usam informações de gradientes. Entre as aplicações no dimensionamento de redes de distribuição de água, pode se destacar os algoritmos evolucionários dos tipos:

- Redes Neurais Artificiais;

- Algoritmos genéticos (AG), tais como: Simulated Annealing (SA), Harmony Search Optimization, Shuffled Frog Leaping Algorithm, Ant Colony Optimization (ACO) e Honey-Bee Mating Optimization (HBMO).

As redes neurais artificiais são sistemas projetados para modelar um problema baseado no funcionamento do cérebro. Possuem a capacidade de modelar comportamentos não lineares, apresentando grande capacidade de aprendizado e generalização. São ferramentas eficientes para modelagem e previsão da demanda, além de operação de sistema de água.

Segundo Mohan e Babu (2010), o algoritmo genético AG é um algoritmo estocástico adaptável baseado em seleção natural e genética (GOLDBERG, 1989) e aplicado com sucesso para a otimização de redes de água (SIMPSON et al, 1994; SAVIC; 
WALTERS, 1997; HALHAL et al, 1997; GUPTA et al, 1999; PRASAD; PARK, 2004; KADU et al, 2008).

O Simulated Annealing (SA) (KIRKPATRICK et al, 1983) é um algoritmo metaheurística que simula 0 processo de recozimento físico (no qual o metal gradualmente acalma-se de uma temperatura muito alta para alcançar uma forma cristalina sólida), também bem sucedida na exploração dos ótimos diâmetros de tubo (LOGANATHAN et al, 1995; CUNHA; SOUSA, 1999). Meta-heurística é um método de aproximação das soluções ideais para resolução de problemas de otimização.

Geem et al. (2002) desenvolveram a aproximação Harmony Search Optimization para resolver problemas de dimensionamento de rede, enquanto Eusuff e Lansey (2003) desenvolveram o algoritmo Shuffled Frog Leaping.

Ant Colony Optimization (ACO) é outro algoritmo de otimização estocástico, que é baseado no comportamento de forrageamento de formigas (DORIGO et al, 1996). A adaptabilidade da ACO para a otimização de redes de águas foi demonstrada por Maier et al. (2003).

A pesquisa de Tabu que imita o processo da memória humana (Glover 1986) foi usado por Cunha e Ribeiro (2004) para otimização de redes de águas.

O acasalamento para as abelhas (HBMO) é um algoritmo de otimização estocástico que duplica o comportamento biológico das abelhas (ABBASS, 2001). A aplicabilidade do HBMO para a otimização de redes de águas foi demonstrada por Mohan et al. (2010).

Diniz (2004) apresentou um modelo híbrido, que após calcular as cargas e vazões para o regime permanente e para o regime extensivo, utiliza o algoritmo genético para otimizar o controle operacional de redes hidráulicas. Foi utilizado o método matricial para calcular os regimes permanente e extensivo. A parte do modelo computacional hidrodinâmico desenvolvido é aplicado para dimensionar uma rede projetada e verificar a operação de uma rede existente. A otimização deste modelo através de algoritmo genético é aplicada apenas em redes de abastecimento que apresentem problemas operacionais e que necessitem ser resolvidos com a implantação ou que possuam válvulas instaladas. 


\section{PROPOSIÇÃO DE MÉTODO DE OTIMIZAÇÃO GLOBAL}

Neste item é apresentada a proposta de método para o dimensionamento otimizado de rede de abastecimento de água em malhas, através de critério de custo global.

Esse método será aplicado para o dimensionamento otimizado de rede de distribuição de água com as seguintes condições:

- Topografia plana com variações entre cotas em torno de $5 \mathrm{~m}$;

- Coeficientes usuais de variação de consumo $K_{1}=1,2$ e $K_{2}=1,5$;

- Regime de escoamento permanente;

- Cálculo das perdas de carga através do emprego da fórmula universal;

- No cálculo foi considerada apenas a parcela da perda de carga distribuída, sendo que a parcela localizada foi desconsiderada, devido ao comprimento relativamente longo da rede e as velocidades relativamente baixas;

- Sistema de bombeamento com rotação constante;

- Material das tubulações em PEAD, PVC e Ferro Fundido (FoFo);

- Superfície para implantação da rede em terra, passeio em concreto, viário em paralelepípedo ou em asfalto (Tráfego leve, médio ou pesado).

\subsection{MÉTODO MATRICIAL NÃO LINEAR}

Como o dimensionamento de redes em malhas se enquadra em um processo matemático não linear, optou-se, neste trabalho, pela utilização do método matricial com programação não linear (PNL), para se obter o dimensionamento mais econômico.

O método está dividido em três partes, onde na primeira a rede de água é dimensionada de tal forma que atende aos critérios hidráulicos e de menor custo global, porém não são comerciais. Na segunda etapa, é feito o refinamento dos diâmetros comerciais, conforme o material da tubulação de cada trecho. Na última etapa, é feita a confirmação que o custo obtido representa o mínimo global.

Para o dimensionamento tradicional de rede de distribuição de água, normalmente não é considerado o critério de custo global, apenas aos critérios hidráulicos. 
Os critérios hidráulicos a serem atendidos foram apresentados no item 4.5 sobre os critérios de dimensionamento, enquanto que a composição do custo global é referente à equação apresentada abaixo.

$$
C_{\text {global }}=C_{\text {implantação }}+C_{\text {operação }}
$$

Sendo:

$C_{\text {global }}=$ custo global do sistema $(\mathrm{R} \$)$;

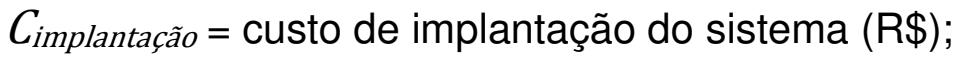

$C_{\text {operação }}=$ custo de operação do sistema $(\mathrm{R} \$)$.

Vale lembrar que o custo global não representa necessariamente o custo final para implantação de obra da rede de distribuição de água, porém representa a soma dos principais custos envolvidos na metodologia de otimização do dimensionamento.

Nos itens a seguir, é detalhada a composição dos custos de implantação e de operação do sistema.

Como valor de referência neste trabalho, adotou-se um custo referencial unitário, obtido através da seguinte equação.

$$
C_{\text {referencial }}=\frac{C_{\text {global }}}{L_{\text {total }}}
$$

Sendo:

$C_{\text {referencial }}=$ custo referencial unitário $(\mathrm{R} \$ / \mathrm{m})$;

$C_{\text {global }}=$ custo global do sistema $(\mathrm{R} \$)$;

$L_{\text {total }}=$ comprimento total de rede $(\mathrm{m})$.

A função objetivo é o menor custo global do sistema, onde as variáveis de decisão são os diâmetros e as vazões. As variáveis de estado são as pressões e as velocidades.

Para o dimensionamento, inicialmente é necessário estimar valores arbitrários das vazões e diâmetros de cada trecho da rede, além da pressurização inicial. Os demais dados necessários são:

- Extensões dos trechos; 
- Elevações e vazões de cada nó;

- Características do pavimento (material e tipo de tráfego);

- Tipo de tubulação (material e rugosidade);

- Características da pressurização inicial (rendimento global e horas de funcionamento anual);

- Vida útil do sistema;

- Taxa de juros anual e fator de atualização para valor presente; e

- Tarifa de energia (por demanda e por consumo).

A partir dos dados, as equações que envolvem a perda de carga e vazões nos circuitos são solucionadas com emprego de método matricial não linear. Para isso, todas as equações do sistema são resolvidas simultaneamente a cada iteração.

Pelo método, a perda de carga dissipada na rede em cada iteração é aproximada como função da vazão e do diâmetro, conforme apresentado na equação 5.3 .

Sendo:

$$
\Delta H_{i, j}=f_{i} \frac{L \cdot\left|Q_{i, j}\right|}{D \cdot 2 g \cdot A_{i}^{2}} Q_{i, j}
$$

$\Delta H_{i, j}=$ perda de carga no trecho, onde i é o nó inicial e j o nó final (m);

$f_{i}=$ coeficiente de atrito do trecho;

$\mathrm{L}=$ comprimento do trecho $(\mathrm{m})$;

$D=$ diâmetro da tubulação do trecho $(\mathrm{m})$;

$A_{i}=$ área da tubulação do trecho $\left(\mathrm{m}^{2}\right)$;

$Q_{i j}=$ vazão no trecho $\left(\mathrm{m}^{3} / \mathrm{s}\right)$;

$g=$ aceleração da gravidade $\left(\mathrm{m} / \mathrm{s}^{2}\right)$.

A determinação da carga necessária do sistema de pressurização inicial é feita em função do atendimento dos limites de pressão impostos no nós e das perdas de cargas dissipadas envolvidas em cada trecho da rede.

Segundo Martins (2006), existe uma equação que relaciona a velocidade máxima admitida numa tubulação e o seu diâmetro. A partir dessa equação podemos relacionar a vazão e o diâmetro, conforme apresentado na equação 5.4 .

$$
V=\frac{4 Q}{\pi D^{2}}=0,0967 \cdot D^{0,4392}
$$


Através da aplicação lei da conservação de energia, a diferença de energia entre dois pontos é igual à soma de todas as perdas de carga (atrito e localizada) acrescida às energias adicionais (bombas) nos trechos. A partir dessa lei, é possível estabelecer uma equação para cada circuito, conforme a equação 5.5 .

$$
\sum \Delta H_{i, j}=0
$$

Sendo:

$\Sigma \Delta H_{i, j}=$ Somatório da perda de carga no circuito, onde i é o nó inicial e j o nó final.

A partir da lei de conservação de massa aplicada aos nós da rede, a soma do valor da vazão de entrada e de saída em cada nó é nula, conforme a equação 5.6.

$$
\sum Q_{i}=0
$$

Sendo:

$\Sigma \Delta Q_{i}=$ Somatório da vazão no nó i (L/s).

A partir de valores arbitrários de vazões e diâmetros para cada trecho, a solução do sistema é obtida através da convergência de resultados por intermédio de iterações, utilizando o método do Gradiente Reduzido Generalizado (GRG2), que se trata de um algoritmo de programação não linear, desenvolvido por Lasdon et al. (1984). O modelo da programação não linear, a partir do GRG2, foi formulado e processado através da ferramenta Solver da planilha eletrônica Excel da Microsoft.

Além do atendimento dos critérios hidráulicos de velocidade, pressão e diâmetro, os resultados do dimensionamento foram considerados adequados quando a soma das perdas de carga em cada circuito e a soma das vazões em cada nó era igual ao menor que o do valor de tolerância. O valor de tolerância adotado para a soma das vazões em cada nó foi de 0,01 L/s e para a soma das perdas de carga em cada circuito foi de $0,001 \mathrm{kPa}$.

Após o dimensionamento da primeira etapa, é definida a pressurização inicial necessária, além dos diâmetros ótimos e vazões de cada trecho, porém os diâmetros não são comerciais.

$\mathrm{Na}$ segunda etapa, os diâmetros ótimos obtidos são refinados para diâmetros comerciais, conforme tipo da tubulação. Esse refinamento é feito através da 
alteração do fator entre o diâmetro ótimo e o comercial. Para a primeira etapa, o valor usado foi 0 , onde o diâmetro obtido é o ótimo, porém não o comercial. $\mathrm{Na}$ segunda etapa, o valor do fator foi alterado para 1,05 , onde o diâmetro obtido é o comercial, utilizando o critério de adotar o diâmetro mais próximo com $5 \%$ de tolerância.

$\mathrm{Na}$ terceira etapa, foi comprovado que os diâmetros obtidos se tratavam realmente do menor custo global, não sendo apenas um menor custo local. Para essa comprovação, eram realizadas mais algumas interações para efeito de comparação com a alteração em alguns diâmetros e no valor da pressão inicial do sistema. Os diâmetros eram alterados caso os valores das velocidades e das perdas de carga em cada trecho estivessem com valores muito baixos ou elevados. O valor da pressão inicial era alterado em função das menores cargas observadas em cada nó do sistema.

A composição do custo de implantação e de operação da rede de água são descritos nos itens a seguir.

\subsection{CUSTO DE IMPLANTAÇÃO}

O custo de implantação é a soma dos principais custos dos serviços e de material necessários para implantação da rede de água, conforme equação abaixo.

Sendo:

$$
C_{\text {implantação }}=C_{\text {seviços }}+C_{\text {material }}
$$

$C_{\text {implantação }}$ custo de implantação do sistema $(\mathrm{R} \$)$;

$C_{\text {serviços }}=$ custo de serviços para implantação do sistema $(\mathrm{R} \$)$;

$C_{\text {material }}=$ custo de materiais para implantação do sistema $(\mathrm{R} \$)$.

\subsubsection{Custo de Serviços}

Para o desenvolvimento deste trabalho, foram analisados os serviços com maior impacto no custo geral, tais como:

- Escavação, reaterro e compactação de vala;

- Carga, transporte e descarga de material até $10 \mathrm{~km}$;

- Assentamento de tubulação;

- Remoção e recomposição de pavimento, além de transporte. 
Foi adotado que alguns serviços não eram necessários para a implantação da rede de água, sendo os mesmos desconsiderados na análise do custo global, tais como:

- Sinalização de trânsito;

- Passadiços e travessias;

- Desmatamento e limpeza de área;

- Remoção de terra vegetal;

- Escavação de jazidas de solo;

- Escavação em rocha;

- Escoramento de vala;

- Esgotamento com bombas de superfície ou submersas;

- Rebaixamento de lençol freático;

- Lastros para assentamento de tubulação;

- Ligação de água a rede pública.

Para os serviços de movimento de terra e assentamento de tubulação, foi utilizado como referência de preço o Sistema Nacional de Pesquisa de Custos e Índices da Construção Civil (SINAPI) para o estado de São Paulo com data-base de Janeiro de 2011 (CAIXA ECONÔMICA FEDERAL, 2011).

O SINAPI, criado em 1969, tem como objetivo a produção de informações de custos e índices de forma sistematizada e com abrangência nacional, visando a elaboração e avaliação de orçamentos, como também acompanhamento de custos.

Em 2002, o Congresso Nacional aprovou através da Lei de Diretrizes Orçamentárias (LDO) a adoção do SINAPI como referência para delimitação dos custos de execução de obras públicas.

Devido à dificuldade no uso dos preços unitários do SINAPI para remoção e recomposição de pavimentos, foi utilizado como referência de preço os custos unitários da Secretaria Municipal de Infraestrutura Urbana e Obras (SIURB) da prefeitura de São Paulo com data-base de Julho de 2010 (SECRETARIA MUNICIPAL DE INFRAESTRUTURA URBANA E OBRAS, 2010).

Em todas as licitações realizadas pela SIURB em São Paulo é adotada a tabela de custo unitário como referência, onde os preços dos insumos são obtidos através de trabalho feito pela Fundação Instituto de Pesquisas Econômicas (FIPE). 
Como a data-base da tabela mais recente da SIURB é de Julho de 2010, os preços foram trazidos para valor presente através de aplicação de fator $(1,020463)$, segundo o Índice Nacional de Custo da Construção (INCC) levantado pela Fundação Getúlio Vargas (FGV) desde Janeiro de 1944.

As quantidades de escavação, reaterro e compactação de vala, além de carga, transporte e descarga de material foram levantadas seguindo os critérios do Manual de Especificação Técnica, Regulamentação de Preços e Critérios de Medição elaborado pela Companhia de Saneamento Básico do Estado de São Paulo (SABESP), onde são definidos as profundidades e larguras de valas, conforme tipo de superfície e diâmetro e material da tubulação.

Em relação aos recobrimentos das tubulações da rede de distribuição, os valores adotados variam em função da locação da mesma, conforme Tabela 5.1.

Tabela 5.1 - Recobrimento das Tubulações

\begin{tabular}{cc}
\hline Locação da Rede de Água & Recobrimento (m) \\
\hline passeio & 0,7 \\
\hline viario pavimentado & 1,0 \\
\hline viario em terra & 1,2 \\
\hline Fonte: Sabesp (1996) &
\end{tabular}

Em relação às larguras de valas para implantação das redes de distribuição, o quadro abaixo apresenta os valores adotados. Foi adotado que as valas não são escoradas e com profundidade de até $2 \mathrm{~m}$.

Tabela 5.2 - Largura das Valas

\begin{tabular}{cc}
\hline Diâmetro $(\mathbf{m m})$ & $\begin{array}{c}\text { Largura de Vala - Sem escoramento e } \\
\text { profundidade até } \mathbf{~} \mathbf{~ m}(\mathbf{m})\end{array}$ \\
\hline 50 a 150 & 0,50 \\
\hline 150 & 0,55 \\
\hline 200 & 0,60 \\
\hline 250 & 0,65 \\
\hline 300 & 0,70 \\
\hline 350 & 0,75 \\
\hline 400 & 0,85 \\
\hline
\end{tabular}

Fonte: Sabesp (1996)

A partir dos dados acima, foi obtido os volumes de escavação em função do diâmetro da tubulação e da extensão de cada trecho.

Para o volume de reaterro e compactação, foi utilizado o volume de escavação exceto o volume da tubulação e o volume de recomposição apenas para pavimento asfáltico (macadame hidráulico e binder). 
Foi adotado que o solo escavado é de boa qualidade, não havendo a necessidade de importação e troca de material para reaterro.

Para o material encaminhado para bota-fora (volume da tubulação e o volume de recomposição apenas para pavimento asfáltico), foram adotados os serviços de carga, transporte e descarga mecânica de material para distância de até $10 \mathrm{Km}$.

As quantidades de remoção e recomposição de pavimentos foram levantadas seguindo os critérios da Instrução IR-01/2004 de Reparação de Pavimentos Flexíveis danificados por abertura de Valas da SIURB da prefeitura de São Paulo, onde é definida a reparação de pavimentos flexíveis danificados em decorrência da abertura de valas na via pública (SECRETARIA MUNICIPAL DE INFRAESTRUTURA URBANA E OBRAS, 2004).

Na Figura 5.1, é apresentada a recomendação da faixa a recapear devido à abertura de vala contínua. Vale ressaltar que nessa instrução a largura da faixa a recapear deve ser maior ou igual a $3 \mathrm{~m}$.

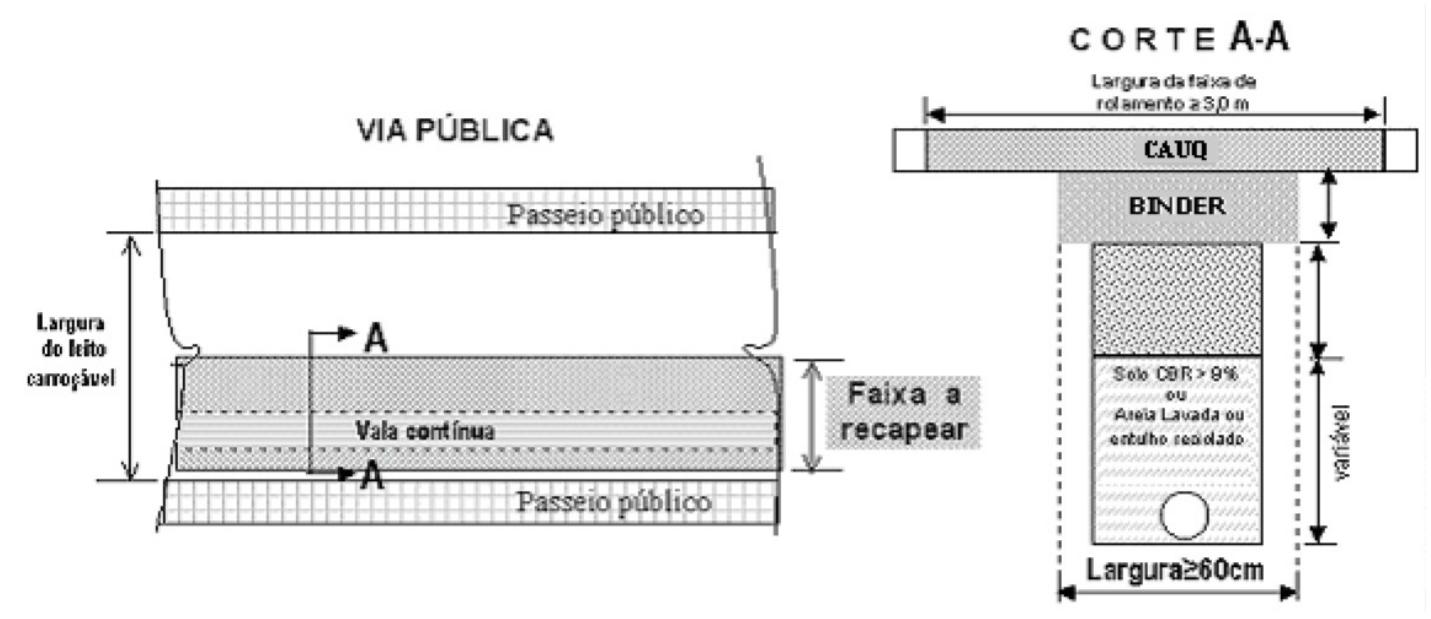

Figura 5.1 - Faixa a recapear devido à abertura de vala contínua conforme IR-001 da SIURB A instrução IR-001 recomenda alternativas de serviços de pavimentação para a reposição do pavimento danificado por abertura de valas, conforme o tipo de tráfego, sendo: leve, médio ou pesado.

Nas Figura 5.2 a Figura 5.4 e Tabela 5.3, são apresentados as recomendações de camadas e espessuras para a reposição do pavimento danificado por abertura de valas, conforme o tipo de tráfego (leve, médio ou pesado). 
Tabela 5.3 - Espessuras das camadas de reposição de pavimento conforme tipo de tráfego

\begin{tabular}{cccc}
\hline Tipo de Tráfego & $\begin{array}{c}\text { Macadame Hidáulico } \\
\text { (BGS) }\end{array}$ & Binder & $\begin{array}{c}\text { Concreto Asfáltico } \\
\text { Usinado a Quente } \\
\text { (CAUQ) }\end{array}$ \\
\hline Leve & 0,10 & 0,04 & 0,04 \\
\hline Médio & 0,12 & 0,07 & 0,05 \\
\hline Pesado & 0,15 & 0,10 & 0,05 \\
\hline
\end{tabular}

Fonte: IR-001 da SIURB (2004)

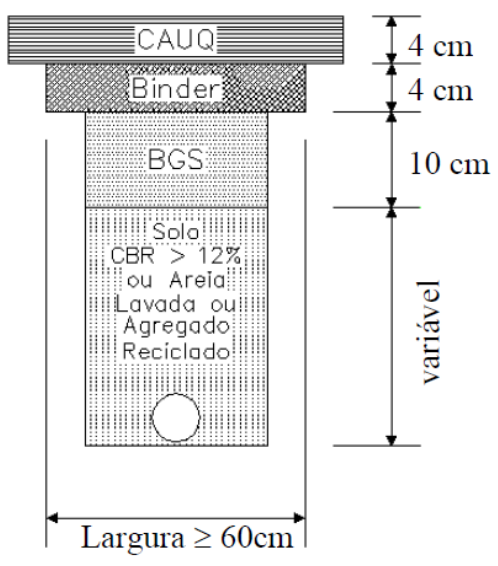

Figura 5.2 - Seção do Tipo 1 para tráfego leve conforme IR-001 da SIURB

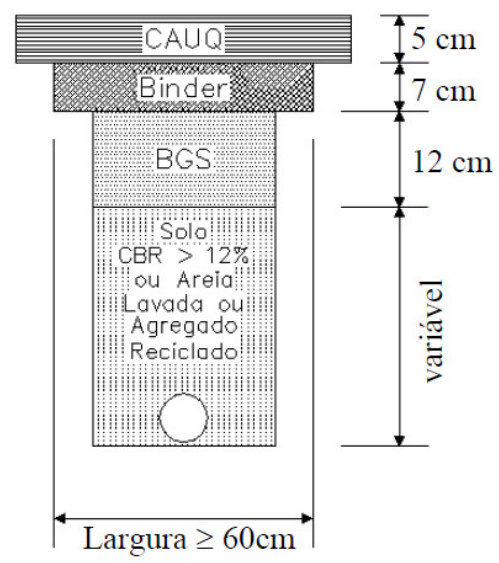

Figura 5.3 - Seção do Tipo 2 para tráfego médio conforme IR-001 da SIURB

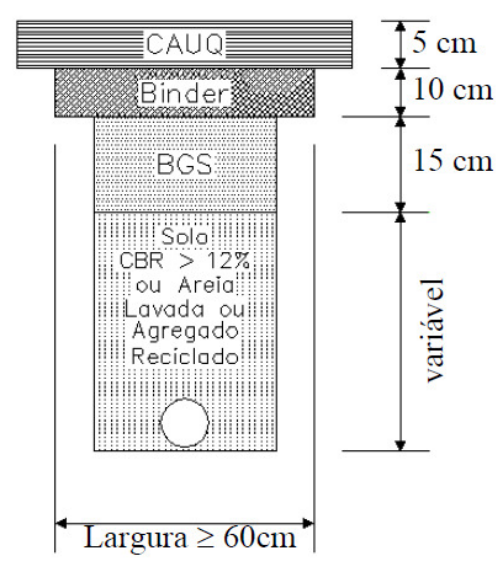

Figura 5.4 - Seção do Tipo 4 para tráfego pesado conforme IR-001 da SIURB 
Na Tabela 5.4, são apresentadas as larguras adotadas para reposição de pavimento conforme tipo de camada para levantamento de quantidades.

Tabela 5.4 - Larguras Adotadas para Reposição de Pavimento conforme tipo de camada

\begin{tabular}{lc}
\hline \multicolumn{1}{c}{ Camada de Reposição de Pavimento } & Largura Adotada $(\mathbf{m})$ \\
\hline Concreto Asfáltico Usinado a Quente (CAUQ) & 3,0 \\
\hline Imprimação Betuminosa Ligante & 3,0 \\
\hline Binder & Largura da Vala $+0,2$ \\
\hline Imprimação Betuminosa Impermeabilizante & Largura da Vala $+0,2$ \\
\hline Macadame Hidáulico (BGS) & Largura da Vala \\
\hline Fonte: IR-001 da SIURB (2004) &
\end{tabular}

Para viários em paralelepípedo, foi considerado que após a remoção os mesmos são reutilizados na reposição.

Para a reposição de passeios de concreto, foi adotado espessura de $7 \mathrm{~cm}$.

Para transporte de Concreto, foi considerada a distância de até $10 \mathrm{Km}$.

Para transporte de Binder e Concreto Asfáltico Usinado a Quente, foi adotada a distância de até $1 \mathrm{Km}$ (Ida e Volta).

Conforme citado anteriormente, foram utilizados como referência os preços unitários de serviço do Sistema Nacional de Pesquisa de Custos e Índices da Construção Civil (SINAPI) para o estado de São Paulo com data-base de Janeiro de 2011 e da Secretaria Municipal de Infraestrutura Urbana e Obras (SIURB) da prefeitura de São Paulo com data-base de Julho de 2010.

Os serviços considerados neste estudo foram:

- Escavação, reaterro e compactação de vala;

- Carga, transporte e descarga de material até $10 \mathrm{~km}$;

- Assentamento de tubulação;

- Remoção e recomposição de pavimento, além de transporte.

A seguir são apresentadas as tabelas com os preços unitários adotados.

Tabela 5.5 - Preços Unitário de Movimento de Terra

\begin{tabular}{cccc}
\hline Serviço & $\begin{array}{c}\text { Escavação Mecânica } \\
\text { de Vala em qualquer } \\
\text { tipo de terreno exceto } \\
\text { rocha até 4,0 m de } \\
\text { profundidade }\end{array}$ & $\begin{array}{c}\text { Reaterro e } \\
\text { Compactação } \\
\text { Mecânica de Vala }\end{array}$ & $\begin{array}{c}\text { Carga, Transporte e } \\
\text { Descarga Mecânica } \\
\text { de Material até 10 Km }\end{array}$ \\
\hline Código SINAPI & 73599 & $74015 / 001$ & $74140 / 003$ \\
\hline Custo $\left(\mathrm{R} \$ / \mathrm{m}^{3}\right)$ & 6,47 & 18,61 & 8,60 \\
\hline
\end{tabular}

Fonte: SINAPI (Janeiro de 2011) 
Tabela 5.6 - Preços Unitário de Assentamento de Tubulação de PVC

\begin{tabular}{ccc}
\hline Diâmetro $(\mathbf{m m})$ & Código SINAPI & Assentamento $(\mathbf{R} \mathbf{\$} / \mathbf{m})$ \\
\hline 50 & $73888 / 001$ & 1,02 \\
\hline 75 & $73888 / 002$ & 1,38 \\
\hline 100 & $73888 / 003$ & 1,74 \\
\hline 150 & $73888 / 004$ & 2,00 \\
\hline 200 & $73888 / 005$ & 2,40 \\
\hline 250 & $73888 / 006$ & 2,84 \\
\hline 300 & $73888 / 007$ & 3,62 \\
\hline 350 & $73888 / 008$ & 4,18 \\
\hline 400 & $73888 / 009$ & 5,75 \\
\hline 500 & $73888 / 010$ & 6,65 \\
\hline
\end{tabular}

Fonte: SINAPI (Janeiro de 2011)

Devido à ausência de referências de custo de assentamento de tubulações de PEAD, adotou-se o mesmo custo utilizado para tubulações de PVC.

Tabela 5.7 - Preços Unitário de Assentamento de Tubulação de Ferro Fundido Diâmetro (mm) Código SINAPI Assentamento (R $\$ / \mathrm{m})$

\begin{tabular}{ccc}
\hline 80 & $73887 / 001$ & 1,88 \\
\hline 100 & $73887 / 002$ & 2,25 \\
\hline 150 & $73887 / 003$ & 3,89 \\
\hline 200 & $73887 / 004$ & 4,98 \\
\hline 250 & $73887 / 005$ & 6,01 \\
\hline 300 & $73887 / 006$ & 6,79 \\
\hline 350 & $73887 / 007$ & 7,93 \\
\hline 400 & $73887 / 008$ & 9,07 \\
\hline 450 & $73887 / 009$ & 10,20 \\
\hline 500 & $73887 / 010$ & 11,31
\end{tabular}

Fonte: SINAPI (Janeiro de 2011)

Tabela 5.8 - Preços Unitário de Remoção de Pavimentação

\begin{tabular}{lcc}
\hline Tipo de Superfície & Código SIURB & Remoção $\left(\mathbf{R} \mathbf{\$} / \mathbf{m}^{2}\right)$ \\
\hline Concreto & $05-03-00$ & 9,30 \\
\hline Paralelepípedos & $05-36-00$ & 5,12 \\
\hline Asfalto & $05-04-00$ & 8,10 \\
\hline
\end{tabular}

Fonte: SIURB (Julho de 2010 atualizado para Janeiro de

2011 através do INCC-DI)

Tabela 5.9 - Preços Unitário de Transporte de Material de Pavimentação

\begin{tabular}{lcc}
\hline \multicolumn{1}{c}{ Tipo de Camada } & $\begin{array}{c}\text { Binder } \\
(\mathbf{R} \mathbf{\$} / \mathbf{m})\end{array}$ & $\begin{array}{c}\text { Concreto Asfáltico Usinado a Quente } \\
\left(\mathbf{R} \mathbf{\$} / \mathbf{m}^{3}\right)\end{array}$ \\
\hline Transporte até 1 Km (Ida e Volta) & 6,65 & 6,65 \\
\hline Código SIURB & $05-79-01$ & $05-78-01$ \\
\hline Fonte: SIURB (Julho de 2010 atualizado para Janeiro de 2011 através do INCC-DI)
\end{tabular}

Tabela 5.10 - Preços Unitário de Transporte de Concreto

\begin{tabular}{lc}
\hline \multicolumn{1}{c}{ Tipo de Superfície } & $\begin{array}{c}\text { Concreto } \\
\left(\mathbf{R} \$ / \mathbf{m}^{2}\right)\end{array}$ \\
\hline Transporte de $10 \mathrm{Km}$ & 3,50 \\
\hline Código SIURB & $05-81-00$ \\
\hline Fon
\end{tabular}

Fonte: SIURB (Julho de 2010 atualizado para Janeiro de 2011 através do INCC-DI) 
Tabela 5.11 - Preços Unitário de Execução de Pavimentação

\begin{tabular}{|c|c|c|c|c|c|}
\hline $\begin{array}{l}\text { Tipo de } \\
\text { Camada }\end{array}$ & $\begin{array}{l}\text { Macadame } \\
\text { Hidáulico } \\
\left(\mathbf{R} \$ / \mathrm{m}^{3}\right)\end{array}$ & $\begin{array}{l}\text { Binder } \\
\left(\mathrm{R} \$ / \mathrm{m}^{3}\right)\end{array}$ & $\begin{array}{c}\text { Concreto } \\
\text { Asfáltico } \\
\text { Usinado a } \\
\text { Quente } \\
\left(\mathrm{R} \$ / \mathrm{m}^{3}\right) \\
\end{array}$ & $\begin{array}{c}\text { Imprimação } \\
\text { Betuminosa } \\
\text { Ligante } \\
\left(\mathbf{R} \$ \mathbf{m}^{2}\right)\end{array}$ & $\begin{array}{c}\text { Imprimação } \\
\text { Betuminosa } \\
\text { Impermeabilizante } \\
\left(R \$ / \mathbf{m}^{2}\right)\end{array}$ \\
\hline $\begin{array}{l}\text { Custo de } \\
\text { Execução }\end{array}$ & 144,93 & 331,08 & 403,76 & 1,86 & 3,76 \\
\hline $\begin{array}{l}\text { Código } \\
\text { SIURB }\end{array}$ & 05-21-01 & $05-25-02$ & $05-28-00$ & $05-26-00$ & $05-27-00$ \\
\hline
\end{tabular}

Fonte: SIURB (Julho de 2010 atualizado para Janeiro de 2011 através do INCC-DI)

Tabela 5.12 - Preços Unitário de Recomposição de Pavimentação

\begin{tabular}{lcc}
\hline \multicolumn{1}{c}{ Tipo de Superfície } & Código SIURB & $\begin{array}{c}\mathbf{R e c o m p o s i c ̧ a ̃ o ~} \\
\left(\mathbf{R} \mathbf{\$} \mathbf{m}^{\mathbf{2}}\right)\end{array}$ \\
\hline Concreto & $05-42-00$ & 24,68 \\
\hline Paralelepípedos & $05-71-00$ & 18,98 \\
\hline Fonte: SIURB (Julho de 2010 atualizado para Janeiro de 2011 \\
através do INCC-DI)
\end{tabular}

Para auxiliar nas iterações para o dimensionamento, os custos de assentamento de cada material foram equacionados em relação aos diâmetros, conforme pode ser observado nas figuras a seguir.

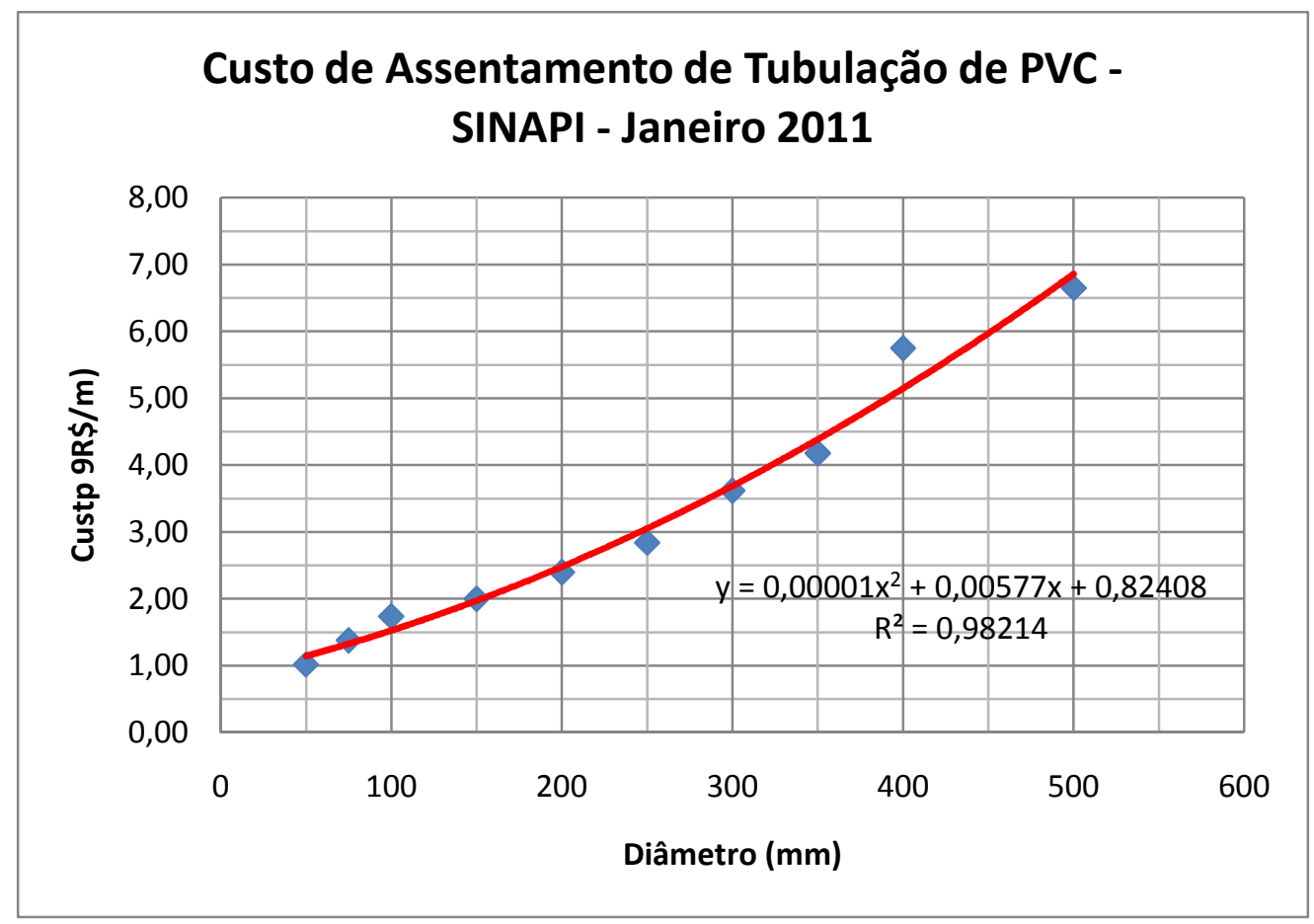

Figura 5.5 - Gráfico do custo de assentamento de tubulação de PVC em função do diâmetro 


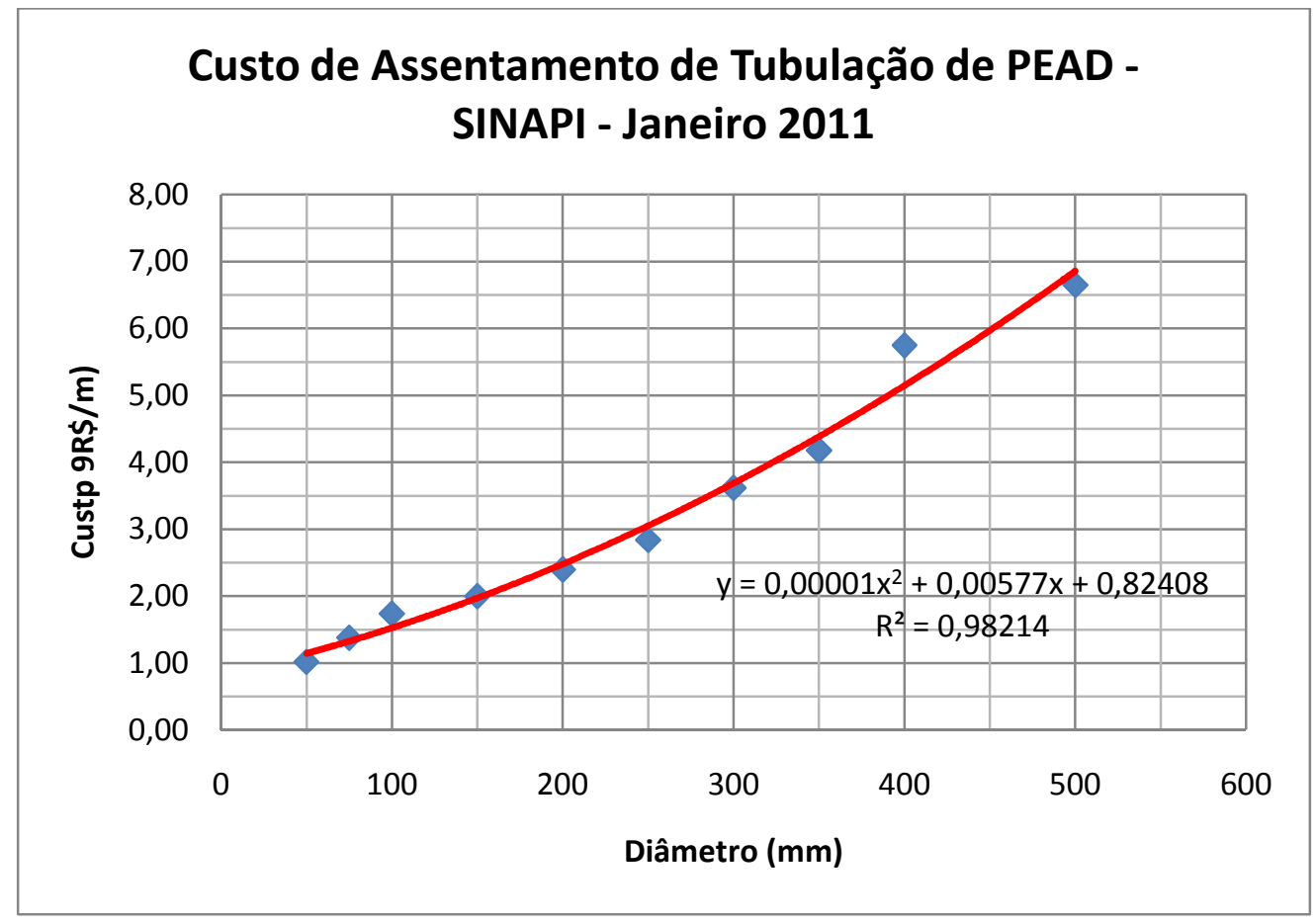

Figura 5.6 - Gráfico do custo de assentamento de tubulação de PEAD em função do diâmetro

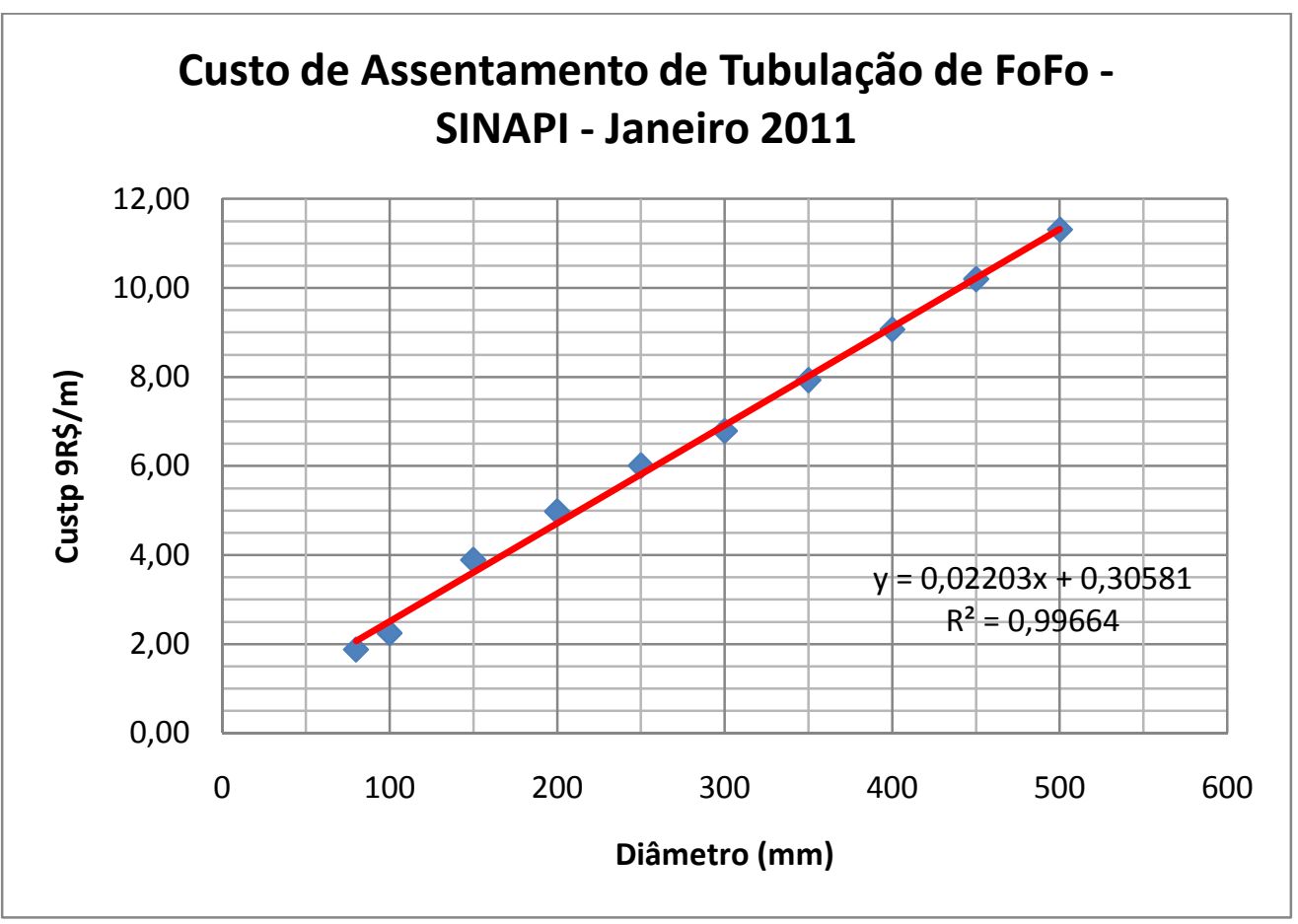

Figura 5.7 - Gráfico do custo de assentamento de tubulação de Ferro Fundido em função do diâmetro 


\subsubsection{Custo de Material}

No custo de material, foi considerado apenas o custo de fornecimento da tubulação conforme tipo de material, sendo desconsiderados os custos de conexões, ligações domiciliares, válvulas, hidrantes, bombas de recalque e eventuais reservatórios.

Para a aplicação de metodologia proposta, foram analisadas alternativas com a variação dos materiais das tubulações de distribuição de água, sendo adotados os materiais mais usuais, tais como: PVC, PEAD e Ferro Fundido.

Através de iterações, o modelo determina qual o melhor diâmetro e vazão para cada trecho em função das características da tubulação, da implantação e de operação da rede de água, além dos critérios hidráulicos.

Em relação às tubulações de PVC (cloreto de polivinil), foram adotadas as tubulações com junta elástica das seguintes linhas: PBA de Classe CL 20 para diâmetros até $100 \mathrm{~mm}$ e DEFoFo (diâmetro equivalente ao tubo de ferro fundido) para diâmetros entre 150 a $500 \mathrm{~mm}$. Foi adotado que a rugosidade equivalente do PVC é de 0,02 $\mathrm{mm}$.

$\mathrm{Na}$ Tabela 4.1 a seguir, são apresentadas as principais características das tubulações de PVC.

Tabela 5.13 - Características do Tubos de PVC

\begin{tabular}{ccccc}
\hline $\begin{array}{c}\text { Diâmetro } \\
\text { Nominal } \\
(\mathbf{m m})\end{array}$ & $\begin{array}{c}\text { Diâmetro } \\
\text { Externo } \\
(\mathbf{m m})\end{array}$ & $\begin{array}{c}\text { Espessura } \\
(\mathbf{m m})\end{array}$ & $\begin{array}{c}\text { Comprimento } \\
\text { da Tubulação } \\
(\mathbf{m})\end{array}$ & $\begin{array}{c}\text { Pressão de } \\
\text { Serviço } \\
(\mathbf{M P a})\end{array}$ \\
\hline 50 & 60 & 4,3 & 6,0 & 1,0 \\
\hline 75 & 85 & 6,1 & 6,0 & 1,0 \\
\hline 100 & 110 & 7,8 & 6,0 & 1,0 \\
\hline 150 & 170 & 6,8 & 6,0 & 1,0 \\
\hline 200 & 222 & 8,9 & 6,0 & 1,0 \\
\hline 250 & 274 & 11,0 & 6,0 & 1,0 \\
\hline 300 & 326 & 13,1 & 6,0 & 1,0 \\
\hline 400 & 429 & 17,2 & 6,0 & 1,0 \\
\hline 500 & 532 & 21,3 & 6,0 & 1,0 \\
\hline
\end{tabular}

Fonte: GOMES (2004)

Em relação às tubulações de PEAD, foram adotadas as tubulações PE-80 para soldagem com SDR 11 (relação do diâmetro externo e a espessura) e classe de pressão PN 12,5. Foi adotado que a rugosidade equivalente do PEAD é de 0,02 mm.

$\mathrm{Na}$ Tabela 5.14, são apresentadas as principais características das tubulações de PEAD. 
Tabela 5.14 - Características do Tubos de PEAD

\begin{tabular}{cccccc}
\hline $\begin{array}{c}\text { Diâmetro } \\
\text { Externo } \\
(\mathbf{m m})\end{array}$ & $\begin{array}{c}\text { Diâmetro } \\
\text { Interno } \\
(\mathbf{m m})\end{array}$ & SDR & $\begin{array}{c}\text { Espessura } \\
(\mathbf{m m})\end{array}$ & $\begin{array}{c}\text { Comprimento Fornecido } \\
(\mathbf{m})\end{array}$ & $\begin{array}{c}\text { Classe de } \\
\text { Pressão }\end{array}$ \\
\hline 50 & 41 & 11 & 4,6 & $\begin{array}{c}6,12 \text { ou } 18 \text { (tubos) } \\
50,100 \text { ou 200 (bobinas) }\end{array}$ & PN 12,5 \\
\hline 63 & 51 & 11 & 5,8 & $\begin{array}{c}6,12 \text { ou 18 (tubos) } \\
50,100 \text { ou 200 (bobinas) }\end{array}$ & PN 12,5 \\
\hline 75 & 61 & 11 & 6,9 & $\begin{array}{c}6,12 \text { ou 18 (tubos) } \\
50,100 \text { ou 200 (bobinas) }\end{array}$ & PN 12,5 \\
\hline 90 & 73 & 11 & 8,2 & $\begin{array}{c}6,12 \text { ou 18 (tubos) } \\
50,100 \text { ou 200 (bobinas) }\end{array}$ & PN 12,5 \\
\hline 110 & 90 & 11 & 10,0 & $\begin{array}{c}6,12 \text { ou } 18 \text { (tubos) } \\
50,100 \text { ou 200 (bobinas) }\end{array}$ & PN 12,5 \\
\hline 125 & 102 & 11 & 11,4 & $\begin{array}{c}6,12 \text { ou 18 (tubos) } \\
50,100 \text { ou 200 (bobinas) }\end{array}$ & PN 12,5 \\
\hline 140 & 114 & 11 & 12,8 & 6,12 ou 18 (tubos) & PN 12,5 \\
\hline 160 & 131 & 11 & 14,6 & 6,12 ou 18 (tubos) & PN 12,5 \\
\hline 180 & 147 & 11 & 16,4 & 6,12 ou 18 (tubos) & PN 12,5 \\
\hline 200 & 164 & 11 & 18,2 & 6,12 ou 18 (tubos) & PN 12,5 \\
\hline 225 & 184 & 11 & 20,5 & 6,12 ou 18 (tubos) & PN 12,5 \\
\hline 250 & 204 & 11 & 22,8 & 6,12 ou 18 (tubos) & PN 12,5 \\
\hline 280 & 229 & 11 & 25,5 & 6,12 ou 18 (tubos) & PN 12,5 \\
\hline 315 & 258 & 11 & 28,7 & 6,12 ou 18 (tubos) & PN 12,5 \\
\hline 355 & 290 & 11 & 32,3 & 6,12 ou 18 (tubos) & PN 12,5 \\
\hline 400 & 327 & 11 & 36,4 & 6,12 ou 18 (tubos) & PN 12,5 \\
\hline 450 & 368 & 11 & 41,0 & 6,12 ou 18 (tubos) & PN 12,5 \\
\hline 500 & 409 & 11 & 45,5 & 6,12 ou 18 (tubos) & PN 12,5 \\
\hline
\end{tabular}

Fonte: DANIELETTO(2007)

Em relação às tubulações de Ferro Fundido Dúctil, foram adotadas as tubulações com junta elástica da Classe K9. Foi adotado que a rugosidade equivalente do ferro fundido é de $0,1 \mathrm{~mm}$.

$\mathrm{Na}$ Tabela 5.15, são apresentadas as principais características das tubulações de Ferro Fundido.

Tabela 5.15 - Características do Tubos de Ferro Fundido

\begin{tabular}{ccccc}
\hline $\begin{array}{c}\text { Diâmetro } \\
\text { Nominal } \\
(\mathbf{m m})\end{array}$ & $\begin{array}{c}\text { Diâmetro } \\
\text { Externo } \\
(\mathbf{m m})\end{array}$ & $\begin{array}{c}\text { Espessura } \\
(\mathbf{m m})\end{array}$ & $\begin{array}{c}\text { Comprimento } \\
\text { da Tubulação } \\
(\mathbf{m})\end{array}$ & $\begin{array}{c}\text { Pressão de } \\
\text { Serviço } \\
(\mathbf{M P a})\end{array}$ \\
\hline 80 & 98 & 6,0 & 6,0 & 6,4 \\
\hline 100 & 118 & 6,1 & 6,0 & 6,4 \\
\hline 150 & 170 & 6,3 & 6,0 & 6,4 \\
\hline 200 & 222 & 6,4 & 6,0 & 6,4 \\
\hline 250 & 274 & 6,8 & 6,0 & 6,4 \\
\hline 300 & 326 & 7,2 & 6,0 & 6,4 \\
\hline 350 & 378 & 7,7 & 6,0 & 6,4 \\
\hline 400 & 429 & 8,1 & 6,0 & 6,4 \\
\hline 450 & 480 & 8,6 & 6,0 & 6,4 \\
\hline 500 & 532 & 9,0 & 6,0 & 6,4 \\
\hline
\end{tabular}

Fonte: GOMES (2004)

Para tubulações de PEAD e PVC, foi utilizado como referência o banco de preços de insumo do SINAPI com data-base de janeiro de 2011 para o estado de São Paulo. 
Para tubulações de ferro fundido, devido à ausência de referência no banco de preço do SINAPI, foi usado o banco de preços de insumos da SABESP com database de dezembro de 2009. Os preços foram trazidos para valor presente através de aplicação de fator (1,086472), segundo o Índice Nacional de Custo da Construção (INCC) levantado pela Fundação Getúlio Vargas (FGV).

Nos quadros a seguir, são apresentados os custos unitários das tubulações conforme tipo de material.

Tabela 5.16 - Custo dos Tubos de PVC por diâmetro

\begin{tabular}{ccc}
\hline Diâmetro Nominal $(\mathbf{m m})$ & Código SINAPI & Custo $(\mathbf{R} \$ \mathbf{m})$ \\
\hline 50 & 00009844 & 8,33 \\
\hline 75 & 00009845 & 13,06 \\
\hline 100 & 00009825 & 27,74 \\
\hline 150 & 00009828 & 42,56 \\
\hline 200 & 00009829 & 72,43 \\
\hline 250 & 00009826 & 110,21 \\
\hline 300 & 00009827 & 155,88 \\
\hline
\end{tabular}

Fonte: SINAPI (Janeiro de 2011)

Tabela 5.17 - Custo dos Tubos de PEAD por diâmetro

\begin{tabular}{ccc}
\hline Diâmetro Externo $(\mathbf{m m})$ & Código SINAPI & Custo $(\mathbf{R} \mathbf{\text { /m}})$ \\
\hline 50 & 00025883 & 9,60 \\
\hline 75 & 00025886 & 21,44 \\
\hline 110 & 00025888 & 45,51 \\
\hline 160 & 00025878 & 96,61 \\
\hline 200 & 00025880 & 150,60 \\
\hline 315 & 00025881 & 373,13 \\
\hline 400 & 00025882 & 600,99 \\
\hline 500 & 00025884 & 938,58 \\
\hline
\end{tabular}

Fonte: SINAPI (Janeiro de 2011)

Tabela 5.18 - Custo dos Tubos de Ferro Fundido por diâmetro

\begin{tabular}{ccc}
\hline Diâmetro Nominal $(\mathbf{m m})$ & Código SABESP & Custo $(\mathbf{R} \mathbf{\$} \mathbf{m})$ \\
\hline 80 & 54751 & 120,09 \\
\hline 100 & 54752 & 128,90 \\
\hline 150 & 54753 & 166,65 \\
\hline 200 & 54754 & 214,48 \\
\hline 250 & 54755 & 279,69 \\
\hline 300 & 54756 & 322,14 \\
\hline 350 & 54757 & 398,26 \\
\hline 400 & 54758 & 449,41 \\
\hline
\end{tabular}

Fonte: SABESP (Dezembro de 2009 atualizado para Janeiro de 2011 pelo INCC-DI)

Para auxiliar nas iterações para o dimensionamento, os custos de cada material foram equacionados em relação aos diâmetros, conforme pode ser observado nas figuras a seguir. 


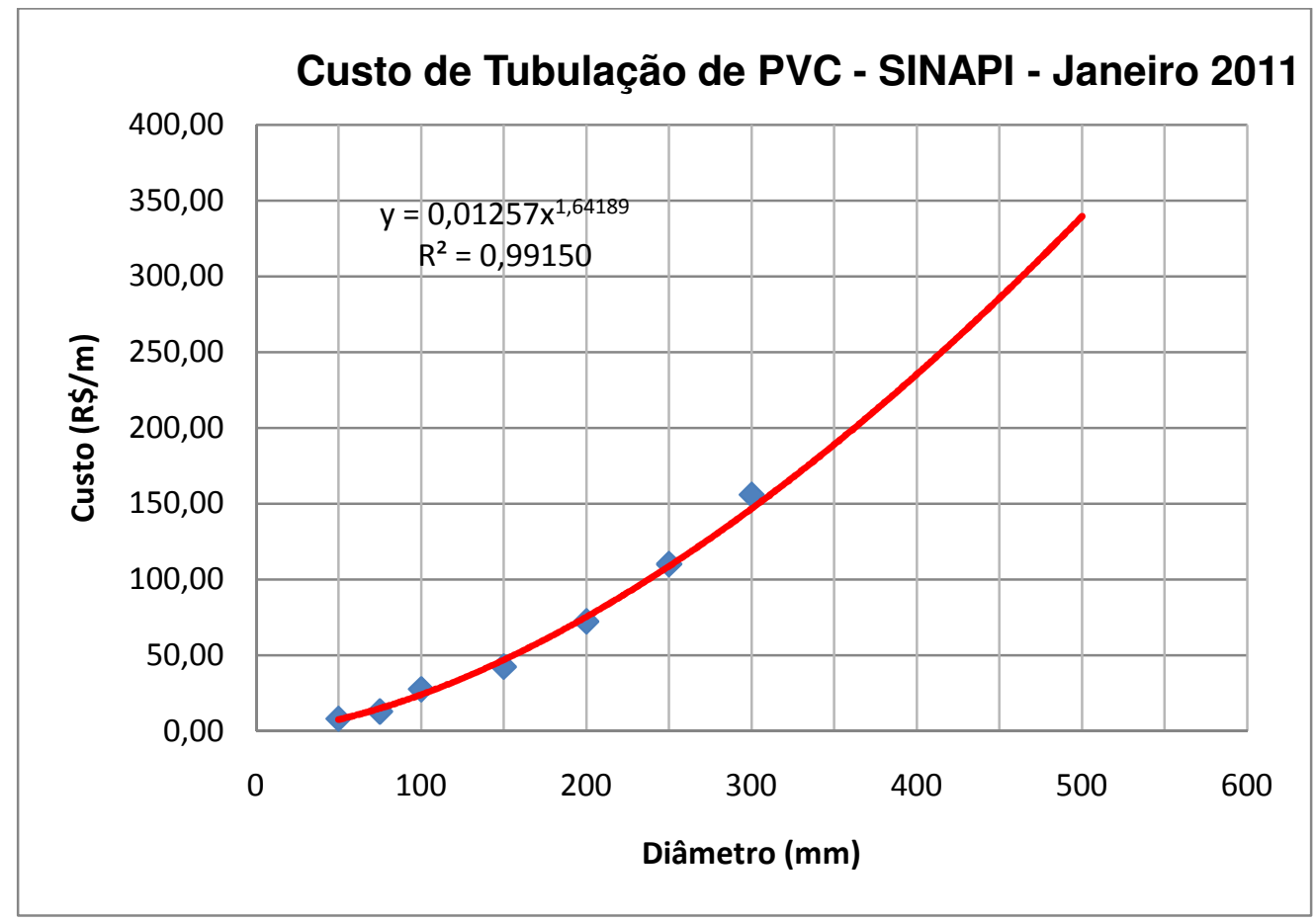

Figura 5.8 - Gráfico do custo da tubulação de PVC em relação ao diâmetro

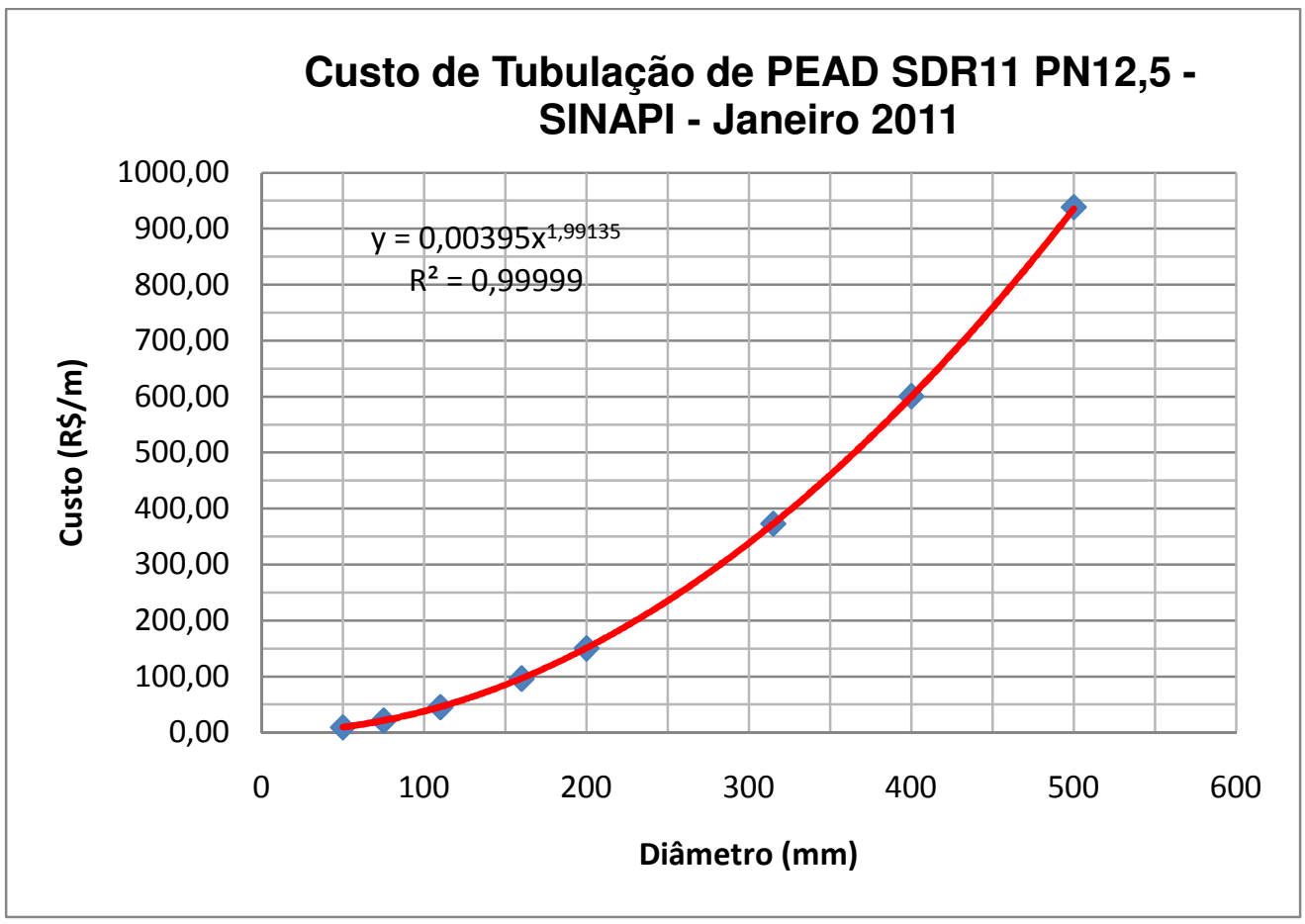

Figura 5.9 - Gráfico do custo da tubulação de PEAD em relação ao diâmetro 


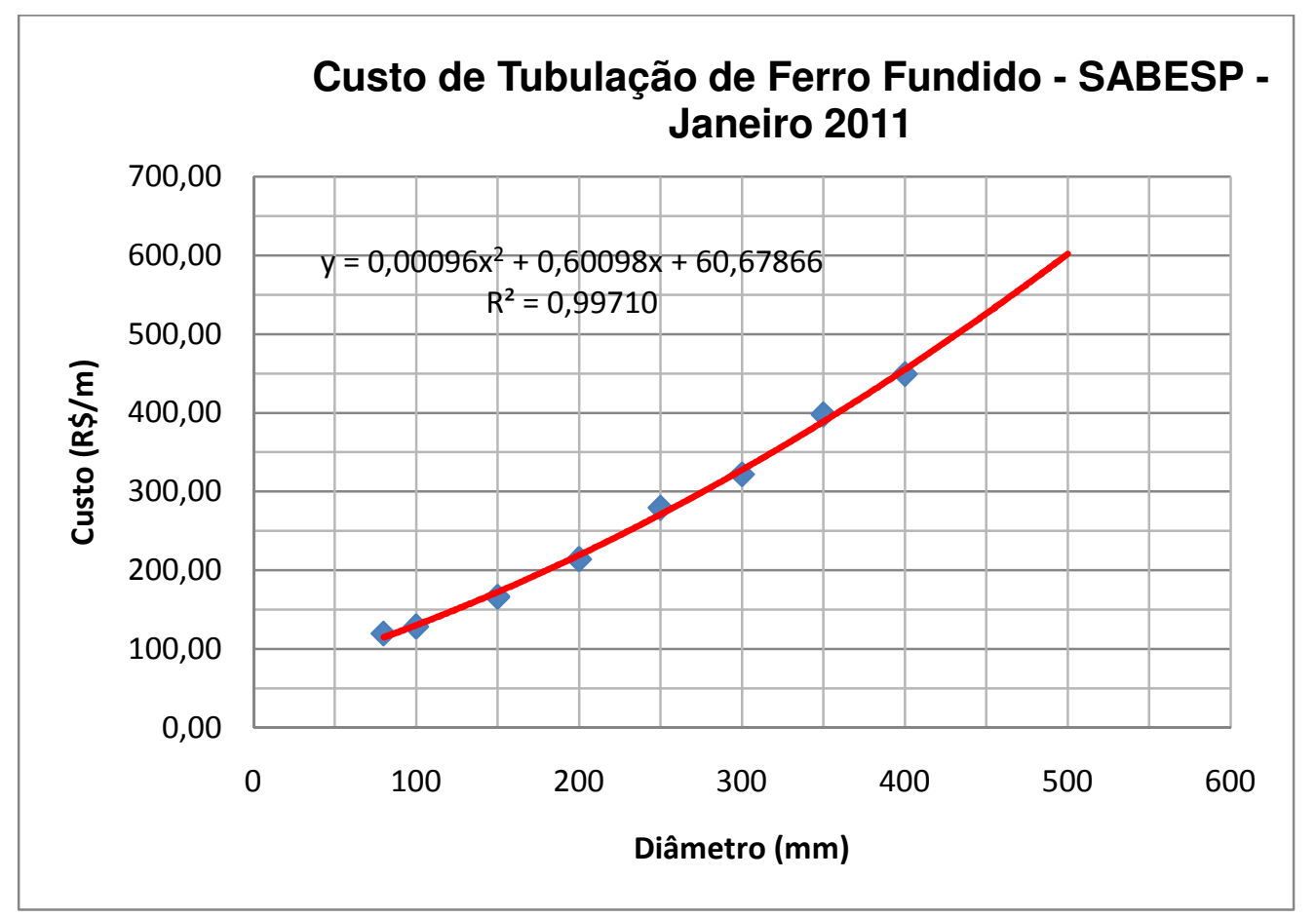

Figura 5.10 - Gráfico do custo da tubulação de Ferro Fundido em relação ao diâmetro

\subsection{CUSTO DE OPERAÇÃO}

O custo de operação está relacionado aos custos de energia elétrica ao longo da vida útil. Nesta metodologia, foram consideradas as tarifas de energia adotadas atualmente no mercado e os consumos energéticos para o sistema de pressurização e para a potência dissipada na rede.

O custo de operação é a soma dos principais custos necessários para operação da rede de água, conforme equação abaixo.

Sendo:

$$
C_{\text {operação }}=C_{\text {inicial }}+C_{\text {dissipada }}
$$

$C_{\text {operação }}$ custo de operação do sistema $(\mathrm{R} \$)$;

$C_{\text {inicial }}=$ custo de energia elétrica do sistema de pressurização inicial $(\mathrm{R} \$)$;

$C_{\text {dissipada }}=$ custo de energia elétrica da potência dissipada na rede $(\mathrm{R} \$)$.

\subsubsection{Pressurização Inicial do Sistema}

O sistema de pressurização inicial desta metodologia pode ser entendido como:

- Booster com bomba centrífuga para a pressurização da rede de distribuição de água; ou 
- Sistema de recalque através de bomba centrífuga para um reservatório elevado, que alimenta a rede de distribuição de água.

Foram adotadas as seguintes características para o sistema de pressurização inicial, conforme Tabela 5.19 .

Tabela 5.19 - Características do Sistema de Pressurização Inicial

\begin{tabular}{ccc}
\hline Item & Unidade & Valor \\
\hline Rendimento Global do Sistema de Bombeamento & $\%$ & 70 \\
\hline Funcionamento Diário & h/dia & 18 \\
\hline Funcionamento Anual & h/ano & 6570 \\
\hline Vida Útil & anos & 20 \\
\hline
\end{tabular}

Para Gomes (2004), os rendimentos globais de sistemas de bombeamento dimensionados adequadamente, variam, normalmente em torno de 60 a $85 \%$. Neste trabalho foi adotado um rendimento global médio de $70 \%$.

Por questões de segurança e/ou da tarifa de energia, é recomendado que o período de funcionamento diário do sistema de bombeamento não deva exceder 21 horas.

Normalmente o sistema de bombeamento é dimensionado para uma vida útil ou horizonte de projeto de 20 ou 30 anos.

Uma das respostas do modelo aplicado é a otimização da altura manométrica do bombeamento em função das características do sistema de abastecimento.

A partir da equação 5.9, o valor da potência do sistema de pressurização inicial é obtido em função da vazão de bombeamento e da carga inicial, além do rendimento global do sistema de bombeamento.

$$
P_{\text {inicial }}=\frac{\gamma \cdot Q_{b} \cdot H_{m}}{\eta}
$$

Sendo:

$P_{\text {inicial }}=$ Potência de um bombeamento inicial no sistema $(\mathrm{kW})$;

$\gamma=$ peso específico da água $\left(\mathrm{N} / \mathrm{m}^{3}\right)$;

$Q_{b}=$ vazão do sistema de bombeamento $\left(\mathrm{m}^{3} / \mathrm{s}\right)$;

$H_{m}=$ Altura manométrica do sistema de bombeamento (m);

$\eta=$ rendimento global do sistema de bombeamento. 


\subsubsection{Potência Dissipada}

Embora pareça redundante considerar a potência do sistema de pressurização e a dissipada na rede, pois a última estaria inserida na primeira, na metodologia adotada neste trabalho trata-se de parâmetro importante para a obtenção do dimensionamento otimizado.

Através da fórmula universal é determinada as perdas de carga dissipadas em cada trecho da rede de distribuição de água, através da equação 5.3. Utilizando a equação abaixo, o valor da potência dissipada na rede é obtido em função da vazão e da perda de carga em cada trecho, além do rendimento global do sistema de bombeamento.

$$
P_{\text {dissipada }}=\frac{\gamma \cdot \sum Q_{i} \cdot \Delta H_{i}}{\eta}
$$

Sendo:

$P_{\text {dissipada }}=$ Potência de um bombeamento equivalente a dissipação na rede $(\mathrm{kW})$;

$\gamma=$ peso específico da água $\left(\mathrm{N} / \mathrm{m}^{3}\right)$;

$Q_{i}=$ vazão no trecho i $\left(\mathrm{m}^{3} / \mathrm{s}\right)$;

$\Delta H_{i}=$ perda de carga no trecho $\mathrm{i}(\mathrm{m})$;

$\eta=$ rendimento global do sistema de bombeamento equivalente.

Conforme Martins (2006), essa potência representa a energia gasta por unidade de tempo na operação do sistema, podendo ser empregada como elemento de comparação, considerando-se os demais custos intervenientes como variáveis em função do diâmetro da tubulação.

\subsubsection{Custos de Energia Elétrica}

As tarifas de energia elétrica são determinadas pela Agência Nacional de Energia Elétrica (ANEEL).

Para efeito de aplicação das tarifas de energia elétrica, os consumidores são identificados por classes e subclasses de consumo. São elas:

- Residencial - na qual se enquadram, também, os consumidores residenciais de baixa renda cuja tarifa é estabelecida de acordo com critérios específicos; 
- Industrial - na qual se enquadram as unidades consumidoras que desenvolvem atividade industrial, inclusive o transporte de matéria prima, insumo ou produto resultante do seu processamento;

- Comercial, Serviços e Outras Atividades - na qual se enquadram os serviços de transporte, comunicação e telecomunicação e outros afins;

- Rural - na qual se enquadram as atividades de agropecuária, cooperativa de eletrificação rural, indústria rural, coletividade rural e serviço público de irrigação rural;

- Poder Público - na qual se enquadram as atividades dos Poderes Públicos: Federal, Estadual ou Distrital e Municipal;

- Iluminação Pública - na qual se enquadra a iluminação de ruas, praças, jardins, estradas e outros logradouros de domínio público de uso comum e livre acesso, de responsabilidade de pessoa jurídica de direito público;

- Serviço Público - na qual se enquadram os serviços de água, esgoto e saneamento; e

- Consumo Próprio - que se refere ao fornecimento destinado ao consumo de energia elétrica da própria empresa de distribuição.

As tarifas de energia elétrica são definidas com base em dois componentes: demanda de potência e consumo de energia.

A demanda de potência é medida em quilowatt e corresponde à média da potência elétrica solicitada pelo consumidor à empresa distribuidora, durante um intervalo de tempo especificado normalmente 15 minutos e é faturada pelo maior valor medido durante o período de fornecimento, normalmente de 30 dias.

O consumo de energia é medido em quilowatt-hora ou em megawatt-hora (MWh) e corresponde ao valor acumulado pelo uso da potência elétrica disponibilizada ao consumidor ao longo de um período de consumo, normalmente de 30 dias.

Para determinação do consumo de energia do sistema de pressurização inicial, foi utilizada a seguinte equação.

Sendo:

$$
E_{\text {inicial }}=P_{\text {inicial }} \cdot h_{\text {ano }}
$$

$E_{\text {inicial }}=$ consumo de energia anual do sistema de pressurização $(\mathrm{kWh})$;

$P_{\text {inicial }}=$ Potência de um bombeamento inicial no sistema (kW); 
$h_{a n o}=$ horas de funcionamento do sistema por ano (h).

Para determinação do consumo de energia da potência dissipada na rede, foi utilizada a equação (5.12).

Sendo:

$$
E_{\text {dissipada }}=P_{\text {dissipada }} \cdot h_{\text {ano }}
$$

$E_{\text {dissipada }}=$ Consumo de energia anual equivalente ao bombeamento da potência dissipada na rede $(\mathrm{kWh})$;

$P_{\text {dissipada }}=$ Potência de um bombeamento equivalente a dissipação na rede $(\mathrm{kW})$;

$h_{a n o}=$ Horas de funcionamento do sistema equivalente de bombeamento por ano (h).

Define-se estrutura tarifária como sendo o conjunto de tarifas aplicáveis aos componentes de consumo de energia elétrica e/ou demanda de potência, de acordo com a modalidade de fornecimento.

No Brasil, as tarifas de energia elétrica estão estruturadas em dois grandes grupos de consumidores: "grupo A" e "grupo B".

As tarifas do "grupo A" são para consumidores atendidos pela rede de alta tensão, de 2,3 a 230 quilovolts $(\mathrm{kV})$, e recebem denominações com letras e algarismos indicativos da tensão de fornecimento, como segue:

- A1 para o nível de tensão de 230 kV ou mais;

- A2 para o nível de tensão de 88 a 138 kV;

- A3 para o nível de tensão de $69 \mathrm{kV}$;

- A3a para o nível de tensão de 30 a 44 kV;

- A4 para o nível de tensão de 2,3 a 25 kV;

- AS para sistema subterrâneo.

Segundo Gomes (2004), a operação da rede pública de abastecimento de água e esgotamento sanitário se enquadra na categoria de serviços público, normalmente liaga em alta e média tensão (Grupo A). 
Em São Paulo, a maioria das unidades da SABESP pertence ao Grupo A e Subgrupo A4 para tensões de 2,3 a $25 \mathrm{kV}$. Neste estudo foi adotado as tarifas por consumo para o Subgrupo A4.

As tarifas do "grupo A" são construídas em três modalidades de fornecimento: convencional, horo-sazonal azul e horo-sazonal verde, sendo que a convenção por cores é apenas para facilitar a referência.

A estrutura tarifária convencional é caracterizada pela aplicação de tarifas de consumo de energia e/ou demanda de potência independentemente das horas de utilização do dia e dos períodos do ano. A tarifa convencional apresenta um valor para a demanda de potência em reais por quilowatt e outro para o consumo de energia em reais por megawatt-hora.

A estrutura tarifária horo-sazonal é caracterizada pela aplicação de tarifas diferenciadas de consumo de energia elétrica e de demanda de potência, de acordo com as horas de utilização do dia e dos períodos do ano. O objetivo dessa estrutura tarifária é racionalizar o consumo de energia elétrica ao longo do dia e do ano, motivando o consumidor, pelo valor diferenciado das tarifas, a consumir mais energia elétrica nos horários do dia e nos períodos do ano em que ela for mais barata.

Para as horas do dia são estabelecidos dois períodos, denominados postos tarifários. O posto tarifário "ponta" corresponde ao período de maior consumo de energia elétrica, que ocorre entre às 17:30 e 20;30 em São Paulo. Este período é diferente para cada estado. O posto tarifário "fora da ponta" compreende as demais horas dos dias úteis e as 24 horas dos sábados, domingos e feriados. As tarifas no horário de "ponta" são mais elevadas do que no horário "fora de ponta".

Já para o ano, são estabelecidos dois períodos: "período seco", quando a incidência de chuvas é menor, e "período úmido" quando é maior o volume de chuvas. As tarifas no período seco são mais altas, refletindo o maior custo de produção de energia elétrica devido à menor quantidade de água nos reservatórios das usinas hidrelétricas, provocando a eventual necessidade de complementação da carga por geração térmica, que é mais cara. O período seco compreende os meses de maio a novembro e o período úmido os meses de dezembro a abril. 
A tarifa horo-sazonal azul é a modalidade de fornecimento estruturada para a aplicação de tarifas diferenciadas de consumo de energia elétrica, de acordo com as horas de utilização do dia e dos períodos do ano, bem como de tarifas diferenciadas de demanda de potência de acordo com as horas de utilização do dia.

A tarifa horo-sazonal azul tem a seguinte estrutura:

Demanda de potência $(\mathrm{R} \$ / \mathrm{kW})$ :

- Um valor para o horário de ponta;

- Um valor para o horário fora de ponta.

Consumo de energia ( $\mathrm{R} \$ / \mathrm{MWh})$ :

- Um valor para o horário de ponta em período úmido;

- Um valor para o horário fora de ponta em período úmido;

- Um valor para o horário de ponta em período seco;

- Um valor para o horário fora de ponta em período seco.

A tarifa horo-sazonal verde é a modalidade de fornecimento estruturada para a aplicação de tarifas diferenciadas de consumo de energia elétrica, de acordo com as horas de utilização do dia e dos períodos do ano, bem como de uma única tarifa de demanda de potência.

A tarifa horo-sazonal verde tem a seguinte estrutura:

Demanda de potência $(\mathrm{R} \$ / \mathrm{kW})$ :

- valor único.

Consumo de energia ( $\mathrm{R} \$ / \mathrm{MWh})$ :

- Um valor para o horário de ponta em período úmido;

- Um valor para o horário fora de ponta em período úmido;

- Um valor para o horário de ponta em período seco;

- Um valor para o horário fora de ponta em período seco.

\subsubsection{Preços Unitários}

Para o desenvolvimento do modelo, foram adotados os preços unitários atuais aplicados pelo AES Eletropaulo para São Paulo, conforme o tipo de tarifa aplicada. 
Na Tabela 5.20 , são apresentadas as tarifas de energia para Subgrupo A4 da AES Eletropaulo aplicadas a partir de 04/07/10, segundo Resolução № 1.025 de 29/06/10 da ANEEL.

Tabela 5.20 - Tarifas de Energia para Subgrupo A4 - AES Eletropaulo a partir de 04/07/10

\begin{tabular}{|c|c|c|c|c|c|}
\hline Tarifa & & Tipo & & $\begin{array}{c}\text { Custo por Demanda } \\
(\mathrm{R} \$ / \mathrm{KW})\end{array}$ & $\begin{array}{c}\text { Custo por Consumo } \\
(\mathbf{R} \$ / M W h)\end{array}$ \\
\hline Convencional & & - & & 31,31 & 161,32 \\
\hline \multirow{8}{*}{$\begin{array}{l}\text { Horo- } \\
\text { Sazionais }\end{array}$} & \multirow{4}{*}{$\begin{array}{l}\text { Tarifa } \\
\text { Azul }\end{array}$} & Ponta & Seca & 32,39 & 249,04 \\
\hline & & Ponta & Úmida & 32,39 & 226,21 \\
\hline & & $\begin{array}{l}\text { Fora de } \\
\text { Ponta }\end{array}$ & Seca & 7,99 & 159,12 \\
\hline & & $\begin{array}{c}\text { Fora de } \\
\text { Ponta }\end{array}$ & Úmida & 7,99 & 145,87 \\
\hline & \multirow{4}{*}{$\begin{array}{l}\text { Tarifa } \\
\text { Verde }\end{array}$} & Ponta & Seca & 7,99 & 1001,06 \\
\hline & & Ponta & Úmida & 7,99 & 958,23 \\
\hline & & $\begin{array}{l}\text { Fora de } \\
\text { Ponta }\end{array}$ & Seca & 7,99 & 159,12 \\
\hline & & $\begin{array}{c}\text { Fora de } \\
\text { Ponta } \\
\end{array}$ & Úmida & 7,99 & 145,87 \\
\hline
\end{tabular}

Fonte: AES ELETROPAULO (Resolução № 1.025 de 29/06/10 da ANEEL - DOU de 02/07/2010)

\subsubsection{Custo de Operação em Valor Presente}

O custo de operação do sistema de pressurização inicial é obtido através da equação 5.13.

Sendo:

$$
C_{\text {inicial }}=P_{\text {inicial }} \cdot C_{\text {demanda }}+E_{\text {inicial }} \cdot C_{\text {consumo }}
$$

$C_{\text {inicial }}=$ Custo de energia elétrica do sistema de pressurização inicial $(\mathrm{R} \$)$;

$P_{\text {inicial }}=$ Potência de um bombeamento inicial no sistema $(\mathrm{kW})$;

$E_{\text {inicial }}=$ Consumo de energia anual do sistema de pressurização $(\mathrm{kWh})$;

$C_{\text {demanda }}=$ Tarifa de energia elétrica por demanda de potência $(\mathrm{R} \$ / \mathrm{kW})$;

$C_{\text {consumo }}=$ Tarifa de energia elétrica por consumo $(\mathrm{R} \$ / \mathrm{kWh})$.

De maneira similar, o custo de potência dissipada na rede é obtido através da equação 5.14 .

Sendo:

$$
C_{\text {dissipada }}=P_{\text {dissipada }} \cdot C_{\text {demanda }}+E_{\text {dissipada }} \cdot C_{\text {consumo }}
$$

$C_{\text {dissipada }}=$ Custo de energia elétrica da potência dissipada na rede $(\mathrm{R} \$)$.

$P_{\text {dissipada }}=$ Potência de um bombeamento equivalente a dissipação na rede $(\mathrm{kW})$; 
$E_{\text {dissipada }}=$ Consumo de energia anual equivalente ao bombeamento da potência dissipada na rede $(\mathrm{kWh})$;

$C_{\text {demanda }}=$ Tarifa de energia elétrica por demanda de potência $(\mathrm{R} \$ / \mathrm{kW})$;

$C_{\text {consumo }}=$ Tarifa de energia elétrica por consumo $(\mathrm{R} \$ / \mathrm{kWh})$.

O custo de operação para valor presente é obtido através da equação 5.15 .

$$
C_{\text {operação presente }}=F_{A} \cdot\left(C_{\text {inicial }}+C_{\text {dissipada }}\right)
$$

Sendo:

$C_{\text {operação presente }}=$ Custo de operação para valor presente $(\mathrm{R} \$)$;

$C_{\text {inicial }}=$ Custo de energia elétrica do sistema de pressurização inicial $(\mathrm{R} \$)$;

$C_{\text {dissipada }}=$ Custo de energia elétrica da potência dissipada na rede $(\mathrm{R} \$)$.

$F_{A}=$ Fator de atualização do custo energético.

Para a determinação do fator de atualização do custo energético, foi usada a equação 5.16 .

$$
F_{A}=\frac{(1+i)^{n}-1}{i \cdot(1+i)^{n}}
$$

Sendo:

$F_{A}=$ Fator de atualização do custo energético;

$i=$ Taxa de juros anual;

$n=$ Vida útil do sistema (anos).

A taxa de juros depende de fatores econômicos, financeiros e políticos, sendo complicada a determinação de seu valor.

Para esse estudo, foi considerada uma taxa nula de aumento de energia para cálculo do fator de atualização do custo energético. 


\section{ESTUDO DE CASO}

Para a aplicação da metodologia proposta, foi usado o exemplo aplicado por Martins (2006) em área no litoral do Estado de São Paulo. Os dados disponíveis dessa área eram os dados censitários e levantamentos planialtimétricos digitalizados.

\subsection{DESCRIÇÃO DA ÁREA}

A área, em processo de urbanização intensa, compreende 131,2 ha ocupando uma região com pequena declividade, típica de áreas litorâneas, sendo que a maior diferença entre as cotas de terreno é de 4,07 m.

O traçado da rede foi feito em dois anéis principais, de forma a atender todas as áreas, sendo o nó inicial (N1) um reservatório elevado alimentado por uma bomba de recalque ou um booster alimentado por uma adutora.

Para esse estudo, foram consideradas as seguintes condições de superfície para implantação da rede de água, sendo:

- Viário em terra;

- Passeio em concreto;

- Viário em paralelepípedo;

- Viário em asfalto para tráfego leve;

- Viário em asfalto para tráfego médio;

- Viário em asfalto para tráfego pesado.

Exceto o viário em terra, todas as demais superfícies necessitam de remoção e recomposição de pavimento para implantação de rede de água.

Na Figura 6.2, é apresentada características da área de estudada, tais como topografia e viários.

Na Figura 6.2, é apresentado o esquema hidráulico da área estudada apenas com as tubulações principais. 


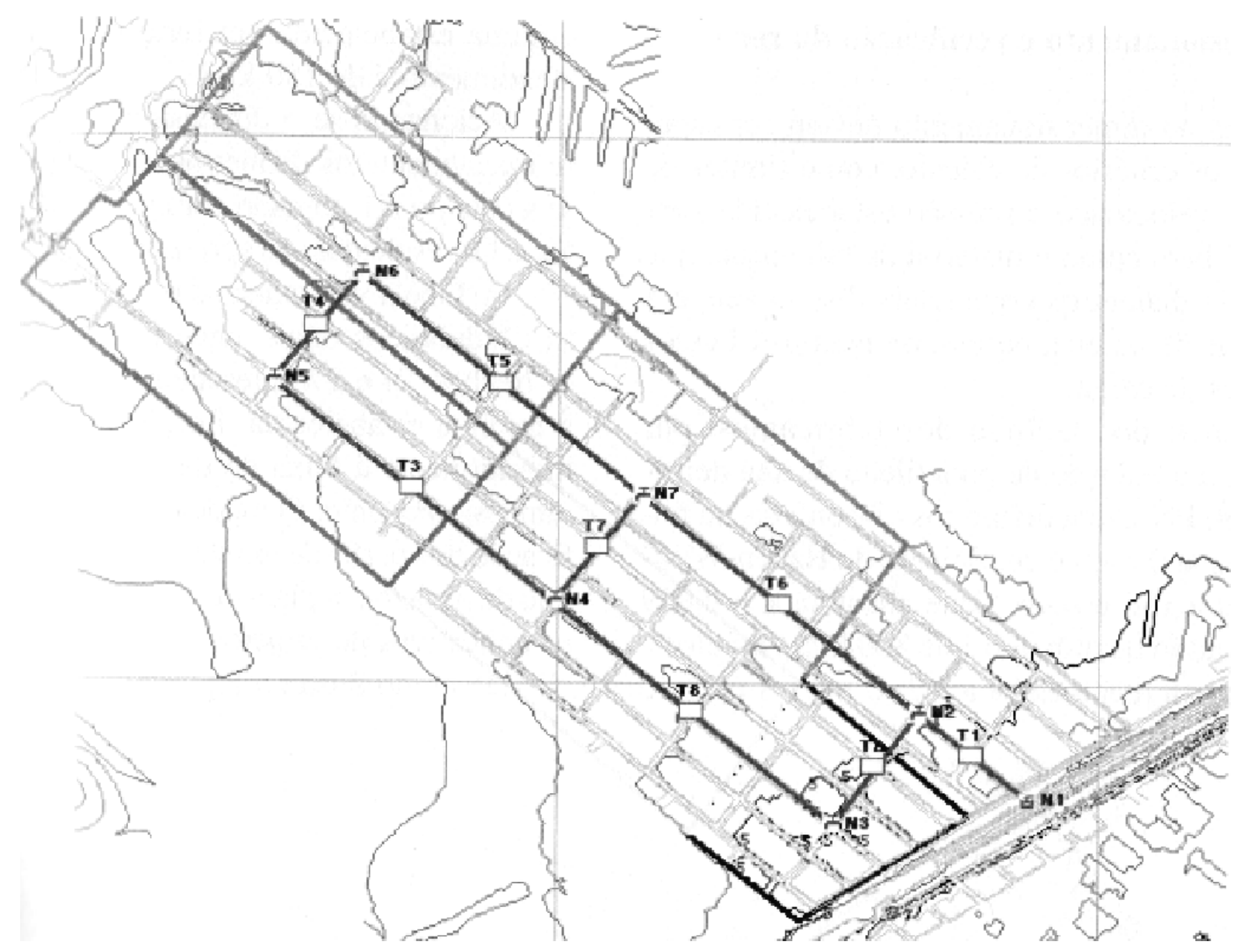

Figura 6.1 - Características da área de estudo no litoral de São Paulo

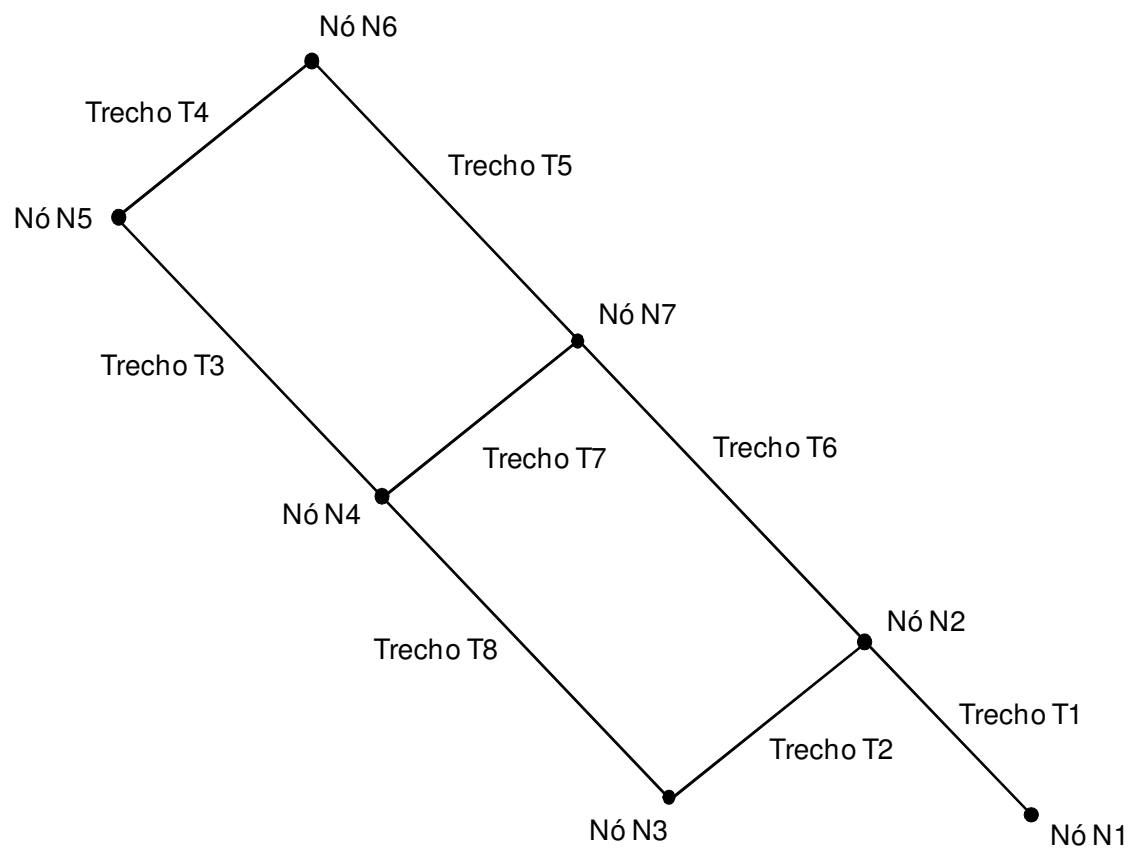

Figura 6.2 - Esquema Hidráulico da área de estudo no litoral de São Paulo 
O nó 1 está na cota mais elevada $(4,56 \mathrm{~m})$, sendo o local considerado para implantação de um reservatório elevado ou de um booster para abastecimento da área estudada. Os nós 2 e 3 estão em cota um pouco mais baixa de 3,5 m. Os nós 4 e 7 estão em cota intermediária de $1,5 \mathrm{~m}$. Os nós 5 e 6 estão nas cotas mais baixas, sendo, respectivamente, 0,5 e $0,49 \mathrm{~m}$. Para efeito de cálculo e por segurança, foi adotado que a cota do nó é a mesma que a do terreno.

$\mathrm{Na}$ Tabela 6.1, são apresentadas as cotas de cada nó da rede de água.

Tabela 6.1 - Cota de cada nó da rede de água

\begin{tabular}{cccccccc}
\hline Nó & N1 & N2 & N3 & N4 & N5 & N6 & N7 \\
\hline Cota do nó $(\mathrm{m})$ & 4,56 & 3,50 & 3,50 & 1,50 & 0,50 & 0,49 & 1,50 \\
\hline
\end{tabular}

$\mathrm{Na}$ Tabela 6.2, são apresentados as extensões de cada trecho da rede de água.

Tabela 6.2 - Extensões de cada trecho de rede de água

\begin{tabular}{cc}
\hline Trecho & Extensão $(\mathbf{m})$ \\
\hline T1 & 258,48 \\
\hline T2 & 255,93 \\
\hline T3 & 657,53 \\
\hline T4 & 253,28 \\
\hline T5 & 660,47 \\
\hline T6 & 644,10 \\
\hline T7 & 253,02 \\
\hline T8 & 657,18 \\
\hline Total & $\mathbf{3 6 3 9 , 9 9}$
\end{tabular}

Fonte: MARTINS (2006)

\subsection{DADOS PARA O DIMENSIONAMENTO}

Os dados para a determinação da demanda de água foram obtidos a partir da projeção da população para o final do horizonte de projeto (2022), através dos dados dos levantamentos censitários. A densidade populacional obtida para o final de plano é de 318 habitantes/ha. O consumo específico por economia foi estimado em $470 \mathrm{l} / \mathrm{economia/dia}$, equivalente a um consumo per capita de aproximadamente 120 L/habitante/dia.

Após dividir a região estuda em zonas homogêneas de acordo com as características de ocupação, foram obtidas as demandas pontuais de abastecimento, conforme apresentado na tabela abaixo. 
Tabela 6.3 - Demandas pontuais por nó para o dimensionamento da rede de água

\begin{tabular}{cccccccccc}
\hline Nó & $\begin{array}{c}\text { Área } \\
\text { (ha) }\end{array}$ & $\begin{array}{c}\text { Densidade } \\
\text { (hab/ha) }\end{array}$ & $\begin{array}{c}\text { Per Capita } \\
\text { (L/hab/dia) }\end{array}$ & $\mathbf{K 1}$ & $\mathbf{K 2}$ & $\begin{array}{c}\text { Perdas } \\
\text { (\%) }\end{array}$ & $\begin{array}{c}\text { Vazão } \\
\text { (L/s) }\end{array}$ & $\begin{array}{c}\text { Incêndio } \\
\text { (L/s) }\end{array}$ & $\begin{array}{c}\text { Vazão } \\
\text { Pontual } \\
\text { Total } \\
\text { (L/s) }\end{array}$ \\
\hline N2 & 14,531 & 318 & 120 & 1,2 & 1,5 & 15 & 13,591 & 10 & 23,591 \\
\hline N3 & 11,373 & 318 & 120 & 1,2 & 1,5 & 15 & 10,637 & 10 & 20,637 \\
\hline N4 & 24,116 & 318 & 120 & 1,2 & 1,5 & 15 & 22,556 & 10 & 32,556 \\
\hline N5 & 29,132 & 318 & 120 & 1,2 & 1,5 & 15 & 27,247 & 10 & 37,247 \\
\hline N6 & 26,467 & 318 & 120 & 1,2 & 1,5 & 15 & 24,754 & 10 & 34,754 \\
\hline$N 7$ & 22,05 & 318 & 120 & 1,2 & 1,5 & 15 & 20,623 & 10 & 30,623 \\
\hline
\end{tabular}

Fonte: MARTINS (2006)

\subsection{DIMENSIONAMENTO OTIMIZADO}

O dimensionamento de rede de distribuição de água por critério de custo global foi feita através dos métodos matriciais utilizando o método do Gradiente Reduzido Generalizado (GRG2), que se trata de um algoritmo de programação não linear, através do uso do aplicativo Excel, utilizando a função Solver para minimização da função objetivo (custo total global).

A função objetivo foi minimizada, tendo como variáveis de decisão as vazões e os diâmetros de cada trecho de rede. As variáveis de estado são as pressões e as velocidades.

As restrições para o dimensionamento impostas ao modelo foram às seguintes:

- Diâmetro máximo da rede: 500 mm;

- Diâmetro mínimo da rede: $50 \mathrm{~mm}$;

- Velocidade máxima nos trechos: 2,0 m/s;

- Velocidade mínima nos trechos: 0,5 m/s;

- Pressão máxima nos nós: $500 \mathrm{KPa}$;

- Pressão mínima nos nós: 100 kPa;

- Somatório das vazões nos nós: tolerância máxima de 0,01L/s;

- Somatório das perdas de carga em cada circuito: tolerância máxima de 0,001 $\mathrm{kPa}$.

Em relação à restrição de velocidade máxima nos trechos ser até $3,5 \mathrm{~m} / \mathrm{s}$ segundo norma, o uso do limite máximo de $2,0 \mathrm{~m} / \mathrm{s}$ é usual para tubulações de diâmetro até $600 \mathrm{~mm}$. 
A partir das demandas de abastecimento nos nós e das restrições impostas ao modelo, foram elaborados os dimensionamentos, onde os resultados são apresentados nos itens a seguir e as planilhas completas no apêndice.

\subsubsection{Dimensionamento Otimizado por Tipo de Pavimento}

Para este dimensionamento, as únicas variáveis eram o tipo de material da tubulação e as condições da superfície para implantação da rede de água, além da altura manométrica da pressurização no nó inicial e da vazão e do diâmetro de cada trecho de rede.

Foram fixados os seguintes parâmetros, tais como:

- Sistema de pressurização inicial

- Rendimento Global do Sistema de Bombeamento: 70\%;

- Funcionamento Diário: $18 \mathrm{~h} /$ dia;

○ Funcionamento Anual: 6570 h/ano;

○ Vida Útil: 20 anos.

- Custo de energia elétrica

- Grupo A (Alta e Média Tensão);

- Sub-Grupo A4 (2,3 KV a $25 \mathrm{KV})$;

- Tarifa: Convencional;

- Custo de Energia por Demanda: 31,31 R $\$ / K W$;

- Custo de Energia por Consumo: 0,16132 R $\$ / K W h$;

- Taxa de Juros: 8,00 \% ao ano;

- Fator de Atualização: 10,60.

Após dimensionamento, foram obtidos os seguintes resultados por tipo de tubulação de água apresentados nas figuras a seguir. 


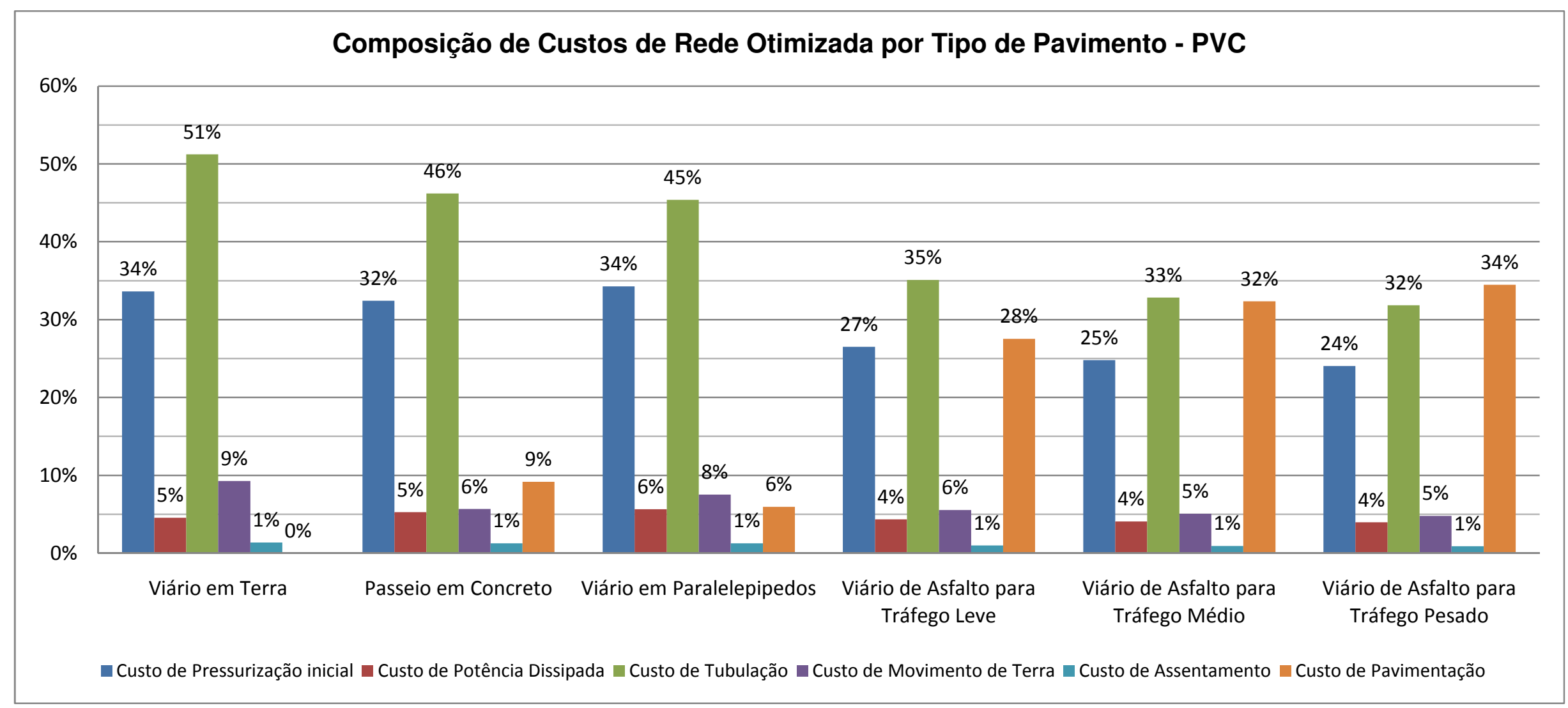

Figura 6.3 - Composição de Custos de Rede Otimizada por Tipo de Pavimento - PVC 


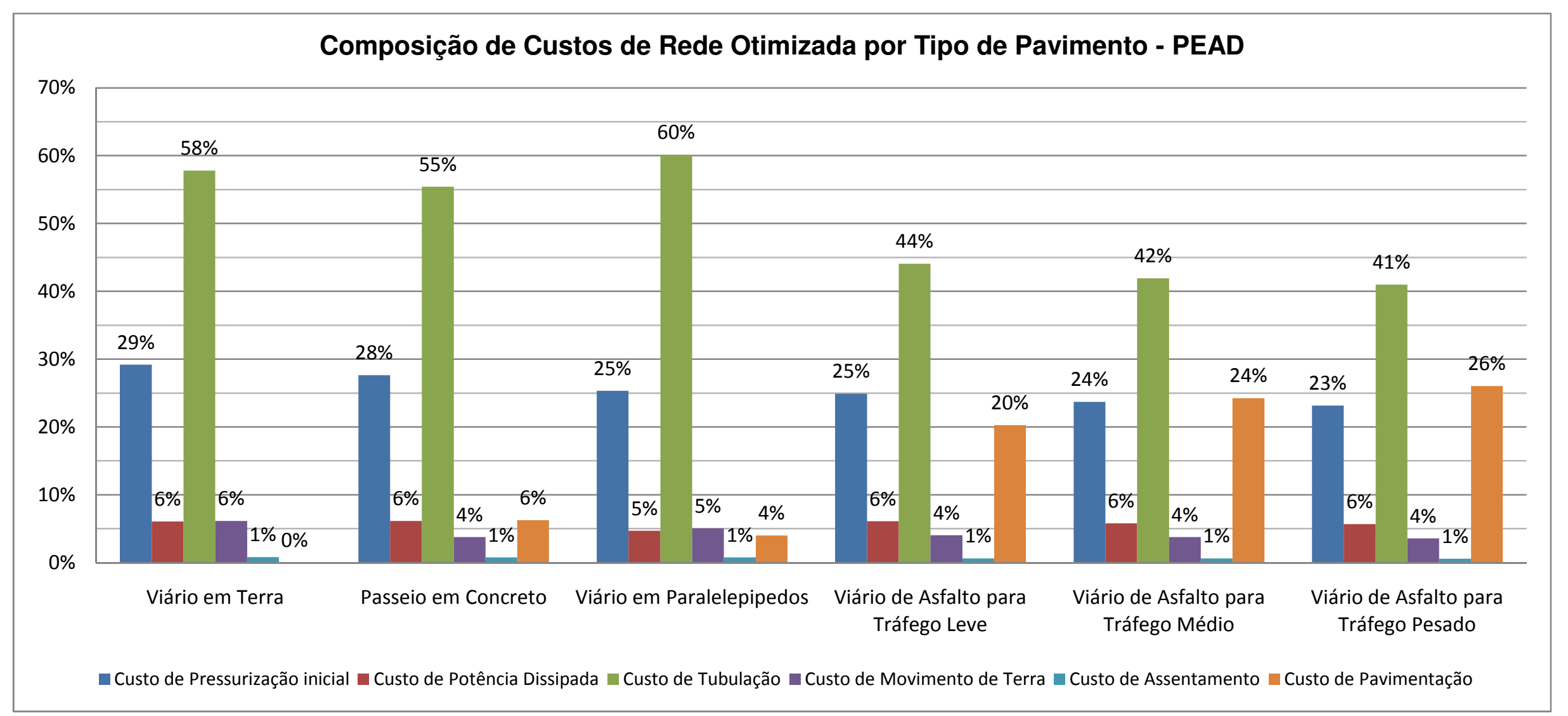

Figura 6.4 - Composição de Custos de Rede Otimizada por Tipo de Pavimento - PEAD 


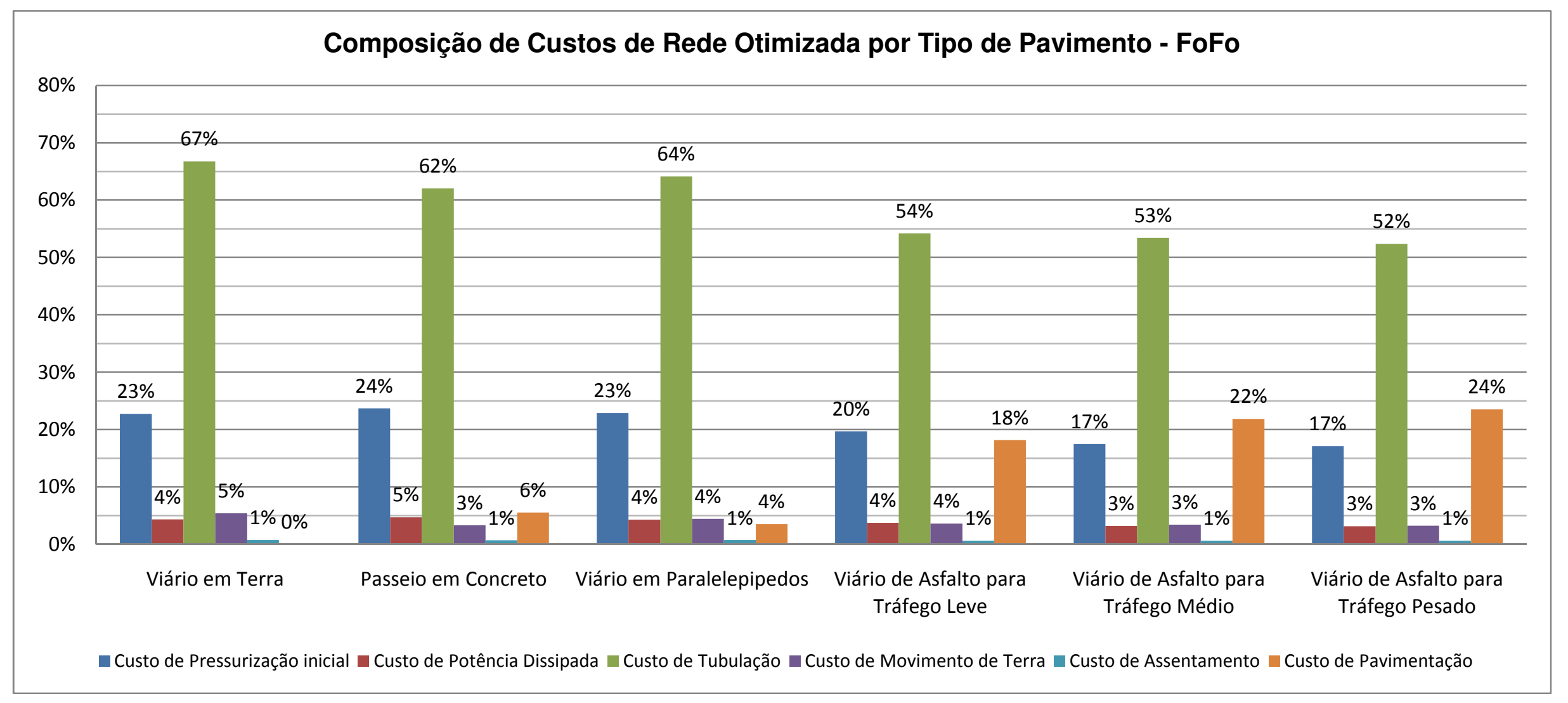

Figura 6.5 - Composição de Custos de Rede Otimizada por Tipo de Pavimento - FoFo 


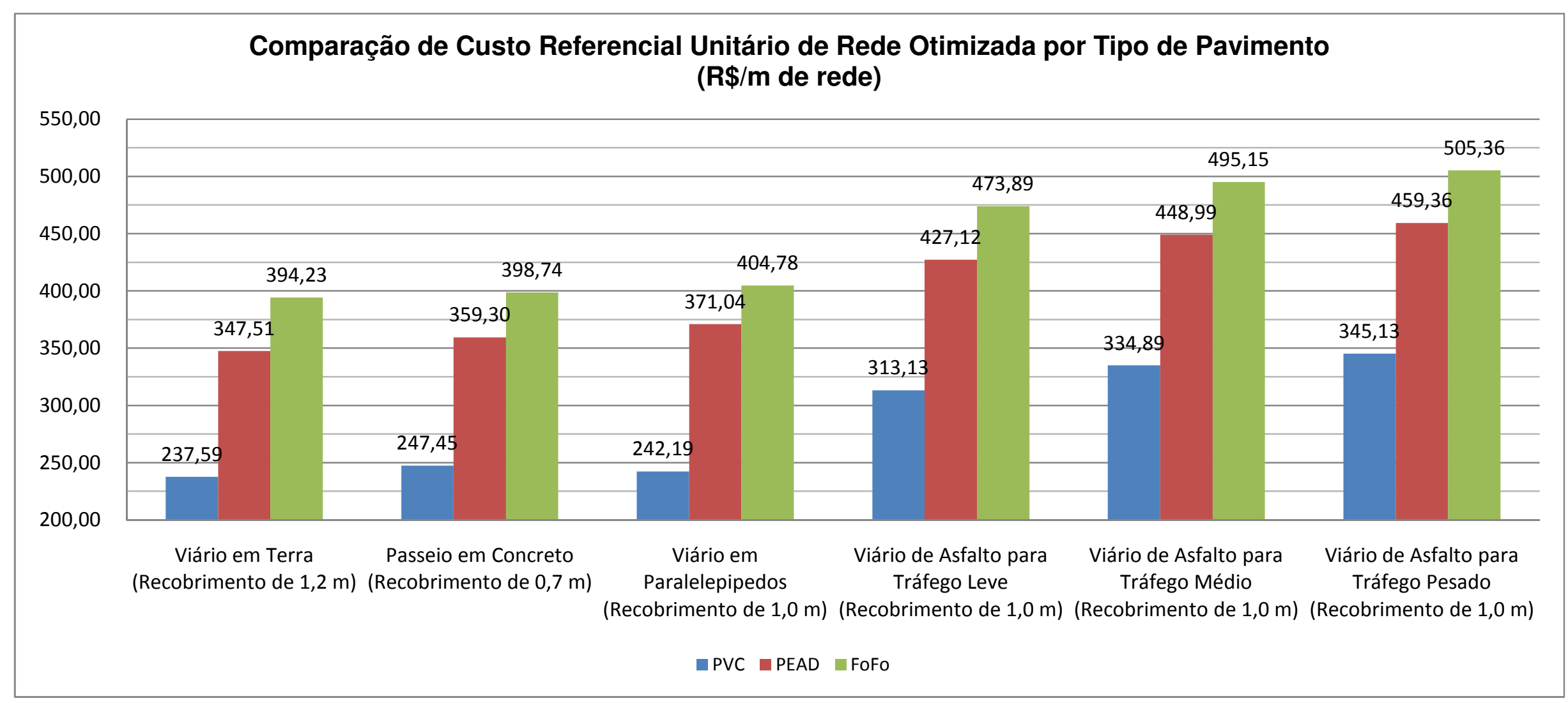

Figura 6.6 - Comparação de Custo Referencial Unitário de Rede Otimizada por Tipo de Pavimento 


\subsubsection{Dimensionamento Otimizado com Variação da Tarifa de Energia Elétrica}

Para este dimensionamento, as únicas variáveis eram o tipo de material da tubulação e as tarifas de energia elétrica, além da altura manométrica da pressurização no nó inicial e da vazão e do diâmetro de cada trecho de rede.

Foram fixados os seguintes parâmetros, tais como:

- Sistema de pressurização inicial

- Rendimento Global do Sistema de Bombeamento: 70\%;

- Funcionamento Diário: 18 h/dia;

○ Funcionamento Anual: 6570 h/ano;

- Vida Útil: 20 anos.

- Condições da superfície para implantação da rede de água

- Viário em paralelepípedo.

- Custo de energia elétrica

- Grupo A (Alta e Média Tensão);

- Sub-Grupo A4 (2,3 KV a $25 \mathrm{KV})$;

- Taxa de Juros: 8,00 \% ao ano;

○ Fator de Atualização: 10,60.

O dimensionamento foi elaborado para as tubulações de maior e menor custo de material, respectivamente, FoFo e PVC, para o pavimento em paralelepípedo, onde os custos de com energia elétrica são os maiores para os dois tipos de tubulação.

Os custos das tarifas de energia elétrica adotados neste dimensionamento foram em função da Tabela 5.20.

Após dimensionamento, foram obtidos os seguintes resultados por tarifa para tubulação de água em PVC e FoFo apresentados nas figuras a seguir. 


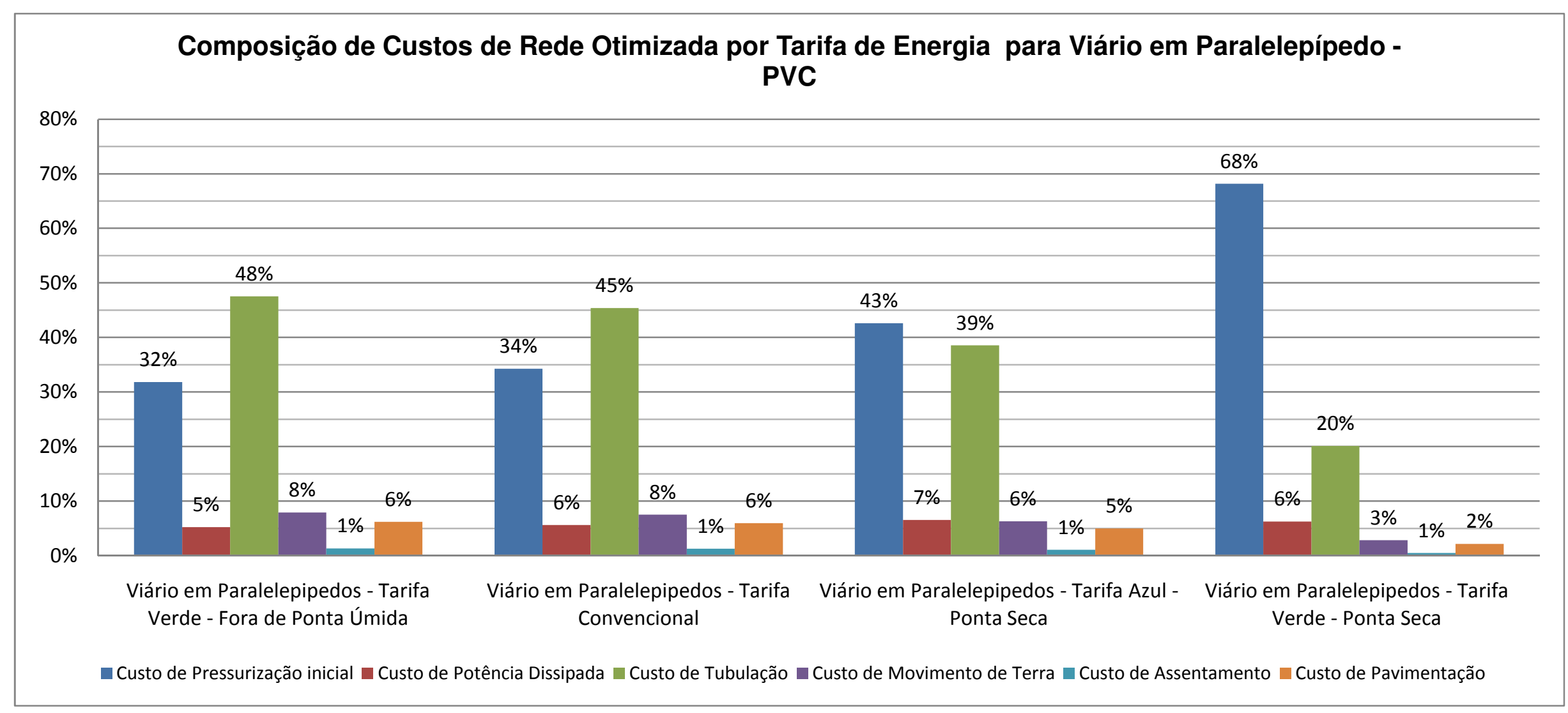

Figura 6.7 - Composição de Custos de Rede Otimizada por Tarifa de Energia para Viário em Paralelepípedo - PVC 


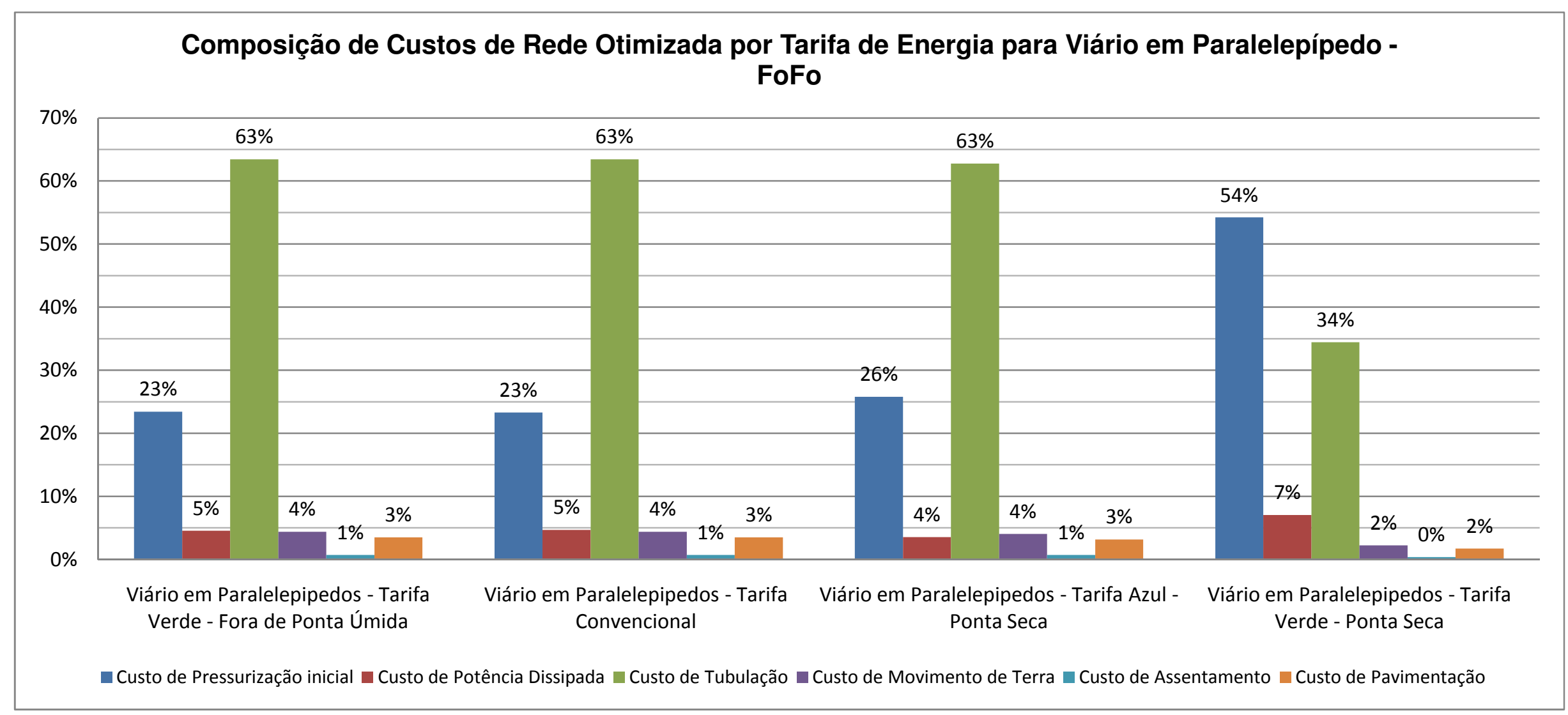

Figura 6.8 - Composição de Custos de Rede Otimizada por Tarifa de Energia para Viário em Paralelepípedo - FoFo 


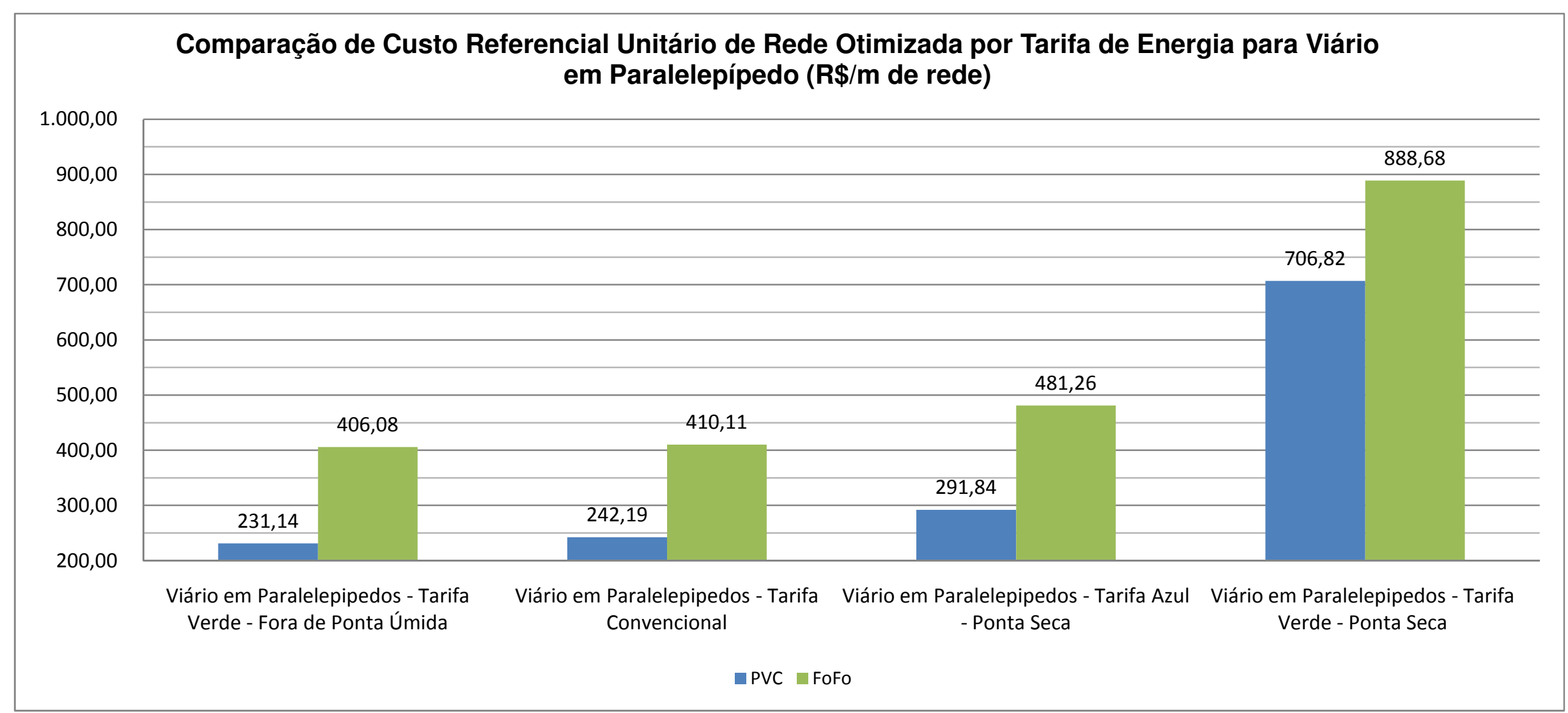

Figura 6.9 - Comparação de Custo Referencial Unitário de Rede Otimizada por Tarifa de Energia para Viário em Paralelepípedo 


\subsubsection{Dimensionamento Otimizado com Variação na Taxa de Juros}

Para este dimensionamento, as únicas variáveis eram o tipo de material da tubulação e as taxas de juros, além da altura manométrica da pressurização no nó inicial e da vazão e do diâmetro de cada trecho de rede.

Conforme citado anteriormente, a taxa de juros depende de fatores econômicos, financeiros e políticos, sendo complicada a determinação de seu valor. Para esse estudo, foi considerada uma taxa nula de aumento de energia para cálculo do fator de atualização do custo energético.

Foram fixados os seguintes parâmetros, tais como:

- Sistema de pressurização inicial

- Rendimento Global do Sistema de Bombeamento: 70\%;

- Funcionamento Diário: $18 \mathrm{~h} / \mathrm{dia}$;

- Funcionamento Anual: 6570 h/ano;

○ Vida Útil: 20 anos.

- Condições da superfície para implantação da rede de água

- Viário em paralelepípedo.

- Custo de energia elétrica

- Grupo A (Alta e Média Tensão);

- Sub-Grupo A4 (2,3 KV a $25 \mathrm{KV})$;

- Tarifa: Convencional;

- Custo de Energia por Demanda: $31,31 \mathrm{R} \$ / \mathrm{KW}$;

- Custo de Energia por Consumo: 0,16132 R\$/KWh.

O dimensionamento foi elaborado para as tubulações de maior e menor custo de material, respectivamente, FoFo e PVC, para o pavimento em paralelepípedo, onde os custos de com energia elétrica são os maiores para os dois tipos de tubulação.

Após dimensionamento, foram obtidos os seguintes resultados por taxa de juro para tubulação de água em PVC e FoFo apresentados nas figuras a seguir. 


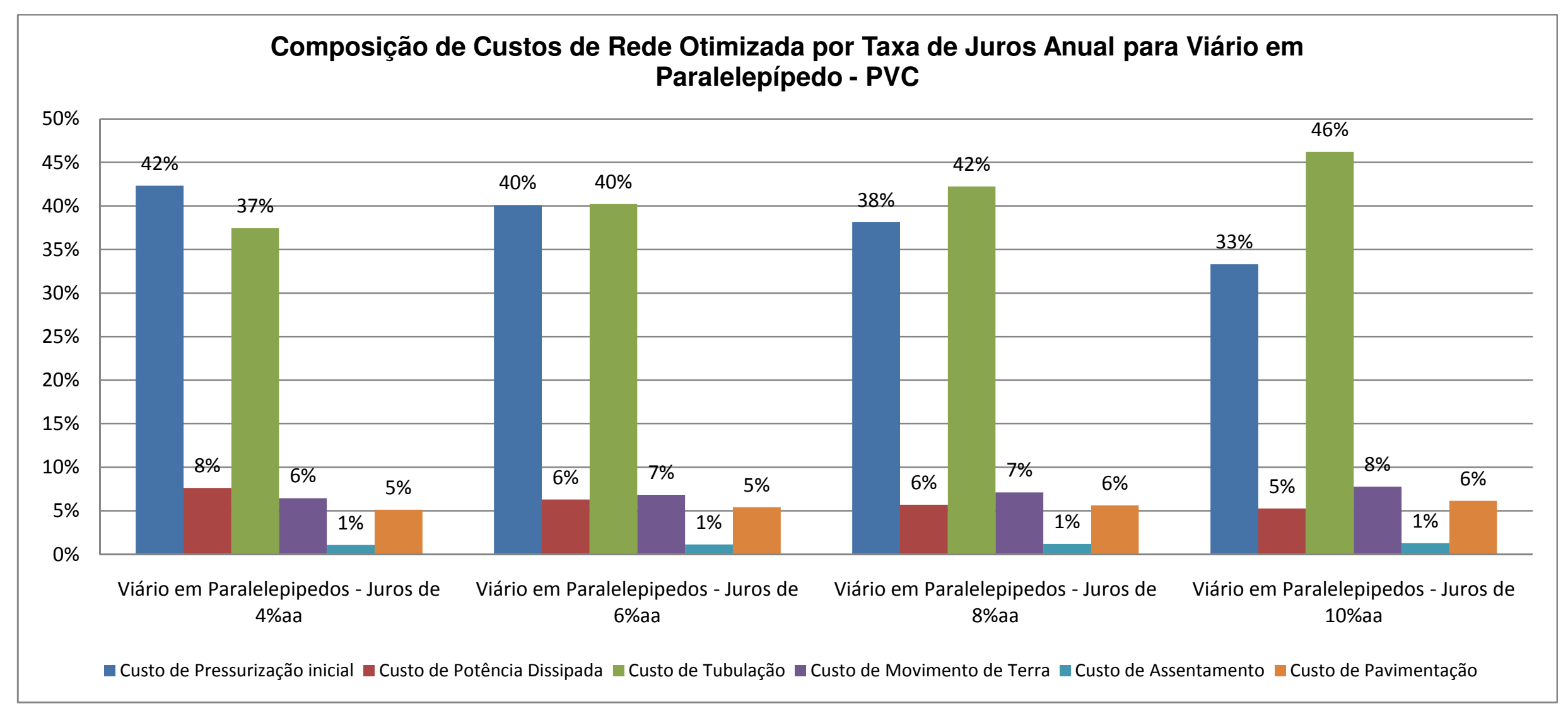

Figura 6.10 - Composição de Custos de Rede Otimizada por Taxa de Juros Anual para Viário em Paralelepípedo - PVC 


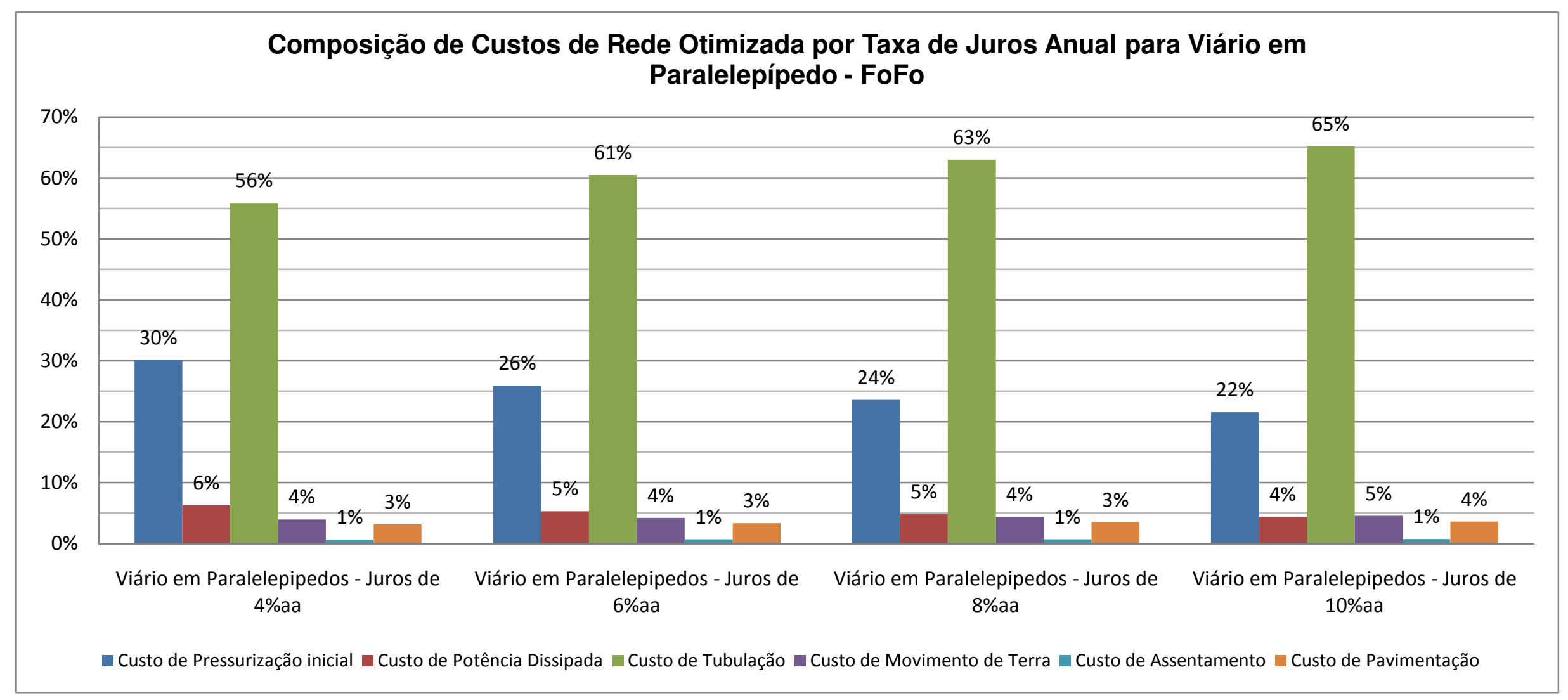

Figura 6.11 - Composição de Custos de Rede Otimizada por Taxa de Juros Anual para Viário em Paralelepípedo - FoFo 


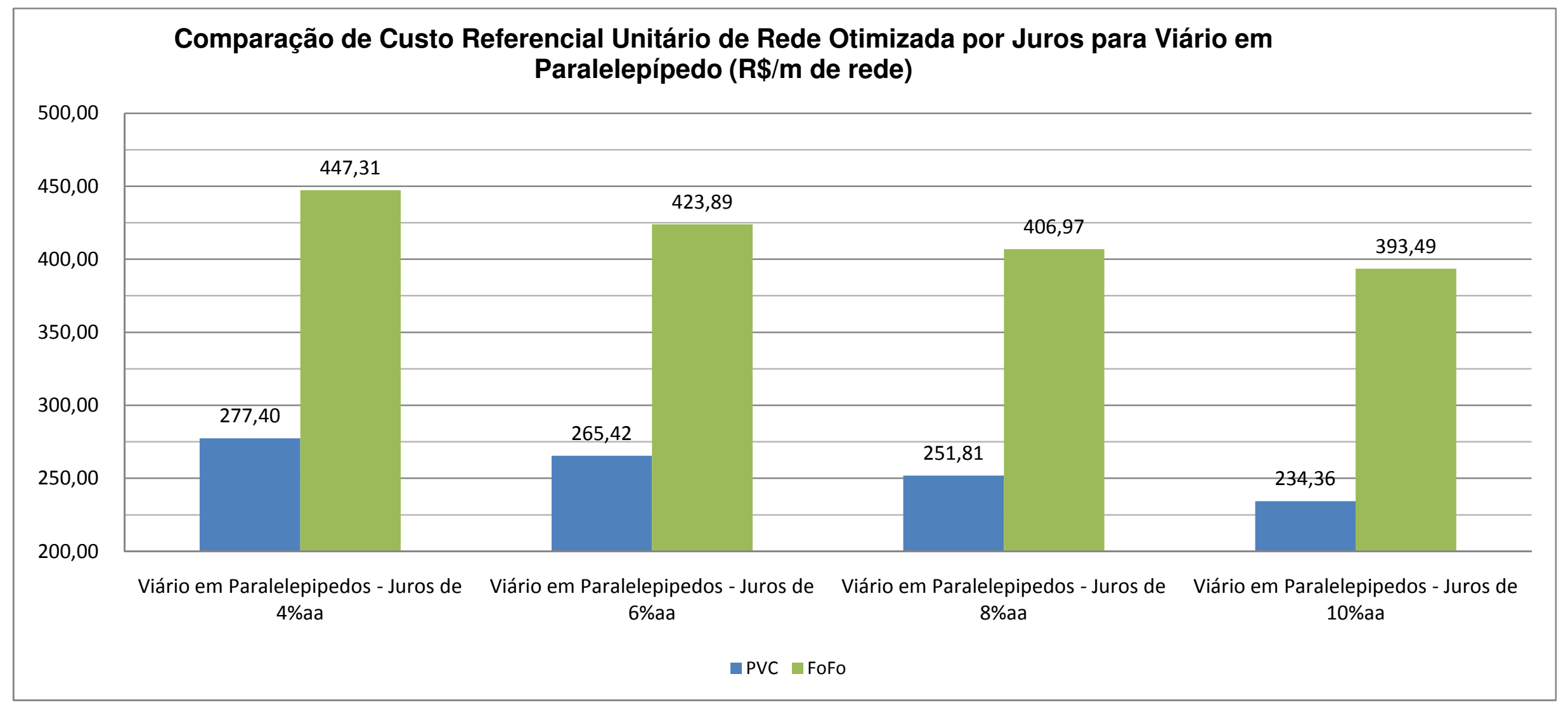

Figura 6.12 - Comparação Comparação de Custo Referencial Unitário de Rede Otimizada por Juros para Viário em Paralelepípedo 


\subsubsection{Dimensionamento Otimizado com Variação na Vida Útil}

Para este dimensionamento, as únicas variáveis eram o tipo de material da tubulação e a vida útil do sistema de pressurização inicial, além da altura manométrica da pressurização no nó inicial e da vazão e do diâmetro de cada trecho de rede.

Conforme citado anteriormente, a taxa de juros depende de fatores econômicos, financeiros e políticos, sendo complicada a determinação de seu valor. Para esse estudo, foi considerada uma taxa nula de aumento de energia para cálculo do fator de atualização do custo energético.

Foram fixados os seguintes parâmetros, tais como:

- Sistema de pressurização inicial

- Rendimento Global do Sistema de Bombeamento: 70\%;

- Funcionamento Diário: $18 \mathrm{~h} / \mathrm{dia}$;

○ Funcionamento Anual: 6570 h/ano.

- Condições da superfície para implantação da rede de água

- Viário em paralelepípedo.

- Custo de energia elétrica

- Grupo A (Alta e Média Tensão);

- Sub-Grupo A4 (2,3 KV a $25 \mathrm{KV})$;

- Tarifa: Convencional;

- Custo de Energia por Demanda: $31,31 \mathrm{R} \$ / \mathrm{KW}$;

- Custo de Energia por Consumo: 0,16132 R\$/KWh;

- Taxa de Juros: 8,00 \% ao ano;

- Fator de Atualização: 10,60.

O dimensionamento foi elaborado para as tubulações de maior e menor custo de material, respectivamente, FoFo e PVC, para o pavimento em paralelepípedo, onde os custos de com energia elétrica são os maiores para os dois tipos de tubulação.

Após dimensionamento, foram obtidos os seguintes resultados pela vida útil do sistema de pressurização inicial para tubulação de água em PVC e FoFo apresentados nas figuras a seguir. 


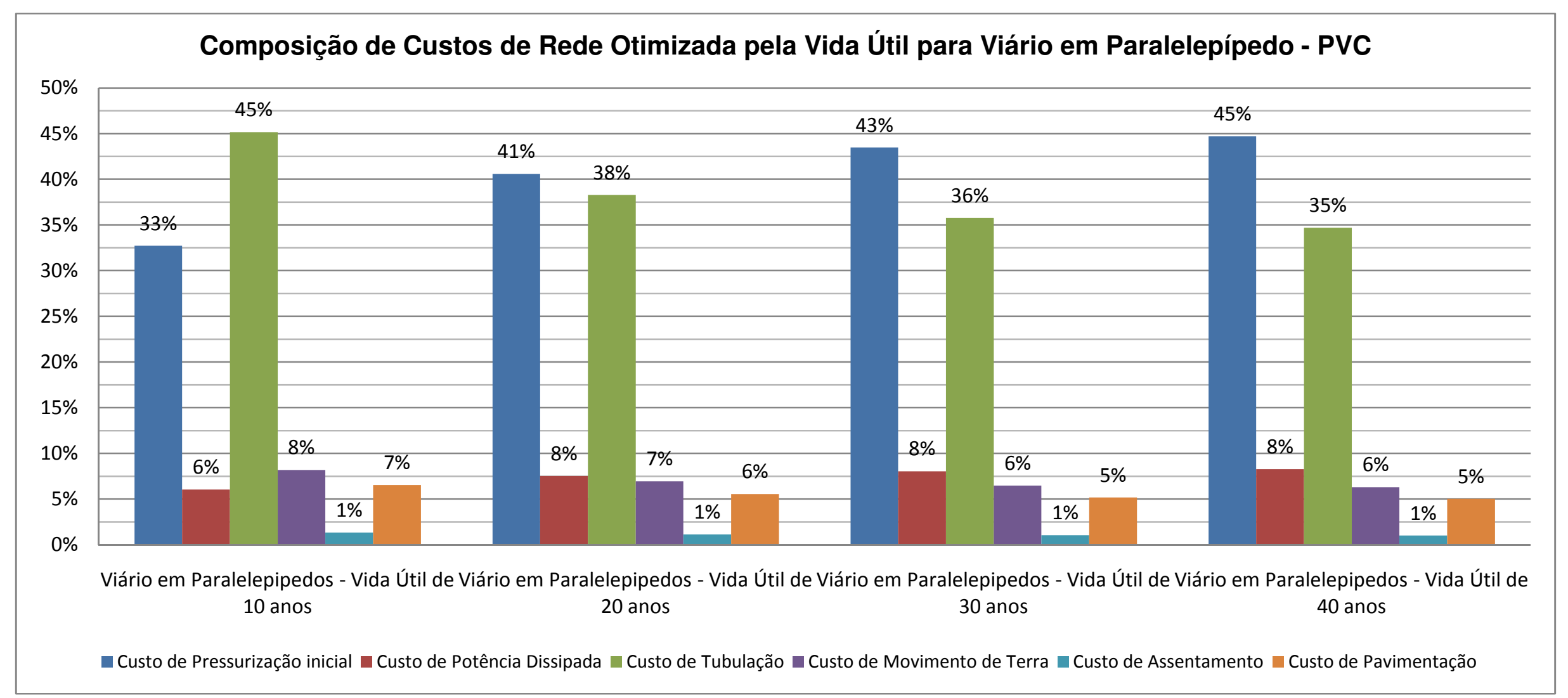

Figura 6.13 - Composição de Custos de Rede Otimizada pela Vida Útil para Viário em Paralelepípedo - PVC 


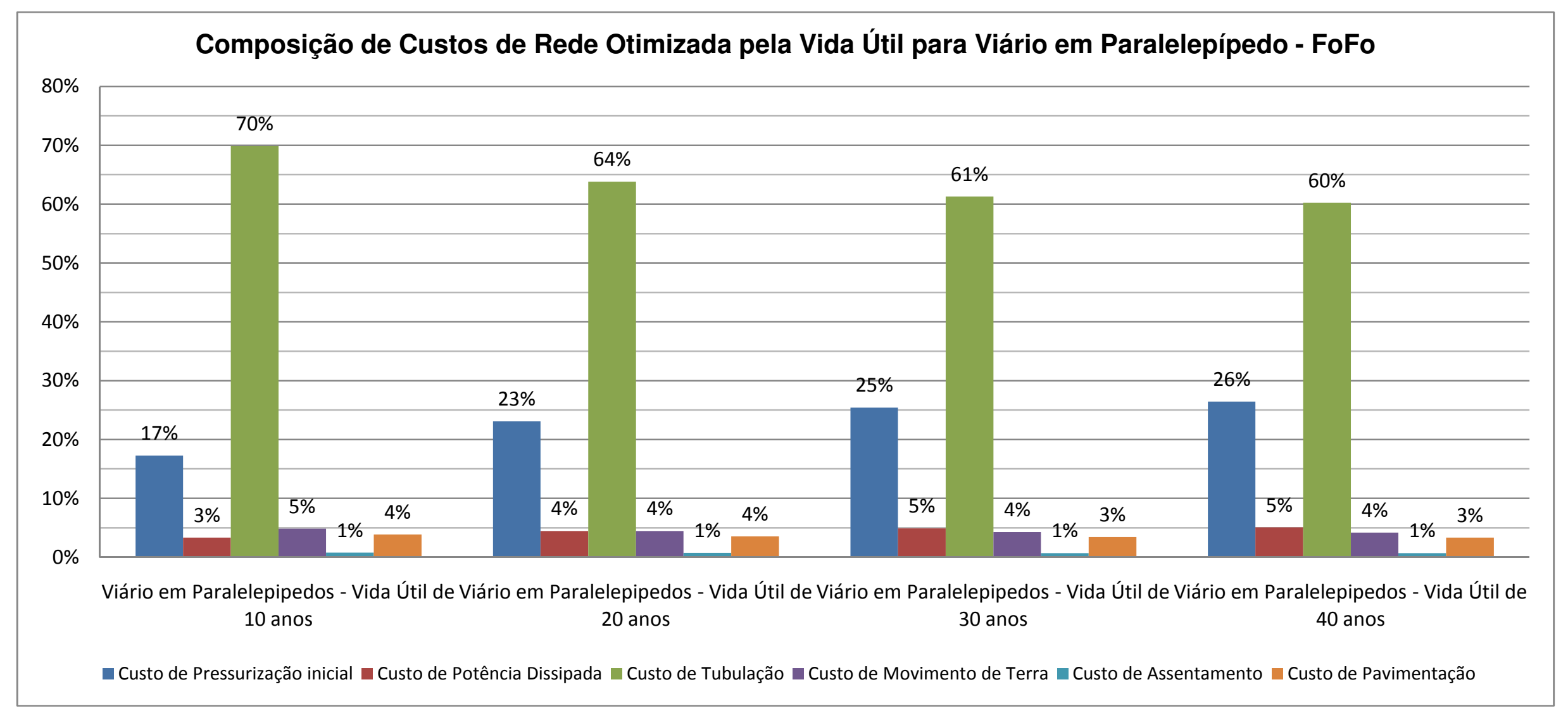

Figura 6.14 - Composição de Custos de Rede Otimizada por Taxa de Juros Anual para Viário em Paralelepípedo - FoFo 


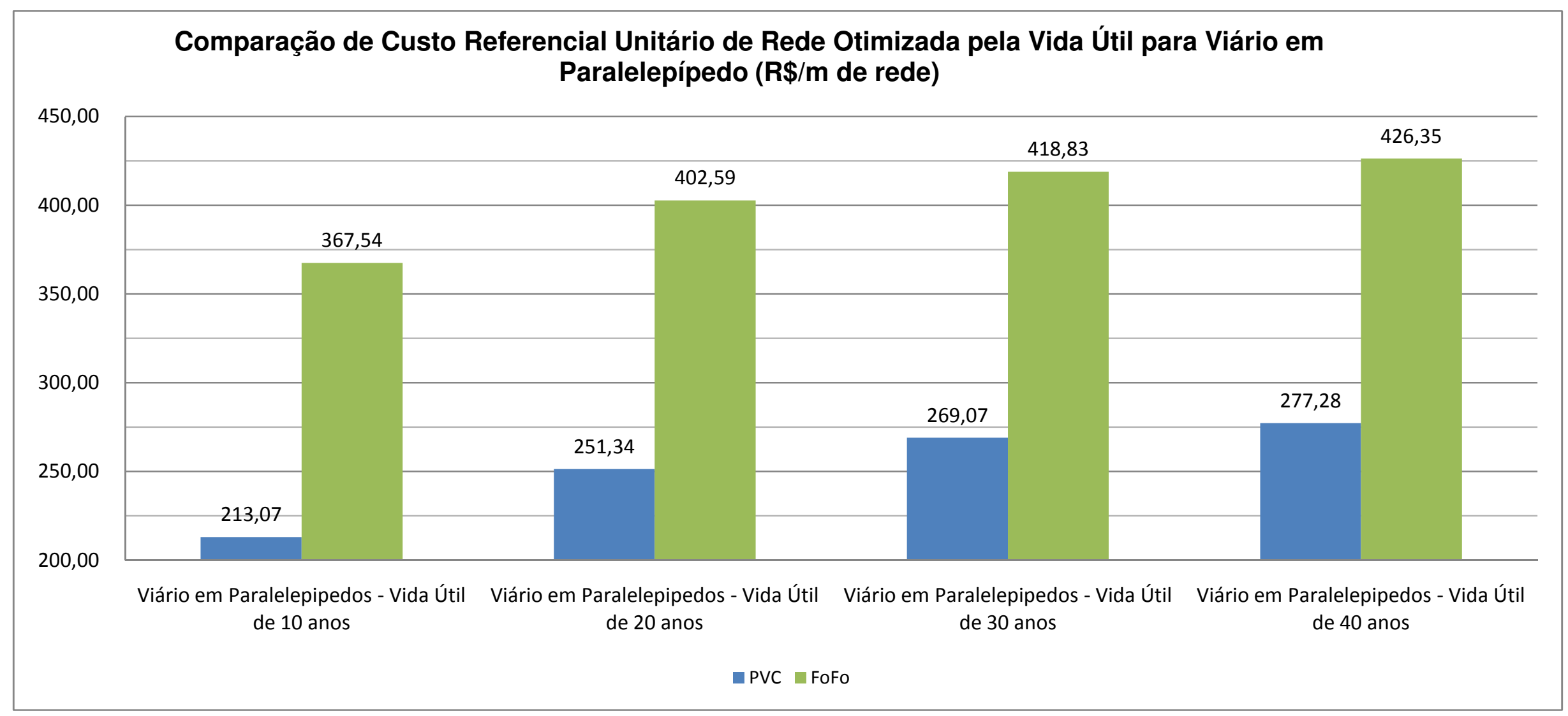

Figura 6.15 - Comparação de Custo Referencial Unitário de Rede Otimizada pela Vida Útil para Viário em Paralelepípedo 


\subsubsection{Dimensionamento Otimizado com Aumento do Custo da Tubulação de PVC}

Para este dimensionamento, as únicas variáveis eram o custo da tubulação de PVC e a altura manométrica da pressurização no nó inicial e da vazão e do diâmetro de cada trecho de rede.

O PVC é obtido a partir de insumo proveniente de sal marinho (57\%) e insumo proveniente de fontes não renováveis, como petróleo e o gás natural (43\%).

Como o PVC é a tubulação mais barata entre as analisadas neste estudo, foi verificado o comportamento do custo referencial unitário em função do aumento no custo da tubulação de PVC. Esse aumento pode vir a ocorrer principalmente devido a fatores externos, tais como, crises nos mais importantes países produtores de petróleo, resultando na elevação mundial do preço do petróleo.

A comparação não foi feita com a tubulação de PEAD, pois ela é composta de por termoplástico derivado do eteno, que também é um derivado do petróleo, ou seja, com o seu preço também sujeito a variação do preço do petróleo. A comparação foi feita em relação a tubulação de FoFo nas mesmas condições descritas abaixo.

Foram fixados os seguintes parâmetros, tais como:

- Sistema de pressurização inicial

- Rendimento Global do Sistema de Bombeamento: 70\%;

- Funcionamento Diário: 18 h/dia;

- Funcionamento Anual: 6570 h/ano;

○ Vida Útil: 20 anos.

- Condições da superfície para implantação da rede de água

- Viário em paralelepípedo.

- Custo de energia elétrica

- Grupo A (Alta e Média Tensão);

- Sub-Grupo A4 (2,3 KV a 25 KV);

- Tarifa: Convencional;

- Custo de Energia por Demanda: 31,31 R\$/KW;

- Custo de Energia por Consumo: 0,16132 R\$/KWh;

- Taxa de Juros: 8,00 \% ao ano;

- Fator de Atualização: 10,60. 
Após dimensionamento, foram obtidos os seguintes resultados em função do custo da tubulação de PVC apresentados nas figuras a seguir. 


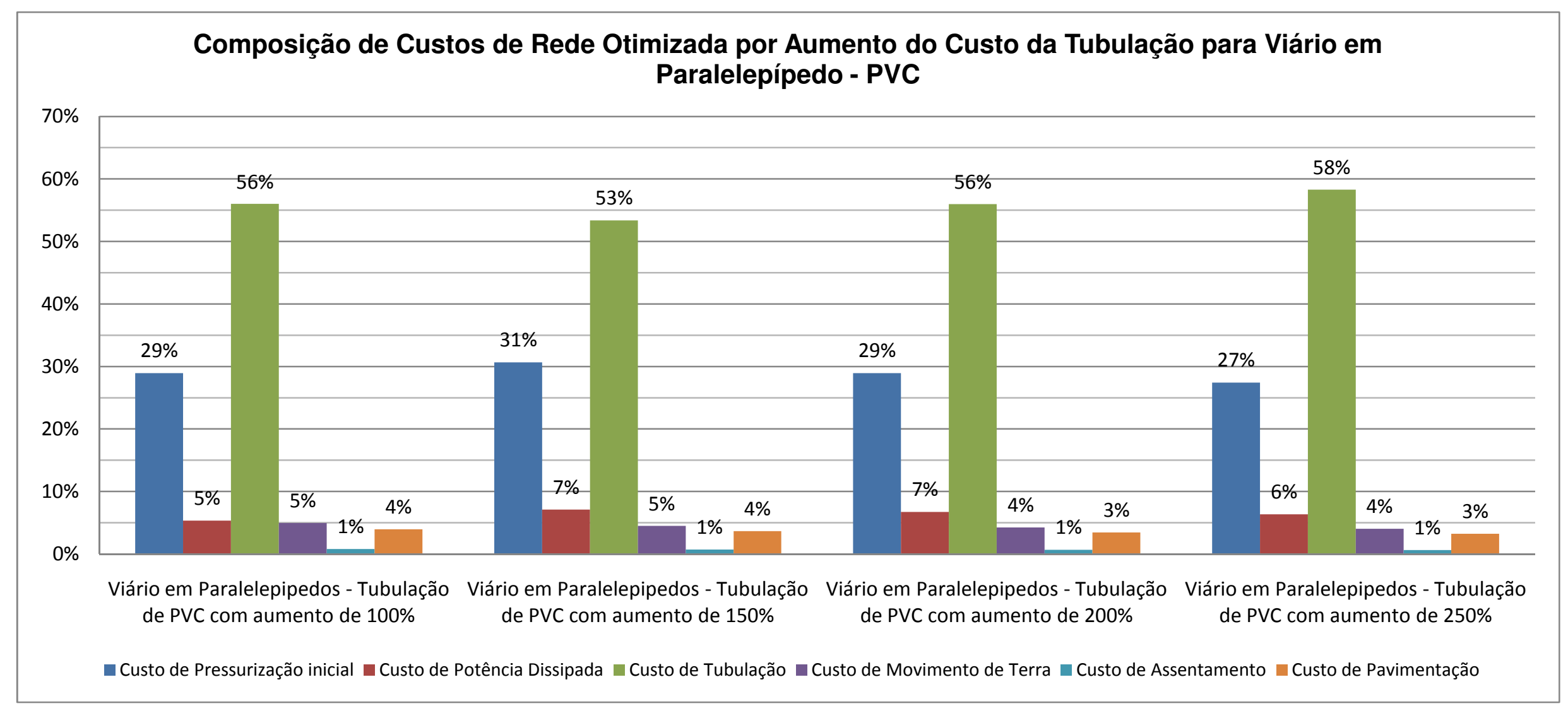

Figura 6.16 - Composição de Custos de Rede Otimizada por Aumento do Custo da Tubulação para Viário em Paralelepípedo - PVC 


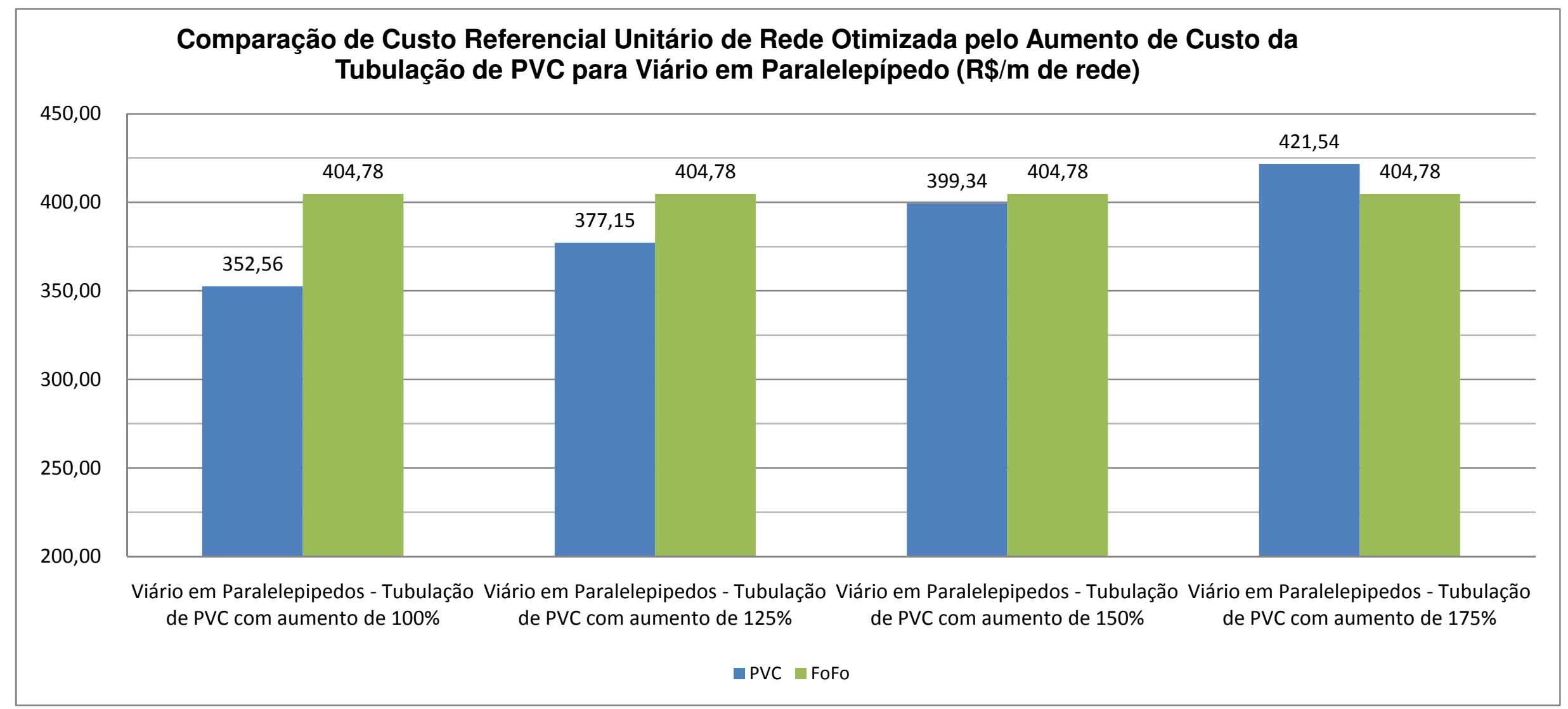

Figura 6.17 - Comparação de Custo Referencial Unitário de Rede Otimizada pelo Aumento de Custo da Tubulação de PVC para Viário em Paralelepípedo 


\section{DISCUSSÃO}

A metodologia proposta se mostrou de fácil utilização, uma vez que os métodos matriciais foram resolvidos através do uso do aplicativo Excel, utilizando a função Solver para que os resultados convergissem para a minimização da função objetivo (custo total global) e pode ser estendida para os aplicativos usuais de cálculo de rede do mercado, como o Crede, o EPAnet e o WaterCAD.

Do ponto de vista da eficiência computacional, o número e o tempo de processamento das iterações é muito curto para este estudo de caso e não permite avaliar o que acontece com redes mais complexas, mas isto não é um impedimento pois as limitações computacionais são cada vez menos significativas nestes tipos de problemas.

Um dos problemas verificados foi que uma vez obtido os resultados do dimensionamento otimizado, havia a necessidade de comprovar que os mesmos se tratavam realmente do menor custo global, não sendo apenas um menor custo local. Para essa comprovação, eram realizadas mais algumas interações para efeito de comparação com a alteração em alguns diâmetros e no valor da pressão inicial do sistema. Os diâmetros eram alterados caso os valores das velocidades e das perdas de carga em cada trecho estivessem com valores muito baixos ou elevados. O valor da pressão inicial era alterado em função das menores cargas observadas em cada nó do sistema.

A aplicação desta metodologia proposta se mostrou adequada para sistema com as seguintes características, tais como:

- Área de implantação com topografia plana com variações entre cotas em torno de $5 \mathrm{~m}$;

- Regime de escoamento permanente;

- Redes de distribuição com comprimento relativamente longo, onde as perdas de carga localizadas podem ser desprezadas;

- Sistema de bombeamento com rotação constante;

- Material das tubulações em PEAD, PVC e Ferro Fundido (FoFo);

- Superfície para implantação da rede em terra, passeio em concreto, viário em paralelepípedo ou em asfalto (Tráfego leve, médio ou pesado). 
A partir dos resultados do estudo de caso proposto, foi verificado que no geral:

- Para todos os tipos de pavimento exceto os de asfalto, os custos mais representativos são de tubulação e da pressurização inicial (em média 75\% do total);

- O custo referencial unitário para tubulações em PVC é sempre o mais baixo e que o do Ferro Fundido é sempre o mais alto, ficando o PEAD sempre em posição intermediária.

A partir dos resultados obtidos no dimensionamento otimizado por tipo de pavimento, foi verificado que:

- Para redes em PVC, os custos são crescentes para os seguintes recobrimentos:

- 1,2 m para viário em terra;

- 1,0 m para viário em paralelepípedo considerando reaproveitamento na reposição;

- 0,7 m para passeio em concreto;

- 1,0 m para viário em asfalto de tráfego leve;

- 1,0 m para viário em asfalto de tráfego médio;

- 1,0 m para viário em asfalto de tráfego pesado.

- Para redes em PEAD e FoFo, os custos são crescentes para os seguintes recobrimentos:

- $1,2 \mathrm{~m}$ para viário em terra;

- 0,7 m para passeio em concreto;

- 1,0 m para viário em paralelepípedo considerando reaproveitamento na reposição;

- 1,0 m para viário em asfalto de tráfego leve;

- 1,0 m para viário em asfalto de tráfego médio;

○ 1,0 m para viário em asfalto de tráfego pesado.

A partir dos resultados obtidos no dimensionamento otimizado com variação da tarifa de energia elétrica, foi verificado que:

- O aumento da tarifa de energia é inversamente proporcional a pressurização inicial do sistema. Para a tarifa mais cara (Tarifa Verde - Ponta Seca), a pressurização inicial do sistema não pode ser inferior a $100 \mathrm{kPa}$, resultando 
no aumento significativo do custo do mesmo, que é o valor mínimo imposto. Uma idéia que pode ser explorada é a de se utilizar pressurizadores localizados, como forma de reduzir o custo global;

- O aumento da tarifa de energia é diretamente proporcional ao custo de tubulação da rede de água, resultando no aumento dos diâmetros e consequentemente dos custos das tubulações de cada trecho.

A partir dos resultados obtidos no dimensionamento otimizado com variação na taxa de juros, foi verificado que:

- A variação da taxa de juros não afeta de forma sensível a necessidade de pressurização inicial do sistema, bem como os diâmetros, resultando este um fator refratário;

- Assim a taxa de juros pode ser negligenciada em análises mais simplificadas.

A partir dos resultados obtidos no dimensionamento otimizado com variação na vida útil, foi verificado que:

- Quanto maior a vida útil do sistema, maior é o peso do custo energético, influenciado pelo fator de atualização;

- A variação da vida útil não afeta de forma sensível a necessidade de pressurização inicial do sistema, bem como os diâmetros, resultando este um fator refratário;

- A vida útil do sistema não pode ser negligenciada em qualquer análise.

A partir dos resultados obtidos no dimensionamento otimizado com aumento do custo da tubulação de PVC, foi verificado que:

- O uso de tubulação de FoFo em vez de PVC só passa a ser mais vantajoso quando o preço da tubulação de PVC sofrer um aumento de cerca de $175 \%$ e o preço da tubulação de FoFo se mantiver estável.

Recomenda-se que para futuros trabalhos sejam relacionados com os seguintes temas, tais como:

- Aplicabilidade e desempenho da metodologia proposta para redes de distribuição de água em malha mais complexas, onde a topografia não é plana; 
- Aperfeiçoar o método de otimização utilizando algoritmos capazes de trabalhar bem com mínimos e máximos locais, assim como dados discretos, que não foram um problema neste estudo, mas podem ser em topologias mais complexas, recomenda-se a utilização de algoritmos evolucionários, como o proposto por Diniz (2004), e que atualmente já estão disponíveis nos aplicativos comerciais tais como o Excel da Microsoft;

- Determinação e aplicação de coeficientes usuais de variação de consumo $\mathrm{K}_{1}$ e $\mathrm{K}_{2}$ diferentes dos usualmente adotados;

- Aplicação de valores de perdas físicas diferenciados, conforme cada tipo de material das tubulações;

- Consideração do envelhecimento das tubulações ao longo da vida útil e o impacto na rugosidade equivalente e no fator de atrito do mesmo;

- Avaliação de implantação do sistema em etapas em conformidade com os cenários de evolução da demanda;

- Utilização de sistema de bombeamento variável com inversor de freqüência considerando as variações de vazões horárias de consumo;

- Utilização de pressurização setorizada (tanques hidropneumáticos e/ou boosters) em pontos localizados de forma a reduzir o peso da pressurização inicial;

- Desenvolvimento de modelo mais complexo com a inserção de bombas, válvulas de controle de pressão e de vazão nos circuitos para aplicabilidade em redes de distribuição de água em malha em geral, para o regime permanente estendido (variações horárias de consumo). 


\section{CONCLUSÕES}

Este trabalho teve por objetivo a formulação de um método de análise de redes de distribuição de água a partir da otimização do custo global, através de um procedimento de fácil aplicação e que permitisse a comparação de diversas alternativas para de configuração dos parâmetros: 'rede' - 'pressurização' - 'serviços de implantação' e 'operação'.

A metodologia de dimensionamento proposta possui base conceitual e é de fácil aplicação com o uso do aplicativo Excel da Microsoft, utilizando a função Solver, que, através da convergência de resultados por intermédio de iterações, utiliza o método do Gradiente Reduzido Generalizado (GRG2), baseado num algoritmo de programação não linear, desenvolvido por Lasdon et al. (1984).

O próprio uso da planilha Excel indica que o método é simples e de fácil implantação e aprimoramento de forma a vencer as limitações adotadas neste estudo.

A flexibilidade do sistema de solução, através da matriz não linearizada, tabelas e curvas de custo permite concluir que sua extrapolação para topologias de rede mais complexas é imediata.

A metodologia proposta se mostrou adequada para as características do sistema analisado, mencionadas anteriormente, isto é limitadas aos materiais, política de custo de energia e procedimentos de serviços usuais no Brasil e em particular em São Paulo.

A partir dos resultados obtidos nos vários dimensionamentos otimizados, foi verificado que no geral:

- Os custos mais representativos são de tubulação e da pressurização inicial (em média $75 \%$ do total);

- O custo referencial unitário para tubulações de PVC é sempre o mais baixo e que o do Ferro Fundido é sempre o mais alto, ficando o PEAD sempre em posição intermediária;

- Tal conclusão genérica na verdade pode variar pouco em função de alguma alteração no método construtivo e serviços complementares, porém não devem mudar, na atual matriz de custos, este resultado. Todavia, dada a 
facilidade do método, em qualquer situação real de projeto este resultado pode ser ratificado.

A partir dos resultados obtidos no dimensionamento otimizado por tipo de pavimento, foi verificado que:

- Para redes em PVC, os custos são crescentes para os seguintes recobrimentos:

- 1,2 m para viário em terra;

- 1,0 m para viário em paralelepípedo considerando reaproveitamento na reposição;

- 0,7 m para passeio em concreto;

- 1,0 m para viário em asfalto de tráfego leve;

- 1,0 m para viário em asfalto de tráfego médio;

- 1,0 m para viário em asfalto de tráfego pesado.

- Para redes em PEAD e FoFo, os custos são crescentes para os seguintes recobrimentos:

- $1,2 \mathrm{~m}$ para viário em terra;

- 0,7 m para passeio em concreto;

- 1,0 m para viário em paralelepípedo considerando reaproveitamento na reposição;

- 1,0 m para viário em asfalto de tráfego leve;

- 1,0 m para viário em asfalto de tráfego médio;

- 1,0 $\mathrm{m}$ para viário em asfalto de tráfego pesado.

A partir dos resultados obtidos no dimensionamento otimizado com variação da tarifa de energia elétrica, foi verificado que:

- O aumento da tarifa de energia é inversamente proporcional a pressurização inicial do sistema. Para a tarifa mais cara (Tarifa Verde - Ponta Seca), a pressurização inicial do sistema não pode ser inferior a $100 \mathrm{kPa}$, resultando no aumento significativo do custo do mesmo, que é o valor mínimo imposto. Uma idéia que pode ser explorada é a de se utilizar pressurizadores localizados, como forma de reduzir o custo global; 
- O aumento da tarifa de energia é diretamente proporcional ao custo de tubulação da rede de água, resultando no aumento dos diâmetros e consequentemente dos custos das tubulações de cada trecho.

A partir dos resultados obtidos no dimensionamento otimizado com variação na taxa de juros, foi verificado que:

- A variação da taxa de juros não afeta de forma sensível a necessidade de pressurização inicial do sistema, bem como os diâmetros, resultando este um fator refratário;

- Assim a taxa de juros pode ser negligenciada em análises mais simplificadas.

A partir dos resultados obtidos no dimensionamento otimizado com variação na vida útil, foi verificado que:

- Quanto maior a vida útil do sistema, maior é o peso do custo energético, influenciado pelo fator de atualização;

- A variação da vida útil não afeta de forma sensível a necessidade de pressurização inicial do sistema, bem como os diâmetros, resultando este um fator refratário;

- A vida útil do sistema não pode ser negligenciada em qualquer análise.

A partir dos resultados obtidos no dimensionamento otimizado com aumento do custo da tubulação de PVC, foi verificado que:

- O uso de tubulação de FoFo em vez de PVC só passa a ser mais vantajoso quando o preço da tubulação de PVC sofrer um aumento de cerca de $175 \%$ e o preço da tubulação de FoFo se mantiver estável. 


\section{REFERÊNCIAS}

ABBASS, H. A. A Monogenous MBO Approach To Satisfiability. In: International. Conference on Computational Intelligence for Modelling, Control and Automation CIMCA, 2001, Las Vegas. Anais...Las Vegas: Canberra University. Publication, 2001.

AES ELETROPAULO. Tarifas de Energia. São Paulo: AES Eletropaulo, 2010. Disponível em: < http://www.aeseletropaulo.com.br>. Acesso em 13 fev. 2011.

AGÊNCIA NACIONAL DE ENERGIA ELÉTRICA. Tarifas de Fornecimento de Energia Elétrica. Brasília: ANEEL, 2005. Disponível em: <http://www.aneel.gov.br>. Acesso em 19 fev. 2011.

ALPEROVITS, E.; SHAMIR, U. Design of optimal water distribution systems, v. 13, n. 6, p. 885-900, ago. 1977.

ASSOCIAÇÃO BRASILEIRA DE NORMAS TÉCNICAS. NBR 12218: Projeto de rede de distribuição de água para abastecimento público. Rio de Janeiro, 1994.

AZEVEDO NETTO, J.M. et al. Manual de Hidráulica. 8를 Edição. São Paulo: Edgard Blücher, 1998. 669 p.

CAIXA ECONÔMICA FEDERAL. SINAPI - Índices da Construção Civil Relatório de Insumos Jan/11. São Paulo: CEF, 2011. Disponível em: < http://www1.caixa.gov.br/gov/gov social/municipal/programa des urbano/SINAPl/in dex.asp >. Acesso em 13 fev. 2011.

CAIXA ECONÔMICA FEDERAL. SINAPI - Índices da Construção Civil Relatório de Serviços Jan/11. São Paulo: CEF, 2011. Disponível em: < http://www1.caixa.gov.br/gov/gov social/municipal/programa des urbano/SINAPI/in dex.asp >. Acesso em 13 fev. 2011.

CARVALHO, P. S. O. "EficientE" - Um Método de Dimensionamento Econômico para Redes de Distribuição de Água. 2007. 128 p. Dissertação (Mestre) Universidade Federal da Paraíba, João Pessoa, 2007.

CHIU, C.L. et al. Application of Probability and Entropy Concepts in Pipe-Flow Study. Journal of Hydraulic Engineering. n. 119, p. 742-756,1993. 
COMPANHIA DE SANEAMENTO BÁSICO DO ESTADO DE SÃO PAULO. Banco de Insumos - Dez/2009. São Paulo: SABESP, 2009. 52 p.

COMPANHIA DE SANEAMENTO BÁSICO DO ESTADO DE SÃO PAULO. Especificação Técnica, Regulamentação de Preços e Critérios de Medição. $2^{a}$ Edição. São Paulo: SABESP, 1996. 1145 p.

CROSS, H. Analysis of Flow in Networks of Conduits or Conductors. Urbana: University of Illinois, n. 286, 1936.

CUNHA, M.; RIBEIRO, L. Tabu Search Algorithms For Water Network Optimization.

European Journal of Operational Research, n. 157, p. 746-758, 2004.

CUNHA, M.; SOUSA, J. Water Distribution Network Design Optimization: Simulated Annealing Approach, . Journal of Water Resources Planning and Management, $\mathrm{n}$. 125, p. 215-221. 1999.

DANIELETTO, J.R.B. Manual de Tubulações de Polietileno e Polipropileno. São Paulo: Linha Aberta, 2007. 528 p.

DINIZ, V. E. M. G. Otimização de Operação de Rede por um Modelo Híbrido (Hidrodinâmico - Genético). 2004. 132 p. Tese (Doutorado) - Escola Politécnica da Universidade de São Paulo, São Paulo, 2004.

DORIGO, M. et al. Ant System: Optimization By A Colony Of Cooperating Agents. IEEE Transactions on Systems, Man, and Cibernética, Parte B: Cibernética, n. 26, p. 29-41, 1996.

DUAN, N. et al. Optimal Reliability Based Design Of Pumping And Distribution Systems. Journal of Hydraulic Engineering, n. 116, p. 249-268, 1990.

EL-BAHRAWY, A.; SMITH, A. A. A Methodology for Optimal Design of Pipe Distribution Networks. Canadian Journal of Civil Engineering, n. 14, p. 207-215, 1987.

EUSUFF, M. M.; LANSEY, K. E. Optimization Of Water Distribution Network Design Using The Shuffled Frog Leaping Algorithm. Journal of Water Resources Planning and Management, n. 129, p. 210-225, 2003.

FEATHERSTONE, R.; EL-JUMAILY, K. Optimal Diameter Selection For Pipe Networks. Journal of Hydraulic Engineering, n. 109,p. 221-234, 1983. 
FORMIGA, K. T. M.; Metodologia de Otimização de Redes Malhadas Através da Programação Não Linear, 1999, 158p. Dissertação (Mestrado) - Universidade Federal da Paraíba, Campina Grande, 1999.

FUJIWARA, O.; KHANG, D. B. A Two-Phase Decomposition Method For Optimal Design Of Looped. Water Resources Research, n. 23, p. 977-982., 1987.

GEEM, Z. W. et al. Harmony Search Optimization: Application To Pipe Network Design. International Journal of Modelling and Simulation, n. 22, p. 125-133, 2002.

GOLDBERG, D. E. Genetic Algorithms In Search, Optimization And Machine Learning, Reading: Addison-Wesley, 1989, 403 p.

GOMES, H.P. Sistemas de Abastecimento de Água - Dimensionamento Econômico e Operação de Redes e Elevatórias. 2ª Edição. João Pessoa: UFPB, 2004. $238 \mathrm{p}$.

GOMES, H. P.; FORMIGA, K. T. M. PNL2000 - Método Prático de Dimensionamento Econômico de Redes Malhadas de Abastecimento de Água. Revista Brasileira de Recursos Hídricos, v. 6, n. 4, p. 91-108, out./dez. 2001.

GOMES, H. P.; LEAL, A.F. Dimensionamento de Redes Urbanas de Abastecimento de Água a partir do Método Granados. In: XIX Congreso Latinoamericano de Hidráulica, 19, 2000, Córdoba. Anais... Córdoba: IAHR, 2000, p. 183- 192.

GLOVER, F. Future Paths For Integer Programming And Links To Artificial Intelligence. Computers \& Operations Research, n. 13, p. 533-549, 1986.

GRANADOS, A. Infraentructuras de Regadios - Redes Colectivas de Riego a Presión. Madrid: Servicio de Publicación de E.T.S.I. de Caminos de La Universidad Politécnica de Madrid, 1986.

GUPTA, I. et al. Genetic Algorithm For Optimization Of Water Distribution Systems. Environmental Modelling \& Software, v. 4, p. 437-446, 1999.

HALHAL, D. et al. Water Network Rehabilitation With Structured Messy Genetic Algorithm. Journal of Water Resources Planning and Management, n. 123, p. 137-146, 1997. 
HASSEGAWA, C. M.; FILHO, K. Z.; IGNÁCIO, R. V. V. Caracterização dos Perfis de Consumo da Região Metropolitana de São Paulo. In: Congresso Brasileiro de Engenharia Sanitária e Ambiental, 20., p. 1899- 1098, mai. 1999, Rio de Janeiro. Resumo do trabalho. Rio de Janeiro: ABES, 1999. Disponível em: $<$ http://www.bvsde.paho.org >. Acesso em 07 fev. 2011.

Kadu, M. S. et al. Optimal Design of Water Distribution Networks Using Genetic Algorithm With Reduction In Search Space. In: One-Day National Conference on Geotechniques and Environment for Sustainable Development, 2005, India.

KIRKPATRICK, S. et al. Optimization By Simulated Annealing. Science, n. 220, p. 671-680, 1983.

KURODA, E. K.; PÁDUA, V. L. (Org.). Abastecimento de Água para Consumo Humano. Belo Horizonte: UFMG, 2006. 859 p.

LANSEY, K. E.; MAYS, L. W. Optimization Model For Design Of Water Distribution Systems. In: Reliability analysis of water distribution system, Reston: L. R. Mays, 1989.

LASDON et al. GRG2 User's Guide. Austin: University of Texas at Austin, 1984.

LEAL, A.F. Estudo Comparativo de Métodos de Otimização de Redes Malhadas Pressurizadas. 1995. 1 V. Dissertação (Mestre) - Universidade Federal da Paraíba, Campina Grande, 1995.

LOGANATHAN, G. V. et al. Design Heuristic For Globally Minimum Cost WaterDistribution Systems. Journal of Water Resources Planning and Man, n. 121, p. 182-192, 1995.

MAIER, H. R., et al. Ant Colony Optimization For The Design Of Water Distribution Systems. Journal of Water Resources Planning and Management, n. 129, p. 200-209, 2003.

MARTINS, J.A. Redes de Distribuição de Água. Capítulo 13. In: Técnica de Abastecimento e Tratamento de Água. Vol. I. CETESB. São Paulo, 1976.

MARTINS, J.R.S. Método da Linearização. In: Abastecimento de Água. $3^{a}$ Edição. São Paulo: Departamento de Engenharia Hidráulica e Sanitária da Escola Politécnica da Universidade de São Paulo, 2006. p. 416-429. 
MAYS, L. W. Water Distribution Systems Handbook. Tempe: McGraw-Hill, 1999. Paginação irregular.

McKEON, B. J. et al. Friction Factor for Smooth Pipe Flow. Journal of Fluid Mech. Cambridge: Cambridge University Press, v. 511, p. 41-44, 2004.

MOHAN, S.; BABU, K. S. J. Optimal Water Distribution Network Design with HoneyBee Mating Optimization. Journal Of Computing In Civil Engineering, v. 24, n. 1, p. 117-126, jan./feb. 2010. Disponível em: <http://www.ascelibrary.org >. Acesso em 22 set. 2010.

MONBALIU, J.; JO, J. H.; FRAISSE, C. W.; VADAS, R. G. Computer aided design pipe network. In: Water resource systems applications. Friesen Printers, Winnipeg. Canada, 1990.

MORAES, A. G. Entropia Máxima na Modelação do Fator de Atrito $(f)$ de Escoamento Forçado. 2010. 151 p. Tese (Doutorado) - Escola Politécnica da Universidade de São Paulo, São Paulo, 2010.

MORENO, J. Avaliação e Gestão de Riscos no Controle da Qualidade de Água em Redes de Distribuição: Estudo de Caso. 2009. 579 p. Tese (Doutorado) Escola de Engenharia de São Carlos da Universidade de São Paulo, São Carlos, 2009.

PRASAD, T. D.; PARK, N. S. Multiobjective Genetic Algorithms For Design Of Water Distribution Networks. Journal of Water Resources Planning and Management, n.. 130; p. 73-82; 2004.

PORTO, R.M.. Hidráulica Básica. São Carlos: EESC/USP, 1998. 540 p.

PRINCE, A.A. Rede de Distribuição. In: Abastecimento de água para consumo humano. HELLER, L e PÁDUA V.L. (orgs.). Belo Horizonte. UFMG, 2006. P.603-661. QUINDRY, G. E. et al. Optimization of Looped Water Distribution Systems. Journal of the Environmental Engineering Division, n. 107, p.665-679, 1981.

SALVINO, M. M. Método de Dimensionamento e Controle Operacional Otimizado para Redes de Distribuição de Água. 2009. 62 p. Dissertação (Mestre) - Universidade Federal da Paraíba, João Pessoa, 2009. 
SANTOS, M. C. C. Simulação de Cenários de Operação de Sistemas de Distribuição de Água Através do Método PNL2000. 2002. Dissertação (Mestre) Universidade Federal da Paraíba, Campina Grande, 2002.

SAVIC, D. A.; WALTERS, G. A. Genetic Algorithms For Leastcost Design Of Water Distribution Networks. Journal of Water Resources Planning and Management, $n$. 123, p. 67-77, 1997.

SECRETARIA MUNICIPAL DE INFRAESTRUTURA URBANA E OBRAS. Custos Unitários de Infraestrutura Urbana Julho de 2010. São Paulo: SIURB, 2010. Disponível em: <http://www.prefeitura.sp.gov.br>. Acesso em 14 fev. 2011.

SECRETARIA MUNICIPAL DE INFRAESTRUTURA URBANA E OBRAS. IR01/2004 Instrução de Reparação de Pavimentos Flexíveis Danificados por Abertura de Valas. São Paulo: SIURB, 2004. Disponível em: <http://www.prefeitura.sp.gov.br>. Acesso em 14 fev. 2011.

SECRETARIA NACIONAL DE SANEAMENTO AMBIENTAL. Sistema Nacional de Informações sobre Saneamento: diagnóstico dos serviços de água e esgotos 2008. Brasília: MCIDADES.SNSA, 2010. Disponível em: <http://www.snis.gov.br>. Acesso em 22 jul. 2010.

SHAMIR, U. Optimal Design And Operation Of Water Distribution Systems. Water Resources Research, n. 10, p. 27-36, 1974.

SIMPSON, A. R. et al. Genetic Algorithms Compared To Other Techniques For Pipe Optimization. Journal of Water Resources Planning and Management, n. 120, p. 423-443, 1994.

SU, Y. L. et al. Reliabilitybased Optimization Model For Water Distribution Systems. Journal of Hydraulic Engineering, n. 113, p. 1539-1556, 1987.

TSUTIYA, M.T. Abastecimento de Água. 3ª Edição. São Paulo: Departamento de Engenharia Hidráulica e Sanitária da Escola Politécnica da Universidade de São Paulo, 2006. 643 p.

.Redução do Custo de Energia Elétrica em Sistemas de Abastecimento de Água. São Paulo: ABES/SP, 2006. 185 p.

VASAN, A.; SIMONOVIC, S. P. Optimization of Water Distribution Network Design Using Differential Evolution. Journal of Water Resources Planning and 
Management, v. 136, n. 2, p. 279-287, mar./apr. 2010. Disponível em: $<$ http://www.ascelibrary.org >. Acesso em 22 set. 2010.

WALSKI, T. M.; CHASE, D.; SAVIC D. Water Distribution Modeling. 1st ed. Waterbury: Haestad Press, 2001. 441 p.

Water Distribution System Analysis Before Digital Computers. In: Annual Water Distribution Systems Analysis Symposium, 8., 2006, Cincinnati. Paper. Cincinnati: ASCE, 2006. Disponível em: <http://www.ascelibrary.org>. Acesso em 06 out. 2010. 


\section{APÊNDICE A1 - Planilha de Dimensionamento para Viário em Terra - PVC}

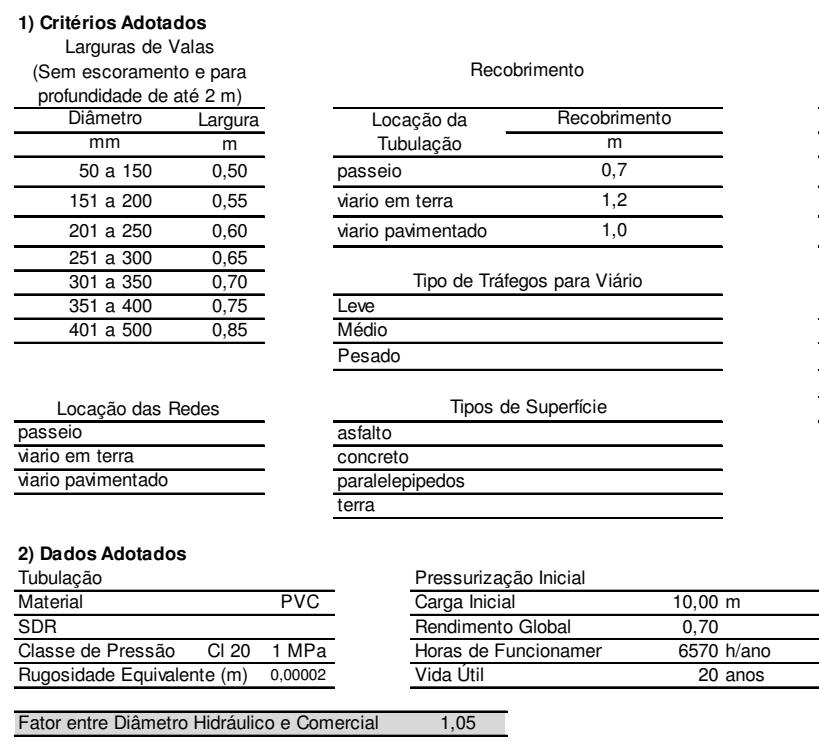

Largura Adotadas para Reposição de Pavimentos Devido Abertura de
Valas $(\mathrm{m})$

Espessuras Adotadas para Reposição de Pavimentos Devido Abertura de Valas (m)

\begin{tabular}{lccc}
\hline Tráfego & Leve & Médio & Pesado \\
\hline Binder & 0,04 & 0,07 & 0,10 \\
\hline Concreto Asfáltico Usinado a Quente & 0,04 & 0,05 & 0,05 \\
\hline Macadame Hidállico & 0,10 & 0,12 & 0,15 \\
\hline
\end{tabular}
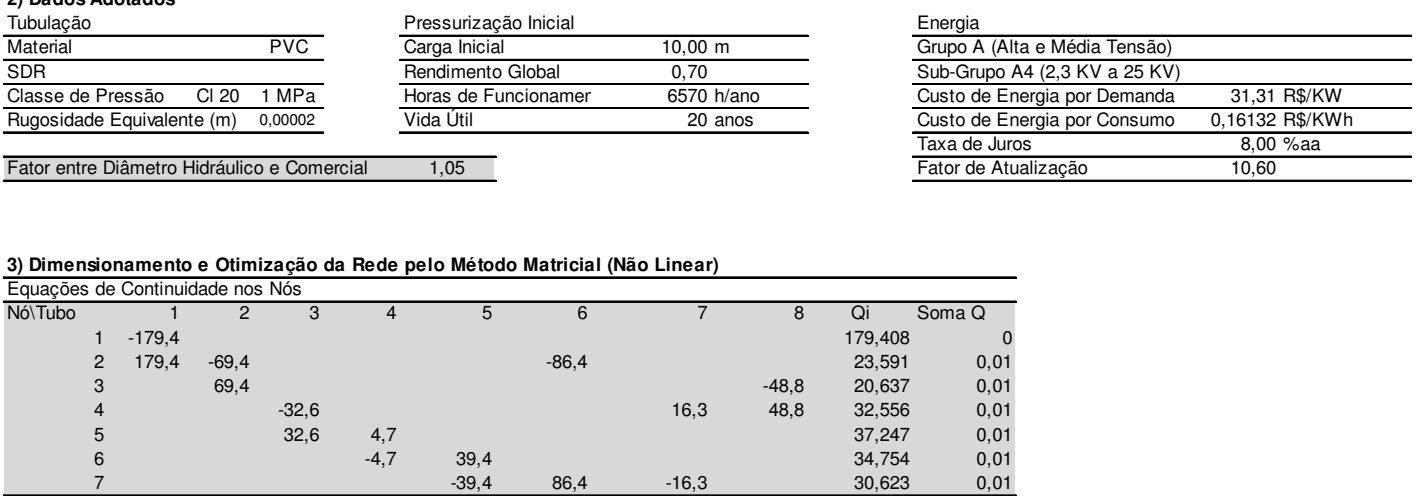

\begin{tabular}{|c|c|c|c|c|c|c|c|c|c|}
\hline \\
\hline \multicolumn{10}{|c|}{ 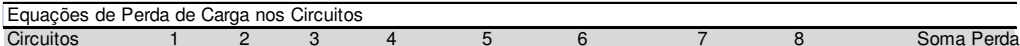 } \\
\hline 1 & & $-0,656$ & & & & 1,027 & 0,461 & $-0,832$ & $1 \mathrm{E}-04$ \\
\hline 2 & & & $-0,371$ & 0,287 & 0,546 & & $-0,461$ & & $1 \mathrm{E}-04$ \\
\hline
\end{tabular}

\begin{tabular}{|c|c|c|c|c|c|c|c|c|c|c|c|c|c|c|}
\hline \multirow{2}{*}{ Trecho } & \multicolumn{2}{|c|}{ Nó Montante } & \multicolumn{2}{|c|}{ No Jusante } & \multirow{2}{*}{$\begin{array}{r}\begin{array}{c}\text { Extensão } \\
\text { do Trecho }\end{array} \\
\text { (m) }\end{array}$} & \multirow{2}{*}{$\begin{array}{c}\begin{array}{c}\text { Vazão do } \\
\text { Trecho }\end{array} \\
1 / \mathrm{s}\end{array}$} & \multirow{2}{*}{$\begin{array}{c}\begin{array}{c}\text { Diâmetro } \\
\text { Nominal } \\
\text { Comercial }\end{array} \\
(\mathrm{mm})\end{array}$} & \multirow{2}{*}{$\begin{array}{c}\begin{array}{c}\text { Diâmetro } \\
\text { Ótimo }\end{array} \\
(\mathrm{mm}) \\
\end{array}$} & \multirow{2}{*}{$\begin{array}{c}\text { Velocidade } \\
(\mathrm{m} / \mathrm{s})\end{array}$} & \multirow{2}{*}{$\begin{array}{l}\text { Fator de } \\
\text { Atrito } f\end{array}$} & \multirow{2}{*}{$\begin{array}{c}\text { Perda de Carga } \\
\text { (m) }\end{array}$} & \multirow{2}{*}{$\begin{array}{c}\begin{array}{c}\text { Carga } \\
\text { Montante }\end{array} \\
(\mathrm{m})\end{array}$} & \multirow{2}{*}{$\begin{array}{c}\text { Carga Jusante } \\
(\mathrm{m})\end{array}$} & \multirow{2}{*}{$\begin{array}{c}\text { Potência Dissipada } \\
\text { kW }\end{array}$} \\
\hline & Nome & Cota & Nome & Cota & & & & & & & & & & \\
\hline $\mathrm{T} 1$ & N1 & 4,56 & N2 & 3,50 & 258,48 & $\begin{array}{l}179,4 \\
\end{array}$ & 500 & 420 & 0,91 & 0,0063 & 0,14 & 10,00 & 10,92 & 0,35 \\
\hline T2 & N2 & 3,50 & N3 & 3,50 & 255,93 & 69,4 & 250 & 261 & 1,41 & 0,0063 & 0,66 & 10,92 & 10,27 & 0,64 \\
\hline T3 & $\mathrm{N} 4$ & 1,50 & N5 & 0,49 & 657,53 & 32,6 & 250 & 223 & 0,66 & 0,0063 & 0,37 & 11,44 & 12,07 & 0,17 \\
\hline T4 & N5 & 0,49 & N6 & 0,50 & 253,28 & 4,7 & 100 & 99 & 0,59 & 0,0063 & 0,29 & 12,07 & 11,78 & 0,02 \\
\hline T5 & N6 & 0,50 & N7 & 1,50 & 660,47 & 39,4 & 250 & 237 & 0,80 & 0,0063 & 0,55 & 11,78 & 10,23 & 0,30 \\
\hline T6 & N2 & 3,50 & N7 & 1,50 & 644,10 & 86,4 & 300 & 275 & 1,22 & 0,0063 & 1,03 & 10,92 & 11,90 & 1,24 \\
\hline $\mathrm{T7}$ & N7 & 1,50 & $\mathrm{~N} 4$ & 1,50 & 253,02 & 16,3 & 150 & 147 & 0,92 & 0,0063 & 0,46 & 11,90 & 11,44 & 0,11 \\
\hline T8 & N3 & 3,50 & $\mathrm{~N} 4$ & 1,50 & 657,18 & 48,8 & 250 & 259 & 0,99 & 0,0063 & 0,83 & 10,92 & 12,09 & 0,57 \\
\hline & & & & Soma & 3639,99 & & & & & & & & & 3,39 \\
\hline
\end{tabular}

4) Resumo do Dimensionamento Otimizado

\begin{tabular}{|c|c|c|}
\hline & Potência Dissipada & Pressurização Inicial \\
\hline Soma & 3,39 & 25,12 \\
\hline Energia & $22.267,50$ & $165.019,48$ \\
\hline$F A$ & 10,60 & 10,60 \\
\hline Sub-Total & $39.215,42$ & $290.616,66$ \\
\hline
\end{tabular}

\begin{tabular}{|c|c|c|}
\hline Custos & & Porcentagem \\
\hline Custo de Tubulação $\mathrm{R} \$$ & $443.077,51$ & $51,23 \%$ \\
\hline Custo de Movimento de Terra $\mathrm{R} \$$ & $80.087,19$ & $9,26 \%$ \\
\hline Custo de Assentamento $\mathrm{R} \$$ & $11.845,85$ & $1,37 \%$ \\
\hline Custo de Pavimentação $\mathrm{R} \$$ & & $0,00 \%$ \\
\hline Custo da Pressurização Inicial $R \$$ & $290.616,66$ & $33,60 \%$ \\
\hline Custo da Potência Dissipada $R \$$ & $39.215,42$ & $4,53 \%$ \\
\hline Total Global (Função Objetivo) R\$ & $864.842,62$ & $100,00 \%$ \\
\hline Total Referencial Unitário R\$ & 237,59 & por metro de rede \\
\hline
\end{tabular}


5) Quantitativos e Custos de Implantação das Redes de Abastecimento

\begin{tabular}{|c|c|c|c|c|c|c|c|c|c|c|}
\hline Trecho & $\begin{array}{l}\text { Locação da } \\
\text { Tubulaçãao }\end{array}$ & Tipo de Superfície & Tipo de Tráfego & & & & & & & \\
\hline T1 & viario em terra & terra & - & & & & & & & \\
\hline T2 & viario em terra & terra & - & & & & & & & \\
\hline T3 & viario em terra & terra & - & & & & & & & \\
\hline T4 & viario em terra & terra & - & & & & & & & \\
\hline T5 & viario em terra & terra & - & & & & & & & \\
\hline T6 & viario em terra & terra & - & & & & & & & \\
\hline 77 & viario em terra & terra & - & & & & & & & \\
\hline T8 & viario em terra & terra & - & & & & & & & \\
\hline \multirow{3}{*}{ Trecho } & \multicolumn{6}{|c|}{ Vala } & \multicolumn{4}{|c|}{ Tubulação } \\
\hline & Largura & Profundidade & Escavação & Reaterro & Bota-Fora & TOTAL & Assentamento & Material & & TOTAL \\
\hline & $\mathrm{m}$ & $\mathrm{m}$ & $\mathrm{m}^{3}$ & $\mathrm{~m}^{3}$ & $\mathrm{~m}^{3}$ & $\mathrm{R} \$$ & $R \$$ & $\mathrm{R} \$$ & & $\mathrm{R} \$$ \\
\hline T1 & 0,85 & 1,70 & 373,50 & 322,75 & 50,75 & $8.859,44$ & $1.772,49$ & $87.766,04$ & & $89.538,54$ \\
\hline T2 & 0,60 & 1,45 & 222,66 & 210,10 & 12,56 & $5.458,54$ & 781,41 & $27.846,08$ & & $28.627,49$ \\
\hline T3 & 0,60 & 1,45 & 572,05 & 539,77 & 32,28 & $\begin{array}{l}14.023,95 \\
\end{array}$ & $2.007,59$ & $71.541,56$ & & $73.549,15$ \\
\hline T4 & 0,50 & 1,30 & 164,63 & 162,64 & 1,99 & $4.109,06$ & 386,69 & $6.121,70$ & & $6.508,39$ \\
\hline T5 & 0,60 & 1,45 & 574,61 & 542,19 & 32,42 & $14.086,66$ & $2.016,56$ & $71.861,44$ & & $73.878,01$ \\
\hline T6 & 0,65 & 1,50 & 628,00 & 582,47 & 45,53 & $15.294,43$ & $2.375,48$ & $94.537,19$ & & $96.912,66$ \\
\hline 77 & 0,50 & 1,35 & 170,79 & 166,32 & 4,47 & $4.238,62$ & 499,10 & $11.900,01$ & & $12.399,11$ \\
\hline \multirow[t]{2}{*}{ T8 } & 0,60 & 1,45 & 571,75 & 539,49 & 32,26 & $14.016,49$ & $2.006,52$ & $71.503,48$ & & $73.510,00$ \\
\hline & & & & & Soma & $\mathrm{R} \$ \quad \mathbf{8 0 . 0 8 7 , 1 9}$ & $\mathrm{R} \$ \quad 11.845,85$ & $\mathrm{R} \$ 443.077,51$ & $\mathrm{R} \$$ & $454.923,35$ \\
\hline \multirow{4}{*}{ Trecho } & \multicolumn{6}{|c|}{ Pavimentação } & & & & \\
\hline & \multicolumn{6}{|c|}{ Vala } & & & & \\
\hline & Área & Área de Concreto & $\begin{array}{c}\text { Área de } \\
\text { Paralelepipedos }\end{array}$ & $\begin{array}{l}\text { Área de } \\
\text { Asfalto }\end{array}$ & Área de Binder & $\begin{array}{c}\text { Área de Concreto } \\
\text { Astático Usinado a } \\
\text { Quente }\end{array}$ & & & & \\
\hline & $\mathrm{m}^{2}$ & $\mathrm{~m}^{2}$ & $\mathrm{~m}^{2}$ & $\mathrm{~m}^{2}$ & $\mathrm{~m}^{2}$ & $\mathrm{~m}^{2}$ & & & & \\
\hline $\mathrm{T} 1$ & 219,71 & 0,00 & 0,00 & 0,00 & 0,00 & 0,00 & & & & \\
\hline T2 & 153,56 & 0,00 & 0,00 & 0,00 & 0,00 & 0,00 & & & & \\
\hline T3 & 394,52 & 0,00 & 0,00 & 0,00 & 0,00 & 0,00 & & & & \\
\hline T4 & 126,64 & 0,00 & 0,00 & 0,00 & 0,00 & 0,00 & & & & \\
\hline T5 & 396,28 & 0,00 & 0,00 & 0,00 & 0,00 & 0,00 & & & & \\
\hline T6 & 418,67 & 0,00 & 0,00 & 0,00 & 0,00 & 0,00 & & & & \\
\hline 77 & 126,51 & 0,00 & 0,00 & 0,00 & 0,00 & 0,00 & & & & \\
\hline T8 & 394,31 & 0,00 & 0,00 & 0,00 & 0,00 & 0,00 & & & & \\
\hline \multirow{4}{*}{ Trecho } & \multicolumn{10}{|c|}{ Pavimentação } \\
\hline & \multicolumn{3}{|c|}{ Volume } & \multicolumn{2}{|r|}{ Area } & \multicolumn{5}{|c|}{ Custos } \\
\hline & Macadame Hidáulico & Binder & $\begin{array}{l}\text { Concreto Astáltico } \\
\text { Usinado a Quente }\end{array}$ & $\begin{array}{l}\text { Imprimação } \\
\text { Betuminosa } \\
\text { Ligante }\end{array}$ & $\begin{array}{c}\text { Imprimação } \\
\text { Betuminosa } \\
\text { Impermeabiliza } \\
\text { nte }\end{array}$ & Remoção & Recomposição & Transporte & & TOTAL \\
\hline & $\mathrm{m}^{3}$ & $\mathrm{~m}^{3}$ & $\mathrm{~m}^{3}$ & $\mathrm{~m}^{2}$ & $\mathrm{~m}^{2}$ & $\mathrm{R} \$$ & $\mathrm{R} \$$ & $\mathrm{R} \$$ & & $\mathrm{R} \$$ \\
\hline $\mathrm{T} 1$ & 0,00 & 0,00 & 0,00 & 0,00 & 0,00 & 0,00 & 0,00 & 0,00 & & 0,00 \\
\hline $\mathrm{T} 2$ & 0,00 & 0,00 & 0,00 & 0,00 & 0,00 & 0,00 & 0,00 & 0,00 & & 0,00 \\
\hline T3 & 0,00 & 0,00 & 0,00 & 0,00 & 0,00 & 0,00 & 0,00 & 0,00 & & 0,00 \\
\hline $\mathrm{T} 4$ & 0,00 & 0,00 & 0,00 & 0,00 & 0,00 & 0,00 & 0,00 & 0,00 & & 0,00 \\
\hline T5 & 0,00 & 0,00 & 0,00 & 0,00 & 0,00 & 0,00 & 0,00 & 0,00 & & 0,00 \\
\hline T6 & 0,00 & 0,00 & 0,00 & 0,00 & 0,00 & 0,00 & 0,00 & 0,00 & & 0,00 \\
\hline$T 7$ & 0,00 & 0,00 & 0,00 & 0,00 & 0,00 & 0,00 & 0,00 & 0,00 & & 0,00 \\
\hline T8 & 0,00 & 0,00 & 0,00 & 0,00 & 0,00 & 0,00 & 0,00 & 0,00 & & 0,00 \\
\hline
\end{tabular}




\section{APÊNDICE A2 - Planilha de Dimensionamento para Passeio em Concreto - PVC}

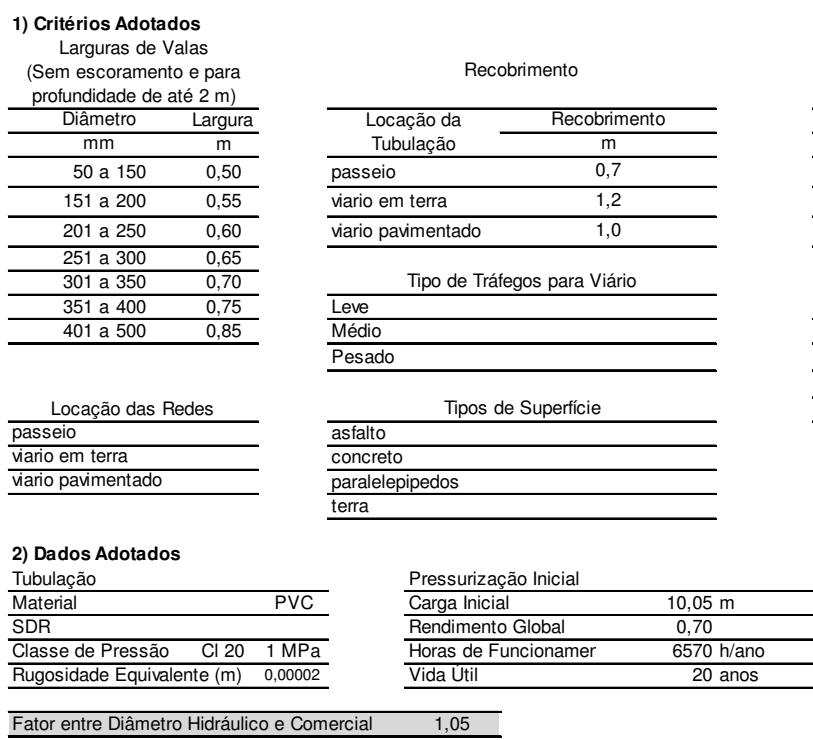

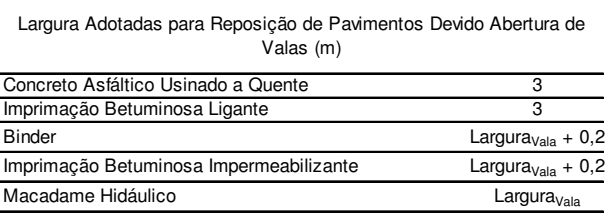

Espessuras Adotadas para Reposição de Pavimentos Devido Abertura de Valas (m) \begin{tabular}{lccc}
\multicolumn{4}{c}{ Espessuras Adotadas para Reposição de Pavimentos Devido Abertura de Valas $(\mathrm{m})$} \\
\hline Tráfego & Leve & Médio & Pesado \\
\hline Binder & 0,04 & 0,07 & 0,10 \\
\hline Concreto Asfáltico Usinado a Quente & 0,04 & 0,05 & 0,05 \\
\hline Macadame Hidáulico & 0,10 & 0,12 & 0,15 \\
\hline
\end{tabular}

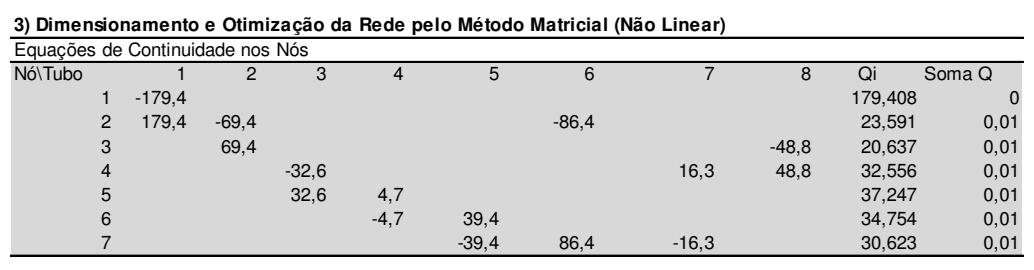

\begin{tabular}{|c|c|c|c|c|c|c|c|c|c|}
\hline \multicolumn{10}{|c|}{ Equações de Perda de Carga nos Circuitos } \\
\hline Circuitos & 1 & 2 & 3 & 4 & 5 & 6 & 7 & 8 & Soma Perda \\
\hline 1 & & $-0,656$ & & & & 1,027 & 0,461 & $-0,832$ & 0,0001 \\
\hline 2 & & & $-0,371$ & 0,286 & 0,546 & & $-0,461$ & & 0,0001 \\
\hline
\end{tabular}

Tabela da Função Objetivo

\begin{tabular}{|c|c|c|c|c|c|c|c|c|c|c|c|c|c|c|}
\hline \multirow{2}{*}{ Trecho } & \multicolumn{2}{|c|}{ Nó Montante } & \multicolumn{2}{|c|}{ No Jusante } & \multirow{2}{*}{$\begin{array}{c}\begin{array}{c}\text { Extensão } \\
\text { do Trecho }\end{array} \\
\text { (m) }\end{array}$} & \multirow{2}{*}{$\begin{array}{c}\begin{array}{c}\text { Vazão do } \\
\text { Trecho }\end{array} \\
\text { I/s } \\
\end{array}$} & \multirow{2}{*}{$\begin{array}{c}\begin{array}{c}\text { Diâmetro } \\
\text { Nominal } \\
\text { Comercial }\end{array} \\
(\mathrm{mm}) \\
\end{array}$} & \multirow{2}{*}{$\begin{array}{c}\begin{array}{c}\text { Diâmetro } \\
\text { Ótimo }\end{array} \\
(\mathrm{mm}) \\
\end{array}$} & \multirow{2}{*}{$\begin{array}{c}\text { Velocidade } \\
(\mathrm{m} / \mathrm{s})\end{array}$} & \multirow[t]{2}{*}{$\begin{array}{l}\text { Fator de } \\
\text { Atrito } f\end{array}$} & \multirow{2}{*}{$\begin{array}{c}\text { Perda de Carga } \\
(\mathrm{m})\end{array}$} & \multirow{2}{*}{$\begin{array}{c}\begin{array}{c}\text { Carga } \\
\text { Montante }\end{array} \\
(\mathrm{m}) \\
\end{array}$} & \multirow{2}{*}{$\begin{array}{c}\text { Carga Jusante } \\
(\mathrm{m})\end{array}$} & \multirow{2}{*}{$\begin{array}{c}\text { Potência Dissipada } \\
\mathrm{kW}\end{array}$} \\
\hline & Nome & Cota & Nome & Cota & & & & & & & & & & \\
\hline $\mathrm{T1}$ & $\mathrm{N} 1$ & 4,56 & N2 & 3,50 & 258,48 & 179,4 & 400 & 400 & 1,42 & 0,0063 & 0,42 & 10,05 & 10,69 & 1,06 \\
\hline T2 & N2 & 3,50 & N3 & 3,50 & 255,93 & 69,4 & 250 & 250 & 1,41 & 0,0063 & 0,66 & 10,69 & 10,03 & 0,64 \\
\hline T3 & $\mathrm{N} 4$ & 1,50 & N5 & 0,49 & 657,53 & 32,6 & 250 & 250 & 0,66 & 0,0063 & 0,37 & 11,20 & 11,84 & 0,17 \\
\hline T4 & N5 & 0,49 & N6 & 0,50 & 253,28 & 4,7 & 100 & 100 & 0,59 & 0,0063 & 0,29 & 11,84 & 11,55 & 0,02 \\
\hline T5 & N6 & 0,50 & N7 & 1,50 & 660,47 & 39,4 & 250 & 250 & 0,80 & 0,0063 & 0,55 & 11,55 & 10,00 & 0,30 \\
\hline T6 & N2 & 3,50 & N7 & 1,50 & 644,10 & 86,4 & 300 & 300 & 1,22 & 0,0063 & 1,03 & 10,69 & 11,66 & 1,24 \\
\hline 77 & N7 & 1,50 & $\mathrm{~N} 4$ & 1,50 & 253,02 & 16,3 & 150 & 150 & 0,92 & 0,0063 & 0,46 & 11,66 & 11,20 & 0,11 \\
\hline T8 & N3 & 3,50 & $\mathrm{~N} 4$ & 1,50 & 657,18 & 48,8 & 250 & 250 & 0,99 & 0,0063 & 0,83 & 10,69 & 11,86 & 0,57 \\
\hline
\end{tabular}

4) Resumo do Dimensionamento Otimizado

\begin{tabular}{|c|c|c|}
\hline & Potência Dissipada & Pressurização Inicial \\
\hline Soma & 4,10 & 25,24 \\
\hline Energia & $26.948,60$ & $165.842,07$ \\
\hline $\mathrm{FA}$ & 10,60 & 10,60 \\
\hline Sub-Total & $47.459,32$ & $292.065,33$ \\
\hline
\end{tabular}

\begin{tabular}{|c|c|c|}
\hline Custos & & Porcentagem \\
\hline Custo de Tubulação $\mathrm{R} \$$ & $416.154,57$ & $46,20 \%$ \\
\hline Custo de Movimento de Terra $R \$$ & $51.039,39$ & $5,67 \%$ \\
\hline Custo de Assentamento R\$ & $11.403,68$ & $1,27 \%$ \\
\hline Custo de Pavimentação $\mathrm{R} \$$ & $82.610,58$ & $9,17 \%$ \\
\hline Custo da Pressurização Inicial $R \$$ & $292.065,33$ & $32,43 \%$ \\
\hline Custo da Potência Dissipada $\mathrm{R} \$$ & $47.459,32$ & $5,27 \%$ \\
\hline Total Global (Função Objetivo) R\$ & $900.732,87$ & $100,00 \%$ \\
\hline Total Referencial Unitário $\mathrm{R} \$$ & 247,45 & por metro de rede \\
\hline
\end{tabular}


5) Quantitativos e Custos de Implantação das Redes de Abastecimento

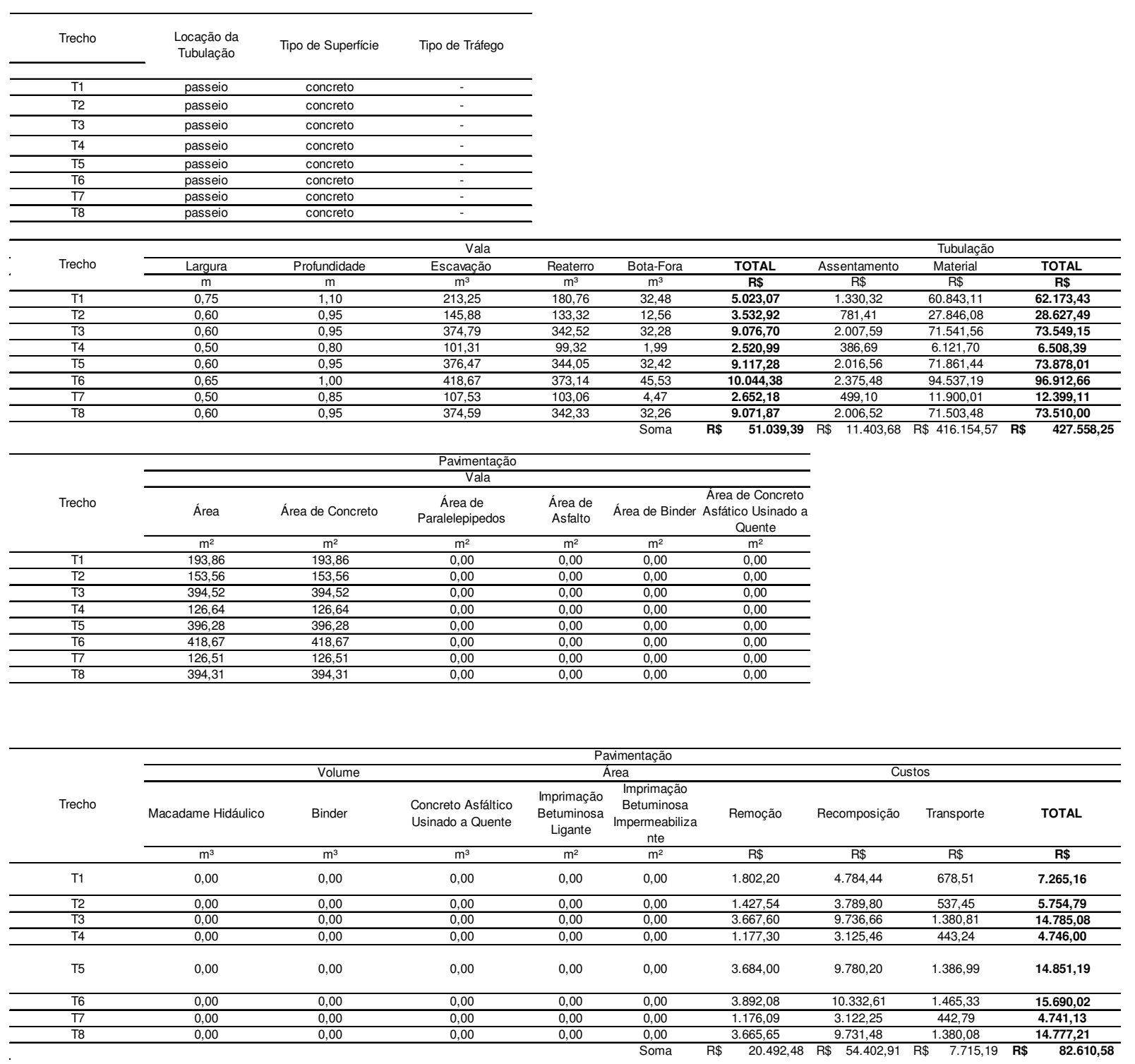




\section{APÊNDICE A3 - Planilha de Dimensionamento para Viário em Paralelepípedo - PVC}

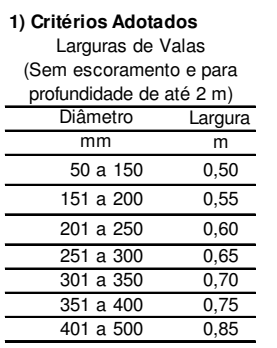

Locação das Redes

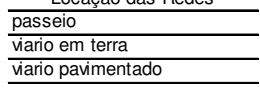

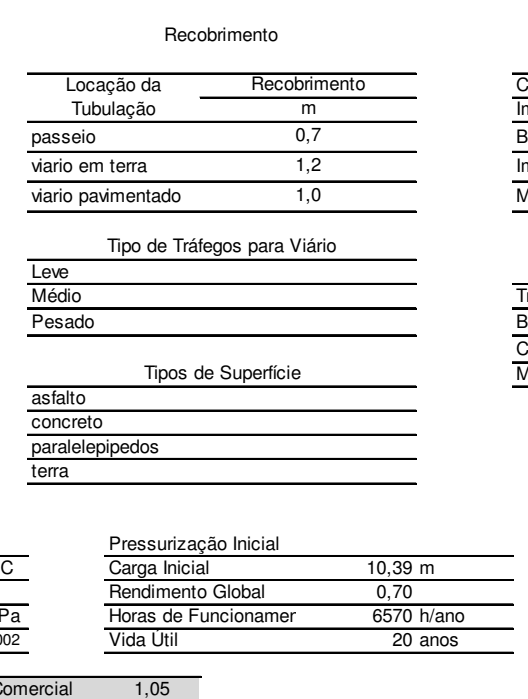

1,05
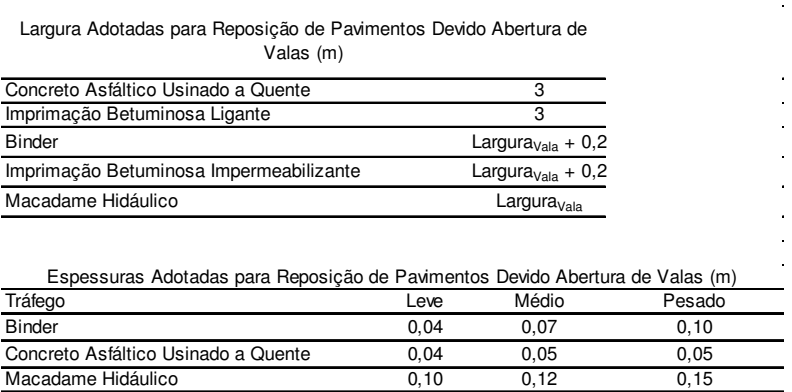

Macadame Hidáulico

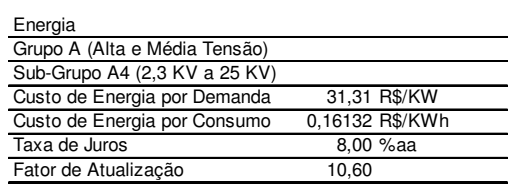

2) Dados Adotados

Tubulação

Materia

SDR

\begin{tabular}{lll} 
Classe de Pressão & $\mathrm{Cl} 20$ & $1 \mathrm{MPa}$ \\
\hline
\end{tabular}

\begin{tabular}{ll}
\hline Rugosidade Equivalente $(\mathrm{m})$ & 0,00002 \\
\hline
\end{tabular}

Fator entre Diâmetro Hidráulico e Comercia

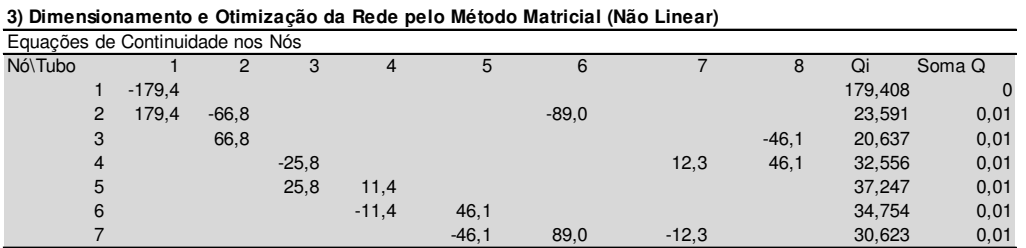

\begin{tabular}{cccccccccr}
\hline Equações de Perda de Carga nos Circuitos & & & & & \\
\hline Circuitos & 1 & 2 & 3 & 4 & 5 & 6 & 7 & 8 & Soma Perda \\
& & & & & & & & \\
1 & $-0,607$ & & & & 1,091 & 0,260 & $-0,744$ & 0,0001 \\
2 & & $-0,713$ & 0,225 & 0,748 & & $-0,260$ & & 0,0001 \\
\hline
\end{tabular}

Tabela da Função Objetivo

\begin{tabular}{|c|c|c|c|c|c|c|c|c|c|c|c|c|c|c|}
\hline \multirow{2}{*}{ Trecho } & \multicolumn{2}{|c|}{ Nó Montante } & \multicolumn{2}{|c|}{ No Jusante } & \multirow{2}{*}{$\begin{array}{c}\begin{array}{c}\text { Extensão } \\
\text { do Trecho }\end{array} \\
\text { (m) }\end{array}$} & \multirow{2}{*}{$\begin{array}{c}\text { Vazão do } \\
\text { Trecho }\end{array}$} & \multirow{2}{*}{$\begin{array}{c}\begin{array}{c}\text { Diâmetro } \\
\text { Nominal } \\
\text { Comercial }\end{array} \\
(\mathrm{mm})\end{array}$} & \multirow{2}{*}{$\begin{array}{c}\begin{array}{c}\text { Diâmetro } \\
\text { Ótimo }\end{array} \\
(\mathrm{mm})\end{array}$} & \multirow{2}{*}{$\begin{array}{l}\text { Velocidade } \\
(\mathrm{m} / \mathrm{s})\end{array}$} & \multirow[t]{2}{*}{$\begin{array}{l}\text { Fator de } \\
\text { Atrito } f\end{array}$} & \multirow{2}{*}{$\begin{array}{c}\text { Perda de Carga } \\
(\mathrm{m})\end{array}$} & \multirow{2}{*}{$\begin{array}{c}\begin{array}{c}\text { Carga } \\
\text { Montante }\end{array} \\
(\mathrm{m})\end{array}$} & \multirow{2}{*}{$\begin{array}{c}\text { Carga Jusante } \\
(\mathrm{m})\end{array}$} & \multirow{2}{*}{$\begin{array}{c}\text { Potência Dissipada } \\
\mathrm{kW}\end{array}$} \\
\hline & Nome & Cota & Nome & Cota & & & & & & & & & & \\
\hline T1 & $\mathrm{N} 1$ & 4,56 & N2 & 3,50 & 258,48 & 179,4 & 400 & 401 & 1,42 & 0,0063 & 0,42 & 10,39 & 11,04 & 1,06 \\
\hline T2 & N2 & 3,50 & N3 & 3,50 & 255,93 & 66,8 & 250 & 251 & 1,36 & 0,0063 & 0,61 & 11,04 & 10,43 & 0,57 \\
\hline T3 & $\mathrm{N} 4$ & 1,50 & N5 & 0,49 & 657,53 & 25,8 & 200 & 201 & 0,82 & 0,0063 & 0,71 & 11,69 & 11,98 & 0,26 \\
\hline T4 & N5 & 0,49 & N6 & 0,50 & 253,28 & 11,4 & 150 & 150 & 0,64 & 0,0063 & 0,22 & 11,98 & 11,75 & 0,04 \\
\hline T5 & N6 & 0,50 & N7 & 1,50 & 660,47 & 46,1 & 250 & 249 & 0,94 & 0,0063 & 0,75 & 11,75 & 10,00 & 0,48 \\
\hline T6 & N2 & 3,50 & N7 & 1,50 & 644,10 & 89,0 & 300 & 301 & 1,26 & 0,0063 & 1,09 & 11,04 & 11,94 & 1,36 \\
\hline 77 & N7 & 1,50 & $\mathrm{~N} 4$ & 1,50 & 253,02 & 12,3 & 150 & 150 & 0,69 & 0,0063 & 0,26 & 11,94 & 11,69 & 0,04 \\
\hline T8 & N3 & 3,50 & N4 & 1,50 & 657,18 & 46,1 & 250 & 223 & 0,94 & 0,0063 & 0,74 & 11,04 & 12,29 & 0,48 \\
\hline
\end{tabular}

4) Resumo do Dimensionamento Otimizado

\begin{tabular}{|c|c|c|c|}
\hline \multicolumn{3}{|c|}{ Potência Dissipada } & Pressurização Inicial \\
\hline Soma & & 4,29 & 26,11 \\
\hline Energia & & $28.175,84$ & $171.534,57$ \\
\hline FA & & 10,60 & 10,60 \\
\hline Sub-Total & $\mathbf{R} \$$ & $49.620,62$ & $302.090,42$ \\
\hline
\end{tabular}

\begin{tabular}{|c|c|c|}
\hline Custos & & Porcentagem \\
\hline Custo de Tubulação $R \$$ & $399.999,17$ & $45,37 \%$ \\
\hline Custo de Movimento de Terra $\mathrm{R} \$$ & $66.390,90$ & $7,53 \%$ \\
\hline Custo de Assentamento $\mathrm{R} \$$ & $11.140,60$ & $1,26 \%$ \\
\hline Custo de Pavimentação $\mathrm{R} \$$ & $52.339,54$ & $5,94 \%$ \\
\hline Custo da Pressurização Inicial $R \$$ & $302.090,42$ & $34,27 \%$ \\
\hline Custo da Potência Dissipada $\mathrm{R} \$$ & $49.620,62$ & $5,63 \%$ \\
\hline Total Global (Função Objetivo) R\$ & $881.581,25$ & $100,00 \%$ \\
\hline Total Referencial Unitário $\mathrm{R} \$$ & 242,19 & por metro de rede \\
\hline
\end{tabular}


5) Quantitativos e Custos de Implantação das Redes de Abastecimento

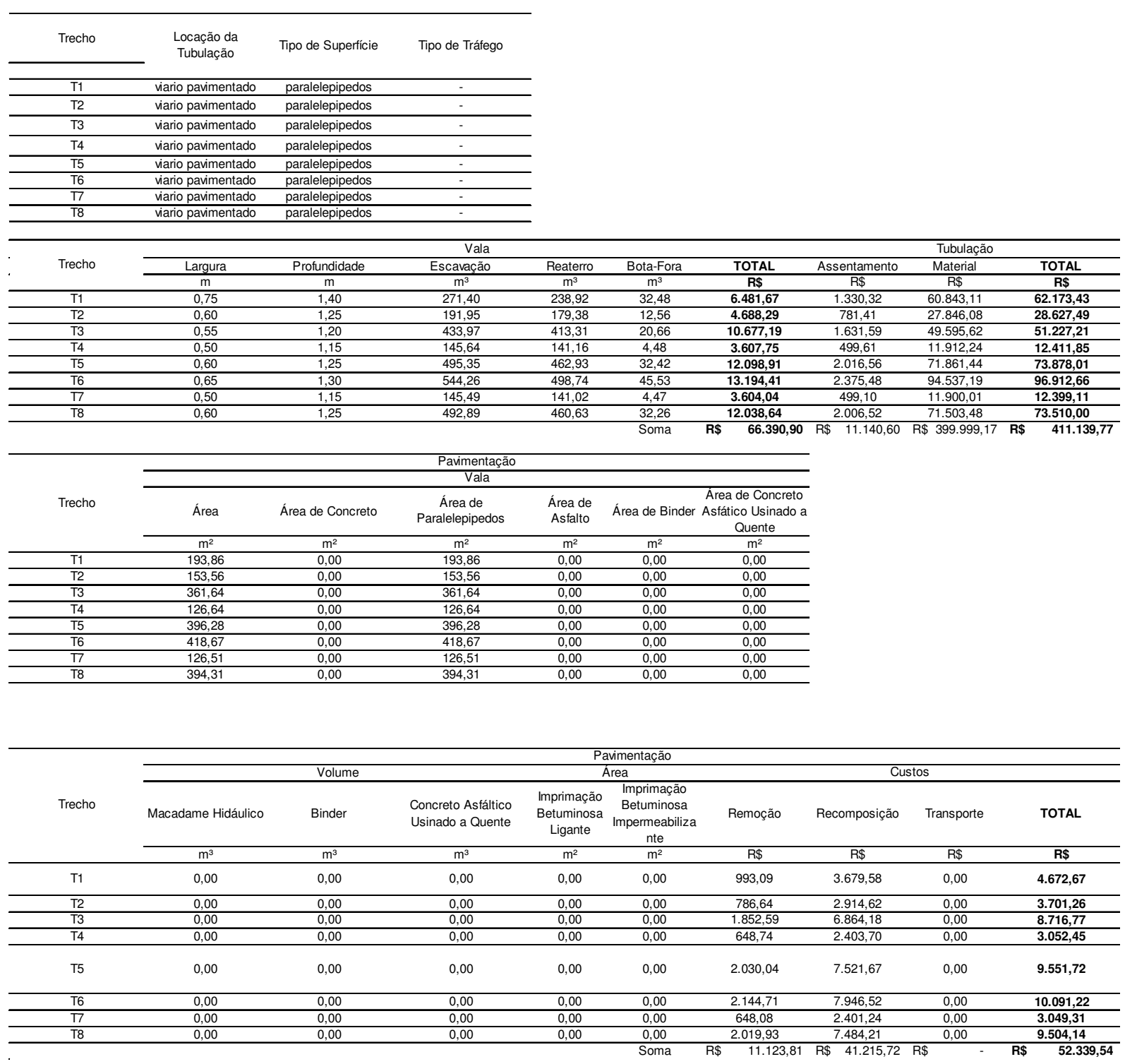




\section{APÊNDICE A4 - Planilha de Dimensionamento para Viário em Asfalto para Tráfego Leve - PVC}

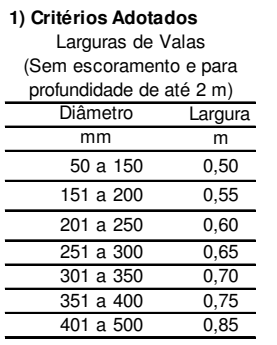

Locação das Redes

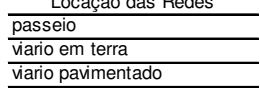

Recobrimento

\begin{tabular}{lc}
\hline \multicolumn{1}{c}{ Locação da } & Recobrimento \\
\cline { 2 - 2 } Tubulação & $\mathrm{m}$ \\
\hline passeio & 0,7 \\
\hline viario em terra & 1,2 \\
\hline viario pavimentado & 1,0 \\
\hline
\end{tabular}

\begin{tabular}{l}
\hline \multicolumn{1}{c}{ Tipo de Tráfegos para Viário } \\
\hline Leve \\
\hline Médio \\
\hline Pesado \\
\hline \multicolumn{1}{c}{ Tipos de Superfície } \\
\hline asfalto \\
\hline concreto \\
\hline paralelepipedos \\
\hline
\end{tabular}

2) Dados Adotados Tubulação

Materia

SDR \begin{tabular}{ll}
\hline Rugosidade Equivalente $(\mathrm{m}) \quad 0,00002$ \\
\hline
\end{tabular}

Fator entre Diâmetro Hidráulico e Comercia
Pressurização Inicial

\begin{tabular}{lr}
\hline Carga Inicial & 10,39 \\
\hline Rendimento Global & 0,70
\end{tabular}

\begin{tabular}{lc}
\hline Horas de Funcionamer & 0,70 \\
\hline & $6570 \mathrm{~h} /$ ano \\
\hline
\end{tabular}

Vida Útil

1,05

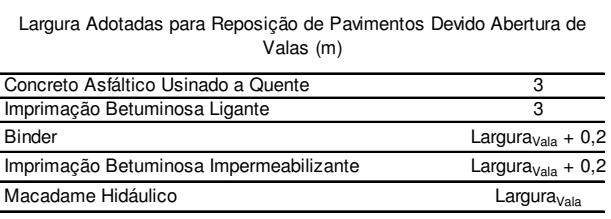

Espessuras Adotadas para Reposição de Pavimentos Devido Abertura de Valas (m) Tráfego

Binder

$\begin{array}{llll} & \text { Lo4 } & 0,07 & 0,10\end{array}$

\begin{tabular}{lll} 
& 0,04 & 0,07 \\
\hline Macadame Hidáulico & 0,04 & 0,05 \\
\hline
\end{tabular}

0,05

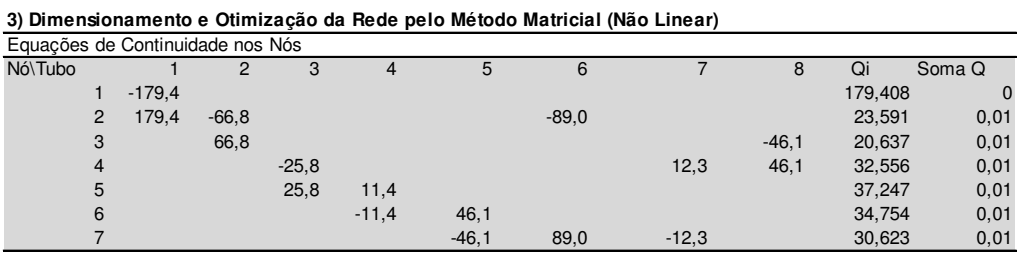

\begin{tabular}{cccccccccr}
\hline Equações de Perda de Carga nos Circuitos & & & & & \\
\hline Circuitos & 1 & 2 & 3 & 4 & 5 & 6 & 7 & 8 & Soma Perda \\
& & & & & & & & \\
1 & $-0,607$ & & & & 1,091 & 0,260 & $-0,744$ & 0,0001 \\
2 & & $-0,713$ & 0,225 & 0,748 & & $-0,260$ & & 0,0001 \\
\hline
\end{tabular}

Tabela da Função Objetivo

\begin{tabular}{|c|c|c|c|c|c|c|c|c|c|c|c|c|c|c|}
\hline \multirow{2}{*}{ Trecho } & \multicolumn{2}{|c|}{ Nó Montante } & \multicolumn{2}{|c|}{ No Jusante } & \multirow{2}{*}{$\begin{array}{c}\begin{array}{c}\text { Extensão } \\
\text { do Trecho }\end{array} \\
(\mathrm{m})\end{array}$} & \multirow{2}{*}{$\begin{array}{c}\text { Vazão do } \\
\text { Trecho }\end{array}$} & \multirow{2}{*}{$\begin{array}{c}\begin{array}{c}\text { Diâmetro } \\
\text { Nominal } \\
\text { Comercial }\end{array} \\
(\mathrm{mm})\end{array}$} & \multirow{2}{*}{$\begin{array}{c}\text { Diâmetro } \\
\text { Ótimo }\end{array}$} & \multirow{2}{*}{$\begin{array}{c}\text { Velocidade } \\
(\mathrm{m} / \mathrm{s})\end{array}$} & \multirow[t]{2}{*}{$\begin{array}{l}\text { Fator de } \\
\text { Atrito } f\end{array}$} & \multirow{2}{*}{$\begin{array}{l}\text { Perda de Carga } \\
(\mathrm{m})\end{array}$} & \multirow{2}{*}{$\begin{array}{c}\begin{array}{c}\text { Carga } \\
\text { Montante }\end{array} \\
(\mathrm{m})\end{array}$} & \multirow{2}{*}{$\begin{array}{c}\text { Carga Jusante } \\
(\mathrm{m})\end{array}$} & \multirow{2}{*}{$\begin{array}{c}\text { Potência Dissipada } \\
\mathrm{kW}\end{array}$} \\
\hline & Nome & Cota & Nome & Cota & & & & & & & & & & \\
\hline $\mathrm{T1}$ & $\mathrm{N} 1$ & 4,56 & $\mathrm{~N} 2$ & 3,50 & 258,48 & 179,4 & 400 & 400 & 1,42 & 0,0063 & 0,42 & 10,39 & 11,04 & 1,06 \\
\hline T2 & N2 & 3,50 & N3 & 3,50 & 255,93 & 66,8 & 250 & 250 & 1,36 & 0,0063 & 0,61 & 11,04 & 10,43 & 0,57 \\
\hline T3 & $\mathrm{N} 4$ & 1,50 & N5 & 0,49 & 657,53 & 25,8 & 200 & 200 & 0,82 & 0,0063 & 0,71 & 11,69 & 11,98 & 0,26 \\
\hline T4 & N5 & 0,49 & N6 & 0,50 & 253,28 & 11,4 & 150 & 150 & 0,64 & 0,0063 & 0,22 & 11,98 & 11,75 & 0,04 \\
\hline T5 & N6 & 0,50 & N7 & 1,50 & 660,47 & 46,1 & 250 & 250 & 0,94 & 0,0063 & 0,75 & 11,75 & 10,00 & 0,48 \\
\hline T6 & N2 & 3,50 & N7 & 1,50 & 644,10 & 89,0 & 300 & 300 & 1,26 & 0,0063 & 1,09 & 11,04 & 11,94 & 1,36 \\
\hline$T 7$ & N7 & 1,50 & $\mathrm{~N} 4$ & 1,50 & 253,02 & 12,3 & 150 & 150 & 0,69 & 0,0063 & 0,26 & 11,94 & 11,69 & 0,04 \\
\hline T8 & N3 & 3,50 & $\mathrm{~N} 4$ & 1,50 & 657,18 & 46,1 & 250 & 250 & 0,94 & 0,0063 & 0,74 & 11,04 & 12,29 & 0,48 \\
\hline
\end{tabular}

4) Resumo do Dimensionamento Otimizado

\begin{tabular}{|c|c|c|c|}
\hline & Poté & Dissipada & Pressurização Inicial \\
\hline Soma & & 4,29 & 26,11 \\
\hline Energia & & $28.175,84$ & $171.534,57$ \\
\hline FA & & 10,60 & 10,60 \\
\hline Sub-Total & $\mathrm{R} \$$ & $49.620,62$ & $302.090,42$ \\
\hline
\end{tabular}

\begin{tabular}{|c|c|c|}
\hline Custos & & Porcentagem \\
\hline Custo de Tubulação $\mathrm{R} \$$ & $399.999,17$ & $35,09 \%$ \\
\hline Custo de Movimento de Terra $R \$$ & $63.056,32$ & $5,53 \%$ \\
\hline Custo de Assentamento $\mathrm{R} \$$ & $11.140,60$ & $0,98 \%$ \\
\hline Custo de Pavimentação $\mathrm{R} \$$ & $313.893,46$ & $27,54 \%$ \\
\hline Custo da Pressurização Inicial $\mathrm{R} \$$ & $302.090,42$ & $26,50 \%$ \\
\hline Custo da Potência Dissipada $\mathrm{R} \$$ & $49.620,62$ & $4,35 \%$ \\
\hline Total Global (Função Objetivo) R\$ & $1.139 .800,59$ & $100,00 \%$ \\
\hline Total Referencial Unitário R\$ & 313,13 & por metro de rede \\
\hline
\end{tabular}


5) Quantitativos e Custos de Implantação das Redes de Abastecimento

\begin{tabular}{|c|c|c|c|c|c|c|c|c|c|c|}
\hline Trecho & $\begin{array}{l}\text { Locação da } \\
\text { Tubulação }\end{array}$ & Tipo de Superfície & Tipo de Tráfego & & & & & & & \\
\hline $\mathrm{T} 1$ & viario pavimentado & asfalto & Leve & & & & & & & \\
\hline $\mathrm{T} 2$ & vario pavimentado & asfalto & Leve & & & & & & & \\
\hline T3 & viario pavimentado & asfalto & Leve & & & & & & & \\
\hline T4 & viario pavimentado & asfalto & Leve & & & & & & & \\
\hline T5 & viario pavimentado & asfalto & Leve & & & & & & & \\
\hline T6 & viario pavimentado & asfalto & Leve & & & & & & & \\
\hline 77 & vario pavimentado & asfalto & Leve & & & & & & & \\
\hline T8 & viario pavimentado & asfalto & Leve & & & & & & & \\
\hline \multirow{3}{*}{ Trecho } & \multicolumn{6}{|c|}{ Vala } & \multicolumn{4}{|c|}{ Tubulação } \\
\hline & Largura & Profundidade & Escavação & Reaterro & Bota-Fora & TOTAL & Assentamento & Material & & TOTAL \\
\hline & $\mathrm{m}$ & $\mathrm{m}$ & $\mathrm{m}^{3}$ & $\mathrm{~m}^{3}$ & $\mathrm{~m}^{3}$ & $\mathbf{R} \$$ & $\mathrm{R} \$$ & $\mathrm{R} \$$ & & $\mathrm{R} \$$ \\
\hline $\mathrm{T} 1$ & 0,75 & 1,40 & 271,40 & 209,71 & 61,69 & $6.189,30$ & $1.330,32$ & $60.843,11$ & & $62.173,43$ \\
\hline $\mathrm{T} 2$ & 0,60 & 1,25 & 191,95 & 155,84 & 36,11 & $4.452,60$ & 781,41 & $27.846,08$ & & $28.627,49$ \\
\hline T3 & 0,55 & 1,20 & 433,97 & 357,42 & 76,55 & $10.117,73$ & $1.631,59$ & $49.595,62$ & & $51.227,21$ \\
\hline $\mathrm{T} 4$ & 0,50 & 1,15 & 145,64 & 121,40 & 24,23 & $3.409,99$ & 499,61 & $11.912,24$ & & $12.411,85$ \\
\hline T5 & 0,60 & 1,25 & 495,35 & 402,17 & 93,18 & $11.490,67$ & $2.016,56$ & $71.861,44$ & & $73.878,01$ \\
\hline T6 & 0,65 & 1,30 & 544,26 & 434,97 & 109,29 & $12.556,11$ & $2.375,48$ & $94.537,19$ & & $96.912,66$ \\
\hline 77 & 0,50 & 1,15 & 145,49 & 121,28 & 24,21 & $3.406,49$ & 499,10 & $11.900,01$ & & $12.399,11$ \\
\hline \multirow[t]{2}{*}{ T8 } & 0,60 & 1,25 & 492,89 & 400,17 & 92,72 & $11.433,43$ & $2.006,52$ & $71.503,48$ & & $73.510,00$ \\
\hline & & & & & Soma & $63.056,32$ & $\mathrm{R} \$ \quad 11.140,60$ & $\mathrm{R} \$ 399.999,17$ & $\mathbf{R} \$$ & $411.139,77$ \\
\hline \multicolumn{11}{|c|}{ Pavimentação } \\
\hline \multirow[t]{2}{*}{ Trecho } & Área & Área de Concreto & $\begin{array}{c}\text { Área de } \\
\text { Paralelepipedos }\end{array}$ & $\begin{array}{l}\text { Área de } \\
\text { Asfalto }\end{array}$ & Área de Binder & $\begin{array}{c}\text { Área de Concreto } \\
\text { Asfático Usinado a } \\
\text { Quente }\end{array}$ & & & & \\
\hline & $\mathrm{m}^{2}$ & $\mathrm{~m}^{2}$ & $\mathrm{~m}^{2}$ & $\mathrm{~m}^{2}$ & $\mathrm{~m}^{2}$ & $\mathrm{~m}^{2}$ & & & & \\
\hline $\mathrm{T} 1$ & 193,86 & 0,00 & 0,00 & 193,86 & 245,56 & 775,44 & & & & \\
\hline $\mathrm{T} 2$ & 153,56 & 0,00 & 0,00 & 153,56 & 204,74 & 767,79 & & & & \\
\hline T3 & 361,64 & 0,00 & 0,00 & 361,64 & 493,15 & $1.972,59$ & & & & \\
\hline T4 & 126,64 & 0,00 & 0,00 & 126,64 & 177,30 & 759,84 & & & & \\
\hline T5 & 396,28 & 0,00 & 0,00 & 396,28 & 528,38 & $1.981,41$ & & & & \\
\hline T6 & 418,67 & 0,00 & 0,00 & 418,67 & 547,49 & $1.932,30$ & & & & \\
\hline$\pi 7$ & 126,51 & 0,00 & 0,00 & 126,51 & 177,11 & 759,06 & & & & \\
\hline T8 & 394,31 & 0,00 & 0,00 & 394,31 & 525,74 & $1.971,54$ & & & & \\
\hline \multirow{4}{*}{ Trecho } & \multicolumn{10}{|c|}{ Pavimentação } \\
\hline & \multicolumn{3}{|c|}{ Volume } & \multicolumn{2}{|c|}{ Area } & \multicolumn{5}{|c|}{ Custos } \\
\hline & Macadame Hidáulico & Binder & $\begin{array}{l}\text { Concreto Asfáltico } \\
\text { Usinado a Quente }\end{array}$ & $\begin{array}{l}\text { Imprimação } \\
\text { Betuminosa } \\
\text { Ligante }\end{array}$ & $\begin{array}{l}\text { Imprimação } \\
\text { Betuminosa } \\
\text { Impermeabiliza } \\
\text { nte }\end{array}$ & Remoção & Recomposição & Transporte & & TOTAL \\
\hline & $\mathrm{m}^{3}$ & $\mathrm{~m}^{3}$ & $\mathrm{~m}^{3}$ & $\mathrm{~m}^{2}$ & $\mathrm{~m}^{2}$ & $\mathrm{R} \$$ & $\mathrm{R} \$$ & $\mathrm{R} \$$ & & $\mathbf{R} \$$ \\
\hline $\mathrm{T} 1$ & 19,39 & 9,82 & 31,02 & 245,56 & 775,44 & $1.570,75$ & $21.953,10$ & 271,72 & & $23.795,57$ \\
\hline $\mathrm{T} 2$ & 15,36 & 8,19 & 30,71 & 204,74 & 767,79 & $1.244,20$ & $20.600,46$ & 258,83 & & $22.103,49$ \\
\hline T3 & 36,16 & 19,73 & 78,90 & 493,15 & $1.972,59$ & $2.930,19$ & $51.953,36$ & 656,22 & & $55.539,78$ \\
\hline $\mathrm{T} 4$ & 12,66 & 7,09 & 30,39 & 177,30 & 759,84 & $1.026,10$ & $\begin{array}{l}19.637,63 \\
\end{array}$ & 249,41 & & $20.913,13$ \\
\hline T5 & 39,63 & 21,14 & 79,26 & 528,38 & $1.981,41$ & $3.210,87$ & $53.162,93$ & 667,95 & & $57.041,74$ \\
\hline T6 & 41,87 & 21,90 & 77,29 & 547,49 & $1.932,30$ & $3.392,22$ & $52.798,31$ & 659,96 & & $56.850,49$ \\
\hline 77 & 12,65 & 7,08 & 30,36 & 177,11 & 759,06 & $1.025,04$ & $19.617,47$ & 249,15 & & $20.891,66$ \\
\hline T8 & 39,43 & 21,03 & 78,86 & 525,74 & $1.971,54$ & $3.194,87$ & $52.898,11$ & 664,62 & & $56.757,60$ \\
\hline & & & & & Soma & $17.594,24$ & $\mathrm{R} \$ 292.621,37$ & $\mathrm{R} \$ \quad 3.677,86$ & RS & 313.893, \\
\hline
\end{tabular}




\section{APÊNDICE A5 - Planilha de Dimensionamento para Viário em Asfalto para Tráfego Médio - PVC}

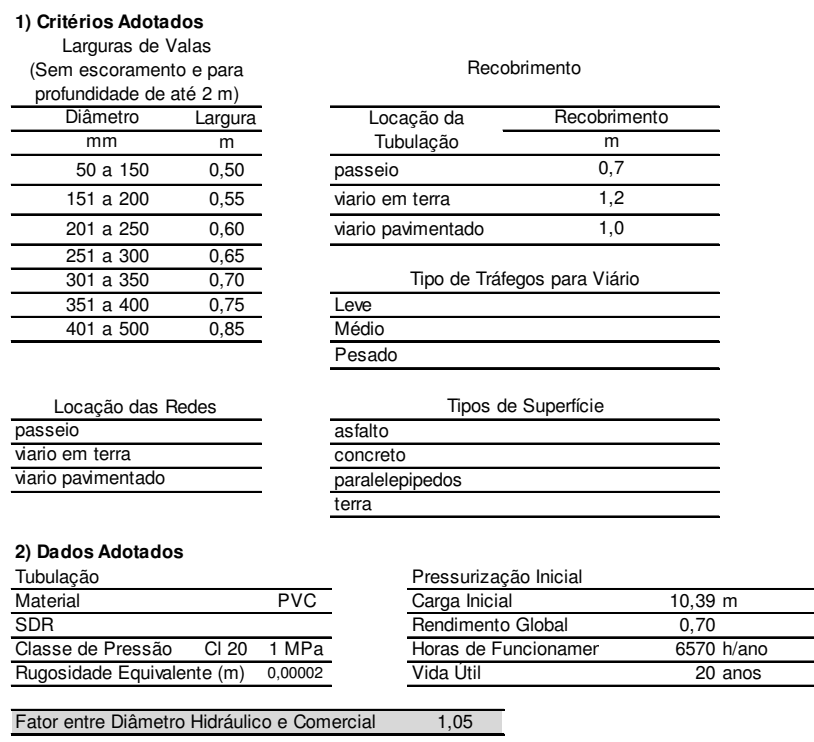

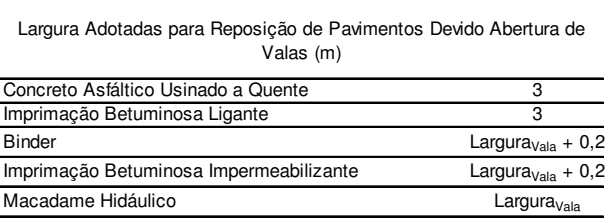

Espessuras Adotadas para Reposição de Pavimentos Devido Abertura de Valas (m) \begin{tabular}{lccc}
\multicolumn{4}{c}{ Espessuras Adotadas para Reposição de Pavimentos Devido Abertura de Valas $(\mathrm{m})$} \\
\hline Tráfego & Leve & Médio & Pesado \\
\hline Binder & 0,04 & 0,07 & 0,10 \\
\hline Concreto Asfáltico Usinado a Quente & 0,04 & 0,05 & 0,05 \\
\hline Macadame Hidáulico & 0,10 & 0,12 & 0,15 \\
\hline
\end{tabular}

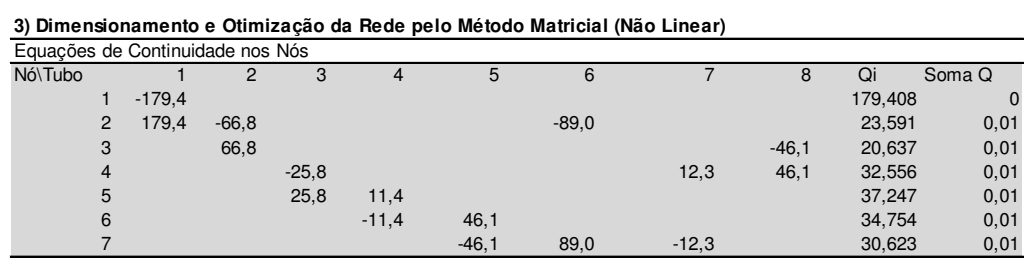

\begin{tabular}{|c|c|c|c|c|c|c|c|c|c|}
\hline \multicolumn{10}{|c|}{ Equações de Perda de Carga nos Circuitos } \\
\hline Circuitos & 1 & 2 & 3 & 4 & 5 & 6 & 7 & 8 & Soma Perda \\
\hline 1 & & $-0,607$ & & & & 1,091 & 0,260 & $-0,744$ & 0,0001 \\
\hline 2 & & & $-0,713$ & 0,225 & 0,748 & & $-0,260$ & & 0,0001 \\
\hline
\end{tabular}

\begin{tabular}{|c|c|c|c|c|c|c|c|c|c|c|c|c|c|c|}
\hline \multirow{2}{*}{ Trecho } & \multicolumn{2}{|c|}{ Nó Montante } & \multicolumn{2}{|c|}{ No Jusante } & \multirow{2}{*}{$\begin{array}{c}\begin{array}{c}\text { Extensão } \\
\text { do Trecho }\end{array} \\
\text { (m) } \\
\end{array}$} & \multirow{2}{*}{$\begin{array}{c}\begin{array}{c}\text { Vazão do } \\
\text { Trecho }\end{array} \\
\text { I/s } \\
\end{array}$} & \multirow{2}{*}{$\begin{array}{c}\begin{array}{c}\text { Diâmetro } \\
\text { Nominal } \\
\text { Comercial }\end{array} \\
(\mathrm{mm}) \\
\end{array}$} & \multirow{2}{*}{$\begin{array}{c}\begin{array}{c}\text { Diâmetro } \\
\text { Ótimo }\end{array} \\
(\mathrm{mm}) \\
\end{array}$} & \multirow{2}{*}{$\begin{array}{c}\text { Velocidade } \\
(\mathrm{m} / \mathrm{s})\end{array}$} & \multirow[t]{2}{*}{$\begin{array}{l}\text { Fator de } \\
\text { Atrito } f\end{array}$} & \multirow{2}{*}{$\begin{array}{c}\text { Perda de Carga } \\
(\mathrm{m})\end{array}$} & \multirow{2}{*}{$\begin{array}{c}\begin{array}{c}\text { Carga } \\
\text { Montante }\end{array} \\
(\mathrm{m}) \\
\end{array}$} & \multirow{2}{*}{$\begin{array}{c}\text { Carga Jusante } \\
(\mathrm{m}) \\
\end{array}$} & \multirow{2}{*}{$\begin{array}{c}\text { Potência Dissipada } \\
\mathrm{kW}\end{array}$} \\
\hline & Nome & Cota & Nome & Cota & & & & & & & & & & \\
\hline $\mathrm{T1}$ & $\mathrm{N} 1$ & 4,56 & N2 & 3,50 & 258,48 & 179,4 & 400 & 400 & 1,42 & 0,0063 & 0,42 & 10,39 & 11,04 & 1,06 \\
\hline T2 & N2 & 3,50 & N3 & 3,50 & 255,93 & 66,8 & 250 & 250 & 1,36 & 0,0063 & 0,61 & 11,04 & 10,43 & 0,57 \\
\hline T3 & $\mathrm{N} 4$ & 1,50 & N5 & 0,49 & 657,53 & 25,8 & 200 & 200 & 0,82 & 0,0063 & 0,71 & 11,69 & 11,98 & 0,26 \\
\hline T4 & N5 & 0,49 & N6 & 0,50 & 253,28 & 11,4 & 150 & 150 & 0,64 & 0,0063 & 0,22 & 11,98 & 11,75 & 0,04 \\
\hline T5 & N6 & 0,50 & N7 & 1,50 & 660,47 & 46,1 & 250 & 250 & 0,94 & 0,0063 & 0,75 & 11,75 & 10,00 & 0,48 \\
\hline T6 & N2 & 3,50 & N7 & 1,50 & 644,10 & 89,0 & 300 & 300 & 1,26 & 0,0063 & 1,09 & 11,04 & 11,94 & 1,36 \\
\hline 77 & N7 & 1,50 & $\mathrm{~N} 4$ & 1,50 & 253,02 & 12,3 & 150 & 150 & 0,69 & 0,0063 & 0,26 & 11,94 & 11,69 & 0,04 \\
\hline T8 & N3 & 3,50 & $\mathrm{~N} 4$ & 1,50 & 657,18 & 46,1 & 250 & 250 & 0,94 & 0,0063 & 0,74 & 11,04 & 12,29 & 0,48 \\
\hline & & & & Soma & 3639,99 & & & & & & & & & 4,29 \\
\hline
\end{tabular}

4) Resumo do Dimensionamento Otimizado

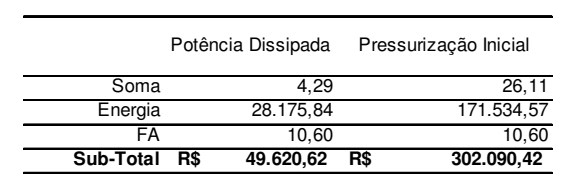

\begin{tabular}{|c|c|c|}
\hline Custos & & Porcentagem \\
\hline Custo de Tubulação $\mathrm{R} \$$ & $399.999,17$ & $32,81 \%$ \\
\hline Custo de Movimento de Terra $R \$$ & $61.750,88$ & $5,07 \%$ \\
\hline Custo de Assentamento R\$ & $11.140,60$ & $0,91 \%$ \\
\hline Custo de Pavimentação $\mathrm{R} \$$ & $394.381,41$ & $32,35 \%$ \\
\hline Custo da Pressurização Inicial $R \$$ & $302.090,42$ & $24,78 \%$ \\
\hline Custo da Potência Dissipada $\mathrm{R} \$$ & $49.620,62$ & $4,07 \%$ \\
\hline Total Global (Função Objetivo) R\$ & $1.218 .983,10$ & $100,00 \%$ \\
\hline Total Referencial Unitário $\mathrm{R} \$$ & 334,89 & por metro de rede \\
\hline
\end{tabular}


5) Quantitativos e Custos de Implantação das Redes de Abastecimento

\begin{tabular}{|c|c|c|c|c|c|c|c|c|c|c|}
\hline Trecho & $\begin{array}{l}\text { Locação da } \\
\text { Tubulação }\end{array}$ & Tipo de Superfície & Tipo de Tráfego & & & & & & & \\
\hline $\mathrm{T} 1$ & viario pavimentado & asfalto & Médio & & & & & & & \\
\hline $\mathrm{T} 2$ & vario pavimentado & asfalto & Médio & & & & & & & \\
\hline T3 & viario pavimentado & asfalto & Médio & & & & & & & \\
\hline T4 & viario pavimentado & asfalto & Médio & & & & & & & \\
\hline T5 & viario pavimentado & asfalto & Médio & & & & & & & \\
\hline T6 & viario pavimentado & asfalto & Médio & & & & & & & \\
\hline 77 & vario pavimentado & asfalto & Médio & & & & & & & \\
\hline T8 & viario pavimentado & asfalto & Médio & & & & & & & \\
\hline \multirow{3}{*}{ Trecho } & \multicolumn{6}{|c|}{ Vala } & \multicolumn{4}{|c|}{ Tubulação } \\
\hline & Largura & Profundidade & Escavação & Reaterro & Bota-Fora & TOTAL & Assentamento & Material & & TOTAL \\
\hline & $\mathrm{m}$ & $\mathrm{m}$ & $\mathrm{m}^{3}$ & $\mathrm{~m}^{3}$ & $\mathrm{~m}^{3}$ & $\mathbf{R} \$$ & $\mathrm{R} \$$ & $\mathrm{R} \$$ & & $\mathrm{R} \$$ \\
\hline $\mathrm{T} 1$ & 0,75 & 1,40 & 271,40 & 198,47 & 72,93 & $6.076,75$ & $1.330,32$ & $60.843,11$ & & $62.173,43$ \\
\hline $\mathrm{T} 2$ & 0,60 & 1,25 & 191,95 & 146,63 & 45,32 & $4.360,37$ & 781,41 & $27.846,08$ & & $28.627,49$ \\
\hline T3 & 0,55 & 1,20 & 433,97 & 335,40 & 98,57 & $9.897,23$ & $1.631,59$ & $49.595,62$ & & $51.227,21$ \\
\hline $\mathrm{T} 4$ & 0,50 & 1,15 & 145,64 & 113,55 & 32,08 & $3.331,40$ & 499,61 & $11.912,24$ & & $12.411,85$ \\
\hline T5 & 0,60 & 1,25 & 495,35 & 378,39 & 116,96 & $11.252,66$ & $2.016,56$ & $71.861,44$ & & $73.878,01$ \\
\hline T6 & 0,65 & 1,30 & 544,26 & 410,17 & 134,09 & $12.307,89$ & $2.375,48$ & $94.537,19$ & & $96.912,66$ \\
\hline 77 & 0,50 & 1,15 & 145,49 & 113,44 & 32,05 & $3.327,98$ & 499,10 & $11.900,01$ & & $12.399,11$ \\
\hline \multirow[t]{2}{*}{ T8 } & 0,60 & 1,25 & 492,89 & 376,51 & 116,38 & $11.196,61$ & $2.006,52$ & $71.503,48$ & & $73.510,00$ \\
\hline & & & & & Soma & $61.750,88$ & $\mathrm{R} \$ \quad 11.140,60$ & $\mathrm{R} \$ 399.999,17$ & $\mathbf{R} \$$ & $411.139,77$ \\
\hline \multicolumn{11}{|c|}{ Pavimentação } \\
\hline \multirow[t]{2}{*}{ Trecho } & Área & Área de Concreto & $\begin{array}{c}\text { Área de } \\
\text { Paralelepipedos }\end{array}$ & $\begin{array}{l}\text { Área de } \\
\text { Asfalto }\end{array}$ & Área de Binder & $\begin{array}{c}\text { Área de Concreto } \\
\text { Asfático Usinado a } \\
\text { Quente }\end{array}$ & & & & \\
\hline & $\mathrm{m}^{2}$ & $\mathrm{~m}^{2}$ & $\mathrm{~m}^{2}$ & $\mathrm{~m}^{2}$ & $\mathrm{~m}^{2}$ & $\mathrm{~m}^{2}$ & & & & \\
\hline $\mathrm{T} 1$ & 193,86 & 0,00 & 0,00 & 193,86 & 245,56 & 775,44 & & & & \\
\hline $\mathrm{T} 2$ & 153,56 & 0,00 & 0,00 & 153,56 & 204,74 & 767,79 & & & & \\
\hline T3 & 361,64 & 0,00 & 0,00 & 361,64 & 493,15 & $1.972,59$ & & & & \\
\hline T4 & 126,64 & 0,00 & 0,00 & 126,64 & 177,30 & 759,84 & & & & \\
\hline T5 & 396,28 & 0,00 & 0,00 & 396,28 & 528,38 & $1.981,41$ & & & & \\
\hline T6 & 418,67 & 0,00 & 0,00 & 418,67 & 547,49 & $1.932,30$ & & & & \\
\hline$\pi 7$ & 126,51 & 0,00 & 0,00 & 126,51 & 177,11 & 759,06 & & & & \\
\hline T8 & 394,31 & 0,00 & 0,00 & 394,31 & 525,74 & $1.971,54$ & & & & \\
\hline \multirow{4}{*}{ Trecho } & \multicolumn{10}{|c|}{ Pavimentação } \\
\hline & \multicolumn{3}{|c|}{ Volume } & \multicolumn{2}{|c|}{ Area } & \multicolumn{5}{|c|}{ Custos } \\
\hline & Macadame Hidáulico & Binder & $\begin{array}{l}\text { Concreto Asfáltico } \\
\text { Usinado a Quente }\end{array}$ & $\begin{array}{l}\text { Imprimação } \\
\text { Betuminosa } \\
\text { Ligante }\end{array}$ & $\begin{array}{l}\text { Imprimação } \\
\text { Betuminosa } \\
\text { Impermeabiliza } \\
\text { nte }\end{array}$ & Remoção & Recomposição & Transporte & & TOTAL \\
\hline & $\mathrm{m}^{3}$ & $\mathrm{~m}^{3}$ & $\mathrm{~m}^{3}$ & $\mathrm{~m}^{2}$ & $\mathrm{~m}^{2}$ & $\mathrm{R} \$$ & $\mathrm{R} \$$ & $\mathrm{R} \$$ & & $\mathbf{R} \$$ \\
\hline $\mathrm{T} 1$ & 23,26 & 17,19 & 38,77 & 245,56 & 775,44 & $1.570,75$ & $28.084,85$ & 372,33 & & $30.027,93$ \\
\hline $\mathrm{T} 2$ & 18,43 & 14,33 & 38,39 & 204,74 & 767,79 & $1.244,20$ & $26.179,15$ & 350,78 & & $27.774,13$ \\
\hline T3 & 43,40 & 34,52 & 98,63 & 493,15 & $1.972,59$ & $2.930,19$ & $65.864,17$ & 885,90 & & $69.680,27$ \\
\hline T4 & 15,20 & 12,41 & 37,99 & 177,30 & 759,84 & $1.026,10$ & $24.833,57$ & 335,35 & & $26.195,02$ \\
\hline T5 & 47,55 & 36,99 & 99,07 & 528,38 & $1.981,41$ & $3.210,87$ & $67.559,66$ & 905,24 & & $71.675,76$ \\
\hline T6 & 50,24 & 38,32 & 96,62 & 547,49 & $1.932,30$ & $3.392,22$ & $67.251,43$ & 897,81 & & $71.541,46$ \\
\hline 77 & 15,18 & 12,40 & 37,95 & 177,11 & 759,06 & $1.025,04$ & $24.808,07$ & 335,01 & & $26.168,13$ \\
\hline T8 & 47,32 & 36,80 & 98,58 & 525,74 & $1.971,54$ & $3.194,87$ & $67.223,12$ & 900,73 & & $71.318,73$ \\
\hline & & & & & Soma & $17.594,24$ & $\mathrm{R} \$ 371.804,02$ & $4.983,15$ & $\mathbf{R} \$$ & 394.381, \\
\hline
\end{tabular}




\section{APÊNDICE A6 - Planilha de Dimensionamento para Viário em Asfalto para Tráfego Pesado - PVC}

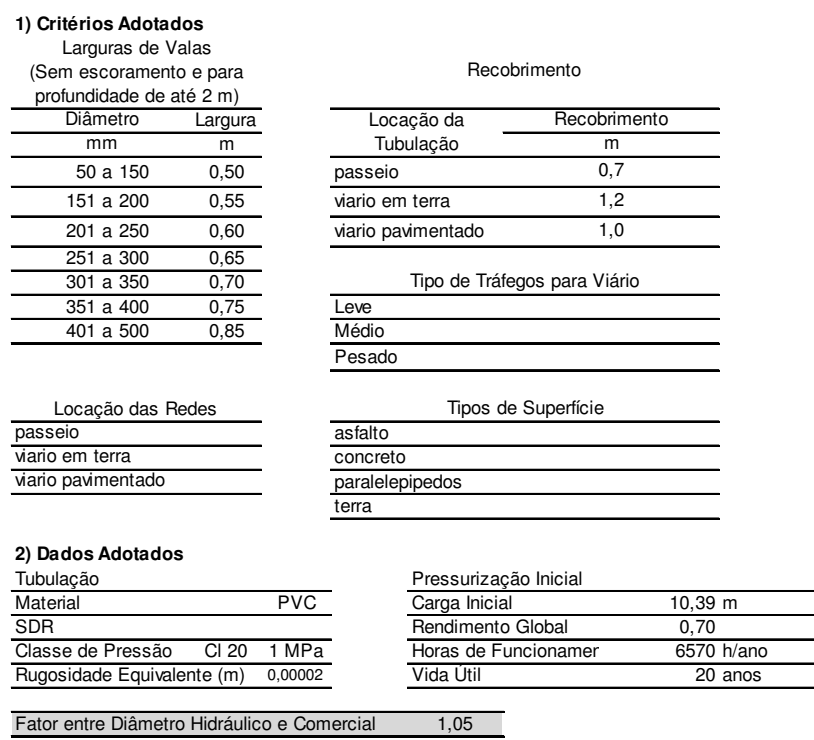

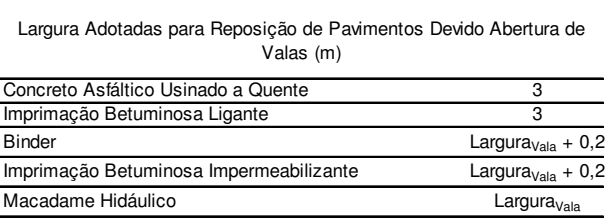

Espessuras Adotadas para Reposição de Pavimentos Devido Abertura de Valas (m) \begin{tabular}{lccc}
\multicolumn{4}{c}{ Espessuras Adotadas para Reposição de Pavimentos Devido Abertura de Valas $(\mathrm{m})$} \\
\hline Tráfego & Leve & Médio & Pesado \\
\hline Binder & 0,04 & 0,07 & 0,10 \\
\hline Concreto Asfáltico Usinado a Quente & 0,04 & 0,05 & 0,05 \\
\hline Macadame Hidáulico & 0,10 & 0,12 & 0,15 \\
\hline
\end{tabular}

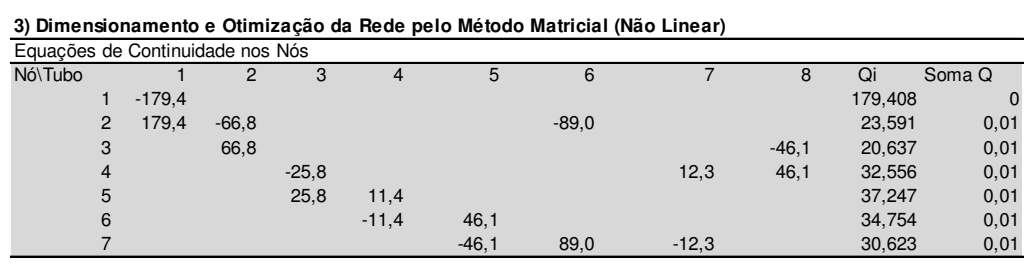

\begin{tabular}{|c|c|c|c|c|c|c|c|c|c|}
\hline \multicolumn{10}{|c|}{ Equações de Perda de Carga nos Circuitos } \\
\hline Circuitos & 1 & 2 & 3 & 4 & 5 & 6 & 7 & 8 & Soma Perda \\
\hline 1 & & 0,607 & & & & 1,091 & 0,260 & $-0,744$ & 0,0001 \\
\hline 2 & & & $-0,713$ & 0,225 & 0,748 & & $-0,260$ & & 0,0001 \\
\hline
\end{tabular}

\begin{tabular}{|c|c|c|c|c|c|c|c|c|c|c|c|c|c|c|}
\hline \multirow{2}{*}{ Trecho } & \multicolumn{2}{|c|}{ Nó Montante } & \multicolumn{2}{|c|}{ No Jusante } & \multirow{2}{*}{$\begin{array}{c}\begin{array}{c}\text { Extensão } \\
\text { do Trecho }\end{array} \\
\text { (m) } \\
\end{array}$} & \multirow{2}{*}{$\begin{array}{c}\begin{array}{c}\text { Vazão do } \\
\text { Trecho }\end{array} \\
\text { I/s } \\
\end{array}$} & \multirow{2}{*}{$\begin{array}{c}\begin{array}{c}\text { Diâmetro } \\
\text { Nominal } \\
\text { Comercial }\end{array} \\
(\mathrm{mm}) \\
\end{array}$} & \multirow{2}{*}{$\begin{array}{c}\begin{array}{c}\text { Diâmetro } \\
\text { Ótimo }\end{array} \\
(\mathrm{mm}) \\
\end{array}$} & \multirow{2}{*}{$\begin{array}{c}\text { Velocidade } \\
(\mathrm{m} / \mathrm{s})\end{array}$} & \multirow[t]{2}{*}{$\begin{array}{l}\text { Fator de } \\
\text { Atrito } f\end{array}$} & \multirow{2}{*}{$\begin{array}{c}\text { Perda de Carga } \\
(\mathrm{m})\end{array}$} & \multirow{2}{*}{$\begin{array}{c}\begin{array}{c}\text { Carga } \\
\text { Montante }\end{array} \\
(\mathrm{m}) \\
\end{array}$} & \multirow{2}{*}{$\begin{array}{c}\text { Carga Jusante } \\
(\mathrm{m}) \\
\end{array}$} & \multirow{2}{*}{$\begin{array}{c}\text { Potência Dissipada } \\
\mathrm{kW}\end{array}$} \\
\hline & Nome & Cota & Nome & Cota & & & & & & & & & & \\
\hline $\mathrm{T1}$ & $\mathrm{N} 1$ & 4,56 & N2 & 3,50 & 258,48 & 179,4 & 400 & 400 & 1,42 & 0,0063 & 0,42 & 10,39 & 11,04 & 1,06 \\
\hline T2 & N2 & 3,50 & N3 & 3,50 & 255,93 & 66,8 & 250 & 250 & 1,36 & 0,0063 & 0,61 & 11,04 & 10,43 & 0,57 \\
\hline T3 & $\mathrm{N} 4$ & 1,50 & N5 & 0,49 & 657,53 & 25,8 & 200 & 200 & 0,82 & 0,0063 & 0,71 & 11,69 & 11,98 & 0,26 \\
\hline T4 & N5 & 0,49 & N6 & 0,50 & 253,28 & 11,4 & 150 & 150 & 0,64 & 0,0063 & 0,22 & 11,98 & 11,75 & 0,04 \\
\hline T5 & N6 & 0,50 & N7 & 1,50 & 660,47 & 46,1 & 250 & 250 & 0,94 & 0,0063 & 0,75 & 11,75 & 10,00 & 0,48 \\
\hline T6 & N2 & 3,50 & N7 & 1,50 & 644,10 & 89,0 & 300 & 300 & 1,26 & 0,0063 & 1,09 & 11,04 & 11,94 & 1,36 \\
\hline 77 & N7 & 1,50 & $\mathrm{~N} 4$ & 1,50 & 253,02 & 12,3 & 150 & 150 & 0,69 & 0,0063 & 0,26 & 11,94 & 11,69 & 0,04 \\
\hline T8 & N3 & 3,50 & $\mathrm{~N} 4$ & 1,50 & 657,18 & 46,1 & 250 & 250 & 0,94 & 0,0063 & 0,74 & 11,04 & 12,29 & 0,48 \\
\hline & & & & Soma & 3639,99 & & & & & & & & & 4,29 \\
\hline
\end{tabular}

4) Resumo do Dimensionamento Otimizado

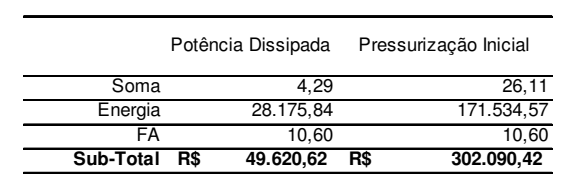

\begin{tabular}{|c|c|c|}
\hline Custos & & Porcentagem \\
\hline Custo de Tubulação $\mathrm{R} \$$ & $399.999,17$ & $31,84 \%$ \\
\hline Custo de Movimento de Terra $R \$$ & $60.228,08$ & $4,79 \%$ \\
\hline Custo de Assentamento R\$ & $11.140,60$ & $0,89 \%$ \\
\hline Custo de Pavimentação $\mathrm{R} \$$ & $433.199,74$ & $34,48 \%$ \\
\hline Custo da Pressurização Inicial $R \$$ & $302.090,42$ & $24,05 \%$ \\
\hline Custo da Potência Dissipada $R \$$ & $49.620,62$ & $3,95 \%$ \\
\hline Total Global (Função Objetivo) R\$ & $1.256 .278,64$ & $100,00 \%$ \\
\hline Total Referencial Unitário $\mathrm{R} \$$ & 345,13 & por metro de rede \\
\hline
\end{tabular}


5) Quantitativos e Custos de Implantação das Redes de Abastecimento

\begin{tabular}{|c|c|c|c|c|c|c|c|c|c|}
\hline Trecho & $\begin{array}{l}\text { Locação da } \\
\text { Tubulação }\end{array}$ & Tipo de Superfície & Tipo de Tráfego & & & & & & \\
\hline $\mathrm{T} 1$ & viario pavimentado & asfalto & Pesado & & & & & & \\
\hline T2 & viario pavimentado & asfalto & Pesado & & & & & & \\
\hline T3 & viario pavimentado & asfalto & Pesado & & & & & & \\
\hline T4 & viario pavimentado & asfalto & Pesado & & & & & & \\
\hline T5 & viario pavimentado & asfalto & Pesado & & & & & & \\
\hline T6 & viario pavimentado & asfalto & Pesado & & & & & & \\
\hline$T 7$ & viario pavimentado & asfalto & Pesado & & & & & & \\
\hline T8 & viario pavimentado & asfalto & Pesado & & & & & & \\
\hline \multirow{3}{*}{ Trecho } & \multicolumn{6}{|c|}{ Vala } & \multicolumn{3}{|c|}{ Tubulação } \\
\hline & Largura & $\begin{array}{l}\text { Profundidade } \\
\end{array}$ & Escavação & Reaterro & Bota-Fora & TOTAL & Assentamento & Material & TOTAL \\
\hline & $\mathrm{m}$ & $\mathrm{m}$ & $\mathrm{m}^{3}$ & $\mathrm{~m}^{3}$ & $\mathrm{~m}^{3}$ & $\mathrm{R} \$$ & $R \$$ & $\mathrm{R} \$$ & $\mathrm{R} \$$ \\
\hline $\mathrm{T} 1$ & 0,75 & 1,40 & 271,40 & 185,29 & 86,12 & $5.944,79$ & $1.330,32$ & $60.843,11$ & $62.173,43$ \\
\hline T2 & 0,60 & 1,25 & 191,95 & 135,88 & 56,07 & $4.252,77$ & 781,41 & $27.846,08$ & $28.627,49$ \\
\hline T3 & 0,55 & 1,20 & 433,97 & 309,75 & 124,22 & $9.640,54$ & $1.631,59$ & $49.595,62$ & $51.227,21$ \\
\hline T4 & 0,50 & 1,15 & 145,64 & 104,43 & 41,20 & $3.240,12$ & 499,61 & $11.912,24$ & $12.411,85$ \\
\hline T5 & 0,60 & 1,25 & 495,35 & 350,65 & 144,70 & $10.974,99$ & $2.016,56$ & $71.861,44$ & $73.878,01$ \\
\hline T6 & 0,65 & 1,30 & 544,26 & 381,19 & 163,08 & $12.017,75$ & $2.375,48$ & $94.537,19$ & $96.912,66$ \\
\hline 77 & 0,50 & 1,15 & 145,49 & 104,33 & 41,16 & $3.236,80$ & 499,10 & $11.900,01$ & $12.399,11$ \\
\hline \multirow[t]{2}{*}{ T8 } & 0,60 & 1,25 & 492,89 & 348,91 & 143,98 & $10.920,32$ & $2.006,52$ & $71.503,48$ & $73.510,00$ \\
\hline & & & & & Soma & $\mathrm{R} \$ \quad 60.228,08$ & $\mathrm{R} \$ \quad 11.140,60$ & $\mathrm{R} \$ 399.999,17 \quad \mathrm{R} \$$ & $411.139,77$ \\
\hline \multicolumn{10}{|c|}{ Pavimentação } \\
\hline \multirow{3}{*}{ Trecho } & \multicolumn{6}{|c|}{ Vala } & & & \\
\hline & Área & Área de Concreto & $\begin{array}{c}\text { Área de } \\
\text { Paralelepipedos }\end{array}$ & $\begin{array}{l}\text { Área de } \\
\text { Asfalto }\end{array}$ & Área de Binder & $\begin{array}{c}\text { Área de Concreto } \\
\text { Asfático Usinado a } \\
\text { Quente }\end{array}$ & & & \\
\hline & $\mathrm{m}^{2}$ & $\mathrm{~m}^{2}$ & $\mathrm{~m}^{2}$ & $\mathrm{~m}^{2}$ & $\mathrm{~m}^{2}$ & $\mathrm{~m}^{2}$ & & & \\
\hline T1 & 193,86 & 0,00 & 0,00 & 193,86 & 245,56 & 775,44 & & & \\
\hline T2 & 153,56 & 0,00 & 0,00 & 153,56 & 204,74 & 767,79 & & & \\
\hline T3 & 361,64 & 0,00 & 0,00 & 361,64 & 493,15 & $1.972,59$ & & & \\
\hline T4 & 126,64 & 0,00 & 0,00 & 126,64 & 177,30 & 759,84 & & & \\
\hline T5 & 396,28 & 0,00 & 0,00 & 396,28 & 528,38 & $1.981,41$ & & & \\
\hline T6 & 418,67 & 0,00 & 0,00 & 418,67 & 547,49 & $1.932,30$ & & & \\
\hline$T 7$ & 126,51 & 0,00 & 0,00 & 126,51 & 177,11 & 759,06 & & & \\
\hline T8 & 394,31 & 0,00 & 0,00 & 394,31 & 525,74 & $1.971,54$ & & & \\
\hline \multirow{4}{*}{ Trecho } & \multicolumn{9}{|c|}{ Pavimentação } \\
\hline & \multicolumn{3}{|c|}{ Volume } & \multicolumn{2}{|r|}{ Area } & \multicolumn{4}{|c|}{ Custos } \\
\hline & Macadame Hidáulico & Binder & $\begin{array}{l}\text { Concreto Asfáltico } \\
\text { Usinado a Quente }\end{array}$ & $\begin{array}{c}\text { Imprimação } \\
\text { Betuminosa } \\
\text { Ligante }\end{array}$ & $\begin{array}{c}\text { Imprimação } \\
\text { Betuminosa } \\
\text { Impermeabiliza } \\
\text { nte }\end{array}$ & Remoção & Recomposição & Transporte & TOTAL \\
\hline & $\mathrm{m}^{3}$ & $\mathrm{~m}^{3}$ & $\mathrm{~m}^{3}$ & $\mathrm{~m}^{2}$ & $\mathrm{~m}^{2}$ & $\mathrm{R} \$$ & $\mathrm{R} \$$ & $\mathrm{R} \$$ & $\mathrm{R} \$$ \\
\hline $\mathrm{T} 1$ & 29,08 & 24,56 & 38,77 & 245,56 & 775,44 & $1.570,75$ & $31.366,66$ & 421,35 & $33.358,76$ \\
\hline T2 & 23,03 & 20,47 & 38,39 & 204,74 & 767,79 & $1.244,20$ & $28.880,38$ & 391,65 & $30.516,23$ \\
\hline T3 & 54,25 & 49,31 & 98,63 & 493,15 & $1.972,59$ & $2.930,19$ & $72.334,64$ & 984,34 & $76.249,16$ \\
\hline $\mathrm{T} 4$ & 19,00 & 17,73 & 37,99 & 177,30 & 759,84 & $1.026,10$ & $27.145,14$ & $\begin{array}{l}370,74 \\
\end{array}$ & $28.541,98$ \\
\hline T5 & 59,44 & 52,84 & 99,07 & 528,38 & $1.981,41$ & $3.210,87$ & $74.530,63$ & $1.010,71$ & $78.752,20$ \\
\hline T6 & 62,80 & 54,75 & 96,62 & 547,49 & $1.932,30$ & $3.392,22$ & $74.509,52$ & $1.007,08$ & $78.908,82$ \\
\hline$T 7$ & 18,98 & $\frac{4,10}{17,71}$ & 37,95 & 177,11 & 759,06 & $\begin{array}{l}.025,04 \\
1.025,04\end{array}$ & $27.117,27$ & 370,36 & $28.512,68$ \\
\hline T8 & 59,15 & 52,57 & 98,58 & 525,74 & $1.971,54$ & $3.194,87$ & $74.159,37$ & $1.005,67$ & $78.359,92$ \\
\hline & & & & & Soma & $17.594,24$ & $\$ 410.043,61$ & $5.561,89$ & 433.199 \\
\hline
\end{tabular}




\section{APÊNDICE A7 - Planilha de Dimensionamento para Viário em Terra - PEAD}

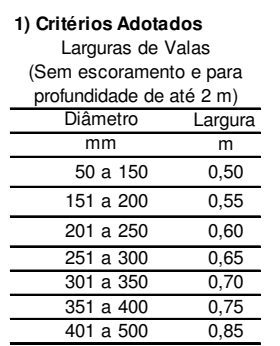

Locação das Redes

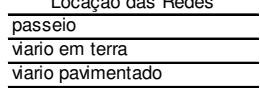

Recobrimento

\begin{tabular}{lc}
\hline \multicolumn{1}{c}{ Locação da } & Recobrimento \\
\cline { 2 - 2 } Tubulação & $\mathrm{m}$ \\
\hline passeio & 0,7 \\
\hline viario em terra & 1,2 \\
\hline viario pavimentado & 1,0 \\
\hline
\end{tabular}

\begin{tabular}{l}
\hline \multicolumn{1}{c}{ Tipo de Tráfegos para Viário } \\
\hline Leve \\
\hline Médio \\
\hline Pesado \\
\hline Tipos de Superfície \\
\hline asfalto \\
\hline parcreto \\
\hline terra
\end{tabular}

2) Dados Adotados

Tubulação

SDR

Rugosidade Equivalente $(\mathrm{m}) \quad 0,00002$

Fator entre Diâmetro Hidráulico e Comercial

Pressurização Inicial

\begin{tabular}{lr}
\hline Carga Inicial & 12,70 \\
\hline Rendimento Global & 0,70
\end{tabular}

\begin{tabular}{lc}
\hline Horas de Funcionamer & 0,70 \\
\hline Vida & $6570 \mathrm{~h} /$ ano \\
\hline
\end{tabular}

Vida Útil

1,05

Largura Adotadas para Reposição de Pavimentos Devido Abertura de
Valas $(\mathrm{m})$

Espessuras Adotadas para Reposição de Pavimentos Devido Abertura de Valas (m) Tráfego Binder $\begin{array}{rrr}0,04 & 0,07 & 0,10 \\ 0,04 & 0,05 & 0,05\end{array}$

\begin{tabular}{lll}
0,04 & 0,0 \\
\hline & 0,10 & 0,12
\end{tabular}

\begin{tabular}{|c|c|c|c|c|c|c|c|c|c|c|}
\hline \multicolumn{11}{|c|}{ Equações de Continuidade nos Nós } \\
\hline NólTubo & 1 & 2 & 3 & 4 & 5 & 6 & 7 & 8 & Qi & Soma Q \\
\hline & $-179,4$ & & & & & & & & 179,408 & 0 \\
\hline & 179,4 & $-60,1$ & & & & $-95,7$ & & & 23,591 & 0,01 \\
\hline & & 60,1 & & & & & & $-39,5$ & 20,637 & 0,01 \\
\hline & & & $-33,1$ & & & & 26,2 & 39,5 & 32,556 & 0,01 \\
\hline & & & 33,1 & 4,1 & & & & & 37,247 & 0,01 \\
\hline & & & & $-4,1$ & 38,8 & & & & 34,754 & 0,01 \\
\hline & & & & & $-38,8$ & 95,7 & $-26,2$ & & 30,623 & 0,01 \\
\hline
\end{tabular}

\begin{tabular}{cccccccccr}
\hline Equações de Perda de Carga nos Circuitos & & & & & \\
\hline Circuitos & 1 & 2 & 3 & 4 & 5 & 6 & 7 & 8 & Soma Perda \\
& & & & & & & & \\
1 & $-0,763$ & & & & 1,483 & 0,771 & $-1,491$ & 0,0001 \\
2 & & $-1,052$ & 0,372 & 1,450 & & $-0,771$ & & 0,0001 \\
\hline
\end{tabular}

Tabela da Função Objetivo

\begin{tabular}{|c|c|c|c|c|c|c|c|c|c|c|c|c|c|c|}
\hline \multirow{2}{*}{ Trecho } & \multicolumn{2}{|c|}{ Nó Montante } & \multicolumn{2}{|c|}{ No Jusante } & \multirow{2}{*}{$\begin{array}{c}\begin{array}{c}\text { Extensão } \\
\text { do Trecho }\end{array} \\
\text { (m) }\end{array}$} & \multirow{2}{*}{$\begin{array}{c}\begin{array}{c}\text { Vazão do } \\
\text { Trecho }\end{array} \\
\text { l/s } \\
\end{array}$} & \multirow{2}{*}{$\begin{array}{c}\begin{array}{c}\text { Diâmetro } \\
\text { Interno } \\
\text { Comercial }\end{array} \\
(\mathrm{mm}) \\
\end{array}$} & \multirow{2}{*}{$\begin{array}{c}\text { Diâmetro } \\
\text { Ótimo }\end{array}$} & \multirow{2}{*}{$\begin{array}{c}\text { Velocidade } \\
(\mathrm{m} / \mathrm{s})\end{array}$} & \multirow[t]{2}{*}{$\begin{array}{l}\text { Fator de } \\
\text { Atrito } f\end{array}$} & \multirow{2}{*}{$\begin{array}{c}\text { Perda de Carga } \\
(\mathrm{m})\end{array}$} & \multirow{2}{*}{$\begin{array}{c}\begin{array}{c}\text { Carga } \\
\text { Montante }\end{array} \\
(\mathrm{m}) \\
\end{array}$} & \multirow{2}{*}{$\begin{array}{c}\text { Carga Jusante } \\
(\mathrm{m})\end{array}$} & \multirow{2}{*}{$\begin{array}{c}\text { Potência Dissipada } \\
\mathrm{kW}\end{array}$} \\
\hline & Nome & Cota & Nome & Cota & & & & & & & & & & \\
\hline $\mathrm{T} 1$ & $\mathrm{~N} 1$ & 4,56 & N2 & 3,50 & 258,48 & 179,4 & 368 & 356 & 1,68 & 0,0063 & 0,64 & 12,70 & 13,13 & 1,61 \\
\hline T2 & N2 & 3,50 & N3 & 3,50 & 255,93 & 60,1 & 229 & 231 & 1,46 & 0,0063 & 0,76 & 13,13 & 12,36 & 0,64 \\
\hline T3 & $\mathrm{N} 4$ & 1,50 & N5 & 0,49 & 657,53 & 33,1 & 204 & 202 & 1,01 & 0,0063 & 1,05 & 12,87 & 12,83 & 0,49 \\
\hline T4 & N5 & 0,49 & N6 & 0,50 & 253,28 & 4,1 & 90 & 90 & 0,64 & 0,0063 & 0,37 & 12,83 & 12,45 & 0,02 \\
\hline T5 & N6 & 0,50 & N7 & 1,50 & 660,47 & 38,8 & 204 & 198 & 1,18 & 0,0063 & 1,45 & 12,45 & 10,00 & 0,79 \\
\hline T6 & N2 & 3,50 & N7 & 1,50 & 644,10 & 95,7 & 290 & 285 & 1,44 & 0,0063 & 1,48 & 13,13 & 13,64 & 1,99 \\
\hline 77 & N7 & 1,50 & $\mathrm{~N} 4$ & 1,50 & 253,02 & 26,2 & 164 & 160 & 1,24 & 0,0063 & 0,77 & 13,64 & 12,87 & 0,28 \\
\hline T8 & N3 & 3,50 & $\mathrm{~N} 4$ & 1,50 & 657,18 & 39,5 & 204 & 206 & 1,20 & 0,0063 & 1,49 & 13,13 & 13,64 & 0,82 \\
\hline
\end{tabular}

4) Resumo do Dimensionamento Otimizado

\begin{tabular}{|c|c|c|c|}
\hline \multicolumn{3}{|c|}{ Potência Dissipada } & Pressurização Inicial \\
\hline Soma & & 6,64 & 31,91 \\
\hline Energia & & $43.628,19$ & $209.646,26$ \\
\hline $\mathrm{FA}$ & & 10,60 & 10,60 \\
\hline Sub-Total & $\mathrm{R} \$$ & $76.833,84$ & $369.209,12$ \\
\hline
\end{tabular}

\begin{tabular}{|c|c|c|}
\hline Custos & & Porcentagem \\
\hline Custo de Tubulação $\mathrm{R} \$$ & $730.937,65$ & $57,78 \%$ \\
\hline Custo de Movimento de Terra $R \$$ & $77.849,20$ & $6,15 \%$ \\
\hline Custo de Assentamento $\mathrm{R} \$$ & $10.108,56$ & $0,80 \%$ \\
\hline Custo de Pavimentação $\mathrm{R} \$$ & - & $0,00 \%$ \\
\hline Custo da Pressurização Inicial $R \$$ & $369.209,12$ & $29,19 \%$ \\
\hline Custo da Potência Dissipada $R \$$ & $76.833,84$ & $6,07 \%$ \\
\hline Total Global (Função Objetivo) R\$ & $1.264 .938,37$ & $100,00 \%$ \\
\hline Total Referencial Unitário R\$ & 347,51 & por metro de rede \\
\hline
\end{tabular}


5) Quantitativos e Custos de Implantação das Redes de Abastecimento

\begin{tabular}{|c|c|c|c|c|c|c|c|c|c|c|}
\hline Trecho & $\begin{array}{l}\text { Locação da } \\
\text { Tubulação }\end{array}$ & Tipo de Superfície & $\begin{array}{l}\text { Tipo de } \\
\text { Tráfego }\end{array}$ & & & & & & & \\
\hline $\mathrm{T} 1$ & viario em terra & terra & - & & & & & & & \\
\hline $\mathrm{T} 2$ & viario em terra & terra & - & & & & & & & \\
\hline T3 & viario em terra & terra & - & & & & & & & \\
\hline T4 & viario em terra & terra & - & & & & & & & \\
\hline $\mathrm{T5}$ & viario em terra & terra & - & & & & & & & \\
\hline T6 & viario em terra & terra & - & & & & & & & \\
\hline 77 & viario em terra & terra & - & & & & & & & \\
\hline T8 & viario em terra & terra & - & & & & & & & \\
\hline \multirow{3}{*}{ Trecho } & \multicolumn{6}{|c|}{ Vala } & \multicolumn{4}{|c|}{ Tubulação } \\
\hline & Largura & Profundidade & Escavação & Reaterro & Bota-Fora & TOTAL & Assentamento & Material & & TOTAL \\
\hline & $\mathrm{m}$ & $\mathrm{m}$ & $\mathrm{m}^{3}$ & $\mathrm{~m}^{3}$ & $\mathrm{~m}^{3}$ & $\mathrm{R} \$$ & $\mathrm{R} \$$ & $\mathrm{R} \$$ & & $\mathrm{R} \$$ \\
\hline $\mathrm{T} 1$ & 0,75 & 1,57 & 303,97 & 276,48 & 27,49 & $7.348,43$ & $1.202,59$ & $131.379,21$ & & $132.581,79$ \\
\hline T2 & 0,60 & 1,43 & 219,43 & 208,89 & 10,54 & $5.397,90$ & 717,98 & $50.579,92$ & & $51.297,90$ \\
\hline T3 & 0,60 & 1,40 & 554,06 & 532,49 & 21,58 & $13.679,88$ & $1.663,02$ & $103.631,11$ & & $105.294,13$ \\
\hline T4 & 0,50 & 1,29 & 163,37 & 161,75 & 1,61 & $4.081,08$ & 366,02 & $7.794,35$ & & $8.160,37$ \\
\hline T5 & 0,60 & 1,40 & 556,54 & 534,87 & 21,67 & $13.741,04$ & $1.670,45$ & $104.094,47$ & & $105.764,93$ \\
\hline T6 & 0,65 & 1,49 & 623,98 & 581,32 & 42,66 & $15.222,33$ & $2.293,82$ & $204.286,73$ & & $206.580,55$ \\
\hline$T 7$ & 0,55 & 1,36 & 189,76 & 184,44 & 5,32 & $4.705,94$ & 532,54 & $25.595,92$ & & $26.128,46$ \\
\hline \multirow[t]{2}{*}{ T8 } & 0,60 & 1,40 & 553,77 & 532,20 & 21,56 & $13.672,60$ & $1.662,13$ & $103.575,95$ & & $105.238,08$ \\
\hline & & & & & Soma & $77.849,20$ & $\begin{array}{ll}\mathrm{R} \$ & 10.108,56\end{array}$ & $R \$ 730.937,65$ & $\mathrm{R} \$$ & $741.046,21$ \\
\hline \multicolumn{7}{|c|}{ Pavimentação } & & & & \\
\hline \multirow{3}{*}{ Trecho } & \multicolumn{6}{|c|}{ Vala } & & & & \\
\hline & Área & Área de Concreto & $\begin{array}{c}\text { Area de } \\
\text { Paralelepiped } \\
\text { os }\end{array}$ & $\begin{array}{l}\text { Área de } \\
\text { Asfalto }\end{array}$ & Área de Binder & $\begin{array}{l}\text { Área de Concreto Asfático } \\
\text { Usinado a Quente }\end{array}$ & & & & \\
\hline & $\mathrm{m}^{2}$ & $\mathrm{~m}^{2}$ & $\mathrm{~m}^{2}$ & $\mathrm{~m}^{2}$ & $\mathrm{~m}^{2}$ & $\mathrm{~m}^{2}$ & & & & \\
\hline $\mathrm{T} 1$ & 193,86 & 0,00 & 0,00 & 0,00 & 0,00 & 0,00 & & & & \\
\hline T2 & 153,56 & 0,00 & 0,00 & 0,00 & 0,00 & 0,00 & & & & \\
\hline T3 & 394,52 & 0,00 & 0,00 & 0,00 & 0,00 & 0,00 & & & & \\
\hline T4 & 126,64 & 0,00 & 0,00 & 0,00 & 0,00 & 0,00 & & & & \\
\hline T5 & 396,28 & 0,00 & 0,00 & 0,00 & 0,00 & 0,00 & & & & \\
\hline T6 & 418,67 & 0,00 & 0,00 & 0,00 & 0,00 & 0,00 & & & & \\
\hline$T 7$ & 139,16 & 0,00 & 0,00 & 0,00 & 0,00 & 0,00 & & & & \\
\hline $\mathrm{T} 8$ & 394,31 & 0,00 & 0,00 & 0,00 & 0,00 & 0,00 & & & & \\
\hline \multirow{4}{*}{ Trecho } & \multicolumn{10}{|c|}{ Pavimentação } \\
\hline & \multicolumn{3}{|c|}{ Volume } & \multicolumn{2}{|r|}{ Area } & \multicolumn{5}{|c|}{ Custos } \\
\hline & Macadame Hidálico & Binder & $\begin{array}{c}\text { Concreto } \\
\text { Astáltico } \\
\text { Usinado a } \\
\text { Quente }\end{array}$ & $\begin{array}{l}\text { Imprimação } \\
\text { Betuminosa } \\
\text { Ligante }\end{array}$ & $\begin{array}{c}\text { Imprimação } \\
\text { Betuminosa } \\
\text { Impermeabiliza } \\
\text { nte }\end{array}$ & Remoção & Recomposição & Transporte & & TOTAL \\
\hline & $\mathrm{m}^{3}$ & $\mathrm{~m}^{3}$ & $\mathrm{~m}^{3}$ & $\mathrm{~m}^{2}$ & $\mathrm{~m}^{2}$ & $\mathrm{R} \$$ & $\mathrm{R} \$$ & $\mathrm{R} \$$ & & $\mathbf{R} \$$ \\
\hline $\mathrm{T} 1$ & 0,00 & 0,00 & 0,00 & 0,00 & 0,00 & 0,00 & 0,00 & 0,00 & & 0,00 \\
\hline $\mathrm{T} 2$ & 0,00 & 0,00 & 0,00 & 0,00 & 0,00 & 0,00 & 0,00 & 0,00 & & 0,00 \\
\hline T3 & 0,00 & 0,00 & 0,00 & 0,00 & 0,00 & 0,00 & 0,00 & 0,00 & & 0,00 \\
\hline $\mathrm{T} 4$ & 0,00 & 0,00 & 0,00 & 0,00 & 0,00 & 0,00 & 0,00 & 0,00 & & 0,00 \\
\hline T5 & 0,00 & 0,00 & 0,00 & 0,00 & 0,00 & 0,00 & 0,00 & 0,00 & & 0,00 \\
\hline T6 & 0,00 & 0,00 & 0,00 & 0,00 & 0,00 & 0,00 & 0,00 & 0,00 & & 0,00 \\
\hline 77 & 0,00 & 0,00 & 0,00 & 0,00 & 0,00 & 0,00 & 0,00 & 0,00 & & 0,00 \\
\hline T8 & 0,00 & 0,00 & 0,00 & 0,00 & 0,00 & 0,00 & 0,00 & 0,00 & & 0,00 \\
\hline
\end{tabular}




\section{APÊNDICE A8 - Planilha de Dimensionamento para Passeio em Concreto - PEAD}

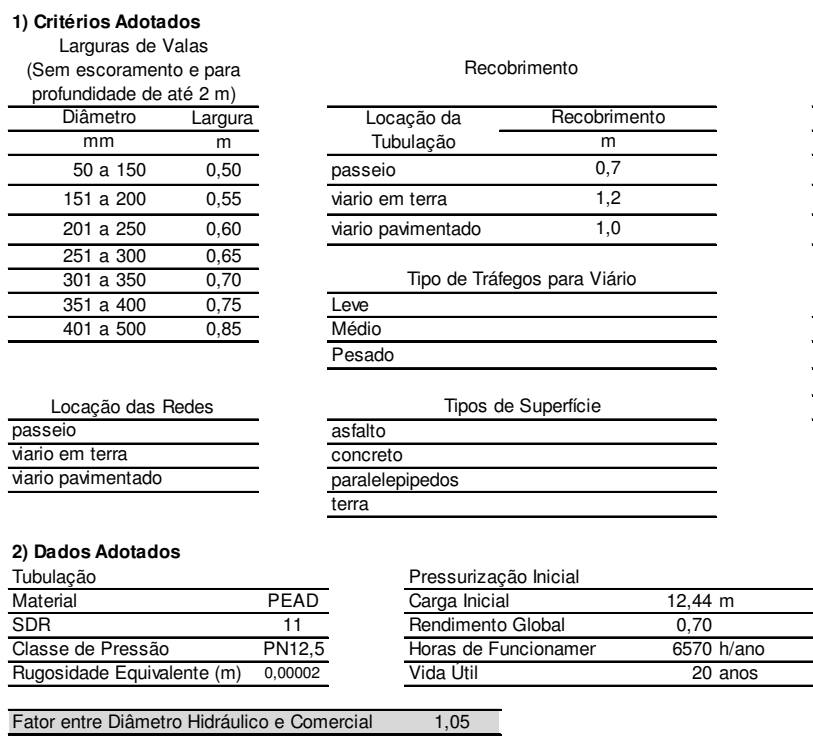

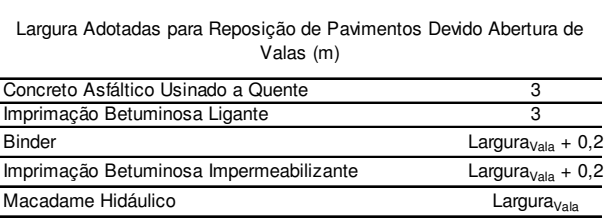

Espessuras Adotadas para Reposição de Pavimentos Devido Abertura de Valas (m)

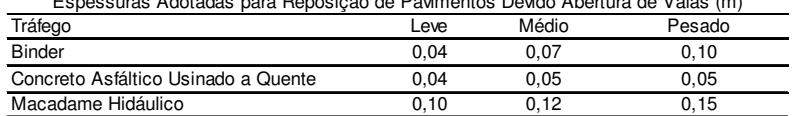

Energia
\begin{tabular}{lc}
\hline Grupo A (Alta e Média Tensão) \\
\hline Sub-Grupo A4 (2,3 KV a 25 KV) \\
\hline Custo de Energia por Demanda & $31,31 \mathrm{R} \$ / \mathrm{kW}$ \\
\hline Custo de Energia por Consumo & $0,16132 \mathrm{R} \$ / \mathrm{KWh}$ \\
\hline Taxa de Juros & $8,00 \% \mathrm{aa}$ \\
\hline Fator de Atualização & 10,60 \\
\hline
\end{tabular}

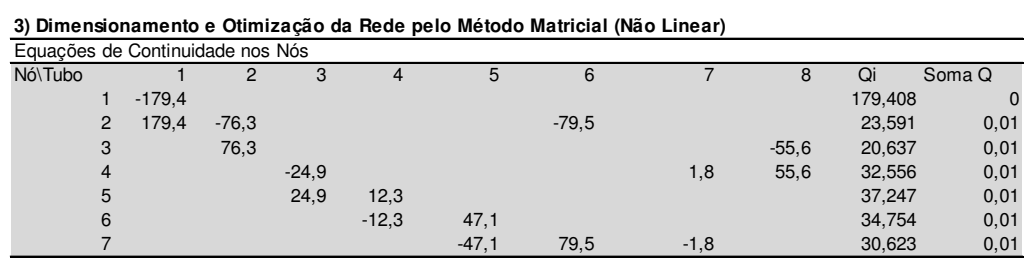

\begin{tabular}{cccccccccr}
\hline Equações de Perda de Carga nos Circuitos & & & & & \\
\hline Circuitos & 1 & 2 & 3 & 4 & 5 & 6 & 7 & 8 & Soma Perda \\
1 & $-0,682$ & & & & 1,865 & 0,495 & $-1,678$ & 0,0001 \\
2 & & & & & & & & \\
& & $-1,003$ & 0,290 & 1,208 & & $-0,495$ & & 0,0001 \\
\hline
\end{tabular}

Tabela da Função Objetivo

\begin{tabular}{|c|c|c|c|c|c|c|c|c|c|c|c|c|c|c|}
\hline \multirow{2}{*}{ Trecho } & \multicolumn{2}{|c|}{ Nó Montante } & \multicolumn{2}{|c|}{ No Jusante } & \multirow{2}{*}{$\begin{array}{r}\begin{array}{r}\text { Extensão } \\
\text { do Trecho }\end{array} \\
\text { (m) }\end{array}$} & \multirow{2}{*}{$\begin{array}{c}\begin{array}{c}\text { Vazão do } \\
\text { Trecho }\end{array} \\
\text { I/s } \\
\end{array}$} & \multirow{2}{*}{$\begin{array}{c}\begin{array}{c}\text { Diâmetro } \\
\text { Interno } \\
\text { Comercial }\end{array} \\
(\mathrm{mm}) \\
\end{array}$} & \multirow{2}{*}{$\begin{array}{c}\begin{array}{c}\text { Diâmetro } \\
\text { Ótimo }\end{array} \\
(\mathrm{mm}) \\
\end{array}$} & \multirow{2}{*}{$\begin{array}{c}\text { Velocidade } \\
(\mathrm{m} / \mathrm{s})\end{array}$} & \multirow[t]{2}{*}{$\begin{array}{l}\text { Fator de } \\
\text { Atrito } f\end{array}$} & \multirow{2}{*}{$\begin{array}{c}\text { Perda de Carga } \\
(\mathrm{m})\end{array}$} & \multirow{2}{*}{$\begin{array}{c}\begin{array}{c}\text { Carga } \\
\text { Montante }\end{array} \\
(\mathrm{m}) \\
\end{array}$} & \multirow{2}{*}{$\begin{array}{c}\text { Carga Jusante } \\
(\mathrm{m})\end{array}$} & \multirow{2}{*}{$\begin{array}{c}\text { Potência Dissipada } \\
\mathrm{kW}\end{array}$} \\
\hline & Nome & Cota & Nome & Cota & & & & & & & & & & \\
\hline $\mathrm{T} 1$ & $\mathrm{~N} 1$ & 4,56 & N2 & 3,50 & 258,48 & 179,4 & 368 & 350 & 1,68 & 0,0063 & 0,64 & 12,44 & 12,86 & 1,61 \\
\hline T2 & N2 & 3,50 & N3 & 3,50 & 255,93 & 76,3 & 258 & 251 & 1,46 & 0,0063 & 0,68 & 12,86 & 12,18 & 0,73 \\
\hline T3 & $\mathrm{N} 4$ & 1,50 & N5 & 0,49 & 657,53 & 24,9 & 184 & 184 & 0,93 & 0,0063 & 1,00 & 12,50 & 12,50 & 0,35 \\
\hline T4 & N5 & 0,49 & N6 & 0,50 & 253,28 & 12,3 & 147 & 140 & 0,72 & 0,0063 & 0,29 & 12,50 & 12,21 & 0,05 \\
\hline T5 & N6 & 0,50 & N7 & 1,50 & 660,47 & 47,1 & 229 & 215 & 1,14 & 0,0063 & 1,21 & 12,21 & 10,00 & 0,80 \\
\hline T6 & N2 & 3,50 & N7 & 1,50 & 644,10 & 79,5 & 258 & 250 & 1,52 & 0,0063 & 1,86 & 12,86 & 13,00 & 2,08 \\
\hline 77 & N7 & 1,50 & $\mathrm{~N} 4$ & 1,50 & 253,02 & 1,8 & 61 & 60 & 0,61 & 0,0063 & 0,49 & 13,00 & 12,50 & 0,01 \\
\hline T8 & N3 & 3,50 & $\mathrm{~N} 4$ & 1,50 & 657,18 & 55,6 & 229 & 225 & 1,35 & 0,0063 & 1,68 & 12,86 & 13,18 & 1,31 \\
\hline
\end{tabular}

4) Resumo do Dimensionamento Otimizado

\begin{tabular}{|c|c|c|}
\hline & Potência Dissipada & Pressurização Inicial \\
\hline Soma & 6,93 & 31,24 \\
\hline Energia & $45.512,08$ & $205.241,93$ \\
\hline $\mathrm{FA}$ & 10,60 & 10,60 \\
\hline Sub-Total & $80.151,56$ & $361.452,64$ \\
\hline
\end{tabular}

\begin{tabular}{|c|c|c|}
\hline Custos & & Porcentagem \\
\hline Custo de Tubulação $R \$$ & $725.066,87$ & $55,44 \%$ \\
\hline Custo de Movimento de Terra $\mathrm{R} \$$ & $49.273,28$ & $3,77 \%$ \\
\hline Custo de Assentamento $\mathrm{R} \$$ & $10.052,92$ & $0,77 \%$ \\
\hline Custo de Pavimentação $\mathrm{R} \$$ & $81.858,05$ & $6,26 \%$ \\
\hline Custo da Pressurização Inicial $R \$$ & $361.452,64$ & $27,64 \%$ \\
\hline Custo da Potência Dissipada $R \$$ & $80.151,56$ & $6,13 \%$ \\
\hline Total Global (Função Objetivo) R\$ & $1.307 .855,33$ & $100,00 \%$ \\
\hline Total Referencial Unitário $\mathbf{R} \$$ & 359,30 & por metro de rede \\
\hline
\end{tabular}


5) Quantitativos e Custos de Implantação das Redes de Abastecimento

\begin{tabular}{|c|c|c|c|c|c|c|c|c|c|}
\hline Trecho & $\begin{array}{l}\text { Locação da } \\
\text { Tubulação }\end{array}$ & Tipo de Superfície & $\begin{array}{l}\text { Tipo de } \\
\text { Tráfego }\end{array}$ & & & & & & \\
\hline $\mathrm{T} 1$ & passeio & concreto & - & & & & & & \\
\hline $\mathrm{T} 2$ & passeio & concreto & - & & & & & & \\
\hline T3 & passeio & concreto & - & & & & & & \\
\hline T4 & passeio & concreto & - & & & & & & \\
\hline$T 5$ & passeio & concreto & - & & & & & & \\
\hline T6 & passeio & concreto & - & & & & & & \\
\hline 77 & passeio & concreto & - & & & & & & \\
\hline $\mathrm{T} 8$ & passeio & concreto & - & & & & & & \\
\hline \multirow{3}{*}{ Trecho } & \multicolumn{6}{|c|}{ Vala } & \multicolumn{3}{|c|}{ Tubulação } \\
\hline & Largura & Profundidade & Escavação & Reaterro & Bota-Fora & TOTAL & Assentamento & Material & TOTAL \\
\hline & $\mathrm{m}$ & $\mathrm{m}$ & $\mathrm{m}^{3}$ & $\mathrm{~m}^{3}$ & $\mathrm{~m}^{3}$ & $\mathrm{R} \$$ & $\mathrm{R} \$$ & $\mathrm{R} \$$ & $\mathbf{R} \$$ \\
\hline $\mathrm{T} 1$ & 0,75 & 1,07 & 207,04 & 179,55 & 27,49 & $4.917,43$ & $1.202,59$ & $131.379,21$ & $132.581,79$ \\
\hline $\mathrm{T} 2$ & 0,65 & 0,96 & 159,30 & 145,96 & 13,34 & $3.861,75$ & 805,07 & $63.937,67$ & $64.742,74$ \\
\hline T3 & 0,55 & 0,88 & 319,69 & 302,21 & 17,48 & $7.842,84$ & $1.520,02$ & $84.054,12$ & $85.574,14$ \\
\hline $\mathrm{T} 4$ & 0,50 & 0,85 & 107,29 & 102,98 & 4,31 & $2.647,67$ & 492,87 & $20.761,68$ & $21.254,55$ \\
\hline$T 5$ & 0,60 & 0,93 & 368,15 & 340,94 & 27,20 & $8.960,80$ & $1.852,87$ & $130.529,90$ & $132.382,77$ \\
\hline T6 & 0,65 & 0,96 & 400,91 & 367,34 & 33,57 & $9.718,89$ & $2.026,12$ & $160.912,17$ & $162.938,29$ \\
\hline$T 7$ & 0,50 & 0,76 & 96,30 & 95,56 & 0,74 & $2.407,74$ & 309,74 & $3.612,44$ & $3.922,18$ \\
\hline \multirow[t]{2}{*}{$\mathrm{T} 8$} & 0,60 & 0,93 & 366,31 & 339,24 & 27,07 & $8.916,16$ & $1.843,64$ & $129.879,69$ & $131.723,33$ \\
\hline & & & & & Soma & $49.273,28$ & $\begin{array}{ll}R \$ 10.052,92 \\
\end{array}$ & $\mathrm{R} \$ 725.066,87 \quad \mathbf{R} \$$ & $735.119,79$ \\
\hline \multirow{2}{*}{\multicolumn{7}{|c|}{$\frac{\text { Pavimentação }}{\text { Vala }}$}} & & & \\
\hline & & & & ala & & & & & \\
\hline \multirow[t]{2}{*}{ Trecho } & Área & Área de Concreto & $\begin{array}{c}\text { Area de } \\
\text { Paralelepiped } \\
\text { os }\end{array}$ & $\begin{array}{l}\text { Área de } \\
\text { Asfalto }\end{array}$ & Área de Binder & $\begin{array}{l}\text { Área de Concreto Astático } \\
\text { Usinado a Quente }\end{array}$ & & & \\
\hline & $\mathrm{m}^{2}$ & $\mathrm{~m}^{2}$ & $\mathrm{~m}^{2}$ & $\mathrm{~m}^{2}$ & $\mathrm{~m}^{2}$ & $\mathrm{~m}^{2}$ & & & \\
\hline $\mathrm{T} 1$ & 193,86 & 193,86 & 0,00 & 0,00 & 0,00 & 0,00 & & & \\
\hline $\mathrm{T} 2$ & 166,35 & 166,35 & 0,00 & 0,00 & 0,00 & 0,00 & & & \\
\hline T3 & 361,64 & 361,64 & 0,00 & 0,00 & 0,00 & 0,00 & & & \\
\hline $\mathrm{T} 4$ & 126,64 & 126,64 & 0,00 & 0,00 & 0,00 & 0,00 & & & \\
\hline$T 5$ & 396,28 & 396,28 & 0,00 & 0,00 & 0,00 & 0,00 & & & \\
\hline T6 & 418,67 & 418,67 & 0,00 & 0,00 & 0,00 & 0,00 & & & \\
\hline$T 7$ & 126,51 & 126,51 & 0,00 & 0,00 & 0,00 & 0,00 & & & \\
\hline T8 & 394,31 & 394,31 & 0,00 & 0,00 & 0,00 & 0,00 & & & \\
\hline \multirow{4}{*}{ Trecho } & \multicolumn{9}{|c|}{ Pavimentação } \\
\hline & \multicolumn{3}{|c|}{ Volume } & \multicolumn{2}{|r|}{ Área } & \multicolumn{4}{|c|}{ Custos } \\
\hline & Macadame Hidáulico & Binder & $\begin{array}{l}\text { Concreto } \\
\text { Asfáltico } \\
\text { Usinado a } \\
\text { Quente }\end{array}$ & $\begin{array}{l}\text { Imprimação } \\
\text { Betuminosa } \\
\text { Ligante }\end{array}$ & $\begin{array}{c}\text { Imprimação } \\
\text { Betuminosa } \\
\text { Impermeabiliza } \\
\text { nte }\end{array}$ & Remoção & Recomposição & Transporte & TOTAL \\
\hline & $\mathrm{m}^{3}$ & $\mathrm{~m}^{3}$ & $\mathrm{~m}^{3}$ & $\mathrm{~m}^{2}$ & $\mathrm{~m}^{2}$ & $\mathrm{R} \$$ & $\mathrm{R} \$$ & $\mathrm{R} \$$ & $\mathbf{R} \$$ \\
\hline $\mathrm{T} 1$ & 0,00 & 0,00 & 0,00 & 0,00 & 0,00 & $1.802,20$ & $4.784,44$ & 678,51 & $7.265,16$ \\
\hline $\mathrm{T} 2$ & 0,00 & 0,00 & 0,00 & 0,00 & 0,00 & $1.546,50$ & $4.105,61$ & 582,24 & $6.234,35$ \\
\hline T3 & 0,00 & 0,00 & 0,00 & 0,00 & 0,00 & $3.361,97$ & $8.925,28$ & $1.265,75$ & $13.552,99$ \\
\hline T4 & 0,00 & 0,00 & 0,00 & 0,00 & 0,00 & $1.177,30$ & $3.125,46$ & 443,24 & $4.746,00$ \\
\hline T5 & 0,00 & 0,00 & 0,00 & 0,00 & 0,00 & $3.684,00$ & $9.780,20$ & $1.386,99$ & $14.851,19$ \\
\hline T6 & 0,00 & 0,00 & 0,00 & 0,00 & 0,00 & $3.892,08$ & $10.332,61$ & $1.465,33$ & $15.690,02$ \\
\hline 77 & 0,00 & 0,00 & 0,00 & 0,00 & 0,00 & $1.176,09$ & $3.122,25$ & 442,79 & $4.741,13$ \\
\hline T8 & 0,00 & 0,00 & 0,00 & 0,00 & 0,00 & $3.665,65$ & $9.731,48$ & $1.380,08$ & $14.777,21$ \\
\hline & & & & & Soma & 20. & $53.907,34$ & $7.644,91$ & 81.85 \\
\hline
\end{tabular}




\section{APÊNDICE A9 - Planilha de Dimensionamento para Viário em Paralelepípedo - PEAD}

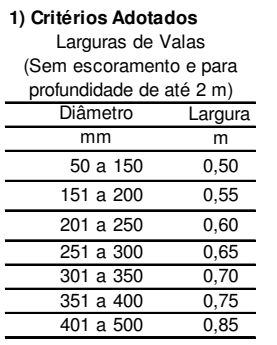

Locação das Redes

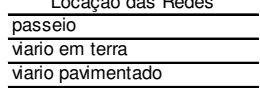

Recobrimento

\begin{tabular}{lc}
\hline \multicolumn{1}{c}{ Locação da } & Recobrimento \\
\cline { 2 - 2 } Tubulação & $\mathrm{m}$ \\
\hline passeio & 0,7 \\
\hline viario em terra & 1,2 \\
\hline viario pavimentado & 1,0 \\
\hline
\end{tabular}

\begin{tabular}{l}
\hline \multicolumn{1}{c}{ Tipo de Tráfegos para Viário } \\
\hline Leve \\
\hline Médio \\
\hline Pesado \\
\hline Tipos de Superfície \\
\hline asfalto \\
\hline parcreto \\
\hline terra
\end{tabular}

2) Dados Adotados

Tubulação

Material

SDR

\begin{tabular}{ll}
\hline Rugosidade Equivalente $(\mathrm{m})$ & 0,00002 \\
\hline
\end{tabular}

Fator entre Diâmetro Hidráulico e Comercia
Pressurização Inicial

\begin{tabular}{lr}
\hline Carga Inicial & 11,77 \\
\hline Rendimento Global & 0,70
\end{tabular}

\begin{tabular}{lc}
\hline Horas de Funcionamer & 0,70 \\
\hline Vida & $6570 \mathrm{~h} / \mathrm{ano}$ \\
\hline
\end{tabular}

Vida Útil

1,05

Largura Adotadas para Reposição de Pavimentos Devido Abertura de
Valas $(\mathrm{m})$

Espessuras Adotadas para Reposição de Pavimentos Devido Abertura de Valas $(\mathrm{m})$ Tráfego Binder $\begin{array}{rrr}0,04 & 0,07 & 0,10 \\ 0,04 & 0,05 & 0,05\end{array}$

Macadame Hidáulico $\quad 0,04 \quad 0,05$

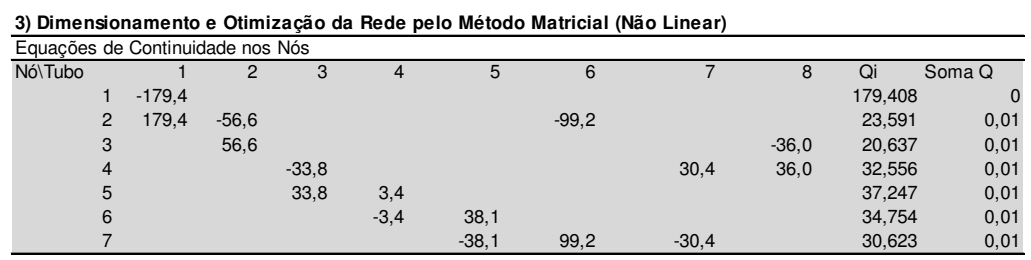

\begin{tabular}{cccccccccr}
\hline Equações de Perda de Carga nos Circuitos & & & & & & \\
\hline Circuitos & 1 & 2 & 3 & 4 & 5 & 6 & 7 & 8 & Soma Perda \\
& & & & & & & & \\
1 & $-0,677$ & & & & 0,877 & 1,037 & $-1,238$ & $1 \mathrm{E}-04$ \\
2 & & $-0,621$ & 0,258 & 1,399 & & $-1,037$ & & 0,0001 \\
\hline
\end{tabular}

Tabela da Função Objetivo

\begin{tabular}{|c|c|c|c|c|c|c|c|c|c|c|c|c|c|c|}
\hline \multirow{2}{*}{ Trecho } & \multicolumn{2}{|c|}{ Nó Montante } & \multicolumn{2}{|c|}{ No Jusante } & \multirow{2}{*}{$\begin{array}{l}\begin{array}{l}\text { Extensão } \\
\text { do Trecho }\end{array} \\
\text { (m) }\end{array}$} & \multirow{2}{*}{$\begin{array}{c}\begin{array}{c}\text { Vazão do } \\
\text { Trecho }\end{array} \\
\text { l/s }\end{array}$} & \multirow{2}{*}{$\begin{array}{c}\text { Diâmetro } \\
\text { Interno } \\
\text { Comercial }\end{array}$} & \multirow{2}{*}{$\begin{array}{c}\begin{array}{c}\text { Diâmetro } \\
\text { Ótimo }\end{array} \\
(\mathrm{mm})\end{array}$} & \multirow{2}{*}{$\begin{array}{c}\text { Velocidade } \\
(\mathrm{m} / \mathrm{s})\end{array}$} & \multirow[t]{2}{*}{$\begin{array}{l}\text { Fator de } \\
\text { Atrito } f\end{array}$} & \multirow{2}{*}{$\begin{array}{c}\text { Perda de Carga } \\
(\mathrm{m})\end{array}$} & \multirow{2}{*}{$\begin{array}{c}\begin{array}{c}\text { Carga } \\
\text { Montante }\end{array} \\
(\mathrm{m})\end{array}$} & \multirow{2}{*}{$\begin{array}{l}\text { Carga Jusante } \\
(\mathrm{m})\end{array}$} & \multirow{2}{*}{$\begin{array}{c}\text { Potência Dissipada } \\
\mathrm{kW}\end{array}$} \\
\hline & Nome & Cota & Nome & Cota & & & & & & & & & & \\
\hline T1 & $\mathrm{N} 1$ & 4,56 & N2 & 3,50 & 258,48 & 179,4 & 368 & 350 & 1,68 & 0,0063 & 0,64 & 11,77 & 12,19 & 1,61 \\
\hline $\mathrm{T} 2$ & N2 & 3,50 & N3 & 3,50 & 255,93 & 56,6 & 229 & 220 & 1,37 & 0,0063 & 0,68 & 12,19 & 11,52 & 0,54 \\
\hline T3 & $\mathrm{N} 4$ & 1,50 & N5 & 0,49 & 657,53 & 33,8 & 229 & 217 & 0,82 & 0,0063 & 0,62 & 12,28 & 12,66 & 0,29 \\
\hline T4 & N5 & 0,49 & N6 & 0,50 & 253,28 & 3,4 & 90 & 80 & 0,53 & 0,0063 & 0,26 & 12,66 & 12,40 & 0,01 \\
\hline T5 & N6 & 0,50 & N7 & 1,50 & 660,47 & 38,1 & 204 & 208 & 1,16 & 0,0063 & 1,40 & 12,40 & 10,00 & 0,75 \\
\hline T6 & N2 & 3,50 & N7 & 1,50 & 644,10 & 99,2 & 327 & 307 & 1,18 & 0,0063 & 0,88 & 12,19 & 13,31 & 1,22 \\
\hline T7 & N7 & 1,50 & $\mathrm{~N} 4$ & 1,50 & 253,02 & 30,4 & 164 & 166 & 1,44 & 0,0063 & 1,04 & 13,31 & 12,28 & 0,44 \\
\hline T8 & N3 & 3,50 & $\mathrm{~N} 4$ & 1,50 & 657,18 & 36,0 & 204 & 211 & 1,09 & 0,0063 & 1,24 & 12,19 & 12,95 & 0,62 \\
\hline
\end{tabular}

4) Resumo do Dimensionamento Otimizado

\begin{tabular}{|c|c|c|c|}
\hline & \multicolumn{2}{|c|}{ Potência Dissipada } & Pressurização Inicial \\
\hline Soma & & 5,48 & 29,56 \\
\hline Energia & & $36.008,49$ & $194.213,04$ \\
\hline$F A$ & & 10,60 & 10,60 \\
\hline Sub-Total & $\mathbf{R} \$$ & $63.414,73$ & $342.029,60$ \\
\hline
\end{tabular}

\begin{tabular}{|c|c|c|}
\hline Custos & & Porcentagem \\
\hline Custo de Tubulação $R \$$ & $812.043,60$ & $60,13 \%$ \\
\hline Custo de Movimento de Terra $\mathrm{R} \$$ & $68.260,36$ & $5,05 \%$ \\
\hline Custo de Assentamento $\mathrm{R} \$$ & $10.611,30$ & $0,79 \%$ \\
\hline Custo de Pavimentação $\mathrm{R} \$$ & $54.213,15$ & $4,01 \%$ \\
\hline Custo da Pressurização Inicial $\mathrm{R} \$$ & $342.029,60$ & $25,32 \%$ \\
\hline Custo da Potência Dissipada $R \$$ & $63.414,73$ & $4,70 \%$ \\
\hline Total Global (Função Objetivo) R\$ & $1.350 .572,74$ & $100,00 \%$ \\
\hline Total Referencial Unitário R\$ & 371,04 & por metro de rede \\
\hline
\end{tabular}


5) Quantitativos e Custos de Implantação das Redes de Abastecimento

\begin{tabular}{|c|c|c|c|c|c|c|c|c|c|c|}
\hline Trecho & $\begin{array}{l}\text { Locação da } \\
\text { Tubulação }\end{array}$ & Tipo de Superfície & $\begin{array}{l}\text { Tipo de } \\
\text { Tráfego }\end{array}$ & & & & & & & \\
\hline $\mathrm{T} 1$ & viario pavimentado & paralelepipedos & - & & & & & & & \\
\hline $\mathrm{T} 2$ & vario pavimentado & paralelepipedos & - & & & & & & & \\
\hline T3 & viario pavimentado & paralelepipedos & - & & & & & & & \\
\hline T4 & viario pavimentado & paralelepipedos & - & & & & & & & \\
\hline T5 & viario pavimentado & paralelepipedos & - & & & & & & & \\
\hline T6 & vario pavimentado & paralelepipedos & - & & & & & & & \\
\hline$T 7$ & viario pavimentado & paralelepipedos & - & & & & & & & \\
\hline T8 & viario pavimentado & paralelepipedos & - & & & & & & & \\
\hline \multirow{3}{*}{ Trecho } & \multicolumn{6}{|c|}{ Vala } & \multicolumn{4}{|c|}{ Tubulação } \\
\hline & Largura & Profundidade & Escavação & Reaterro & Bota-Fora & TOTAL & Assentamento & Material & & TOTAL \\
\hline & $\mathrm{m}$ & $\mathrm{m}$ & $\mathrm{m}^{3}$ & $\mathrm{~m}^{3}$ & $\mathrm{~m}^{3}$ & $\mathrm{R} \$$ & $\mathrm{R} \$$ & $\mathrm{R} \$$ & & $\mathrm{R} \$$ \\
\hline $\mathrm{T} 1$ & 0,75 & 1,37 & 265,20 & 237,71 & 27,49 & $6.376,03$ & $1.202,59$ & $131.379,21$ & & $132.581,79$ \\
\hline $\mathrm{T} 2$ & 0,60 & 1,23 & 188,72 & 178,18 & 10,54 & $4.627,65$ & 717,98 & $50.579,92$ & & $51.297,90$ \\
\hline T3 & 0,60 & 1,23 & 484,86 & 457,78 & 27,08 & $11.889,27$ & $1.844,62$ & $129.948,86$ & & $131.793,48$ \\
\hline T4 & 0,50 & 1,09 & 138,04 & 136,43 & 1,61 & $3.445,85$ & 366,02 & $7.794,35$ & & $8.160,37$ \\
\hline T5 & 0,60 & 1,20 & 477,28 & 455,61 & 21,67 & $11.753,29$ & $1.670,45$ & $104.094,47$ & & $105.764,93$ \\
\hline T6 & 0,70 & 1,33 & 598,39 & 544,24 & 54,16 & $14.465,61$ & $2.614,96$ & $259.074,93$ & & $261.689,89$ \\
\hline$T 7$ & 0,55 & 1,16 & 161,93 & 156,61 & 5,32 & $4.007,91$ & 532,54 & $25.595,92$ & & $26.128,46$ \\
\hline \multirow[t]{2}{*}{ T8 } & 0,60 & 1,20 & 474,90 & 453,34 & 21,56 & $11.694,75$ & $1.662,13$ & $103.575,95$ & & $105.238,08$ \\
\hline & & & & & Soma & $68.260,36$ & $\begin{array}{ll}\mathrm{R} \$ & 10.611,30\end{array}$ & $\mathrm{R} \$ 812.043,60$ & $\mathrm{R} \$$ & $822.654,90$ \\
\hline \multicolumn{7}{|c|}{ Pavimentação } & & & & \\
\hline \multirow{3}{*}{ Trecho } & \multicolumn{6}{|c|}{ Vala } & & & & \\
\hline & Área & Área de Concreto & $\begin{array}{c}\text { Area de } \\
\text { Paralelepiped } \\
\text { os }\end{array}$ & $\begin{array}{l}\text { Área de } \\
\text { Asfalto }\end{array}$ & Área de Binder & $\begin{array}{l}\text { Área de Concreto Asfático } \\
\text { Usinado a Quente }\end{array}$ & & & & \\
\hline & $\mathrm{m}^{2}$ & $\mathrm{~m}^{2}$ & $\mathrm{~m}^{2}$ & $\mathrm{~m}^{2}$ & $\mathrm{~m}^{2}$ & $\mathrm{~m}^{2}$ & & & & \\
\hline $\mathrm{T} 1$ & 193,86 & 0,00 & 193,86 & 0,00 & 0,00 & 0,00 & & & & \\
\hline $\mathrm{T} 2$ & 153,56 & 0,00 & 153,56 & 0,00 & 0,00 & 0,00 & & & & \\
\hline T3 & 394,52 & 0,00 & 394,52 & 0,00 & 0,00 & 0,00 & & & & \\
\hline T4 & 126,64 & 0,00 & 126,64 & 0,00 & 0,00 & 0,00 & & & & \\
\hline T5 & 396,28 & 0,00 & 396,28 & 0,00 & 0,00 & 0,00 & & & & \\
\hline T6 & 450,87 & 0,00 & 450,87 & 0,00 & 0,00 & 0,00 & & & & \\
\hline$T 7$ & 139,16 & 0,00 & 139,16 & 0,00 & 0,00 & 0,00 & & & & \\
\hline T8 & 394,31 & 0,00 & 394,31 & 0,00 & 0,00 & 0,00 & & & & \\
\hline \multirow{4}{*}{ Trecho } & \multicolumn{10}{|c|}{ Pavimentação } \\
\hline & \multicolumn{3}{|c|}{ Volume } & \multicolumn{2}{|c|}{ Area } & \multicolumn{5}{|c|}{ Custos } \\
\hline & Macadame Hidáulico & Binder & $\begin{array}{l}\text { Concreto } \\
\text { Asfáltico } \\
\text { Usinado a } \\
\text { Quente }\end{array}$ & $\begin{array}{c}\text { Imprimação } \\
\text { Betuminosa } \\
\text { Ligante }\end{array}$ & $\begin{array}{c}\text { Imprimação } \\
\text { Betuminosa } \\
\text { Impermeabiliza } \\
\text { nte }\end{array}$ & Remoção & Recomposição & Transporte & & TOTAL \\
\hline & $\mathrm{m}^{3}$ & $\mathrm{~m}^{3}$ & $\mathrm{~m}^{3}$ & $\mathrm{~m}^{2}$ & $\mathrm{~m}^{2}$ & $\mathrm{R} \$$ & $\mathrm{R} \$$ & $\mathrm{R} \$$ & & $\mathrm{R} \$$ \\
\hline $\mathrm{T} 1$ & 0,00 & 0,00 & 0,00 & 0,00 & 0,00 & 993,09 & $3.679,58$ & 0,00 & & $4.672,67$ \\
\hline T2 & 0,00 & 0,00 & 0,00 & 0,00 & 0,00 & 786,64 & $2.914,62$ & 0,00 & & $3.701,26$ \\
\hline T3 & 0,00 & 0,00 & 0,00 & 0,00 & 0,00 & $2.021,01$ & $7.488,19$ & 0,00 & & $9.509,20$ \\
\hline $\mathrm{T} 4$ & 0,00 & 0,00 & 0,00 & 0,00 & 0,00 & 648,74 & $2.403,70$ & 0,00 & & $3.052,45$ \\
\hline T5 & 0,00 & 0,00 & 0,00 & 0,00 & 0,00 & $2.030,04$ & $7.521,67$ & 0,00 & & $9.551,72$ \\
\hline T6 & 0,00 & 0,00 & 0,00 & 0,00 & 0,00 & $2.309,68$ & $8.557,79$ & 0,00 & & $10.867,47$ \\
\hline$T 7$ & 0,00 & 0,00 & 0,00 & 0,00 & 0,00 & 712,88 & $2.641,36$ & 0,00 & & $3.354,24$ \\
\hline T8 & 0,00 & 0,00 & 0,00 & 0,00 & 0,00 & $2.019,93$ & $7.484,21$ & 0,00 & & $9.504,14$ \\
\hline
\end{tabular}




\section{APÊNDICE A10 - Planilha de Dimensionamento para Viário em Asfalto para Tráfego Leve - PEAD}

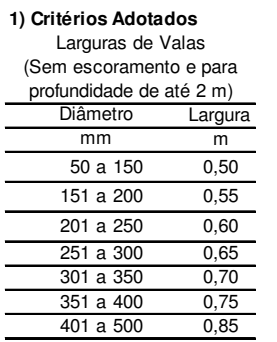

Locação das Redes

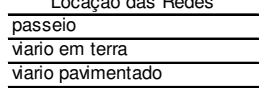

Recobrimento

\begin{tabular}{lc}
\hline \multicolumn{1}{c}{ Locação da } & Recobrimento \\
\cline { 2 - 2 } Tubulação & $\mathrm{m}$ \\
\hline passeio & 0,7 \\
\hline viario em terra & 1,2 \\
\hline viario pavimentado & 1,0 \\
\hline
\end{tabular}

\begin{tabular}{l}
\hline \multicolumn{1}{c}{ Tipo de Tráfegos para Viário } \\
\hline Leve \\
\hline Médio \\
\hline Pesado \\
\hline Tipos de Superfície \\
\hline asfalto \\
\hline parcreto \\
\hline terra
\end{tabular}

2) Dados Adotados

Tubulação

SDR

\begin{tabular}{ll} 
Rugosidade Equivalente $(\mathrm{m})$ & 0,00002 \\
\hline
\end{tabular}

Fator entre Diâmetro Hidráulico e Comercia

Pressurização Inicial

\begin{tabular}{lr}
\hline Carga Inicial & 13,32 \\
\hline Rendimento Global & 0,70
\end{tabular}

Horas de Funcionamer $\quad 6570 \mathrm{~h} / \mathrm{ano}$

Vida Útil

1,05

Largura Adotadas para Reposição de Pavimentos Devido Abertura de
Valas $(\mathrm{m})$

Espessuras Adotadas para Reposição de Pavimentos Devido Abertura de Valas $(\mathrm{m})$ Tráfego

Binder

$\begin{array}{llll} & \text { Lon } & 0,07 & 0,10\end{array}$

\begin{tabular}{lll}
0,04 & 0,0 \\
\hline & 0,10 & 0,12
\end{tabular}

$0,12-0,05$

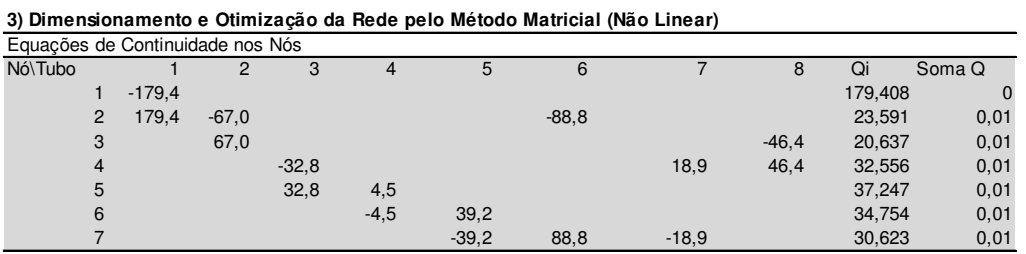

\begin{tabular}{cccccccccr}
\hline Equações de Perda de Carga nos Circuitos & & & & & \\
\hline Circuitos & 1 & 2 & 3 & 4 & 5 & 6 & 7 & 8 & Soma Perda \\
& & & & & & & & \\
1 & $-0,948$ & & & & 2,324 & 0,682 & $-2,058$ & 0,0001 \\
2 & & $-1,029$ & 0,234 & 1,477 & & $-0,682$ & & 0,0001 \\
\hline
\end{tabular}

Tabela da Função Objetivo

\begin{tabular}{|c|c|c|c|c|c|c|c|c|c|c|c|c|c|c|}
\hline \multirow{2}{*}{ Trecho } & \multicolumn{2}{|c|}{ Nó Montante } & \multicolumn{2}{|c|}{ No Jusante } & \multirow{2}{*}{$\begin{array}{l}\begin{array}{l}\text { Extensão } \\
\text { do Trecho }\end{array} \\
\text { (m) }\end{array}$} & \multirow{2}{*}{$\begin{array}{c}\text { Vazão do } \\
\text { Trecho }\end{array}$} & \multirow{2}{*}{$\begin{array}{c}\begin{array}{c}\text { Diâmetro } \\
\text { Interno } \\
\text { Comercial }\end{array} \\
(\mathrm{mm})\end{array}$} & \multirow{2}{*}{$\begin{array}{c}\begin{array}{c}\text { Diâmetro } \\
\text { Ótimo }\end{array} \\
(\mathrm{mm})\end{array}$} & \multirow{2}{*}{$\begin{array}{c}\text { Velocidade } \\
(\mathrm{m} / \mathrm{s})\end{array}$} & \multirow[t]{2}{*}{$\begin{array}{l}\text { Fator de } \\
\text { Atrito } f\end{array}$} & \multirow{2}{*}{$\begin{array}{c}\text { Perda de Carga } \\
(\mathrm{m})\end{array}$} & \multirow{2}{*}{$\begin{array}{c}\begin{array}{c}\text { Carga } \\
\text { Montante }\end{array} \\
(\mathrm{m})\end{array}$} & \multirow{2}{*}{$\begin{array}{c}\text { Carga Jusante } \\
(\mathrm{m})\end{array}$} & \multirow{2}{*}{$\begin{array}{c}\text { Potência Dissipada } \\
\mathrm{kW}\end{array}$} \\
\hline & Nome & Cota & Nome & Cota & & & & & & & & & & \\
\hline T1 & N1 & 4,56 & N2 & 3,50 & 258,48 & 179,4 & 368 & 350 & 1,68 & 0,0063 & 0,64 & 13,32 & 13,75 & 1,61 \\
\hline $\mathrm{T} 2$ & N2 & 3,50 & N3 & 3,50 & 255,93 & 67,0 & 229 & 237 & 1,62 & 0,0063 & 0,95 & 13,75 & 12,80 & 0,89 \\
\hline T3 & $\mathrm{N} 4$ & 1,50 & N5 & 0,49 & 657,53 & 32,8 & 204 & 201 & 1,00 & 0,0063 & 1,03 & 12,74 & 12,72 & 0,47 \\
\hline T4 & N5 & 0,49 & N6 & 0,50 & 253,28 & 4,5 & 102 & 103 & 0,54 & 0,0063 & 0,23 & 12,72 & 12,48 & 0,01 \\
\hline T5 & N6 & 0,50 & N7 & 1,50 & 660,47 & 39,2 & 204 & 205 & 1,19 & 0,0063 & 1,48 & 12,48 & 10,00 & 0,81 \\
\hline T6 & N2 & 3,50 & N7 & 1,50 & 644,10 & 88,8 & 258 & 254 & 1,70 & 0,0063 & 2,32 & 13,75 & 13,42 & 2,89 \\
\hline 77 & N7 & 1,50 & $\mathrm{~N} 4$ & 1,50 & 253,02 & 18,9 & 147 & 151 & 1,11 & 0,0063 & 0,68 & 13,42 & 12,74 & 0,18 \\
\hline T8 & N3 & 3,50 & N4 & 1,50 & 657,18 & 46,4 & 204 & 208 & 1,41 & 0,0063 & 2,06 & 13,75 & 13,69 & 1,34 \\
\hline
\end{tabular}

4) Resumo do Dimensionamento Otimizado

\begin{tabular}{|c|c|c|c|}
\hline & Poté & Dissipada & Pressurização Inicial \\
\hline Soma & & 8,20 & 33,46 \\
\hline Energia & & $53.879,78$ & $219.855,78$ \\
\hline FA & & 10,60 & 10,60 \\
\hline Sub-Total & $\mathrm{R} \$$ & $94.887,97$ & $387.189,16$ \\
\hline
\end{tabular}

\begin{tabular}{|c|c|c|}
\hline Custos & & Porcentagem \\
\hline Custo de Tubulação $\mathrm{R} \$$ & $684.952,86$ & $44,06 \%$ \\
\hline Custo de Movimento de Terra $\mathrm{R} \$$ & $62.717,72$ & $4,03 \%$ \\
\hline Custo de Assentamento R\$ & $9.825,98$ & $0,63 \%$ \\
\hline Custo de Pavimentação $\mathrm{R} \$$ & $315.141,51$ & $20,27 \%$ \\
\hline Custo da Pressurização Inicial $\mathrm{R} \$$ & $387.189,16$ & $24,90 \%$ \\
\hline Custo da Potência Dissipada $R \$$ & $94.887,97$ & $6,10 \%$ \\
\hline Total Global (Função Objetivo) R\$ & $1.554 .715,19$ & $100,00 \%$ \\
\hline Total Referencial Unitário $\mathbf{R} \$$ & 427,12 & por metro de rede \\
\hline
\end{tabular}


5) Quantitativos e Custos de Implantação das Redes de Abastecimento

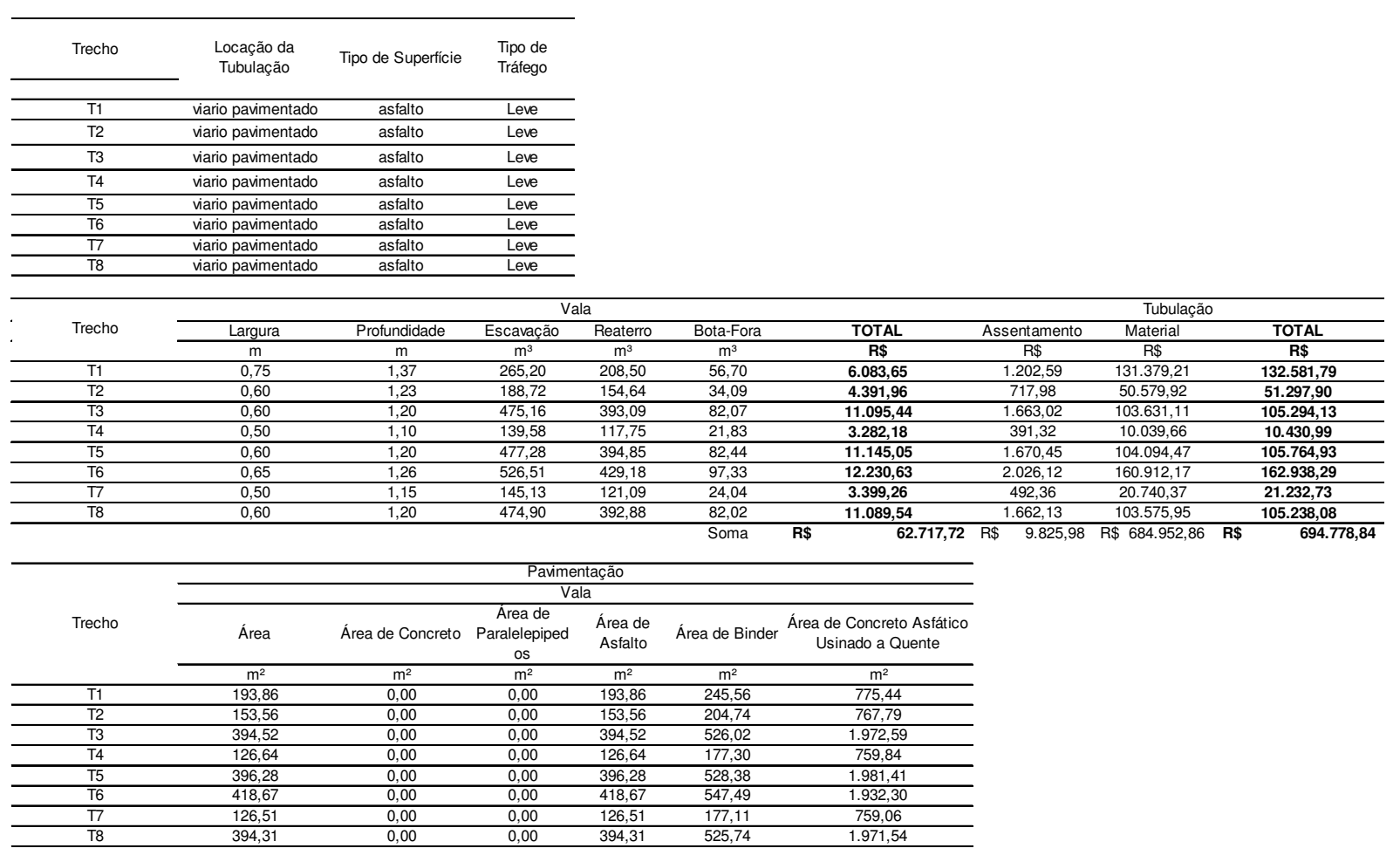

\begin{tabular}{|c|c|c|c|c|c|c|c|c|c|}
\hline \multirow{4}{*}{ Trecho } & \multicolumn{9}{|c|}{ Pavimentação } \\
\hline & \multicolumn{3}{|c|}{ Volume } & \multicolumn{2}{|c|}{ Área } & \multicolumn{4}{|c|}{ Custos } \\
\hline & Macadame Hidáulico & Binder & $\begin{array}{l}\text { Concreto } \\
\text { Asfáltico } \\
\text { Usinado a } \\
\text { Quente }\end{array}$ & $\begin{array}{c}\text { Imprimação } \\
\text { Betuminosa } \\
\text { Ligante }\end{array}$ & $\begin{array}{c}\text { Imprimação } \\
\text { Betuminosa } \\
\text { Impermeabiliza } \\
\text { nte }\end{array}$ & Remoção & Recomposição & Transporte & TOTAL \\
\hline & $\mathrm{m}^{3}$ & $\mathrm{~m}^{3}$ & $\mathrm{~m}^{3}$ & $\mathrm{~m}^{2}$ & $\mathrm{~m}^{2}$ & $\mathrm{R} \$$ & $\mathrm{R} \$$ & $\mathrm{R} \$$ & $\mathbf{R} \$$ \\
\hline $\mathrm{T} 1$ & 19,39 & 9,82 & 31,02 & 245,56 & 775,44 & $1.570,75$ & $21.953,10$ & 271,72 & $23.795,57$ \\
\hline $\mathrm{T} 2$ & 15,36 & 8,19 & 30,71 & 204,74 & 767,79 & $1.244,20$ & $20.600,46$ & 258,83 & $22.103,49$ \\
\hline T3 & 39,45 & 21,04 & 78,90 & 526,02 & $1.972,59$ & $3.196,57$ & $52.926,28$ & 664,97 & $56.787,83$ \\
\hline T4 & 12,66 & 7,09 & 30,39 & 177,30 & 759,84 & $1.026,10$ & $19.637,63$ & 249,41 & $20.913,13$ \\
\hline T5 & 39,63 & 21,14 & 79,26 & 528,38 & $1.981,41$ & $3.210,87$ & $53.162,93$ & 667,95 & $57.041,74$ \\
\hline T6 & $\begin{array}{lll}41,87 \\
\end{array}$ & 21,90 & 77,29 & 547,49 & $1.932,30$ & $3.392,22$ & $52.798,31$ & 659,96 & $56.850,49$ \\
\hline 77 & 12,65 & 7,08 & 30,36 & 177,11 & 759,06 & $1.025,04$ & $19.617,47$ & 249,15 & $20.891,66$ \\
\hline T8 & 39,43 & 21,03 & 78,86 & 525,74 & $1.971,54$ & $3.194,87$ & $52.898,11$ & 664,62 & $56.757,60$ \\
\hline
\end{tabular}




\section{APÊNDICE A11 - Planilha de Dimensionamento para Viário em Asfalto para Tráfego Médio - PEAD}

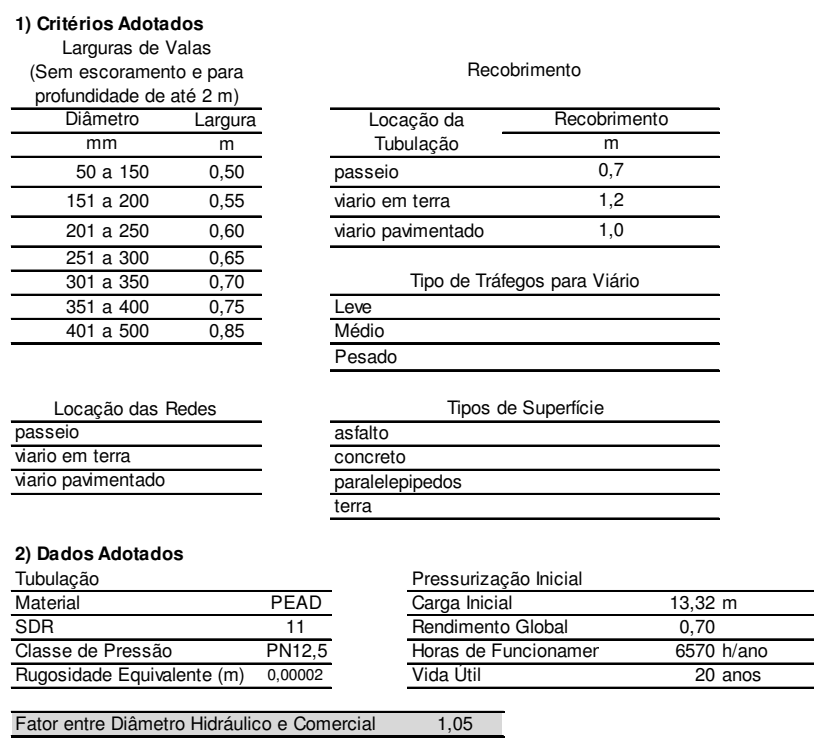

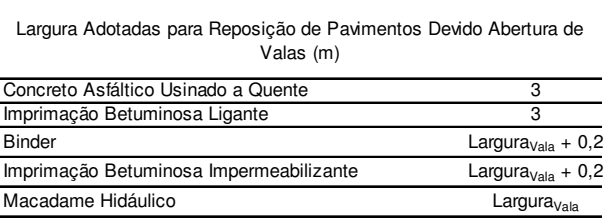

Espessuras Adotadas para Reposição de Pavimentos Devido Abertura de Valas (m) \begin{tabular}{lccc}
\hline Tráfego & Leve & Médio & Pesado \\
\hline Binder & 0,04 & 0,07 & 0,10 \\
\hline Concen
\end{tabular} Concreto Asfáltico Usinado a Quente $\quad 0,04 \quad 0,05 \quad 0,05$ Macadame Hidáulico $\quad 0,10 \quad 0,12$ 0,15

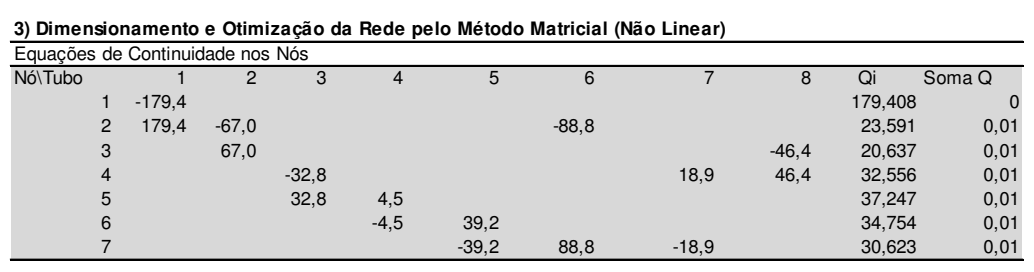

\begin{tabular}{|c|c|c|c|c|c|c|c|c|c|}
\hline \multicolumn{10}{|c|}{ Equações de Perda de Carga nos Circuitos } \\
\hline Circuitos & 1 & 2 & 3 & 4 & 5 & 6 & 7 & 8 & Soma Perda \\
\hline 1 & & $-0,948$ & & & & 2,324 & 0,682 & $-2,058$ & 0,0001 \\
\hline 2 & & & $-1,029$ & 0,234 & 1,477 & & $-0,682$ & & 0,0001 \\
\hline
\end{tabular}

Tabela da Função Objetivo

\begin{tabular}{|c|c|c|c|c|c|c|c|c|c|c|c|c|c|c|}
\hline \multirow{2}{*}{ Trecho } & \multicolumn{2}{|c|}{ Nó Montante } & \multicolumn{2}{|c|}{ No Jusante } & \multirow{2}{*}{$\begin{array}{r}\begin{array}{r}\text { Extensão } \\
\text { do Trecho }\end{array} \\
\text { (m) }\end{array}$} & \multirow{2}{*}{$\begin{array}{c}\begin{array}{c}\text { Vazão do } \\
\text { Trecho }\end{array} \\
\text { I/s } \\
\end{array}$} & \multirow{2}{*}{$\begin{array}{c}\begin{array}{c}\text { Diâmetro } \\
\text { Interno } \\
\text { Comercial }\end{array} \\
(\mathrm{mm}) \\
\end{array}$} & \multirow{2}{*}{$\begin{array}{c}\begin{array}{c}\text { Diâmetro } \\
\text { Ótimo }\end{array} \\
(\mathrm{mm}) \\
\end{array}$} & \multirow{2}{*}{$\begin{array}{c}\text { Velocidade } \\
(\mathrm{m} / \mathrm{s})\end{array}$} & \multirow{2}{*}{$\begin{array}{l}\text { Fator de } \\
\text { Atrito } f\end{array}$} & \multirow{2}{*}{$\begin{array}{c}\text { Perda de Carga } \\
(\mathrm{m})\end{array}$} & \multirow{2}{*}{$\begin{array}{c}\begin{array}{c}\text { Carga } \\
\text { Montante }\end{array} \\
(\mathrm{m})\end{array}$} & \multirow{2}{*}{$\begin{array}{c}\text { Carga Jusante } \\
(\mathrm{m})\end{array}$} & \multirow{2}{*}{$\begin{array}{c}\text { Potência Dissipada } \\
\mathrm{kW}\end{array}$} \\
\hline & Nome & Cota & Nome & Cota & & & & & & & & & & \\
\hline $\mathrm{T} 1$ & $\mathrm{~N} 1$ & 4,56 & N2 & 3,50 & 258,48 & 179,4 & 368 & 345 & 1,68 & 0,0063 & 0,64 & 13,32 & 13,75 & 1,61 \\
\hline T2 & N2 & 3,50 & N3 & 3,50 & 255,93 & 67,0 & 229 & 235 & 1,62 & 0,0063 & 0,95 & 13,75 & 12,80 & 0,89 \\
\hline T3 & $\mathrm{N} 4$ & 1,50 & N5 & 0,49 & 657,53 & 32,8 & 204 & 201 & 1,00 & 0,0063 & 1,03 & 12,74 & 12,72 & 0,47 \\
\hline T4 & N5 & 0,49 & N6 & 0,50 & 253,28 & 4,5 & 102 & 102 & 0,54 & 0,0063 & 0,23 & 12,72 & 12,48 & 0,01 \\
\hline T5 & N6 & 0,50 & N7 & 1,50 & 660,47 & 39,2 & 204 & 204 & 1,19 & 0,0063 & 1,48 & 12,48 & 10,00 & 0,81 \\
\hline T6 & N2 & 3,50 & N7 & 1,50 & 644,10 & 88,8 & 258 & 254 & 1,70 & 0,0063 & 2,32 & 13,75 & 13,42 & 2,89 \\
\hline 77 & N7 & 1,50 & $\mathrm{~N} 4$ & 1,50 & 253,02 & 18,9 & 147 & 150 & 1,11 & 0,0063 & 0,68 & 13,42 & 12,74 & 0,18 \\
\hline T8 & N3 & 3,50 & $\mathrm{~N} 4$ & 1,50 & 657,18 & 46,4 & 204 & 209 & 1,41 & 0,0063 & 2,06 & 13,75 & 13,69 & 1,34 \\
\hline
\end{tabular}

4) Resumo do Dimensionamento Otimizado

\begin{tabular}{|c|c|c|c|}
\hline & \multicolumn{2}{|c|}{ Potência Dissipada } & Pressurização Inicial \\
\hline Soma & & 8,20 & 33,46 \\
\hline Energia & & $53.879,78$ & $219.855,78$ \\
\hline$F A$ & & 10,60 & 10,60 \\
\hline Sub-Total & $\mathbf{R} \$$ & $94.887,97$ & $387.189,16$ \\
\hline
\end{tabular}

\begin{tabular}{|c|c|c|}
\hline Custos & & Porcentagem \\
\hline Custo de Tubulação $\mathrm{R} \$$ & $684.952,86$ & $41,91 \%$ \\
\hline Custo de Movimento de Terra $R \$$ & $61.395,83$ & $3,76 \%$ \\
\hline Custo de Assentamento $\mathrm{R} \$$ & $9.825,98$ & $0,60 \%$ \\
\hline Custo de Pavimentação $\mathrm{R} \$$ & $396.057,85$ & $24,23 \%$ \\
\hline Custo da Pressurização Inicial $\mathrm{R} \$$ & $387.189,16$ & $23,69 \%$ \\
\hline Custo da Potência Dissipada $R \$$ & $94.887,97$ & $5,81 \%$ \\
\hline Total Global (Função Objetivo) R\$ & $1.634 .309,64$ & $100,00 \%$ \\
\hline Total Referencial Unitário R\$ & 448,99 & por metro de rede \\
\hline
\end{tabular}


5) Quantitativos e Custos de Implantação das Redes de Abastecimento

\begin{tabular}{|c|c|c|c|c|c|c|c|c|c|}
\hline Trecho & $\begin{array}{l}\text { Locação da } \\
\text { Tubulação }\end{array}$ & Tipo de Superfície & $\begin{array}{l}\text { Tipo de } \\
\text { Tráfego }\end{array}$ & & & & & & \\
\hline $\mathrm{T} 1$ & viario pavimentado & asfalto & Médio & & & & & & \\
\hline $\mathrm{T} 2$ & viario pavimentado & asfalto & Médio & & & & & & \\
\hline T3 & vario pavimentado & asfalto & Médio & & & & & & \\
\hline T4 & vario pavimentado & asfalto & Médio & & & & & & \\
\hline$T 5$ & viario pavimentado & asfalto & Médio & & & & & & \\
\hline T6 & viario pavimentado & asfalto & Médio & & & & & & \\
\hline$T 7$ & vario pavimentado & asfalto & Médio & & & & & & \\
\hline T8 & viario pavimentado & asfalto & Médio & & & & & & \\
\hline \multirow{3}{*}{ Trecho } & \multicolumn{6}{|c|}{ Vala } & \multicolumn{3}{|c|}{ Tubulação } \\
\hline & Largura & Profundidade & Escavação & Reaterro & Bota-Fora & TOTAL & Assentamento & Material & TOTAL \\
\hline & $\mathrm{m}$ & $\mathrm{m}$ & $\mathrm{m}^{3}$ & $\mathrm{~m}^{3}$ & $\mathrm{~m}^{3}$ & $\mathrm{R} \$$ & $\mathrm{R} \$$ & $\mathrm{R} \$$ & $\mathrm{R} \$$ \\
\hline $\mathrm{T} 1$ & 0,75 & 1,37 & 265,20 & 197,26 & 67,94 & $5.971,10$ & $1.202,59$ & $131.379,21$ & $132.581,79$ \\
\hline $\mathrm{T} 2$ & 0,60 & 1,23 & 188,72 & 145,42 & 43,30 & $4.299,73$ & 717,98 & $50.579,92$ & $51.297,90$ \\
\hline T3 & 0,60 & 1,20 & 475,16 & 369,42 & 105,74 & $10.858,50$ & $1.663,02$ & $103.631,11$ & $105.294,13$ \\
\hline T4 & 0,50 & 1,10 & 139,58 & 109,90 & 29,69 & $3.203,58$ & 391,32 & $10.039,66$ & $10.430,99$ \\
\hline T5 & 0,60 & 1,20 & 477,28 & 371,07 & 106,21 & $10.907,05$ & $1.670,45$ & $104.094,47$ & $105.764,93$ \\
\hline T6 & 0,65 & 1,26 & 526,51 & 404,38 & 122,13 & $11.982,40$ & $2.026,12$ & $160.912,17$ & $162.938,29$ \\
\hline$T 7$ & 0,50 & 1,15 & 145,13 & 113,25 & 31,89 & $3.320,75$ & 492,36 & $20.740,37$ & $21.232,73$ \\
\hline \multirow[t]{2}{*}{ T8 } & 0,60 & 1,20 & 474,90 & 369,22 & 105,68 & $10.852,72$ & $1.662,13$ & $103.575,95$ & $105.238,08$ \\
\hline & & & & & Soma & $61.395,83$ & $\begin{array}{ll}\mathrm{R} \$ & 9.825,98 \\
\end{array}$ & $\mathrm{R} \$ 684.952,86 \quad \mathrm{R} \$$ & $694.778,84$ \\
\hline \multirow{2}{*}{\multicolumn{7}{|c|}{$\frac{\text { Pavimentação }}{\text { Vala }}$}} & & & \\
\hline & & & & & & & & & \\
\hline \multirow[t]{2}{*}{ Trecho } & Área & Área de Concreto & $\begin{array}{c}\text { Area de } \\
\text { Paralelepiped } \\
\text { os }\end{array}$ & $\begin{array}{l}\text { Área de } \\
\text { Asfalto }\end{array}$ & Área de Binder & $\begin{array}{l}\text { Área de Concreto Asfático } \\
\text { Usinado a Quente }\end{array}$ & & & \\
\hline & $\mathrm{m}^{2}$ & $\mathrm{~m}^{2}$ & $\mathrm{~m}^{2}$ & $\mathrm{~m}^{2}$ & $\mathrm{~m}^{2}$ & $\mathrm{~m}^{2}$ & & & \\
\hline $\mathrm{T} 1$ & 193,86 & 0,00 & 0,00 & 193,86 & 245,56 & 775,44 & & & \\
\hline $\mathrm{T} 2$ & 153,56 & 0,00 & 0,00 & 153,56 & 204,74 & 767,79 & & & \\
\hline T3 & 394,52 & 0,00 & 0,00 & 394,52 & 526,02 & $1.972,59$ & & & \\
\hline T4 & 126,64 & 0,00 & 0,00 & 126,64 & 177,30 & 759,84 & & & \\
\hline T5 & 396,28 & 0,00 & 0,00 & 396,28 & 528,38 & $1.981,41$ & & & \\
\hline T6 & 418,67 & 0,00 & 0,00 & 418,67 & 547,49 & $1.932,30$ & & & \\
\hline$T 7$ & 126,51 & 0,00 & 0,00 & 126,51 & 177,11 & 759,06 & & & \\
\hline T8 & 394,31 & 0,00 & 0,00 & 394,31 & 525,74 & $1.971,54$ & & & \\
\hline \multirow{4}{*}{ Trecho } & \multicolumn{9}{|c|}{ Pavimentação } \\
\hline & \multicolumn{3}{|c|}{ Volume } & \multicolumn{2}{|r|}{ Area } & \multicolumn{4}{|c|}{ Custos } \\
\hline & Macadame Hidáulico & Binder & $\begin{array}{c}\text { Concreto } \\
\text { Asfáltico } \\
\text { Usinado a } \\
\text { Quente }\end{array}$ & $\begin{array}{l}\text { Imprimação } \\
\text { Betuminosa } \\
\text { Ligante }\end{array}$ & $\begin{array}{c}\text { Imprimação } \\
\text { Betuminosa } \\
\text { Impermeabiliza } \\
\text { nte }\end{array}$ & Remoção & Recomposição & Transporte & TOTAL \\
\hline & $\mathrm{m}^{3}$ & $\mathrm{~m}^{3}$ & $\mathrm{~m}^{3}$ & $\mathrm{~m}^{2}$ & $\mathrm{~m}^{2}$ & $\mathrm{R} \$$ & $\mathrm{R} \$$ & $\mathrm{R} \$$ & $\mathrm{R} \$$ \\
\hline $\mathrm{T} 1$ & 23,26 & 17,19 & 38,77 & 245,56 & 775,44 & $1.570,75$ & $28.084,85$ & 372,33 & $30.027,93$ \\
\hline T2 & 18,43 & 14,33 & 38,39 & 204,74 & 767,79 & $1.244,20$ & $26.179,15$ & 350,78 & $27.774,13$ \\
\hline T3 & 47,34 & 36,82 & 98,63 & 526,02 & $1.972,59$ & $3.196,57$ & $67.258,92$ & 901,21 & $71.356,71$ \\
\hline T4 & 15,20 & 12,41 & 37,99 & 177,30 & 759,84 & $1.026,10$ & $24.833,57$ & 335,35 & $26.195,02$ \\
\hline T5 & 47,55 & 36,99 & 99,07 & 528,38 & $1.981,41$ & $3.210,87$ & $67.559,66$ & 905,24 & $71.675,76$ \\
\hline T6 & 50,24 & 38,32 & 96,62 & 547,49 & $1.932,30$ & $3.392,22$ & $67.251,43$ & 897,81 & $71.541,46$ \\
\hline$\pi 7$ & 15,18 & 12,40 & 37,95 & 177,11 & 759,06 & $1.025,04$ & $24.808,07$ & 335,01 & $26.168,13$ \\
\hline T8 & 47,32 & 36,80 & 98,58 & 525,74 & $1.971,54$ & $3.194,87$ & $67.223,12$ & 900,73 & $71.318,73$ \\
\hline
\end{tabular}




\section{APÊNDICE A12 - Planilha de Dimensionamento para Viário em Asfalto para Tráfego Pesado - PEAD}

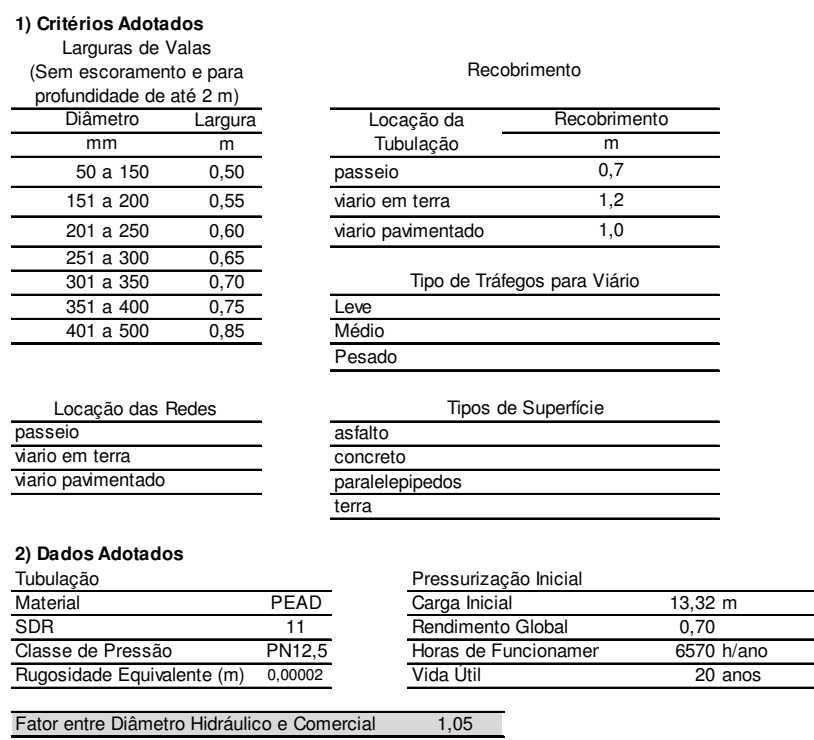

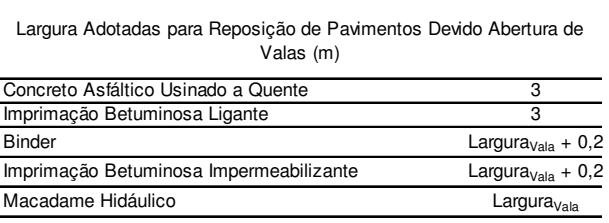

Espessuras Adotadas para Reposição de Pavimentos Devido Abertura de Valas (m)

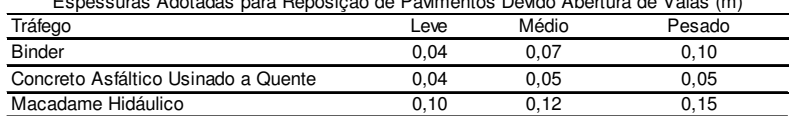

Energia
\begin{tabular}{lc}
\hline Grupo A (Alta e Média Tensão) \\
\hline Sub-Grupo A4 (2,3 KV a 25 KV) \\
\hline Custo de Energia por Demanda & $31,31 \mathrm{R} \$ / \mathrm{kW}$ \\
\hline Custo de Energia por Consumo & $0,16132 \mathrm{R} \$ / \mathrm{KWh}$ \\
\hline Taxa de Juros & $8,00 \% \mathrm{aa}$ \\
\hline Fator de Atualização & 10,60 \\
\hline
\end{tabular}

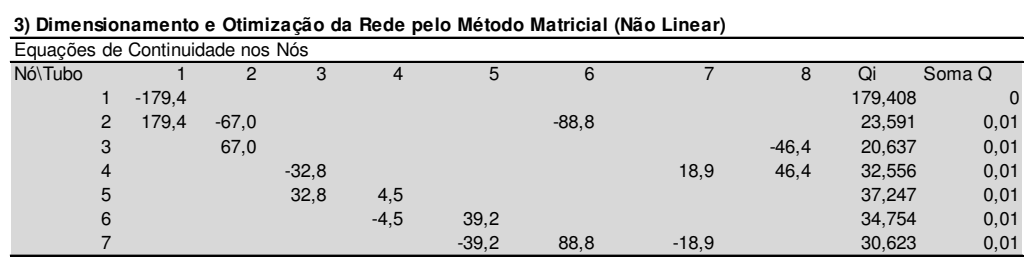

\begin{tabular}{|c|c|c|c|c|c|c|c|c|c|}
\hline \multicolumn{10}{|c|}{ Equações de Perda de Carga nos Circuitos } \\
\hline Circuitos & 1 & 2 & 3 & 4 & 5 & 6 & 7 & 8 & Soma Perda \\
\hline 1 & & $-0,948$ & & & & 2,324 & 0,682 & $-2,058$ & 0,0001 \\
\hline 2 & & & $-1,029$ & 0,234 & 1,477 & & $-0,682$ & & $1 \mathrm{E}-04$ \\
\hline
\end{tabular}

Tabela da Função Objetivo

\begin{tabular}{|c|c|c|c|c|c|c|c|c|c|c|c|c|c|c|}
\hline \multirow{2}{*}{ Trecho } & \multicolumn{2}{|c|}{ Nó Montante } & \multicolumn{2}{|c|}{ No Jusante } & \multirow{2}{*}{$\begin{array}{r}\begin{array}{r}\text { Extensão } \\
\text { do Trecho }\end{array} \\
\text { (m) }\end{array}$} & \multirow{2}{*}{$\begin{array}{c}\begin{array}{c}\text { Vazão do } \\
\text { Trecho }\end{array} \\
\text { I/s } \\
\end{array}$} & \multirow{2}{*}{$\begin{array}{c}\begin{array}{c}\text { Diâmetro } \\
\text { Interno } \\
\text { Comercial }\end{array} \\
(\mathrm{mm}) \\
\end{array}$} & \multirow{2}{*}{$\begin{array}{c}\begin{array}{c}\text { Diâmetro } \\
\text { Ótimo }\end{array} \\
(\mathrm{mm}) \\
\end{array}$} & \multirow{2}{*}{$\begin{array}{c}\text { Velocidade } \\
(\mathrm{m} / \mathrm{s})\end{array}$} & \multirow{2}{*}{$\begin{array}{l}\text { Fator de } \\
\text { Atrito } f\end{array}$} & \multirow{2}{*}{$\begin{array}{c}\text { Perda de Carga } \\
(\mathrm{m})\end{array}$} & \multirow{2}{*}{$\begin{array}{c}\begin{array}{c}\text { Carga } \\
\text { Montante }\end{array} \\
(\mathrm{m})\end{array}$} & \multirow{2}{*}{$\begin{array}{c}\text { Carga Jusante } \\
(\mathrm{m})\end{array}$} & \multirow{2}{*}{$\begin{array}{c}\text { Potência Dissipada } \\
\mathrm{kW}\end{array}$} \\
\hline & Nome & Cota & Nome & Cota & & & & & & & & & & \\
\hline $\mathrm{T} 1$ & $\mathrm{~N} 1$ & 4,56 & N2 & 3,50 & 258,48 & 179,4 & 368 & 345 & 1,68 & 0,0063 & 0,64 & 13,32 & 13,75 & 1,61 \\
\hline T2 & N2 & 3,50 & N3 & 3,50 & 255,93 & 67,0 & 229 & 235 & 1,62 & 0,0063 & 0,95 & 13,75 & 12,80 & 0,89 \\
\hline T3 & $\mathrm{N} 4$ & 1,50 & N5 & 0,49 & 657,53 & 32,8 & 204 & 201 & 1,00 & 0,0063 & 1,03 & 12,74 & 12,72 & 0,47 \\
\hline T4 & N5 & 0,49 & N6 & 0,50 & 253,28 & 4,5 & 102 & 102 & 0,54 & 0,0063 & 0,23 & 12,72 & 12,48 & 0,01 \\
\hline T5 & N6 & 0,50 & N7 & 1,50 & 660,47 & 39,2 & 204 & 204 & 1,19 & 0,0063 & 1,48 & 12,48 & 10,00 & 0,81 \\
\hline T6 & N2 & 3,50 & N7 & 1,50 & 644,10 & 88,8 & 258 & 254 & 1,70 & 0,0063 & 2,32 & 13,75 & 13,42 & 2,89 \\
\hline 77 & N7 & 1,50 & $\mathrm{~N} 4$ & 1,50 & 253,02 & 18,9 & 147 & 150 & 1,11 & 0,0063 & 0,68 & 13,42 & 12,74 & 0,18 \\
\hline T8 & N3 & 3,50 & $\mathrm{~N} 4$ & 1,50 & 657,18 & 46,4 & 204 & 209 & 1,41 & 0,0063 & 2,06 & 13,75 & 13,69 & 1,34 \\
\hline
\end{tabular}

4) Resumo do Dimensionamento Otimizado

\begin{tabular}{|c|c|c|c|}
\hline & \multicolumn{2}{|c|}{ Potência Dissipada } & Pressurização Inicial \\
\hline Soma & & 8,20 & 33,46 \\
\hline Energia & & $53.879,78$ & $219.855,78$ \\
\hline$F A$ & & 10,60 & 10,60 \\
\hline Sub-Total & $\mathbf{R} \$$ & $94.887,97$ & $387.189,16$ \\
\hline
\end{tabular}

\begin{tabular}{|c|c|c|}
\hline Custos & & Porcentagem \\
\hline Custo de Tubulação $\mathrm{R} \$$ & $684.952,86$ & $40,96 \%$ \\
\hline Custo de Movimento de Terra $R \$$ & $59.853,28$ & $3,58 \%$ \\
\hline Custo de Assentamento $\mathrm{R} \$$ & $9.825,98$ & $0,59 \%$ \\
\hline Custo de Pavimentação $\mathrm{R} \$$ & $435.352,23$ & $26,04 \%$ \\
\hline Custo da Pressurização Inicial $\mathrm{R} \$$ & $387.189,16$ & $23,16 \%$ \\
\hline Custo da Potência Dissipada $R \$$ & $94.887,97$ & $5,67 \%$ \\
\hline Total Global (Função Objetivo) R\$ & $1.672 .061,48$ & $100,00 \%$ \\
\hline Total Referencial Unitário R\$ & 459,36 & por metro de rede \\
\hline
\end{tabular}


5) Quantitativos e Custos de Implantação das Redes de Abastecimento

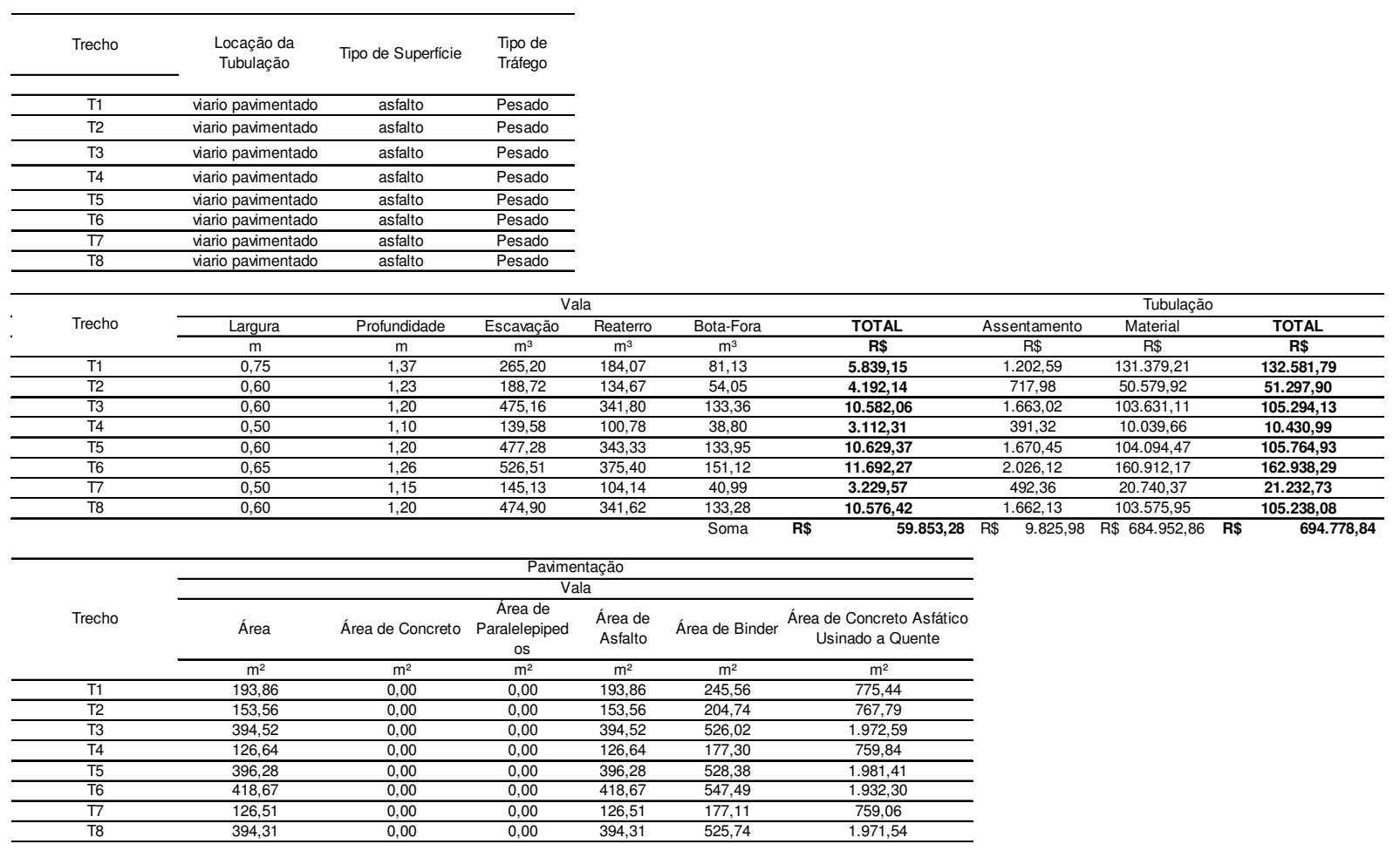

\begin{tabular}{|c|c|c|c|c|c|c|c|c|c|}
\hline \multirow{4}{*}{ Trecho } & \multicolumn{9}{|c|}{ Pavimentação } \\
\hline & \multicolumn{3}{|c|}{ Volume } & \multicolumn{2}{|c|}{ Área } & \multicolumn{4}{|c|}{ Custos } \\
\hline & Macadame Hidáulico & Binder & $\begin{array}{l}\text { Concreto } \\
\text { Asfáltico } \\
\text { Usinado a } \\
\text { Quente }\end{array}$ & $\begin{array}{l}\text { Imprimação } \\
\text { Betuminosa } \\
\text { Ligante }\end{array}$ & $\begin{array}{c}\text { Imprimação } \\
\text { Betuminosa } \\
\text { Impermeabiliza } \\
\text { nte }\end{array}$ & Remoção & Recomposição & Transporte & TOTAL \\
\hline & $\mathrm{m}^{3}$ & $\mathrm{~m}^{3}$ & $\mathrm{~m}^{3}$ & $\mathrm{~m}^{2}$ & $\mathrm{~m}^{2}$ & $\mathrm{R} \$$ & $\mathrm{R} \$$ & $\mathrm{R} \$$ & $\mathrm{R} \$$ \\
\hline $\mathrm{T} 1$ & 29,08 & 24,56 & 38,77 & 245,56 & 775,44 & $1.570,75$ & $31.366,66$ & 421,35 & $33.358,76$ \\
\hline $\mathrm{T} 2$ & 23,03 & 20,47 & 38,39 & 204,74 & 767,79 & $1.244,20$ & $28.880,38$ & 391,65 & $30.516,23$ \\
\hline T3 & 59,18 & 52,60 & 98,63 & 526,02 & $1.972,59$ & $3.196,57$ & $74.198,87$ & $1.006,21$ & $78.401,65$ \\
\hline T4 & 19,00 & 17,73 & 37,99 & 177,30 & 759,84 & $1.026,10$ & $27.145,14$ & 370,74 & $28.541,98$ \\
\hline T5 & 59,44 & 52,84 & 99,07 & 528,38 & $1.981,41$ & $3.210,87$ & $74.530,63$ & $1.010,71$ & $78.752,20$ \\
\hline T6 & 62,80 & 54,75 & 96,62 & 547,49 & $1.932,30$ & $3.392,22$ & $74.509,52$ & $1.007,08$ & $78.908,82$ \\
\hline 77 & 18,98 & 17,71 & 37,95 & 177,11 & 759,06 & $1.025,04$ & $27.117,27$ & 370,36 & $28.512,68$ \\
\hline T8 & 59,15 & 52,57 & 98,58 & 525,74 & $1.971,54$ & $3.194,87$ & $74.159,37$ & $1.005,67$ & $78.359,92$ \\
\hline
\end{tabular}




\section{APÊNDICE A13 - Planilha de Dimensionamento para Viário em Terra - FoFo}

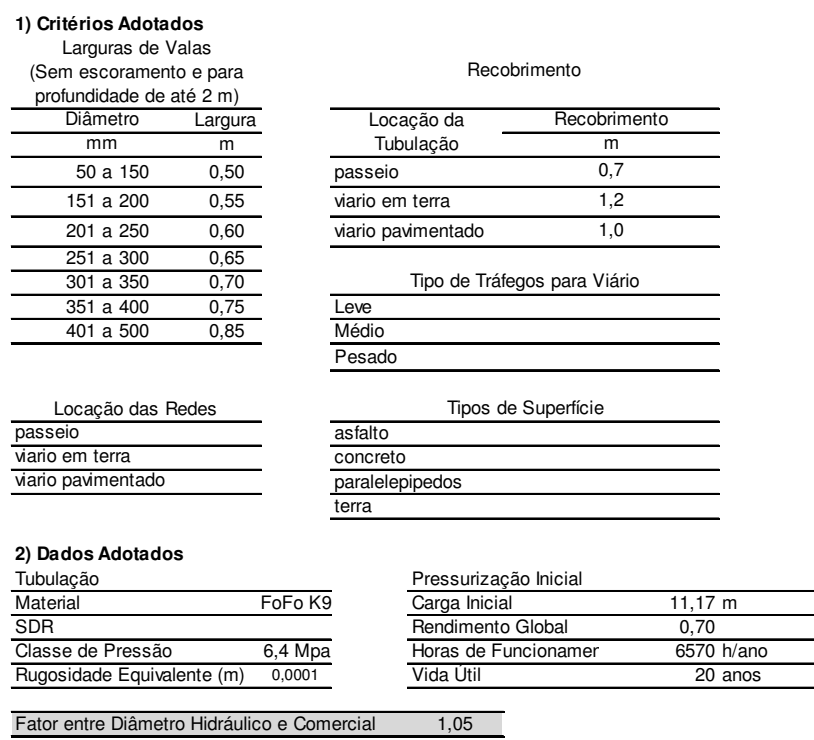

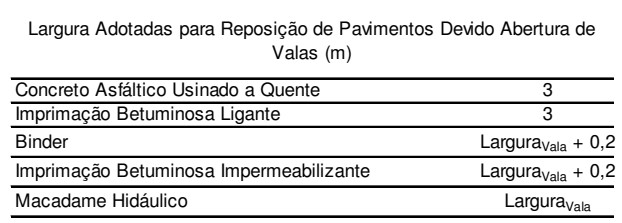

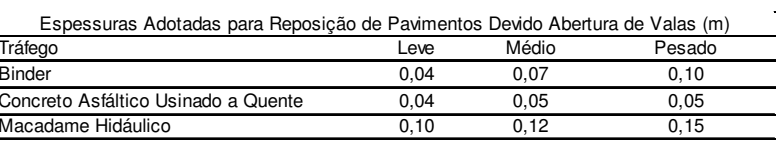

Macadame Hidáulico

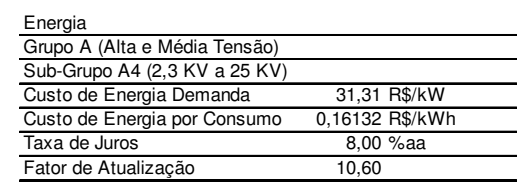

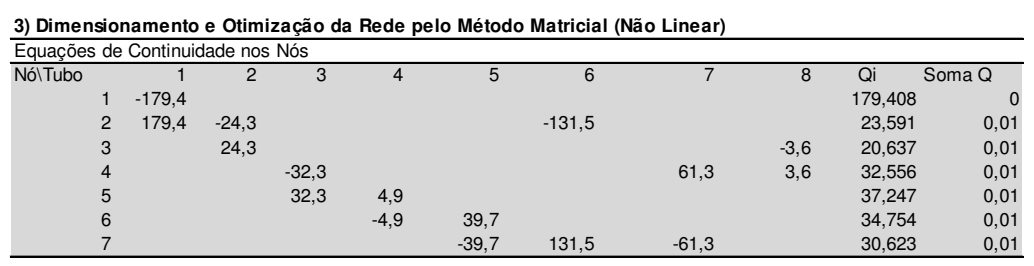

\begin{tabular}{cccccccccr}
\hline Equações de Perda de Carga nos Circuitos & & & & & & \\
\hline Circuitos & 1 & 2 & 3 & 4 & 5 & 6 & 7 & 8 & Soma Perda \\
1 & $-0,317$ & & & & 1,429 & 0,655 & $-1,767$ & 0,0001 \\
2 & & & & & & & & \\
& & $-0,474$ & 0,412 & 0,716 & & $-0,655$ & & 0,0001 \\
\hline
\end{tabular}

\begin{tabular}{|c|c|c|c|c|c|c|c|c|c|c|c|c|c|c|}
\hline \multirow{2}{*}{ Trecho } & \multicolumn{2}{|c|}{ Nó Montante } & \multicolumn{2}{|c|}{ No Jusante } & \multirow{2}{*}{$\begin{array}{r}\begin{array}{r}\text { Extensão } \\
\text { do Trecho }\end{array} \\
\text { (m) }\end{array}$} & \multirow{2}{*}{$\begin{array}{c}\text { Vazão do } \\
\text { Trecho }\end{array}$} & \multirow{2}{*}{$\begin{array}{c}\begin{array}{c}\text { Diâmetro } \\
\text { Nominal } \\
\text { Comercial }\end{array} \\
(\mathrm{mm}) \\
\end{array}$} & \multirow{2}{*}{$\begin{array}{c}\begin{array}{c}\text { Diâmetro } \\
\text { Ótimo }\end{array} \\
(\mathrm{mm}) \\
\end{array}$} & \multirow{2}{*}{$\begin{array}{c}\text { Velocidade } \\
(\mathrm{m} / \mathrm{s}) \\
\end{array}$} & \multirow[t]{2}{*}{$\begin{array}{l}\text { Fator de } \\
\text { Atrito } f\end{array}$} & \multirow{2}{*}{$\begin{array}{c}\text { Perda de Carga } \\
(\mathrm{m})\end{array}$} & \multirow{2}{*}{$\begin{array}{c}\begin{array}{c}\text { Carga } \\
\text { Montante }\end{array} \\
(\mathrm{m})\end{array}$} & \multirow{2}{*}{$\begin{array}{c}\text { Carga Jusante } \\
(\mathrm{m})\end{array}$} & \multirow{2}{*}{$\begin{array}{c}\text { Potência Dissipada } \\
\mathrm{kW}\end{array}$} \\
\hline & Nome & Cota & Nome & Cota & & & & & & & & & & \\
\hline $\mathrm{T1}$ & $\mathrm{N} 1$ & 4,56 & N2 & 3,50 & 258,48 & 179,4 & 400 & 401 & 1,42 & 0,0082 & 0,55 & 11,17 & 11,69 & 1,37 \\
\hline T2 & N2 & 3,50 & N3 & 3,50 & 255,93 & 24,3 & 200 & 200 & 0,77 & 0,0082 & 0,32 & 11,69 & 11,37 & 0,11 \\
\hline T3 & $\mathrm{N} 4$ & 1,50 & N5 & 0,49 & 657,53 & 32,3 & 250 & 232 & 0,66 & 0,0082 & 0,47 & 11,60 & 12,13 & 0,21 \\
\hline $\mathrm{T} 4$ & N5 & 0,49 & N6 & 0,50 & 253,28 & 4,9 & 100 & 100 & 0,62 & 0,0082 & 0,41 & 12,13 & 11,72 & 0,03 \\
\hline T5 & N6 & 0,50 & N7 & 1,50 & 660,47 & 39,7 & 250 & 251 & 0,81 & 0,0082 & 0,72 & 11,72 & 10,00 & 0,40 \\
\hline T6 & N2 & 3,50 & N7 & 1,50 & 644,10 & 131,5 & 350 & 351 & 1,36 & 0,0082 & 1,43 & 11,69 & 12,26 & 2,63 \\
\hline$T 7$ & N7 & 1,50 & $\mathrm{~N} 4$ & 1,50 & 253,02 & 61,3 & 250 & 251 & 1,24 & 0,0082 & 0,65 & 12,26 & 11,60 & 0,56 \\
\hline T8 & N3 & 3,50 & $\mathrm{~N} 4$ & 1,50 & 657,18 & 3,6 & 80 & 80 & 0,72 & 0,0082 & 1,77 & 11,69 & 11,92 & 0,09 \\
\hline
\end{tabular}

4) Resumo do Dimensionamento Otimizado

\begin{tabular}{|c|c|c|}
\hline & Potência Dissipada & Pressurização Inicial \\
\hline Soma & 5,41 & 28,06 \\
\hline Energia & $35.513,87$ & $185.208,08$ \\
\hline $\mathrm{FA}$ & 10,60 & 10,60 \\
\hline Sub-Total & $62.543,66$ & $326.126,53$ \\
\hline
\end{tabular}

\begin{tabular}{|c|c|c|}
\hline Custos & & Porcentagem \\
\hline Custo de Tubulação $R \$$ & $958.112,41$ & $66,77 \%$ \\
\hline Custo de Movimento de Terra $\mathrm{R} \$$ & $77.354,42$ & $5,39 \%$ \\
\hline Custo de Assentamento $\mathrm{R} \$$ & $10.871,45$ & $0,76 \%$ \\
\hline Custo de Pavimentação $R \$$ & & $0,00 \%$ \\
\hline Custo da Pressurização Inicial $\mathrm{R} \$$ & $326.126,53$ & $22,73 \%$ \\
\hline Custo da Potência Dissipada $R \$$ & $62.543,66$ & $4,36 \%$ \\
\hline Total Global (Função Objetivo) R\$ & $1.435 .008,46$ & $100,00 \%$ \\
\hline Total Referencial Unitário R\$ & 394,23 & por metro de rede \\
\hline
\end{tabular}


5) Quantitativos e Custos de Implantação das Redes de Abastecimento

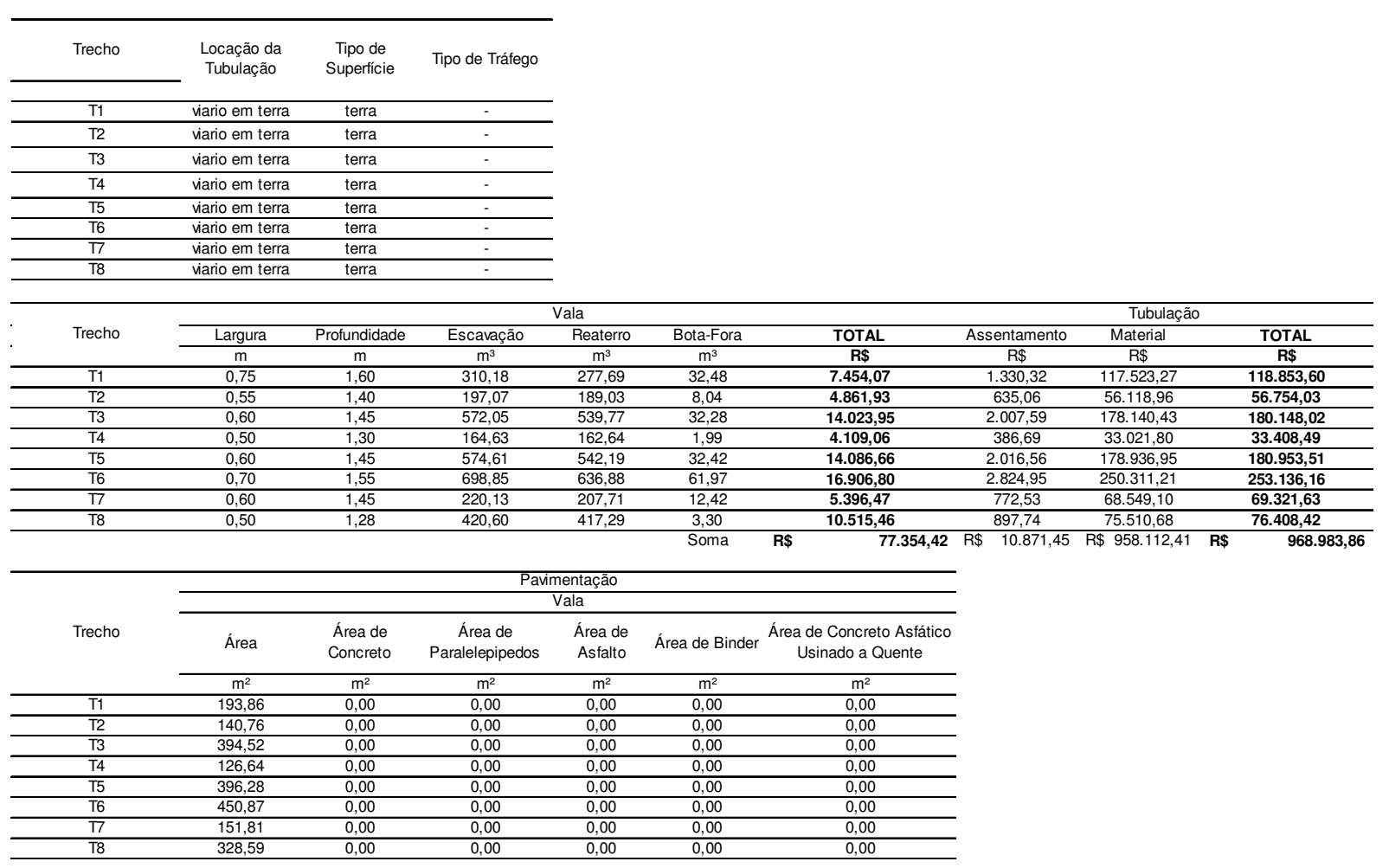

\begin{tabular}{|c|c|c|c|c|c|c|c|c|c|}
\hline \multirow{4}{*}{ Trecho } & \multicolumn{9}{|c|}{ Pavimentação } \\
\hline & \multicolumn{3}{|c|}{ Volume } & \multicolumn{2}{|c|}{ Área } & \multicolumn{4}{|c|}{ Custos } \\
\hline & $\begin{array}{l}\text { Macadame } \\
\text { Hidáulico }\end{array}$ & Binder & $\begin{array}{l}\text { Concreto } \\
\text { Asfáltico Usinado } \\
\text { a Quente }\end{array}$ & $\begin{array}{l}\text { Imprimação } \\
\text { Betuminosa } \\
\text { Ligante }\end{array}$ & $\begin{array}{c}\text { Imprimação } \\
\text { Betuminosa } \\
\text { Impermeabiliza } \\
\text { nte } \\
\end{array}$ & Remoção & Recomposição & Transporte & TOTAL \\
\hline & $\mathrm{m}^{3}$ & $\mathrm{~m}^{3}$ & $\mathrm{~m}^{3}$ & $\mathrm{~m}^{2}$ & $\mathrm{~m}^{2}$ & $\mathrm{R} \$$ & $\mathrm{R} \$$ & $\mathrm{R} \$$ & $\mathbf{R} \$$ \\
\hline $\mathrm{T} 1$ & 0,00 & 0,00 & 0,00 & 0,00 & 0,00 & 0,00 & 0,00 & 0,00 & 0,00 \\
\hline $\mathrm{T} 2$ & 0,00 & 0,00 & 0,00 & 0,00 & 0,00 & 0,00 & 0,00 & 0,00 & 0,00 \\
\hline T3 & 0,00 & 0,00 & 0,00 & 0,00 & 0,00 & 0,00 & 0,00 & 0,00 & 0,00 \\
\hline $\mathrm{T} 4$ & 0,00 & 0,00 & 0,00 & 0,00 & 0,00 & 0,00 & 0,00 & 0,00 & 0,00 \\
\hline T5 & 0,00 & 0,00 & 0,00 & 0,00 & 0,00 & 0,00 & 0,00 & 0,00 & 0,00 \\
\hline T6 & 0,00 & 0,00 & 0,00 & 0,00 & 0,00 & 0,00 & 0,00 & 0,00 & 0,00 \\
\hline 77 & 0,00 & 0,00 & 0,00 & 0,00 & 0,00 & 0,00 & 0,00 & 0,00 & 0,00 \\
\hline $\mathrm{T} 8$ & 0,00 & 0,00 & 0,00 & 0,00 & 0,00 & 0,00 & 0,00 & 0,00 & 0,00 \\
\hline & & & & & Soma & & $\mathrm{R} \$$ & & \\
\hline
\end{tabular}




\section{APÊNDICE A14 - Planilha de Dimensionamento para Passeio em Concreto - FoFo}

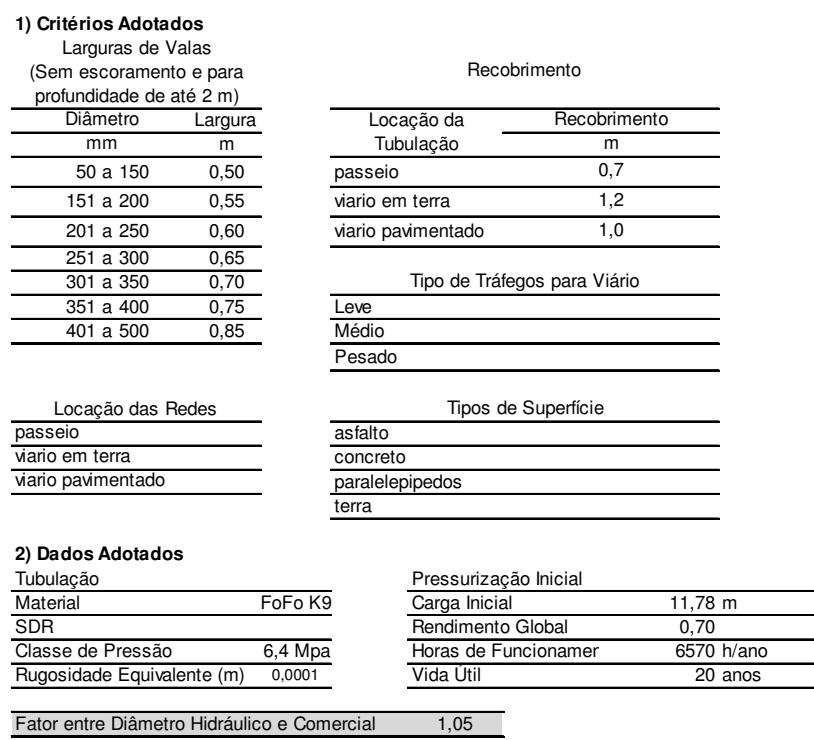

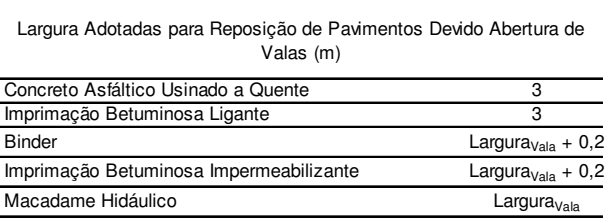

Espessuras Adotadas para Reposição de Pavimentos Devido Abertura de Valas (m)

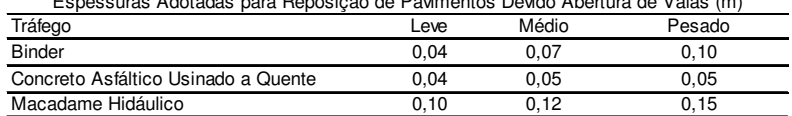

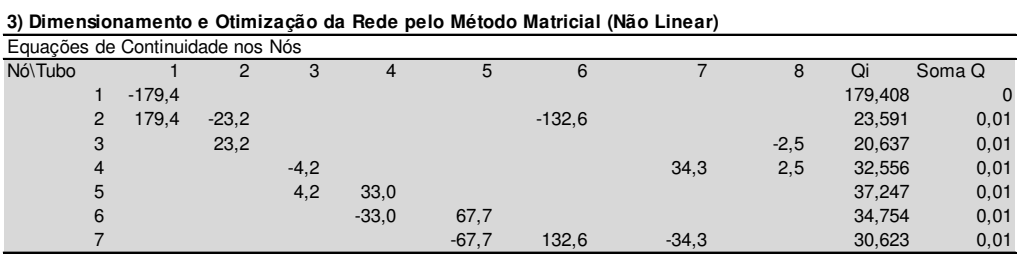

\begin{tabular}{|c|c|c|c|c|c|c|c|c|c|}
\hline \multicolumn{10}{|c|}{ Equações de Perda de Carga nos Circuitos } \\
\hline Circuitos & 1 & 2 & 3 & 4 & 5 & 6 & 7 & 8 & Soma Perda \\
\hline 1 & & $-1,219$ & & & & 1,453 & 0,625 & $-0,860$ & 0,0001 \\
\hline 2 & & & $-0,795$ & 0,580 & 0,840 & & $-0,625$ & & $1 \mathrm{E}-04$ \\
\hline
\end{tabular}

Tabela da Função Objetivo

\begin{tabular}{|c|c|c|c|c|c|c|c|c|c|c|c|c|c|c|}
\hline \multirow{2}{*}{ Trecho } & \multicolumn{2}{|c|}{ Nó Montante } & \multicolumn{2}{|c|}{ No Jusante } & \multirow{2}{*}{$\begin{array}{c}\begin{array}{c}\text { Extensão } \\
\text { do Trecho }\end{array} \\
(\mathrm{m}) \\
\end{array}$} & \multirow{2}{*}{$\begin{array}{c}\text { Vazão do } \\
\text { Trecho }\end{array}$} & \multirow{2}{*}{$\begin{array}{c}\text { Diâmetro } \\
\text { Nominal } \\
\text { Comercial }\end{array}$} & \multirow{2}{*}{$\begin{array}{c}\text { Diâmetro } \\
\text { Ótimo }\end{array}$} & \multirow{2}{*}{$\begin{array}{c}\text { Velocidade } \\
(\mathrm{m} / \mathrm{s})\end{array}$} & \multirow[t]{2}{*}{$\begin{array}{l}\text { Fator de } \\
\text { Atrito } f\end{array}$} & \multirow{2}{*}{$\begin{array}{l}\text { Perda de Carga } \\
(\mathrm{m})\end{array}$} & \multirow{2}{*}{$\begin{array}{c}\begin{array}{c}\text { Carga } \\
\text { Montante }\end{array} \\
(\mathrm{m})\end{array}$} & \multirow{2}{*}{$\begin{array}{c}\text { Carga Jusante } \\
(\mathrm{m})\end{array}$} & \multirow{2}{*}{$\begin{array}{c}\text { Potência Dissipada } \\
\mathrm{kW}\end{array}$} \\
\hline & Nome & Cota & Nome & Cota & & & & & & & & & & \\
\hline T1 & $\mathrm{N} 1$ & 4,56 & N2 & 3,50 & 258,48 & 179,4 & 400 & 401 & 1,42 & 0,0082 & 0,55 & 11,78 & 12,29 & 1,37 \\
\hline $\mathrm{T} 2$ & N2 & 3,50 & N3 & 3,50 & 255,93 & 23,2 & 150 & 150 & 1,31 & 0,0082 & 1,22 & 12,29 & 11,08 & 0,40 \\
\hline T3 & $\mathrm{N} 4$ & 1,50 & N5 & 0,49 & 657,53 & 4,2 & 100 & 100 & 0,54 & 0,0082 & 0,80 & 12,22 & 12,43 & 0,05 \\
\hline T4 & N5 & 0,49 & N6 & 0,50 & 253,28 & 33,0 & 200 & 194 & 1,05 & 0,0082 & 0,58 & 12,43 & 11,84 & 0,27 \\
\hline T5 & N6 & 0,50 & N7 & 1,50 & 660,47 & 67,7 & 300 & 298 & 0,96 & 0,0082 & 0,84 & 11,84 & 10,00 & 0,80 \\
\hline T6 & N2 & 3,50 & N7 & 1,50 & 644,10 & 132,6 & 350 & 353 & 1,37 & 0,0082 & 1,45 & 12,29 & 12,84 & 2,70 \\
\hline$T 7$ & N7 & 1,50 & $\mathrm{~N} 4$ & 1,50 & 253,02 & 34,3 & 200 & 201 & 1,09 & 0,0082 & 0,63 & 12,84 & 12,22 & 0,30 \\
\hline$T 8$ & N3 & 3,50 & $\mathrm{~N} 4$ & 1,50 & 657,18 & 2,5 & 80 & 80 & 0,50 & 0,0082 & 0,86 & 12,29 & 13,43 & 0,03 \\
\hline
\end{tabular}

4) Resumo do Dimensionamento Otimizado

\begin{tabular}{|c|c|c|c|}
\hline \multicolumn{3}{|c|}{ Potência Dissipada } & Pressurização Inicial \\
\hline Soma & & 5,91 & 29,58 \\
\hline Energia & & $38.829,57$ & $195.289,94$ \\
\hline $\mathrm{FA}$ & & 10,60 & 10,60 \\
\hline Sub-Total & $\mathbf{R} \$$ & $68.382,95$ & $343.879,32$ \\
\hline
\end{tabular}

\begin{tabular}{|c|c|c|}
\hline Custos & & Porcentagem \\
\hline Custo de Tubulação $\mathrm{R} \$$ & $900.439,21$ & $62,04 \%$ \\
\hline Custo de Movimento de Terra $R \$$ & $48.324,19$ & $3,33 \%$ \\
\hline Custo de Assentamento $\mathrm{R} \$$ & $10.253,91$ & $0,71 \%$ \\
\hline Custo de Pavimentação $\mathrm{R} \$$ & $80.117,64$ & $5,52 \%$ \\
\hline Custo da Pressurização Inicial $R \$$ & $343.879,32$ & $23,69 \%$ \\
\hline Custo da Potência Dissipada $R \$$ & $68.382,95$ & $4,71 \%$ \\
\hline Total Global (Função Objetivo) R\$ & $1.451 .397,21$ & $100,00 \%$ \\
\hline Total Referencial Unitário R\$ & 398,74 & por metro de rede \\
\hline
\end{tabular}


5) Quantitativos e Custos de Implantação das Redes de Abastecimento

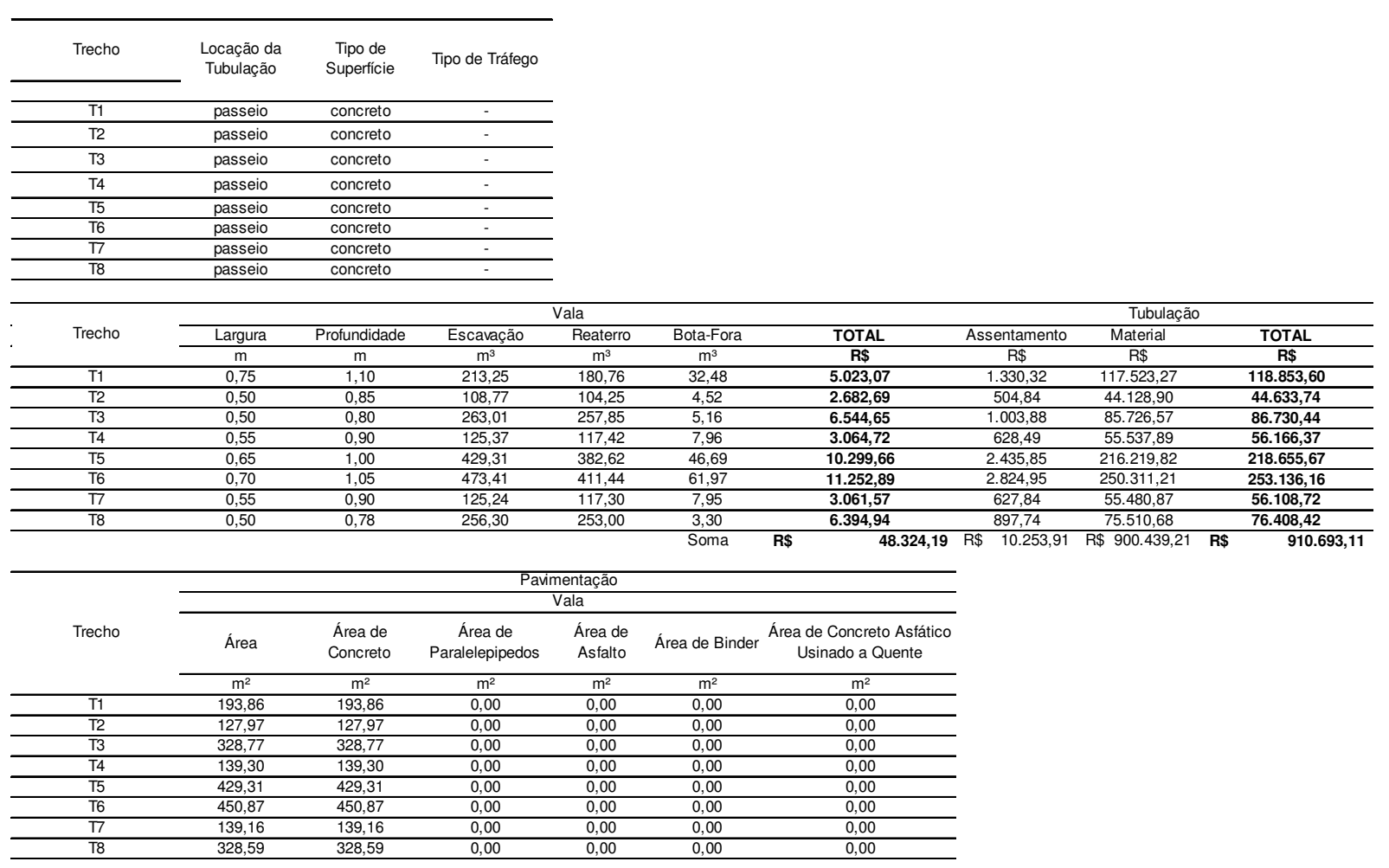

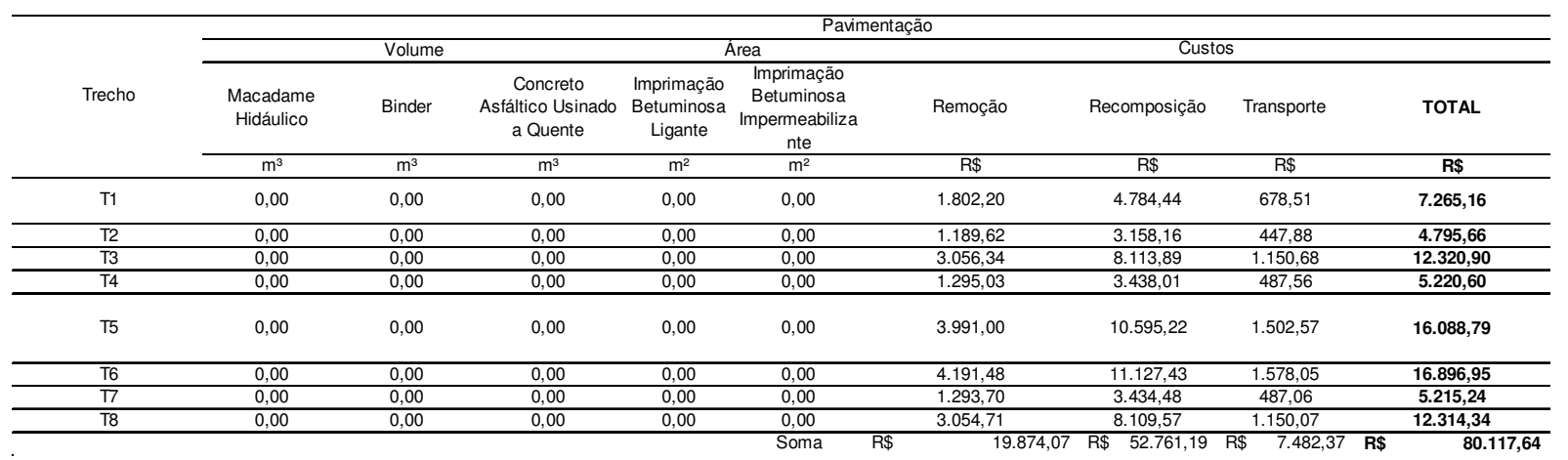




\section{APÊNDICE A15 - Planilha de Dimensionamento para Viário em Paralelepípedo - FoFo}

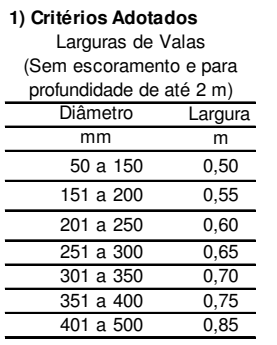

Locação das Redes

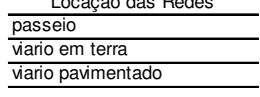

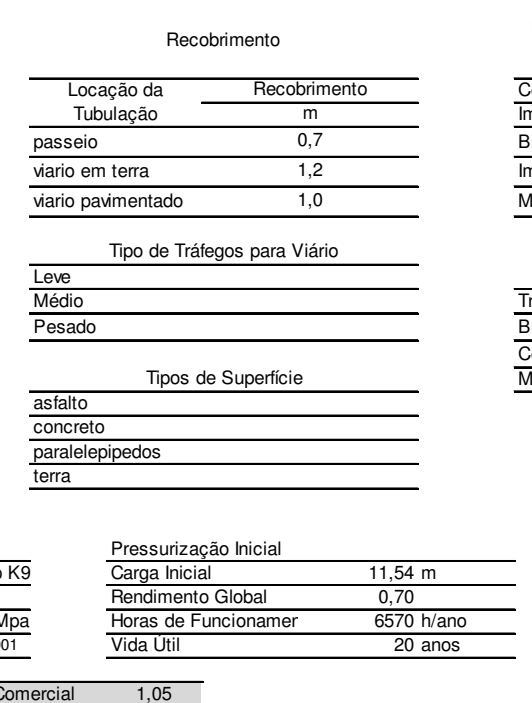
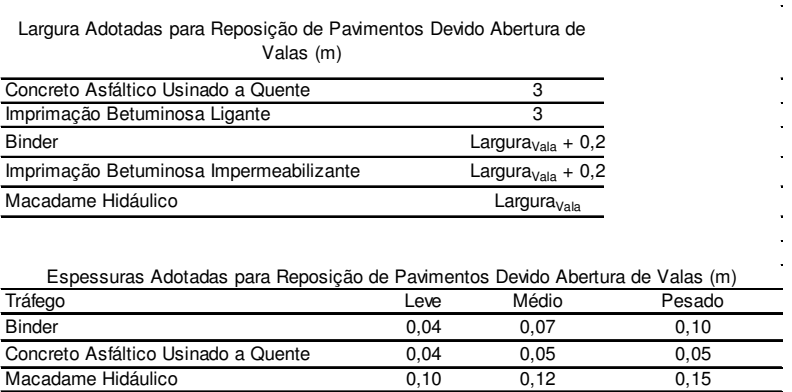

Espessuras Adotadas para Reposição de Pavimentos Devido Abertura de Valas ( $\mathrm{m}$

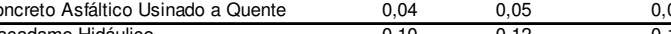

Macadame Hidáulico

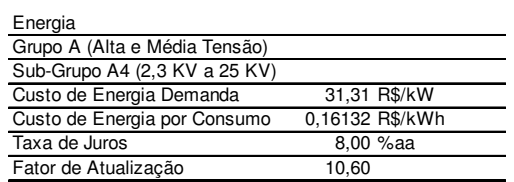

2) Dados Adotados

Tubulação

Materia

Classe de Pressão $\quad 6,4 \mathrm{Mpa}$

\begin{tabular}{lll}
\hline Rugosidade Equivalente $(\mathrm{m})$ & 0,0001 \\
\hline
\end{tabular}

Fator entre Diâmetro Hidráulico e Comercial

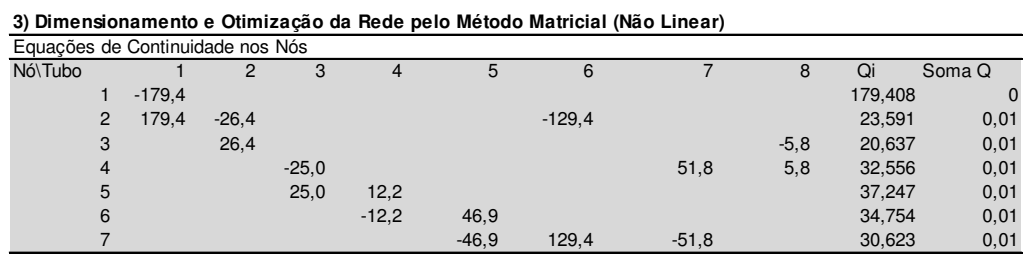

\begin{tabular}{|c|c|c|c|c|c|c|c|c|c|}
\hline \multicolumn{10}{|c|}{ Equações de Perda de Carga nos Circuitos } \\
\hline Circuitos & 1 & 2 & 3 & 4 & 5 & 6 & 7 & 8 & Soma Perda \\
\hline 1 & & $-0,376$ & & & & 1,383 & 0,469 & $-1,475$ & 0,0001 \\
\hline 2 & & & $-0,868$ & 0,334 & 1,003 & & $-0,469$ & & $1 \mathrm{E}-04$ \\
\hline
\end{tabular}

Tabela da Função Objetivo

\begin{tabular}{|c|c|c|c|c|c|c|c|c|c|c|c|c|c|c|}
\hline \multirow{2}{*}{ Trecho } & \multicolumn{2}{|c|}{ Nó Montante } & \multicolumn{2}{|c|}{ No Jusante } & \multirow{2}{*}{$\begin{array}{r}\begin{array}{l}\text { Extensão } \\
\text { do Trecho }\end{array} \\
\text { (m) }\end{array}$} & \multirow{2}{*}{$\begin{array}{c}\begin{array}{c}\text { Vazão do } \\
\text { Trecho }\end{array} \\
\text { l/s }\end{array}$} & \multirow{2}{*}{$\begin{array}{c}\text { Diâmetro } \\
\text { Nominal } \\
\text { Comercial }\end{array}$} & \multirow{2}{*}{$\begin{array}{c}\begin{array}{c}\text { Diâmetro } \\
\text { Ótimo }\end{array} \\
(\mathrm{mm})\end{array}$} & \multirow{2}{*}{$\begin{array}{l}\text { Velocidade } \\
(\mathrm{m} / \mathrm{s})\end{array}$} & \multirow{2}{*}{$\begin{array}{l}\text { Fator de } \\
\text { Atrito } f\end{array}$} & \multirow{2}{*}{$\begin{array}{c}\text { Perda de Carga } \\
(\mathrm{m})\end{array}$} & \multirow{2}{*}{$\begin{array}{c}\begin{array}{c}\text { Carga } \\
\text { Montante }\end{array} \\
(\mathrm{m})\end{array}$} & \multirow{2}{*}{$\begin{array}{l}\text { Carga Jusante } \\
(\mathrm{m})\end{array}$} & \multirow{2}{*}{$\begin{array}{c}\text { Potência Dissipada } \\
\mathrm{kW}\end{array}$} \\
\hline & Nome & Cota & Nome & Cota & & & & & & & & & & \\
\hline T1 & $\mathrm{N} 1$ & 4,56 & N2 & 3,50 & 258,48 & 179,4 & 400 & 401 & 1,42 & 0,0082 & 0,55 & 11,54 & 12,06 & 1,37 \\
\hline $\mathrm{T} 2$ & N2 & 3,50 & N3 & 3,50 & 255,93 & 26,4 & 200 & 200 & 0,84 & 0,0082 & 0,38 & 12,06 & 11,68 & 0,14 \\
\hline T3 & $\mathrm{N} 4$ & 1,50 & N5 & 0,49 & 657,53 & 25,0 & 200 & 174 & 0,79 & 0,0082 & 0,87 & 12,21 & 12,34 & 0,30 \\
\hline T4 & N5 & 0,49 & N6 & 0,50 & 253,28 & 12,2 & 150 & 150 & 0,69 & 0,0082 & 0,33 & 12,34 & 12,00 & 0,06 \\
\hline T5 & N6 & 0,50 & N7 & 1,50 & 660,47 & 46,9 & 250 & 250 & 0,95 & 0,0082 & 1,00 & 12,00 & 10,00 & 0,66 \\
\hline T6 & N2 & 3,50 & N7 & 1,50 & 644,10 & 129,4 & 350 & 366 & 1,34 & 0,0082 & 1,38 & 12,06 & 12,67 & 2,50 \\
\hline$T 7$ & N7 & 1,50 & N4 & 1,50 & 253,02 & 51,8 & 250 & 250 & 1,05 & 0,0082 & 0,47 & 12,67 & 12,21 & 0,34 \\
\hline T8 & N3 & 3,50 & $\mathrm{~N} 4$ & 1,50 & 657,18 & 5,8 & 100 & 100 & 0,73 & 0,0082 & 1,48 & 12,06 & 12,58 & 0,12 \\
\hline
\end{tabular}

4) Resumo do Dimensionamento Otimizado

\begin{tabular}{|c|c|c|c|}
\hline \multicolumn{3}{|c|}{ Potência Dissipada } & Pressurização Inicial \\
\hline Soma & & 5,50 & 28,99 \\
\hline Energia & & $36.121,78$ & $191.353,05$ \\
\hline$F A$ & & 10,60 & 10,60 \\
\hline Sub-Total & $\mathbf{R} \$$ & $63.614,26$ & $336.946,98$ \\
\hline
\end{tabular}

\begin{tabular}{|c|c|c|}
\hline Custos & & Porcentagem \\
\hline Custo de Tubulação $R \$$ & $944.972,07$ & $64,14 \%$ \\
\hline Custo de Movimento de Terra $\mathrm{R} \$$ & $65.315,09$ & $4,43 \%$ \\
\hline Custo de Assentamento $\mathrm{R} \$$ & $10.713,97$ & $0,73 \%$ \\
\hline Custo de Pavimentação $\mathrm{R} \$$ & $51.833,19$ & $3,52 \%$ \\
\hline Custo da Pressurização Inicial $\mathrm{R} \$$ & $336.946,98$ & $22,87 \%$ \\
\hline Custo da Potência Dissipada $R \$$ & $63.614,26$ & $4,32 \%$ \\
\hline Total Global (Função Objetivo) R\$ & $1.473 .395,57$ & $100,00 \%$ \\
\hline Total Referencial Unitário R\$ & 404,78 & por metro de rede \\
\hline
\end{tabular}




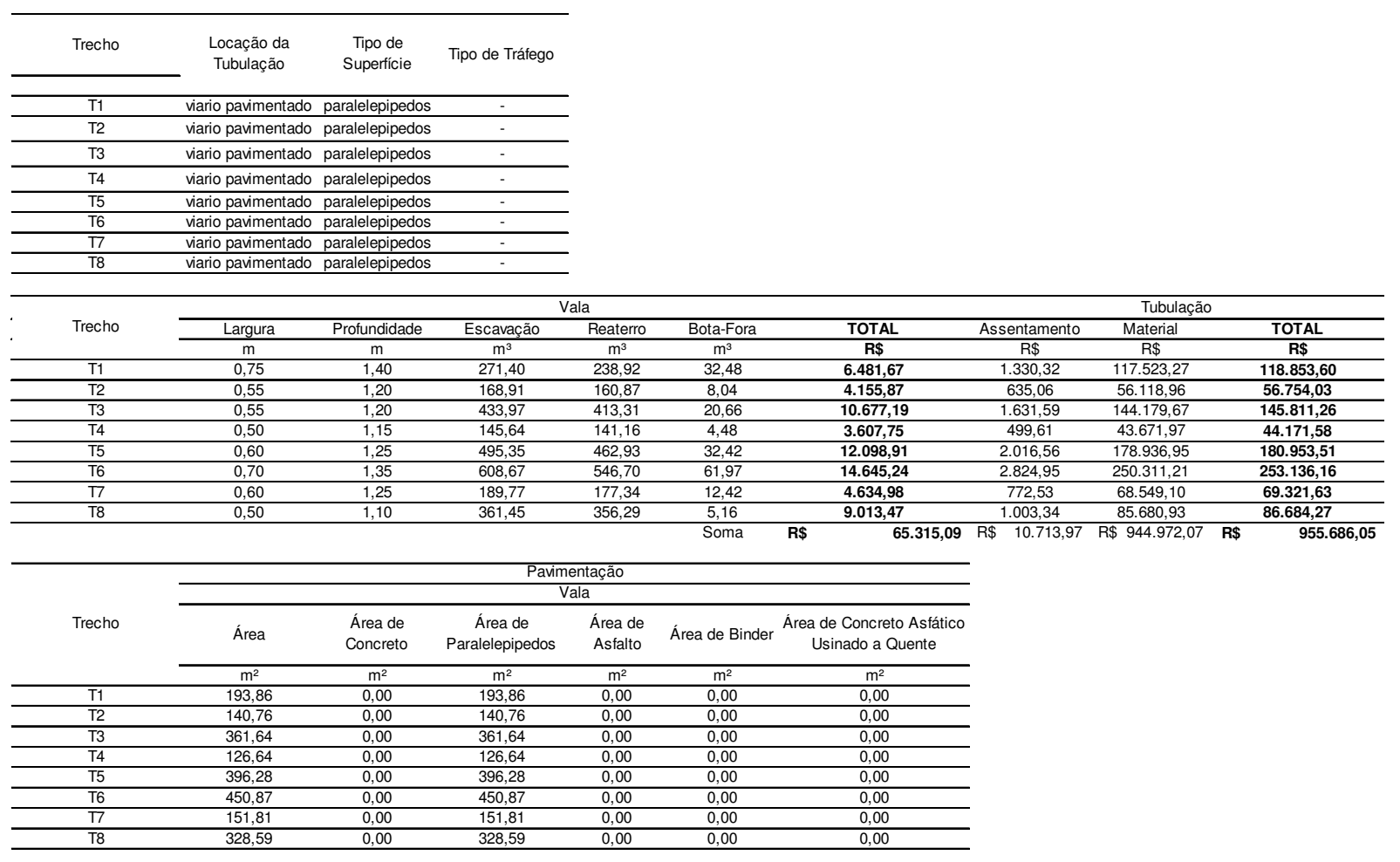

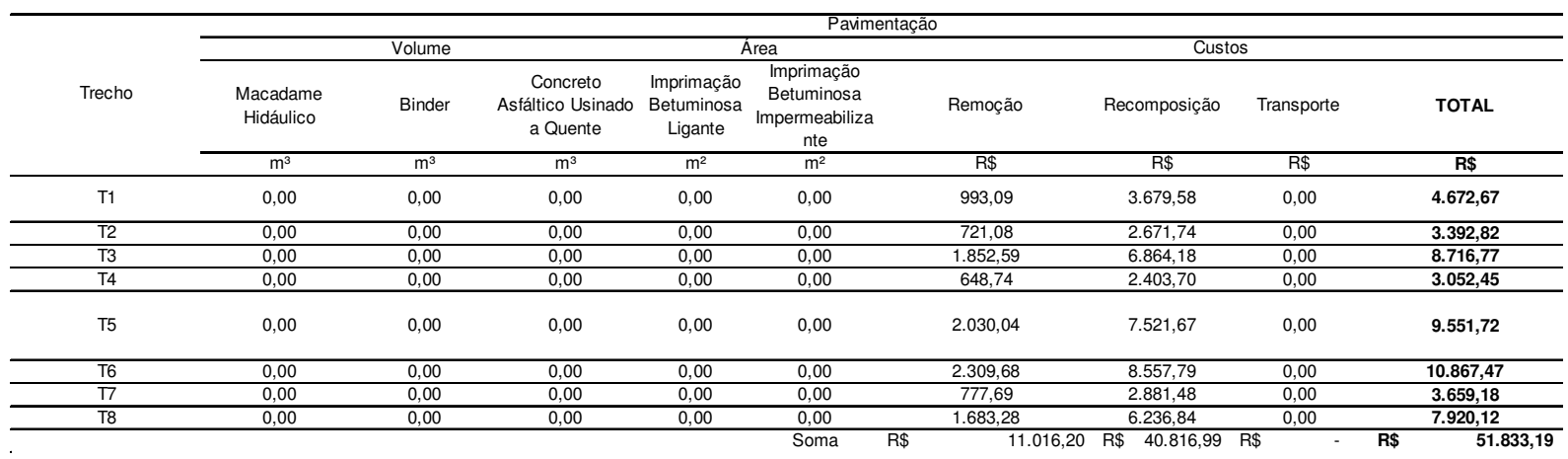




\section{APÊNDICE A16 - Planilha de Dimensionamento para Viário em Asfalto para Tráfego Leve - FoFo}

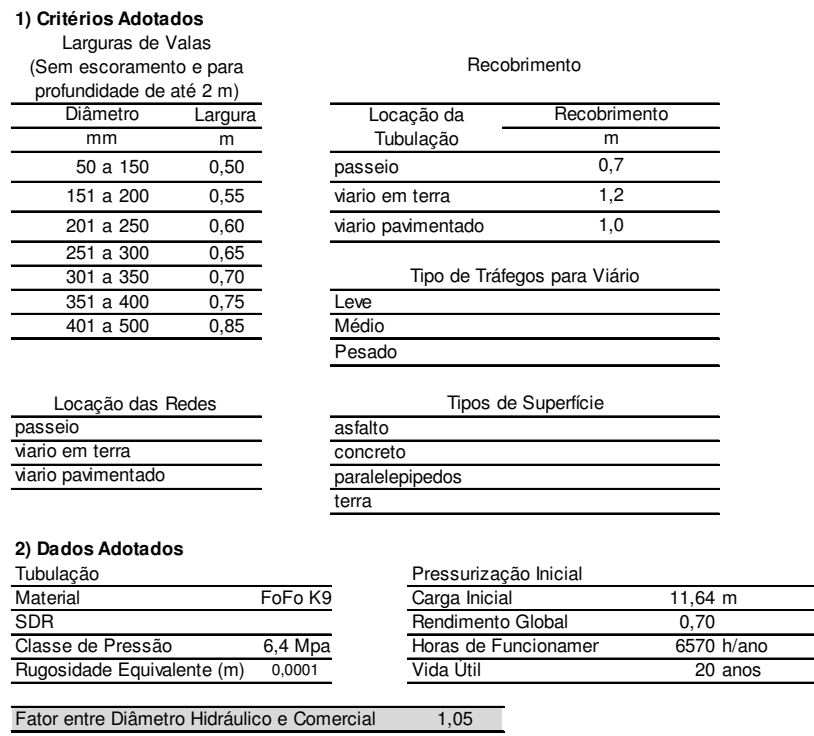

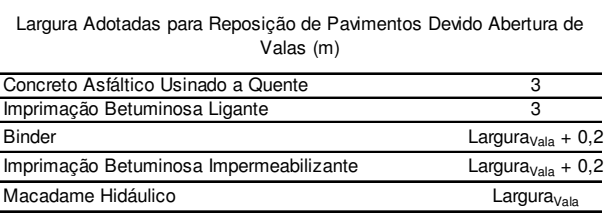

Espessuras Adotadas para Reposição de Pavimentos Devido Abertura de Valas (m)

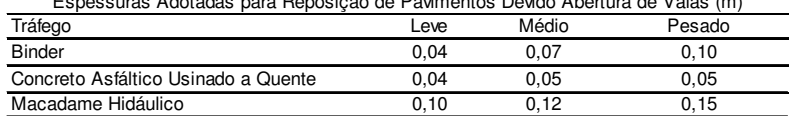

Energia
\begin{tabular}{lc}
\hline Grupo A (Alta e Média Tensão) \\
\hline Sub-Grupo A4 (2,3 KV a 25 KV) \\
\hline Custo de Energia Demanda & $31,31 \mathrm{R} \$ / \mathrm{kW}$ \\
\hline Custo de Energia por Consumo & $0,16132 \mathrm{R} \$ \mathrm{kWh}$ \\
\hline Taxa de Juros & $8,00 \% \mathrm{aa}$ \\
\hline Fator de Atualização & 10,60 \\
\hline
\end{tabular}

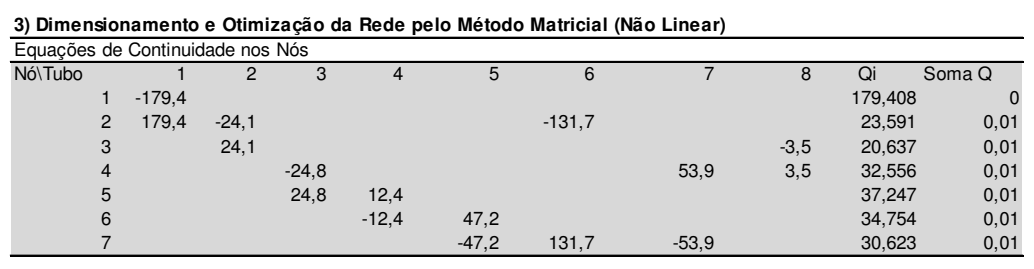

\begin{tabular}{|c|c|c|c|c|c|c|c|c|c|}
\hline \multicolumn{10}{|c|}{ Equações de Perda de Carga nos Circuitos } \\
\hline Circuitos & 1 & 2 & 3 & 4 & 5 & 6 & 7 & 8 & Soma Perda \\
\hline 1 & & $-0,313$ & & & & 1,432 & 0,507 & $-1,626$ & 0,0001 \\
\hline 2 & & & $-0,853$ & 0,346 & 1,013 & & $-0,507$ & & 0,0001 \\
\hline
\end{tabular}

Tabela da Função Objetivo

\begin{tabular}{|c|c|c|c|c|c|c|c|c|c|c|c|c|c|c|}
\hline \multirow{2}{*}{ Trecho } & \multicolumn{2}{|c|}{ Nó Montante } & \multicolumn{2}{|c|}{ No Jusante } & \multirow{2}{*}{$\begin{array}{l}\begin{array}{l}\text { Extensão } \\
\text { do Trecho }\end{array} \\
\text { (m) }\end{array}$} & \multirow{2}{*}{$\begin{array}{c}\begin{array}{c}\text { Vazão do } \\
\text { Trecho }\end{array} \\
1 / \mathrm{s}\end{array}$} & \multirow{2}{*}{$\begin{array}{c}\text { Diâmetro } \\
\text { Nominal } \\
\text { Comercial }\end{array}$} & \multirow{2}{*}{$\begin{array}{c}\begin{array}{c}\text { Diâmetro } \\
\text { Ótimo }\end{array} \\
(\mathrm{mm})\end{array}$} & \multirow{2}{*}{$\begin{array}{l}\text { Velocidade } \\
(\mathrm{m} / \mathrm{s})\end{array}$} & \multirow{2}{*}{$\begin{array}{l}\text { Fator de } \\
\text { Atrito } f\end{array}$} & \multirow{2}{*}{$\begin{array}{c}\text { Perda de Carga } \\
(\mathrm{m})\end{array}$} & \multirow{2}{*}{$\begin{array}{c}\begin{array}{c}\text { Carga } \\
\text { Montante }\end{array} \\
(\mathrm{m})\end{array}$} & \multirow{2}{*}{$\begin{array}{c}\text { Carga Jusante } \\
(\mathrm{m})\end{array}$} & \multirow{2}{*}{$\begin{array}{c}\text { Potência Dissipada } \\
\text { kW }\end{array}$} \\
\hline & Nome & Cota & Nome & Cota & & & & & & & & & & \\
\hline $\mathrm{T} 1$ & $\mathrm{~N} 1$ & 4,56 & N2 & 3,50 & 258,48 & 179,4 & 400 & 393 & 1,42 & 0,0082 & 0,55 & 11,64 & 12,15 & 1,37 \\
\hline T2 & N2 & 3,50 & N3 & 3,50 & 255,93 & 24,1 & 200 & 200 & 0,77 & 0,0082 & 0,31 & 12,15 & 11,84 & 0,11 \\
\hline T3 & $\mathrm{N} 4$ & 1,50 & N5 & 0,49 & 657,53 & 24,8 & 200 & 196 & 0,79 & 0,0082 & 0,85 & 12,21 & 12,37 & 0,30 \\
\hline T4 & N5 & 0,49 & N6 & 0,50 & 253,28 & 12,4 & 150 & 151 & 0,70 & 0,0082 & 0,35 & 12,37 & 12,01 & 0,06 \\
\hline T5 & N6 & 0,50 & N7 & 1,50 & 660,47 & 47,2 & 250 & 246 & 0,96 & 0,0082 & 1,01 & 12,01 & 10,00 & 0,67 \\
\hline T6 & N2 & 3,50 & N7 & 1,50 & 644,10 & 131,7 & 350 & 346 & 1,36 & 0,0082 & 1,43 & 12,15 & 12,72 & 2,64 \\
\hline$T 7$ & N7 & 1,50 & N4 & 1,50 & 253,02 & 53,9 & 250 & 250 & 1,09 & 0,0082 & 0,51 & 12,72 & 12,21 & 0,38 \\
\hline T8 & N3 & 3,50 & $\mathrm{~N} 4$ & 1,50 & 657,18 & 3,5 & 80 & 80 & 0,69 & 0,0082 & 1,63 & 12,15 & 12,53 & 0,08 \\
\hline & & & & Soma & 3639,99 & & & & & & & & & 5,61 \\
\hline
\end{tabular}

4) Resumo do Dimensionamento Otimizado

\begin{tabular}{|c|c|c|}
\hline & Potência Dissipada & Pressurização Inicial \\
\hline Soma & 5,61 & 29,22 \\
\hline Energia & $36.843,21$ & $192.921,99$ \\
\hline$F A$ & 10,60 & 10,60 \\
\hline Sub-Total & $64.884,76$ & $339.709,68$ \\
\hline
\end{tabular}

\begin{tabular}{|c|c|c|}
\hline Custos & & Porcentagem \\
\hline Custo de Tubulação $R \$$ & $934.801,82$ & $54,19 \%$ \\
\hline Custo de Movimento de Terra $\mathrm{R} \$$ & $61.863,72$ & $3,59 \%$ \\
\hline Custo de Assentamento $\mathrm{R} \$$ & $10.608,37$ & $0,61 \%$ \\
\hline Custo de Pavimentação $R \$$ & $313.095,98$ & $18,15 \%$ \\
\hline Custo da Pressurização Inicial $R \$$ & $339.709,68$ & $19,69 \%$ \\
\hline Custo da Potência Dissipada $R \$$ & $64.884,76$ & $3,76 \%$ \\
\hline Total Global (Função Objetivo) R\$ & $1.724 .964,34$ & $100,00 \%$ \\
\hline Total Referencial Unitário R\$ & 473,89 & por metro de rede \\
\hline
\end{tabular}


5) Quantitativos e Custos de Implantação das Redes de Abastecimento

\begin{tabular}{|c|c|c|c|c|c|c|c|c|c|}
\hline Trecho & $\begin{array}{l}\text { Locação da } \\
\text { Tubulação }\end{array}$ & $\begin{array}{l}\text { Tipo de } \\
\text { Superfície }\end{array}$ & Tipo de Tráfego & & & & & & \\
\hline $\mathrm{T} 1$ & viario pavimentado & asfalto & Leve & & & & & & \\
\hline $\mathrm{T} 2$ & viario pavimentado & asfalto & Leve & & & & & & \\
\hline T3 & viario pavimentado & asfalto & Leve & & & & & & \\
\hline T4 & viario pavimentado & asfalto & Leve & & & & & & \\
\hline 75 & viario pavimentado & asfalto & Leve & & & & & & \\
\hline T6 & viario pavimentado & asfalto & Leve & & & & & & \\
\hline$\pi 7$ & viario pavimentado & asfalto & Leve & & & & & & \\
\hline $\mathrm{T} 8$ & viario pavimentado & asfalto & Leve & & & & & & \\
\hline \multirow{3}{*}{ Trecho } & \multicolumn{6}{|c|}{ Vala } & \multicolumn{3}{|c|}{ Tubulação } \\
\hline & Largura & Profundidade & Escavação & Reaterro & Bota-Fora & TOTAL & Assentamento & Material & TOTAL \\
\hline & $\mathrm{m}$ & $\mathrm{m}$ & $m^{3}$ & $\mathrm{~m}^{3}$ & $\mathrm{~m}^{3}$ & $\mathbf{R} \$$ & $\mathrm{R} \$$ & $\mathrm{R} \$$ & $\mathbf{R} \$$ \\
\hline $\mathrm{T} 1$ & 0,75 & 1,40 & 271,40 & 209,71 & 61,69 & $6.189,30$ & $1.330,32$ & $117.523,27$ & $118.853,60$ \\
\hline $\mathrm{T} 2$ & 0,55 & 1,20 & 168,91 & 139,12 & 29,79 & $3.938,12$ & 635,06 & $56.118,96$ & $56.754,03$ \\
\hline T3 & 0,55 & 1,20 & 433,97 & 357,42 & 76,55 & $10.117,73$ & $1.631,59$ & $144.179,67$ & $145.811,26$ \\
\hline T4 & 0,50 & 1,15 & 145,64 & 121,40 & 24,23 & $3.409,99$ & 499,61 & $43.671,97$ & $44.171,58$ \\
\hline$T 5$ & 0,60 & 1,25 & 495,35 & 402,17 & 93,18 & $11.490,67$ & $2.016,56$ & $178.936,95$ & $180.953,51$ \\
\hline T6 & 0,70 & 1,35 & 608,67 & 478,43 & 130,24 & $13.961,81$ & $2.824,95$ & $250.311,21$ & $253.136,16$ \\
\hline 77 & 0,60 & 1,25 & 189,77 & 154,07 & 35,70 & $4.401,97$ & 772,53 & $68.549,10$ & $69.321,63$ \\
\hline \multirow[t]{2}{*}{ T8 } & 0,50 & 1,08 & 354,88 & 300,31 & 54,56 & $8.354,14$ & 897,74 & $75.510,68$ & $\begin{array}{l}76.408,42 \\
\end{array}$ \\
\hline & & & & & Soma & $61.863,72$ & $\mathrm{R} \$ \quad 10.608,37$ & $\mathrm{R} \$ 934.801,82 \quad \mathbf{R} \$$ & $945.410,19$ \\
\hline \multicolumn{10}{|c|}{$\frac{\text { Pavimentação }}{\text { Vala }}$} \\
\hline \multirow{3}{*}{ Trecho } & & & & Jala & & & & & \\
\hline & Área & $\begin{array}{l}\text { Área de } \\
\text { Concreto }\end{array}$ & $\begin{array}{c}\text { Área de } \\
\text { Paralelepipedos }\end{array}$ & $\begin{array}{l}\text { Área de } \\
\text { Asfalto }\end{array}$ & Área de Binder & $\begin{array}{l}\text { Área de Concreto Astático } \\
\text { Usinado a Quente }\end{array}$ & & & \\
\hline & $\mathrm{m}^{2}$ & $\mathrm{~m}^{2}$ & $\mathrm{~m}^{2}$ & $\mathrm{~m}^{2}$ & $\mathrm{~m}^{2}$ & $\mathrm{~m}^{2}$ & & & \\
\hline $\mathrm{T} 1$ & 193,86 & 0,00 & 0,00 & 193,86 & 245,56 & 775,44 & & & \\
\hline $\mathrm{T} 2$ & 140,76 & 0,00 & 0,00 & 140,76 & 191,95 & 767,79 & & & \\
\hline T3 & 361,64 & 0,00 & 0,00 & 361,64 & 493,15 & $1.972,59$ & & & \\
\hline $\mathrm{T} 4$ & 126,64 & 0,00 & 0,00 & 126,64 & 177,30 & 759,84 & & & \\
\hline $\mathrm{T5}$ & 396,28 & 0,00 & 0,00 & 396,28 & 528,38 & $1.981,41$ & & & \\
\hline T6 & 450,87 & 0,00 & 0,00 & 450,87 & 579,69 & $1.932,30$ & & & \\
\hline 77 & 151,81 & 0,00 & 0,00 & 151,81 & 202,42 & 759,06 & & & \\
\hline T8 & 328,59 & 0,00 & 0,00 & 328,59 & 460,03 & $1.971,54$ & & & \\
\hline \multirow{4}{*}{ Trecho } & \multicolumn{9}{|c|}{ Pavimentação } \\
\hline & \multicolumn{3}{|c|}{ Volume } & \multicolumn{2}{|c|}{ Área } & \multicolumn{4}{|c|}{ Custos } \\
\hline & $\begin{array}{l}\text { Macadame } \\
\text { Hidáulico }\end{array}$ & Binder & $\begin{array}{l}\text { Concreto } \\
\text { Asfáltico Usinado } \\
\text { a Quente }\end{array}$ & $\begin{array}{c}\text { Imprimação } \\
\text { Betuminosa } \\
\text { Ligante }\end{array}$ & $\begin{array}{c}\text { Imprimação } \\
\text { Betuminosa } \\
\text { Impermeabiliza } \\
\text { nte }\end{array}$ & Remoção & Recomposição & Transporte & TOTAL \\
\hline & $\mathrm{m}^{3}$ & $\mathrm{~m}^{3}$ & $\mathrm{~m}^{3}$ & $\mathrm{~m}^{2}$ & $\mathrm{~m}^{2}$ & $\mathrm{R} \$$ & $\mathrm{R} \$$ & $\mathrm{R} \$$ & $\mathrm{R} \$$ \\
\hline $\mathrm{T} 1$ & 19,39 & 9,82 & 31,02 & 245,56 & 775,44 & $1.570,75$ & $21.953,10$ & 271,72 & $23.795,57$ \\
\hline T2 & 14,08 & 7,68 & 30,71 & 191,95 & 767,79 & $1.140,52$ & $20.221,78$ & 255,42 & $21.617,71$ \\
\hline T3 & 36,16 & 19,73 & 78,90 & 493,15 & $1.972,59$ & $2.930,19$ & $51.953,36$ & 656,22 & $55.539,78$ \\
\hline $\mathrm{T} 4$ & 12,66 & 7,09 & 30,39 & 177,30 & 759,84 & $1.026,10$ & $19.637,63$ & 249,41 & $20.913,13$ \\
\hline T5 & 39,63 & 21,14 & 79,26 & 528,38 & $1.981,41$ & $3.210,87$ & $53.162,93$ & 667,95 & $57.041,74$ \\
\hline T6 & 45,09 & 23,19 & 77,29 & 579,69 & $1.932,30$ & $3.653,16$ & $53.751,35$ & 668,53 & $\begin{array}{l}58.073,05 \\
\end{array}$ \\
\hline 77 & 15,18 & 8,10 & 30,36 & 202,42 & 759,06 & $1.230,05$ & $20.366,23$ & 255,88 & $21.852,17$ \\
\hline T8 & 32,86 & 18,40 & 78,86 & 460,03 & $1.971,54$ & $2.662,39$ & $50.953,31$ & 647,13 & \begin{tabular}{|l|}
$54.262,84$ \\
\end{tabular} \\
\hline
\end{tabular}




\section{APÊNDICE A17 - Planilha de Dimensionamento para Viário em Asfalto para Tráfego Médio - FoFo}

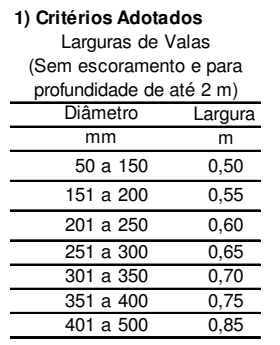

Locação das Redes

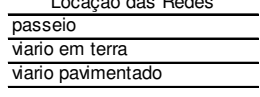

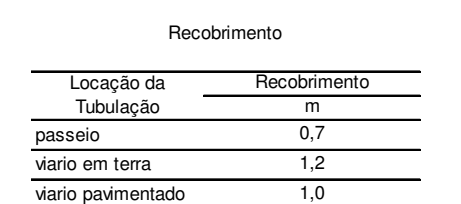

viario pavimentado 1,0

\begin{tabular}{l}
\hline \multicolumn{1}{c}{ Tipo de Tráfegos para Viário } \\
\hline Leve \\
\hline Médio \\
\hline Pesado \\
\hline Tipos de Superfície \\
\hline asfalto \\
\hline pancreto \\
\hline terra
\end{tabular}

2) Dados Adotados

Tubulação

Materia

SDR

$6,4 \mathrm{Mp}$

\begin{tabular}{ll}
\hline Rugosidade Equivalente $(\mathrm{m}) \quad 0,0001$ \\
\hline
\end{tabular}

Fator entre Diâmetro Hidráulico e Comercia
Pressurização Inicial

\begin{tabular}{lr}
\hline Carga Inicial & 10,80 \\
\hline Rendimento Global & 0,70 \\
\hline
\end{tabular}

Horas de Funcionamer $\quad 6570 \mathrm{~h} / \mathrm{ano}$ Vida Útil

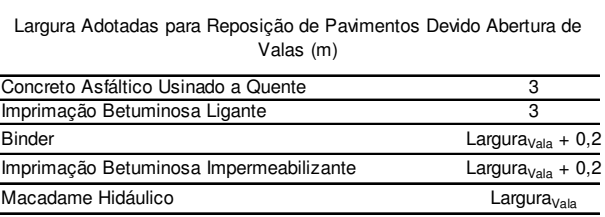
Espessuras Adotadas para Reposição de Pavimentos Devido Abertura de Valas (m) rálego

Concreto Asfáltico Usinado a Quente $\quad 0,04$

Macadame Hidáulico

\begin{tabular}{|c|c|}
\hline nergia & \\
\hline Grupo A (Alta e Média Tensão) & \\
\hline Sub-Grupo A4 (2,3 KV a $25 \mathrm{KV})$ & \\
\hline Custo de Energia Demanda & $31,31 \mathrm{R} \$ / \mathrm{kW}$ \\
\hline Custo de Energia por Consumo & $0,16132 \mathrm{R} \$ / \mathrm{kWh}$ \\
\hline Taxa de Juros & $8,00 \%$ aa \\
\hline Fator de Atualização & 10,60 \\
\hline
\end{tabular}

3) Dimensionamento e Otimização da Rede pelo Método Matricial (Não Linear)

\begin{tabular}{|c|c|c|c|c|c|c|c|c|c|c|}
\hline \multicolumn{11}{|c|}{ Equações de Continuidade nos Nós } \\
\hline 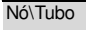 & 1 & 2 & 3 & 4 & 5 & 6 & 7 & 8 & Qi & Soma Q \\
\hline & $-179,4$ & & & & & & & & 179,408 & 0 \\
\hline & 179,4 & $-33,4$ & & & & $-122,4$ & & & 23,591 & 0,01 \\
\hline & & 33,4 & & & & & & $-12,7$ & 20,637 & 0,01 \\
\hline & & & $-4,1$ & & & & 23,9 & 12,7 & 32,556 & 0,01 \\
\hline & & & 4,1 & 33,2 & & & & & 37,247 & 0,01 \\
\hline & & & & $-33,2$ & 67,9 & & & & 34,754 & 0,01 \\
\hline & & & & & $-67,9$ & 122,4 & $-23,9$ & & 30,623 & 0,01 \\
\hline
\end{tabular}

\begin{tabular}{cccccccccr}
\hline Equações de Perda de Carga nos Circuitos & & & & & \\
\hline Circuitos & 1 & 2 & 3 & 4 & 5 & 6 & 7 & 8 & Soma Perda \\
& & & & & & & & \\
1 & $-0,600$ & & & & 1,238 & 0,304 & $-0,943$ & 0,0001 \\
2 & & $-0,732$ & 0,192 & 0,844 & & $-0,304$ & & $1 \mathrm{E}-04$ \\
\hline
\end{tabular}

Tabela da Função Objetivo

\begin{tabular}{|c|c|c|c|c|c|c|c|c|c|c|c|c|c|c|}
\hline \multirow{2}{*}{ Trecho } & \multicolumn{2}{|c|}{ Nó Montante } & \multicolumn{2}{|c|}{ No Jusante } & \multirow{2}{*}{$\begin{array}{l}\begin{array}{l}\text { Extensão } \\
\text { do Trecho }\end{array} \\
\text { (m) }\end{array}$} & \multirow{2}{*}{$\begin{array}{c}\begin{array}{c}\text { Vazão do } \\
\text { Trecho }\end{array} \\
\text { l/s }\end{array}$} & \multirow{2}{*}{$\begin{array}{c}\text { Diâmetro } \\
\text { Nominal } \\
\text { Comercial }\end{array}$} & \multirow{2}{*}{$\begin{array}{c}\begin{array}{c}\text { Diâmetro } \\
\text { Ótimo }\end{array} \\
(\mathrm{mm})\end{array}$} & \multirow{2}{*}{$\begin{array}{l}\text { Velocidade } \\
(\mathrm{m} / \mathrm{s})\end{array}$} & \multirow{2}{*}{$\begin{array}{l}\text { Fator de } \\
\text { Atrito } f\end{array}$} & \multirow{2}{*}{$\begin{array}{c}\text { Perda de Carga } \\
(\mathrm{m})\end{array}$} & \multirow{2}{*}{$\begin{array}{c}\begin{array}{c}\text { Carga } \\
\text { Montante }\end{array} \\
(\mathrm{m})\end{array}$} & \multirow{2}{*}{$\begin{array}{c}\text { Carga Jusante } \\
(\mathrm{m})\end{array}$} & \multirow{2}{*}{$\begin{array}{c}\text { Potência Dissipada } \\
\mathrm{kW}\end{array}$} \\
\hline & Nome & Cota & Nome & Cota & & & & & & & & & & \\
\hline T1 & $\mathrm{N} 1$ & 4,56 & N2 & 3,50 & 258,48 & 179,4 & 400 & 401 & 1,42 & 0,0082 & 0,55 & 10,80 & 11,31 & 1,37 \\
\hline $\mathrm{T} 2$ & N2 & 3,50 & N3 & 3,50 & 255,93 & 33,4 & 200 & 183 & 1,06 & 0,0082 & 0,60 & 11,31 & 10,71 & 0,28 \\
\hline T3 & $\mathrm{N} 4$ & 1,50 & N5 & 0,49 & 657,53 & 4,1 & 100 & 100 & 0,52 & 0,0082 & 0,73 & 11,77 & 12,04 & 0,04 \\
\hline T4 & N5 & 0,49 & N6 & 0,50 & 253,28 & 33,2 & 250 & 237 & 0,67 & 0,0082 & 0,19 & 12,04 & 11,84 & 0,09 \\
\hline T5 & N6 & 0,50 & N7 & 1,50 & 660,47 & 67,9 & 300 & 300 & 0,96 & 0,0082 & 0,84 & 11,84 & 10,00 & 0,80 \\
\hline T6 & N2 & 3,50 & N7 & 1,50 & 644,10 & 122,4 & 350 & 350 & 1,27 & 0,0082 & 1,24 & 11,31 & 12,07 & 2,12 \\
\hline$T 7$ & N7 & 1,50 & N4 & 1,50 & 253,02 & 23,9 & 200 & 192 & 0,76 & 0,0082 & 0,30 & 12,07 & 11,77 & 0,10 \\
\hline T8 & N3 & 3,50 & $\mathrm{~N} 4$ & 1,50 & 657,18 & 12,7 & 150 & 147 & 0,72 & 0,0082 & 0,94 & 11,31 & 12,37 & 0,17 \\
\hline
\end{tabular}

4) Resumo do Dimensionamento Otimizado

\begin{tabular}{|c|c|c|c|}
\hline & Poté & Dissipada & Pressurização Inicial \\
\hline Soma & & 4,98 & 27,11 \\
\hline Energia & & $32.721,15$ & $178.993,46$ \\
\hline FA & & 10,60 & 10,60 \\
\hline Sub-Total & $\mathrm{R} \$$ & $57.625,39$ & $315.183,42$ \\
\hline
\end{tabular}

\begin{tabular}{|c|c|c|}
\hline Custos & & Porcentagem \\
\hline Custo de Tubulação $\mathrm{R} \$$ & $963.314,95$ & $53,45 \%$ \\
\hline Custo de Movimento de Terra $\mathrm{R} \$$ & $61.315,67$ & $3,40 \%$ \\
\hline Custo de Assentamento R\$ & $10.927,56$ & $0,61 \%$ \\
\hline Custo de Pavimentação $\mathrm{R} \$$ & $393.964,11$ & $21,86 \%$ \\
\hline Custo da Pressurização Inicial $R \$$ & $315.183,42$ & $17,49 \%$ \\
\hline Custo da Potência Dissipada $\mathrm{R} \$$ & $57.625,39$ & $3,20 \%$ \\
\hline Total Global (Função Objetivo) R\$ & $1.802 .331,09$ & $100,00 \%$ \\
\hline Total Referencial Unitário $\mathrm{R} \$$ & 495,15 & por metro de rede \\
\hline
\end{tabular}


5) Quantitativos e Custos de Implantação das Redes de Abastecimento

\begin{tabular}{|c|c|c|c|c|c|c|c|c|c|}
\hline Trecho & $\begin{array}{l}\text { Locação da } \\
\text { Tubulação }\end{array}$ & $\begin{array}{c}\text { Tipo de } \\
\text { Superfície }\end{array}$ & Tipo de Tráfego & & & & & & \\
\hline $\mathrm{T} 1$ & viario pavimentado & asfalto & Médio & & & & & & \\
\hline $\mathrm{T} 2$ & viario pavimentado & asfalto & Médio & & & & & & \\
\hline T3 & viario pavimentado & asfalto & Médio & & & & & & \\
\hline T4 & viario pavimentado & asfalto & Médio & & & & & & \\
\hline $\mathrm{T5}$ & viario pavimentado & asfalto & Médio & & & & & & \\
\hline T6 & viario pavimentado & asfalto & Médio & & & & & & \\
\hline$\pi 7$ & viario pavimentado & asfalto & Médio & & & & & & \\
\hline \multirow[t]{2}{*}{ T8 } & viario pavimentado & asfalto & Médio & & & & & & \\
\hline & \multicolumn{6}{|c|}{ Vala } & & Tubulação & \\
\hline \multirow[t]{2}{*}{ Trecho } & Largura & Profundidade & Escavação & Reaterro & Bota-Fora & TOTAL & Assentamento & Material & TOTAL \\
\hline & $\mathrm{m}$ & $\mathrm{m}$ & $\mathrm{m}^{3}$ & $\mathrm{~m}^{3}$ & $\mathrm{~m}^{3}$ & $\mathbf{R} \$$ & $\mathrm{R} \$$ & $\mathrm{R} \$$ & $\mathbf{R} \$$ \\
\hline $\mathrm{T} 1$ & 0,75 & 1,40 & 271,40 & 198,47 & 72,93 & $6.076,75$ & $1.330,32$ & $117.523,27$ & $118.853,60$ \\
\hline $\mathrm{T} 2$ & 0,55 & 1,20 & 168,91 & 130,55 & 38,37 & $3.852,29$ & 635,06 & $56.118,96$ & $56.754,03$ \\
\hline T3 & 0,50 & 1,10 & 361,64 & 284,81 & 76,83 & $8.300,85$ & $1.003,88$ & $85.726,57$ & $86.730,44$ \\
\hline T4 & 0,60 & 1,25 & 189,96 & 145,11 & 44,85 & $4.315,22$ & 773,32 & $68.619,54$ & $69.392,87$ \\
\hline T5 & 0,65 & 1,30 & 558,10 & 420,60 & 137,50 & $12.620,70$ & $2.435,85$ & $216.219,82$ & $218.655,67$ \\
\hline T6 & 0,70 & 1,35 & 608,67 & 452,02 & 156,65 & $13.697,47$ & $2.824,95$ & $250.311,21$ & $253.136,16$ \\
\hline$T 7$ & 0,55 & 1,20 & 166,99 & 129,06 & 37,93 & $3.808,49$ & 627,84 & $55.480,87$ & $56.108,72$ \\
\hline \multirow[t]{2}{*}{ T8 } & 0,50 & 1,15 & 377,88 & 294,63 & 83,25 & $8.643,90$ & $1.296,33$ & $113.314,70$ & $114.611,03$ \\
\hline & & & & & Soma & $61.315,67$ & $\mathrm{R} \$ \quad 10.927,56$ & $\mathrm{R} \$ 963.314,95 \quad \mathrm{R} \$$ & $974.242,51$ \\
\hline \multirow{2}{*}{\multicolumn{7}{|c|}{$\begin{array}{c}\text { Pavimentação } \\
\text { Vala }\end{array}$}} & & & \\
\hline & & & & & & & & & \\
\hline \multirow[t]{2}{*}{ Trecho } & Área & $\begin{array}{l}\text { Área de } \\
\text { Concreto }\end{array}$ & $\begin{array}{c}\text { Área de } \\
\text { Paralelepipedos }\end{array}$ & $\begin{array}{l}\text { Área de } \\
\text { Asfalto }\end{array}$ & Área de Binder & $\begin{array}{l}\text { Área de Concreto Asfático } \\
\text { Usinado a Quente }\end{array}$ & & & \\
\hline & $\mathrm{m}^{2}$ & $\mathrm{~m}^{2}$ & $\mathrm{~m}^{2}$ & $\mathrm{~m}^{2}$ & $\mathrm{~m}^{2}$ & $\mathrm{~m}^{2}$ & & & \\
\hline $\mathrm{T} 1$ & 193,86 & 0,00 & 0,00 & 193,86 & 245,56 & 775,44 & & & \\
\hline T2 & 140,76 & 0,00 & 0,00 & 140,76 & 191,95 & 767,79 & & & \\
\hline T3 & 328,77 & 0,00 & 0,00 & 328,77 & 460,27 & $1.972,59$ & & & \\
\hline T4 & 151,97 & 0,00 & 0,00 & 151,97 & 202,62 & 759,84 & & & \\
\hline T5 & 429,31 & 0,00 & 0,00 & 429,31 & 561,40 & $1.981,41$ & & & \\
\hline T6 & 450,87 & 0,00 & 0,00 & 450,87 & 579,69 & $1.932,30$ & & & \\
\hline$\pi 7$ & 139,16 & 0,00 & 0,00 & 139,16 & 189,77 & 759,06 & & & \\
\hline T8 & 328,59 & 0,00 & 0,00 & 328,59 & 460,03 & $1.971,54$ & & & \\
\hline
\end{tabular}

\begin{tabular}{|c|c|c|c|c|c|c|c|c|c|}
\hline \multirow{4}{*}{ Trecho } & \multicolumn{9}{|c|}{ Pavimentação } \\
\hline & \multicolumn{3}{|c|}{ Volume } & \multicolumn{2}{|c|}{ Área } & \multicolumn{4}{|c|}{ Custos } \\
\hline & $\begin{array}{l}\text { Macadame } \\
\text { Hidáulico }\end{array}$ & Binder & $\begin{array}{l}\text { Concreto } \\
\text { Astáltico Usinado } \\
\text { a Quente }\end{array}$ & $\begin{array}{l}\text { Imprimação } \\
\text { Betuminosa } \\
\text { Ligante }\end{array}$ & $\begin{array}{c}\text { Imprimação } \\
\text { Betuminosa } \\
\text { Impermeabiliza } \\
\text { nte }\end{array}$ & Remoção & Recomposição & Transporte & TOTAL \\
\hline & $\mathrm{m}^{3}$ & $\mathrm{~m}^{3}$ & $\mathrm{~m}^{3}$ & $\mathrm{~m}^{2}$ & $\mathrm{~m}^{2}$ & $\mathrm{R} \$$ & $\mathrm{R} \$$ & $\mathrm{R} \$$ & $\mathbf{R} \$$ \\
\hline $\mathrm{T} 1$ & 23,26 & 17,19 & 38,77 & 245,56 & 775,44 & $1.570,75$ & $28.084,85$ & 372,33 & $30.027,93$ \\
\hline T2 & 16,89 & 13,44 & 38,39 & 191,95 & 767,79 & $1.140,52$ & $25.636,27$ & 344,82 & $27.121,61$ \\
\hline T3 & 39,45 & 32,22 & 98,63 & 460,27 & $1.972,59$ & $2.663,81$ & $64.469,42$ & 870,59 & $68.003,82$ \\
\hline $\mathrm{T} 4$ & 18,24 & 14,18 & 37,99 & 202,62 & 759,84 & $\begin{array}{l}1.231,32 \\
\end{array}$ & $25.908,08$ & 347,15 & $27.486,54$ \\
\hline T5 & 51,52 & 39,30 & 99,07 & 561,40 & $1.981,41$ & $3.478,44$ & $68.960,64$ & 920,62 & $73.359,70$ \\
\hline T6 & 54,10 & 40,58 & 96,62 & 579,69 & $1.932,30$ & $3.653,16$ & $68.617,69$ & 912,80 & $73.183,66$ \\
\hline$\pi 7$ & 16,70 & 13,28 & 37,95 & 189,77 & 759,06 & $1.127,55$ & $25.344,78$ & 340,90 & $26.813,23$ \\
\hline T8 & 39,43 & 32,20 & 98,58 & 460,03 & $1.971,54$ & $2.662,39$ & $64.435,11$ & 870,13 & $67.967,63$ \\
\hline
\end{tabular}




\section{APÊNDICE A18 - Planilha de Dimensionamento para Viário em Asfalto para Tráfego Pesado - FoFo}

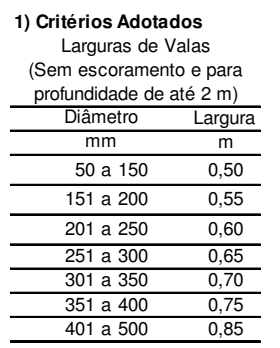

Locação das Redes

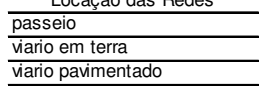

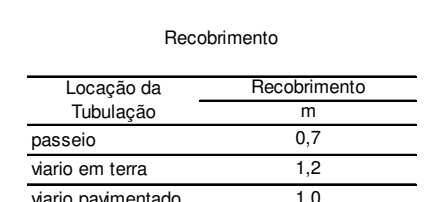

viario pavimentado 1,0

\begin{tabular}{l}
\hline \multicolumn{1}{c}{ Tipo de Tráfegos para Viário } \\
\hline Leve \\
\hline Médio \\
\hline Pesado \\
\hline \\
\hline asfalto $\quad$ Tipos de Superfície \\
\hline concreto \\
\hline paralelepipedos \\
\hline
\end{tabular}

2) Dados Adotados

Tubulação

Materia

SDR

6,4 Mp

\begin{tabular}{lr}
\hline Rugosidade Equivalente $(\mathrm{m}) \quad 0,0001$ \\
\hline
\end{tabular}

Fator entre Diâmetro Hidráulico e Comercia
Pressurização Inicial

\begin{tabular}{lr}
\hline Carga Inicial & 10,80 \\
\hline Rendimento Global & 0,70 \\
\hline
\end{tabular}

Horas de Funcionamer $\quad 6570 \mathrm{~h} / \mathrm{ano}$

Vida Útil

1,05

Largura Adotadas para Reposição de Pavimentos Devido Abertura de
Valas $(\mathrm{m})$

Espessuras Adotadas para Reposição de Pavimentos Devido Abertura de Valas (m) Tráfego Binder

Concreto Asfáltico Usinado a Quente $\quad 0,04$

Macadame Hidáulico $\quad 0,10$

\begin{tabular}{ccc} 
eve & Médio & Pesado \\
\hline, 04 & 0,07 & 0,10 \\
\hline, 04 & 0,05 & 0,05 \\
\hline, 10 & 0,12 & 0,15
\end{tabular}

Energia

Grupo A (Alta e Média Tensão)

Sub-Grupo A4 (2,3 KV a $25 \mathrm{KV})$

Custo de Energia Demanda

$\begin{array}{lr}\text { Custo de Energia por Consumo } & 0,16132 \mathrm{R} \$ / \mathrm{kW}\end{array}$

\begin{tabular}{lc} 
Taxa de Juros & $8,00 \%$ \\
\hline Fator de Atualização & 10,60
\end{tabular}

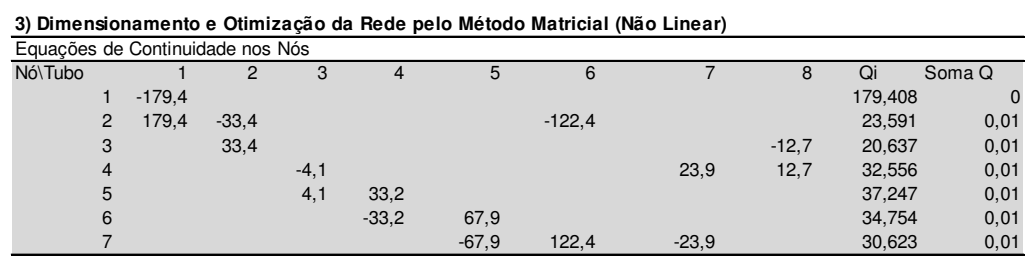

\begin{tabular}{cccccccccr}
\hline Equações de Perda de Carga nos Circuitos & & & & & \\
\hline Circuitos & 1 & 2 & 3 & 4 & 5 & 6 & 7 & 8 & Soma Perda \\
& & & & & & & & \\
1 & $-0,600$ & & & & 1,238 & 0,304 & $-0,943$ & 0,0001 \\
2 & & $-0,732$ & 0,192 & 0,844 & & $-0,304$ & & $1 \mathrm{E}-04$ \\
\hline
\end{tabular}

Tabela da Função Objetivo

\begin{tabular}{|c|c|c|c|c|c|c|c|c|c|c|c|c|c|c|}
\hline \multirow{2}{*}{ Trecho } & \multicolumn{2}{|c|}{ Nó Montante } & \multicolumn{2}{|c|}{ No Jusante } & \multirow{2}{*}{$\begin{array}{c}\begin{array}{c}\text { Extensão } \\
\text { do Trecho }\end{array} \\
(\mathrm{m})\end{array}$} & \multirow{2}{*}{$\begin{array}{c}\text { Vazão do } \\
\text { Trecho }\end{array}$} & \multirow{2}{*}{$\begin{array}{c}\begin{array}{c}\text { Diâmetro } \\
\text { Nominal } \\
\text { Comercial }\end{array} \\
(\mathrm{mm}) \\
\end{array}$} & \multirow{2}{*}{$\begin{array}{c}\text { Diâmetro } \\
\text { Ótimo }\end{array}$} & \multirow{2}{*}{$\begin{array}{c}\text { Velocidade } \\
(\mathrm{m} / \mathrm{s})\end{array}$} & \multirow[t]{2}{*}{$\begin{array}{l}\text { Fator de } \\
\text { Atrito } f\end{array}$} & \multirow{2}{*}{$\begin{array}{c}\text { Perda de Carga } \\
(\mathrm{m})\end{array}$} & \multirow{2}{*}{$\begin{array}{c}\begin{array}{c}\text { Carga } \\
\text { Montante }\end{array} \\
(\mathrm{m})\end{array}$} & \multirow{2}{*}{$\begin{array}{c}\text { Carga Jusante } \\
(\mathrm{m})\end{array}$} & \multirow{2}{*}{$\begin{array}{c}\text { Potência Dissipada } \\
\mathrm{kW}\end{array}$} \\
\hline & Nome & Cota & Nome & Cota & & & & & & & & & & \\
\hline $\mathrm{T1}$ & $\mathrm{N} 1$ & 4,56 & $\mathrm{~N} 2$ & 3,50 & 258,48 & 179,4 & 400 & 401 & 1,42 & 0,0082 & 0,55 & 10,80 & 11,31 & 1,37 \\
\hline T2 & N2 & 3,50 & N3 & 3,50 & 255,93 & 33,4 & 200 & 184 & 1,06 & 0,0082 & 0,60 & 11,31 & 10,71 & 0,28 \\
\hline T3 & $\mathrm{N} 4$ & 1,50 & N5 & 0,49 & 657,53 & 4,1 & 100 & 100 & 0,52 & 0,0082 & 0,73 & 11,77 & 12,04 & 0,04 \\
\hline T4 & N5 & 0,49 & N6 & 0,50 & 253,28 & 33,2 & 250 & 237 & 0,67 & 0,0082 & 0,19 & 12,04 & 11,84 & 0,09 \\
\hline T5 & N6 & 0,50 & N7 & 1,50 & 660,47 & 67,9 & 300 & 299 & 0,96 & 0,0082 & 0,84 & 11,84 & 10,00 & 0,80 \\
\hline T6 & N2 & 3,50 & N7 & 1,50 & 644,10 & 122,4 & 350 & 350 & 1,27 & 0,0082 & 1,24 & 11,31 & 12,07 & 2,12 \\
\hline$T 7$ & N7 & 1,50 & $\mathrm{~N} 4$ & 1,50 & 253,02 & 23,9 & 200 & 189 & 0,76 & 0,0082 & 0,30 & 12,07 & 11,77 & 0,10 \\
\hline T8 & N3 & 3,50 & $\mathrm{~N} 4$ & 1,50 & 657,18 & 12,7 & 150 & 148 & 0,72 & 0,0082 & 0,94 & 11,31 & 12,37 & 0,17 \\
\hline
\end{tabular}

4) Resumo do Dimensionamento Otimizado

\begin{tabular}{|c|c|c|c|}
\hline & Poté & Dissipada & Pressurização Inicial \\
\hline Soma & & 4,98 & 27,11 \\
\hline Energia & & $32.721,15$ & $178.993,46$ \\
\hline FA & & 10,60 & 10,60 \\
\hline Sub-Total & $\mathrm{R} \$$ & $57.625,39$ & $315.183,42$ \\
\hline
\end{tabular}

\begin{tabular}{|c|c|c|}
\hline Custos & & Porcentagem \\
\hline Custo de Tubulação $R \$$ & $963.314,95$ & $52,37 \%$ \\
\hline Custo de Movimento de Terra $\mathrm{R} \$$ & $59.797,78$ & $3,25 \%$ \\
\hline Custo de Assentamento R\$ & $10.927,56$ & $0,59 \%$ \\
\hline Custo de Pavimentação $\mathrm{R} \$$ & $432.663,95$ & $23,52 \%$ \\
\hline Custo da Pressurização Inicial $\mathrm{R} \$$ & $315.183,42$ & $17,13 \%$ \\
\hline Custo da Potência Dissipada $\mathrm{R} \$$ & $57.625,39$ & $3,13 \%$ \\
\hline Total Global (Função Objetivo) R\$ & $1.839 .513,05$ & $100,00 \%$ \\
\hline Total Referencial Unitário $\mathrm{R} \$$ & 505,36 & por metro de rede \\
\hline
\end{tabular}


5) Quantitativos e Custos de Implantação das Redes de Abastecimento

\begin{tabular}{|c|c|c|c|c|c|c|c|c|c|}
\hline Trecho & $\begin{array}{l}\text { Locação da } \\
\text { Tubulação }\end{array}$ & $\begin{array}{l}\text { Tipo de } \\
\text { Superfície }\end{array}$ & Tipo de Tráfego & & & & & & \\
\hline $\mathrm{T} 1$ & viario pavimentado & asfalto & Pesado & & & & & & \\
\hline $\mathrm{T} 2$ & viario pavimentado & asfalto & Pesado & & & & & & \\
\hline T3 & viario pavimentado & asfalto & Pesado & & & & & & \\
\hline T4 & viario pavimentado & asfalto & Pesado & & & & & & \\
\hline $\mathrm{T5}$ & viario pavimentado & asfalto & Pesado & & & & & & \\
\hline T6 & viario pavimentado & asfalto & Pesado & & & & & & \\
\hline$\pi 7$ & viario pavimentado & asfalto & Pesado & & & & & & \\
\hline T8 & viario pavimentado & asfalto & Pesado & & & & & & \\
\hline \multirow{3}{*}{ Trecho } & \multicolumn{6}{|c|}{ Vala } & \multicolumn{3}{|c|}{ Tubulação } \\
\hline & Largura & Profundidade & Escavação & Reaterro & Bota-Fora & TOTAL & Assentamento & Material & TOTAL \\
\hline & $\mathrm{m}$ & $\mathrm{m}$ & $m^{3}$ & $\mathrm{~m}^{3}$ & $\mathrm{~m}^{3}$ & $\mathbf{R} \$$ & $\mathrm{R} \$$ & $\mathrm{R} \$$ & $\mathbf{R} \$$ \\
\hline $\mathrm{T} 1$ & 0,75 & 1,40 & 271,40 & 185,29 & 86,12 & $5.944,79$ & $1.330,32$ & $117.523,27$ & $118.853,60$ \\
\hline $\mathrm{T} 2$ & 0,55 & 1,20 & 168,91 & 120,56 & 48,35 & $3.752,38$ & 635,06 & $56.118,96$ & $56.754,03$ \\
\hline T3 & 0,50 & 1,10 & 361,64 & 261,14 & 100,51 & $8.063,90$ & $1.003,88$ & $85.726,57$ & $86.730,44$ \\
\hline T4 & 0,60 & 1,25 & 189,96 & 134,47 & 55,49 & $4.208,74$ & 773,32 & $68.619,54$ & $\begin{array}{l}69.392,87 \\
\end{array}$ \\
\hline T5 & 0,65 & 1,30 & 558,10 & 390,88 & 167,22 & $12.323,19$ & $2.435,85$ & $216.219,82$ & $218.655,67$ \\
\hline T6 & 0,70 & 1,35 & 608,67 & 421,11 & 187,57 & $13.387,99$ & $2.824,95$ & $250.311,21$ & $253.136,16$ \\
\hline 77 & 0,55 & 1,20 & 166,99 & 119,19 & 47,80 & $3.709,72$ & 627,84 & $55.480,87$ & $56.108,72$ \\
\hline \multirow[t]{2}{*}{ T8 } & 0,50 & 1,15 & 377,88 & 270,97 & 106,90 & $8.407,08$ & $1.296,33$ & $113.314,70$ & $114.611,03$ \\
\hline & & & & & Soma & $59.797,78$ & $\mathrm{R} \$ \quad 10.927,56$ & $\mathrm{R} \$ 963.314,95 \quad \mathbf{R} \$$ & $974.242,51$ \\
\hline \multicolumn{10}{|c|}{$\begin{array}{c}\text { Pavimentação } \\
\text { Vala }\end{array}$} \\
\hline \multirow{3}{*}{ Trecho } & & & & Jala & & & & & \\
\hline & Área & $\begin{array}{l}\text { Área de } \\
\text { Concreto }\end{array}$ & $\begin{array}{c}\text { Área de } \\
\text { Paralelepipedos }\end{array}$ & $\begin{array}{l}\text { Área de } \\
\text { Asfalto }\end{array}$ & Área de Binder & $\begin{array}{l}\text { Área de Concreto Astático } \\
\text { Usinado a Quente }\end{array}$ & & & \\
\hline & $\mathrm{m}^{2}$ & $\mathrm{~m}^{2}$ & $\mathrm{~m}^{2}$ & $\mathrm{~m}^{2}$ & $\mathrm{~m}^{2}$ & $\mathrm{~m}^{2}$ & & & \\
\hline $\mathrm{T} 1$ & 193,86 & 0,00 & 0,00 & 193,86 & 245,56 & 775,44 & & & \\
\hline $\mathrm{T} 2$ & 140,76 & 0,00 & 0,00 & 140,76 & 191,95 & 767,79 & & & \\
\hline T3 & 328,77 & 0,00 & 0,00 & 328,77 & 460,27 & $1.972,59$ & & & \\
\hline $\mathrm{T} 4$ & 151,97 & 0,00 & 0,00 & 151,97 & 202,62 & 759,84 & & & \\
\hline T5 & 429,31 & 0,00 & 0,00 & 429,31 & 561,40 & $1.981,41$ & & & \\
\hline T6 & 450,87 & 0,00 & 0,00 & 450,87 & 579,69 & $1.932,30$ & & & \\
\hline 77 & 139,16 & 0,00 & 0,00 & 139,16 & 189,77 & 759,06 & & & \\
\hline T8 & 328,59 & 0,00 & 0,00 & 328,59 & 460,03 & $1.971,54$ & & & \\
\hline \multirow{4}{*}{ Trecho } & \multicolumn{9}{|c|}{ Pavimentação } \\
\hline & \multicolumn{3}{|c|}{ Volume } & \multicolumn{2}{|c|}{ Área } & \multicolumn{4}{|c|}{ Custos } \\
\hline & $\begin{array}{l}\text { Macadame } \\
\text { Hidáulico }\end{array}$ & Binder & $\begin{array}{c}\text { Concreto } \\
\text { Asfáltico Usinado } \\
\text { a Quente }\end{array}$ & $\begin{array}{l}\text { Imprimação } \\
\text { Betuminosa } \\
\text { Ligante }\end{array}$ & $\begin{array}{l}\text { Imprimação } \\
\text { Betuminosa } \\
\text { Impermeabiliza } \\
\text { nte }\end{array}$ & Remoção & Recomposição & Transporte & TOTAL \\
\hline & $\mathrm{m}^{3}$ & $\mathrm{~m}^{3}$ & $\mathrm{~m}^{3}$ & $\mathrm{~m}^{2}$ & $\mathrm{~m}^{2}$ & $\mathrm{R} \$$ & $\mathrm{R} \$$ & $\mathrm{R} \$$ & $\mathrm{R} \$$ \\
\hline $\mathrm{T} 1$ & 29,08 & 24,56 & 38,77 & 245,56 & 775,44 & $1.570,75$ & $31.366,66$ & 421,35 & $33.358,76$ \\
\hline T2 & 21,11 & 19,19 & 38,39 & 191,95 & 767,79 & $1.140,52$ & $28.154,77$ & 383,13 & $29.678,42$ \\
\hline T3 & 49,31 & 46,03 & 98,63 & 460,27 & $1.972,59$ & $2.663,81$ & $70.470,40$ & 962,46 & \begin{tabular}{|l|l|}
$74.096,68$ \\
\end{tabular} \\
\hline $\mathrm{T} 4$ & 22,80 & 20,26 & 37,99 & 202,62 & 759,84 & $1.231,32$ & $28.581,34$ & 387,59 & $30.200,25$ \\
\hline T5 & 64,40 & 56,14 & 99,07 & 561,40 & $1.981,41$ & $3.478,44$ & $76.403,20$ & $1.032,68$ & $80.914,32$ \\
\hline T6 & 67,63 & 57,97 & 96,62 & 579,69 & $1.932,30$ & $3.653,16$ & $76.335,67$ & $1.028,51$ & $81.017,35$ \\
\hline$T 7$ & 20,87 & 18,98 & 37,95 & 189,77 & 759,06 & $1.127,55$ & $27.834,64$ & 378,78 & $29.340,96$ \\
\hline T8 & 49,29 & 46,00 & 98,58 & 460,03 & $1.971,54$ & $2.662,39$ & $70.432,89$ & 961,95 & $\begin{array}{l}4.057,23 \\
\end{array}$ \\
\hline
\end{tabular}




\section{APÊNDICE B1 - Planilha de Dimensionamento para Tarifa Verde - Fora de Ponta Úmida e Viário em Paralelepípedo - PVC}

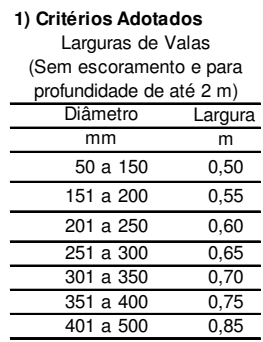

Locação das Redes

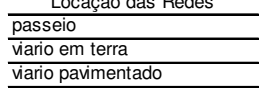

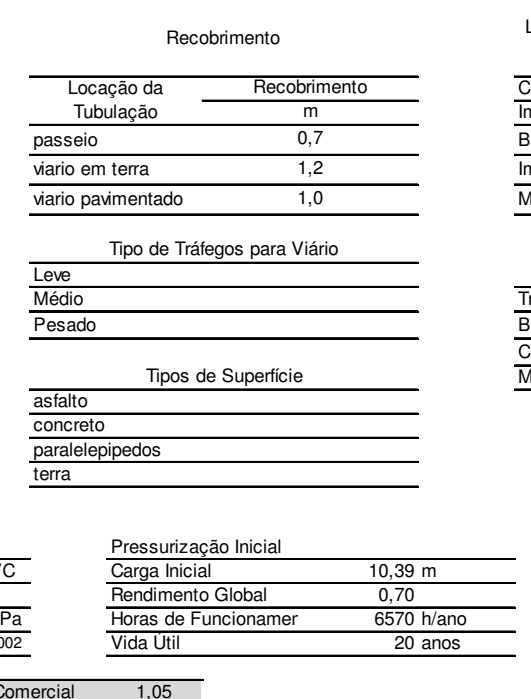

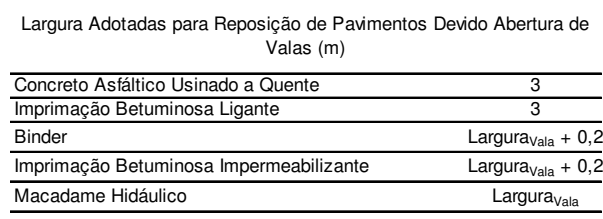

\begin{tabular}{lccc}
\multicolumn{4}{c}{ Espessuras Adotadas para Reposição de Pavimentos Devido Abertura de Valas $(\mathrm{m})$} \\
\hline Tráfego & Leve & Médio & Pesado \\
\hline Binder & 0,04 & 0,07 & 0,10 \\
\hline Concreto Asfáltico Usinado a Quente & 0,04 & 0,05 & 0,05 \\
\hline Macadame Hidáulico & 0,10 & 0,12 & 0,15 \\
\hline
\end{tabular}

$\begin{aligned} & \text { Largura Adotadas para Reposição de Pavimentos Devido Abertura de } \\
& \text { Valas }(\mathrm{m})\end{aligned}$
\begin{tabular}{|lc}
\hline Concreto Asfáltico Usinado a Quente & 3 \\
\hline Imprimação Betuminosa Ligante & 3 \\
\hline Binder & Larguravala $+0,2$ \\
\hline Imprimação Betuminosa Impermeabilizante & Larguravala $+0,2$ \\
\hline Macadame Hidáulico & Larguravala \\
\hline
\end{tabular}

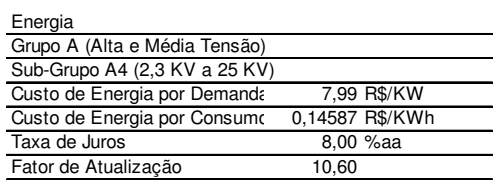

2) Dados Adotados

Tubulação

Materia

\begin{tabular}{lll} 
Classe de Pressão & $\mathrm{Cl} 20$ & $1 \mathrm{MPa}$ \\
\hline
\end{tabular} \begin{tabular}{ll}
\hline Rugosidade Equivalente (m) & 0,00002 \\
\hline
\end{tabular}

Fator entre Diâmetro Hidráulico e Comercial

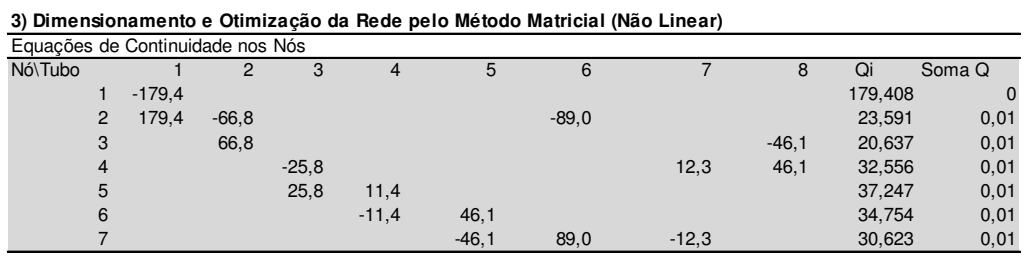

\begin{tabular}{cccccccccr}
\hline Equações de Perda de Carga nos Circuitos & & & & & & \\
\hline & 1 & 2 & 3 & 4 & 5 & 6 & 7 & 8 & Soma Perda \\
1 & $-0,607$ & & & & 1,091 & 0,260 & $-0,744$ & 0,0001 \\
2 & & & & & & & & \\
2 & & $-0,713$ & 0,225 & 0,748 & & $-0,260$ & & $1 E-04$ \\
\hline
\end{tabular}

Tabela da Função Objetivo

\begin{tabular}{|c|c|c|c|c|c|c|c|c|c|c|c|c|c|c|}
\hline \multirow{2}{*}{ Trecho } & \multicolumn{2}{|c|}{ Nó Montante } & \multicolumn{2}{|c|}{ No Jusante } & \multirow{2}{*}{$\begin{array}{c}\begin{array}{c}\text { Extensão } \\
\text { do Trecho }\end{array} \\
\text { (m) }\end{array}$} & \multirow{2}{*}{$\begin{array}{c}\begin{array}{c}\text { Vazão do } \\
\text { Trecho }\end{array} \\
\text { l/s }\end{array}$} & \multirow{2}{*}{$\begin{array}{c}\text { Diâmetro } \\
\text { Nominal } \\
\text { Comercial }\end{array}$} & \multirow{2}{*}{$\begin{array}{c}\begin{array}{c}\text { Diâmetro } \\
\text { Ótimo }\end{array} \\
(\mathrm{mm})\end{array}$} & \multirow{2}{*}{$\begin{array}{c}\text { Velocidade } \\
(\mathrm{m} / \mathrm{s})\end{array}$} & \multirow[t]{2}{*}{$\begin{array}{l}\text { Fator de } \\
\text { Atrito } f\end{array}$} & \multirow{2}{*}{ Perda de Carga } & \multirow{2}{*}{$\begin{array}{c}\begin{array}{c}\text { Carga } \\
\text { Montante }\end{array} \\
(\mathrm{m})\end{array}$} & \multirow{2}{*}{$\begin{array}{c}\text { Carga Jusante } \\
(\mathrm{m})\end{array}$} & \multirow{2}{*}{$\begin{array}{c}\text { Potência Dissipada } \\
\mathrm{kW}\end{array}$} \\
\hline & Nome & Cota & Nome & Cota & & & & & & & & & & \\
\hline $\mathrm{T1}$ & $\mathrm{N} 1$ & 4,56 & N2 & 3,50 & 258,48 & 179,4 & 400 & 401 & 1,42 & 0,0063 & 0,42 & 10,39 & 11,04 & 1,06 \\
\hline T2 & N2 & 3,50 & N3 & 3,50 & 255,93 & 66,8 & 250 & 251 & 1,36 & 0,0063 & 0,61 & 111,04 & 10,43 & 0,57 \\
\hline T3 & $\mathrm{N} 4$ & 1,50 & N5 & 0,49 & 657,53 & 25,8 & 200 & 201 & 0,82 & 0,0063 & 0,71 & 11,69 & 11,98 & 0,26 \\
\hline T4 & N5 & 0,49 & N6 & 0,50 & 253,28 & 11,4 & 150 & 150 & 0,64 & 0,0063 & 0,22 & 11,98 & 11,75 & 0,04 \\
\hline T5 & N6 & 0,50 & N7 & 1,50 & 660,47 & 46,1 & 250 & 249 & 0,94 & 0,0063 & 0,75 & 11,75 & 10,00 & 0,48 \\
\hline T6 & N2 & 3,50 & N7 & 1,50 & 644,10 & 89,0 & 300 & 301 & 1,26 & 0,0063 & 1,09 & 11,04 & 11,94 & 1,36 \\
\hline$T 7$ & N7 & 1,50 & N4 & 1,50 & 253,02 & 12,3 & 150 & 150 & 0,69 & 0,0063 & 0,26 & 11,94 & 11,69 & 0,04 \\
\hline T8 & N3 & 3,50 & N4 & 1,50 & 657,18 & 46,1 & 250 & 223 & 0,94 & 0,0063 & 0,74 & 11,04 & 12,29 & 0,48 \\
\hline
\end{tabular}

4) Resumo do Dimensionamento Otimizado

\begin{tabular}{|c|c|c|c|}
\hline \multicolumn{3}{|c|}{ Potência Dissipada } & Pressurização Inicial \\
\hline Soma & & 4,29 & 26,11 \\
\hline Energia & & $28.175,84$ & $171.534,57$ \\
\hline FA & & 10,60 & 10,60 \\
\hline Sub-Total & $\mathbf{R} \$$ & $43.944,23$ & $267.532,60$ \\
\hline
\end{tabular}

\begin{tabular}{|c|c|c|}
\hline Custos & & Porcentagem \\
\hline Custo de Tubulação $\mathrm{R} \$$ & $399.999,17$ & $47,54 \%$ \\
\hline Custo de Movimento de Terra $R \$$ & $66.390,90$ & $7,89 \%$ \\
\hline Custo de Assentamento $\mathrm{R} \$$ & $11.140,60$ & $1,32 \%$ \\
\hline Custo de Pavimentação $R \$$ & $52.339,54$ & $6,22 \%$ \\
\hline Custo da Pressurização Inicial $\mathrm{R} \$$ & $267.532,60$ & $31,80 \%$ \\
\hline Custo da Potência Dissipada $R \$$ & $43.944,23$ & $5,22 \%$ \\
\hline Total Global (Função Objetivo) R\$ & $841.347,04$ & $100,00 \%$ \\
\hline Total Referncial Unitário $\mathbf{R} \$$ & 231,14 & por metro de rede \\
\hline
\end{tabular}


5) Quantitativos e Custos de Implantação das Redes de Abastecimento

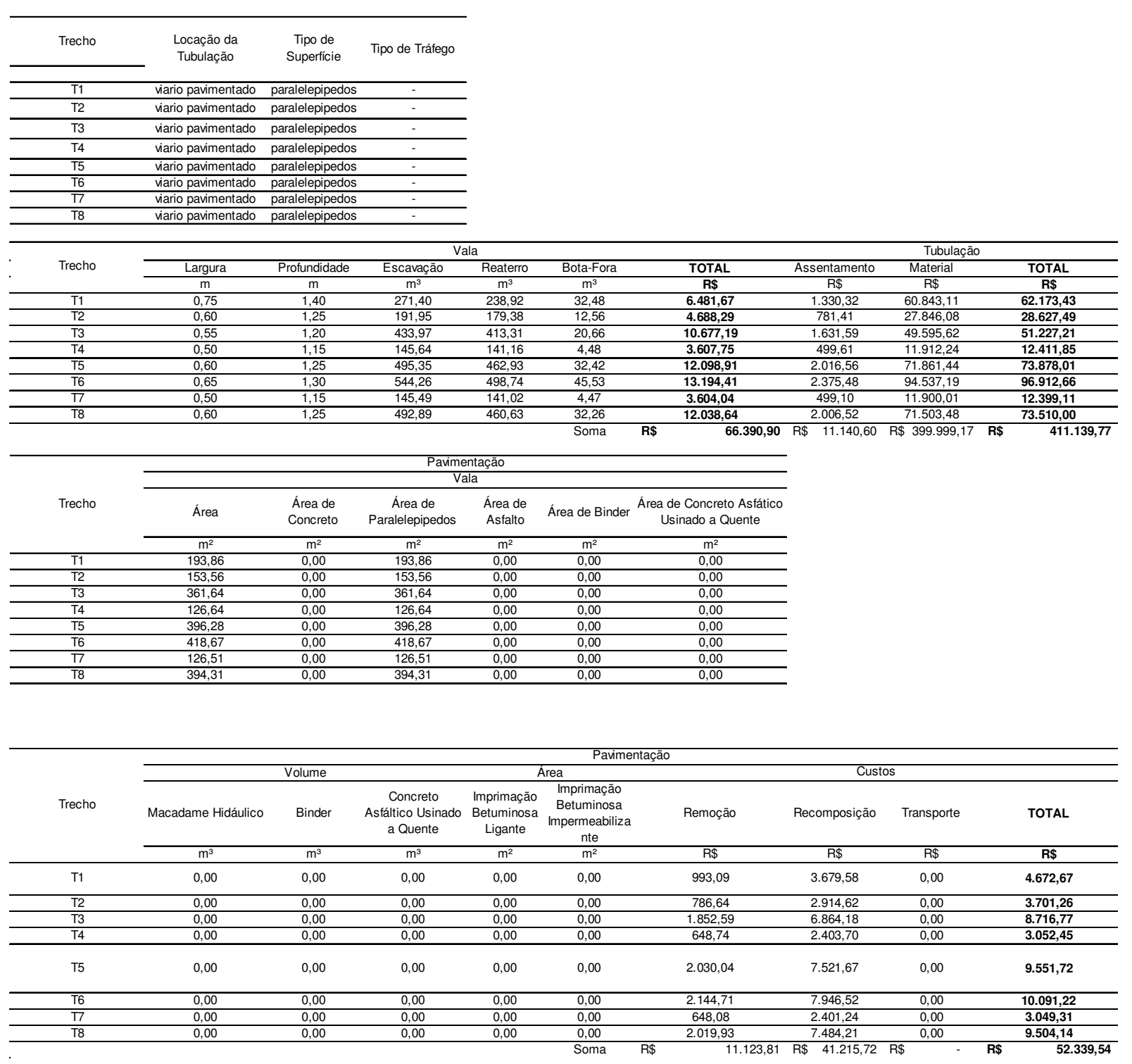




\section{APÊNDICE B2 - Planilha de Dimensionamento para Tarifa Convencional e Viário em Paralelepípedo - PVC}

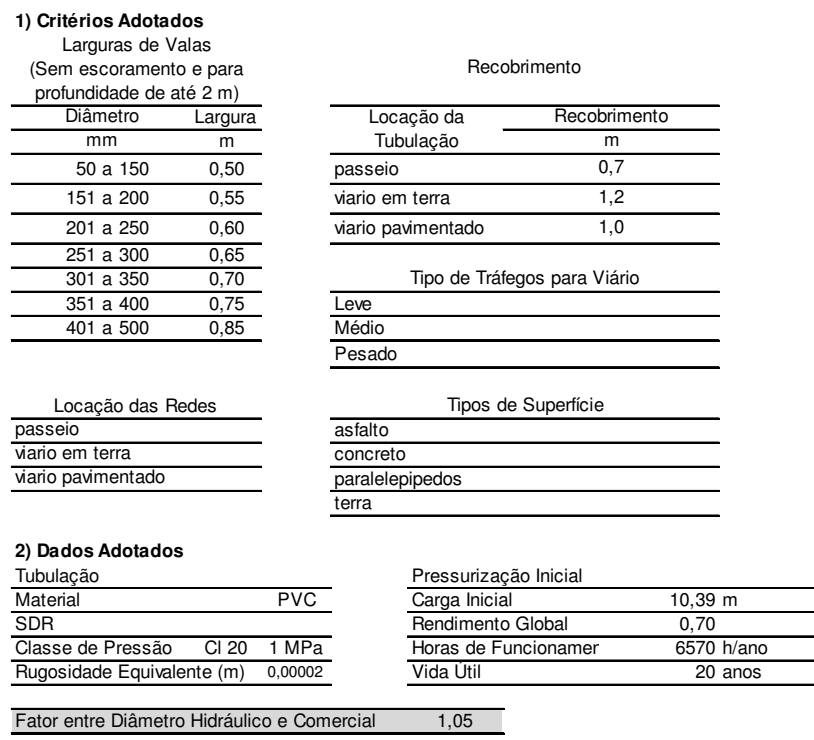

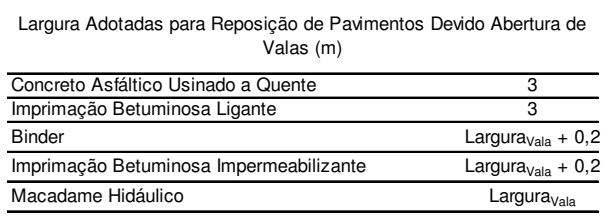

Espessuras Adotadas para Reposição de Pavimentos Devido Abertura de Valas (m)

\begin{tabular}{lccc}
\hline Tráfego & Leve & Médio & Pesado \\
\hline Binder & 0,04 & 0,07 & 0,10 \\
\hline Concreto Asfáltico Usinado a Quente & 0,04 & 0,05 & 0,05 \\
\hline Macadame Hidáulico & 0,10 & 0,12 & 0,15 \\
\hline
\end{tabular}

Energia
\begin{tabular}{ll}
\hline Grupo A (Alta e Média Tensão) \\
\hline Sub-Grupo A4 (2,3 KV a 25 KV) \\
\hline Custo de Energia por Demandi & $31,31 \mathrm{R} \$ / \mathrm{KW}$ \\
\hline Custo de Energia por Consumc & $0,16132 \mathrm{R} \$ / \mathrm{KWh}$ \\
\hline Taxa de Juros & $8,00 \% \mathrm{aa}$ \\
\hline Fator de Atualização & 10,60 \\
\hline
\end{tabular}

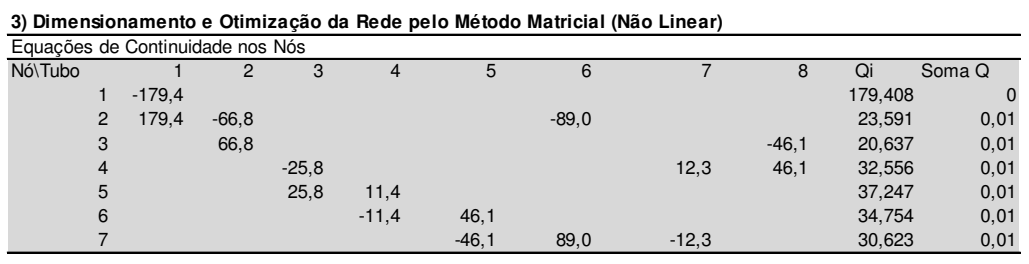

\begin{tabular}{|c|c|c|c|c|c|c|c|c|c|}
\hline \multicolumn{10}{|c|}{ Equações de Perda de Carga nos Circuitos } \\
\hline Circuitos & 1 & $\frac{2}{2}$ & 3 & 4 & 5 & 6 & 7 & 8 & Soma Perda \\
\hline 1 & & $-0,607$ & & & & 1,091 & 0,260 & $-0,744$ & 0,0001 \\
\hline 2 & & & $-0,713$ & 0,225 & 0,748 & & $-0,260$ & & $1 \mathrm{E}-04$ \\
\hline
\end{tabular}

Tabela da Função Objetivo

\begin{tabular}{|c|c|c|c|c|c|c|c|c|c|c|c|c|c|c|}
\hline \multirow{2}{*}{ Trecho } & \multicolumn{2}{|c|}{ Nó Montante } & \multicolumn{2}{|c|}{ No Jusante } & \multirow{2}{*}{$\begin{array}{r}\begin{array}{l}\text { Extensão } \\
\text { do Trecho }\end{array} \\
\text { (m) }\end{array}$} & \multirow{2}{*}{$\begin{array}{c}\begin{array}{c}\text { Vazão do } \\
\text { Trecho }\end{array} \\
1 / \mathrm{s}\end{array}$} & \multirow{2}{*}{$\begin{array}{c}\text { Diâmetro } \\
\text { Nominal } \\
\text { Comercial }\end{array}$} & \multirow{2}{*}{$\begin{array}{c}\begin{array}{c}\text { Diâmetro } \\
\text { Ótimo }\end{array} \\
(\mathrm{mm})\end{array}$} & \multirow{2}{*}{$\begin{array}{c}\text { Velocidade } \\
(\mathrm{m} / \mathrm{s})\end{array}$} & \multirow{2}{*}{$\begin{array}{l}\text { Fator de } \\
\text { Atrito } f\end{array}$} & \multirow{2}{*}{ Perda de Carga } & \multirow{2}{*}{$\begin{array}{c}\begin{array}{c}\text { Carga } \\
\text { Montante }\end{array} \\
(\mathrm{m})\end{array}$} & \multirow{2}{*}{$\begin{array}{c}\text { Carga Jusante } \\
(\mathrm{m})\end{array}$} & \multirow{2}{*}{$\begin{array}{c}\text { Potência Dissipada } \\
\mathrm{kW}\end{array}$} \\
\hline & Nome & Cota & Nome & Cota & & & & & & & & & & \\
\hline $\mathrm{T} 1$ & $\mathrm{~N} 1$ & 4,56 & N2 & 3,50 & 258,48 & 179,4 & 400 & 401 & 1,42 & 0,0063 & 0,42 & 10,39 & 11,04 & 1,06 \\
\hline T2 & N2 & 3,50 & N3 & 3,50 & 255,93 & 66,8 & 250 & 251 & 1,36 & 0,0063 & 0,61 & 11,04 & 10,43 & 0,57 \\
\hline T3 & $\mathrm{N} 4$ & 1,50 & N5 & 0,49 & 657,53 & 25,8 & 200 & 201 & 0,82 & 0,0063 & 0,71 & 11,69 & 11,98 & 0,26 \\
\hline T4 & N5 & 0,49 & N6 & 0,50 & 253,28 & 11,4 & 150 & 150 & 0,64 & 0,0063 & 0,22 & 11,98 & 11,75 & 0,04 \\
\hline T5 & N6 & 0,50 & N7 & 1,50 & 660,47 & 46,1 & 250 & 249 & 0,94 & 0,0063 & 0,75 & 11,75 & 10,00 & 0,48 \\
\hline T6 & N2 & 3,50 & N7 & 1,50 & 644,10 & 89,0 & 300 & 301 & 1,26 & 0,0063 & 1,09 & 11,04 & 11,94 & 1,36 \\
\hline$T 7$ & N7 & 1,50 & N4 & 1,50 & 253,02 & 12,3 & 150 & 150 & 0,69 & 0,0063 & 0,26 & 11,94 & 11,69 & 0,04 \\
\hline T8 & N3 & 3,50 & N4 & 1,50 & 657,18 & 46,1 & 250 & 223 & 0,94 & 0,0063 & 0,74 & 11,04 & 12,29 & 0,48 \\
\hline & & & & Soma & 3639,99 & & & & & & & & & 4,29 \\
\hline
\end{tabular}

4) Resumo do Dimensionamento Otimizado

\begin{tabular}{|c|c|c|}
\hline & Potência Dissipada & Pressurização Inicial \\
\hline Soma & 4,29 & 26,11 \\
\hline Energia & $28.175,84$ & $171.534,57$ \\
\hline FA & 10,60 & 10,60 \\
\hline Sub-Total & $49.620,62$ & $302.090,42$ \\
\hline
\end{tabular}

\begin{tabular}{|c|c|c|}
\hline Custos & & Porcentagem \\
\hline Custo de Tubulação $\mathrm{R} \$$ & $399.999,17$ & $45,37 \%$ \\
\hline Custo de Movimento de Terra $\mathrm{R} \$$ & $66.390,90$ & $7,53 \%$ \\
\hline Custo de Assentamento R\$ & $11.140,60$ & $1,26 \%$ \\
\hline Custo de Pavimentação $R \$$ & $52.339,54$ & $5,94 \%$ \\
\hline Custo da Pressurização Inicial $R \$$ & $302.090,42$ & $34,27 \%$ \\
\hline Custo da Potência Dissipada $R \$$ & $49.620,62$ & $5,63 \%$ \\
\hline Total Global (Função Objetivo) R\$ & $881.581,25$ & $100,00 \%$ \\
\hline Total Referncial Unitário R\$ & 242,19 & por metro de rede \\
\hline
\end{tabular}


5) Quantitativos e Custos de Implantação das Redes de Abastecimento

\begin{tabular}{|c|c|c|c|c|c|c|c|c|c|}
\hline Trecho & $\begin{array}{l}\text { Locação da } \\
\text { Tubulação }\end{array}$ & $\begin{array}{c}\text { Tipo de } \\
\text { Superfície }\end{array}$ & Tipo de Tráfego & & & & & & \\
\hline $\mathrm{T} 1$ & viario pavimentado & paralelepipedos & - & & & & & & \\
\hline $\mathrm{T} 2$ & vario pavimentado & paralelepipedos & - & & & & & & \\
\hline T3 & viario pavimentado & paralelepipedos & - & & & & & & \\
\hline T4 & viario pavimentado & paralelepipedos & - & & & & & & \\
\hline T5 & viario pavimentado & paralelepipedos & - & & & & & & \\
\hline T6 & viario pavimentado & paralelepipedos & - & & & & & & \\
\hline 77 & viario pavimentado & paralelepipedos & - & & & & & & \\
\hline $\mathrm{T} 8$ & viario pavimentado & paralelepipedos & - & & & & & & \\
\hline \multirow{3}{*}{ Trecho } & \multicolumn{6}{|c|}{ Vala } & \multicolumn{3}{|c|}{ Tubulação } \\
\hline & Largura & $\begin{array}{l}\text { Profundidade } \\
\end{array}$ & Escavação & Reaterro & Bota-Fora & TOTAL & Assentamento & Material & TOTAL \\
\hline & $\mathrm{m}$ & $\mathrm{m}$ & $\mathrm{m}^{3}$ & $\mathrm{~m}^{3}$ & $\mathrm{~m}^{3}$ & $\mathbf{R} \$$ & $\mathrm{R} \$$ & $\mathrm{R} \$$ & $\mathbf{R} \$$ \\
\hline $\mathrm{T} 1$ & 0,75 & 1,40 & 271,40 & 238,92 & 32,48 & $6.481,67$ & $1.330,32$ & $60.843,11$ & $62.173,43$ \\
\hline $\mathrm{T} 2$ & 0,60 & 1,25 & 191,95 & 179,38 & 12,56 & $4.688,29$ & 781,41 & $27.846,08$ & $28.627,49$ \\
\hline T3 & 0,55 & 1,20 & 433,97 & 413,31 & 20,66 & $10.677,19$ & $1.631,59$ & $49.595,62$ & $51.227,21$ \\
\hline $\mathrm{T} 4$ & 0,50 & 1,15 & 145,64 & 141,16 & 4,48 & $3.607,75$ & 499,61 & $11.912,24$ & $12.411,85$ \\
\hline T5 & 0,60 & 1,25 & 495,35 & 462,93 & 32,42 & $12.098,91$ & $2.016,56$ & $71.861,44$ & $73.878,01$ \\
\hline T6 & 0,65 & 1,30 & 544,26 & 498,74 & 45,53 & $13.194,41$ & $2.375,48$ & $94.537,19$ & $96.912,66$ \\
\hline$T 7$ & 0,50 & 1,15 & 145,49 & 141,02 & 4,47 & $3.604,04$ & 499,10 & $11.900,01$ & $12.399,11$ \\
\hline \multirow[t]{2}{*}{ T8 } & 0,60 & 1,25 & 492,89 & 460,63 & 32,26 & $12.038,64$ & $2.006,52$ & $71.503,48$ & $73.510,00$ \\
\hline & & & & & Soma & $66.390,90$ & $\mathrm{R} \$ \quad 11.140,60$ & $\mathrm{R} \$ 399.999,17 \quad \mathrm{R} \$$ & $411.139,77$ \\
\hline \multirow{2}{*}{\multicolumn{10}{|c|}{$\frac{\text { Pavimentaçäo }}{\text { Vala }}$}} \\
\hline & & & & & & & & & \\
\hline \multirow[t]{2}{*}{ Trecho } & Área & $\begin{array}{l}\text { Área de } \\
\text { Concreto }\end{array}$ & $\begin{array}{c}\text { Área de } \\
\text { Paralelepipedos }\end{array}$ & $\begin{array}{l}\text { Área de } \\
\text { Asfalto }\end{array}$ & Área de Binder & $\begin{array}{l}\text { Área de Concreto Astático } \\
\text { Usinado a Quente }\end{array}$ & & & \\
\hline & $\mathrm{m}^{2}$ & $\mathrm{~m}^{2}$ & $\mathrm{~m}^{2}$ & $\mathrm{~m}^{2}$ & $\mathrm{~m}^{2}$ & $\mathrm{~m}^{2}$ & & & \\
\hline $\mathrm{T} 1$ & 193,86 & 0,00 & 193,86 & 0,00 & 0,00 & 0,00 & & & \\
\hline $\mathrm{T} 2$ & 153,56 & 0,00 & 153,56 & 0,00 & 0,00 & 0,00 & & & \\
\hline T3 & 361,64 & 0,00 & 361,64 & 0,00 & 0,00 & 0,00 & & & \\
\hline T4 & 126,64 & 0,00 & 126,64 & 0,00 & 0,00 & 0,00 & & & \\
\hline T5 & 396,28 & 0,00 & 396,28 & 0,00 & 0,00 & 0,00 & & & \\
\hline T6 & 418,67 & 0,00 & 418,67 & 0,00 & 0,00 & 0,00 & & & \\
\hline 77 & 126,51 & 0,00 & 126,51 & 0,00 & 0,00 & 0,00 & & & \\
\hline T8 & 394,31 & 0,00 & 394,31 & 0,00 & 0,00 & 0,00 & & & \\
\hline \multirow{4}{*}{ Trecho } & \multicolumn{9}{|c|}{ Pavimentação } \\
\hline & \multicolumn{3}{|c|}{ Volume } & \multicolumn{2}{|c|}{ Area } & \multicolumn{4}{|c|}{ Custos } \\
\hline & Macadame Hidáulico & Binder & $\begin{array}{l}\text { Concreto } \\
\text { Asfáltico Usinado } \\
\text { a Quente }\end{array}$ & $\begin{array}{c}\text { Imprimação } \\
\text { Betuminosa } \\
\text { Ligante }\end{array}$ & $\begin{array}{c}\text { Imprimação } \\
\text { Betuminosa } \\
\text { Impermeabiliza } \\
\text { nte }\end{array}$ & Remoção & Recomposição & Transporte & TOTAL \\
\hline & $\mathrm{m}^{3}$ & $\mathrm{~m}^{3}$ & $\mathrm{~m}^{3}$ & $\mathrm{~m}^{2}$ & $\mathrm{~m}^{2}$ & $\mathrm{R} \$$ & $\mathrm{R} \$$ & $\mathrm{R} \$$ & $\mathbf{R} \$$ \\
\hline $\mathrm{T} 1$ & 0,00 & 0,00 & 0,00 & 0,00 & 0,00 & 993,09 & $3.679,58$ & 0,00 & $4.672,67$ \\
\hline $\mathrm{T} 2$ & 0,00 & 0,00 & 0,00 & 0,00 & 0,00 & 786,64 & $2.914,62$ & 0,00 & $3.701,26$ \\
\hline T3 & 0,00 & 0,00 & 0,00 & 0,00 & 0,00 & $1.852,59$ & $6.864,18$ & 0,00 & $8.716,77$ \\
\hline T4 & 0,00 & 0,00 & 0,00 & 0,00 & 0,00 & 648,74 & $2.403,70$ & 0,00 & $3.052,45$ \\
\hline T5 & 0,00 & 0,00 & 0,00 & 0,00 & 0,00 & $2.030,04$ & $7.521,67$ & 0,00 & $9.551,72$ \\
\hline T6 & 0,00 & 0,00 & 0,00 & 0,00 & 0,00 & $2.144,71$ & $7.946,52$ & 0,00 & $10.091,22$ \\
\hline 77 & 0,00 & 0,00 & 0,00 & 0,00 & 0,00 & 648,08 & $2.401,24$ & 0,00 & $3.049,31$ \\
\hline T8 & 0,00 & 0,00 & 0,00 & 0,00 & 0,00 & $2.019,93$ & $7.484,21$ & 0,00 & $9.504,14$ \\
\hline & & & & & Soma & $11.123,81$ & $\mathrm{R} \$ \quad 41.215,72$ & $\mathbf{R} \$$ & $52.339,54$ \\
\hline
\end{tabular}




\section{APÊNDICE B3 - Planilha de Dimensionamento para Tarifa Azul - Ponta Seca e Viário em Paralelepípedo - PVC}

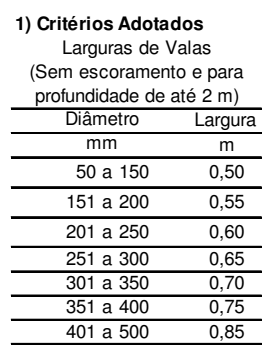

Locação das Redes

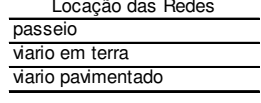

Recobrimento

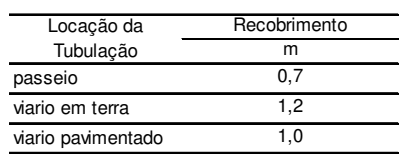

Tipo de Tráfegos para Viário

\begin{tabular}{l}
\multicolumn{1}{c}{ Tipo de Tráfegos para Viário } \\
\hline Leve \\
\hline Médio \\
\hline Pesado \\
\hline Tipos de Superfície \\
\hline asfalto \\
\hline concreto \\
\hline paralelepipedos \\
\hline terra
\end{tabular}

2) Dados Adotados

Tubulação

Materia

SDR

\begin{tabular}{lll} 
& & \\
Classe de Pressão & $\mathrm{Cl} 20$ & $1 \mathrm{MPa}$ \\
\hline
\end{tabular}

\begin{tabular}{ll}
\hline Rugosidade Equivalente (m) & 0,00002 \\
\hline
\end{tabular}

Fator entre Diâmetro Hidráulico e Comercia
Pressurização Inicial

Carga Inicial

\begin{tabular}{lc}
\hline Carga Inicial & $10,18 \mathrm{~m}$ \\
\hline Rendimento Global & 0,70 \\
\hline Horas de Funcionamer & $6570 \mathrm{~h}$
\end{tabular}

Vida Útil

1,05

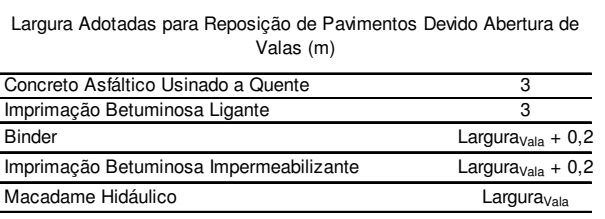

Espessuras Adotadas para Reposição de Pavimentos Devido Abertura de Valas (m) \begin{tabular}{lccc}
\hline Tráfego & Leve & Médio & Pesado
\end{tabular}

\begin{tabular}{llll}
\hline Binder & 0,04 & 0,07 & 0,10
\end{tabular}

\begin{tabular}{lll}
0,04 & 0,05 \\
\hline
\end{tabular}

Macadame Hidáulico

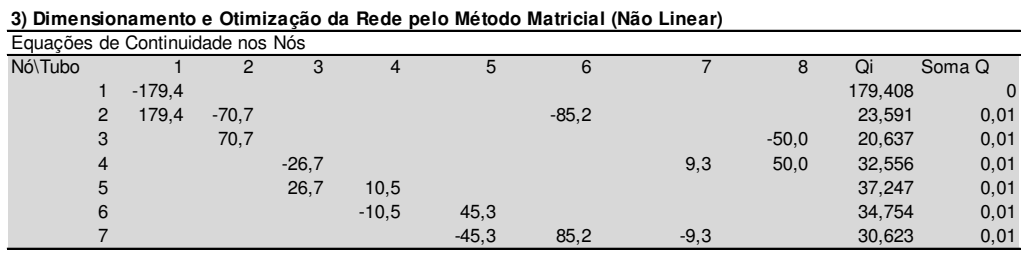

\begin{tabular}{cccccccccc}
\hline Equações de Perda de Carga nos Circuitos & & & & & & \\
\hline Circuitos & 1 & 2 & 3 & 4 & 5 & 6 & 7 & 8 & Soma Perda \\
& & & & & & & & \\
1 & $-0,273$ & & & & 0,998 & 0,149 & $-0,874$ & 0,0001 \\
2 & & $-0,762$ & 0,191 & 0,719 & & $-0,149$ & & 0,0001 \\
\hline
\end{tabular}

Tabela da Função Objetivo

\begin{tabular}{|c|c|c|c|c|c|c|c|c|c|c|c|c|c|c|}
\hline \multirow{2}{*}{ Trecho } & \multicolumn{2}{|c|}{ Nó Montante } & \multicolumn{2}{|c|}{ No Jusante } & \multirow{2}{*}{$\begin{array}{c}\begin{array}{c}\text { Extensão } \\
\text { do Trecho }\end{array} \\
(\mathrm{m})\end{array}$} & \multirow{2}{*}{$\begin{array}{c}\begin{array}{c}\text { Vazão do } \\
\text { Trecho }\end{array} \\
1 / \mathrm{s}\end{array}$} & \multirow{2}{*}{$\begin{array}{c}\text { Diâmetro } \\
\text { Nominal } \\
\text { Comercial }\end{array}$} & \multirow{2}{*}{$\begin{array}{c}\begin{array}{c}\text { Diâmetro } \\
\text { Ótimo }\end{array} \\
(\mathrm{mm})\end{array}$} & \multirow{2}{*}{$\begin{array}{c}\text { Velocidade } \\
(\mathrm{m} / \mathrm{s})\end{array}$} & \multirow{2}{*}{$\begin{array}{l}\text { Fator de } \\
\text { Atrito } f\end{array}$} & \multirow{2}{*}{$\frac{\text { Perda de Carga }}{\text { (m) }}$} & \multirow{2}{*}{$\frac{\begin{array}{c}\text { Carga } \\
\text { Montante }\end{array}}{(\mathrm{m})}$} & \multirow{2}{*}{$\begin{array}{c}\text { Carga Jusante } \\
(\mathrm{m})\end{array}$} & \multirow{2}{*}{$\begin{array}{c}\text { Potência Dissipada } \\
\mathrm{kW}\end{array}$} \\
\hline & Nome & Cota & Nome & Cota & & & & & & & & & & \\
\hline $\mathrm{T} 1$ & $\mathrm{~N} 1$ & 4,56 & N2 & 3,50 & 258,48 & 179,4 & 400 & 401 & 1,42 & 0,0063 & 0,42 & 10,18 & 10,82 & 1,06 \\
\hline $\mathrm{T} 2$ & N2 & 3,50 & N3 & 3,50 & 255,93 & 70,7 & 300 & 300 & 1,00 & 0,0063 & 0,27 & 10,82 & 10,55 & 0,27 \\
\hline T3 & $\mathrm{N} 4$ & 1,50 & N5 & 0,49 & 657,53 & 26,7 & 200 & 201 & 0,85 & 0,0063 & 0,76 & 11,67 & 11,92 & 0,29 \\
\hline T4 & N5 & 0,49 & N6 & 0,50 & 253,28 & 10,5 & 150 & 150 & 0,59 & 0,0063 & 0,19 & 11,92 & 11,72 & 0,03 \\
\hline T5 & N6 & 0,50 & N7 & 1,50 & 660,47 & 45,3 & 250 & 249 & 0,92 & 0,0063 & 0,72 & 11,72 & 10,00 & 0,46 \\
\hline T6 & N2 & 3,50 & N7 & 1,50 & 644,10 & 85,2 & 300 & 301 & 1,20 & 0,0063 & 1,00 & 10,82 & 11,82 & 1,19 \\
\hline$T 7$ & N7 & 1,50 & $\mathrm{~N} 4$ & 1,50 & 253,02 & 9,3 & 150 & 150 & 0,52 & 0,0063 & 0,15 & 11,82 & 11,67 & 0,02 \\
\hline T8 & N3 & 3,50 & N4 & 1,50 & 657,18 & 50,0 & 250 & 223 & 1,02 & 0,0063 & 0,87 & 10,82 & 11,95 & 0,61 \\
\hline
\end{tabular}

4) Resumo do Dimensionamento Otimizado

\begin{tabular}{|c|c|c|}
\hline & Potência Dissipada & Pressurização Inicial \\
\hline Soma & 3,92 & 25,57 \\
\hline Energia & $25.753,52$ & $167.965,48$ \\
\hline FA & 10,60 & 10,60 \\
\hline Sub-Total & $69.354,12$ & $452.330,37$ \\
\hline
\end{tabular}

\begin{tabular}{|c|c|c|}
\hline Custos & & Porcentagem \\
\hline Custo de Tubulação $\mathrm{R} \$$ & $409.716,98$ & $38,57 \%$ \\
\hline Custo de Movimento de Terra $\mathrm{R} \$$ & $66.945,35$ & $6,30 \%$ \\
\hline Custo de Assentamento $\mathrm{R} \$$ & $11.303,07$ & $1,06 \%$ \\
\hline Custo de Pavimentação $\mathrm{R} \$$ & $52.647,98$ & $4,96 \%$ \\
\hline Custo da Pressurização Inicial $\mathrm{R} \$$ & $452.330,37$ & $42,58 \%$ \\
\hline Custo da Potência Dissipada $R \$$ & $69.354,12$ & $6,53 \%$ \\
\hline Total Global (Função Objetivo) R\$ & $1.062 .297,87$ & $100,00 \%$ \\
\hline Total Referncial Unitário R\$ & 291,84 & por metro de rede \\
\hline
\end{tabular}


5) Quantitativos e Custos de Implantação das Redes de Abastecimento

\begin{tabular}{|c|c|c|c|c|c|c|c|c|c|}
\hline Trecho & $\begin{array}{l}\text { Locação da } \\
\text { Tubulação }\end{array}$ & $\begin{array}{l}\text { Tipo de } \\
\text { Superfície }\end{array}$ & Tipo de Tráfego & & & & & & \\
\hline $\mathrm{T} 1$ & viario pavimentado & paralelepipedos & - & & & & & & \\
\hline $\mathrm{T} 2$ & viario pavimentado & paralelepipedos & - & & & & & & \\
\hline T3 & vario pavimentado & paralelepipedos & - & & & & & & \\
\hline T4 & vario pavimentado & paralelepipedos & - & & & & & & \\
\hline $\mathrm{T5}$ & viario pavimentado & paralelepipedos & - & & & & & & \\
\hline T6 & viario pavimentado & paralelepipedos & - & & & & & & \\
\hline 77 & viario pavimentado & paralelepipedos & - & & & & & & \\
\hline \multirow[t]{2}{*}{ T8 } & viario pavimentado & paralelepipedos & - & & & & & & \\
\hline & \multicolumn{6}{|c|}{ Vala } & \multicolumn{3}{|c|}{ Tubulação } \\
\hline \multirow[t]{2}{*}{ Trecho } & Largura & $\begin{array}{l}\text { Profundidade } \\
\end{array}$ & Escavação & Reaterro & Bota-Fora & TOTAL & Assentamento & Material & TOTAL \\
\hline & $\mathrm{m}$ & $\mathrm{m}$ & $\mathrm{m}^{3}$ & $\mathrm{~m}^{3}$ & $\mathrm{~m}^{3}$ & $\mathrm{R} \$$ & $\mathrm{R} \$$ & $\mathrm{R} \$$ & $\mathrm{R} \$$ \\
\hline $\mathrm{T} 1$ & 0,75 & 1,40 & 271,40 & 238,92 & 32,48 & $6.481,67$ & $1.330,32$ & $60.843,11$ & $\begin{array}{l}62.173,43 \\
\end{array}$ \\
\hline $\mathrm{T} 2$ & 0,65 & 1,30 & 216,26 & 198,17 & 18,09 & $5.242,73$ & 943,88 & $37.563,89$ & $38.507,77$ \\
\hline T3 & 0,55 & 1,20 & 433,97 & 413,31 & 20,66 & $10.677,19$ & $1.631,59$ & $49.595,62$ & $51.227,21$ \\
\hline T4 & 0,50 & 1,15 & 145,64 & 141,16 & 4,48 & $3.607,75$ & 499,61 & $11.912,24$ & $12.411,85$ \\
\hline T5 & 0,60 & 1,25 & 495,35 & 462,93 & 32,42 & $12.098,91$ & $2.016,56$ & $71.861,44$ & $73.878,01$ \\
\hline T6 & 0,65 & 1,30 & 544,26 & 498,74 & 45,53 & $13.194,41$ & $2.375,48$ & $94.537,19$ & $96.912,66$ \\
\hline 77 & 0,50 & 1,15 & 145,49 & 141,02 & 4,47 & $3.604,04$ & 499,10 & $11.900,01$ & $12.399,11$ \\
\hline \multirow[t]{2}{*}{ T8 } & 0,60 & 1,25 & 492,89 & 460,63 & 32,26 & $12.038,64$ & $2.006,52$ & $71.503,48$ & $73.510,00$ \\
\hline & & & & & Soma & $66.945,35$ & $\begin{array}{ll}\mathrm{R} \$ 11.303,07 \\
\end{array}$ & $\mathrm{R} \$ 409.716,98 \quad \mathrm{R} \$$ & $421.020,06$ \\
\hline \multicolumn{10}{|c|}{$\frac{\text { Pavimentação }}{\text { Vala }}$} \\
\hline & & & $V^{2}$ & & & & & & \\
\hline \multirow[t]{2}{*}{ Trecho } & Área & $\begin{array}{l}\text { Área de } \\
\text { Concreto }\end{array}$ & $\begin{array}{c}\text { Área de } \\
\text { Paralelepipedos }\end{array}$ & $\begin{array}{l}\text { Área de } \\
\text { Asfalto }\end{array}$ & Área de Binder & $\begin{array}{l}\text { Area de Concreto Astático } \\
\text { Usinado a Quente }\end{array}$ & & & \\
\hline & $\mathrm{m}^{2}$ & $\mathrm{~m}^{2}$ & $\mathrm{~m}^{2}$ & $\mathrm{~m}^{2}$ & $\mathrm{~m}^{2}$ & $\mathrm{~m}^{2}$ & & & \\
\hline $\mathrm{T} 1$ & 193,86 & 0,00 & 193,86 & 0,00 & 0,00 & 0,00 & & & \\
\hline $\mathrm{T} 2$ & 166,35 & 0,00 & 166,35 & 0,00 & 0,00 & 0,00 & & & \\
\hline T3 & 361,64 & 0,00 & 361,64 & 0,00 & 0,00 & 0,00 & & & \\
\hline T4 & 126,64 & 0,00 & 126,64 & 0,00 & 0,00 & 0,00 & & & \\
\hline T5 & 396,28 & 0,00 & 396,28 & 0,00 & 0,00 & 0,00 & & & \\
\hline T6 & 418,67 & 0,00 & 418,67 & 0,00 & 0,00 & 0,00 & & & \\
\hline 77 & 126,51 & 0,00 & 126,51 & 0,00 & 0,00 & 0,00 & & & \\
\hline T8 & 394,31 & 0,00 & 394,31 & 0,00 & 0,00 & 0,00 & & & \\
\hline
\end{tabular}

\begin{tabular}{|c|c|c|c|c|c|c|c|c|c|}
\hline \multirow{4}{*}{ Trecho } & \multicolumn{9}{|c|}{ Pavimentação } \\
\hline & \multicolumn{3}{|c|}{ Volume } & \multicolumn{2}{|c|}{ Área } & \multicolumn{4}{|c|}{ Custos } \\
\hline & Macadame Hidáulico & Binder & $\begin{array}{l}\text { Concreto } \\
\text { Astáltico Usinado } \\
\text { a Quente }\end{array}$ & $\begin{array}{l}\text { Imprimação } \\
\text { Betuminosa } \\
\text { Ligante }\end{array}$ & $\begin{array}{l}\text { Imprimação } \\
\text { Betuminosa } \\
\text { Impermeabiliza } \\
\text { nte }\end{array}$ & Remoção & Recomposição & Transporte & TOTAL \\
\hline & $\mathrm{m}^{3}$ & $\mathrm{~m}^{3}$ & $\mathrm{~m}^{3}$ & $\mathrm{~m}^{2}$ & $\mathrm{~m}^{2}$ & $\mathrm{R} \$$ & $\mathrm{R} \$$ & $\mathrm{R} \$$ & $\mathrm{R} \$$ \\
\hline $\mathrm{T} 1$ & 0,00 & 0,00 & 0,00 & 0,00 & 0,00 & 993,09 & $3.679,58$ & 0,00 & $4.672,67$ \\
\hline $\mathrm{T} 2$ & 0,00 & 0,00 & 0,00 & 0,00 & 0,00 & 852,19 & $3.157,51$ & 0,00 & $4.009,70$ \\
\hline T3 & 0,00 & 0,00 & 0,00 & 0,00 & 0,00 & $1.852,59$ & $6.864,18$ & 0,00 & $8.716,77$ \\
\hline T4 & 0,00 & 0,00 & 0,00 & 0,00 & 0,00 & 648,74 & $2.403,70$ & 0,00 & $3.052,45$ \\
\hline T5 & 0,00 & 0,00 & 0,00 & 0,00 & 0,00 & $2.030,04$ & $7.521,67$ & 0,00 & $9.551,72$ \\
\hline T6 & 0,00 & 0,00 & 0,00 & 0,00 & 0,00 & $2.144,71$ & $7.946,52$ & 0,00 & $10.091,22$ \\
\hline 77 & 0,00 & 0,00 & 0,00 & 0,00 & 0,00 & 648,08 & $2.401,24$ & 0,00 & $3.049,31$ \\
\hline T8 & 0,00 & 0,00 & 0,00 & 0,00 & 0,00 & $2.019,93$ & $7.484,21$ & 0,00 & $9.504,14$ \\
\hline
\end{tabular}




\section{APÊNDICE B4 - Planilha de Dimensionamento para Tarifa Verde - Ponta Seca e Viário em Paralelepípedo - PVC}

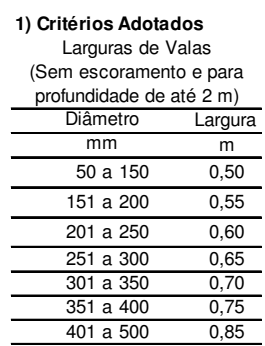

Locação das Redes

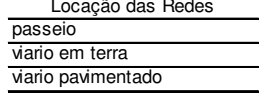

Recobrimento

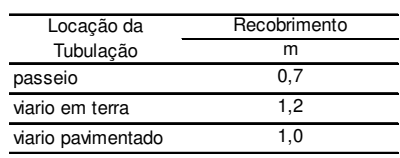

Tipo de Tráfegos para Viário

\begin{tabular}{l}
\multicolumn{1}{c}{ Tipo de Tráfegos para Viário } \\
\hline Leve \\
\hline Médio \\
\hline Pesado \\
\hline Tipos de Superfície \\
\hline asfalto \\
\hline concreto \\
\hline paralelepipedos \\
\hline terra
\end{tabular}

2) Dados Adotados

Tubulação

Materia

SDR

Classe de Pressão $\quad \mathrm{Cl} 20 \quad 1 \mathrm{MPa}$

\begin{tabular}{ll} 
Rugosidade Equivalente $(\mathrm{m})$ & 0,00002 \\
\hline
\end{tabular}

Fator entre Diâmetro Hidráulico e Comercia
Pressurização Inicial

Carga Inicial

Rendimento Global

Vida Ütil

1,05

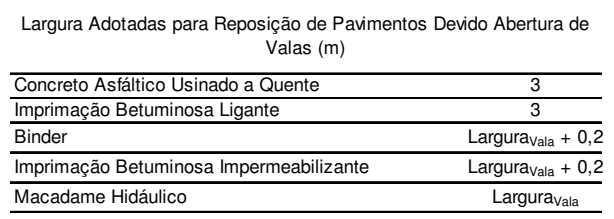

Espessuras Adotadas para Reposição de Pavimentos Devido Abertura de Valas (m) \begin{tabular}{lccc}
\hline Tráfego & Leve & Médio & Pesado
\end{tabular}

\begin{tabular}{llll}
\hline Binder & 0,04 & 0,07 & 0,10
\end{tabular}

\begin{tabular}{lll}
\hline Concreto Asfáltico Usinado a Quente & 0,04 & 0,0 \\
\hline Macadame Hidáulico & 0,10 & 0,1
\end{tabular}

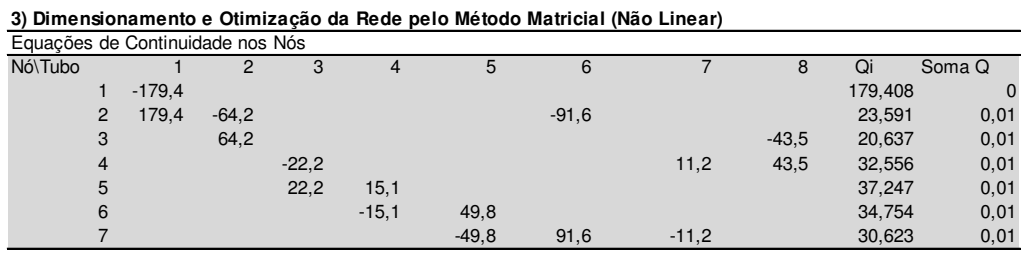

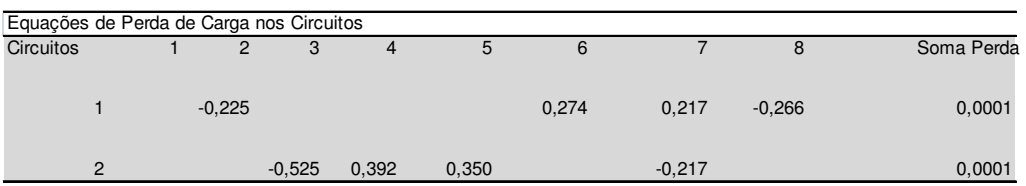

Tabela da Função Objetivo

\begin{tabular}{|c|c|c|c|c|c|c|c|c|c|c|c|c|c|c|}
\hline \multirow{2}{*}{ Trecho } & \multicolumn{2}{|c|}{ Nó Montante } & \multicolumn{2}{|c|}{ No Jusante } & \multirow{2}{*}{$\begin{array}{r}\begin{array}{c}\text { Extensão } \\
\text { do Trecho }\end{array} \\
\text { (m) }\end{array}$} & \multirow{2}{*}{$\begin{array}{c}\begin{array}{c}\text { Vazão do } \\
\text { Trecho }\end{array} \\
\text { l/s }\end{array}$} & \multirow{2}{*}{$\begin{array}{c}\text { Diâmetro } \\
\text { Nominal } \\
\text { Comercial }\end{array}$} & \multirow{2}{*}{$\begin{array}{c}\begin{array}{c}\text { Diâmetro } \\
\text { Ótimo }\end{array} \\
(\mathrm{mm})\end{array}$} & \multirow{2}{*}{$\begin{array}{c}\text { Velocidade } \\
(\mathrm{m} / \mathrm{s})\end{array}$} & \multirow{2}{*}{$\begin{array}{l}\text { Fator de } \\
\text { Atrito } f\end{array}$} & \multirow{2}{*}{$\begin{array}{c}\text { Perda de Carga } \\
(\mathrm{m})\end{array}$} & \multirow{2}{*}{$\begin{array}{c}\begin{array}{c}\text { Carga } \\
\text { Montante }\end{array} \\
(\mathrm{m})\end{array}$} & \multirow{2}{*}{$\begin{array}{c}\text { Carga Jusante } \\
(\mathrm{m})\end{array}$} & \multirow{2}{*}{$\begin{array}{c}\text { Potência Dissipada } \\
\mathrm{kW}\end{array}$} \\
\hline & Nome & Cota & Nome & Cota & & & & & & & & & & \\
\hline T1 & $\mathrm{N} 1$ & 4,56 & N2 & 3,50 & 258,48 & 179,4 & 400 & 400 & 1,42 & 0,0063 & 0,42 & 10,00 & 10,64 & 1,06 \\
\hline T2 & N2 & 3,50 & N3 & 3,50 & 255,93 & 64,2 & 300 & 300 & 0,91 & 0,0063 & 0,23 & 10,64 & 10,42 & 0,20 \\
\hline T3 & N4 & 1,50 & N5 & 0,49 & 657,53 & 22,2 & 200 & 200 & 0,70 & 0,0063 & 0,53 & 12,15 & 12,63 & 0,16 \\
\hline T4 & N5 & 0,49 & N6 & 0,50 & 253,28 & 15,1 & 150 & 150 & 0,85 & 0,0063 & 0,39 & 12,63 & 12,23 & 0,08 \\
\hline T5 & N6 & 0,50 & N7 & 1,50 & 660,47 & 49,8 & 300 & 300 & 0,70 & 0,0063 & 0,35 & 12,23 & 10,88 & 0,24 \\
\hline T6 & N2 & 3,50 & N7 & 1,50 & 644,10 & 91,6 & 400 & 400 & 0,73 & 0,0063 & 0,27 & 10,64 & 12,37 & 0,35 \\
\hline$T 7$ & N7 & 1,50 & N4 & 1,50 & 253,02 & 11,2 & 150 & 150 & 0,63 & 0,0063 & 0,22 & 12,37 & 12,15 & 0,03 \\
\hline T8 & N3 & 3,50 & N4 & 1,50 & 657,18 & 43,5 & 300 & 300 & 0,61 & 0,0063 & 0,27 & 10,64 & 12,37 & 0,16 \\
\hline & & & & Soma & 3639,99 & & & & & & & & & 2,30 \\
\hline
\end{tabular}

4) Resumo do Dimensionamento Otimizado

\begin{tabular}{|c|c|c|}
\hline & Potência Dissipada & Pressurização Inicial \\
\hline Soma & 2,30 & 25,12 \\
\hline Energia & $15.111,03$ & $165.019,48$ \\
\hline FA & 10,60 & 10,60 \\
\hline Sub-Total $\mathbf{R}$ & $160.596,07$ & $1.753 .783,25$ \\
\hline
\end{tabular}

\begin{tabular}{|c|c|c|}
\hline Custos & & Porcentagem \\
\hline Custo de Tubulação $\mathrm{R} \$$ & $516.825,20$ & $20,09 \%$ \\
\hline Custo de Movimento de Terra $\mathrm{R} \$$ & $72.757,01$ & $2,83 \%$ \\
\hline Custo de Assentamento $\mathrm{R} \$$ & $13.079,08$ & $0,51 \%$ \\
\hline Custo de Pavimentação $\mathrm{R} \$$ & $55.788,46$ & $2,17 \%$ \\
\hline Custo da Pressurização Inicial $\mathrm{R} \$$ & $1.753 .783,25$ & $68,17 \%$ \\
\hline Custo da Potência Dissipada $R \$$ & $160.596,07$ & $6,24 \%$ \\
\hline Total Global (Função Objetivo) R\$ & $2.572 .829,06$ & $100,00 \%$ \\
\hline Total Referncial Unitário $\mathbf{R} \$$ & 706,82 & por metro de rede \\
\hline
\end{tabular}


5) Quantitativos e Custos de Implantação das Redes de Abastecimento

\begin{tabular}{|c|c|c|c|c|c|c|c|c|c|}
\hline Trecho & $\begin{array}{l}\text { Locação da } \\
\text { Tubulação }\end{array}$ & $\begin{array}{l}\text { Tipo de } \\
\text { Superfície }\end{array}$ & Tipo de Tráfego & & & & & & \\
\hline $\mathrm{T} 1$ & viario pavimentado & paralelepipedos & - & & & & & & \\
\hline $\mathrm{T} 2$ & viario pavimentado & paralelepipedos & - & & & & & & \\
\hline T3 & vario pavimentado & paralelepipedos & - & & & & & & \\
\hline T4 & vario pavimentado & paralelepipedos & - & & & & & & \\
\hline $\mathrm{T5}$ & viario pavimentado & paralelepipedos & - & & & & & & \\
\hline T6 & viario pavimentado & paralelepipedos & - & & & & & & \\
\hline 77 & viario pavimentado & paralelepipedos & - & & & & & & \\
\hline \multirow[t]{2}{*}{ T8 } & viario pavimentado & paralelepipedos & - & & & & & & \\
\hline & \multicolumn{6}{|c|}{ Vala } & \multicolumn{3}{|c|}{ Tubulação } \\
\hline \multirow[t]{2}{*}{ Trecho } & Largura & $\begin{array}{l}\text { Profundidade } \\
\end{array}$ & Escavação & Reaterro & Bota-Fora & TOTAL & Assentamento & Material & TOTAL \\
\hline & $\mathrm{m}$ & $\mathrm{m}$ & $\mathrm{m}^{3}$ & $\mathrm{~m}^{3}$ & $\mathrm{~m}^{3}$ & $\mathrm{R} \$$ & $\mathrm{R} \$$ & $\mathrm{R} \$$ & $\mathrm{R} \$$ \\
\hline $\mathrm{T} 1$ & 0,75 & 1,40 & 271,40 & 238,92 & 32,48 & $6.481,67$ & $1.330,32$ & $60.843,11$ & $\begin{array}{l}62.173,43 \\
\end{array}$ \\
\hline $\mathrm{T} 2$ & 0,65 & 1,30 & 216,26 & 198,17 & 18,09 & $5.242,73$ & 943,88 & $37.563,89$ & \begin{tabular}{|l|l|}
$38.507,77$ \\
\end{tabular} \\
\hline T3 & 0,55 & 1,20 & 433,97 & 413,31 & 20,66 & $10.677,19$ & $1.631,59$ & $49.595,62$ & $51.227,21$ \\
\hline T4 & 0,50 & 1,15 & 145,64 & 141,16 & 4,48 & $3.607,75$ & 499,61 & $11.912,24$ & $12.411,85$ \\
\hline T5 & 0,65 & 1,30 & 558,10 & 511,41 & 46,69 & $13.529,75$ & $2.435,85$ & $96.939,88$ & $99.375,73$ \\
\hline T6 & 0,75 & 1,40 & 676,31 & 595,37 & 80,94 & $16.151,52$ & $3.315,00$ & $151.613,45$ & $154.928,46$ \\
\hline 77 & 0,50 & 1,15 & 145,49 & 141,02 & 4,47 & $3.604,04$ & 499,10 & $11.900,01$ & $12.399,11$ \\
\hline \multirow[t]{2}{*}{$\mathrm{T} 8$} & 0,65 & 1,30 & 555,32 & 508,86 & 46,45 & $13.462,36$ & $2.423,72$ & $96.456,99$ & $98.880,71$ \\
\hline & & & & & Soma & $72.757,01$ & $\begin{array}{ll}\mathrm{R} \$ 13.079,08 \\
\end{array}$ & $\begin{array}{lll}\mathrm{R} \$ 516.825,20 & \mathrm{R} \$\end{array}$ & $529.904,28$ \\
\hline \multirow{2}{*}{\multicolumn{10}{|c|}{$\frac{\text { Pavimentação }}{\text { Vala }}$}} \\
\hline & & & & & & & & & \\
\hline \multirow[t]{2}{*}{ Trecho } & Área & $\begin{array}{l}\text { Área de } \\
\text { Concreto }\end{array}$ & $\begin{array}{c}\text { Área de } \\
\text { Paralelepipedos }\end{array}$ & $\begin{array}{l}\text { Área de } \\
\text { Asfalto }\end{array}$ & Área de Binder & $\begin{array}{l}\text { Area de Concreto Astático } \\
\text { Usinado a Quente }\end{array}$ & & & \\
\hline & $\mathrm{m}^{2}$ & $\mathrm{~m}^{2}$ & $\mathrm{~m}^{2}$ & $\mathrm{~m}^{2}$ & $\mathrm{~m}^{2}$ & $\mathrm{~m}^{2}$ & & & \\
\hline $\mathrm{T} 1$ & 193,86 & 0,00 & 193,86 & 0,00 & 0,00 & 0,00 & & & \\
\hline $\mathrm{T} 2$ & 166,35 & 0,00 & 166,35 & 0,00 & 0,00 & 0,00 & & & \\
\hline T3 & 361,64 & 0,00 & 361,64 & 0,00 & 0,00 & 0,00 & & & \\
\hline T4 & 126,64 & 0,00 & 126,64 & 0,00 & 0,00 & 0,00 & & & \\
\hline$T 5$ & 429,31 & 0,00 & 429,31 & 0,00 & 0,00 & 0,00 & & & \\
\hline T6 & 483,08 & 0,00 & 483,08 & 0,00 & 0,00 & 0,00 & & & \\
\hline 77 & 126,51 & 0,00 & 126,51 & 0,00 & 0,00 & 0,00 & & & \\
\hline T8 & 427,17 & 0,00 & 427,17 & 0,00 & 0,00 & 0,00 & & & \\
\hline
\end{tabular}

\begin{tabular}{|c|c|c|c|c|c|c|c|c|c|}
\hline \multirow{4}{*}{ Trecho } & \multicolumn{9}{|c|}{ Pavimentação } \\
\hline & \multicolumn{3}{|c|}{ Volume } & \multicolumn{2}{|c|}{ Área } & \multicolumn{4}{|c|}{ Custos } \\
\hline & Macadame Hidáulico & Binder & $\begin{array}{l}\text { Concreto } \\
\text { Astáltico Usinado } \\
\text { a Quente }\end{array}$ & $\begin{array}{l}\text { Imprimação } \\
\text { Betuminosa } \\
\text { Ligante }\end{array}$ & $\begin{array}{l}\text { Imprimação } \\
\text { Betuminosa } \\
\text { Impermeabiliza } \\
\text { nte }\end{array}$ & Remoção & Recomposição & Transporte & TOTAL \\
\hline & $\mathrm{m}^{3}$ & $\mathrm{~m}^{3}$ & $\mathrm{~m}^{3}$ & $\mathrm{~m}^{2}$ & $\mathrm{~m}^{2}$ & $\mathrm{R} \$$ & $\mathrm{R} \$$ & $\mathrm{R} \$$ & $\mathrm{R} \$$ \\
\hline $\mathrm{T} 1$ & 0,00 & 0,00 & 0,00 & 0,00 & 0,00 & 993,09 & $3.679,58$ & 0,00 & $4.672,67$ \\
\hline $\mathrm{T} 2$ & 0,00 & 0,00 & 0,00 & 0,00 & 0,00 & 852,19 & $3.157,51$ & 0,00 & $4.009,70$ \\
\hline T3 & 0,00 & 0,00 & 0,00 & 0,00 & 0,00 & $1.852,59$ & $6.864,18$ & 0,00 & $8.716,77$ \\
\hline T4 & 0,00 & 0,00 & 0,00 & 0,00 & 0,00 & 648,74 & $2.403,70$ & 0,00 & $3.052,45$ \\
\hline T5 & 0,00 & 0,00 & 0,00 & 0,00 & 0,00 & $2.199,21$ & $8.148,48$ & 0,00 & $10.347,69$ \\
\hline T6 & 0,00 & 0,00 & 0,00 & 0,00 & 0,00 & $2.474,66$ & $9.169,06$ & 0,00 & $11.643,72$ \\
\hline 77 & 0,00 & 0,00 & 0,00 & 0,00 & 0,00 & 648,08 & $2.401,24$ & 0,00 & $3.049,31$ \\
\hline T8 & 0,00 & 0,00 & 0,00 & 0,00 & 0,00 & $2.188,26$ & $8.107,89$ & 0,00 & $10.296,15$ \\
\hline
\end{tabular}




\section{APÊNDICE B5 - Planilha de Dimensionamento para Tarifa Verde - Fora de Ponta Úmida e Viário em Paralelepípedo - FoFo}

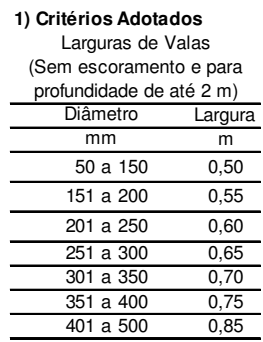

Locação das Redes

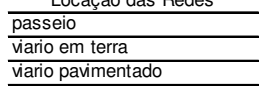

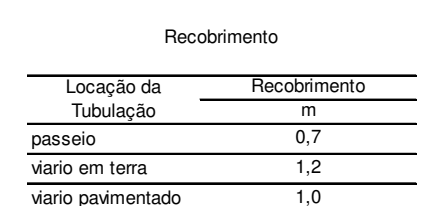

\begin{tabular}{ll}
\hline vario pavimentado & 1,0
\end{tabular}

\begin{tabular}{l}
\hline \multicolumn{1}{c}{ Tipo de Tráfegos para Viário } \\
\hline Leve \\
\hline Médio \\
\hline Pesado \\
\hline Tipos de Superfície \\
\hline asfalto \\
\hline pancreto \\
\hline terra
\end{tabular}

2) Dados Adotados

Tubulação

Material

\begin{tabular}{ll}
\hline Rugosidade Equivalente $(\mathrm{m}) \quad 0,0001$ \\
\hline
\end{tabular}

Fator entre Diâmetro Hidráulico e Comercia
Pressurização Inicial

\begin{tabular}{lr}
\hline Carga Inicial & 13,45 \\
\hline Rendimento Global & 0,70
\end{tabular}

Horas de Funcionamer $\quad 6570 \mathrm{~h} /$ ano

Vida Útil

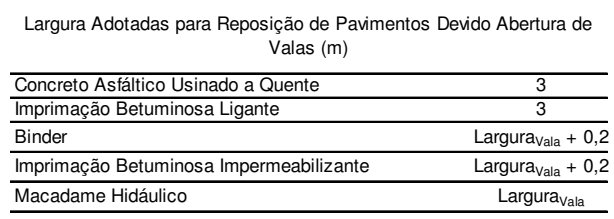

Espessuras Adotadas para Reposição de Pavimentos Devido Abertura de Valas ( $m$ ) \begin{tabular}{lccc}
\hline Tráfego & Leve & Médio & Pesado \\
\hline Binder & 0,04 & 0,07 & 0,10 \\
\hline Concreto Asfáltico Usinado a Quente & 0,04 & 0,05 & 0,05 \\
\hline Macadame Hidáulico & 0,10 & 0,12 & 0,15
\end{tabular}
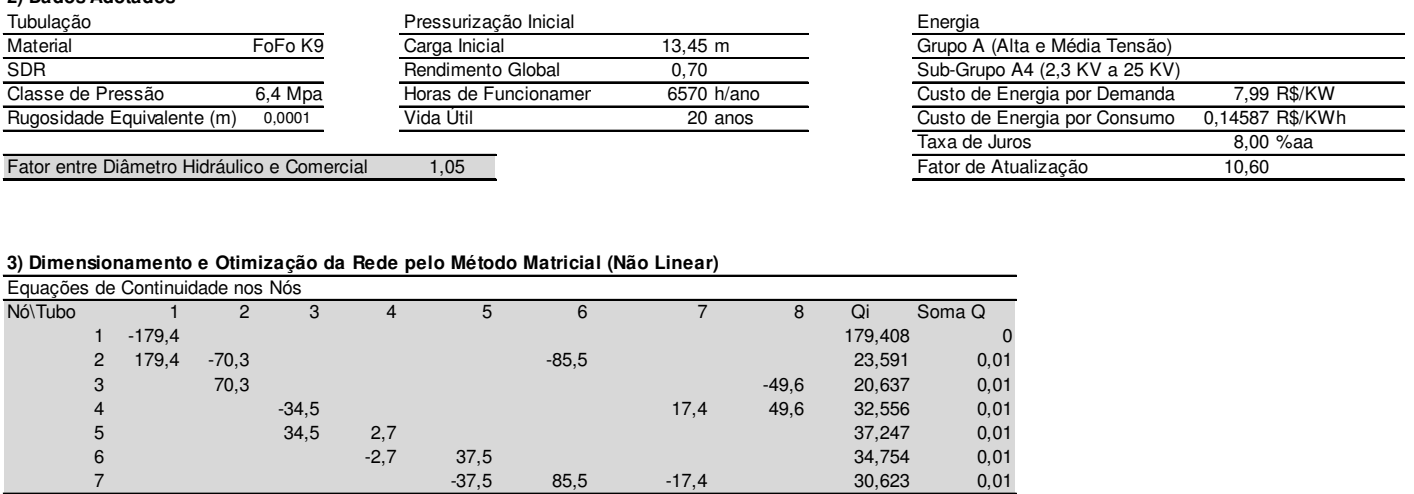

\begin{tabular}{cccccccccr}
\hline Equações de Perda de Carga nos Circuitos & & & & & \\
\hline Circuitos & 1 & 2 & 3 & 4 & 5 & 6 & 7 & 8 & Soma Perda \\
& & & & & & & & \\
1 & $-0,872$ & & & & 1,306 & 0,682 & $-1,117$ & 0,0001 \\
2 & & $-1,650$ & 0,382 & 1,950 & & $-0,682$ & & 0,0001 \\
\hline
\end{tabular}

Tabela da Função Objetivo

\begin{tabular}{|c|c|c|c|c|c|c|c|c|c|c|c|c|c|c|}
\hline \multirow{2}{*}{ Trecho } & \multicolumn{2}{|c|}{ Nó Montante } & \multicolumn{2}{|c|}{ No Jusante } & \multirow{2}{*}{$\begin{array}{c}\begin{array}{c}\text { Extensão } \\
\text { do Trecho }\end{array} \\
\text { (m) }\end{array}$} & \multirow{2}{*}{$\begin{array}{c}\text { Vazão do } \\
\text { Trecho } \\
\text { I/s }\end{array}$} & \multirow{2}{*}{$\begin{array}{c}\text { Diâmetro } \\
\text { Nominal } \\
\text { Comercial }\end{array}$} & \multirow{2}{*}{$\begin{array}{c}\begin{array}{c}\text { Diâmetro } \\
\text { Ótimo }\end{array} \\
(\mathrm{mm})\end{array}$} & \multirow{2}{*}{$\begin{array}{c}\text { Velocidade } \\
(\mathrm{m} / \mathrm{s})\end{array}$} & \multirow{2}{*}{$\begin{array}{l}\text { Fator de } \\
\text { Atrito } f\end{array}$} & \multirow{2}{*}{$\begin{array}{c}\text { Perda de Carga } \\
(\mathrm{m})\end{array}$} & \multirow{2}{*}{$\begin{array}{c}\begin{array}{c}\text { Carga } \\
\text { Montante }\end{array} \\
(\mathrm{m})\end{array}$} & \multirow{2}{*}{$\begin{array}{c}\text { Carga Jusante } \\
(\mathrm{m})\end{array}$} & \multirow{2}{*}{$\begin{array}{c}\text { Potência Dissipada } \\
\text { kW }\end{array}$} \\
\hline & Nome & Cota & Nome & Cota & & & & & & & & & & \\
\hline T1 & $\mathrm{N} 1$ & 4,56 & N2 & 3,50 & 258,48 & 179,4 & 400 & 400 & 1,42 & 0,0082 & 0,55 & 13,45 & 13,97 & 1,37 \\
\hline $\mathrm{T} 2$ & N2 & 3,50 & N3 & 3,50 & 255,93 & 70,3 & 250 & 250 & 1,43 & 0,0082 & 0,87 & 13,97 & 13,10 & 0,86 \\
\hline T3 & $\mathrm{N} 4$ & 1,50 & N5 & 0,49 & 657,53 & 34,5 & 200 & 200 & 1,10 & 0,0082 & 1,65 & 13,98 & 13,34 & 0,80 \\
\hline T4 & N5 & 0,49 & N6 & 0,50 & 253,28 & 2,7 & 80 & 80 & 0,54 & 0,0082 & 0,38 & 13,34 & 12,95 & 0,01 \\
\hline T5 & N6 & 0,50 & N7 & 1,50 & 660,47 & 37,5 & 200 & 200 & 1,19 & 0,0082 & 1,95 & 12,95 & 10,00 & 1,02 \\
\hline T6 & N2 & 3,50 & N7 & 1,50 & 644,10 & 85,5 & 300 & 300 & 1,21 & 0,0082 & 1,31 & 13,97 & 14,66 & 1,56 \\
\hline 77 & N7 & 1,50 & $\mathrm{~N} 4$ & 1,50 & 253,02 & 17,4 & 150 & 150 & 0,98 & 0,0082 & 0,68 & 14,66 & 13,98 & 0,17 \\
\hline T8 & N3 & 3,50 & $\mathrm{~N} 4$ & 1,50 & 657,18 & 49,6 & 250 & 250 & 1,01 & 0,0082 & 1,12 & 13,97 & 14,85 & 0,78 \\
\hline
\end{tabular}

4) Resumo do Dimensionamento Otimizado

\begin{tabular}{|c|c|c|c|}
\hline & \multicolumn{2}{|c|}{ Potência Dissipada } & Pressurização Inicial \\
\hline Soma & & 6,57 & 33,79 \\
\hline Energia & & $43.182,52$ & $222.025,99$ \\
\hline $\mathrm{FA}$ & & 10,60 & 10,60 \\
\hline Sub-Total & $\mathbf{R} \$$ & $67.349,29$ & $346.281,16$ \\
\hline
\end{tabular}

\begin{tabular}{|c|c|c|}
\hline Custos & & Porcentagem \\
\hline Custo de Tubulação $R \$$ & $937.500,39$ & $63,43 \%$ \\
\hline Custo de Movimento de Terra $\mathrm{R} \$$ & $64.826,65$ & $4,39 \%$ \\
\hline Custo de Assentamento $\mathrm{R} \$$ & $10.609,30$ & $0,72 \%$ \\
\hline Custo de Pavimentação $\mathrm{R} \$$ & $51.543,56$ & $3,49 \%$ \\
\hline Custo da Pressurização Inicial $R \$$ & $346.281,16$ & $23,43 \%$ \\
\hline Custo da Potência Dissipada R\$ & $67.349,29$ & $4,56 \%$ \\
\hline Total Global (Função Objetivo) R\$ & $1.478 .110,36$ & $100,00 \%$ \\
\hline Total Referencial Unitário R\$ & 406,08 & por metro de rede \\
\hline
\end{tabular}


5) Quantitativos e Custos de Implantação das Redes de Abastecimento

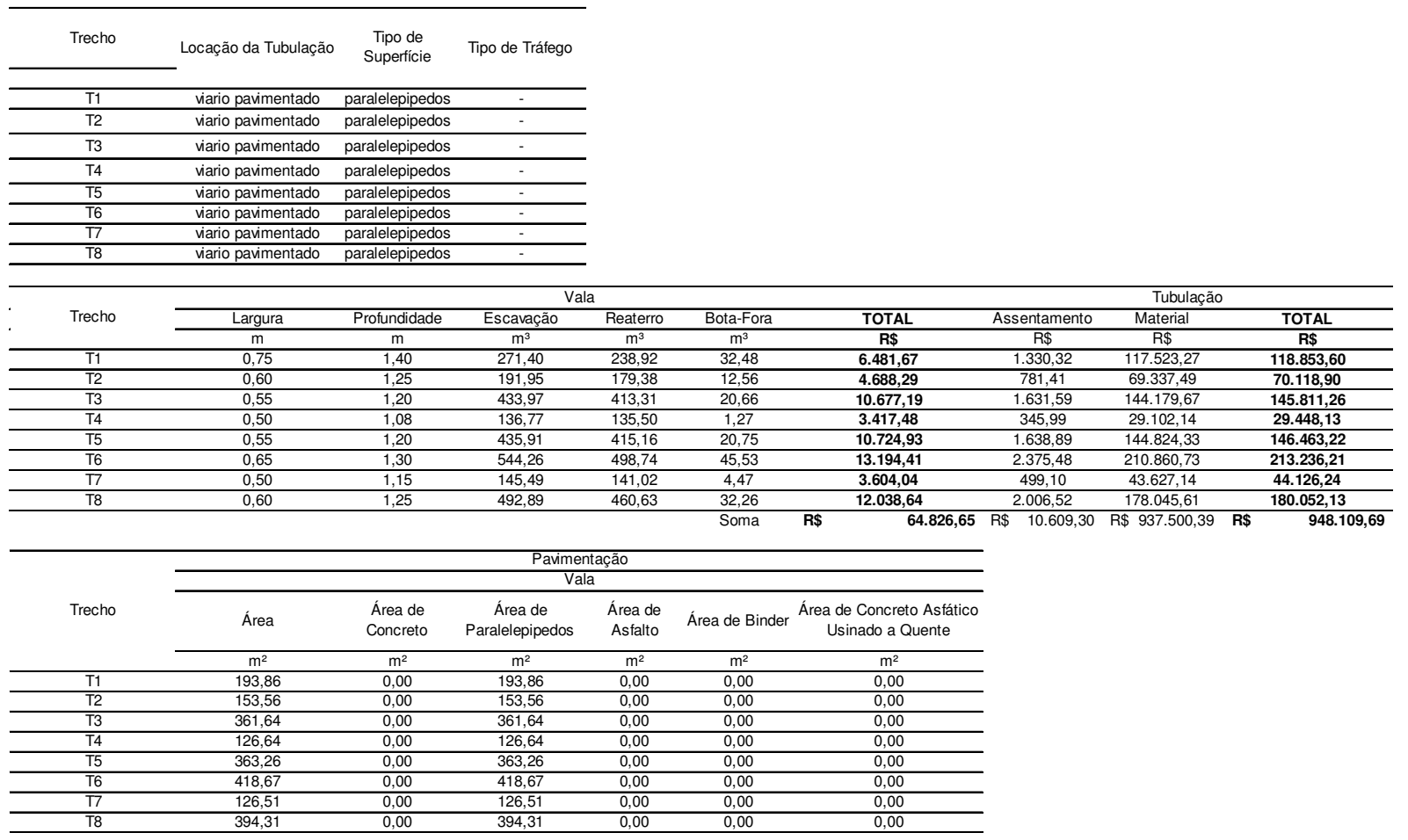

\begin{tabular}{|c|c|c|c|c|c|c|c|c|c|}
\hline \multirow{4}{*}{ Trecho } & \multicolumn{9}{|c|}{ Pavimentação } \\
\hline & \multicolumn{3}{|c|}{ Volume } & \multicolumn{2}{|c|}{ Área } & \multicolumn{4}{|c|}{ Custos } \\
\hline & Macadame Hidáulico & Binder & $\begin{array}{l}\text { Concreto } \\
\text { Asfáltico Usinado } \\
\text { a Quente }\end{array}$ & $\begin{array}{l}\text { Imprimação } \\
\text { Betuminosa } \\
\text { Ligante }\end{array}$ & $\begin{array}{l}\text { Imprimação } \\
\text { Betuminosa } \\
\text { Impermeabiliza } \\
\text { nte }\end{array}$ & Remoção & Recomposição & Transporte & TOTAL \\
\hline & $\mathrm{m}^{3}$ & $\mathrm{~m}^{3}$ & $\mathrm{~m}^{3}$ & $\mathrm{~m}^{2}$ & $\mathrm{~m}^{2}$ & $\mathrm{R} \$$ & $\mathrm{R} \$$ & $\mathrm{R} \$$ & $\mathbf{R} \$$ \\
\hline $\mathrm{T} 1$ & 0,00 & 0,00 & 0,00 & 0,00 & 0,00 & 993,09 & $3.679,58$ & 0,00 & $4.672,67$ \\
\hline $\mathrm{T} 2$ & 0,00 & 0,00 & 0,00 & 0,00 & 0,00 & 786,64 & $2.914,62$ & 0,00 & $3.701,26$ \\
\hline T3 & 0,00 & 0,00 & 0,00 & 0,00 & 0,00 & $1.852,59$ & $6.864,18$ & 0,00 & $8.716,77$ \\
\hline T4 & 0,00 & 0,00 & 0,00 & 0,00 & 0,00 & 648,74 & $2.403,70$ & 0,00 & $3.052,45$ \\
\hline T5 & 0,00 & 0,00 & 0,00 & 0,00 & 0,00 & $1.860,87$ & $6.894,87$ & 0,00 & $8.755,74$ \\
\hline T6 & 0,00 & 0,00 & 0,00 & 0,00 & 0,00 & $2.144,71$ & $7.946,52$ & 0,00 & $10.091,22$ \\
\hline 77 & 0,00 & 0,00 & 0,00 & 0,00 & 0,00 & 648,08 & $2.401,24$ & 0,00 & $3.049,31$ \\
\hline T8 & 0,00 & 0,00 & 0,00 & 0,00 & 0,00 & $2.019,93$ & $7.484,21$ & 0,00 & $9.504,14$ \\
\hline
\end{tabular}




\section{APÊNDICE B6 - Planilha de Dimensionamento para Tarifa Convencional e Viário em Paralelepípedo - FoFo}

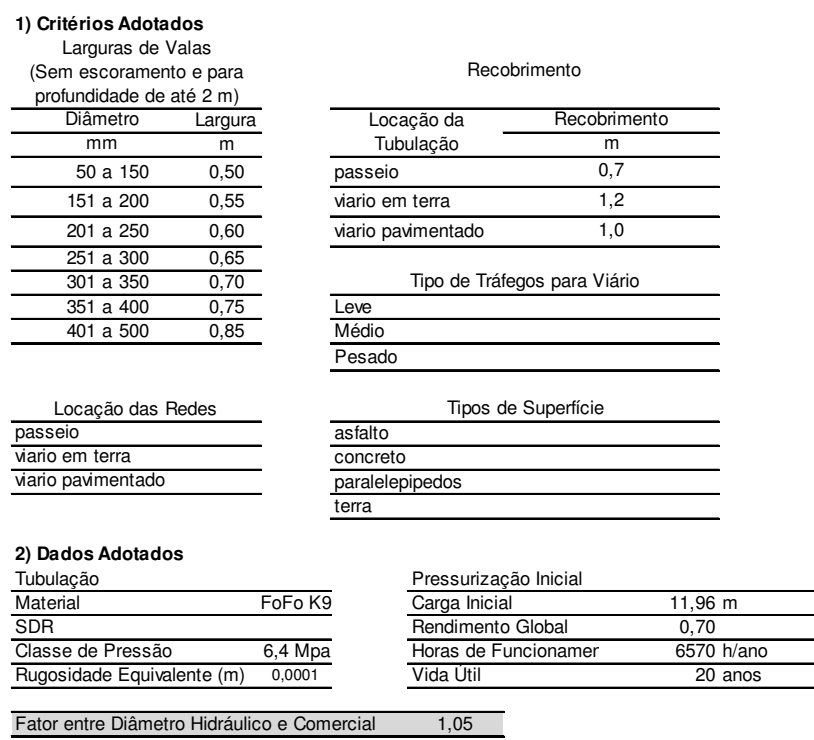

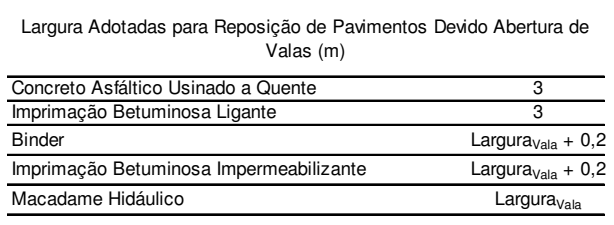

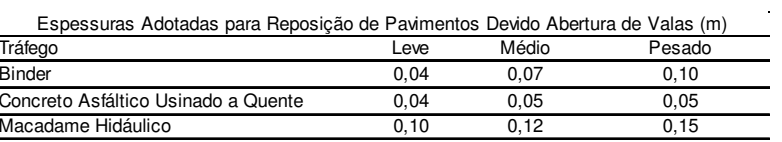

Macadame Hidáulico

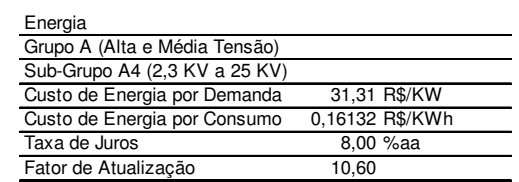

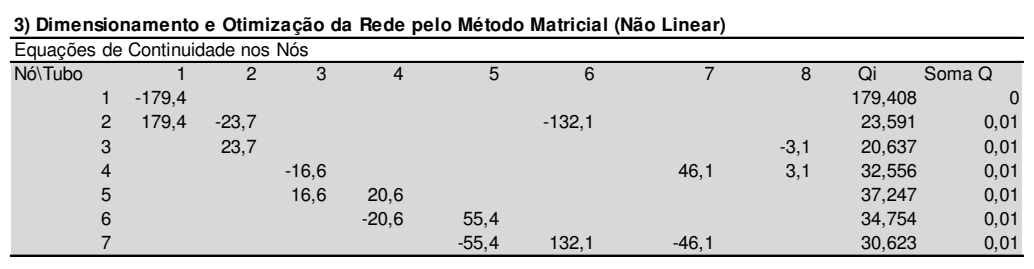

\begin{tabular}{|c|c|c|c|c|c|c|c|c|c|}
\hline \multicolumn{10}{|c|}{ Equações de Perda de Carga nos Circuitos } \\
\hline Circuitos & 1 & 2 & 3 & 4 & 5 & 6 & 7 & 8 & Soma Perda \\
\hline 1 & & $-1,277$ & & & & 1,441 & 1,132 & $-1,295$ & 0,0001 \\
\hline 2 & & & $-0,384$ & 0,954 & 0,561 & & $-1,132$ & & 0,0001 \\
\hline
\end{tabular}

\begin{tabular}{|c|c|c|c|c|c|c|c|c|c|c|c|c|c|c|}
\hline \multirow[t]{2}{*}{ Trecho } & \multicolumn{2}{|c|}{ Nó Montante } & \multicolumn{2}{|c|}{ No Jusante } & \multirow{2}{*}{$\begin{array}{c}\begin{array}{c}\text { Extensão } \\
\text { do Trecho }\end{array} \\
(\mathrm{m}) \\
\end{array}$} & \multirow{2}{*}{$\begin{array}{c}\text { Vazão do } \\
\text { Trecho }\end{array}$} & \multirow{2}{*}{$\begin{array}{c}\begin{array}{c}\text { Diâmetro } \\
\text { Nominal } \\
\text { Comercial }\end{array} \\
(\mathrm{mm})\end{array}$} & \multirow{2}{*}{$\begin{array}{c}\begin{array}{c}\text { Diâmetro } \\
\text { Ótimo }\end{array} \\
(\mathrm{mm}) \\
\end{array}$} & \multirow{2}{*}{$\begin{array}{c}\text { Velocidade } \\
(\mathrm{m} / \mathrm{s})\end{array}$} & \multirow[t]{2}{*}{$\begin{array}{l}\text { Fator de } \\
\text { Atrito } f\end{array}$} & \multirow{2}{*}{$\begin{array}{c}\text { Perda de Carga } \\
(\mathrm{m}) \\
\end{array}$} & \multirow{2}{*}{$\begin{array}{c}\begin{array}{c}\text { Carga } \\
\text { Montante }\end{array} \\
(\mathrm{m})\end{array}$} & \multirow{2}{*}{$\begin{array}{c}\text { Carga Jusante } \\
(\mathrm{m})\end{array}$} & \multirow{2}{*}{$\begin{array}{c}\text { Potência Dissipada } \\
\mathrm{kW}\end{array}$} \\
\hline & Nome & Cota & Nome & Cota & & & & & & & & & & \\
\hline $\mathrm{T} 1$ & N1 & 4,56 & N2 & 3,50 & 258,48 & 179,4 & 400 & 401 & 1,42 & 0,0082 & 0,55 & 11,96 & 12,47 & 1,37 \\
\hline T2 & N2 & 3,50 & N3 & 3,50 & 255,93 & 23,7 & 150 & 151 & 1,34 & 0,0082 & 1,28 & 12,47 & 11,19 & 0,42 \\
\hline T3 & N4 & 1,50 & N5 & 0,49 & 657,53 & 16,6 & 200 & 175 & 0,53 & 0,0082 & 0,38 & 11,90 & 12,52 & 0,09 \\
\hline T4 & N5 & 0,49 & N6 & 0,50 & 253,28 & 20,6 & 150 & 151 & 1,16 & 0,0082 & 0,95 & 12,52 & 11,56 & 0,28 \\
\hline T5 & N6 & 0,50 & N7 & 1,50 & 660,47 & 55,4 & 300 & 270 & 0,78 & 0,0082 & 0,56 & 11,56 & 10,00 & 0,43 \\
\hline T6 & N2 & 3,50 & N7 & 1,50 & 644,10 & 132,1 & 350 & 351 & 1,37 & 0,0082 & 1,44 & 12,47 & 13,03 & 2,66 \\
\hline 77 & N7 & 1,50 & $\mathrm{~N} 4$ & 1,50 & 253,02 & 46,1 & 200 & 201 & 1,46 & 0,0082 & 1,13 & 13,03 & 11,90 & 0,73 \\
\hline T8 & N3 & 3,50 & N4 & 1,50 & 657,18 & 3,1 & 80 & 80 & 0,61 & 0,0082 & 1,29 & 12,47 & 13,18 & 0,06 \\
\hline & & & & Soma & 3639,99 & & & & & & & & & 6,05 \\
\hline
\end{tabular}

4) Resumo do Dimensionamento Otimizado

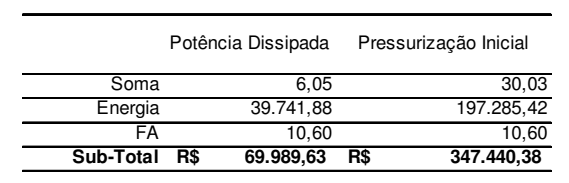

\begin{tabular}{|c|c|c|}
\hline Custos & & Porcentagem \\
\hline Custo de Tubulação $R \$$ & $947.026,39$ & $63,44 \%$ \\
\hline Custo de Movimento de Terra $\mathrm{R} \$$ & $65.562,97$ & $4,39 \%$ \\
\hline Custo de Assentamento $\mathrm{R} \$$ & $10.752,75$ & $0,72 \%$ \\
\hline Custo de Pavimentação $\mathrm{R} \$$ & $52.015,79$ & $3,48 \%$ \\
\hline Custo da Pressurização Inicial $\mathrm{R} \$$ & $347.440,38$ & $23,27 \%$ \\
\hline Custo da Potência Dissipada $\mathrm{R} \$$ & $69.989,63$ & $4,69 \%$ \\
\hline Total Global (Função Objetivo) R\$ & $1.492 .787,92$ & $100,00 \%$ \\
\hline Total Referencial Unitário $\mathbf{R} \$$ & 410,11 & por metro de rede \\
\hline
\end{tabular}


5) Quantitativos e Custos de Implantação das Redes de Abastecimento

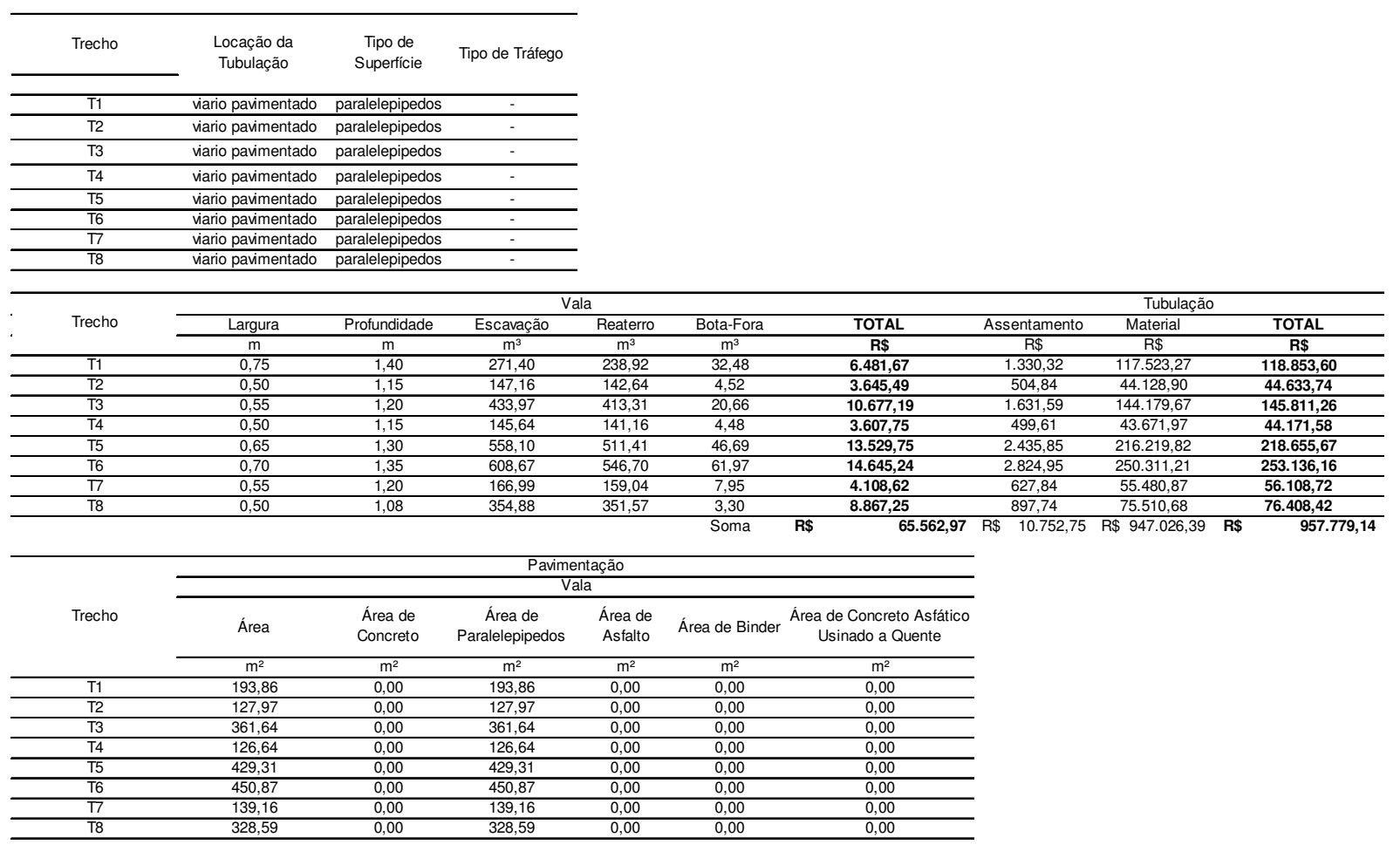

\begin{tabular}{|c|c|c|c|c|c|c|c|c|c|}
\hline \multirow{4}{*}{ Trecho } & \multicolumn{9}{|c|}{ Pavimentação } \\
\hline & \multicolumn{3}{|c|}{ Volume } & \multicolumn{2}{|c|}{ Area } & \multicolumn{4}{|c|}{ Custos } \\
\hline & Macadame Hidáulico & Binder & $\begin{array}{l}\text { Concreto } \\
\text { Astáltico Usinado } \\
\text { a Quente }\end{array}$ & $\begin{array}{l}\text { Imprimação } \\
\text { Betuminosa } \\
\text { Ligante }\end{array}$ & $\begin{array}{l}\text { Imprimação } \\
\text { Betuminosa } \\
\text { Impermeabiliza } \\
\text { nte }\end{array}$ & Remoção & Recomposição & Transporte & TOTAL \\
\hline & $\mathrm{m}^{3}$ & $\mathrm{~m}^{3}$ & $\mathrm{~m}^{3}$ & $\mathrm{~m}^{2}$ & $\mathrm{~m}^{2}$ & $\mathrm{R} \$$ & $\mathrm{R} \$$ & $\mathrm{R} \$$ & $\mathbf{R} \$$ \\
\hline $\mathrm{T} 1$ & 0,00 & 0,00 & 0,00 & 0,00 & 0,00 & 993,09 & $3.679,58$ & 0,00 & $4.672,67$ \\
\hline $\mathrm{T} 2$ & 0,00 & 0,00 & 0,00 & 0,00 & 0,00 & 655,53 & $2.428,85$ & 0,00 & $3.084,38$ \\
\hline T3 & 0,00 & 0,00 & 0,00 & 0,00 & 0,00 & $1.852,59$ & $6.864,18$ & 0,00 & $8.716,77$ \\
\hline $\mathrm{T} 4$ & 0,00 & 0,00 & 0,00 & 0,00 & 0,00 & $\begin{array}{ll}648,74 \\
\end{array}$ & $2.403,70$ & 0,00 & $3.052,45$ \\
\hline T5 & 0,00 & 0,00 & 0,00 & 0,00 & 0,00 & $2.199,21$ & $8.148,48$ & 0,00 & $10.347,69$ \\
\hline T6 & 0,00 & 0,00 & 0,00 & 0,00 & 0,00 & $2.309,68$ & $8.557,79$ & 0,00 & $10.867,47$ \\
\hline 77 & 0,00 & 0,00 & 0,00 & 0,00 & 0,00 & 712,88 & $2.641,36$ & 0,00 & $3.354,24$ \\
\hline T8 & 0,00 & 0,00 & 0,00 & 0,00 & 0,00 & $1.683,28$ & $6.236,84$ & 0,00 & $7.920,12$ \\
\hline
\end{tabular}




\section{APÊNDICE B7 - Planilha de Dimensionamento para Tarifa Azul - Ponta Seca e Viário em Paralelepípedo - FoFo}

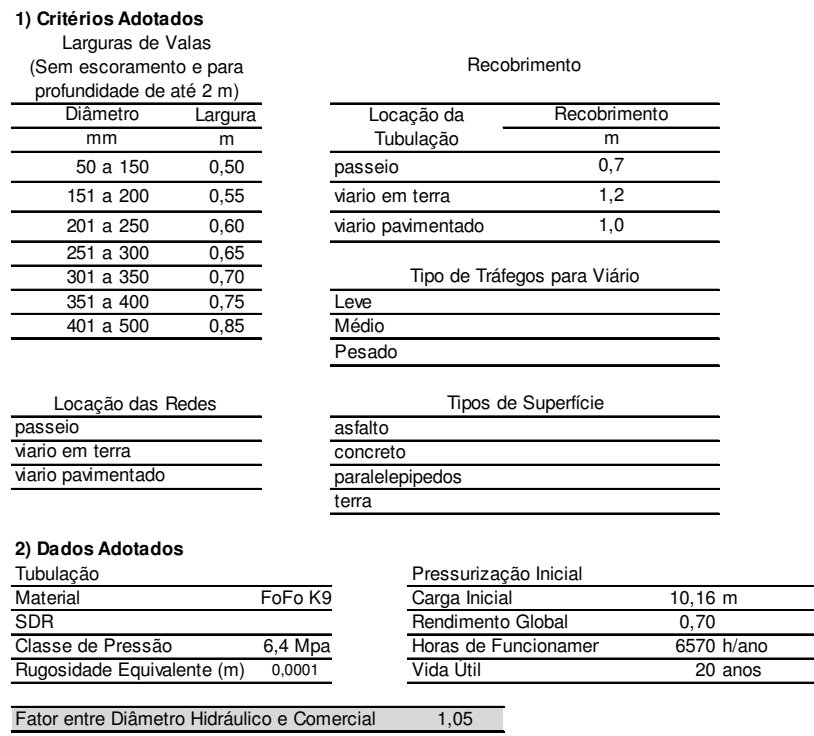

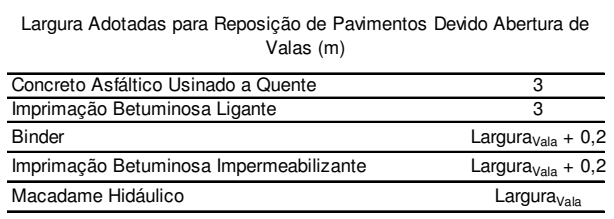

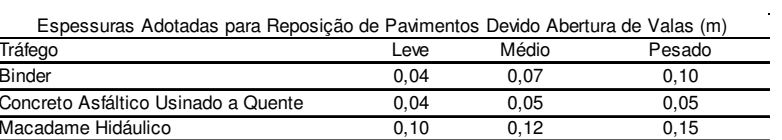

Macadame Hidáulico

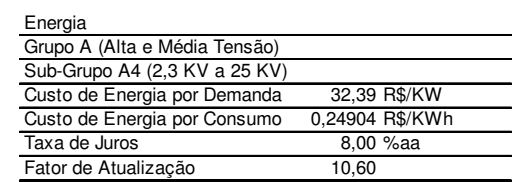

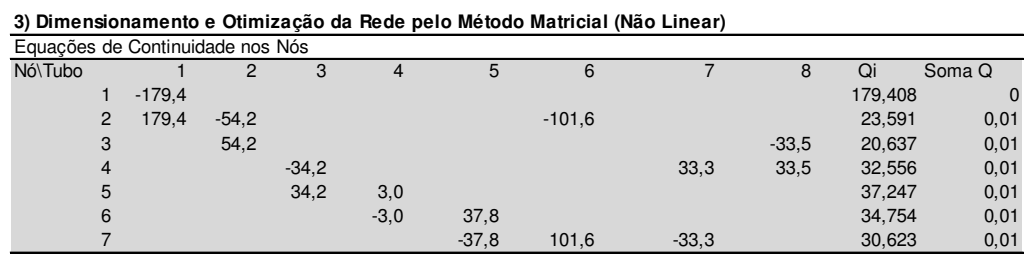

\begin{tabular}{|c|c|c|c|c|c|c|c|c|c|}
\hline \multicolumn{10}{|c|}{ Equações de Perda de Carga nos Circuitos } \\
\hline Circuitos & 1 & 2 & 3 & 4 & 5 & 6 & 7 & 8 & Soma Perda \\
\hline 1 & & $-0,518$ & & & & 0,438 & 0,589 & $-0,509$ & $1 \mathrm{E}-04$ \\
\hline 2 & & & $-0,531$ & 0,471 & 0,649 & & $-0,589$ & & $1 \mathrm{E}-04$ \\
\hline
\end{tabular}

Tabela da Função Objetivo

\begin{tabular}{|c|c|c|c|c|c|c|c|c|c|c|c|c|c|c|}
\hline \multirow{2}{*}{ Trecho } & \multicolumn{2}{|c|}{ Nó Montante } & \multicolumn{2}{|c|}{ No Jusante } & \multirow{2}{*}{$\begin{array}{c}\begin{array}{c}\text { Extensão } \\
\text { do Trecho }\end{array} \\
(\mathrm{m}) \\
\end{array}$} & \multirow{2}{*}{$\begin{array}{c}\text { Vazão do } \\
\text { Trecho }\end{array}$} & \multirow{2}{*}{$\begin{array}{c}\begin{array}{c}\text { Diâmetro } \\
\text { Nominal } \\
\text { Comercial }\end{array} \\
(\mathrm{mm})\end{array}$} & \multirow{2}{*}{$\begin{array}{c}\text { Diâmetro } \\
\text { Ótimo }\end{array}$} & \multirow{2}{*}{$\begin{array}{c}\text { Velocidade } \\
(\mathrm{m} / \mathrm{s})\end{array}$} & \multirow{2}{*}{$\begin{array}{l}\text { Fator de } \\
\text { Atrito } f\end{array}$} & \multirow{2}{*}{$\begin{array}{c}\text { Perda de Carga } \\
\text { (m) }\end{array}$} & \multirow{2}{*}{$\begin{array}{c}\begin{array}{c}\text { Carga } \\
\text { Montante }\end{array} \\
(\mathrm{m}) \\
\end{array}$} & \multirow{2}{*}{$\begin{array}{c}\text { Carga Jusante } \\
(\mathrm{m})\end{array}$} & \multirow{2}{*}{$\begin{array}{c}\text { Potência Dissipada } \\
\text { kW }\end{array}$} \\
\hline & Nome & Cota & Nome & Cota & & & & & & & & & & \\
\hline T1 & $\mathrm{N} 1$ & 4,56 & N2 & 3,50 & 258,48 & 179,4 & 400 & 400 & 1,42 & 0,0082 & 0,55 & 10,16 & 10,68 & 1,37 \\
\hline T2 & N2 & 3,50 & N3 & 3,50 & 255,93 & 54,2 & 250 & 250 & 1,10 & 0,0082 & 0,52 & 10,68 & 10,16 & 0,39 \\
\hline T3 & $\mathrm{N} 4$ & 1,50 & N5 & 0,49 & 657,53 & 34,2 & 250 & 250 & 0,70 & 0,0082 & 0,53 & 11,65 & 12,13 & 0,25 \\
\hline T4 & N5 & 0,49 & N6 & 0,50 & 253,28 & 3,0 & 80 & 80 & 0,60 & 0,0082 & 0,47 & 12,13 & 11,65 & 0,02 \\
\hline T5 & N6 & 0,50 & N7 & 1,50 & 660,47 & 37,8 & 250 & 250 & 0,77 & 0,0082 & 0,65 & 11,65 & 10,00 & 0,34 \\
\hline T6 & N2 & 3,50 & N7 & 1,50 & 644,10 & 101,6 & 400 & 400 & 0,81 & 0,0082 & 0,44 & 10,68 & 12,24 & 0,62 \\
\hline 77 & N7 & 1,50 & $\mathrm{~N} 4$ & 1,50 & 253,02 & 33,3 & 200 & 200 & 1,06 & 0,0082 & 0,59 & 12,24 & 11,65 & 0,27 \\
\hline T8 & N3 & 3,50 & $\mathrm{~N} 4$ & 1,50 & 657,18 & 33,5 & 250 & 250 & 0,68 & 0,0082 & 0,51 & 10,68 & 12,17 & 0,24 \\
\hline
\end{tabular}

4) Resumo do Dimensionamento Otimizado

\begin{tabular}{|c|c|c|c|}
\hline \multicolumn{3}{|c|}{ Potência Dissipada } & \multirow{2}{*}{$\begin{array}{r}\text { Pressurização Inicial } \\
25,53\end{array}$} \\
\hline Soma & & 3,52 & \\
\hline Energia & & $23.130,23$ & $167.701,70$ \\
\hline$F A$ & & 10,60 & 10,60 \\
\hline Sub-Tota & $\mathrm{R} \$$ & $62.289,62$ & $451.620,01$ \\
\hline
\end{tabular}

\begin{tabular}{|c|c|c|}
\hline Custos & & Porcentagem \\
\hline Custo de Tubulação $R \$$ & $1.099 .420,15$ & $62,76 \%$ \\
\hline Custo de Movimento de Terra $\mathrm{R} \$$ & $71.030,18$ & $4,05 \%$ \\
\hline Custo de Assentamento R\$ & $12.431,24$ & $0,71 \%$ \\
\hline Custo de Pavimentação $\mathrm{R} \$$ & $54.989,40$ & $3,14 \%$ \\
\hline Custo da Pressurização Inicial $R \$$ & $451.620,01$ & $25,78 \%$ \\
\hline Custo da Potência Dissipada $R \$$ & $62.289,62$ & $3,56 \%$ \\
\hline Total Global (Função Objetivo) R\$ & $1.751 .780,59$ & $100,00 \%$ \\
\hline Total Referencial Unitário $\mathbf{R} \$$ & 481,26 & por metro de rede \\
\hline
\end{tabular}


5) Quantitativos e Custos de Implantação das Redes de Abastecimento

\begin{tabular}{|c|c|c|c|c|c|c|c|c|c|}
\hline Trecho & $\begin{array}{l}\text { Locação da } \\
\text { Tubulação }\end{array}$ & $\begin{array}{l}\text { Tipo de } \\
\text { Superfície }\end{array}$ & Tipo de Tráfego & & & & & & \\
\hline $\mathrm{T} 1$ & viario pavimentado & paralelepipedos & - & & & & & & \\
\hline $\mathrm{T} 2$ & viario pavimentado & paralelepipedos & - & & & & & & \\
\hline T3 & vario pavimentado & paralelepipedos & - & & & & & & \\
\hline T4 & vario pavimentado & paralelepipedos & - & & & & & & \\
\hline $\mathrm{T5}$ & viario pavimentado & paralelepipedos & - & & & & & & \\
\hline T6 & viario pavimentado & paralelepipedos & - & & & & & & \\
\hline 77 & viario pavimentado & paralelepipedos & - & & & & & & \\
\hline \multirow[t]{2}{*}{ T8 } & viario pavimentado & paralelepipedos & - & & & & & & \\
\hline & \multicolumn{6}{|c|}{ Vala } & \multicolumn{3}{|c|}{ Tubulação } \\
\hline \multirow[t]{2}{*}{ Trecho } & Largura & $\begin{array}{l}\text { Profundidade } \\
\end{array}$ & Escavação & Reaterro & Bota-Fora & TOTAL & Assentamento & Material & TOTAL \\
\hline & $\mathrm{m}$ & $\mathrm{m}$ & $\mathrm{m}^{3}$ & $\mathrm{~m}^{3}$ & $\mathrm{~m}^{3}$ & $\mathrm{R} \$$ & $\mathrm{R} \$$ & $\mathrm{R} \$$ & $\mathrm{R} \$$ \\
\hline $\mathrm{T} 1$ & 0,75 & 1,40 & 271,40 & 238,92 & 32,48 & $6.481,67$ & $1.330,32$ & $117.523,27$ & $118.853,60$ \\
\hline $\mathrm{T} 2$ & 0,60 & 1,25 & 191,95 & 179,38 & 12,56 & $4.688,29$ & 781,41 & $69.337,49$ & $70.118,90$ \\
\hline T3 & 0,60 & 1,25 & 493,15 & 460,87 & 32,28 & $12.045,05$ & $2.007,59$ & $178.140,43$ & $180.148,02$ \\
\hline T4 & 0,50 & 1,08 & 136,77 & 135,50 & 1,27 & $3.417,48$ & 345,99 & $29.102,14$ & $29.448,13$ \\
\hline T5 & 0,60 & 1,25 & 495,35 & 462,93 & 32,42 & $12.098,91$ & $2.016,56$ & $178.936,95$ & $180.953,51$ \\
\hline T6 & 0,75 & 1,40 & 676,31 & 595,37 & 80,94 & $16.151,52$ & $3.315,00$ & $292.853,37$ & $296.168,37$ \\
\hline 77 & 0,55 & 1,20 & 166,99 & 159,04 & 7,95 & $4.108,62$ & 627,84 & $55.480,87$ & $56.108,72$ \\
\hline \multirow[t]{2}{*}{$\mathrm{T} 8$} & 0,60 & 1,25 & 492,89 & 460,63 & 32,26 & $12.038,64$ & $2.006,52$ & $178.045,61$ & $180.052,13$ \\
\hline & & & & & Soma & $71.030,18$ & $\begin{array}{ll}\mathrm{R} \$ & 12.431,24\end{array}$ & 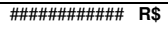 & $1.111 .851,39$ \\
\hline \multirow{2}{*}{\multicolumn{10}{|c|}{$\frac{\text { Pavimentação }}{\text { Vala }}$}} \\
\hline & & & & & & & & & \\
\hline \multirow[t]{2}{*}{ Trecho } & Área & $\begin{array}{l}\text { Área de } \\
\text { Concreto }\end{array}$ & $\begin{array}{c}\text { Área de } \\
\text { Paralelepipedos }\end{array}$ & $\begin{array}{l}\text { Área de } \\
\text { Asfalto }\end{array}$ & Área de Binder & $\begin{array}{l}\text { Area de Concreto Asfático } \\
\text { Usinado a Quente }\end{array}$ & & & \\
\hline & $\mathrm{m}^{2}$ & $\mathrm{~m}^{2}$ & $\mathrm{~m}^{2}$ & $\mathrm{~m}^{2}$ & $\mathrm{~m}^{2}$ & $\mathrm{~m}^{2}$ & & & \\
\hline $\mathrm{T} 1$ & 193,86 & 0,00 & 193,86 & 0,00 & 0,00 & 0,00 & & & \\
\hline $\mathrm{T} 2$ & 153,56 & 0,00 & 153,56 & 0,00 & 0,00 & 0,00 & & & \\
\hline T3 & 394,52 & 0,00 & 394,52 & 0,00 & 0,00 & 0,00 & & & \\
\hline T4 & 126,64 & 0,00 & 126,64 & 0,00 & 0,00 & 0,00 & & & \\
\hline T5 & 396,28 & 0,00 & 396,28 & 0,00 & 0,00 & 0,00 & & & \\
\hline T6 & 483,08 & 0,00 & 483,08 & 0,00 & 0,00 & 0,00 & & & \\
\hline 77 & 139,16 & 0,00 & 139,16 & 0,00 & 0,00 & 0,00 & & & \\
\hline T8 & 394,31 & 0,00 & 394,31 & 0,00 & 0,00 & 0,00 & & & \\
\hline
\end{tabular}

\begin{tabular}{|c|c|c|c|c|c|c|c|c|c|}
\hline \multirow{4}{*}{ Trecho } & \multicolumn{9}{|c|}{ Pavimentação } \\
\hline & \multicolumn{3}{|c|}{ Volume } & \multicolumn{2}{|c|}{ Área } & \multicolumn{4}{|c|}{ Custos } \\
\hline & Macadame Hidáulico & Binder & $\begin{array}{l}\text { Concreto } \\
\text { Astáltico Usinado } \\
\text { a Quente }\end{array}$ & $\begin{array}{l}\text { Imprimação } \\
\text { Betuminosa } \\
\text { Ligante }\end{array}$ & $\begin{array}{l}\text { Imprimação } \\
\text { Betuminosa } \\
\text { Impermeabiliza } \\
\text { nte }\end{array}$ & Remoção & Recomposição & Transporte & TOTAL \\
\hline & $\mathrm{m}^{3}$ & $\mathrm{~m}^{3}$ & $\mathrm{~m}^{3}$ & $\mathrm{~m}^{2}$ & $\mathrm{~m}^{2}$ & $\mathrm{R} \$$ & $\mathrm{R} \$$ & $\mathrm{R} \$$ & $\mathrm{R} \$$ \\
\hline $\mathrm{T} 1$ & 0,00 & 0,00 & 0,00 & 0,00 & 0,00 & 993,09 & $3.679,58$ & 0,00 & $4.672,67$ \\
\hline $\mathrm{T} 2$ & 0,00 & 0,00 & 0,00 & 0,00 & 0,00 & 786,64 & $2.914,62$ & 0,00 & $3.701,26$ \\
\hline T3 & 0,00 & 0,00 & 0,00 & 0,00 & 0,00 & $2.021,01$ & $7.488,19$ & 0,00 & $9.509,20$ \\
\hline T4 & 0,00 & 0,00 & 0,00 & 0,00 & 0,00 & 648,74 & $2.403,70$ & 0,00 & $3.052,45$ \\
\hline T5 & 0,00 & 0,00 & 0,00 & 0,00 & 0,00 & $2.030,04$ & $7.521,67$ & 0,00 & $9.551,72$ \\
\hline T6 & 0,00 & 0,00 & 0,00 & 0,00 & 0,00 & $2.474,66$ & $9.169,06$ & 0,00 & $11.643,72$ \\
\hline 77 & 0,00 & 0,00 & 0,00 & 0,00 & 0,00 & 712,88 & $2.641,36$ & 0,00 & $3.354,24$ \\
\hline T8 & 0,00 & 0,00 & 0,00 & 0,00 & 0,00 & $2.019,93$ & $7.484,21$ & 0,00 & $9.504,14$ \\
\hline
\end{tabular}




\section{APÊNDICE B8 - Planilha de Dimensionamento para Tarifa Verde - Ponta Seca e Viário em Paralelepípedo - FoFo}

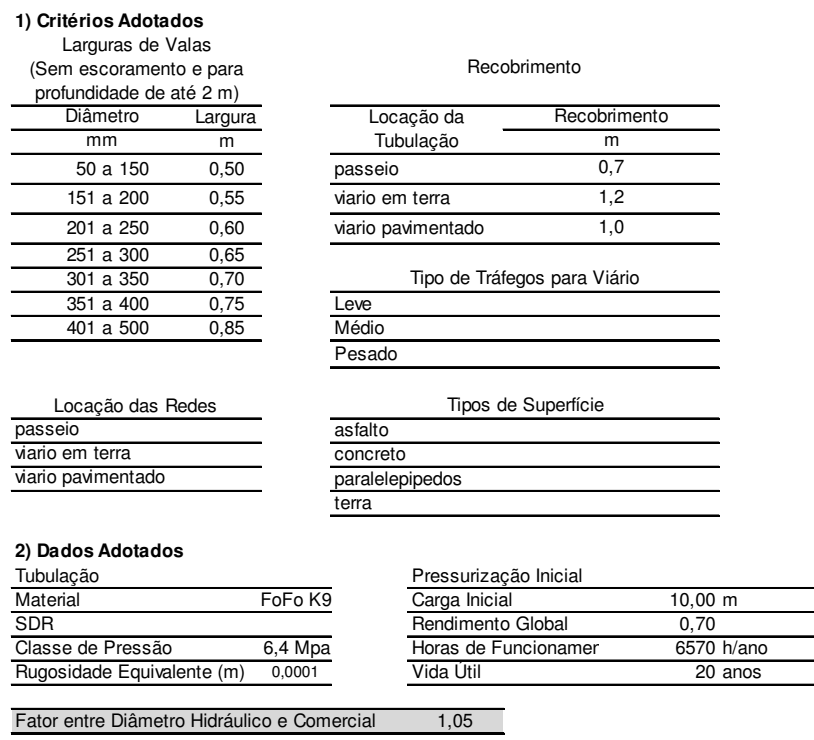

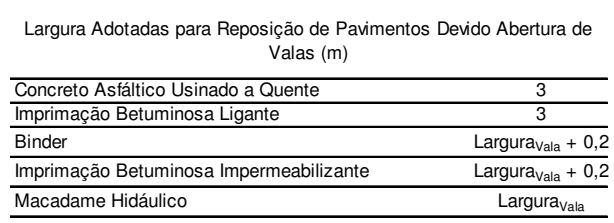

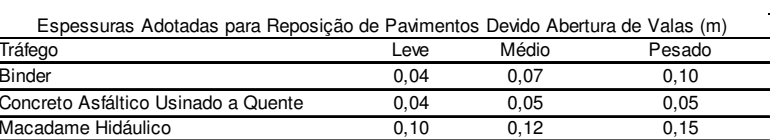

Macadame Hidáulico

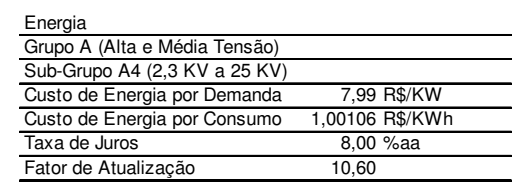

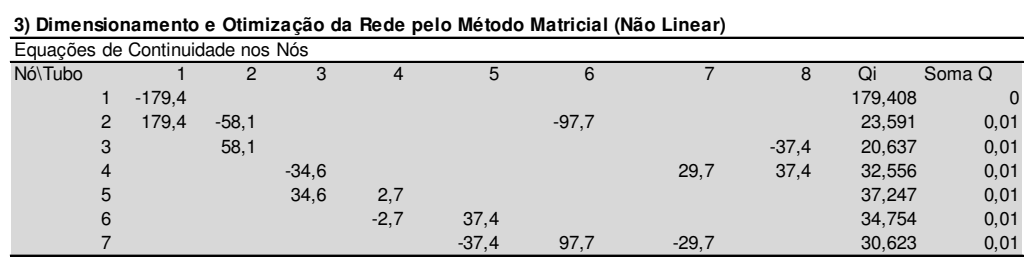

\begin{tabular}{|c|c|c|c|c|c|c|c|c|c|}
\hline \multicolumn{10}{|c|}{ Equações de Perda de Carga nos Circuitos } \\
\hline Circuitos & 1 & 2 & 3 & 4 & 5 & 6 & 7 & 8 & Soma Perda \\
\hline 1 & & 0,239 & & & & 0,405 & 0,469 & $-0,635$ & $1,337 \mathrm{E}-05$ \\
\hline 2 & & & $-0,542$ & 0,373 & 0,638 & & $-0,469$ & & 0,0001 \\
\hline
\end{tabular}

Tabela da Função Objetivo

\begin{tabular}{|c|c|c|c|c|c|c|c|c|c|c|c|c|c|c|}
\hline \multirow{2}{*}{ Trecho } & \multicolumn{2}{|c|}{ Nó Montante } & \multicolumn{2}{|c|}{ No Jusante } & \multirow{2}{*}{$\begin{array}{c}\begin{array}{r}\text { Extensão } \\
\text { do Trecho }\end{array} \\
(\mathrm{m})\end{array}$} & \multirow{2}{*}{$\begin{array}{c}\begin{array}{c}\text { Vazão do } \\
\text { Trecho }\end{array} \\
\text { I/s }\end{array}$} & \multirow{2}{*}{$\begin{array}{c}\begin{array}{c}\text { Diâmetro } \\
\text { Nominal } \\
\text { Comercial }\end{array} \\
(\mathrm{mm})\end{array}$} & \multirow{2}{*}{$\begin{array}{c}\begin{array}{c}\text { Diâmetro } \\
\text { Ótimo }\end{array} \\
(\mathrm{mm}) \\
\end{array}$} & \multirow{2}{*}{$\begin{array}{c}\text { Velocidade } \\
(\mathrm{m} / \mathrm{s})\end{array}$} & \multirow{2}{*}{$\begin{array}{l}\text { Fator de } \\
\text { Atrito } f\end{array}$} & \multirow{2}{*}{$\begin{array}{c}\text { Perda de Carga } \\
(\mathrm{m})\end{array}$} & \multirow{2}{*}{$\begin{array}{c}\begin{array}{c}\text { Carga } \\
\text { Montante }\end{array} \\
(\mathrm{m})\end{array}$} & \multirow{2}{*}{$\begin{array}{c}\text { Carga Jusante } \\
(\mathrm{m})\end{array}$} & \multirow{2}{*}{$\begin{array}{c}\text { Potência Dissipada } \\
\mathrm{kW}\end{array}$} \\
\hline & Nome & Cota & Nome & Cota & & & & & & & & & & \\
\hline $\mathrm{T1}$ & N1 & 4,56 & $\mathrm{~N} 2$ & 3,50 & 258,48 & 179,4 & 400 & 400 & 1,42 & 0,0082 & 0,55 & 10,00 & 10,52 & 1,37 \\
\hline T2 & N2 & 3,50 & N3 & 3,50 & 255,93 & 58,1 & 300 & 300 & 0,82 & 0,0082 & 0,24 & 10,52 & 10,28 & 0,19 \\
\hline T3 & N4 & 1,50 & N5 & 0,49 & 657,53 & 34,6 & 250 & 250 & 0,70 & 0,0082 & 0,54 & 11,64 & 12,11 & 0,26 \\
\hline T4 & N5 & 0,49 & N6 & 0,50 & 253,28 & 2,7 & 80 & 80 & 0,53 & 0,0082 & 0,37 & 12,11 & 11,73 & 0,01 \\
\hline T5 & N6 & 0,50 & N7 & 1,50 & 660,47 & 37,4 & 250 & 250 & 0,76 & 0,0082 & 0,64 & 11,73 & 10,09 & 0,33 \\
\hline T6 & N2 & 3,50 & N7 & 1,50 & 644,10 & 97,7 & 400 & 400 & 0,78 & 0,0082 & 0,40 & 10,52 & 12,11 & 0,55 \\
\hline 77 & N7 & 1,50 & $\mathrm{~N} 4$ & 1,50 & 253,02 & 29,7 & 200 & 200 & 0,94 & 0,0082 & 0,47 & 12,11 & 11,64 & 0,20 \\
\hline T8 & N3 & 3,50 & N4 & 1,50 & 657,18 & 37,4 & 250 & 250 & 0,76 & 0,0082 & 0,63 & 10,52 & 11,88 & 0,33 \\
\hline & & & & Soma & 3639,99 & & & & & & & & & 3,26 \\
\hline
\end{tabular}

4) Resumo do Dimensionamento Otimizado

\begin{tabular}{|c|c|c|}
\hline & sia Dissipada & Pressurização Inicial \\
\hline Soma & 3,26 & 25,12 \\
\hline Energia & $21.420,37$ & $165.019,48$ \\
\hline FA & 10,60 & 10,60 \\
\hline Sub-Total $R$ & $227.650,06$ & $1.753 .783,25$ \\
\hline
\end{tabular}

\begin{tabular}{|c|c|c|}
\hline Custos & & Porcentagem \\
\hline Custo de Tubulação $\mathrm{R} \$$ & $1.113 .867,14$ & $34,43 \%$ \\
\hline Custo de Movimento de Terra $\mathrm{R} \$$ & $71.584,63$ & $2,21 \%$ \\
\hline Custo de Assentamento $\mathrm{R} \$$ & $12.593,72$ & $0,39 \%$ \\
\hline Custo de Pavimentação $\mathrm{R} \$$ & $55.297,84$ & $1,71 \%$ \\
\hline Custo da Pressurização Inicial $\mathrm{R} \$$ & $1.753 .783,25$ & $54,22 \%$ \\
\hline Custo da Potência Dissipada $\mathrm{R} \$$ & $227.650,06$ & $7,04 \%$ \\
\hline Total Global (Função Objetivo) R\$ & $3.234 .776,63$ & $100,00 \%$ \\
\hline Total Referencial Unitário $\mathbf{R} \$$ & 888,68 & por metro de rede \\
\hline
\end{tabular}


5) Quantitativos e Custos de Implantação das Redes de Abastecimento

\begin{tabular}{|c|c|c|c|c|c|c|c|c|c|}
\hline Trecho & $\begin{array}{l}\text { Locação da } \\
\text { Tubulação }\end{array}$ & $\begin{array}{l}\text { Tipo de } \\
\text { Superfície }\end{array}$ & Tipo de Tráfego & & & & & & \\
\hline $\mathrm{T} 1$ & viario pavimentado & paralelepipedos & - & & & & & & \\
\hline $\mathrm{T} 2$ & viario pavimentado & paralelepipedos & - & & & & & & \\
\hline T3 & vario pavimentado & paralelepipedos & - & & & & & & \\
\hline T4 & vario pavimentado & paralelepipedos & - & & & & & & \\
\hline $\mathrm{T5}$ & viario pavimentado & paralelepipedos & - & & & & & & \\
\hline T6 & viario pavimentado & paralelepipedos & - & & & & & & \\
\hline 77 & viario pavimentado & paralelepipedos & - & & & & & & \\
\hline \multirow[t]{2}{*}{ T8 } & viario pavimentado & paralelepipedos & - & & & & & & \\
\hline & \multicolumn{6}{|c|}{ Vala } & \multicolumn{3}{|c|}{ Tubulação } \\
\hline \multirow[t]{2}{*}{ Trecho } & Largura & $\begin{array}{l}\text { Profundidade } \\
\end{array}$ & Escavação & Reaterro & Bota-Fora & TOTAL & Assentamento & Material & TOTAL \\
\hline & $\mathrm{m}$ & $\mathrm{m}$ & $\mathrm{m}^{3}$ & $\mathrm{~m}^{3}$ & $\mathrm{~m}^{3}$ & $\mathrm{R} \$$ & $\mathrm{R} \$$ & $\mathrm{R} \$$ & $\mathrm{R} \$$ \\
\hline $\mathrm{T} 1$ & 0,75 & 1,40 & 271,40 & 238,92 & 32,48 & $6.481,67$ & $1.330,32$ & $117.523,27$ & $118.853,60$ \\
\hline $\mathrm{T} 2$ & 0,65 & 1,30 & 216,26 & 198,17 & 18,09 & $5.242,73$ & 943,88 & $83.784,48$ & $84.728,37$ \\
\hline T3 & 0,60 & 1,25 & 493,15 & 460,87 & 32,28 & $12.045,05$ & $2.007,59$ & $178.140,43$ & $180.148,02$ \\
\hline T4 & 0,50 & 1,08 & 136,77 & 135,50 & 1,27 & $3.417,48$ & 345,99 & $29.102,14$ & $29.448,13$ \\
\hline T5 & 0,60 & 1,25 & 495,35 & 462,93 & 32,42 & $12.098,91$ & $2.016,56$ & $178.936,95$ & $180.953,51$ \\
\hline T6 & 0,75 & 1,40 & 676,31 & 595,37 & 80,94 & $16.151,52$ & $3.315,00$ & $292.853,37$ & $296.168,37$ \\
\hline 77 & 0,55 & 1,20 & 166,99 & 159,04 & 7,95 & $4.108,62$ & 627,84 & $55.480,87$ & $56.108,72$ \\
\hline \multirow[t]{2}{*}{$\mathrm{T} 8$} & 0,60 & 1,25 & 492,89 & 460,63 & 32,26 & $12.038,64$ & $2.006,52$ & $178.045,61$ & $180.052,13$ \\
\hline & & & & & Soma & $71.584,63$ & $\begin{array}{ll}\mathrm{R} \$ & 12.593,72 \\
\end{array}$ & 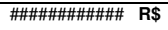 & $1.126 .460,85$ \\
\hline \multirow{2}{*}{\multicolumn{10}{|c|}{$\frac{\text { Pavimentação }}{\text { Vala }}$}} \\
\hline & & & & & & & & & \\
\hline \multirow[t]{2}{*}{ Trecho } & Área & $\begin{array}{l}\text { Área de } \\
\text { Concreto }\end{array}$ & $\begin{array}{c}\text { Área de } \\
\text { Paralelepipedos }\end{array}$ & $\begin{array}{l}\text { Área de } \\
\text { Asfalto }\end{array}$ & Área de Binder & $\begin{array}{l}\text { Area de Concreto Asfático } \\
\text { Usinado a Quente }\end{array}$ & & & \\
\hline & $\mathrm{m}^{2}$ & $\mathrm{~m}^{2}$ & $\mathrm{~m}^{2}$ & $\mathrm{~m}^{2}$ & $\mathrm{~m}^{2}$ & $\mathrm{~m}^{2}$ & & & \\
\hline $\mathrm{T} 1$ & 193,86 & 0,00 & 193,86 & 0,00 & 0,00 & 0,00 & & & \\
\hline $\mathrm{T} 2$ & 166,35 & 0,00 & 166,35 & 0,00 & 0,00 & 0,00 & & & \\
\hline T3 & 394,52 & 0,00 & 394,52 & 0,00 & 0,00 & 0,00 & & & \\
\hline T4 & 126,64 & 0,00 & 126,64 & 0,00 & 0,00 & 0,00 & & & \\
\hline T5 & 396,28 & 0,00 & 396,28 & 0,00 & 0,00 & 0,00 & & & \\
\hline T6 & 483,08 & 0,00 & 483,08 & 0,00 & 0,00 & 0,00 & & & \\
\hline 77 & 139,16 & 0,00 & 139,16 & 0,00 & 0,00 & 0,00 & & & \\
\hline T8 & 394,31 & 0,00 & 394,31 & 0,00 & 0,00 & 0,00 & & & \\
\hline
\end{tabular}

\begin{tabular}{|c|c|c|c|c|c|c|c|c|c|}
\hline \multirow{4}{*}{ Trecho } & \multicolumn{9}{|c|}{ Pavimentação } \\
\hline & \multicolumn{3}{|c|}{ Volume } & \multicolumn{2}{|c|}{ Área } & \multicolumn{4}{|c|}{ Custos } \\
\hline & Macadame Hidáulico & Binder & $\begin{array}{l}\text { Concreto } \\
\text { Astáltico Usinado } \\
\text { a Quente }\end{array}$ & $\begin{array}{l}\text { Imprimação } \\
\text { Betuminosa } \\
\text { Ligante }\end{array}$ & $\begin{array}{l}\text { Imprimação } \\
\text { Betuminosa } \\
\text { Impermeabiliza } \\
\text { nte }\end{array}$ & Remoção & Recomposição & Transporte & TOTAL \\
\hline & $\mathrm{m}^{3}$ & $\mathrm{~m}^{3}$ & $\mathrm{~m}^{3}$ & $\mathrm{~m}^{2}$ & $\mathrm{~m}^{2}$ & $\mathrm{R} \$$ & $\mathrm{R} \$$ & $\mathrm{R} \$$ & $\mathrm{R} \$$ \\
\hline $\mathrm{T} 1$ & 0,00 & 0,00 & 0,00 & 0,00 & 0,00 & 993,09 & $3.679,58$ & 0,00 & $4.672,67$ \\
\hline $\mathrm{T} 2$ & 0,00 & 0,00 & 0,00 & 0,00 & 0,00 & 852,19 & $3.157,51$ & 0,00 & $4.009,70$ \\
\hline T3 & 0,00 & 0,00 & 0,00 & 0,00 & 0,00 & $2.021,01$ & $7.488,19$ & 0,00 & $9.509,20$ \\
\hline T4 & 0,00 & 0,00 & 0,00 & 0,00 & 0,00 & 648,74 & $2.403,70$ & 0,00 & $3.052,45$ \\
\hline T5 & 0,00 & 0,00 & 0,00 & 0,00 & 0,00 & $2.030,04$ & $7.521,67$ & 0,00 & $9.551,72$ \\
\hline T6 & 0,00 & 0,00 & 0,00 & 0,00 & 0,00 & $2.474,66$ & $9.169,06$ & 0,00 & $11.643,72$ \\
\hline 77 & 0,00 & 0,00 & 0,00 & 0,00 & 0,00 & 712,88 & $2.641,36$ & 0,00 & $3.354,24$ \\
\hline T8 & 0,00 & 0,00 & 0,00 & 0,00 & 0,00 & $2.019,93$ & $7.484,21$ & 0,00 & $9.504,14$ \\
\hline
\end{tabular}




\section{APÊNDICE C1 - Planilha de Dimensionamento para Juros de 4\%aa e Viário em Paralelepípedo - PVC}

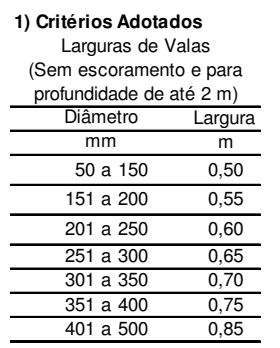

Locação das Redes

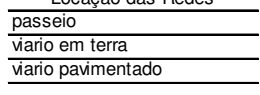

viario em terra

2) Dados Adotados

Tubulação

Materia

SDR

\begin{tabular}{ll} 
Rugosidade Equivalente $(\mathrm{m}) \quad 0,00002$ \\
\hline
\end{tabular}

Fator entre Diâmetro Hidráulico e Comercia
Recobrimento

\begin{tabular}{lc}
\hline \multicolumn{1}{c}{ Locação da } & Recobrimento \\
\cline { 2 - 2 } Tubulação & $\mathrm{m}$ \\
\hline passeio & 0,7 \\
\hline viario em terra & 1,2 \\
\hline viario pavimentado & 1,0 \\
\hline
\end{tabular}

Tipo de Tráfegos para Viário

\begin{tabular}{l}
\hline Leve \\
\hline Médio \\
\hline Pesado \\
\hline \multicolumn{1}{c}{ Tipos de Superfície } \\
\hline asfalto \\
\hline concreto \\
\hline paralelepipedos \\
\hline terra
\end{tabular}

Pressurização Inicial

Carga Inicial

Rendimento Global

Vida Útil
Largura Adotadas para Reposição de Pavimentos Devido Abertura de Valas $(\mathrm{m})$

Concreto Astáltico Usinado a Quente Imprimação Betuminosa Ligante

Binder

Imprimação Betuminosa Impermeabilizante Larguravala $+0,2$

Macadame Hidáulico $\quad$ Largura $_{\text {vala }}$

\begin{tabular}{|c|c|c|c|}
\hline Tráfego & Leve & Médio & Pesado \\
\hline Binder & 0,04 & 0,07 & 0,10 \\
\hline Concreto Asfáltico Usinado a Quente & 0,04 & 0,05 & 0,05 \\
\hline Macadame Hidáulico & 0,10 & 0,12 & 0,15 \\
\hline
\end{tabular}

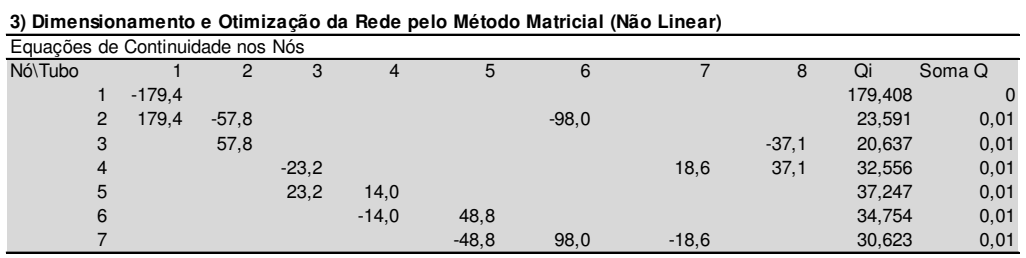

\begin{tabular}{cccccccccr}
\hline Equações de Perda de Carga nos Circuitos & & & & & & \\
\hline Circuitos & 1 & 2 & 3 & 4 & 5 & 6 & 7 & 8 & Soma Perda \\
& & & & & & & & \\
1 & $-0,454$ & & & & 1,323 & 0,601 & $-1,470$ & $1 \mathrm{E}-04$ \\
2 & & $-0,575$ & 0,341 & 0,835 & & $-0,601$ & & $1 \mathrm{E}-04$ \\
\hline
\end{tabular}

Tabela da Função Objetivo

\begin{tabular}{|c|c|c|c|c|c|c|c|c|c|c|c|c|c|c|}
\hline \multirow{2}{*}{ Trecho } & \multicolumn{2}{|c|}{ Nó Montante } & \multicolumn{2}{|c|}{ No Jusante } & \multirow{2}{*}{$\begin{array}{c}\begin{array}{c}\text { Extensão } \\
\text { do Trecho }\end{array} \\
\text { (m) } \\
\end{array}$} & \multirow{2}{*}{$\begin{array}{c}\begin{array}{c}\text { Vazão do } \\
\text { Trecho }\end{array} \\
\text { 1/s }\end{array}$} & \multirow{2}{*}{$\begin{array}{c}\begin{array}{c}\text { Diâmetro } \\
\text { Nominal } \\
\text { Comercial }\end{array} \\
(\mathrm{mm})\end{array}$} & \multirow{2}{*}{$\begin{array}{c}\begin{array}{c}\text { Diâmetro } \\
\text { Ótimo }\end{array} \\
(\mathrm{mm})\end{array}$} & \multirow{2}{*}{$\begin{array}{l}\text { Velocidade } \\
(\mathrm{m} / \mathrm{s})\end{array}$} & \multirow{2}{*}{$\begin{array}{l}\text { Fator de } \\
\text { Atrito } f\end{array}$} & \multirow{2}{*}{$\begin{array}{c}\text { Perda de Carga } \\
(\mathrm{m})\end{array}$} & \multirow{2}{*}{$\begin{array}{c}\begin{array}{c}\text { Carga } \\
\text { Montante }\end{array} \\
(\mathrm{m})\end{array}$} & \multirow{2}{*}{$\begin{array}{c}\text { Carga Jusante } \\
(\mathrm{m})\end{array}$} & \multirow{2}{*}{$\begin{array}{c}\text { Potência Dissipada } \\
\text { kW }\end{array}$} \\
\hline & Nome & Cota & Nome & Cota & & & & & & & & & & \\
\hline T1 & $\mathrm{N} 1$ & 4,56 & N2 & 3,50 & 258,48 & 179,4 & 400 & 400 & 1,42 & 0,0063 & 0,42 & 11,03 & 11,67 & 1,06 \\
\hline T2 & N2 & 3,50 & N3 & 3,50 & 255,93 & 57,8 & 250 & 250 & 1,17 & 0,0063 & 0,45 & 11,67 & 11,22 & 0,37 \\
\hline T3 & $\mathrm{N} 4$ & 1,50 & N5 & 0,49 & 657,53 & 23,2 & 200 & 191 & 0,74 & 0,0063 & 0,58 & 11,75 & 12,18 & 0,19 \\
\hline T4 & N5 & 0,49 & N6 & 0,50 & 253,28 & 14,0 & 150 & 143 & 0,79 & 0,0063 & 0,34 & 12,18 & 11,84 & 0,07 \\
\hline T5 & N6 & 0,50 & N7 & 1,50 & 660,47 & 48,8 & 250 & 220 & 0,99 & 0,0063 & 0,84 & 11,84 & 10,00 & 0,57 \\
\hline T6 & N2 & 3,50 & N7 & 1,50 & 644,10 & 98,0 & 300 & 300 & 1,38 & 0,0063 & 1,32 & 11,67 & 12,35 & 1,82 \\
\hline 77 & N7 & 1,50 & $\mathrm{~N} 4$ & 1,50 & 253,02 & 18,6 & 150 & 150 & 1,05 & 0,0063 & 0,60 & 12,35 & 11,75 & 0,16 \\
\hline T8 & N3 & 3,50 & N4 & 1,50 & 657,18 & 37,1 & 200 & 198 & 1,18 & 0,0063 & 1,47 & 11,67 & 12,21 & 0,76 \\
\hline
\end{tabular}

4) Resumo do Dimensionamento Otimizado

\begin{tabular}{|c|c|c|c|}
\hline & Poté & Dissipada & Pressurização Inicial \\
\hline Soma & & 4,99 & 27,71 \\
\hline Energia & & $32.768,69$ & $182.078,58$ \\
\hline FA & & 14,13 & 14,13 \\
\hline Sub-Total & $\mathrm{R} \$$ & $76.922,66$ & $427.419,25$ \\
\hline
\end{tabular}

\begin{tabular}{|c|c|c|}
\hline Custos & & Porcentagem \\
\hline Custo de Tubulação $\mathrm{R} \$$ & $378.064,91$ & $37,44 \%$ \\
\hline Custo de Movimento de Terra $\mathrm{R} \$$ & $65.023,76$ & $6,44 \%$ \\
\hline Custo de Assentamento $R \$$ & $10.764,81$ & $1,07 \%$ \\
\hline Custo de Pavimentação $R \$$ & $51.547,53$ & $5,11 \%$ \\
\hline Custo da Pressurização Inicial $\mathrm{R} \$$ & $427.419,25$ & $42,33 \%$ \\
\hline Custo da Potência Dissipada $R \$$ & $76.922,66$ & $7,62 \%$ \\
\hline Total Global (Função Objetivo) R\$ & $1.009 .742,92$ & $100,00 \%$ \\
\hline Total Referencial Unitário R\$ & 277,40 & por metro de rede \\
\hline
\end{tabular}


5) Quantitativos e Custos de Implantação das Redes de Abastecimento

\begin{tabular}{|c|c|c|c|c|c|c|c|c|c|}
\hline Trecho & $\begin{array}{l}\text { Locação da } \\
\text { Tubulação }\end{array}$ & $\begin{array}{c}\text { Tipo de } \\
\text { Superfície }\end{array}$ & Tipo de Tráfego & & & & & & \\
\hline $\mathrm{T} 1$ & viario pavimentado & paralelepipedos & - & & & & & & \\
\hline $\mathrm{T} 2$ & viario pavimentado & paralelepipedos & - & & & & & & \\
\hline T3 & viario pavimentado & paralelepipedos & - & & & & & & \\
\hline $\mathrm{T} 4$ & viario pavimentado & paralelepipedos & - & & & & & & \\
\hline T5 & viario pavimentado & paralelepipedos & - & & & & & & \\
\hline T6 & viario pavimentado & paralelepipedos & - & & & & & & \\
\hline 77 & viario pavimentado & paralelepipedos & - & & & & & & \\
\hline T8 & viario pavimentado & $\begin{array}{l}\text { paralelepipedos } \\
\end{array}$ & - & & & & & & \\
\hline \multirow{3}{*}{ Trecho } & \multicolumn{6}{|c|}{ Vala } & \multicolumn{3}{|c|}{ Tubulação } \\
\hline & Largura & $\begin{array}{l}\text { Profundidade } \\
\end{array}$ & Escavação & Reaterro & Bota-Fora & TOTAL & Assentamento & Material & TOTAL \\
\hline & $\mathrm{m}$ & $\mathrm{m}$ & $\mathrm{m}^{3}$ & $\mathrm{~m}^{3}$ & $\mathrm{~m}^{3}$ & $\mathbf{R} \$$ & $\mathrm{R} \$$ & $\mathrm{R} \$$ & $\mathbf{R} \$$ \\
\hline $\mathrm{T} 1$ & 0,75 & 1,40 & 271,40 & 238,92 & 32,48 & $6.481,67$ & $1.330,32$ & $60.843,11$ & $\begin{array}{l}62.173,43 \\
\end{array}$ \\
\hline $\mathrm{T} 2$ & 0,60 & 1,25 & 191,95 & 179,38 & 12,56 & $4.688,29$ & 781,41 & $27.846,08$ & $28.627,49$ \\
\hline T3 & 0,55 & 1,20 & 433,97 & 413,31 & 20,66 & $10.677,19$ & $1.631,59$ & $49.595,62$ & $51.227,21$ \\
\hline T4 & 0,50 & 1,15 & 145,64 & 141,16 & 4,48 & $3.607,75$ & 499,61 & $11.912,24$ & $12.411,85$ \\
\hline T5 & 0,60 & 1,25 & 495,35 & 462,93 & 32,42 & $12.098,91$ & $2.016,56$ & $71.861,44$ & \begin{tabular}{|l|l|}
$73.878,01$ \\
\end{tabular} \\
\hline T6 & 0,65 & 1,30 & 544,26 & 498,74 & 45,53 & $13.194,41$ & $2.375,48$ & $94.537,19$ & $96.912,66$ \\
\hline$T 7$ & 0,50 & 1,15 & 145,49 & 141,02 & 4,47 & $3.604,04$ & 499,10 & $11.900,01$ & $12.399,11$ \\
\hline \multirow[t]{2}{*}{ T8 } & 0,55 & 1,20 & 433,74 & 413,09 & 20,65 & $10.671,50$ & $1.630,72$ & $49.569,22$ & $\begin{array}{l}51.199,94 \\
\end{array}$ \\
\hline & & & & & Soma & $65.023,76$ & $\begin{array}{ll}\mathrm{R} \$ & 10.764,81\end{array}$ & $\mathrm{R} \$ 378.064,91 \quad \mathrm{R} \$$ & $388.829,71$ \\
\hline \multicolumn{10}{|c|}{ Pavimentação } \\
\hline \multirow{3}{*}{ Trecho } & & & $\mathrm{Va}$ & a & & & & & \\
\hline & Área & $\begin{array}{l}\text { Área de } \\
\text { Concreto }\end{array}$ & $\begin{array}{c}\text { Área de } \\
\text { Paralelepipedos }\end{array}$ & $\begin{array}{l}\text { Área de } \\
\text { Asfalto }\end{array}$ & Área de Binder & $\begin{array}{l}\text { Área de Concreto Astático } \\
\text { Usinado a Quente }\end{array}$ & & & \\
\hline & $\mathrm{m}^{2}$ & $\mathrm{~m}^{2}$ & $\mathrm{~m}^{2}$ & $\mathrm{~m}^{2}$ & $\mathrm{~m}^{2}$ & $\mathrm{~m}^{2}$ & & & \\
\hline $\mathrm{T} 1$ & 193,86 & 0,00 & 193,86 & 0,00 & 0,00 & 0,00 & & & \\
\hline $\mathrm{T} 2$ & 153,56 & 0,00 & 153,56 & 0,00 & 0,00 & 0,00 & & & \\
\hline T3 & 361,64 & 0,00 & 361,64 & 0,00 & 0,00 & 0,00 & & & \\
\hline T4 & 126,64 & 0,00 & 126,64 & 0,00 & 0,00 & 0,00 & & & \\
\hline T5 & 396,28 & 0,00 & 396,28 & 0,00 & 0,00 & 0,00 & & & \\
\hline T6 & 418,67 & 0,00 & 418,67 & 0,00 & 0,00 & 0,00 & & & \\
\hline 77 & 126,51 & 0,00 & 126,51 & 0,00 & 0,00 & 0,00 & & & \\
\hline T8 & 361,45 & 0,00 & 361,45 & 0,00 & 0,00 & 0,00 & & & \\
\hline \multirow{4}{*}{ Trecho } & \multicolumn{9}{|c|}{ Pavimentação } \\
\hline & \multicolumn{3}{|c|}{ Volume } & \multicolumn{2}{|c|}{ Area } & \multicolumn{4}{|c|}{ Custos } \\
\hline & Macadame Hidáulico & Binder & $\begin{array}{l}\text { Concreto } \\
\text { Asfáltico Usinado } \\
\text { a Quente }\end{array}$ & $\begin{array}{l}\text { Imprimação } \\
\text { Betuminosa } \\
\text { Ligante }\end{array}$ & $\begin{array}{c}\text { Imprimação } \\
\text { Betuminosa } \\
\text { Impermeabiliza } \\
\text { nte }\end{array}$ & Remoção & Recomposição & Transporte & TOTAL \\
\hline & $\mathrm{m}^{3}$ & $\mathrm{~m}^{3}$ & $\mathrm{~m}^{3}$ & $\mathrm{~m}^{2}$ & $\mathrm{~m}^{2}$ & $\mathrm{R} \$$ & $\mathrm{R} \$$ & $\mathrm{R} \$$ & $\mathbf{R} \$$ \\
\hline $\mathrm{T} 1$ & 0,00 & 0,00 & 0,00 & 0,00 & 0,00 & 993,09 & $3.679,58$ & 0,00 & $4.672,67$ \\
\hline $\mathrm{T} 2$ & 0,00 & 0,00 & 0,00 & 0,00 & 0,00 & 786,64 & $2.914,62$ & 0,00 & $3.701,26$ \\
\hline T3 & 0,00 & 0,00 & 0,00 & 0,00 & 0,00 & $1.852,59$ & $6.864,18$ & 0,00 & $8.716,77$ \\
\hline $\mathrm{T} 4$ & 0,00 & 0,00 & 0,00 & 0,00 & 0,00 & 648,74 & $2.403,70$ & 0,00 & $3.052,45$ \\
\hline T5 & 0,00 & 0,00 & 0,00 & 0,00 & 0,00 & 2.030,04 & $7.521,67$ & 0,00 & $9.551,72$ \\
\hline T6 & 0,00 & 0,00 & 0,00 & 0,00 & 0,00 & $2.144,71$ & $7.946,52$ & 0,00 & $10.091,22$ \\
\hline 77 & 0,00 & 0,00 & 0,00 & 0,00 & 0,00 & 648,08 & $2.401,24$ & 0,00 & $3.049,31$ \\
\hline T8 & 0,00 & 0,00 & 0,00 & 0,00 & 0,00 & $1.851,60$ & $6.860,52$ & 0,00 & $8.712,13$ \\
\hline & & & & & Soma & 10.5 & $\mathrm{R} \$ \quad 40.592,04$ & $\mathbf{R} \$$ & $51.547,53$ \\
\hline
\end{tabular}




\section{APÊNDICE C2 - Planilha de Dimensionamento para Juros de 6\%aa e Viário em Paralelepípedo - PVC}

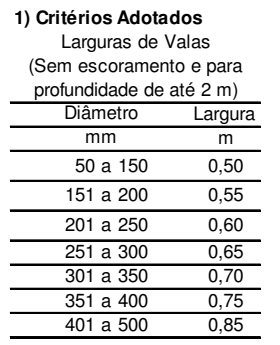

Locação das Redes

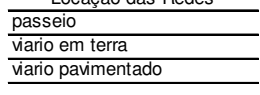

viario em terra

2) Dados Adotados

Tubulação

Materia

SDR

\begin{tabular}{ll} 
Rugosidade Equivalente $(\mathrm{m}) \quad 0,00002$ \\
\hline
\end{tabular}

Fator entre Diâmetro Hidráulico e Comercia
Recobrimento

\begin{tabular}{lc}
\hline \multicolumn{1}{c}{ Locação da } & Recobrimento \\
\cline { 2 - 2 } Tubulação & $\mathrm{m}$ \\
\hline passeio & 0,7 \\
\hline viario em terra & 1,2 \\
\hline viario pavimentado & 1,0 \\
\hline
\end{tabular}

Tipo de Tráfegos para Viário

\begin{tabular}{l}
\hline Leve \\
\hline Médio \\
\hline Pesado \\
\hline \multicolumn{1}{c}{ Tipos de Superfície } \\
\hline asfalto \\
\hline concreto \\
\hline paralelepipedos \\
\hline terra
\end{tabular}

Pressurização Inicial

Carga Inicial

Rendimento Global

Vida Útil

1,05
Largura Adotadas para Reposição de Pavimentos Devido Abertura de Valas $(\mathrm{m})$

\begin{tabular}{ll}
\hline Concreto Asfáltico Usinado a Quente & 3 \\
\hline Imprimacão Betuminosa Ligante & 3
\end{tabular}

\begin{tabular}{lc} 
Imprimação Betuminosa Ligante & 3 \\
\hline Binder & Larguravala $+0,2$
\end{tabular}

Imprimação Betuminosa Impermeabilizante $\quad$ Largura 2

\begin{tabular}{lc}
\hline Macadame Hidáulico & Largura \\
\hline
\end{tabular}

\begin{tabular}{|c|c|c|c|}
\hline Tráfego & Leve & Médio & Pesado \\
\hline Binder & 0,04 & 0,07 & 0,10 \\
\hline Concreto Asfáltico Usinado a Quente & 0,04 & 0,05 & 0,05 \\
\hline Macadame Hidáulico & 0,10 & 0,12 & 0,15 \\
\hline
\end{tabular}

Macadame Hidáulico

Energia

Grupo A (Alta e Média Tensão)

Sub-Grupo A4 (2,3 KV a $25 \mathrm{KV}$

Custo de Energia por Demanda

$31,31 \mathrm{R} \$ / \mathrm{KW}$

Custo de Energia por Consumo $0,16132 \mathrm{R} \$ / \mathrm{KWh}$

Taxa de Juros

12,16

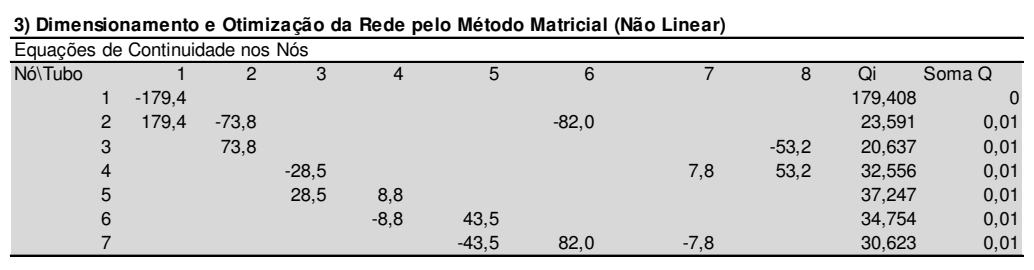

\begin{tabular}{cccccccccr}
\hline Equações de Perda de Carga nos Circuitos & & & & & & \\
\hline Circuitos & 1 & 2 & 3 & 4 & 5 & 6 & 7 & 8 & Soma Perda \\
& & & & & & & & \\
1 & $-0,742$ & & & & 0,925 & 0,806 & $-0,989$ & 0,0001 \\
2 & & $-0,866$ & 1,008 & 0,664 & & $-0,806$ & & $1 \mathrm{E}-04$ \\
\hline
\end{tabular}

Tabela da Função Objetivo

\begin{tabular}{|c|c|c|c|c|c|c|c|c|c|c|c|c|c|c|}
\hline \multirow{2}{*}{ Trecho } & \multicolumn{2}{|c|}{ Nó Montante } & \multicolumn{2}{|c|}{ No Jusante } & \multirow{2}{*}{$\begin{array}{c}\begin{array}{c}\text { Extensão } \\
\text { do Trecho }\end{array} \\
\text { (m) } \\
\end{array}$} & \multirow{2}{*}{$\begin{array}{c}\begin{array}{c}\text { Vazão do } \\
\text { Trecho }\end{array} \\
\text { I/s } \\
\end{array}$} & \multirow{2}{*}{$\begin{array}{c}\begin{array}{c}\text { Diâmetro } \\
\text { Nominal } \\
\text { Comercial }\end{array} \\
(\mathrm{mm})\end{array}$} & \multirow{2}{*}{$\begin{array}{c}\begin{array}{c}\text { Diâmetro } \\
\text { Ótimo }\end{array} \\
(\mathrm{mm})\end{array}$} & \multirow{2}{*}{$\begin{array}{l}\text { Velocidade } \\
(\mathrm{m} / \mathrm{s})\end{array}$} & \multirow{2}{*}{$\begin{array}{l}\text { Fator de } \\
\text { Atrito } f\end{array}$} & \multirow{2}{*}{$\begin{array}{c}\text { Perda de Carga } \\
(\mathrm{m})\end{array}$} & \multirow{2}{*}{$\begin{array}{c}\begin{array}{c}\text { Carga } \\
\text { Montante }\end{array} \\
(\mathrm{m}) \\
\end{array}$} & \multirow{2}{*}{$\begin{array}{c}\text { Carga Jusante } \\
(\mathrm{m})\end{array}$} & \multirow{2}{*}{$\begin{array}{c}\text { Potência Dissipada } \\
\text { kW }\end{array}$} \\
\hline & Nome & Cota & Nome & Cota & & & & & & & & & & \\
\hline T1 & $\mathrm{N} 1$ & 4,56 & N2 & 3,50 & 258,48 & 179,4 & 400 & 401 & 1,42 & 0,0063 & 0,42 & 11,63 & 12,27 & 1,06 \\
\hline T2 & N2 & 3,50 & N3 & 3,50 & 255,93 & 73,8 & 250 & 250 & 1,50 & 0,0063 & 0,74 & 12,27 & 11,53 & 0,77 \\
\hline T3 & $\mathrm{N} 4$ & 1,50 & N5 & 0,49 & 657,53 & 28,5 & 200 & 200 & 0,90 & 0,0063 & 0,87 & 12,54 & 12,68 & 0,35 \\
\hline T4 & N5 & 0,49 & N6 & 0,50 & 253,28 & 8,8 & 100 & 100 & 1,11 & 0,0063 & 1,01 & 12,68 & 11,66 & 0,12 \\
\hline T5 & N6 & 0,50 & N7 & 1,50 & 660,47 & 43,5 & 250 & 250 & 0,88 & 0,0063 & 0,66 & 11,66 & 10,00 & 0,40 \\
\hline T6 & N2 & 3,50 & N7 & 1,50 & 644,10 & 82,0 & 300 & 300 & 1,16 & 0,0063 & 0,92 & 12,27 & 13,34 & 1,06 \\
\hline 77 & N7 & 1,50 & $\mathrm{~N} 4$ & 1,50 & 253,02 & 7,8 & 100 & 100 & 0,99 & 0,0063 & 0,81 & 13,34 & 12,54 & 0,09 \\
\hline T8 & N3 & 3,50 & N4 & 1,50 & 657,18 & 53,2 & 250 & 250 & 1,08 & 0,0063 & 0,99 & 12,27 & 13,28 & 0,74 \\
\hline
\end{tabular}

4) Resumo do Dimensionamento Otimizado

\begin{tabular}{|c|c|c|c|}
\hline & Poté & Dissipada & Pressurização Inicial \\
\hline Soma & & 4,59 & 29,21 \\
\hline Energia & & $30.132,71$ & $191.880,48$ \\
\hline FA & & 12,16 & 12,16 \\
\hline Sub-Total & $\mathrm{R} \$$ & $60.846,62$ & $387.461,97$ \\
\hline
\end{tabular}

\begin{tabular}{|c|c|c|}
\hline Custos & & Porcentagem \\
\hline Custo de Tubulação $\mathrm{R} \$$ & $388.424,03$ & $40,20 \%$ \\
\hline Custo de Movimento de Terra $\mathrm{R} \$$ & $66.123,21$ & $6,84 \%$ \\
\hline Custo de Assentamento $R \$$ & $10.914,88$ & $1,13 \%$ \\
\hline Custo de Pavimentação $R \$$ & $52.339,54$ & $5,42 \%$ \\
\hline Custo da Pressurização Inicial $\mathrm{R} \$$ & $387.461,97$ & $40,11 \%$ \\
\hline Custo da Potência Dissipada $R \$$ & $60.846,62$ & $6,30 \%$ \\
\hline Total Global (Função Objetivo) R\$ & $966.110,24$ & $100,00 \%$ \\
\hline Total Referencial Unitário R\$ & 265,42 & por metro de rede \\
\hline
\end{tabular}


5) Quantitativos e Custos de Implantação das Redes de Abastecimento

\begin{tabular}{|c|c|c|c|c|c|c|c|c|c|}
\hline Trecho & $\begin{array}{l}\text { Locação da } \\
\text { Tubulação }\end{array}$ & $\begin{array}{c}\text { Tipo de } \\
\text { Superfície }\end{array}$ & Tipo de Tráfego & & & & & & \\
\hline $\mathrm{T} 1$ & viario pavimentado & paralelepipedos & - & & & & & & \\
\hline T2 & vario pavimentado & paralelepipedos & - & & & & & & \\
\hline T3 & viario pavimentado & paralelepipedos & - & & & & & & \\
\hline T4 & vario pavimentado & paralelepipedos & - & & & & & & \\
\hline T5 & vario pavimentado & paralelepipedos & - & & & & & & \\
\hline T6 & viario pavimentado & paralelepipedos & - & & & & & & \\
\hline 77 & viario pavimentado & paralelepipedos & - & & & & & & \\
\hline $\mathrm{T} 8$ & viario pavimentado & paralelepipedos & - & & & & & & \\
\hline \multirow{3}{*}{ Trecho } & \multicolumn{6}{|c|}{ Vala } & \multicolumn{3}{|c|}{ Tubulação } \\
\hline & Largura & Profundidade & Escavação & Reaterro & Bota-Fora & TOTAL & Assentamento & Material & TOTAL \\
\hline & $\mathrm{m}$ & $\mathrm{m}$ & $\mathrm{m}^{3}$ & $\mathrm{~m}^{3}$ & $\mathrm{~m}^{3}$ & $\mathbf{R} \$$ & $\mathrm{R} \$$ & $\mathrm{R} \$$ & $\mathbf{R} \$$ \\
\hline $\mathrm{T} 1$ & 0,75 & 1,40 & 271,40 & 238,92 & 32,48 & $6.481,67$ & $1.330,32$ & $60.843,11$ & $62.173,43$ \\
\hline $\mathrm{T} 2$ & 0,60 & 1,25 & 191,95 & 179,38 & 12,56 & $4.688,29$ & 781,41 & $27.846,08$ & $28.627,49$ \\
\hline T3 & 0,55 & 1,20 & 433,97 & 413,31 & 20,66 & $10.677,19$ & $1.631,59$ & $49.595,62$ & $51.227,21$ \\
\hline T4 & 0,50 & 1,10 & 139,30 & 137,31 & 1,99 & $3.473,83$ & 386,69 & $6.121,70$ & $6.508,39$ \\
\hline T5 & 0,60 & 1,25 & 495,35 & 462,93 & 32,42 & $12.098,91$ & $2.016,56$ & $71.861,44$ & $73.878,01$ \\
\hline T6 & 0,65 & 1,30 & 544,26 & 498,74 & 45,53 & $13.194,41$ & $2.375,48$ & $94.537,19$ & $96.912,66$ \\
\hline 77 & 0,50 & 1,10 & 139,16 & 137,17 & 1,99 & $3.470,27$ & 386,29 & $6.115,41$ & $6.501,71$ \\
\hline \multirow[t]{2}{*}{ T8 } & 0,60 & 1,25 & 492,89 & 460,63 & 32,26 & $12.038,64$ & $2.006,52$ & $71.503,48$ & $73.510,00$ \\
\hline & & & & & Soma & $66.123,21$ & $\begin{array}{ll}\mathrm{R} \$ & 10.914,88\end{array}$ & $\mathrm{R} \$ 388.424,03 \quad \mathrm{R} \$$ & $399.338,90$ \\
\hline \multirow{2}{*}{\multicolumn{10}{|c|}{$\begin{array}{l}\text { Paúmentação } \\
\text { Vala }\end{array}$}} \\
\hline & & & $\mathrm{Va}$ & & & & & & \\
\hline \multirow[t]{2}{*}{ Trecho } & Área & $\begin{array}{l}\text { Área de } \\
\text { Concreto }\end{array}$ & $\begin{array}{c}\text { Área de } \\
\text { Paralelepipedos }\end{array}$ & $\begin{array}{l}\text { Área de } \\
\text { Asfalto }\end{array}$ & Área de Binder & $\begin{array}{l}\text { Área de Concreto Astático } \\
\text { Usinado a Quente }\end{array}$ & & & \\
\hline & $\mathrm{m}^{2}$ & $\mathrm{~m}^{2}$ & $\mathrm{~m}^{2}$ & $\mathrm{~m}^{2}$ & $\mathrm{~m}^{2}$ & $\mathrm{~m}^{2}$ & & & \\
\hline $\mathrm{T} 1$ & 193,86 & 0,00 & 193,86 & 0,00 & 0,00 & 0,00 & & & \\
\hline $\mathrm{T} 2$ & 153,56 & 0,00 & 153,56 & 0,00 & 0,00 & 0,00 & & & \\
\hline T3 & 361,64 & 0,00 & 361,64 & 0,00 & 0,00 & 0,00 & & & \\
\hline T4 & 126,64 & 0,00 & 126,64 & 0,00 & 0,00 & 0,00 & & & \\
\hline T5 & 396,28 & 0,00 & 396,28 & 0,00 & 0,00 & 0,00 & & & \\
\hline T6 & 418,67 & 0,00 & 418,67 & 0,00 & 0,00 & 0,00 & & & \\
\hline 77 & 126,51 & 0,00 & 126,51 & 0,00 & 0,00 & 0,00 & & & \\
\hline $\mathrm{T} 8$ & 394,31 & 0,00 & 394,31 & 0,00 & 0,00 & 0,00 & & & \\
\hline \multirow{4}{*}{ Trecho } & \multicolumn{9}{|c|}{ Pavimentação } \\
\hline & \multicolumn{3}{|c|}{ Volume } & \multicolumn{2}{|c|}{ Area } & \multicolumn{4}{|c|}{ Custos } \\
\hline & Macadame Hidáulico & Binder & $\begin{array}{l}\text { Concreto } \\
\text { Asfáltico Usinado } \\
\text { a Quente }\end{array}$ & $\begin{array}{c}\text { Imprimação } \\
\text { Betuminosa } \\
\text { Ligante }\end{array}$ & $\begin{array}{c}\text { Imprimação } \\
\text { Betuminosa } \\
\text { Impermeabiliza } \\
\text { nte }\end{array}$ & Remoção & Recomposição & Transporte & TOTAL \\
\hline & $\mathrm{m}^{3}$ & $\mathrm{~m}^{3}$ & $\mathrm{~m}^{3}$ & $\mathrm{~m}^{2}$ & $\mathrm{~m}^{2}$ & $\mathrm{R} \$$ & $\mathrm{R} \$$ & $\mathrm{R} \$$ & $\mathbf{R} \$$ \\
\hline $\mathrm{T} 1$ & 0,00 & 0,00 & 0,00 & 0,00 & 0,00 & 993,09 & $3.679,58$ & 0,00 & $4.672,67$ \\
\hline $\mathrm{T} 2$ & 0,00 & 0,00 & 0,00 & 0,00 & 0,00 & 786,64 & $2.914,62$ & 0,00 & $3.701,26$ \\
\hline T3 & 0,00 & 0,00 & 0,00 & 0,00 & 0,00 & $1.852,59$ & $6.864,18$ & 0,00 & $8.716,77$ \\
\hline $\mathrm{T} 4$ & 0,00 & 0,00 & 0,00 & 0,00 & 0,00 & $\begin{array}{ll}648,74 \\
\end{array}$ & $2.403,70$ & 0,00 & $3.052,45$ \\
\hline T5 & 0,00 & 0,00 & 0,00 & 0,00 & 0,00 & $2.030,04$ & $7.521,67$ & 0,00 & $9.551,72$ \\
\hline T6 & 0,00 & 0,00 & 0,00 & 0,00 & 0,00 & $2.144,71$ & $7.946,52$ & 0,00 & $\begin{array}{l}10.091,22 \\
\end{array}$ \\
\hline$T 7$ & 0,00 & 0,00 & 0,00 & 0,00 & 0,00 & 648,08 & $2.401,24$ & 0,00 & $3.049,31$ \\
\hline $\mathrm{T} 8$ & 0,00 & 0,00 & 0,00 & 0,00 & 0,00 & $2.019,93$ & $7.484,21$ & 0,00 & $9.504,14$ \\
\hline & & & & & Soma & $11.123,81$ & $\mathrm{R} \$ \quad 41.215,72$ & $\mathbf{R} \$$ & 52.33 \\
\hline
\end{tabular}




\section{APÊNDICE C3 - Planilha de Dimensionamento para Juros de 8\%aa e Viário em Paralelepípedo - PVC}

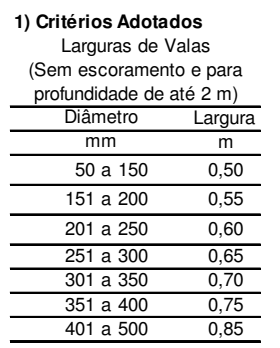

Locação das Redes

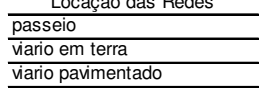

viario em terra

2) Dados Adotados

Tubulação

Materia

SDR

\begin{tabular}{ll} 
Rugosidade Equivalente $(\mathrm{m}) \quad 0,00002$ \\
\hline
\end{tabular}

Fator entre Diâmetro Hidráulico e Comercia
Recobrimento

\begin{tabular}{lc}
\hline \multicolumn{1}{c}{ Locação da } & Recobrimento \\
\cline { 2 - 2 } Tubulação & $\mathrm{m}$ \\
\hline passeio & 0,7 \\
\hline viario em terra & 1,2 \\
\hline viario pavimentado & 1,0 \\
\hline
\end{tabular}

Tipo de Tráfegos para Viário

\begin{tabular}{l}
\hline Leve \\
\hline Médio \\
\hline Pesado \\
\hline \multicolumn{1}{c}{ Tipos de Superfície } \\
\hline asfalto \\
\hline concreto \\
\hline paralelepipedos \\
\hline terra
\end{tabular}

Pressurização Inicial

Carga Inicial

Rendimento Global

Vida Útil

1,05
Largura Adotadas para Reposição de Pavimentos Devido Abertura de Valas (m)

\begin{tabular}{ll}
\hline Concreto Asfáltico Usinado a Quente & 3 \\
\hline Imprimacão Betuminosa Ligante & 3
\end{tabular}

\begin{tabular}{lc} 
Imprimação Betuminosa Ligante & 3 \\
\hline Binder & Larguravala $+0,2$
\end{tabular}

Imprimação Betuminosa Impermeabilizante $\quad$ Largura 2

Macadame Hidáulico $\quad$ Larguravala

\begin{tabular}{|c|c|c|c|}
\hline Tráfego & Leve & Médio & Pesado \\
\hline Binder & 0,04 & 0,07 & 0,10 \\
\hline Concreto Asfáltico Usinado a Quente & 0,04 & 0,05 & 0,05 \\
\hline Macadame Hidáulico & 0,10 & 0,12 & 0,15 \\
\hline
\end{tabular}

Macadame Hidáulico

Energia

Grupo A (Alta e Média Tensão)

Sub-Grupo A4 (2,3 KV a $25 \mathrm{KV}$

Custo de Energia por Demanda

$31,31 \mathrm{R} \$ / \mathrm{KW}$

Custo de Energia por Consumo $0,16132 \mathrm{R} \$ / \mathrm{KWh}$

Taxa de Juros

$8,00 \%$

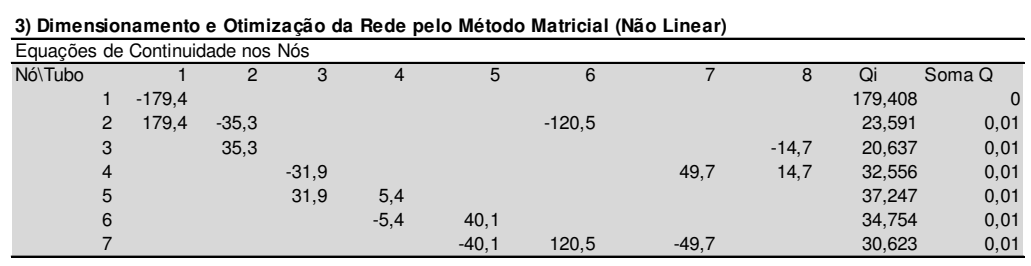

\begin{tabular}{|c|c|c|c|c|c|c|c|c|c|}
\hline \multicolumn{10}{|c|}{ Equações de Perda de Carga nos Circuitos } \\
\hline Circuitos & 1 & 2 & 3 & 4 & 5 & 6 & 7 & 8 & Soma Perda \\
\hline 1 & & $-0,519$ & & & & 0,474 & 1,016 & $-0,971$ & $1 \mathrm{E}-04$ \\
\hline 2 & & & $-1,085$ & 0,377 & 1,723 & & $-1,016$ & & 0,0001 \\
\hline
\end{tabular}

Tabela da Função Objetivo

\begin{tabular}{|c|c|c|c|c|c|c|c|c|c|c|c|c|c|c|}
\hline \multirow{2}{*}{ Trecho } & \multicolumn{2}{|c|}{ Nó Montante } & \multicolumn{2}{|c|}{ No Jusante } & \multirow{2}{*}{$\begin{array}{c}\begin{array}{c}\text { Extensão } \\
\text { do Trecho }\end{array} \\
\text { (m) } \\
\end{array}$} & \multirow{2}{*}{$\begin{array}{c}\begin{array}{c}\text { Vazão do } \\
\text { Trecho }\end{array} \\
\text { 1/s }\end{array}$} & \multirow{2}{*}{$\begin{array}{c}\begin{array}{c}\text { Diâmetro } \\
\text { Nominal } \\
\text { Comercial }\end{array} \\
(\mathrm{mm})\end{array}$} & \multirow{2}{*}{$\begin{array}{c}\begin{array}{c}\text { Diâmetro } \\
\text { Ótimo }\end{array} \\
(\mathrm{mm})\end{array}$} & \multirow{2}{*}{$\begin{array}{l}\text { Velocidade } \\
(\mathrm{m} / \mathrm{s})\end{array}$} & \multirow{2}{*}{$\begin{array}{l}\text { Fator de } \\
\text { Atrito } f\end{array}$} & \multirow{2}{*}{$\begin{array}{l}\text { Perda de Carga } \\
(\mathrm{m})\end{array}$} & \multirow{2}{*}{$\begin{array}{c}\begin{array}{c}\text { Carga } \\
\text { Montante }\end{array} \\
(\mathrm{m})\end{array}$} & \multirow{2}{*}{$\begin{array}{c}\text { Carga Jusante } \\
(\mathrm{m})\end{array}$} & \multirow{2}{*}{$\begin{array}{c}\text { Potência Dissipada } \\
\text { kW }\end{array}$} \\
\hline & Nome & Cota & Nome & Cota & & & & & & & & & & \\
\hline T1 & $\mathrm{N} 1$ & 4,56 & N2 & 3,50 & 258,48 & 179,4 & 400 & 401 & 1,42 & 0,0063 & 0,42 & 12,03 & 12,67 & 1,06 \\
\hline T2 & N2 & 3,50 & N3 & 3,50 & 255,93 & 35,3 & 200 & 200 & 1,12 & 0,0063 & 0,52 & 12,67 & 12,16 & 0,26 \\
\hline T3 & $\mathrm{N} 4$ & 1,50 & N5 & 0,49 & 657,53 & 31,9 & 200 & 200 & 1,01 & 0,0063 & 1,08 & 13,18 & 13,11 & 0,48 \\
\hline T4 & N5 & 0,49 & N6 & 0,50 & 253,28 & 5,4 & 100 & 80 & 0,68 & 0,0063 & 0,38 & 13,11 & 12,72 & 0,03 \\
\hline T5 & N6 & 0,50 & N7 & 1,50 & 660,47 & 40,1 & 200 & 200 & 1,27 & 0,0063 & 1,72 & 12,72 & 10,00 & 0,97 \\
\hline T6 & N2 & 3,50 & N7 & 1,50 & 644,10 & 120,5 & 400 & 350 & 0,96 & 0,0063 & 0,47 & 12,67 & 14,20 & 0,80 \\
\hline 77 & N7 & 1,50 & $\mathrm{~N} 4$ & 1,50 & 253,02 & 49,7 & 200 & 200 & 1,58 & 0,0063 & 1,02 & 14,20 & 13,18 & 0,71 \\
\hline T8 & N3 & 3,50 & $\mathrm{~N} 4$ & 1,50 & 657,18 & 14,7 & 150 & 150 & 0,83 & 0,0063 & 0,97 & 12,67 & 13,70 & 0,20 \\
\hline
\end{tabular}

4) Resumo do Dimensionamento Otimizado

\begin{tabular}{|c|c|c|c|}
\hline & \multicolumn{2}{|c|}{ Potência Dissipada } & Pressurização Inicial \\
\hline Soma & & 4,50 & 30,22 \\
\hline Energia & & $29.581,95$ & $198.575,57$ \\
\hline FA & & 10,60 & 10,60 \\
\hline Sub-Total & $\mathrm{R} \$$ & $52.096,93$ & $349.712,47$ \\
\hline
\end{tabular}

\begin{tabular}{|c|c|c|}
\hline Custos & & Porcentagem \\
\hline Custo de Tubulação $\mathrm{R} \$$ & $387.288,33$ & $42,25 \%$ \\
\hline Custo de Movimento de Terra $\mathrm{R} \$$ & $65.134,58$ & $7,11 \%$ \\
\hline Custo de Assentamento $R \$$ & $10.861,74$ & $1,18 \%$ \\
\hline Custo de Pavimentação $R \$$ & $51.508,53$ & $5,62 \%$ \\
\hline Custo da Pressurização Inicial $\mathrm{R} \$$ & $349.712,47$ & $38,15 \%$ \\
\hline Custo da Potência Dissipada $R \$$ & $52.096,93$ & $5,68 \%$ \\
\hline Total Global (Função Objetivo) R\$ & $916.602,57$ & $100,00 \%$ \\
\hline Total Referencial Unitário R\$ & 251,81 & por metro de rede \\
\hline
\end{tabular}


5) Quantitativos e Custos de Implantação das Redes de Abastecimento

\begin{tabular}{|c|c|c|c|c|c|c|c|c|c|}
\hline Trecho & $\begin{array}{l}\text { Locação da } \\
\text { Tubulação }\end{array}$ & $\begin{array}{l}\text { Tipo de } \\
\text { Superfície }\end{array}$ & Tipo de Tráfego & & & & & & \\
\hline $\mathrm{T} 1$ & viario pavimentado & paralelepipedos & - & & & & & & \\
\hline $\mathrm{T} 2$ & viario pavimentado & paralelepipedos & - & & & & & & \\
\hline T3 & vario pavimentado & paralelepipedos & - & & & & & & \\
\hline T4 & vario pavimentado & paralelepipedos & - & & & & & & \\
\hline $\mathrm{T5}$ & viario pavimentado & paralelepipedos & - & & & & & & \\
\hline T6 & viario pavimentado & paralelepipedos & - & & & & & & \\
\hline 77 & viario pavimentado & paralelepipedos & - & & & & & & \\
\hline \multirow[t]{2}{*}{ T8 } & viario pavimentado & paralelepipedos & - & & & & & & \\
\hline & \multicolumn{6}{|c|}{ Vala } & \multicolumn{3}{|c|}{ Tubulação } \\
\hline \multirow[t]{2}{*}{ Trecho } & Largura & $\begin{array}{l}\text { Profundidade } \\
\end{array}$ & Escavação & Reaterro & Bota-Fora & TOTAL & Assentamento & Material & TOTAL \\
\hline & $\mathrm{m}$ & $\mathrm{m}$ & $\mathrm{m}^{3}$ & $\mathrm{~m}^{3}$ & $\mathrm{~m}^{3}$ & $\mathbf{R} \$$ & $\mathrm{R} \$$ & $\mathrm{R} \$$ & $\mathrm{R} \$$ \\
\hline $\mathrm{T} 1$ & 0,75 & 1,40 & 271,40 & 238,92 & 32,48 & $6.481,67$ & $1.330,32$ & $60.843,11$ & $\begin{array}{l}62.173,43 \\
\end{array}$ \\
\hline $\mathrm{T} 2$ & 0,55 & 1,20 & 168,91 & 160,87 & 8,04 & $4.155,87$ & 635,06 & $19.304,07$ & $19.939,14$ \\
\hline T3 & 0,55 & 1,20 & 433,97 & 413,31 & 20,66 & $10.677,19$ & $1.631,59$ & $49.595,62$ & $51.227,21$ \\
\hline T4 & 0,50 & 1,10 & 139,30 & 137,31 & 1,99 & $3.473,83$ & 386,69 & $6.121,70$ & $6.508,39$ \\
\hline T5 & 0,55 & 1,20 & 435,91 & 415,16 & 20,75 & $10.724,93$ & $1.638,89$ & $49.817,37$ & $51.456,26$ \\
\hline T6 & 0,75 & 1,40 & 676,31 & 595,37 & 80,94 & $16.151,52$ & $3.315,00$ & $151.613,45$ & $154.928,46$ \\
\hline 77 & 0,55 & 1,20 & 166,99 & 159,04 & 7,95 & $4.108,62$ & 627,84 & $19.084,58$ & $19.712,42$ \\
\hline \multirow[t]{2}{*}{$\mathrm{T} 8$} & 0,50 & 1,15 & 377,88 & 366,27 & 11,61 & $9.360,94$ & $1.296,33$ & $30.908,43$ & $32.204,76$ \\
\hline & & & & & Soma & $65.134,58$ & $\begin{array}{ll}\mathrm{R} \$ & 10.861,74\end{array}$ & $\mathrm{R} \$ 387.288,33 \quad \mathrm{R} \$$ & $398.150,07$ \\
\hline \multirow{2}{*}{\multicolumn{10}{|c|}{$\frac{\text { Pavimentação }}{\text { Vala }}$}} \\
\hline & & & & & & & & & \\
\hline \multirow[t]{2}{*}{ Trecho } & Área & $\begin{array}{l}\text { Área de } \\
\text { Concreto }\end{array}$ & $\begin{array}{c}\text { Área de } \\
\text { Paralelepipedos }\end{array}$ & $\begin{array}{l}\text { Área de } \\
\text { Asfalto }\end{array}$ & Área de Binder & $\begin{array}{l}\text { Area de Concreto Astático } \\
\text { Usinado a Quente }\end{array}$ & & & \\
\hline & $\mathrm{m}^{2}$ & $\mathrm{~m}^{2}$ & $\mathrm{~m}^{2}$ & $\mathrm{~m}^{2}$ & $\mathrm{~m}^{2}$ & $\mathrm{~m}^{2}$ & & & \\
\hline $\mathrm{T} 1$ & 193,86 & 0,00 & 193,86 & 0,00 & 0,00 & 0,00 & & & \\
\hline $\mathrm{T} 2$ & 140,76 & 0,00 & 140,76 & 0,00 & 0,00 & 0,00 & & & \\
\hline T3 & 361,64 & 0,00 & 361,64 & 0,00 & 0,00 & 0,00 & & & \\
\hline T4 & 126,64 & 0,00 & 126,64 & 0,00 & 0,00 & 0,00 & & & \\
\hline T5 & 363,26 & 0,00 & 363,26 & 0,00 & 0,00 & 0,00 & & & \\
\hline T6 & 483,08 & 0,00 & 483,08 & 0,00 & 0,00 & 0,00 & & & \\
\hline 77 & 139,16 & 0,00 & 139,16 & 0,00 & 0,00 & 0,00 & & & \\
\hline T8 & 328,59 & 0,00 & 328,59 & 0,00 & 0,00 & 0,00 & & & \\
\hline
\end{tabular}

\begin{tabular}{|c|c|c|c|c|c|c|c|c|c|}
\hline \multirow{4}{*}{ Trecho } & \multicolumn{9}{|c|}{ Pavimentação } \\
\hline & \multicolumn{3}{|c|}{ Volume } & \multicolumn{2}{|c|}{ Área } & \multicolumn{4}{|c|}{ Custos } \\
\hline & Macadame Hidáulico & Binder & $\begin{array}{l}\text { Concreto } \\
\text { Astáltico Usinado } \\
\text { a Quente }\end{array}$ & $\begin{array}{l}\text { Imprimação } \\
\text { Betuminosa } \\
\text { Ligante }\end{array}$ & $\begin{array}{l}\text { Imprimação } \\
\text { Betuminosa } \\
\text { Impermeabiliza } \\
\text { nte }\end{array}$ & Remoção & Recomposição & Transporte & TOTAL \\
\hline & $\mathrm{m}^{3}$ & $\mathrm{~m}^{3}$ & $\mathrm{~m}^{3}$ & $\mathrm{~m}^{2}$ & $\mathrm{~m}^{2}$ & $\mathrm{R} \$$ & $\mathrm{R} \$$ & $\mathrm{R} \$$ & $\mathrm{R} \$$ \\
\hline $\mathrm{T} 1$ & 0,00 & 0,00 & 0,00 & 0,00 & 0,00 & 993,09 & $3.679,58$ & 0,00 & $4.672,67$ \\
\hline $\mathrm{T} 2$ & 0,00 & 0,00 & 0,00 & 0,00 & 0,00 & 721,08 & $2.671,74$ & 0,00 & $3.392,82$ \\
\hline T3 & 0,00 & 0,00 & 0,00 & 0,00 & 0,00 & $1.852,59$ & $6.864,18$ & 0,00 & $8.716,77$ \\
\hline T4 & 0,00 & 0,00 & 0,00 & 0,00 & 0,00 & 648,74 & $2.403,70$ & 0,00 & $3.052,45$ \\
\hline T5 & 0,00 & 0,00 & 0,00 & 0,00 & 0,00 & $1.860,87$ & $6.894,87$ & 0,00 & $8.755,74$ \\
\hline T6 & 0,00 & 0,00 & 0,00 & 0,00 & 0,00 & $2.474,66$ & $9.169,06$ & 0,00 & $11.643,72$ \\
\hline 77 & 0,00 & 0,00 & 0,00 & 0,00 & 0,00 & 712,88 & $2.641,36$ & 0,00 & $3.354,24$ \\
\hline T8 & 0,00 & 0,00 & 0,00 & 0,00 & 0,00 & $1.683,28$ & $6.236,84$ & 0,00 & $7.920,12$ \\
\hline
\end{tabular}




\section{APÊNDICE C4 - Planilha de Dimensionamento para Juros de 10\%aa e Viário em Paralelepípedo - PVC}

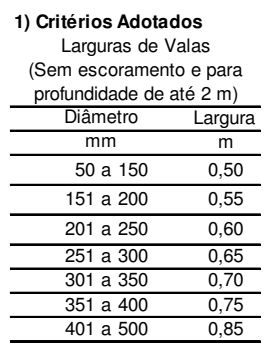

Locação das Redes

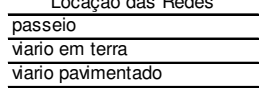

viario em terra

2) Dados Adotados

Tubulação

Materia

SDR

\begin{tabular}{ll} 
Rugosidade Equivalente $(\mathrm{m}) \quad 0,00002$ \\
\hline
\end{tabular}

Fator entre Diâmetro Hidráulico e Comercia
Recobrimento

\begin{tabular}{lc}
\hline \multicolumn{1}{c}{ Locação da } & Recobrimento \\
\cline { 2 - 2 } Tubulação & $\mathrm{m}$ \\
\hline passeio & 0,7 \\
\hline viario em terra & 1,2 \\
\hline viario pavimentado & 1,0 \\
\hline
\end{tabular}

Tipo de Tráfegos para Viário

\begin{tabular}{l}
\hline Leve \\
\hline Médio \\
\hline Pesado \\
\hline \multicolumn{1}{c}{ Tipos de Superfície } \\
\hline asfalto \\
\hline concreto \\
\hline paralelepipedos \\
\hline terra
\end{tabular}

Pressurização Inicial

Carga Inicial

Rendimento Global

Vida Útil

1,05
Largura Adotadas para Reposição de Pavimentos Devido Abertura de Valas $(\mathrm{m})$

\begin{tabular}{ll}
\hline Concreto Asfáltico Usinado a Quente & 3 \\
\hline Imprimacão Betuminosa Ligante & 3
\end{tabular}

\begin{tabular}{lc} 
Imprimação Betuminosa Ligante & 3 \\
\hline Binder & Larguravala $+0,2$
\end{tabular}

Imprimação Betuminosa Impermeabilizante $\quad$ Largura 2

\begin{tabular}{lc}
\hline Macadame Hidáulico & Largura \\
\hline
\end{tabular}

\begin{tabular}{|c|c|c|c|}
\hline Tráfego & Leve & Médio & Pesado \\
\hline Binder & 0,04 & 0,07 & 0,10 \\
\hline Concreto Asfáltico Usinado a Quente & 0,04 & 0,05 & 0,05 \\
\hline Macadame Hidáulico & 0,10 & 0,12 & 0,15 \\
\hline
\end{tabular}

Macadame Hidáulico

Energia

Grupo A (Alta e Média Tensão)

Sub-Grupo A4 (2,3 KV a $25 \mathrm{KV}$

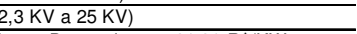

Custo de Energia por Demanda $\quad 31,31 \mathrm{R} \$ / \mathrm{KW}$

Custo de Energia por Consumo $0,16132 \mathrm{R} \$ / \mathrm{KWh}$

\begin{tabular}{lc} 
Taxa de Juros & $10,00 \%$ a \\
\hline Fator de Atualização & 9,36 \\
\hline
\end{tabular}

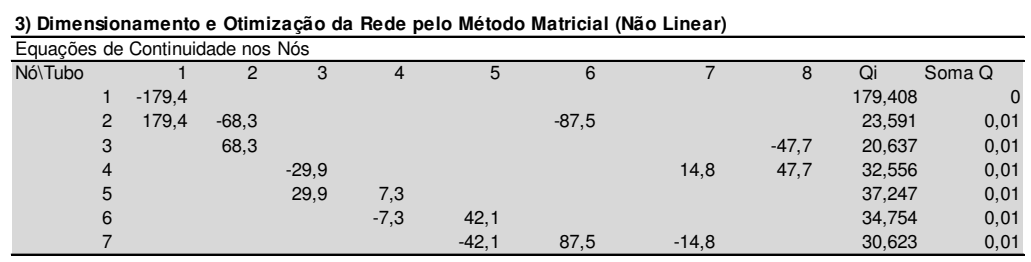

\begin{tabular}{cccccccccr}
\hline Equações de Perda de Carga nos Circuitos & & & & & & \\
\hline Circuitos & 1 & 2 & 3 & 4 & 5 & 6 & 7 & 8 & Soma Perda \\
& & & & & & & & \\
1 & $-0,635$ & & & & 1,053 & 0,377 & $-0,795$ & 0,0001 \\
2 & & $-0,954$ & 0,709 & 0,622 & & $-0,377$ & & $1 \mathrm{E}-04$ \\
\hline
\end{tabular}

Tabela da Função Objetivo

\begin{tabular}{|c|c|c|c|c|c|c|c|c|c|c|c|c|c|c|}
\hline \multirow{2}{*}{ Trecho } & \multicolumn{2}{|c|}{ Nó Montante } & \multicolumn{2}{|c|}{ No Jusante } & \multirow{2}{*}{$\begin{array}{c}\begin{array}{c}\text { Extensão } \\
\text { do Trecho }\end{array} \\
\text { (m) }\end{array}$} & \multirow{2}{*}{$\begin{array}{c}\begin{array}{c}\text { Vazão do } \\
\text { Trecho }\end{array} \\
\text { I/s } \\
\end{array}$} & \multirow{2}{*}{$\begin{array}{c}\begin{array}{c}\text { Diâmetro } \\
\text { Nominal } \\
\text { Comercial }\end{array} \\
(\mathrm{mm})\end{array}$} & \multirow{2}{*}{$\begin{array}{c}\begin{array}{c}\text { Diâmetro } \\
\text { Ótimo }\end{array} \\
(\mathrm{mm})\end{array}$} & \multirow{2}{*}{$\begin{array}{l}\text { Velocidade } \\
(\mathrm{m} / \mathrm{s})\end{array}$} & \multirow{2}{*}{$\begin{array}{l}\text { Fator de } \\
\text { Atrito } f\end{array}$} & \multirow{2}{*}{$\begin{array}{c}\text { Perda de Carga } \\
(\mathrm{m})\end{array}$} & \multirow{2}{*}{$\begin{array}{c}\begin{array}{c}\text { Carga } \\
\text { Montante }\end{array} \\
(\mathrm{m}) \\
\end{array}$} & \multirow{2}{*}{$\begin{array}{c}\text { Carga Jusante } \\
(\mathrm{m})\end{array}$} & \multirow{2}{*}{$\begin{array}{c}\text { Potência Dissipada } \\
\text { kW }\end{array}$} \\
\hline & Nome & Cota & Nome & Cota & & & & & & & & & & \\
\hline T1 & $\mathrm{N} 1$ & 4,56 & N2 & 3,50 & 258,48 & 179,4 & 400 & 401 & 1,42 & 0,0063 & 0,42 & 11,07 & 11,71 & 1,06 \\
\hline T2 & N2 & 3,50 & N3 & 3,50 & 255,93 & 68,3 & 250 & 250 & 1,39 & 0,0063 & 0,64 & 11,71 & 11,08 & 0,61 \\
\hline T3 & $\mathrm{N} 4$ & 1,50 & N5 & 0,49 & 657,53 & 29,9 & 200 & 200 & 0,95 & 0,0063 & 0,95 & 12,28 & 12,34 & 0,40 \\
\hline T4 & N5 & 0,49 & N6 & 0,50 & 253,28 & 7,3 & 100 & 100 & 0,93 & 0,0063 & 0,71 & 12,34 & 11,62 & 0,07 \\
\hline T5 & N6 & 0,50 & N7 & 1,50 & 660,47 & 42,1 & 250 & 250 & 0,85 & 0,0063 & 0,62 & 11,62 & 10,00 & 0,37 \\
\hline T6 & N2 & 3,50 & N7 & 1,50 & 644,10 & 87,5 & 300 & 300 & 1,23 & 0,0063 & 1,05 & 11,71 & 12,66 & 1,29 \\
\hline 77 & N7 & 1,50 & $\mathrm{~N} 4$ & 1,50 & 253,02 & 14,8 & 150 & 150 & 0,83 & 0,0063 & 0,38 & 12,66 & 12,28 & 0,08 \\
\hline T8 & N3 & 3,50 & N4 & 1,50 & 657,18 & 47,7 & 250 & 250 & 0,97 & 0,0063 & 0,79 & 11,71 & 12,92 & 0,53 \\
\hline
\end{tabular}

4) Resumo do Dimensionamento Otimizado

\begin{tabular}{|c|c|c|c|}
\hline & Poté & Dissipada & Pressurização Inicial \\
\hline Soma & & 4,40 & 27,81 \\
\hline Energia & & $28.937,19$ & $182.731,85$ \\
\hline FA & & 9,36 & 9,36 \\
\hline Sub-Total & $\mathrm{R} \$$ & $45.008,28$ & $284.217,16$ \\
\hline
\end{tabular}

\begin{tabular}{|c|c|c|}
\hline Custos & & Porcentagem \\
\hline Custo de Tubulação $\mathrm{R} \$$ & $394.208,63$ & $46,21 \%$ \\
\hline Custo de Movimento de Terra $\mathrm{R} \$$ & $66.256,98$ & $7,77 \%$ \\
\hline Custo de Assentamento $\mathrm{R} \$$ & $11.027,68$ & $1,29 \%$ \\
\hline Custo de Pavimentação $R \$$ & $52.339,54$ & $6,14 \%$ \\
\hline Custo da Pressurização Inicial $\mathrm{R} \$$ & $284.217,16$ & $33,32 \%$ \\
\hline Custo da Potência Dissipada $R \$$ & $45.008,28$ & $5,28 \%$ \\
\hline Total Global (Função Objetivo) R\$ & $853.058,27$ & $100,00 \%$ \\
\hline Total Referencial Unitário R\$ & 234,36 & por metro de rede \\
\hline
\end{tabular}


5) Quantitativos e Custos de Implantação das Redes de Abastecimento

\begin{tabular}{|c|c|c|c|c|c|c|c|c|c|}
\hline Trecho & $\begin{array}{l}\text { Locação da } \\
\text { Tubulação }\end{array}$ & $\begin{array}{l}\text { Tipo de } \\
\text { Superfície }\end{array}$ & Tipo de Tráfego & & & & & & \\
\hline $\mathrm{T} 1$ & viario pavimentado & paralelepipedos & - & & & & & & \\
\hline $\mathrm{T} 2$ & viario pavimentado & paralelepipedos & - & & & & & & \\
\hline T3 & vario pavimentado & paralelepipedos & - & & & & & & \\
\hline T4 & vario pavimentado & paralelepipedos & - & & & & & & \\
\hline $\mathrm{T5}$ & viario pavimentado & paralelepipedos & - & & & & & & \\
\hline T6 & viario pavimentado & paralelepipedos & - & & & & & & \\
\hline 77 & viario pavimentado & paralelepipedos & - & & & & & & \\
\hline \multirow[t]{2}{*}{ T8 } & viario pavimentado & paralelepipedos & - & & & & & & \\
\hline & \multicolumn{6}{|c|}{ Vala } & \multicolumn{3}{|c|}{ Tubulação } \\
\hline \multirow[t]{2}{*}{ Trecho } & Largura & $\begin{array}{l}\text { Profundidade } \\
\end{array}$ & Escavação & Reaterro & Bota-Fora & TOTAL & Assentamento & Material & TOTAL \\
\hline & $\mathrm{m}$ & $\mathrm{m}$ & $\mathrm{m}^{3}$ & $\mathrm{~m}^{3}$ & $\mathrm{~m}^{3}$ & $\mathbf{R} \$$ & $\mathrm{R} \$$ & $\mathrm{R} \$$ & $\mathrm{R} \$$ \\
\hline $\mathrm{T} 1$ & 0,75 & 1,40 & 271,40 & 238,92 & 32,48 & $6.481,67$ & $1.330,32$ & $60.843,11$ & $\begin{array}{l}62.173,43 \\
\end{array}$ \\
\hline $\mathrm{T} 2$ & 0,60 & 1,25 & 191,95 & 179,38 & 12,56 & $4.688,29$ & 781,41 & $27.846,08$ & $28.627,49$ \\
\hline T3 & 0,55 & 1,20 & 433,97 & 413,31 & 20,66 & $10.677,19$ & $1.631,59$ & $49.595,62$ & $51.227,21$ \\
\hline T4 & 0,50 & 1,10 & 139,30 & 137,31 & 1,99 & $3.473,83$ & 386,69 & $6.121,70$ & $6.508,39$ \\
\hline T5 & 0,60 & 1,25 & 495,35 & 462,93 & 32,42 & $12.098,91$ & $2.016,56$ & $71.861,44$ & $73.878,01$ \\
\hline T6 & 0,65 & 1,30 & 544,26 & 498,74 & 45,53 & $13.194,41$ & $2.375,48$ & $94.537,19$ & $96.912,66$ \\
\hline 77 & 0,50 & 1,15 & 145,49 & 141,02 & 4,47 & $3.604,04$ & 499,10 & $11.900,01$ & $12.399,11$ \\
\hline \multirow[t]{2}{*}{ T8 } & 0,60 & 1,25 & 492,89 & 460,63 & 32,26 & $12.038,64$ & $2.006,52$ & $71.503,48$ & $73.510,00$ \\
\hline & & & & & Soma & $66.256,98$ & $\begin{array}{ll}\mathrm{R} \$ \quad 11.027,68 \\
\end{array}$ & $\mathrm{R} \$ 394.208,63 \quad \mathrm{R} \$$ & $405.236,31$ \\
\hline \multirow{2}{*}{\multicolumn{10}{|c|}{$\frac{\text { Pavimentação }}{\text { Vala }}$}} \\
\hline & & & $\mathrm{V}$ & & & & & & \\
\hline \multirow[t]{2}{*}{ Trecho } & Área & $\begin{array}{l}\text { Área de } \\
\text { Concreto }\end{array}$ & $\begin{array}{c}\text { Área de } \\
\text { Paralelepipedos }\end{array}$ & $\begin{array}{l}\text { Área de } \\
\text { Asfalto }\end{array}$ & Área de Binder & $\begin{array}{l}\text { Area de Concreto Astático } \\
\text { Usinado a Quente }\end{array}$ & & & \\
\hline & $\mathrm{m}^{2}$ & $\mathrm{~m}^{2}$ & $\mathrm{~m}^{2}$ & $\mathrm{~m}^{2}$ & $\mathrm{~m}^{2}$ & $\mathrm{~m}^{2}$ & & & \\
\hline $\mathrm{T} 1$ & 193,86 & 0,00 & 193,86 & 0,00 & 0,00 & 0,00 & & & \\
\hline $\mathrm{T} 2$ & 153,56 & 0,00 & 153,56 & 0,00 & 0,00 & 0,00 & & & \\
\hline T3 & 361,64 & 0,00 & 361,64 & 0,00 & 0,00 & 0,00 & & & \\
\hline T4 & 126,64 & 0,00 & 126,64 & 0,00 & 0,00 & 0,00 & & & \\
\hline T5 & 396,28 & 0,00 & 396,28 & 0,00 & 0,00 & 0,00 & & & \\
\hline T6 & 418,67 & 0,00 & 418,67 & 0,00 & 0,00 & 0,00 & & & \\
\hline 77 & 126,51 & 0,00 & 126,51 & 0,00 & 0,00 & 0,00 & & & \\
\hline T8 & 394,31 & 0,00 & 394,31 & 0,00 & 0,00 & 0,00 & & & \\
\hline
\end{tabular}

\begin{tabular}{|c|c|c|c|c|c|c|c|c|c|}
\hline \multirow{4}{*}{ Trecho } & \multicolumn{9}{|c|}{ Pavimentação } \\
\hline & \multicolumn{3}{|c|}{ Volume } & \multicolumn{2}{|c|}{ Área } & \multicolumn{4}{|c|}{ Custos } \\
\hline & Macadame Hidáulico & Binder & $\begin{array}{l}\text { Concreto } \\
\text { Astáltico Usinado } \\
\text { a Quente }\end{array}$ & $\begin{array}{l}\text { Imprimação } \\
\text { Betuminosa } \\
\text { Ligante }\end{array}$ & $\begin{array}{l}\text { Imprimação } \\
\text { Betuminosa } \\
\text { Impermeabiliza } \\
\text { nte }\end{array}$ & Remoção & Recomposição & Transporte & TOTAL \\
\hline & $\mathrm{m}^{3}$ & $\mathrm{~m}^{3}$ & $\mathrm{~m}^{3}$ & $\mathrm{~m}^{2}$ & $\mathrm{~m}^{2}$ & $\mathrm{R} \$$ & $\mathrm{R} \$$ & $\mathrm{R} \$$ & $\mathrm{R} \$$ \\
\hline $\mathrm{T} 1$ & 0,00 & 0,00 & 0,00 & 0,00 & 0,00 & 993,09 & $3.679,58$ & 0,00 & $4.672,67$ \\
\hline $\mathrm{T} 2$ & 0,00 & 0,00 & 0,00 & 0,00 & 0,00 & 786,64 & $2.914,62$ & 0,00 & $3.701,26$ \\
\hline T3 & 0,00 & 0,00 & 0,00 & 0,00 & 0,00 & $1.852,59$ & $6.864,18$ & 0,00 & $8.716,77$ \\
\hline T4 & 0,00 & 0,00 & 0,00 & 0,00 & 0,00 & 648,74 & $2.403,70$ & 0,00 & $3.052,45$ \\
\hline T5 & 0,00 & 0,00 & 0,00 & 0,00 & 0,00 & $2.030,04$ & $7.521,67$ & 0,00 & $9.551,72$ \\
\hline T6 & 0,00 & 0,00 & 0,00 & 0,00 & 0,00 & $2.144,71$ & $7.946,52$ & 0,00 & $10.091,22$ \\
\hline 77 & 0,00 & 0,00 & 0,00 & 0,00 & 0,00 & 648,08 & $2.401,24$ & 0,00 & $3.049,31$ \\
\hline T8 & 0,00 & 0,00 & 0,00 & 0,00 & 0,00 & $2.019,93$ & $7.484,21$ & 0,00 & $9.504,14$ \\
\hline
\end{tabular}




\section{APÊNDICE C5 - Planilha de Dimensionamento para Juros de 4\%aa e Viário em Paralelepípedo - FoFo}

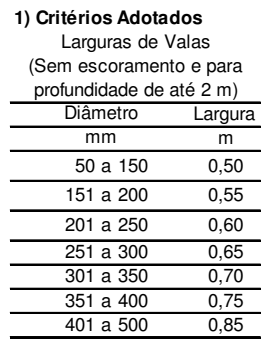

Locação das Redes

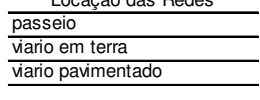

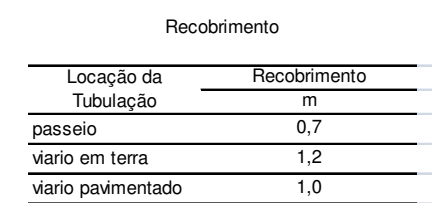

\begin{tabular}{l}
\hline \multicolumn{1}{c}{ Tipo de Tráfegos para Viário } \\
\hline Leve \\
\hline Médio \\
\hline Pesado \\
\hline Tipos de Superfície \\
\hline asfalto \\
\hline pancreto \\
\hline terra
\end{tabular}

2) Dados Adotados

Tubulação

Materia

SDR

\begin{tabular}{ll}
\hline Rugosidade Equivalente (m) & 0,0001 \\
\hline
\end{tabular}

Fator entre Diâmetro Hidráulico e Comercial
Pressurização Inicial

\begin{tabular}{lr}
\hline Carga Inicial & 12,66 \\
\hline Rendimento Global & 0,70 \\
\hline
\end{tabular}

\begin{tabular}{lc}
\hline Horas de Funcionamer & 0,70 \\
\hline Vida & $6570 \mathrm{~h} / \mathrm{ano}$
\end{tabular}

Vida Útil

1,05
Largura Adotadas para Reposição de Pavimentos Devido Abertura de Valas $(\mathrm{m})$ \begin{tabular}{ll}
\hline Concreto Asfáltico Usinado a Quente & 3 \\
\hline Imprimação Betuminosa Ligante & 3 \\
\hline
\end{tabular}

Binder

Imprimação Betuminosa Impermeabilizante $\quad$ Larguravala $+0,2$

Macadame Hidáulico $\quad$ Largura

\begin{tabular}{|c|c|c|c|}
\hline Tráfego & Leve & Médio & Pesado \\
\hline Binder & 0,04 & 0,07 & 0,10 \\
\hline Concreto Asfáltico Usinado a Quente & 0,04 & 0,05 & 0,05 \\
\hline Macadame Hidáulico & 0,10 & 0,12 & 0,15 \\
\hline
\end{tabular}

Macadame Hidáulico

Energia

Grupo A (Alta e Média Tensão)

Sub-Grupo A4 (2,3 KV a 25 KV

Custo de Energia por Demanda

$31,31 \mathrm{R} \$ / \mathrm{KW}$

Custo de Energia por Consumo $\quad 0,16132 \mathrm{R} \$ / \mathrm{KWh}$

Taxa de Juros

14,13

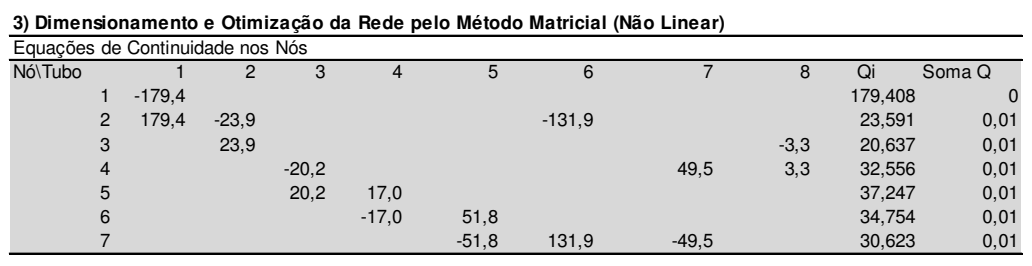

\begin{tabular}{cccccccccr}
\hline Equações de Perda de Carga nos Circuitos & & & & & \\
\hline Circuitos & 1 & 2 & 3 & 4 & 5 & 6 & 7 & 8 & Soma Perda \\
& & & & & & & & \\
1 & $-1,298$ & & & & 1,437 & 1,305 & $-1,443$ & $1 \mathrm{E}-04$ \\
2 & & $-0,566$ & 0,650 & 1,220 & & $-1,305$ & & 0,0001 \\
\hline
\end{tabular}

Tabela da Função Objetivo

\begin{tabular}{|c|c|c|c|c|c|c|c|c|c|c|c|c|c|c|}
\hline \multirow{2}{*}{ Trecho } & \multicolumn{2}{|c|}{ Nó Montante } & \multicolumn{2}{|c|}{ No Jusante } & \multirow{2}{*}{$\begin{array}{c}\begin{array}{c}\text { Extensão } \\
\text { do Trecho }\end{array} \\
\text { (m) } \\
\end{array}$} & \multirow{2}{*}{$\begin{array}{c}\begin{array}{c}\text { Vazão do } \\
\text { Trecho }\end{array} \\
\text { I/s } \\
\end{array}$} & \multirow{2}{*}{$\begin{array}{c}\begin{array}{c}\text { Diâmetro } \\
\text { Nominal } \\
\text { Comercial }\end{array} \\
(\mathrm{mm})\end{array}$} & \multirow{2}{*}{$\begin{array}{c}\begin{array}{c}\text { Diâmetro } \\
\text { Ótimo }\end{array} \\
(\mathrm{mm}) \\
\end{array}$} & \multirow{2}{*}{$\begin{array}{l}\text { Velocidade } \\
(\mathrm{m} / \mathrm{s})\end{array}$} & \multirow{2}{*}{$\begin{array}{l}\text { Fator de } \\
\text { Atrito } f\end{array}$} & \multirow{2}{*}{$\begin{array}{c}\text { Perda de Carga } \\
(\mathrm{m})\end{array}$} & \multirow{2}{*}{$\begin{array}{c}\begin{array}{c}\text { Carga } \\
\text { Montante }\end{array} \\
(\mathrm{m})\end{array}$} & \multirow{2}{*}{$\begin{array}{c}\text { Carga Jusante } \\
(\mathrm{m})\end{array}$} & \multirow{2}{*}{$\begin{array}{c}\text { Potência Dissipada } \\
\text { kW }\end{array}$} \\
\hline & Nome & Cota & Nome & Cota & & & & & & & & & & \\
\hline T1 & $\mathrm{N} 1$ & 4,56 & N2 & 3,50 & 258,48 & 179,4 & 400 & 400 & 1,42 & 0,0082 & 0,55 & 12,66 & 13,18 & 1,37 \\
\hline T2 & N2 & 3,50 & N3 & 3,50 & 255,93 & 23,9 & 150 & 150 & 1,35 & 0,0082 & 1,30 & 13,18 & 11,88 & 0,43 \\
\hline T3 & $\mathrm{N} 4$ & 1,50 & N5 & 0,49 & 657,53 & 20,2 & 200 & 200 & 0,64 & 0,0082 & 0,57 & 12,44 & 12,88 & 0,16 \\
\hline T4 & N5 & 0,49 & N6 & 0,50 & 253,28 & 17,0 & 150 & 149 & 0,96 & 0,0082 & 0,65 & 12,88 & 12,22 & 0,15 \\
\hline T5 & N6 & 0,50 & N7 & 1,50 & 660,47 & 51,8 & 250 & 249 & 1,05 & 0,0082 & 1,22 & 12,22 & 10,00 & 0,88 \\
\hline T6 & N2 & 3,50 & N7 & 1,50 & 644,10 & 131,9 & 350 & 350 & 1,37 & 0,0082 & 1,44 & 13,18 & 13,74 & 2,65 \\
\hline 77 & N7 & 1,50 & $\mathrm{~N} 4$ & 1,50 & 253,02 & 49,5 & 200 & 202 & 1,57 & 0,0082 & 1,30 & 13,74 & 12,44 & 0,90 \\
\hline T8 & N3 & 3,50 & $\mathrm{~N} 4$ & 1,50 & 657,18 & 3,3 & 80 & 80 & 0,65 & 0,0082 & 1,44 & 13,18 & 13,73 & 0,07 \\
\hline
\end{tabular}

4) Resumo do Dimensionamento Otimizado

\begin{tabular}{|c|c|c|}
\hline & Potência Dissipada & Pressurização Inicial \\
\hline Soma & 6,63 & 31,80 \\
\hline Energia & $43.569,83$ & $208.951,67$ \\
\hline FA & 14,13 & 14,13 \\
\hline Sub-Total $R$ & $102.277,72$ & $490.502,33$ \\
\hline
\end{tabular}

\begin{tabular}{|c|c|c|}
\hline Custos & & Porcentagem \\
\hline Custo de Tubulação $\mathrm{R} \$$ & $909.743,52$ & $55,87 \%$ \\
\hline Custo de Movimento de Terra $\mathrm{R} \$$ & $64.132,13$ & $3,94 \%$ \\
\hline Custo de Assentamento $\mathrm{R} \$$ & $10.333,46$ & $0,63 \%$ \\
\hline Custo de Pavimentação $R \$$ & $51.219,82$ & $3,15 \%$ \\
\hline Custo da Pressurização Inicial $\mathrm{R} \$$ & $490.502,33$ & $30,13 \%$ \\
\hline Custo da Potência Dissipada $\mathrm{R} \$$ & $102.277,72$ & $6,28 \%$ \\
\hline Total Global (Função Objetivo) R\$ & $1.628 .208,98$ & $100,00 \%$ \\
\hline Total Referencial Unitário $\mathbf{R} \$$ & 447,31 & por metro de rede \\
\hline
\end{tabular}


5) Quantitativos e Custos de Implantação das Redes de Abastecimento

\begin{tabular}{|c|c|c|c|c|c|c|c|c|c|}
\hline Trecho & $\begin{array}{l}\text { Locação da } \\
\text { Tubulação }\end{array}$ & $\begin{array}{l}\text { Tipo de } \\
\text { Superfície }\end{array}$ & Tipo de Tráfego & & & & & & \\
\hline $\mathrm{T} 1$ & viario pavimentado & paralelepipedos & - & & & & & & \\
\hline $\mathrm{T} 2$ & viario pavimentado & paralelepipedos & - & & & & & & \\
\hline T3 & viario pavimentado & paralelepipedos & - & & & & & & \\
\hline $\mathrm{T} 4$ & viario pavimentado & paralelepipedos & - & & & & & & \\
\hline T5 & viario pavimentado & paralelepipedos & - & & & & & & \\
\hline T6 & viario pavimentado & paralelepipedos & - & & & & & & \\
\hline 77 & viario pavimentado & paralelepipedos & - & & & & & & \\
\hline T8 & viario pavimentado & paralelepipedos & - & & & & & & \\
\hline \multirow{3}{*}{ Trecho } & \multicolumn{6}{|c|}{ Vala } & \multicolumn{3}{|c|}{ Tubulação } \\
\hline & Largura & $\begin{array}{l}\text { Profundidade } \\
\end{array}$ & Escavação & Reaterro & Bota-Fora & TOTAL & Assentamento & Material & TOTAL \\
\hline & $\mathrm{m}$ & $\mathrm{m}$ & $\mathrm{m}^{3}$ & $\mathrm{~m}^{3}$ & $\mathrm{~m}^{3}$ & $\mathbf{R} \$$ & $\mathrm{R} \$$ & $\mathrm{R} \$$ & $\mathbf{R} \$$ \\
\hline $\mathrm{T} 1$ & 0,75 & 1,40 & 271,40 & 238,92 & 32,48 & $6.481,67$ & $1.330,32$ & $117.523,27$ & $118.853,60$ \\
\hline $\mathrm{T} 2$ & 0,50 & 1,15 & 147,16 & 142,64 & 4,52 & $3.645,49$ & 504,84 & $44.128,90$ & $44.633,74$ \\
\hline T3 & 0,55 & 1,20 & 433,97 & 413,31 & 20,66 & $10.677,19$ & $1.631,59$ & $144.179,67$ & $145.811,26$ \\
\hline $\mathrm{T} 4$ & 0,50 & 1,15 & 145,64 & 141,16 & 4,48 & $3.607,75$ & 499,61 & $43.671,97$ & $\begin{array}{l}44.171,58 \\
\end{array}$ \\
\hline T5 & 0,60 & 1,25 & 495,35 & 462,93 & 32,42 & $12.098,91$ & $2.016,56$ & $178.936,95$ & $180.953,51$ \\
\hline T6 & 0,70 & 1,35 & 608,67 & 546,70 & 61,97 & $14.645,24$ & $2.824,95$ & $250.311,21$ & $253.136,16$ \\
\hline$T 7$ & 0,55 & 1,20 & 166,99 & 159,04 & 7,95 & $4.108,62$ & 627,84 & $55.480,87$ & $56.108,72$ \\
\hline \multirow[t]{2}{*}{ T8 } & 0,50 & 1,08 & 354,88 & 351,57 & 3,30 & $8.867,25$ & 897,74 & $75.510,68$ & $\begin{array}{l}76.408,42 \\
\end{array}$ \\
\hline & & & & & Soma & 64.132,13 & $\begin{array}{ll}R \$ 10.333,46 \\
\end{array}$ & $\mathrm{R} \$ 909.743,52 \quad \mathrm{R} \$$ & $920.076,99$ \\
\hline \multicolumn{10}{|c|}{ Pavimentação } \\
\hline \multirow{3}{*}{ Trecho } & & & $\mathrm{Va}$ & a & & & & & \\
\hline & Área & $\begin{array}{l}\text { Área de } \\
\text { Concreto }\end{array}$ & $\begin{array}{c}\text { Área de } \\
\text { Paralelepipedos }\end{array}$ & $\begin{array}{l}\text { Área de } \\
\text { Asfalto }\end{array}$ & Área de Binder & $\begin{array}{l}\text { Área de Concreto Astático } \\
\text { Usinado a Quente }\end{array}$ & & & \\
\hline & $\mathrm{m}^{2}$ & $\mathrm{~m}^{2}$ & $\mathrm{~m}^{2}$ & $\mathrm{~m}^{2}$ & $\mathrm{~m}^{2}$ & $\mathrm{~m}^{2}$ & & & \\
\hline $\mathrm{T} 1$ & 193,86 & 0,00 & 193,86 & 0,00 & 0,00 & 0,00 & & & \\
\hline $\mathrm{T} 2$ & 127,97 & 0,00 & 127,97 & 0,00 & 0,00 & 0,00 & & & \\
\hline T3 & 361,64 & 0,00 & 361,64 & 0,00 & 0,00 & 0,00 & & & \\
\hline T4 & 126,64 & 0,00 & 126,64 & 0,00 & 0,00 & 0,00 & & & \\
\hline T5 & 396,28 & 0,00 & 396,28 & 0,00 & 0,00 & 0,00 & & & \\
\hline T6 & 450,87 & 0,00 & 450,87 & 0,00 & 0,00 & 0,00 & & & \\
\hline 77 & 139,16 & 0,00 & 139,16 & 0,00 & 0,00 & 0,00 & & & \\
\hline $\mathrm{T} 8$ & 328,59 & 0,00 & 328,59 & 0,00 & 0,00 & 0,00 & & & \\
\hline \multirow{4}{*}{ Trecho } & \multicolumn{9}{|c|}{ Pavimentação } \\
\hline & \multicolumn{3}{|c|}{ Volume } & \multicolumn{2}{|c|}{ Area } & \multicolumn{4}{|c|}{ Custos } \\
\hline & Macadame Hidáulico & Binder & $\begin{array}{l}\text { Concreto } \\
\text { Asfáltico Usinado } \\
\text { a Quente }\end{array}$ & $\begin{array}{c}\text { Imprimação } \\
\text { Betuminosa } \\
\text { Ligante }\end{array}$ & $\begin{array}{c}\text { Imprimação } \\
\text { Betuminosa } \\
\text { Impermeabiliza } \\
\text { nte }\end{array}$ & Remoção & Recomposição & Transporte & TOTAL \\
\hline & $\mathrm{m}^{3}$ & $\mathrm{~m}^{3}$ & $\mathrm{~m}^{3}$ & $\mathrm{~m}^{2}$ & $\mathrm{~m}^{2}$ & $\mathrm{R} \$$ & $\mathrm{R} \$$ & $\mathrm{R} \$$ & $\mathbf{R} \$$ \\
\hline $\mathrm{T} 1$ & 0,00 & 0,00 & 0,00 & 0,00 & 0,00 & 993,09 & $3.679,58$ & 0,00 & $4.672,67$ \\
\hline $\mathrm{T} 2$ & 0,00 & 0,00 & 0,00 & 0,00 & 0,00 & 655,53 & $2.428,85$ & 0,00 & $3.084,38$ \\
\hline T3 & 0,00 & 0,00 & 0,00 & 0,00 & 0,00 & $1.852,59$ & $6.864,18$ & 0,00 & $8.716,77$ \\
\hline T4 & 0,00 & 0,00 & 0,00 & 0,00 & 0,00 & 648,74 & $2.403,70$ & 0,00 & $3.052,45$ \\
\hline T5 & 0,00 & 0,00 & 0,00 & 0,00 & 0,00 & $2.030,04$ & $7.521,67$ & 0,00 & $9.551,72$ \\
\hline T6 & 0,00 & 0,00 & 0,00 & 0,00 & 0,00 & $2.309,68$ & $8.557,79$ & 0,00 & $\begin{array}{l}10.867,47 \\
\end{array}$ \\
\hline 77 & 0,00 & 0,00 & 0,00 & 0,00 & 0,00 & 712,88 & $2.641,36$ & 0,00 & $3.354,24$ \\
\hline T8 & 0,00 & 0,00 & 0,00 & 0,00 & 0,00 & $1.683,28$ & $6.236,84$ & 0,00 & $7.920,12$ \\
\hline & & & & & Soma & $10.885,84$ & $\begin{array}{ll}\mathrm{R} \$ \quad 40.333,98 \\
\end{array}$ & $\mathbf{R} \$$ & $51.219,82$ \\
\hline
\end{tabular}




\section{APÊNDICE C6 - Planilha de Dimensionamento para Juros de 6\%aa e Viário em Paralelepípedo - FoFo}

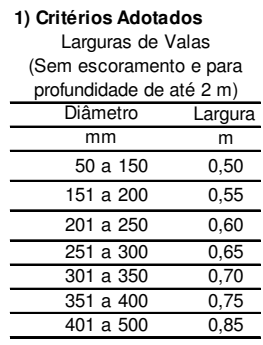

Locação das Redes

\begin{tabular}{l}
\hline passeio \\
\hline viario em terra \\
\hline viario pavimentado \\
\hline
\end{tabular}

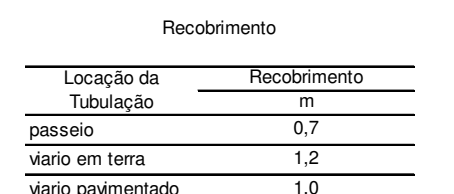

viario pavimentado 1,0

\begin{tabular}{l}
\hline \multicolumn{1}{c}{ Tipo de Tráfegos para Viário } \\
\hline Leve \\
\hline Médio \\
\hline Pesado \\
\hline Tipos de Superfície \\
\hline asfalto \\
\hline pancreto \\
\hline terra
\end{tabular}

2) Dados Adotados

Tubulação

Materia

SDR

\begin{tabular}{lr}
\hline Rugosidade Equivalente $(\mathrm{m}) \quad 0,0001$ \\
\hline
\end{tabular}

Fator entre Diâmetro Hidráulico e Comercia \begin{tabular}{lr}
\hline Carga Inicial & 12,02 \\
\hline Rendimento Global & 0,70 \\
\hline
\end{tabular}

\begin{tabular}{ll} 
Horas de Funcionamer & 0,70 \\
\hline & $6570 \mathrm{~h} / \mathrm{ano}$ \\
\hline
\end{tabular}

Vida Útil
Pressurização Inicial

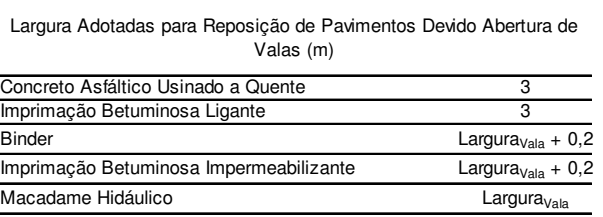

Espessuras Adotadas para Reposição de Pavimentos Devido Abertura de Valas (m) Binder

Binder 0,04

Macadame Hidáulico

Energia

Grupo A (Alta e Média Tensão)

Sub-Grupo A4 (2,3 KV a 25 KV

Custo de Energia por Demanda $31,31 \mathrm{R} \$ / \mathrm{KW}$

Custo de Energia por Consumo $\quad 0,16132 \mathrm{R} \$ / \mathrm{KWh}$

\begin{tabular}{lr}
\hline Taxa de Juros & $6,00 \%$ aa \\
\hline
\end{tabular}

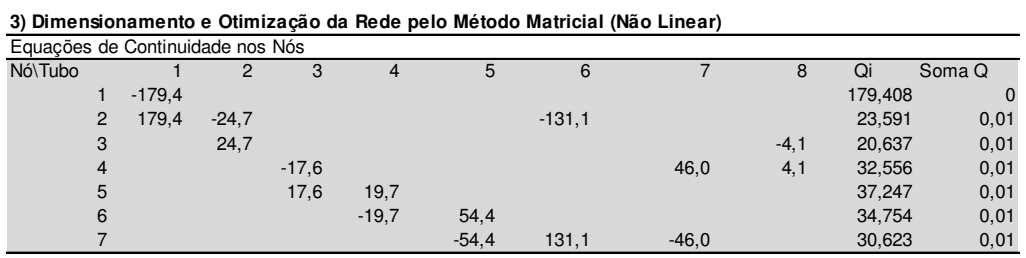

\begin{tabular}{cccccccccr}
\hline Equações de Perda de Carga nos Circuitos & & & & & \\
\hline Circuitos & 1 & 2 & 3 & 4 & 5 & 6 & 7 & 8 & Soma Perda \\
& & & & & & & & \\
1 & $-0,329$ & & & & 1,420 & 1,129 & $-2,220$ & $1 \mathrm{E}-04$ \\
2 & & $-0,427$ & 0,206 & 1,349 & & $-1,129$ & & 0,0001 \\
\hline
\end{tabular}

Tabela da Função Objetivo

\begin{tabular}{|c|c|c|c|c|c|c|c|c|c|c|c|c|c|c|}
\hline \multirow{2}{*}{ Trecho } & \multicolumn{2}{|c|}{ Nó Montante } & \multicolumn{2}{|c|}{ No Jusante } & \multirow{2}{*}{$\begin{array}{c}\begin{array}{c}\text { Extensão } \\
\text { do Trecho }\end{array} \\
\text { (m) } \\
\end{array}$} & \multirow{2}{*}{$\begin{array}{c}\text { Vazão do } \\
\text { Trecho }\end{array}$} & \multirow{2}{*}{$\begin{array}{c}\begin{array}{c}\text { Diâmetro } \\
\text { Nominal } \\
\text { Comercial }\end{array} \\
(\mathrm{mm})\end{array}$} & \multirow{2}{*}{$\begin{array}{c}\begin{array}{c}\text { Diâmetro } \\
\text { Ótimo }\end{array} \\
(\mathrm{mm})\end{array}$} & \multirow{2}{*}{$\begin{array}{c}\text { Velocidade } \\
(\mathrm{m} / \mathrm{s})\end{array}$} & \multirow{2}{*}{$\begin{array}{l}\text { Fator de } \\
\text { Atrito } f\end{array}$} & \multirow{2}{*}{$\begin{array}{c}\text { Perda de Carga } \\
(\mathrm{m})\end{array}$} & \multirow{2}{*}{$\begin{array}{c}\begin{array}{c}\text { Carga } \\
\text { Montante }\end{array} \\
(\mathrm{m})\end{array}$} & \multirow{2}{*}{$\begin{array}{c}\text { Carga Jusante } \\
(\mathrm{m})\end{array}$} & \multirow{2}{*}{$\begin{array}{c}\text { Potência Dissipada } \\
\text { kW }\end{array}$} \\
\hline & Nome & Cota & Nome & Cota & & & & & & & & & & \\
\hline $\mathrm{T} 1$ & $\mathrm{~N} 1$ & 4,56 & N2 & 3,50 & 258,48 & 179,4 & 400 & 401 & 1,42 & 0,0082 & 0,55 & 12,02 & 12,53 & 1,37 \\
\hline T2 & N2 & 3,50 & N3 & 3,50 & 255,93 & 24,7 & 200 & 200 & 0,78 & 0,0082 & 0,33 & 12,53 & 12,20 & 0,11 \\
\hline T3 & $\mathrm{N} 4$ & 1,50 & N5 & 0,49 & 657,53 & 17,6 & 200 & 173 & 0,56 & 0,0082 & 0,43 & 11,98 & 12,56 & 0,10 \\
\hline T4 & N5 & 0,49 & N6 & 0,50 & 253,28 & 19,7 & 200 & 160 & 0,62 & 0,0082 & 0,21 & 12,56 & 12,35 & 0,06 \\
\hline T5 & N6 & 0,50 & N7 & 1,50 & 660,47 & 54,4 & 250 & 250 & 1,11 & 0,0082 & 1,35 & 12,35 & 10,00 & 1,03 \\
\hline T6 & N2 & 3,50 & N7 & 1,50 & 644,10 & 131,1 & 350 & 366 & 1,36 & 0,0082 & 1,42 & 12,53 & 13,11 & 2,61 \\
\hline 77 & N7 & 1,50 & $\mathrm{~N} 4$ & 1,50 & 253,02 & 46,0 & 200 & 201 & 1,46 & 0,0082 & 1,13 & 13,11 & 11,98 & 0,73 \\
\hline T8 & N3 & 3,50 & $\mathrm{~N} 4$ & 1,50 & 657,18 & 4,1 & 80 & 80 & 0,80 & 0,0082 & 2,22 & 12,53 & 12,31 & 0,13 \\
\hline
\end{tabular}

4) Resumo do Dimensionamento Otimizado

\begin{tabular}{|c|c|c|c|}
\hline & Poté & Dissipada & Pressurização Inicial \\
\hline Soma & & 6,14 & 30,18 \\
\hline Energia & & $40.323,90$ & $198.275,22$ \\
\hline FA & & 12,16 & 12,16 \\
\hline Sub-Total & $\mathrm{R} \$$ & $81.425,57$ & $400.374,79$ \\
\hline
\end{tabular}

\begin{tabular}{|c|c|c|}
\hline Custos & & Porcentagem \\
\hline Custo de Tubulação $\mathrm{R} \$$ & $933.599,50$ & $60,51 \%$ \\
\hline Custo de Movimento de Terra $\mathrm{R} \$$ & $65.147,60$ & $4,22 \%$ \\
\hline Custo de Assentamento $\mathrm{R} \$$ & $10.592,56$ & $0,69 \%$ \\
\hline Custo de Pavimentação $R \$$ & $51.833,50$ & $3,36 \%$ \\
\hline Custo da Pressurização Inicial $\mathrm{R} \$$ & $400.374,79$ & $25,95 \%$ \\
\hline Custo da Potência Dissipada $R \$$ & $81.425,57$ & $5,28 \%$ \\
\hline Total Global (Função Objetivo) R\$ & $1.542 .973,53$ & $100,00 \%$ \\
\hline Total Referencial Unitário R\$ & 423,89 & por metro de rede \\
\hline
\end{tabular}


5) Quantitativos e Custos de Implantação das Redes de Abastecimento

\begin{tabular}{|c|c|c|c|c|c|c|c|c|c|}
\hline Trecho & $\begin{array}{l}\text { Locação da } \\
\text { Tubulação }\end{array}$ & $\begin{array}{c}\text { Tipo de } \\
\text { Superfície }\end{array}$ & Tipo de Tráfego & & & & & & \\
\hline $\mathrm{T} 1$ & vario pavimentado & paralelepipedos & - & & & & & & \\
\hline $\mathrm{T} 2$ & viario pavimentado & paralelepipedos & - & & & & & & \\
\hline T3 & viario pavimentado & paralelepipedos & - & & & & & & \\
\hline $\mathrm{T} 4$ & viario pavimentado & paralelepipedos & - & & & & & & \\
\hline $\mathrm{T5}$ & viario pavimentado & paralelepipedos & - & & & & & & \\
\hline T6 & viario pavimentado & paralelepipedos & - & & & & & & \\
\hline 77 & vario pavimentado & paralelepipedos & - & & & & & & \\
\hline T8 & viario pavimentado & paralelepipedos & - & & & & & & \\
\hline \multirow{3}{*}{ Trecho } & \multicolumn{6}{|c|}{ Vala } & \multicolumn{3}{|c|}{ Tubulação } \\
\hline & Largura & Profundidade & Escavação & Reaterro & Bota-Fora & TOTAL & Assentamento & Material & TOTAL \\
\hline & $\mathrm{m}$ & $\mathrm{m}$ & $\mathrm{m}^{3}$ & $\mathrm{~m}^{3}$ & $\mathrm{~m}^{3}$ & $\mathrm{R} \$$ & $\mathrm{R} \$$ & $\mathrm{R} \$$ & $\mathbf{R} \$$ \\
\hline $\mathrm{T} 1$ & 0,75 & 1,40 & 271,40 & 238,92 & 32,48 & $6.481,67$ & $1.330,32$ & $117.523,27$ & $118.853,60$ \\
\hline T2 & 0,55 & 1,20 & 168,91 & 160,87 & 8,04 & $4.155,87$ & 635,06 & $56.118,96$ & $56.754,03$ \\
\hline T3 & 0,55 & 1,20 & 433,97 & 413,31 & 20,66 & $10.677,19$ & $1.631,59$ & $144.179,67$ & $145.811,26$ \\
\hline T4 & 0,55 & 1,20 & 167,16 & 159,21 & 7,96 & $4.112,84$ & 628,49 & $55.537,89$ & $56.166,37$ \\
\hline T5 & 0,60 & 1,25 & 495,35 & 462,93 & 32,42 & $12.098,91$ & $2.016,56$ & $178.936,95$ & $180.953,51$ \\
\hline T6 & 0,70 & 1,35 & 608,67 & 546,70 & 61,97 & $14.645,24$ & $2.824,95$ & $250.311,21$ & $253.136,16$ \\
\hline$\pi 7$ & 0,55 & 1,20 & 166,99 & 159,04 & 7,95 & $4.108,62$ & 627,84 & $55.480,87$ & $56.108,72$ \\
\hline \multirow[t]{2}{*}{ T8 } & 0,50 & 1,08 & 354,88 & 351,57 & 3,30 & $8.867,25$ & 897,74 & $75.510,68$ & $76.408,42$ \\
\hline & & & & & Soma & $65.147,60$ & $\begin{array}{ll}\mathrm{R} \$ & 10.592,56\end{array}$ & $\begin{array}{ll}R \$ 933.599,50 & R \$\end{array}$ & $944.192,07$ \\
\hline \multicolumn{10}{|c|}{ Pavimentaçäo } \\
\hline \multirow{3}{*}{ Trecho } & \multicolumn{6}{|c|}{ Vala } & & & \\
\hline & Área & $\begin{array}{l}\text { Área de } \\
\text { Concreto }\end{array}$ & $\begin{array}{c}\text { Área de } \\
\text { Paralelepipedos }\end{array}$ & $\begin{array}{l}\text { Área de } \\
\text { Asfalto }\end{array}$ & Área de Binder & $\begin{array}{l}\text { Área de Concreto Asfático } \\
\text { Usinado a Quente }\end{array}$ & & & \\
\hline & $\mathrm{m}^{2}$ & $\mathrm{~m}^{2}$ & $\mathrm{~m}^{2}$ & $\mathrm{~m}^{2}$ & $\mathrm{~m}^{2}$ & $\mathrm{~m}^{2}$ & & & \\
\hline $\mathrm{T} 1$ & 193,86 & 0,00 & 193,86 & 0,00 & 0,00 & 0,00 & & & \\
\hline $\mathrm{T} 2$ & 140,76 & 0,00 & 140,76 & 0,00 & 0,00 & 0,00 & & & \\
\hline T3 & 361,64 & 0,00 & 361,64 & 0,00 & 0,00 & 0,00 & & & \\
\hline T4 & 139,30 & 0,00 & 139,30 & 0,00 & 0,00 & 0,00 & & & \\
\hline T5 & 396,28 & 0,00 & 396,28 & 0,00 & 0,00 & 0,00 & & & \\
\hline T6 & 450,87 & 0,00 & 450,87 & 0,00 & 0,00 & 0,00 & & & \\
\hline 77 & 139,16 & 0,00 & 139,16 & 0,00 & 0,00 & 0,00 & & & \\
\hline T8 & 328,59 & 0,00 & 328,59 & 0,00 & 0,00 & 0,00 & & & \\
\hline \multirow{4}{*}{ Trecho } & \multicolumn{9}{|c|}{ Pavimentação } \\
\hline & \multicolumn{3}{|c|}{ Volume } & \multicolumn{2}{|c|}{ Área } & \multicolumn{4}{|c|}{ Custos } \\
\hline & Macadame Hidáulico & Binder & $\begin{array}{l}\text { Concreto } \\
\text { Asfáltico Usinado } \\
\text { a Quente }\end{array}$ & $\begin{array}{l}\text { Imprimação } \\
\text { Betuminosa } \\
\text { Ligante }\end{array}$ & $\begin{array}{c}\text { Imprimação } \\
\text { Betuminosa } \\
\text { Impermeabiliza } \\
\text { nte }\end{array}$ & Remoção & Recomposição & Transporte & TOTAL \\
\hline & $\mathrm{m}^{3}$ & $\mathrm{~m}^{3}$ & $\mathrm{~m}^{3}$ & $\mathrm{~m}^{2}$ & $\mathrm{~m}^{2}$ & $\mathrm{R} \$$ & $\mathrm{R} \$$ & $\mathrm{R} \$$ & $\mathbf{R} \$$ \\
\hline $\mathrm{T} 1$ & 0,00 & 0,00 & 0,00 & 0,00 & 0,00 & 993,09 & $3.679,58$ & 0,00 & $4.672,67$ \\
\hline $\mathrm{T} 2$ & 0,00 & 0,00 & 0,00 & 0,00 & 0,00 & 721,08 & $2.671,74$ & 0,00 & $3.392,82$ \\
\hline T3 & 0,00 & 0,00 & 0,00 & 0,00 & 0,00 & $1.852,59$ & $6.864,18$ & 0,00 & $8.716,77$ \\
\hline T4 & 0,00 & 0,00 & 0,00 & 0,00 & 0,00 & 713,62 & $2.644,08$ & 0,00 & $3.357,69$ \\
\hline T5 & 0,00 & 0,00 & 0,00 & 0,00 & 0,00 & 2.030,04 & $7.521,67$ & 0,00 & $9.551,72$ \\
\hline T6 & 0,00 & 0,00 & 0,00 & 0,00 & 0,00 & $2.309,68$ & $8.557,79$ & 0,00 & $10.867,47$ \\
\hline$T 7$ & 0,00 & 0,00 & 0,00 & 0,00 & 0,00 & 712,88 & $2.641,36$ & 0,00 & $3.354,24$ \\
\hline T8 & 0,00 & 0,00 & 0,00 & 0,00 & 0,00 & $1.683,28$ & $6.236,84$ & 0,00 & $7.920,12$ \\
\hline
\end{tabular}




\section{APÊNDICE C7 - Planilha de Dimensionamento para Juros de 8\%aa e Viário em Paralelepípedo - FoFo}

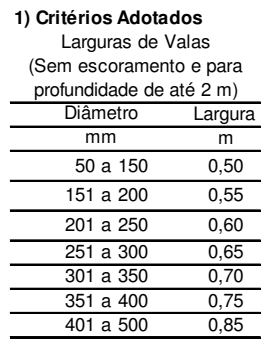

Locação das Redes

\begin{tabular}{l} 
passeio \\
\hline viario em terra \\
\hline viario pavimentado \\
\hline
\end{tabular}

2) Dados Adotados

Tubulação

Materia

SDR

\begin{tabular}{ll}
\hline Rugosidade Equivalente (m) & 0,0001 \\
\hline
\end{tabular}

Fator entre Diâmetro Hidráulico e Comercia
Recobrimento

\begin{tabular}{lc}
\hline \multicolumn{1}{c}{ Locação da } & Recobrimento \\
\cline { 2 - 2 } Tubulação & $\mathrm{m}$ \\
\hline passeio & 0,7 \\
\hline viario em terra & 1,2 \\
\hline viario pavimentado & 1,0 \\
\hline
\end{tabular}

Tipo de Tráfegos para Viário

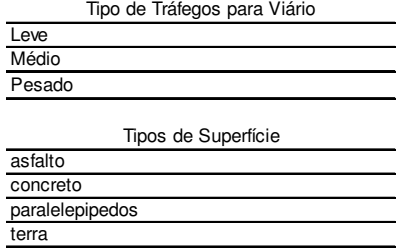

paralele

Pressurização Inicial

\begin{tabular}{lr}
\hline Carga Inicial & 12,02 \\
\hline Rendimento Global & 0,70 \\
\hline
\end{tabular}

\begin{tabular}{ll}
\hline Horas de Funcionamer & $6570 \mathrm{~h} /$ ano \\
\hline
\end{tabular}

Vida Útil

1,05
Largura Adotadas para Reposição de Pavimentos Devido Abertura de Valas $(m)$ \begin{tabular}{ll}
\hline Concreto Asfáltico Usinado a Quente & 3 \\
\hline Imprimação Betuminosa Ligante & 3 \\
\hline
\end{tabular}

Binder

\begin{tabular}{ll} 
Larguravala $+0,2$ \\
\hline Imprimaça Be Betuminosa Impermeabilizante
\end{tabular}

Macadame Hidáulico $\quad$ Largura

\begin{tabular}{|c|c|c|c|}
\hline Tráfego & Leve & Médio & Pesado \\
\hline Binder & 0,04 & 0,07 & 0,10 \\
\hline Joncreto Asfáltico Usinado a Quente & 0,04 & 0,05 & 0,05 \\
\hline acadame Hidáulico & 0,10 & 0,12 & 0,15 \\
\hline
\end{tabular}

Macadame Hidáulico

\begin{tabular}{|c|c|}
\hline Energia & \\
\hline Grupo A (Alta e Média Tensão) & \\
\hline Sub-Grupo A4 (2,3 KV a $25 \mathrm{KV})$ & \\
\hline Custo de Energia por Demanda & $31,31 \mathrm{R} \$ / \mathrm{KW}$ \\
\hline Custo de Energia por Consumo & $0,16132 \mathrm{R} \$ / \mathrm{KWh}$ \\
\hline Taxa de Juros & $8,00 \% \mathrm{aa}$ \\
\hline Fator de Atualização & 10,60 \\
\hline
\end{tabular}

Energia

Sub-Grupo A4 (2,3 KV a $25 \mathrm{KV})$

nergia por Demand

Fator de Atualizacão

10,60

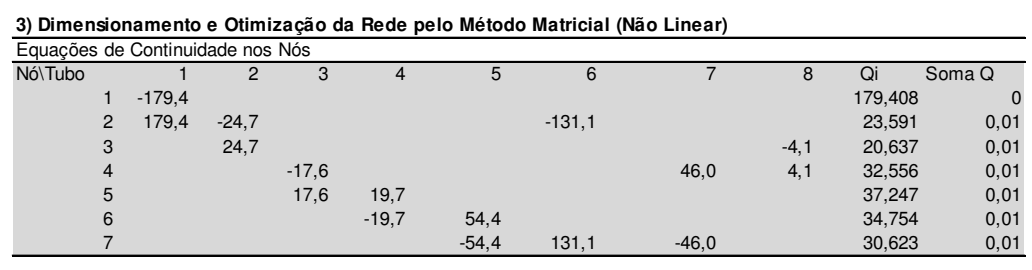

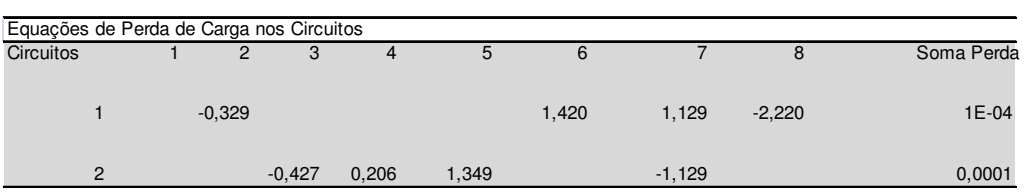

Tabela da Função Objetivo

\begin{tabular}{|c|c|c|c|c|c|c|c|c|c|c|c|c|c|c|}
\hline \multirow{2}{*}{ Trecho } & \multicolumn{2}{|c|}{ Nó Montante } & \multicolumn{2}{|c|}{ No Jusante } & \multirow{2}{*}{$\begin{array}{l}\begin{array}{l}\text { Extensão } \\
\text { do Trecho }\end{array} \\
\text { (m) }\end{array}$} & \multirow{2}{*}{$\begin{array}{c}\begin{array}{c}\text { Vazão do } \\
\text { Trecho }\end{array} \\
\text { I/s } \\
\end{array}$} & \multirow{2}{*}{$\begin{array}{c}\begin{array}{c}\text { Diâmetro } \\
\text { Nominal } \\
\text { Comercial }\end{array} \\
(\mathrm{mm}) \\
\end{array}$} & \multirow{2}{*}{$\begin{array}{c}\text { Diâmetro } \\
\text { Ótimo }\end{array}$} & \multirow{2}{*}{$\begin{array}{c}\text { Velocidade } \\
(\mathrm{m} / \mathrm{s})\end{array}$} & \multirow{2}{*}{$\begin{array}{l}\text { Fator de } \\
\text { Atrito } f\end{array}$} & \multirow{2}{*}{$\begin{array}{c}\text { Perda de Carga } \\
(\mathrm{m})\end{array}$} & \multirow{2}{*}{$\begin{array}{c}\begin{array}{c}\text { Carga } \\
\text { Montante }\end{array} \\
(\mathrm{m})\end{array}$} & \multirow{2}{*}{$\begin{array}{c}\text { Carga Jusante } \\
(\mathrm{m})\end{array}$} & \multirow{2}{*}{$\begin{array}{c}\text { Potência Dissipada } \\
\mathrm{kW}\end{array}$} \\
\hline & Nome & Cota & Nome & Cota & & & & & & & & & & \\
\hline $\mathrm{T1}$ & $\mathrm{N} 1$ & 4,56 & N2 & 3,50 & 258,48 & 179,4 & 400 & 401 & 1,42 & 0,0082 & 0,55 & 12,02 & 12,53 & 1,37 \\
\hline T2 & N2 & 3,50 & N3 & 3,50 & 255,93 & 24,7 & 200 & 200 & 0,78 & 0,0082 & 0,33 & 12,53 & 12,20 & 0,11 \\
\hline T3 & N4 & 1,50 & N5 & 0,49 & 657,53 & 17,6 & 200 & 173 & 0,56 & 0,0082 & 0,43 & 11,98 & 12,56 & 0,10 \\
\hline T4 & N5 & 0,49 & N6 & 0,50 & 253,28 & 19,7 & 200 & 160 & 0,62 & 0,0082 & 0,21 & 12,56 & 12,35 & 0,06 \\
\hline T5 & N6 & 0,50 & N7 & 1,50 & 660,47 & 54,4 & 250 & 250 & 1,11 & 0,0082 & 1,35 & 12,35 & 10,00 & 1,03 \\
\hline T6 & N2 & 3,50 & N7 & 1,50 & 644,10 & 131,1 & 350 & 366 & 1,36 & 0,0082 & 1,42 & 12,53 & 13,11 & 2,61 \\
\hline 77 & N7 & 1,50 & $\mathrm{~N} 4$ & 1,50 & 253,02 & 46,0 & 200 & 201 & 1,46 & 0,0082 & 1,13 & 13,11 & 11,98 & 0,73 \\
\hline T8 & N3 & 3,50 & N4 & 1,50 & 657,18 & 4,1 & 80 & 80 & 0,80 & 0,0082 & 2,22 & 12,53 & 12,31 & 0,13 \\
\hline
\end{tabular}

4) Resumo do Dimensionamento Otimizado

\begin{tabular}{|c|c|c|c|}
\hline & Poté & Dissipada & Pressurização Inicial \\
\hline Soma & & 6,14 & 30,18 \\
\hline Energia & & $40.323,90$ & $198.275,22$ \\
\hline FA & & 10,60 & 10,60 \\
\hline Sub-Total & $\mathrm{R} \$$ & $71.014,63$ & $349.183,52$ \\
\hline
\end{tabular}

\begin{tabular}{|c|c|c|}
\hline Custos & & Porcentagem \\
\hline Custo de Tubulação $\mathrm{R} \$$ & $933.599,50$ & $63,02 \%$ \\
\hline Custo de Movimento de Terra $\mathrm{R} \$$ & $65.147,60$ & $4,40 \%$ \\
\hline Custo de Assentamento $\mathrm{R} \$$ & $10.592,56$ & $0,72 \%$ \\
\hline Custo de Pavimentação $\mathrm{R} \$$ & $51.833,50$ & $3,50 \%$ \\
\hline Custo da Pressurização Inicial $\mathrm{R} \$$ & $349.183,52$ & $23,57 \%$ \\
\hline Custo da Potência Dissipada $R \$$ & $71.014,63$ & $4,79 \%$ \\
\hline Total Global (Função Objetivo) R\$ & $1.481 .371,33$ & $100,00 \%$ \\
\hline Total Referencial Unitário R\$ & 406,97 & por metro de rede \\
\hline
\end{tabular}


5) Quantitativos e Custos de Implantação das Redes de Abastecimento

\begin{tabular}{|c|c|c|c|c|c|c|c|c|c|}
\hline Trecho & $\begin{array}{l}\text { Locação da } \\
\text { Tubulação }\end{array}$ & $\begin{array}{l}\text { Tipo de } \\
\text { Superfície }\end{array}$ & Tipo de Tráfego & & & & & & \\
\hline $\mathrm{T} 1$ & viario pavimentado & paralelepipedos & - & & & & & & \\
\hline $\mathrm{T} 2$ & viario pavimentado & paralelepipedos & - & & & & & & \\
\hline T3 & vario pavimentado & paralelepipedos & - & & & & & & \\
\hline T4 & vario pavimentado & paralelepipedos & - & & & & & & \\
\hline $\mathrm{T5}$ & viario pavimentado & paralelepipedos & - & & & & & & \\
\hline T6 & viario pavimentado & paralelepipedos & - & & & & & & \\
\hline 77 & viario pavimentado & paralelepipedos & - & & & & & & \\
\hline \multirow[t]{2}{*}{ T8 } & viario pavimentado & paralelepipedos & - & & & & & & \\
\hline & \multicolumn{6}{|c|}{ Vala } & \multicolumn{3}{|c|}{ Tubulação } \\
\hline \multirow[t]{2}{*}{ Trecho } & Largura & $\begin{array}{l}\text { Profundidade } \\
\end{array}$ & Escavação & Reaterro & Bota-Fora & TOTAL & Assentamento & Material & TOTAL \\
\hline & $\mathrm{m}$ & $\mathrm{m}$ & $\mathrm{m}^{3}$ & $\mathrm{~m}^{3}$ & $\mathrm{~m}^{3}$ & $\mathbf{R} \$$ & $\mathrm{R} \$$ & $\mathrm{R} \$$ & $\mathrm{R} \$$ \\
\hline $\mathrm{T} 1$ & 0,75 & 1,40 & 271,40 & 238,92 & 32,48 & $6.481,67$ & $1.330,32$ & $117.523,27$ & $118.853,60$ \\
\hline $\mathrm{T} 2$ & 0,55 & 1,20 & 168,91 & 160,87 & 8,04 & $4.155,87$ & 635,06 & $56.118,96$ & \begin{tabular}{|l|l|}
$56.754,03$ \\
\end{tabular} \\
\hline T3 & 0,55 & 1,20 & 433,97 & 413,31 & 20,66 & $10.677,19$ & $1.631,59$ & $144.179,67$ & $145.811,26$ \\
\hline T4 & 0,55 & 1,20 & 167,16 & 159,21 & 7,96 & $4.112,84$ & 628,49 & $55.537,89$ & $56.166,37$ \\
\hline T5 & 0,60 & 1,25 & 495,35 & 462,93 & 32,42 & $12.098,91$ & $2.016,56$ & $178.936,95$ & $180.953,51$ \\
\hline T6 & 0,70 & 1,35 & 608,67 & 546,70 & 61,97 & $14.645,24$ & $2.824,95$ & $250.311,21$ & $253.136,16$ \\
\hline 77 & 0,55 & 1,20 & 166,99 & 159,04 & 7,95 & $4.108,62$ & 627,84 & $55.480,87$ & $56.108,72$ \\
\hline \multirow[t]{2}{*}{$\mathrm{T} 8$} & 0,50 & 1,08 & 354,88 & 351,57 & 3,30 & $8.867,25$ & 897,74 & $75.510,68$ & $76.408,42$ \\
\hline & & & & & Soma & $65.147,60$ & $\begin{array}{ll}\mathrm{R} \$ & 10.592,56\end{array}$ & $\mathrm{R} \$ 933.599,50 \quad \mathrm{R} \$$ & $944.192,07$ \\
\hline & & & Pavime & ação & & & & & \\
\hline & & & $v_{c}$ & & & & & & \\
\hline \multirow[t]{2}{*}{ Trecho } & Área & $\begin{array}{l}\text { Área de } \\
\text { Concreto }\end{array}$ & $\begin{array}{c}\text { Área de } \\
\text { Paralelepipedos }\end{array}$ & $\begin{array}{l}\text { Área de } \\
\text { Asfalto }\end{array}$ & Área de Binder & $\begin{array}{l}\text { Area de Concreto Asfático } \\
\text { Usinado a Quente }\end{array}$ & & & \\
\hline & $\mathrm{m}^{2}$ & $\mathrm{~m}^{2}$ & $\mathrm{~m}^{2}$ & $\mathrm{~m}^{2}$ & $\mathrm{~m}^{2}$ & $\mathrm{~m}^{2}$ & & & \\
\hline $\mathrm{T} 1$ & 193,86 & 0,00 & 193,86 & 0,00 & 0,00 & 0,00 & & & \\
\hline $\mathrm{T} 2$ & 140,76 & 0,00 & 140,76 & 0,00 & 0,00 & 0,00 & & & \\
\hline T3 & 361,64 & 0,00 & 361,64 & 0,00 & 0,00 & 0,00 & & & \\
\hline T4 & 139,30 & 0,00 & 139,30 & 0,00 & 0,00 & 0,00 & & & \\
\hline T5 & 396,28 & 0,00 & 396,28 & 0,00 & 0,00 & 0,00 & & & \\
\hline T6 & 450,87 & 0,00 & 450,87 & 0,00 & 0,00 & 0,00 & & & \\
\hline 77 & 139,16 & 0,00 & 139,16 & 0,00 & 0,00 & 0,00 & & & \\
\hline T8 & 328,59 & 0,00 & 328,59 & 0,00 & 0,00 & 0,00 & & & \\
\hline
\end{tabular}

\begin{tabular}{|c|c|c|c|c|c|c|c|c|c|}
\hline \multirow{4}{*}{ Trecho } & \multicolumn{9}{|c|}{ Pavimentação } \\
\hline & \multicolumn{3}{|c|}{ Volume } & \multicolumn{2}{|c|}{ Área } & \multicolumn{4}{|c|}{ Custos } \\
\hline & Macadame Hidáulico & Binder & $\begin{array}{l}\text { Concreto } \\
\text { Astáltico Usinado } \\
\text { a Quente }\end{array}$ & $\begin{array}{l}\text { Imprimação } \\
\text { Betuminosa } \\
\text { Ligante }\end{array}$ & $\begin{array}{l}\text { Imprimação } \\
\text { Betuminosa } \\
\text { Impermeabiliza } \\
\text { nte }\end{array}$ & Remoção & Recomposição & Transporte & TOTAL \\
\hline & $\mathrm{m}^{3}$ & $\mathrm{~m}^{3}$ & $\mathrm{~m}^{3}$ & $\mathrm{~m}^{2}$ & $\mathrm{~m}^{2}$ & $\mathrm{R} \$$ & $\mathrm{R} \$$ & $\mathrm{R} \$$ & $\mathrm{R} \$$ \\
\hline $\mathrm{T} 1$ & 0,00 & 0,00 & 0,00 & 0,00 & 0,00 & 993,09 & $3.679,58$ & 0,00 & $4.672,67$ \\
\hline $\mathrm{T} 2$ & 0,00 & 0,00 & 0,00 & 0,00 & 0,00 & 721,08 & $2.671,74$ & 0,00 & $3.392,82$ \\
\hline T3 & 0,00 & 0,00 & 0,00 & 0,00 & 0,00 & $1.852,59$ & $6.864,18$ & 0,00 & $8.716,77$ \\
\hline T4 & 0,00 & 0,00 & 0,00 & 0,00 & 0,00 & 713,62 & $2.644,08$ & 0,00 & $3.357,69$ \\
\hline T5 & 0,00 & 0,00 & 0,00 & 0,00 & 0,00 & $2.030,04$ & $7.521,67$ & 0,00 & $9.551,72$ \\
\hline T6 & 0,00 & 0,00 & 0,00 & 0,00 & 0,00 & $2.309,68$ & $8.557,79$ & 0,00 & $10.867,47$ \\
\hline 77 & 0,00 & 0,00 & 0,00 & 0,00 & 0,00 & 712,88 & $2.641,36$ & 0,00 & $3.354,24$ \\
\hline T8 & 0,00 & 0,00 & 0,00 & 0,00 & 0,00 & $1.683,28$ & $6.236,84$ & 0,00 & $7.920,12$ \\
\hline
\end{tabular}




\section{APÊNDICE C8 - Planilha de Dimensionamento para Juros de 10\%aa e Viário em Paralelepípedo - FoFo}

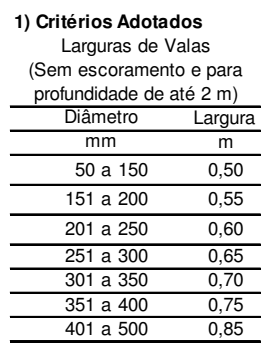

Locação das Redes

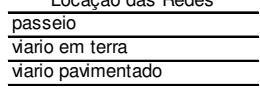

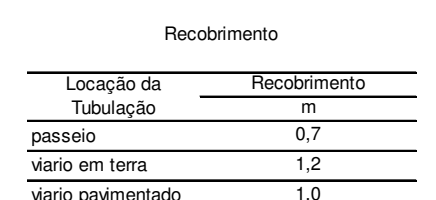

viario pavimentado 1,0

\begin{tabular}{l}
\hline \multicolumn{1}{c}{ Tipo de Tráfegos para Viário } \\
\hline Leve \\
\hline Médio \\
\hline Pesado \\
\hline Tipos de Superfície \\
\hline asfalto \\
\hline pancreto \\
\hline terra
\end{tabular}

2) Dados Adotados

Tubulação

Materia

Rugosidade Equivalente $(\mathrm{m}) \quad 0,0001$

Fator entre Diâmetro Hidráulico e Comercia
Pressurização Inicial

Carga Inicial

\begin{tabular}{lr} 
& $12,02 \mathrm{~m}$ \\
\hline & 0,70
\end{tabular}

Horas de Funcionamer $\quad 6570 \mathrm{~h} /$ ano

Vida Útil

1,05

\begin{tabular}{|c|c|}
\hline Concreto Asfáltico Usinado a Quente & 3 \\
\hline Imprimação Betuminosa Ligante & 3 \\
\hline Binder & Larguravala $+0,2$ \\
\hline Imprimação Betuminosa Impermeabilizante & Largura $_{\text {vala }}+0,2$ \\
\hline Macadame Hidáulico & Largura Vala \\
\hline
\end{tabular}

Espessuras Adotadas para Reposição de Pavimentos Devido Abertura de Valas (m) \begin{tabular}{lccc}
\hline Tráfego & Leve & Médio & Pesado \\
\hline Binder & 0,04 & 0,07 & 0,10 \\
\hline Concreto Asfáltico Usinado a Quente & 0,04 & 0,05 & 0,05 \\
\hline Macadame Hidáulico & 0,10 & 0,12 & 0,15
\end{tabular}

Energia

Grupo A (Alta e Média Tensão)

Sub-Grupo A4 (2,3 KV a $25 \mathrm{KV})$

Custo de Energia por Demanda

$31,31 \mathrm{R} \$ / \mathrm{KW}$

Custo de Energia por Consumo $0,16132 \mathrm{R} \$ / \mathrm{KWh}$

Taxa de Juros

9,36

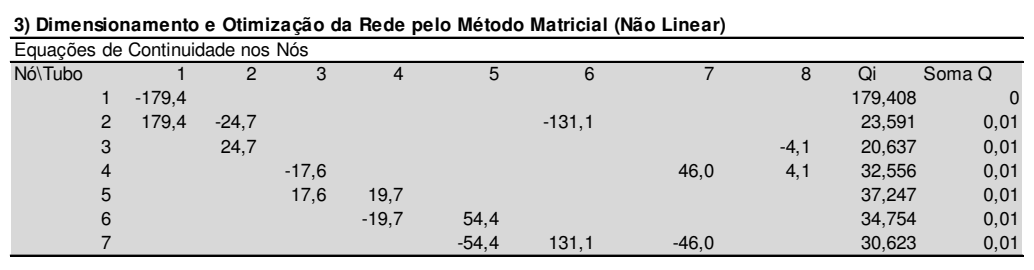

\begin{tabular}{cccccccccr}
\hline Equações de Perda de Carga nos Circuitos & & & & & \\
\hline Circuitos & 1 & 2 & 3 & 4 & 5 & 6 & 7 & 8 & Soma Perda \\
& & & & & & & & \\
1 & $-0,329$ & & & & 1,420 & 1,129 & $-2,220$ & 0,0001 \\
2 & & $-0,427$ & 0,206 & 1,349 & & $-1,129$ & & $1 \mathrm{E}-04$ \\
\hline
\end{tabular}

Tabela da Função Objetivo

\begin{tabular}{|c|c|c|c|c|c|c|c|c|c|c|c|c|c|c|}
\hline \multirow{2}{*}{ Trecho } & \multicolumn{2}{|c|}{ Nó Montante } & \multicolumn{2}{|c|}{ No Jusante } & \multirow{2}{*}{$\begin{array}{c}\begin{array}{c}\text { Extensão } \\
\text { do Trecho }\end{array} \\
\text { (m) } \\
\end{array}$} & \multirow{2}{*}{$\begin{array}{c}\text { Vazão do } \\
\text { Trecho }\end{array}$} & \multirow{2}{*}{$\begin{array}{c}\begin{array}{c}\text { Diâmetro } \\
\text { Nominal } \\
\text { Comercial }\end{array} \\
(\mathrm{mm})\end{array}$} & \multirow{2}{*}{$\begin{array}{c}\begin{array}{c}\text { Diâmetro } \\
\text { Ótimo }\end{array} \\
(\mathrm{mm})\end{array}$} & \multirow{2}{*}{$\begin{array}{c}\text { Velocidade } \\
(\mathrm{m} / \mathrm{s})\end{array}$} & \multirow{2}{*}{$\begin{array}{l}\text { Fator de } \\
\text { Atrito } f\end{array}$} & \multirow{2}{*}{$\begin{array}{c}\text { Perda de Carga } \\
(\mathrm{m})\end{array}$} & \multirow{2}{*}{$\begin{array}{c}\begin{array}{c}\text { Carga } \\
\text { Montante }\end{array} \\
(\mathrm{m})\end{array}$} & \multirow{2}{*}{$\begin{array}{c}\text { Carga Jusante } \\
(\mathrm{m})\end{array}$} & \multirow{2}{*}{$\begin{array}{c}\text { Potência Dissipada } \\
\text { kW }\end{array}$} \\
\hline & Nome & Cota & Nome & Cota & & & & & & & & & & \\
\hline $\mathrm{T} 1$ & $\mathrm{~N} 1$ & 4,56 & N2 & 3,50 & 258,48 & 179,4 & 400 & 401 & 1,42 & 0,0082 & 0,55 & 12,02 & 12,53 & 1,37 \\
\hline T2 & N2 & 3,50 & N3 & 3,50 & 255,93 & 24,7 & 200 & 200 & 0,78 & 0,0082 & 0,33 & 12,53 & 12,20 & 0,11 \\
\hline T3 & $\mathrm{N} 4$ & 1,50 & N5 & 0,49 & 657,53 & 17,6 & 200 & 173 & 0,56 & 0,0082 & 0,43 & 11,98 & 12,56 & 0,10 \\
\hline T4 & N5 & 0,49 & N6 & 0,50 & 253,28 & 19,7 & 200 & 160 & 0,62 & 0,0082 & 0,21 & 12,56 & 12,35 & 0,06 \\
\hline T5 & N6 & 0,50 & N7 & 1,50 & 660,47 & 54,4 & 250 & 250 & 1,11 & 0,0082 & 1,35 & 12,35 & 10,00 & 1,03 \\
\hline T6 & N2 & 3,50 & N7 & 1,50 & 644,10 & 131,1 & 350 & 366 & 1,36 & 0,0082 & 1,42 & 12,53 & 13,11 & 2,61 \\
\hline 77 & N7 & 1,50 & $\mathrm{~N} 4$ & 1,50 & 253,02 & 46,0 & 200 & 201 & 1,46 & 0,0082 & 1,13 & 13,11 & 11,98 & 0,73 \\
\hline T8 & N3 & 3,50 & $\mathrm{~N} 4$ & 1,50 & 657,18 & 4,1 & 80 & 80 & 0,80 & 0,0082 & 2,22 & 12,53 & 12,31 & 0,13 \\
\hline
\end{tabular}

4) Resumo do Dimensionamento Otimizado

\begin{tabular}{|c|c|c|c|}
\hline & Poté & Dissipada & Pressurização Inicial \\
\hline Soma & & 6,14 & 30,18 \\
\hline Energia & & $40.323,90$ & $198.275,22$ \\
\hline FA & & 9,36 & 9,36 \\
\hline Sub-Total & $\mathrm{R} \$$ & $62.718,92$ & $308.392,98$ \\
\hline
\end{tabular}

\begin{tabular}{|c|c|c|}
\hline Custos & & Porcentagem \\
\hline Custo de Tubulação $\mathrm{R} \$$ & $933.599,50$ & $65,18 \%$ \\
\hline Custo de Movimento de Terra $\mathrm{R} \$$ & $65.147,60$ & $4,55 \%$ \\
\hline Custo de Assentamento $\mathrm{R} \$$ & $10.592,56$ & $0,74 \%$ \\
\hline Custo de Pavimentação $R \$$ & $51.833,50$ & $3,62 \%$ \\
\hline Custo da Pressurização Inicial $\mathrm{R} \$$ & $308.392,98$ & $21,53 \%$ \\
\hline Custo da Potência Dissipada $R \$$ & $62.718,92$ & $4,38 \%$ \\
\hline Total Global (Função Objetivo) R\$ & $1.432 .285,07$ & $100,00 \%$ \\
\hline Total Referencial Unitário R\$ & 393,49 & por metro de rede \\
\hline
\end{tabular}


5) Quantitativos e Custos de Implantação das Redes de Abastecimento

\begin{tabular}{|c|c|c|c|c|c|c|c|c|c|}
\hline Trecho & $\begin{array}{l}\text { Locação da } \\
\text { Tubulação }\end{array}$ & $\begin{array}{l}\text { Tipo de } \\
\text { Superfície }\end{array}$ & Tipo de Tráfego & & & & & & \\
\hline $\mathrm{T} 1$ & viario pavimentado & paralelepipedos & - & & & & & & \\
\hline $\mathrm{T} 2$ & viario pavimentado & paralelepipedos & - & & & & & & \\
\hline T3 & vario pavimentado & paralelepipedos & - & & & & & & \\
\hline T4 & vario pavimentado & paralelepipedos & - & & & & & & \\
\hline $\mathrm{T5}$ & viario pavimentado & paralelepipedos & - & & & & & & \\
\hline T6 & viario pavimentado & paralelepipedos & - & & & & & & \\
\hline 77 & viario pavimentado & paralelepipedos & - & & & & & & \\
\hline \multirow[t]{2}{*}{ T8 } & viario pavimentado & paralelepipedos & - & & & & & & \\
\hline & \multicolumn{6}{|c|}{ Vala } & \multicolumn{3}{|c|}{ Tubulação } \\
\hline \multirow[t]{2}{*}{ Trecho } & Largura & $\begin{array}{l}\text { Profundidade } \\
\end{array}$ & Escavação & Reaterro & Bota-Fora & TOTAL & Assentamento & Material & TOTAL \\
\hline & $\mathrm{m}$ & $\mathrm{m}$ & $\mathrm{m}^{3}$ & $\mathrm{~m}^{3}$ & $\mathrm{~m}^{3}$ & $\mathbf{R} \$$ & $\mathrm{R} \$$ & $\mathrm{R} \$$ & $\mathrm{R} \$$ \\
\hline $\mathrm{T} 1$ & 0,75 & 1,40 & 271,40 & 238,92 & 32,48 & $6.481,67$ & $1.330,32$ & $117.523,27$ & $118.853,60$ \\
\hline $\mathrm{T} 2$ & 0,55 & 1,20 & 168,91 & 160,87 & 8,04 & $4.155,87$ & 635,06 & $56.118,96$ & \begin{tabular}{|l|l|}
$56.754,03$ \\
\end{tabular} \\
\hline T3 & 0,55 & 1,20 & 433,97 & 413,31 & 20,66 & $10.677,19$ & $1.631,59$ & $144.179,67$ & $145.811,26$ \\
\hline T4 & 0,55 & 1,20 & 167,16 & 159,21 & 7,96 & $4.112,84$ & 628,49 & $55.537,89$ & $56.166,37$ \\
\hline T5 & 0,60 & 1,25 & 495,35 & 462,93 & 32,42 & $12.098,91$ & $2.016,56$ & $178.936,95$ & $180.953,51$ \\
\hline T6 & 0,70 & 1,35 & 608,67 & 546,70 & 61,97 & $14.645,24$ & $2.824,95$ & $250.311,21$ & $253.136,16$ \\
\hline 77 & 0,55 & 1,20 & 166,99 & 159,04 & 7,95 & $4.108,62$ & 627,84 & $55.480,87$ & $56.108,72$ \\
\hline \multirow[t]{2}{*}{$\mathrm{T} 8$} & 0,50 & 1,08 & 354,88 & 351,57 & 3,30 & $8.867,25$ & 897,74 & $75.510,68$ & $76.408,42$ \\
\hline & & & & & Soma & $65.147,60$ & $\begin{array}{ll}\mathrm{R} \$ & 10.592,56\end{array}$ & $\mathrm{R} \$ 933.599,50 \quad \mathrm{R} \$$ & $944.192,07$ \\
\hline & & & Pavime & ação & & & & & \\
\hline & & & $v_{c}$ & & & & & & \\
\hline \multirow[t]{2}{*}{ Trecho } & Área & $\begin{array}{l}\text { Área de } \\
\text { Concreto }\end{array}$ & $\begin{array}{c}\text { Área de } \\
\text { Paralelepipedos }\end{array}$ & $\begin{array}{l}\text { Área de } \\
\text { Asfalto }\end{array}$ & Área de Binder & $\begin{array}{l}\text { Area de Concreto Asfático } \\
\text { Usinado a Quente }\end{array}$ & & & \\
\hline & $\mathrm{m}^{2}$ & $\mathrm{~m}^{2}$ & $\mathrm{~m}^{2}$ & $\mathrm{~m}^{2}$ & $\mathrm{~m}^{2}$ & $\mathrm{~m}^{2}$ & & & \\
\hline $\mathrm{T} 1$ & 193,86 & 0,00 & 193,86 & 0,00 & 0,00 & 0,00 & & & \\
\hline $\mathrm{T} 2$ & 140,76 & 0,00 & 140,76 & 0,00 & 0,00 & 0,00 & & & \\
\hline T3 & 361,64 & 0,00 & 361,64 & 0,00 & 0,00 & 0,00 & & & \\
\hline T4 & 139,30 & 0,00 & 139,30 & 0,00 & 0,00 & 0,00 & & & \\
\hline T5 & 396,28 & 0,00 & 396,28 & 0,00 & 0,00 & 0,00 & & & \\
\hline T6 & 450,87 & 0,00 & 450,87 & 0,00 & 0,00 & 0,00 & & & \\
\hline 77 & 139,16 & 0,00 & 139,16 & 0,00 & 0,00 & 0,00 & & & \\
\hline T8 & 328,59 & 0,00 & 328,59 & 0,00 & 0,00 & 0,00 & & & \\
\hline
\end{tabular}

\begin{tabular}{|c|c|c|c|c|c|c|c|c|c|}
\hline \multirow{4}{*}{ Trecho } & \multicolumn{9}{|c|}{ Pavimentação } \\
\hline & \multicolumn{3}{|c|}{ Volume } & \multicolumn{2}{|c|}{ Área } & \multicolumn{4}{|c|}{ Custos } \\
\hline & Macadame Hidáulico & Binder & $\begin{array}{l}\text { Concreto } \\
\text { Astáltico Usinado } \\
\text { a Quente }\end{array}$ & $\begin{array}{l}\text { Imprimação } \\
\text { Betuminosa } \\
\text { Ligante }\end{array}$ & $\begin{array}{l}\text { Imprimação } \\
\text { Betuminosa } \\
\text { Impermeabiliza } \\
\text { nte }\end{array}$ & Remoção & Recomposição & Transporte & TOTAL \\
\hline & $\mathrm{m}^{3}$ & $\mathrm{~m}^{3}$ & $\mathrm{~m}^{3}$ & $\mathrm{~m}^{2}$ & $\mathrm{~m}^{2}$ & $\mathrm{R} \$$ & $\mathrm{R} \$$ & $\mathrm{R} \$$ & $\mathrm{R} \$$ \\
\hline $\mathrm{T} 1$ & 0,00 & 0,00 & 0,00 & 0,00 & 0,00 & 993,09 & $3.679,58$ & 0,00 & $4.672,67$ \\
\hline $\mathrm{T} 2$ & 0,00 & 0,00 & 0,00 & 0,00 & 0,00 & 721,08 & $2.671,74$ & 0,00 & $3.392,82$ \\
\hline T3 & 0,00 & 0,00 & 0,00 & 0,00 & 0,00 & $1.852,59$ & $6.864,18$ & 0,00 & $8.716,77$ \\
\hline T4 & 0,00 & 0,00 & 0,00 & 0,00 & 0,00 & 713,62 & $2.644,08$ & 0,00 & $3.357,69$ \\
\hline T5 & 0,00 & 0,00 & 0,00 & 0,00 & 0,00 & $2.030,04$ & $7.521,67$ & 0,00 & $9.551,72$ \\
\hline T6 & 0,00 & 0,00 & 0,00 & 0,00 & 0,00 & $2.309,68$ & $8.557,79$ & 0,00 & $10.867,47$ \\
\hline 77 & 0,00 & 0,00 & 0,00 & 0,00 & 0,00 & 712,88 & $2.641,36$ & 0,00 & $3.354,24$ \\
\hline T8 & 0,00 & 0,00 & 0,00 & 0,00 & 0,00 & $1.683,28$ & $6.236,84$ & 0,00 & $7.920,12$ \\
\hline
\end{tabular}




\section{APÊNDICE D1 - Planilha de Dimensionamento para Vida Útil de 10 anos e Viário em Paralelepípedo - PVC}

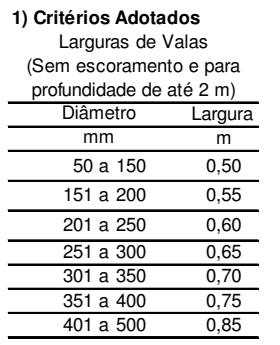

Locação das Redes

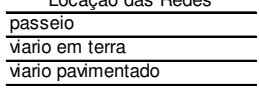

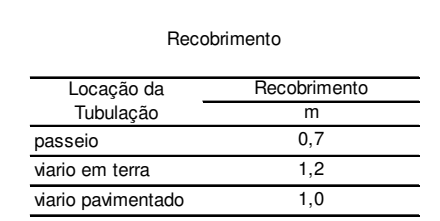

viario pavimentado

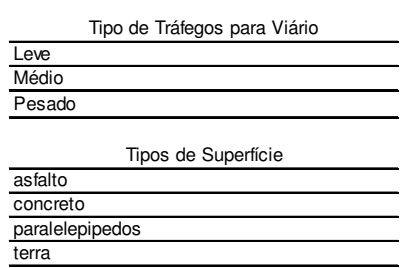

paralelepipedos

terra

\section{2) Dados Adotados}

Tubulação

Material

PVC

Classe de Pressão $\quad \mathrm{Cl} 20 \quad 1 \mathrm{MPa}$

\begin{tabular}{ll}
\hline Rugosidade Equivalente $(\mathrm{m}) \quad 0,00002$ \\
\hline
\end{tabular}

Pressurização Inicial

\begin{tabular}{lr}
\hline Carga Inicial & 12,78 \\
\hline Rendimento Global & 0,70
\end{tabular}

\begin{tabular}{ll}
\hline Horas de Funcionamer & $6570 \mathrm{~h} / \mathrm{ano}$ \\
\hline
\end{tabular}

Vida Útil

\begin{tabular}{ll}
\hline Fator entre Diâmetro Hidráulico e Comercial & 1,05 \\
\hline
\end{tabular}

Largura Adotadas para Reposição de Pavimentos Devido Abertura de Valas (m)

\begin{tabular}{ll}
\hline Concreto Asfáltico Usinado a Quente & 3 \\
\hline Imprimacão Betuminosa Ligante & 3
\end{tabular}

\begin{tabular}{lc}
\hline Imprimação Betuminosa Ligante & 3 \\
\hline Binder & Larguravala $+0,2$
\end{tabular}

\begin{tabular}{ll}
\hline Binder & Larguravala $+0,2$ \\
\hline Imprimação Betuminosa Impermeabilizante & Largura $_{\text {Vala }}+0,2$ \\
\hline
\end{tabular}

\begin{tabular}{ll}
\hline Macadame Hidáulico & Larguravala \\
\hline
\end{tabular}

Espessuras Adotadas para Reposição de Pavimentos Devido Abertura de Valas (m) Tráfego Leve Médio $\quad$ Pesado

\begin{tabular}{lll}
\hline Binder & 0,04 & 0,07 \\
\hline Concreto Asfáltico Usinado a Quente & 0,04 & 0,05
\end{tabular}

\begin{tabular}{lll}
\hline Macadame Hidáulico & 0,10 & 0,12
\end{tabular}

0,12

3) Dimensionamento e Otimização da Rede pelo Método Matricial (Não Linear)

\begin{tabular}{|c|c|c|c|c|c|c|c|c|c|c|}
\hline \multicolumn{11}{|c|}{ Equacões de Continuidade nos Nós } \\
\hline NólTubo & 1 & 2 & 3 & 4 & 5 & 6 & 7 & 8 & Qi & Soma Q \\
\hline & $-179,4$ & & & & & & & & 179,408 & 0 \\
\hline & 179,4 & $-61,0$ & & & & $-94,8$ & & & 23,591 & 0,01 \\
\hline & & 61,0 & & & & & & $-40,4$ & 20,637 & 0,01 \\
\hline & & & $-31,9$ & & & & 24,1 & 40,4 & 32,556 & 0,01 \\
\hline & & & 31,9 & 5,3 & & & & & 37,247 & 0,01 \\
\hline & & & & $-5,3$ & 40,1 & & & & 34,754 & 0,01 \\
\hline & & & & & $-40,1$ & 94,8 & $-24,1$ & & 30,623 & 0,01 \\
\hline
\end{tabular}

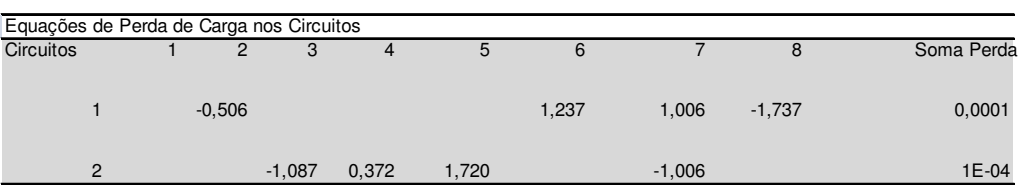

Tabela da Função Objetivo

\begin{tabular}{|c|c|c|c|c|c|c|c|c|c|c|c|c|c|c|}
\hline \multirow{2}{*}{ Trecho } & \multicolumn{2}{|c|}{ Nó Montante } & \multicolumn{2}{|c|}{ No Jusante } & \multirow{2}{*}{$\begin{array}{r}\begin{array}{l}\text { Extensão } \\
\text { do Trecho }\end{array} \\
\text { (m) }\end{array}$} & \multirow{2}{*}{$\begin{array}{c}\begin{array}{c}\text { Vazão do } \\
\text { Trecho }\end{array} \\
\text { 1/s }\end{array}$} & \multirow{2}{*}{$\begin{array}{c}\text { Diâmetro } \\
\text { Nominal } \\
\text { Comercial }\end{array}$} & \multirow{2}{*}{$\begin{array}{c}\begin{array}{c}\text { Diâmetro } \\
\text { Ótimo }\end{array} \\
(\mathrm{mm})\end{array}$} & \multirow{2}{*}{$\begin{array}{c}\text { Velocidade } \\
(\mathrm{m} / \mathrm{s})\end{array}$} & \multirow{2}{*}{$\begin{array}{l}\text { Fator de } \\
\text { Atrito } f\end{array}$} & \multirow{2}{*}{$\begin{array}{c}\begin{array}{c}\text { Perda de } \\
\text { Carga }\end{array} \\
(\mathrm{m})\end{array}$} & \multirow{2}{*}{$\begin{array}{c}\begin{array}{c}\text { Carga } \\
\text { Montante }\end{array} \\
(\mathrm{m})\end{array}$} & \multirow{2}{*}{$\begin{array}{c}\text { Carga Jusante } \\
(\mathrm{m})\end{array}$} & \multirow{2}{*}{$\begin{array}{c}\text { Potência Dissipada } \\
\mathrm{kW}\end{array}$} \\
\hline & Nome & Cota & Nome & Cota & & & & & & & & & & \\
\hline $\mathrm{T} 1$ & $\mathrm{~N} 1$ & 4,56 & N2 & 3,50 & 258,48 & 179,4 & 400 & 400 & 1,42 & 0,0063 & 0,42 & 12,78 & (iii) & $\begin{array}{l}\mathrm{nvv} \\
1,06\end{array}$ \\
\hline T3 & $\mathrm{N} 4$ & 1,50 & N5 & 0,49 & 657,53 & 31,9 & 200 & 200 & 1,01 & 0,0063 & 1,09 & 13,18 & 13,10 & 0,49 \\
\hline T4 & N5 & 0,49 & N6 & 0,50 & 253,28 & 5,3 & 100 & 100 & 0,68 & 0,0063 & 0,37 & 13,10 & 12,72 & 0,03 \\
\hline T5 & N6 & 0,50 & N7 & 1,50 & 660,47 & 40,1 & 200 & 200 & 1,27 & 0,0063 & 1,72 & 12,72 & 10,00 & 0,96 \\
\hline T6 & N2 & 3,50 & N7 & 1,50 & 644,10 & 94,8 & 300 & 300 & 1,34 & 0,0063 & 1,24 & 13,42 & 14,19 & 1,64 \\
\hline
\end{tabular}

4) Resumo do Dimensionamento Otimizado

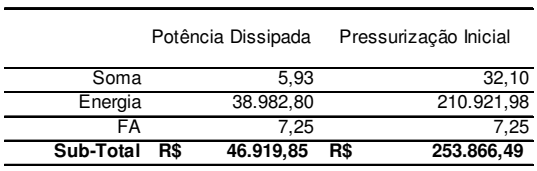

\begin{tabular}{|c|c|c|}
\hline Custos & & Porcentagem \\
\hline Custo de Tubulação $\mathrm{R} \$$ & $350.230,29$ & $45,16 \%$ \\
\hline Custo de Movimento de Terra $\mathrm{R} \$$ & $63.515,87$ & $8,19 \%$ \\
\hline Custo de Assentamento $\mathrm{R} \$$ & $10.274,21$ & $1,32 \%$ \\
\hline Custo de Pavimentação $R \$$ & $50.751,55$ & $6,54 \%$ \\
\hline Custo da Pressurização Inicial $\mathrm{R} \$$ & $253.866,49$ & $32,73 \%$ \\
\hline Custo da Potência Dissipada $\mathrm{R} \$$ & $46.919,85$ & $6,05 \%$ \\
\hline Total Global (Função Objetivo) R\$ & $775.558,26$ & $100,00 \%$ \\
\hline Total Referencial Unitário $\mathbf{R} \$$ & 213,07 & por metro de rede \\
\hline
\end{tabular}


5) Quantitativos e Custos de Implantação das Redes de Abastecimento

\begin{tabular}{|c|c|c|c|c|c|c|c|c|c|}
\hline Trecho & $\begin{array}{l}\text { Locação da } \\
\text { Tubulação }\end{array}$ & $\begin{array}{l}\text { Tipo de } \\
\text { Superfície }\end{array}$ & Tipo de Tráfego & & & & & & \\
\hline $\mathrm{T} 1$ & vario pavimentado & paralelepipedos & - & & & & & & \\
\hline $\mathrm{T} 2$ & viario pavimentado & paralelepipedos & - & & & & & & \\
\hline T3 & viario pavimentado & paralelepipedos & - & & & & & & \\
\hline $\mathrm{T} 4$ & viario pavimentado & paralelepipedos & - & & & & & & \\
\hline T5 & viario pavimentado & paralelepipedos & - & & & & & & \\
\hline T6 & viario pavimentado & paralelepipedos & - & & & & & & \\
\hline 77 & viario pavimentado & paralelepipedos & - & & & & & & \\
\hline T8 & viario pavimentado & paralelepipedos & - & & & & & & \\
\hline \multirow{3}{*}{ Trecho } & \multicolumn{6}{|c|}{ Vala } & \multicolumn{3}{|c|}{ Tubulação } \\
\hline & Largura & Profundidade & Escavação & Reaterro & Bota-Fora & TOTAL & Assentamento & Material & TOTAL \\
\hline & $\mathrm{m}$ & $\mathrm{m}$ & $\mathrm{m}^{3}$ & $\mathrm{~m}^{3}$ & $\mathrm{~m}^{3}$ & $\mathrm{R} \$$ & $\mathrm{R} \$$ & $\mathrm{R} \$$ & $\mathrm{R} \$$ \\
\hline $\mathrm{T} 1$ & 0,75 & 1,40 & 271,40 & 238,92 & 32,48 & $6.481,67$ & $1.330,32$ & $60.843,11$ & $62.173,43$ \\
\hline T2 & 0,60 & 1,25 & 191,95 & 179,38 & 12,56 & $4.688,29$ & 781,41 & $27.846,08$ & $28.627,49$ \\
\hline T3 & 0,55 & 1,20 & 433,97 & 413,31 & 20,66 & $10.677,19$ & $1.631,59$ & $49.595,62$ & $51.227,21$ \\
\hline T4 & 0,50 & 1,10 & 139,30 & 137,31 & 1,99 & $3.473,83$ & 386,69 & $6.121,70$ & $6.508,39$ \\
\hline T5 & 0,55 & 1,20 & 435,91 & 415,16 & 20,75 & $10.724,93$ & $1.638,89$ & $49.817,37$ & $51.456,26$ \\
\hline T6 & 0,65 & 1,30 & 544,26 & 498,74 & 45,53 & $13.194,41$ & $2.375,48$ & $94.537,19$ & $96.912,66$ \\
\hline$\pi 7$ & 0,50 & 1,15 & 145,49 & 141,02 & 4,47 & $3.604,04$ & 499,10 & $11.900,01$ & $12.399,11$ \\
\hline \multirow[t]{2}{*}{ T8 } & 0,55 & 1,20 & 433,74 & 413,09 & 20,65 & $10.671,50$ & $1.630,72$ & $49.569,22$ & $51.199,94$ \\
\hline & & & & & Soma & $63.515,87$ & $\begin{array}{ll}\mathrm{R} \$ & 10.274,21\end{array}$ & $\begin{array}{lll}R \$ 350.230,29 & R \$\end{array}$ & $360.504,50$ \\
\hline \multirow{2}{*}{\multicolumn{10}{|c|}{$\begin{array}{l}\text { Pavimentação } \\
\text { Vala }\end{array}$}} \\
\hline & & & $\mathrm{Va}$ & $a$ & & & & & \\
\hline \multirow[t]{2}{*}{ Trecho } & Área & $\begin{array}{l}\text { Área de } \\
\text { Concreto }\end{array}$ & $\begin{array}{c}\text { Área de } \\
\text { Paralelepipedos }\end{array}$ & $\begin{array}{l}\text { Área de } \\
\text { Asfalto }\end{array}$ & Área de Binder & $\begin{array}{l}\text { Area de Concreto Asfático } \\
\text { Usinado a Quente }\end{array}$ & & & \\
\hline & $\mathrm{m}^{2}$ & $\mathrm{~m}^{2}$ & $\mathrm{~m}^{2}$ & $\mathrm{~m}^{2}$ & $\mathrm{~m}^{2}$ & $\mathrm{~m}^{2}$ & & & \\
\hline $\mathrm{T} 1$ & 193,86 & 0,00 & 193,86 & 0,00 & 0,00 & 0,00 & & & \\
\hline $\mathrm{T} 2$ & 153,56 & 0,00 & 153,56 & 0,00 & 0,00 & 0,00 & & & \\
\hline T3 & 361,64 & 0,00 & 361,64 & 0,00 & 0,00 & 0,00 & & & \\
\hline T4 & 126,64 & 0,00 & 126,64 & 0,00 & 0,00 & 0,00 & & & \\
\hline T5 & 363,26 & 0,00 & 363,26 & 0,00 & 0,00 & 0,00 & & & \\
\hline T6 & 418,67 & 0,00 & 418,67 & 0,00 & 0,00 & 0,00 & & & \\
\hline 77 & 126,51 & 0,00 & 126,51 & 0,00 & 0,00 & 0,00 & & & \\
\hline T8 & 361,45 & 0,00 & 361,45 & 0,00 & 0,00 & 0,00 & & & \\
\hline \multirow{4}{*}{ Trecho } & \multicolumn{9}{|c|}{ Pavimentação } \\
\hline & \multicolumn{3}{|c|}{ Volume } & \multicolumn{2}{|c|}{ Area } & \multicolumn{4}{|c|}{ Custos } \\
\hline & Macadame Hidáulico & Binder & $\begin{array}{l}\text { Concreto } \\
\text { Asfáltico Usinado } \\
\text { a Quente }\end{array}$ & $\begin{array}{l}\text { Imprimação } \\
\text { Betuminosa } \\
\text { Ligante }\end{array}$ & $\begin{array}{c}\text { Imprimação } \\
\text { Betuminosa } \\
\text { Impermeabiliza } \\
\text { nte }\end{array}$ & Remoção & Recomposição & Transporte & TOTAL \\
\hline & $\mathrm{m}^{3}$ & $\mathrm{~m}^{3}$ & $\mathrm{~m}^{3}$ & $\mathrm{~m}^{2}$ & $\mathrm{~m}^{2}$ & $\mathrm{R} \$$ & $\mathrm{R} \$$ & $\mathrm{R} \$$ & $\mathbf{R} \$$ \\
\hline $\mathrm{T} 1$ & 0,00 & 0,00 & 0,00 & 0,00 & 0,00 & 993,09 & $3.679,58$ & 0,00 & $4.672,67$ \\
\hline $\mathrm{T} 2$ & 0,00 & 0,00 & 0,00 & 0,00 & 0,00 & 786,64 & $2.914,62$ & 0,00 & $3.701,26$ \\
\hline T3 & 0,00 & 0,00 & 0,00 & 0,00 & 0,00 & $1.852,59$ & $6.864,18$ & 0,00 & $8.716,77$ \\
\hline $\mathrm{T} 4$ & 0,00 & 0,00 & 0,00 & 0,00 & 0,00 & 648,74 & $2.403,70$ & 0,00 & $3.052,45$ \\
\hline T5 & 0,00 & 0,00 & 0,00 & 0,00 & 0,00 & $1.860,87$ & $6.894,87$ & 0,00 & $8.755,74$ \\
\hline T6 & 0,00 & 0,00 & 0,00 & 0,00 & 0,00 & $2.144,71$ & $7.946,52$ & 0,00 & $10.091,22$ \\
\hline 77 & 0,00 & 0,00 & 0,00 & 0,00 & 0,00 & 648,08 & $2.401,24$ & 0,00 & $3.049,31$ \\
\hline T8 & 0,00 & 0,00 & 0,00 & 0,00 & 0,00 & $1.851,60$ & $6.860,52$ & 0,00 & $8.712,13$ \\
\hline & & & & & Soma & & $\$ 39.965,23$ & $\mathrm{RS}$ & 50.7 \\
\hline
\end{tabular}




\section{APÊNDICE D2 - Planilha de Dimensionamento para Vida Útil de 20 anos e Viário em Paralelepípedo - PVC}

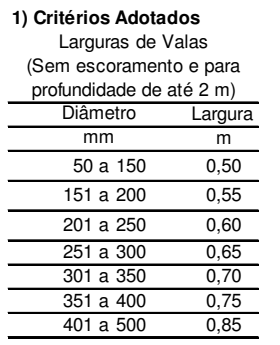

Locação das Redes

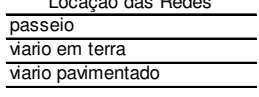

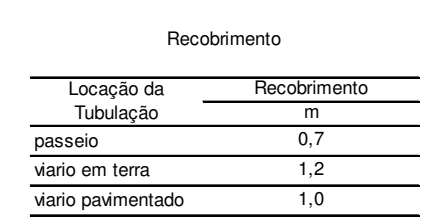

viario pavimentado 1,0

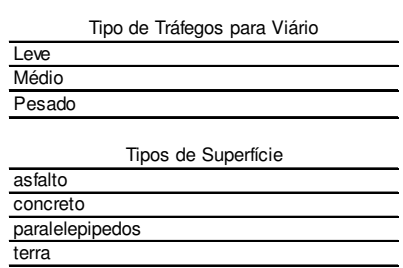

paralelepipedos

2) Dados Adotados

Tubulação

Material

SDR

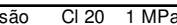

\begin{tabular}{ll} 
Rugosidade Equivalente $(\mathrm{m})$ & 0,00002 \\
\hline
\end{tabular}

Pressurização Inicial

\begin{tabular}{lr}
\hline Carga Inicial & 12,78 \\
\hline Rendimento Global & 0,70
\end{tabular}

Vida Útil

Fator entre Diâmetro Hidráulico e Comercial 1,05

Largura Adotadas para Reposição de Pavimentos Devido Abertura de Valas (m)

\begin{tabular}{|c|c|c|c|}
\hline \multicolumn{3}{|c|}{ Abertura de Valas $(\mathrm{m})$} & \\
\hline Concreto Asfáltico Usinado a Quente & & 3 & \\
\hline Imprimação Betuminosa Ligante & & 3 & \\
\hline Binder & & Larguravala $+0,2$ & \\
\hline Imprimação Betuminosa Impermeabiliz & & Largura $_{\text {Vala }}+0,2$ & \\
\hline Macadame Hidáulico & & Largura $_{\text {Vala }}$ & \\
\hline \multicolumn{4}{|c|}{ Espessuras Adotadas para Reposição de Pavimentos Devido Abertura de Valas (m) } \\
\hline Tráfego & Leve & Médio & Pesado \\
\hline Binder & 0,04 & 0,07 & 0,10 \\
\hline Concreto Asfáltico Usinado a Quente & 0,04 & 0,05 & 0,05 \\
\hline Macadame Hidáulico & 0,10 & 0,12 & 0,15 \\
\hline
\end{tabular}

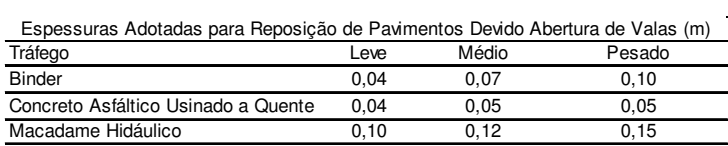

Energia

Grupo A (Alta e Média Tensão)

Sub-Grupo A4 (2,3 KV a $25 \mathrm{KV})$

Custo de Energia por Del $31,31 \mathrm{R} \$ / \mathrm{KW}$

Custo de Energia por Col $0,16132 \mathrm{R} \$ / \mathrm{KWh}$

Taxa de Juros $\quad 8,00 \%$ a

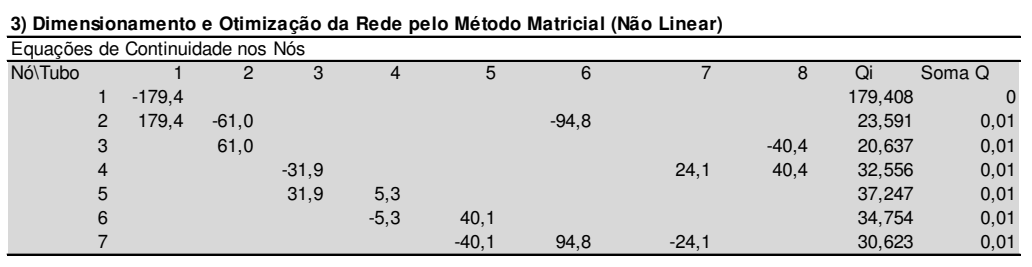

\begin{tabular}{|c|c|c|c|c|c|c|c|c|c|}
\hline \multicolumn{10}{|c|}{ Equações de Perda de Carga nos Circuitos } \\
\hline Circuitos & 1 & $\frac{2}{2}$ & 3 & 4 & 5 & 6 & 7 & 8 & Soma Perda \\
\hline 1 & & $-0,506$ & & & & 1,237 & 1,006 & $-1,737$ & 0,0001 \\
\hline 2 & & & $-1,087$ & 0,372 & 1,720 & & $-1,006$ & & $1 \mathrm{E}-04$ \\
\hline
\end{tabular}

Tabela da Função Objetivo

\begin{tabular}{|c|c|c|c|c|c|c|c|c|c|c|c|c|c|c|}
\hline \multirow{2}{*}{ Trecho } & \multicolumn{2}{|c|}{ Nó Montante } & \multicolumn{2}{|c|}{ No Jusante } & \multirow{2}{*}{$\begin{array}{r}\begin{array}{r}\text { Extensão } \\
\text { do Trecho }\end{array} \\
(\mathrm{m})\end{array}$} & \multirow{2}{*}{$\begin{array}{c}\begin{array}{c}\text { Vazão do } \\
\text { Trecho }\end{array} \\
\text { l/s }\end{array}$} & \multirow{2}{*}{$\begin{array}{c}\begin{array}{c}\text { Diâmetro } \\
\text { Nominal } \\
\text { Comercial }\end{array} \\
(\mathrm{mm})\end{array}$} & \multirow{2}{*}{$\begin{array}{c}\begin{array}{c}\text { Diâmetro } \\
\text { Ótimo }\end{array} \\
(\mathrm{mm})\end{array}$} & \multirow{2}{*}{$\begin{array}{c}\text { Velocidade } \\
(\mathrm{m} / \mathrm{s})\end{array}$} & \multirow[t]{2}{*}{$\begin{array}{l}\text { Fator de } \\
\text { Atrito } f\end{array}$} & \multirow{2}{*}{$\begin{array}{c}\begin{array}{c}\text { Perda de } \\
\text { Carga }\end{array} \\
(\mathrm{m})\end{array}$} & \multirow{2}{*}{$\begin{array}{c}\begin{array}{c}\text { Carga } \\
\text { Montante }\end{array} \\
(\mathrm{m})\end{array}$} & \multirow{2}{*}{$\begin{array}{c}\text { Carga Jusante } \\
(\mathrm{m})\end{array}$} & \multirow{2}{*}{$\begin{array}{c}\text { Potência Dissipada } \\
\text { kW }\end{array}$} \\
\hline & Nome & Cota & Nome & Cota & & & & & & & & & & \\
\hline T1 & N1 & 4,56 & N2 & 3,50 & 258,48 & 179,4 & 400 & 400 & 1,42 & 0,0063 & 0,42 & 12,78 & 13,42 & 1,06 \\
\hline T3 & $\mathrm{N} 4$ & 1,50 & N5 & 0,49 & 657,53 & 31,9 & 200 & 200 & 1,01 & 0,0063 & 1,09 & 13,18 & 13,10 & 0,49 \\
\hline T4 & N5 & 0,49 & N6 & 0,50 & 253,28 & 5,3 & 100 & 100 & 0,68 & 0,0063 & 0,37 & 13,10 & 12,72 & 0,03 \\
\hline T5 & N6 & 0,50 & N7 & 1,50 & 660,47 & 40,1 & 200 & 200 & 1,27 & 0,0063 & 1,72 & 12,72 & 10,00 & 0,96 \\
\hline T6 & N2 & 3,50 & N7 & 1,50 & 644,10 & 94,8 & 300 & 300 & 1,34 & 0,0063 & 1,24 & 13,42 & 14,19 & 1,64 \\
\hline
\end{tabular}

4) Resumo do Dimensionamento Otimizado

\begin{tabular}{|c|c|c|c|}
\hline & \multicolumn{2}{|c|}{ Potência Dissipada } & Pressurização Inicial \\
\hline Soma & & 5,93 & 32,10 \\
\hline Energia & & $38.982,80$ & $210.921,98$ \\
\hline FA & & 10,60 & 10,60 \\
\hline Sub-Total & $\mathbf{R} \$$ & $68.652,82$ & $371.455,80$ \\
\hline
\end{tabular}

\begin{tabular}{|c|c|c|}
\hline Custos & & Porcentagem \\
\hline Custo de Tubulação $\mathrm{R} \$$ & $350.230,29$ & $38,28 \%$ \\
\hline Custo de Movimento de Terra $\mathrm{R} \$$ & $63.515,87$ & $6,94 \%$ \\
\hline Custo de Assentamento $\mathrm{R} \$$ & $10.274,21$ & $1,12 \%$ \\
\hline Custo de Pavimentação $R \$$ & $50.751,55$ & $5,55 \%$ \\
\hline Custo da Pressurização Inicial $\mathrm{R} \$$ & $371.455,80$ & $40,60 \%$ \\
\hline Custo da Potência Dissipada $\mathrm{R} \$$ & $68.652,82$ & $7,50 \%$ \\
\hline Total Global (Função Objetivo) R\$ & $914.880,53$ & $100,00 \%$ \\
\hline Total Referencial Unitário $\mathbf{R} \$$ & 251,34 & por metro de rede \\
\hline
\end{tabular}


5) Quantitativos e Custos de Implantação das Redes de Abastecimento

\begin{tabular}{|c|c|c|c|c|c|c|c|c|c|}
\hline Trecho & $\begin{array}{l}\text { Locação da } \\
\text { Tubulação }\end{array}$ & $\begin{array}{l}\text { Tipo de } \\
\text { Superfície }\end{array}$ & Tipo de Tráfego & & & & & & \\
\hline $\mathrm{T} 1$ & viario pavimentado & paralelepipedos & - & & & & & & \\
\hline $\mathrm{T} 2$ & viario pavimentado & paralelepipedos & - & & & & & & \\
\hline T3 & vario pavimentado & paralelepipedos & - & & & & & & \\
\hline T4 & vario pavimentado & paralelepipedos & - & & & & & & \\
\hline $\mathrm{T5}$ & viario pavimentado & paralelepipedos & - & & & & & & \\
\hline T6 & viario pavimentado & paralelepipedos & - & & & & & & \\
\hline 77 & viario pavimentado & paralelepipedos & - & & & & & & \\
\hline \multirow[t]{2}{*}{ T8 } & viario pavimentado & paralelepipedos & - & & & & & & \\
\hline & \multicolumn{6}{|c|}{ Vala } & \multicolumn{3}{|c|}{ Tubulação } \\
\hline \multirow[t]{2}{*}{ Trecho } & Largura & $\begin{array}{l}\text { Profundidade } \\
\end{array}$ & Escavação & Reaterro & Bota-Fora & TOTAL & Assentamento & Material & TOTAL \\
\hline & $\mathrm{m}$ & $\mathrm{m}$ & $\mathrm{m}^{3}$ & $\mathrm{~m}^{3}$ & $\mathrm{~m}^{3}$ & $\mathbf{R} \$$ & $\mathrm{R} \$$ & $\mathrm{R} \$$ & $\mathrm{R} \$$ \\
\hline $\mathrm{T} 1$ & 0,75 & 1,40 & 271,40 & 238,92 & 32,48 & $6.481,67$ & $1.330,32$ & $60.843,11$ & $\begin{array}{l}62.173,43 \\
\end{array}$ \\
\hline $\mathrm{T} 2$ & 0,60 & 1,25 & 191,95 & 179,38 & 12,56 & $4.688,29$ & 781,41 & $27.846,08$ & $28.627,49$ \\
\hline T3 & 0,55 & 1,20 & 433,97 & 413,31 & 20,66 & $10.677,19$ & $1.631,59$ & $49.595,62$ & $51.227,21$ \\
\hline T4 & 0,50 & 1,10 & 139,30 & 137,31 & 1,99 & $3.473,83$ & 386,69 & $6.121,70$ & $6.508,39$ \\
\hline T5 & 0,55 & 1,20 & 435,91 & 415,16 & 20,75 & $10.724,93$ & $1.638,89$ & $49.817,37$ & $51.456,26$ \\
\hline T6 & 0,65 & 1,30 & 544,26 & 498,74 & 45,53 & $13.194,41$ & $2.375,48$ & $94.537,19$ & $96.912,66$ \\
\hline 77 & 0,50 & 1,15 & 145,49 & 141,02 & 4,47 & $3.604,04$ & 499,10 & $11.900,01$ & $12.399,11$ \\
\hline \multirow[t]{2}{*}{$\mathrm{T} 8$} & 0,55 & 1,20 & 433,74 & 413,09 & 20,65 & $10.671,50$ & $1.630,72$ & $49.569,22$ & $51.199,94$ \\
\hline & & & & & Soma & $63.515,87$ & $\begin{array}{ll}\mathrm{R} \$ 10.274,21 \\
\end{array}$ & $\mathrm{R} \$ 350.230,29 \quad \mathrm{R} \$$ & $360.504,50$ \\
\hline \multirow{2}{*}{\multicolumn{10}{|c|}{$\frac{\text { Pavimentação }}{\text { Vala }}$}} \\
\hline & & & & & & & & & \\
\hline \multirow[t]{2}{*}{ Trecho } & Área & $\begin{array}{l}\text { Área de } \\
\text { Concreto }\end{array}$ & $\begin{array}{c}\text { Área de } \\
\text { Paralelepipedos }\end{array}$ & $\begin{array}{l}\text { Área de } \\
\text { Asfalto }\end{array}$ & Área de Binder & $\begin{array}{l}\text { Area de Concreto Astático } \\
\text { Usinado a Quente }\end{array}$ & & & \\
\hline & $\mathrm{m}^{2}$ & $\mathrm{~m}^{2}$ & $\mathrm{~m}^{2}$ & $\mathrm{~m}^{2}$ & $\mathrm{~m}^{2}$ & $\mathrm{~m}^{2}$ & & & \\
\hline $\mathrm{T} 1$ & 193,86 & 0,00 & 193,86 & 0,00 & 0,00 & 0,00 & & & \\
\hline $\mathrm{T} 2$ & 153,56 & 0,00 & 153,56 & 0,00 & 0,00 & 0,00 & & & \\
\hline T3 & 361,64 & 0,00 & 361,64 & 0,00 & 0,00 & 0,00 & & & \\
\hline T4 & 126,64 & 0,00 & 126,64 & 0,00 & 0,00 & 0,00 & & & \\
\hline T5 & 363,26 & 0,00 & 363,26 & 0,00 & 0,00 & 0,00 & & & \\
\hline T6 & 418,67 & 0,00 & 418,67 & 0,00 & 0,00 & 0,00 & & & \\
\hline 77 & 126,51 & 0,00 & 126,51 & 0,00 & 0,00 & 0,00 & & & \\
\hline T8 & 361,45 & 0,00 & 361,45 & 0,00 & 0,00 & 0,00 & & & \\
\hline
\end{tabular}

\begin{tabular}{|c|c|c|c|c|c|c|c|c|c|}
\hline \multirow{4}{*}{ Trecho } & \multicolumn{9}{|c|}{ Pavimentação } \\
\hline & \multicolumn{3}{|c|}{ Volume } & \multicolumn{2}{|c|}{ Área } & \multicolumn{4}{|c|}{ Custos } \\
\hline & Macadame Hidáulico & Binder & $\begin{array}{l}\text { Concreto } \\
\text { Astáltico Usinado } \\
\text { a Quente }\end{array}$ & $\begin{array}{l}\text { Imprimação } \\
\text { Betuminosa } \\
\text { Ligante }\end{array}$ & $\begin{array}{l}\text { Imprimação } \\
\text { Betuminosa } \\
\text { Impermeabiliza } \\
\text { nte }\end{array}$ & Remoção & Recomposição & Transporte & TOTAL \\
\hline & $\mathrm{m}^{3}$ & $\mathrm{~m}^{3}$ & $\mathrm{~m}^{3}$ & $\mathrm{~m}^{2}$ & $\mathrm{~m}^{2}$ & $\mathrm{R} \$$ & $\mathrm{R} \$$ & $\mathrm{R} \$$ & $\mathrm{R} \$$ \\
\hline $\mathrm{T} 1$ & 0,00 & 0,00 & 0,00 & 0,00 & 0,00 & 993,09 & $3.679,58$ & 0,00 & $4.672,67$ \\
\hline $\mathrm{T} 2$ & 0,00 & 0,00 & 0,00 & 0,00 & 0,00 & 786,64 & $2.914,62$ & 0,00 & $3.701,26$ \\
\hline T3 & 0,00 & 0,00 & 0,00 & 0,00 & 0,00 & $1.852,59$ & $6.864,18$ & 0,00 & $8.716,77$ \\
\hline T4 & 0,00 & 0,00 & 0,00 & 0,00 & 0,00 & 648,74 & $2.403,70$ & 0,00 & $3.052,45$ \\
\hline T5 & 0,00 & 0,00 & 0,00 & 0,00 & 0,00 & $1.860,87$ & $6.894,87$ & 0,00 & $8.755,74$ \\
\hline T6 & 0,00 & 0,00 & 0,00 & 0,00 & 0,00 & $2.144,71$ & $7.946,52$ & 0,00 & $10.091,22$ \\
\hline 77 & 0,00 & 0,00 & 0,00 & 0,00 & 0,00 & 648,08 & $2.401,24$ & 0,00 & $3.049,31$ \\
\hline T8 & 0,00 & 0,00 & 0,00 & 0,00 & 0,00 & $1.851,60$ & $6.860,52$ & 0,00 & $8.712,13$ \\
\hline
\end{tabular}




\section{APÊNDICE D3 - Planilha de Dimensionamento para Vida Útil de 30 anos e Viário em Paralelepípedo - PVC}

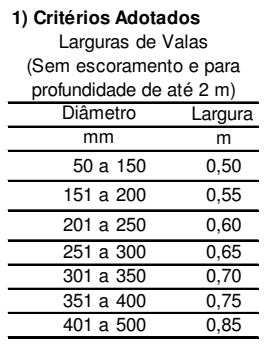

Locação das Redes

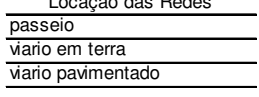

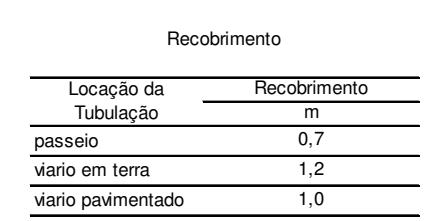

viario pavimentado 1,0

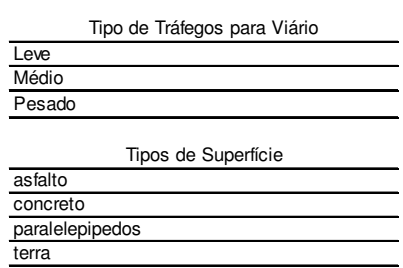

paralelepipedos

2) Dados Adotados

Tubulação

Material

SDR

$\begin{array}{ll} & \\ \mathrm{Cl} & 1 \mathrm{MPa}\end{array}$

\begin{tabular}{ll} 
Rugosidade Equivalente $(\mathrm{m})$ & 0,00002 \\
\hline
\end{tabular}

Pressurização Inicial

Carga Inicial

Vida Útil

\begin{tabular}{ll}
\hline Fator entre Diâmetro Hidráulico e Comercial & 1,05 \\
\hline
\end{tabular}

Largura Adotadas para Reposição de Pavimentos Devido Abertura de Valas (m)

\begin{tabular}{|c|c|c|c|}
\hline \multicolumn{3}{|c|}{ Abertura de Valas $(\mathrm{m})$} & \\
\hline Concreto Asfáltico Usinado a Quente & & 3 & \\
\hline Imprimação Betuminosa Ligante & & 3 & \\
\hline Binder & & Larguravala $+0,2$ & \\
\hline Imprimação Betuminosa Impermeabiliz & & Largura $_{\text {Vala }}+0,2$ & \\
\hline Macadame Hidáulico & & Largura $_{\text {Vala }}$ & \\
\hline \multicolumn{4}{|c|}{ Espessuras Adotadas para Reposição de Pavimentos Devido Abertura de Valas (m) } \\
\hline Tráfego & Leve & Médio & Pesado \\
\hline Binder & 0,04 & 0,07 & 0,10 \\
\hline Concreto Asfáltico Usinado a Quente & 0,04 & 0,05 & 0,05 \\
\hline Macadame Hidáulico & 0,10 & 0,12 & 0,15 \\
\hline
\end{tabular}

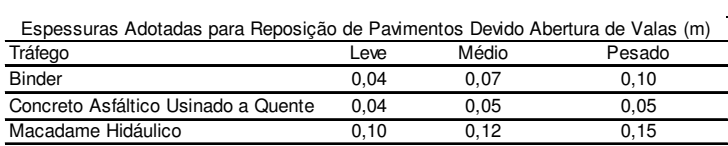

Energia

Grupo A (Alta e Média Tensão)

Sub-Grupo A4 (2,3 KV a $25 \mathrm{KV})$

Custo de Energia por Del $31,31 \mathrm{R} \$ / \mathrm{KW}$

Custo de Energia por Col $0,16132 \mathrm{R} \$ / \mathrm{KWh}$

Taxa de Juros

Fator de Atualização

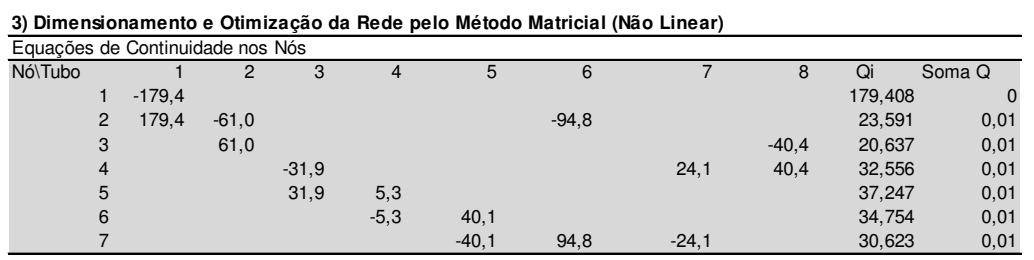

\begin{tabular}{|c|c|c|c|c|c|c|c|c|c|}
\hline \multicolumn{10}{|c|}{ Equações de Perda de Carga nos Circuitos } \\
\hline Circuitos & 1 & $\frac{2}{2}$ & 3 & 4 & 5 & 6 & 7 & 8 & Soma Perda \\
\hline 1 & & $-0,506$ & & & & 1,237 & 1,006 & $-1,737$ & 0,0001 \\
\hline 2 & & & $-1,087$ & 0,372 & 1,720 & & $-1,006$ & & $1 \mathrm{E}-04$ \\
\hline
\end{tabular}

Tabela da Função Objetivo

\begin{tabular}{|c|c|c|c|c|c|c|c|c|c|c|c|c|c|c|}
\hline \multirow{2}{*}{ Trecho } & \multicolumn{2}{|c|}{ Nó Montante } & \multicolumn{2}{|c|}{ No Jusante } & \multirow{2}{*}{$\begin{array}{r}\begin{array}{r}\text { Extensão } \\
\text { do Trecho }\end{array} \\
(\mathrm{m})\end{array}$} & \multirow{2}{*}{$\begin{array}{c}\begin{array}{c}\text { Vazão do } \\
\text { Trecho }\end{array} \\
1 / \mathrm{s}\end{array}$} & \multirow{2}{*}{$\begin{array}{c}\begin{array}{c}\text { Diâmetro } \\
\text { Nominal } \\
\text { Comercial }\end{array} \\
(\mathrm{mm})\end{array}$} & \multirow{2}{*}{$\begin{array}{c}\begin{array}{c}\text { Diâmetro } \\
\text { Ótimo }\end{array} \\
(\mathrm{mm})\end{array}$} & \multirow{2}{*}{$\begin{array}{c}\text { Velocidade } \\
(\mathrm{m} / \mathrm{s})\end{array}$} & \multirow{2}{*}{$\begin{array}{l}\text { Fator de } \\
\text { Atrito } f\end{array}$} & \multirow{2}{*}{$\begin{array}{c}\begin{array}{c}\text { Perda de } \\
\text { Carga }\end{array} \\
(\mathrm{m})\end{array}$} & \multirow{2}{*}{$\begin{array}{c}\begin{array}{c}\text { Carga } \\
\text { Montante }\end{array} \\
(\mathrm{m})\end{array}$} & \multirow{2}{*}{$\begin{array}{c}\text { Carga Jusante } \\
(\mathrm{m})\end{array}$} & \multirow{2}{*}{$\begin{array}{c}\text { Potência Dissipada } \\
\text { kW }\end{array}$} \\
\hline & Nome & Cota & Nome & Cota & & & & & & & & & & \\
\hline $\mathrm{T} 1$ & $\mathrm{~N} 1$ & 4,56 & N2 & 3,50 & 258,48 & 179,4 & 400 & 400 & 1,42 & 0,0063 & 0,42 & 12,78 & 13,42 & 1,06 \\
\hline T4 & N5 & 0,49 & N6 & 0,50 & 253,28 & 5,3 & 100 & 100 & 0,68 & 0,0063 & 0,37 & 13,10 & 12,72 & 0,03 \\
\hline T5 & N6 & 0,50 & N7 & 1,50 & 660,47 & 40,1 & 200 & 200 & 1,27 & 0,0063 & 1,72 & 12,72 & 10,00 & 0,96 \\
\hline T6 & N2 & 3,50 & N7 & 1,50 & 644,10 & 94,8 & 300 & 300 & 1,34 & 0,0063 & 1,24 & 13,42 & 14,19 & 1,64 \\
\hline
\end{tabular}

4) Resumo do Dimensionamento Otimizado

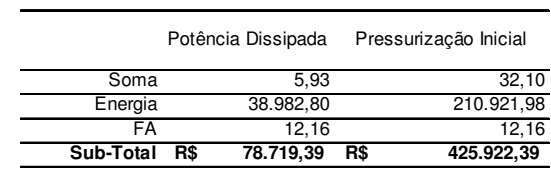

\begin{tabular}{|c|c|c|}
\hline Custos & & Porcentagem \\
\hline Custo de Tubulação $\mathrm{R} \$$ & $350.230,29$ & $35,76 \%$ \\
\hline Custo de Movimento de Terra $\mathrm{R} \$$ & $63.515,87$ & $6,49 \%$ \\
\hline Custo de Assentamento $\mathrm{R} \$$ & $10.274,21$ & $1,05 \%$ \\
\hline Custo de Pavimentação $R \$$ & $50.751,55$ & $5,18 \%$ \\
\hline Custo da Pressurização Inicial $\mathrm{R} \$$ & $425.922,39$ & $43,49 \%$ \\
\hline Custo da Potência Dissipada $\mathrm{R} \$$ & $78.719,39$ & $8,04 \%$ \\
\hline Total Global (Função Objetivo) R\$ & $979.413,69$ & $100,00 \%$ \\
\hline Total Referencial Unitário $\mathbf{R} \$$ & 269,07 & por metro de rede \\
\hline
\end{tabular}


5) Quantitativos e Custos de Implantação das Redes de Abastecimento

\begin{tabular}{|c|c|c|c|c|c|c|c|c|c|}
\hline Trecho & $\begin{array}{l}\text { Locação da } \\
\text { Tubulação }\end{array}$ & $\begin{array}{l}\text { Tipo de } \\
\text { Superfície }\end{array}$ & Tipo de Tráfego & & & & & & \\
\hline $\mathrm{T} 1$ & vario pavimentado & paralelepipedos & - & & & & & & \\
\hline $\mathrm{T} 2$ & viario pavimentado & paralelepipedos & - & & & & & & \\
\hline T3 & viario pavimentado & paralelepipedos & - & & & & & & \\
\hline $\mathrm{T} 4$ & viario pavimentado & paralelepipedos & - & & & & & & \\
\hline T5 & viario pavimentado & paralelepipedos & - & & & & & & \\
\hline T6 & viario pavimentado & paralelepipedos & - & & & & & & \\
\hline 77 & viario pavimentado & paralelepipedos & - & & & & & & \\
\hline T8 & viario pavimentado & paralelepipedos & - & & & & & & \\
\hline \multirow{3}{*}{ Trecho } & \multicolumn{6}{|c|}{ Vala } & \multicolumn{3}{|c|}{ Tubulação } \\
\hline & Largura & Profundidade & Escavação & Reaterro & Bota-Fora & TOTAL & Assentamento & Material & TOTAL \\
\hline & $\mathrm{m}$ & $\mathrm{m}$ & $\mathrm{m}^{3}$ & $\mathrm{~m}^{3}$ & $\mathrm{~m}^{3}$ & $\mathrm{R} \$$ & $\mathrm{R} \$$ & $\mathrm{R} \$$ & $\mathrm{R} \$$ \\
\hline $\mathrm{T} 1$ & 0,75 & 1,40 & 271,40 & 238,92 & 32,48 & $6.481,67$ & $1.330,32$ & $60.843,11$ & $62.173,43$ \\
\hline T2 & 0,60 & 1,25 & 191,95 & 179,38 & 12,56 & $4.688,29$ & 781,41 & $27.846,08$ & $28.627,49$ \\
\hline T3 & 0,55 & 1,20 & 433,97 & 413,31 & 20,66 & $10.677,19$ & $1.631,59$ & $49.595,62$ & $51.227,21$ \\
\hline T4 & 0,50 & 1,10 & 139,30 & 137,31 & 1,99 & $3.473,83$ & 386,69 & $6.121,70$ & $6.508,39$ \\
\hline T5 & 0,55 & 1,20 & 435,91 & 415,16 & 20,75 & $10.724,93$ & $1.638,89$ & $49.817,37$ & $51.456,26$ \\
\hline T6 & 0,65 & 1,30 & 544,26 & 498,74 & 45,53 & $13.194,41$ & $2.375,48$ & $94.537,19$ & $96.912,66$ \\
\hline$\pi 7$ & 0,50 & 1,15 & 145,49 & 141,02 & 4,47 & $3.604,04$ & 499,10 & $11.900,01$ & $12.399,11$ \\
\hline \multirow[t]{2}{*}{ T8 } & 0,55 & 1,20 & 433,74 & 413,09 & 20,65 & $10.671,50$ & $1.630,72$ & $49.569,22$ & $51.199,94$ \\
\hline & & & & & Soma & $63.515,87$ & $\begin{array}{ll}\mathrm{R} \$ & 10.274,21\end{array}$ & $\begin{array}{lll}R \$ 350.230,29 & R \$\end{array}$ & $360.504,50$ \\
\hline \multirow{2}{*}{\multicolumn{10}{|c|}{$\begin{array}{l}\text { Pavimentação } \\
\text { Vala }\end{array}$}} \\
\hline & & & $\mathrm{Va}$ & $a$ & & & & & \\
\hline \multirow[t]{2}{*}{ Trecho } & Área & $\begin{array}{l}\text { Área de } \\
\text { Concreto }\end{array}$ & $\begin{array}{c}\text { Área de } \\
\text { Paralelepipedos }\end{array}$ & $\begin{array}{l}\text { Área de } \\
\text { Asfalto }\end{array}$ & Área de Binder & $\begin{array}{l}\text { Area de Concreto Asfático } \\
\text { Usinado a Quente }\end{array}$ & & & \\
\hline & $\mathrm{m}^{2}$ & $\mathrm{~m}^{2}$ & $\mathrm{~m}^{2}$ & $\mathrm{~m}^{2}$ & $\mathrm{~m}^{2}$ & $\mathrm{~m}^{2}$ & & & \\
\hline $\mathrm{T} 1$ & 193,86 & 0,00 & 193,86 & 0,00 & 0,00 & 0,00 & & & \\
\hline $\mathrm{T} 2$ & 153,56 & 0,00 & 153,56 & 0,00 & 0,00 & 0,00 & & & \\
\hline T3 & 361,64 & 0,00 & 361,64 & 0,00 & 0,00 & 0,00 & & & \\
\hline T4 & 126,64 & 0,00 & 126,64 & 0,00 & 0,00 & 0,00 & & & \\
\hline T5 & 363,26 & 0,00 & 363,26 & 0,00 & 0,00 & 0,00 & & & \\
\hline T6 & 418,67 & 0,00 & 418,67 & 0,00 & 0,00 & 0,00 & & & \\
\hline 77 & 126,51 & 0,00 & 126,51 & 0,00 & 0,00 & 0,00 & & & \\
\hline T8 & 361,45 & 0,00 & 361,45 & 0,00 & 0,00 & 0,00 & & & \\
\hline \multirow{4}{*}{ Trecho } & \multicolumn{9}{|c|}{ Pavimentação } \\
\hline & \multicolumn{3}{|c|}{ Volume } & \multicolumn{2}{|c|}{ Area } & \multicolumn{4}{|c|}{ Custos } \\
\hline & Macadame Hidáulico & Binder & $\begin{array}{l}\text { Concreto } \\
\text { Asfáltico Usinado } \\
\text { a Quente }\end{array}$ & $\begin{array}{l}\text { Imprimação } \\
\text { Betuminosa } \\
\text { Ligante }\end{array}$ & $\begin{array}{c}\text { Imprimação } \\
\text { Betuminosa } \\
\text { Impermeabiliza } \\
\text { nte }\end{array}$ & Remoção & Recomposição & Transporte & TOTAL \\
\hline & $\mathrm{m}^{3}$ & $\mathrm{~m}^{3}$ & $\mathrm{~m}^{3}$ & $\mathrm{~m}^{2}$ & $\mathrm{~m}^{2}$ & $\mathrm{R} \$$ & $\mathrm{R} \$$ & $\mathrm{R} \$$ & $\mathbf{R} \$$ \\
\hline $\mathrm{T} 1$ & 0,00 & 0,00 & 0,00 & 0,00 & 0,00 & 993,09 & $3.679,58$ & 0,00 & $4.672,67$ \\
\hline $\mathrm{T} 2$ & 0,00 & 0,00 & 0,00 & 0,00 & 0,00 & 786,64 & $2.914,62$ & 0,00 & $3.701,26$ \\
\hline T3 & 0,00 & 0,00 & 0,00 & 0,00 & 0,00 & $1.852,59$ & $6.864,18$ & 0,00 & $8.716,77$ \\
\hline $\mathrm{T} 4$ & 0,00 & 0,00 & 0,00 & 0,00 & 0,00 & 648,74 & $2.403,70$ & 0,00 & $3.052,45$ \\
\hline T5 & 0,00 & 0,00 & 0,00 & 0,00 & 0,00 & $1.860,87$ & $6.894,87$ & 0,00 & $8.755,74$ \\
\hline T6 & 0,00 & 0,00 & 0,00 & 0,00 & 0,00 & $2.144,71$ & $7.946,52$ & 0,00 & $10.091,22$ \\
\hline 77 & 0,00 & 0,00 & 0,00 & 0,00 & 0,00 & 648,08 & $2.401,24$ & 0,00 & $3.049,31$ \\
\hline T8 & 0,00 & 0,00 & 0,00 & 0,00 & 0,00 & $1.851,60$ & $6.860,52$ & 0,00 & $8.712,13$ \\
\hline & & & & & Soma & & $\$ 39.965,23$ & $\mathrm{RS}$ & 50.7 \\
\hline
\end{tabular}




\section{APÊNDICE D4 - Planilha de Dimensionamento para Vida Útil de 40 anos e Viário em Paralelepípedo - PVC}

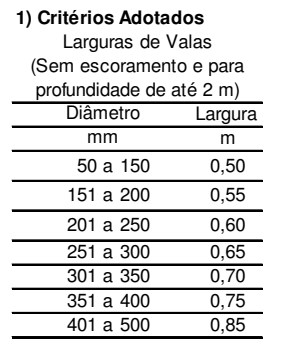

Locação das Redes

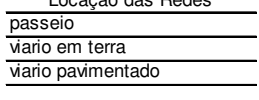

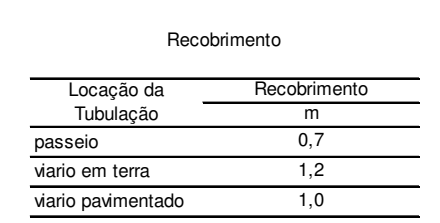

viario pavimentado 1,0

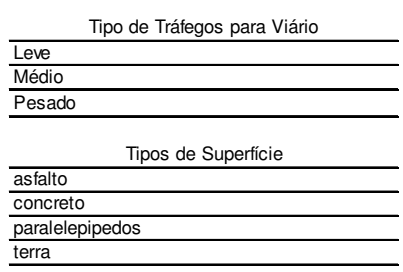

paralelepipedos

2) Dados Adotados

Tubulação

Material

SDR

$\begin{array}{lll} & & \\ \mathrm{Cl} & 20 & 1 \mathrm{MPa}\end{array}$

\begin{tabular}{ll} 
Rugosidade Equivalente $(\mathrm{m})$ & 0,00002 \\
\hline
\end{tabular}

Pressurização Inicial

Carga Inicial

Rendimento Global

Vida Útil

\begin{tabular}{ll}
\hline Fator entre Diâmetro Hidráulico e Comercial & 1,05 \\
\hline
\end{tabular}

Largura Adotadas para Reposição de Pavimentos Devido Abertura de Valas (m)

\begin{tabular}{|c|c|c|c|}
\hline \multicolumn{3}{|c|}{ Abertura de Valas $(\mathrm{m})$} & \\
\hline Concreto Asfáltico Usinado a Quente & & 3 & \\
\hline Imprimação Betuminosa Ligante & & 3 & \\
\hline Binder & & Larguravala $+0,2$ & \\
\hline Imprimação Betuminosa Impermeabiliz & & Largura $_{\text {Vala }}+0,2$ & \\
\hline Macadame Hidáulico & & Largura $_{\text {Vala }}$ & \\
\hline \multicolumn{4}{|c|}{ Espessuras Adotadas para Reposição de Pavimentos Devido Abertura de Valas (m) } \\
\hline Tráfego & Leve & Médio & Pesado \\
\hline Binder & 0,04 & 0,07 & 0,10 \\
\hline Concreto Asfáltico Usinado a Quente & 0,04 & 0,05 & 0,05 \\
\hline Macadame Hidáulico & 0,10 & 0,12 & 0,15 \\
\hline
\end{tabular}

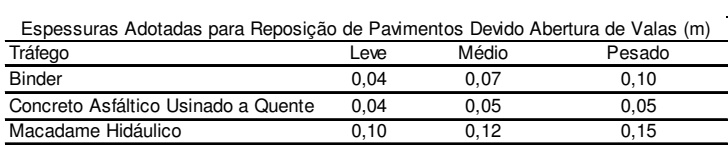

Energia

Grupo A (Alta e Média Tensão)

Sub-Grupo A4 (2,3 KV a $25 \mathrm{KV})$

Custo de Energia por Del $31,31 \mathrm{R} \$ / \mathrm{KW}$

Custo de Energia por Col $0,16132 \mathrm{R} \$ / \mathrm{KWh}$

\begin{tabular}{lr} 
Taxa de Juros & $8,00 \%$ a \\
\hline Fator de Atualizacão & 12,88
\end{tabular}

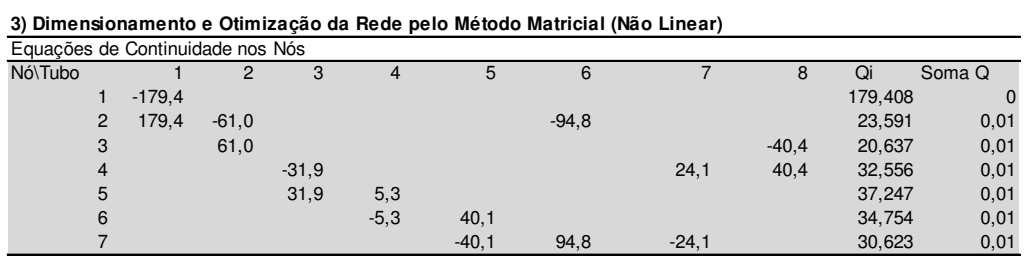

\begin{tabular}{|c|c|c|c|c|c|c|c|c|c|}
\hline \multicolumn{10}{|c|}{ Equações de Perda de Carga nos Circuitos } \\
\hline Circuitos & 1 & $\frac{2}{2}$ & 3 & 4 & 5 & 6 & 7 & 8 & Soma Perda \\
\hline 1 & & $-0,506$ & & & & 1,237 & 1,006 & $-1,737$ & 0,0001 \\
\hline 2 & & & $-1,087$ & 0,372 & 1,720 & & $-1,006$ & & $1 \mathrm{E}-04$ \\
\hline
\end{tabular}

Tabela da Função Objetivo

\begin{tabular}{|c|c|c|c|c|c|c|c|c|c|c|c|c|c|c|}
\hline \multirow{2}{*}{ Trecho } & \multicolumn{2}{|c|}{ Nó Montante } & \multicolumn{2}{|c|}{ No Jusante } & \multirow{2}{*}{$\begin{array}{r}\begin{array}{r}\text { Extensão } \\
\text { do Trecho }\end{array} \\
(\mathrm{m})\end{array}$} & \multirow{2}{*}{$\begin{array}{c}\begin{array}{c}\text { Vazão do } \\
\text { Trecho }\end{array} \\
\text { l/s }\end{array}$} & \multirow{2}{*}{$\begin{array}{c}\begin{array}{c}\text { Diâmetro } \\
\text { Nominal } \\
\text { Comercial }\end{array} \\
(\mathrm{mm})\end{array}$} & \multirow{2}{*}{$\begin{array}{c}\begin{array}{c}\text { Diâmetro } \\
\text { Ótimo }\end{array} \\
(\mathrm{mm})\end{array}$} & \multirow{2}{*}{$\begin{array}{c}\text { Velocidade } \\
(\mathrm{m} / \mathrm{s})\end{array}$} & \multirow[t]{2}{*}{$\begin{array}{l}\text { Fator de } \\
\text { Atrito } f\end{array}$} & \multirow{2}{*}{$\begin{array}{c}\begin{array}{c}\text { Perda de } \\
\text { Carga }\end{array} \\
(\mathrm{m})\end{array}$} & \multirow{2}{*}{$\begin{array}{c}\begin{array}{c}\text { Carga } \\
\text { Montante }\end{array} \\
(\mathrm{m})\end{array}$} & \multirow{2}{*}{$\begin{array}{c}\text { Carga Jusante } \\
(\mathrm{m})\end{array}$} & \multirow{2}{*}{$\begin{array}{c}\text { Potência Dissipada } \\
\text { kW }\end{array}$} \\
\hline & Nome & Cota & Nome & Cota & & & & & & & & & & \\
\hline T1 & N1 & 4,56 & N2 & 3,50 & 258,48 & 179,4 & 400 & 400 & 1,42 & 0,0063 & 0,42 & 12,78 & 13,42 & 1,06 \\
\hline T3 & $\mathrm{N} 4$ & 1,50 & N5 & 0,49 & 657,53 & 31,9 & 200 & 200 & 1,01 & 0,0063 & 1,09 & 13,18 & 13,10 & 0,49 \\
\hline T4 & N5 & 0,49 & N6 & 0,50 & 253,28 & 5,3 & 100 & 100 & 0,68 & 0,0063 & 0,37 & 13,10 & 12,72 & 0,03 \\
\hline T5 & N6 & 0,50 & N7 & 1,50 & 660,47 & 40,1 & 200 & 200 & 1,27 & 0,0063 & 1,72 & 12,72 & 10,00 & 0,96 \\
\hline T6 & N2 & 3,50 & N7 & 1,50 & 644,10 & 94,8 & 300 & 300 & 1,34 & 0,0063 & 1,24 & 13,42 & 14,19 & 1,64 \\
\hline
\end{tabular}

4) Resumo do Dimensionamento Otimizado

\begin{tabular}{|c|c|c|c|}
\hline & Potê & a Dissipada & Pressurização Inicial \\
\hline Soma & & 5,93 & 32,10 \\
\hline Energia & & $38.982,80$ & $210.921,98$ \\
\hline FA & & 12,88 & 12,88 \\
\hline Sub-Total & $\mathbf{R} \$$ & $83.382,16$ & $451.150,98$ \\
\hline
\end{tabular}

\begin{tabular}{|c|c|c|}
\hline Custos & & Porcentagem \\
\hline Custo de Tubulação $R \$$ & $350.230,29$ & $34,70 \%$ \\
\hline Custo de Movimento de Terra $\mathrm{R} \$$ & $63.515,87$ & $6,29 \%$ \\
\hline Custo de Assentamento $\mathrm{R} \$$ & $10.274,21$ & $1,02 \%$ \\
\hline Custo de Pavimentação $R \$$ & $50.751,55$ & $5,03 \%$ \\
\hline Custo da Pressurização Inicial $R \$$ & $451.150,98$ & $44,70 \%$ \\
\hline Custo da Potência Dissipada $\mathrm{R} \$$ & $83.382,16$ & $8,26 \%$ \\
\hline Total Global (Função Objetivo) R\$ & $1.009 .305,05$ & $100,00 \%$ \\
\hline Total Referencial Unitário $\mathrm{R} \$$ & 277,28 & por metro de rede \\
\hline
\end{tabular}


5) Quantitativos e Custos de Implantação das Redes de Abastecimento

\begin{tabular}{|c|c|c|c|c|c|c|c|c|c|}
\hline Trecho & $\begin{array}{l}\text { Locação da } \\
\text { Tubulação }\end{array}$ & $\begin{array}{l}\text { Tipo de } \\
\text { Superfície }\end{array}$ & Tipo de Tráfego & & & & & & \\
\hline $\mathrm{T} 1$ & viario pavimentado & paralelepipedos & - & & & & & & \\
\hline $\mathrm{T} 2$ & viario pavimentado & paralelepipedos & - & & & & & & \\
\hline T3 & vario pavimentado & paralelepipedos & - & & & & & & \\
\hline T4 & vario pavimentado & paralelepipedos & - & & & & & & \\
\hline $\mathrm{T5}$ & viario pavimentado & paralelepipedos & - & & & & & & \\
\hline T6 & viario pavimentado & paralelepipedos & - & & & & & & \\
\hline 77 & viario pavimentado & paralelepipedos & - & & & & & & \\
\hline \multirow[t]{2}{*}{ T8 } & viario pavimentado & paralelepipedos & - & & & & & & \\
\hline & \multicolumn{6}{|c|}{ Vala } & \multicolumn{3}{|c|}{ Tubulação } \\
\hline \multirow[t]{2}{*}{ Trecho } & Largura & $\begin{array}{l}\text { Profundidade } \\
\end{array}$ & Escavação & Reaterro & Bota-Fora & TOTAL & Assentamento & Material & TOTAL \\
\hline & $\mathrm{m}$ & $\mathrm{m}$ & $\mathrm{m}^{3}$ & $\mathrm{~m}^{3}$ & $\mathrm{~m}^{3}$ & $\mathbf{R} \$$ & $\mathrm{R} \$$ & $\mathrm{R} \$$ & $\mathrm{R} \$$ \\
\hline $\mathrm{T} 1$ & 0,75 & 1,40 & 271,40 & 238,92 & 32,48 & $6.481,67$ & $1.330,32$ & $60.843,11$ & $\begin{array}{l}62.173,43 \\
\end{array}$ \\
\hline $\mathrm{T} 2$ & 0,60 & 1,25 & 191,95 & 179,38 & 12,56 & $4.688,29$ & 781,41 & $27.846,08$ & $28.627,49$ \\
\hline T3 & 0,55 & 1,20 & 433,97 & 413,31 & 20,66 & $10.677,19$ & $1.631,59$ & $49.595,62$ & $51.227,21$ \\
\hline T4 & 0,50 & 1,10 & 139,30 & 137,31 & 1,99 & $3.473,83$ & 386,69 & $6.121,70$ & $6.508,39$ \\
\hline T5 & 0,55 & 1,20 & 435,91 & 415,16 & 20,75 & $10.724,93$ & $1.638,89$ & $49.817,37$ & $51.456,26$ \\
\hline T6 & 0,65 & 1,30 & 544,26 & 498,74 & 45,53 & $13.194,41$ & $2.375,48$ & $94.537,19$ & $96.912,66$ \\
\hline 77 & 0,50 & 1,15 & 145,49 & 141,02 & 4,47 & $3.604,04$ & 499,10 & $11.900,01$ & $12.399,11$ \\
\hline \multirow[t]{2}{*}{$\mathrm{T} 8$} & 0,55 & 1,20 & 433,74 & 413,09 & 20,65 & $10.671,50$ & $1.630,72$ & $49.569,22$ & $51.199,94$ \\
\hline & & & & & Soma & $63.515,87$ & $\begin{array}{ll}\mathrm{R} \$ 10.274,21 \\
\end{array}$ & $\mathrm{R} \$ 350.230,29 \quad \mathrm{R} \$$ & $360.504,50$ \\
\hline \multirow{2}{*}{\multicolumn{10}{|c|}{$\frac{\text { Pavimentação }}{\text { Vala }}$}} \\
\hline & & & & & & & & & \\
\hline \multirow[t]{2}{*}{ Trecho } & Área & $\begin{array}{l}\text { Área de } \\
\text { Concreto }\end{array}$ & $\begin{array}{c}\text { Área de } \\
\text { Paralelepipedos }\end{array}$ & $\begin{array}{l}\text { Área de } \\
\text { Asfalto }\end{array}$ & Área de Binder & $\begin{array}{l}\text { Area de Concreto Astático } \\
\text { Usinado a Quente }\end{array}$ & & & \\
\hline & $\mathrm{m}^{2}$ & $\mathrm{~m}^{2}$ & $\mathrm{~m}^{2}$ & $\mathrm{~m}^{2}$ & $\mathrm{~m}^{2}$ & $\mathrm{~m}^{2}$ & & & \\
\hline $\mathrm{T} 1$ & 193,86 & 0,00 & 193,86 & 0,00 & 0,00 & 0,00 & & & \\
\hline $\mathrm{T} 2$ & 153,56 & 0,00 & 153,56 & 0,00 & 0,00 & 0,00 & & & \\
\hline T3 & 361,64 & 0,00 & 361,64 & 0,00 & 0,00 & 0,00 & & & \\
\hline T4 & 126,64 & 0,00 & 126,64 & 0,00 & 0,00 & 0,00 & & & \\
\hline T5 & 363,26 & 0,00 & 363,26 & 0,00 & 0,00 & 0,00 & & & \\
\hline T6 & 418,67 & 0,00 & 418,67 & 0,00 & 0,00 & 0,00 & & & \\
\hline 77 & 126,51 & 0,00 & 126,51 & 0,00 & 0,00 & 0,00 & & & \\
\hline T8 & 361,45 & 0,00 & 361,45 & 0,00 & 0,00 & 0,00 & & & \\
\hline
\end{tabular}

\begin{tabular}{|c|c|c|c|c|c|c|c|c|c|}
\hline \multirow{4}{*}{ Trecho } & \multicolumn{9}{|c|}{ Pavimentação } \\
\hline & \multicolumn{3}{|c|}{ Volume } & \multicolumn{2}{|c|}{ Área } & \multicolumn{4}{|c|}{ Custos } \\
\hline & Macadame Hidáulico & Binder & $\begin{array}{l}\text { Concreto } \\
\text { Astáltico Usinado } \\
\text { a Quente }\end{array}$ & $\begin{array}{l}\text { Imprimação } \\
\text { Betuminosa } \\
\text { Ligante }\end{array}$ & $\begin{array}{l}\text { Imprimação } \\
\text { Betuminosa } \\
\text { Impermeabiliza } \\
\text { nte }\end{array}$ & Remoção & Recomposição & Transporte & TOTAL \\
\hline & $\mathrm{m}^{3}$ & $\mathrm{~m}^{3}$ & $\mathrm{~m}^{3}$ & $\mathrm{~m}^{2}$ & $\mathrm{~m}^{2}$ & $\mathrm{R} \$$ & $\mathrm{R} \$$ & $\mathrm{R} \$$ & $\mathrm{R} \$$ \\
\hline $\mathrm{T} 1$ & 0,00 & 0,00 & 0,00 & 0,00 & 0,00 & 993,09 & $3.679,58$ & 0,00 & $4.672,67$ \\
\hline $\mathrm{T} 2$ & 0,00 & 0,00 & 0,00 & 0,00 & 0,00 & 786,64 & $2.914,62$ & 0,00 & $3.701,26$ \\
\hline T3 & 0,00 & 0,00 & 0,00 & 0,00 & 0,00 & $1.852,59$ & $6.864,18$ & 0,00 & $8.716,77$ \\
\hline T4 & 0,00 & 0,00 & 0,00 & 0,00 & 0,00 & 648,74 & $2.403,70$ & 0,00 & $3.052,45$ \\
\hline T5 & 0,00 & 0,00 & 0,00 & 0,00 & 0,00 & $1.860,87$ & $6.894,87$ & 0,00 & $8.755,74$ \\
\hline T6 & 0,00 & 0,00 & 0,00 & 0,00 & 0,00 & $2.144,71$ & $7.946,52$ & 0,00 & $10.091,22$ \\
\hline 77 & 0,00 & 0,00 & 0,00 & 0,00 & 0,00 & 648,08 & $2.401,24$ & 0,00 & $3.049,31$ \\
\hline T8 & 0,00 & 0,00 & 0,00 & 0,00 & 0,00 & $1.851,60$ & $6.860,52$ & 0,00 & $8.712,13$ \\
\hline
\end{tabular}




\section{APÊNDICE D5 - Planilha de Dimensionamento para Vida Útil de 10 anos e Viário em Paralelepípedo - FoFo}

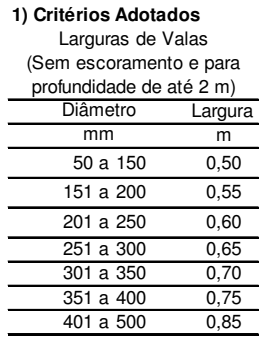

Locação das Redes

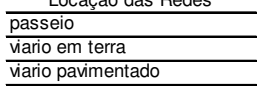

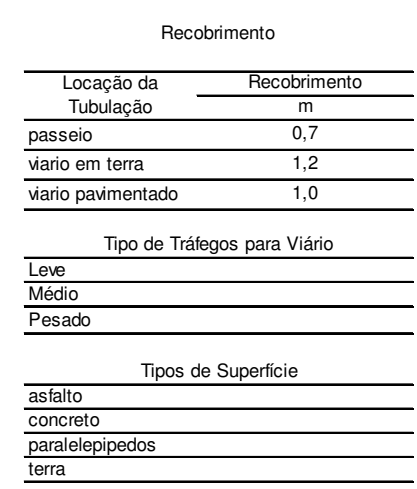

2) Dados Adotados Tubulação

Materia

Classe de Pressão $\quad 6,4 \mathrm{Mpa}$ Rugosidade Equivalente $(\mathrm{m}) \quad 0,0001$

Fator entre Diâmetro Hidráulico e Comercial
Pressurização Inicial \begin{tabular}{lr}
\hline Carga Inicial & 11,64 \\
\hline Rendimento Global & 0,70 \\
\hline
\end{tabular}

Horas de Funcionamer $\quad 6570 \mathrm{~h} / \mathrm{ano}$ Vida Útil

1,05
Largura Adotadas para Reposição de Pavimentos Devido Abertura de Valas (m)

Concreto Asfáltico Usinado a Quente Imprimação Betuminosa Ligante

Binder

Imprimação Betuminosa Impermeabilizante $\quad$ Larguravala $+0,2$

Macadame Hidáulico $\quad$ Larguravala

Espessuras Adotadas para Reposição de Pavimentos Devido Abertura de Valas (m) Tráfego

Binder

$\begin{array}{rr}0,04 & 0,07 \\ 0,04 & 0,05\end{array}$

Concreto Asfáltico Usinado a Quente $\quad 0,04 \quad 0,05$

Macadame Hidáulico

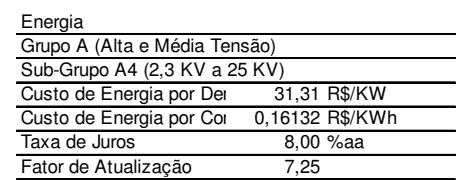

3) Dimensionamento e Otimização da Rede pelo Método Matriciail (Não Linear)

\begin{tabular}{|c|c|c|c|c|c|c|c|c|c|c|}
\hline \multicolumn{11}{|c|}{ Equacões de Continuidade nos Nós } \\
\hline NólTubo & 1 & 2 & 3 & 4 & 5 & 6 & 7 & 8 & Qi & Soma Q \\
\hline & $-179,4$ & & & & & & & & 179,408 & 0 \\
\hline & 179,4 & $-24,1$ & & & & $-131,7$ & & & 23,591 & 0,01 \\
\hline & & 24,1 & & & & & & $-3,5$ & 20,637 & 0,01 \\
\hline & & & $-24,8$ & & & & 53,9 & 3,5 & 32,556 & 0,01 \\
\hline & & & 24,8 & 12,4 & & & & & 37,247 & 0,01 \\
\hline & & & & $-12,4$ & 47,2 & & & & 34,754 & 0,01 \\
\hline & & & & & $-47,2$ & 131,7 & $-53,9$ & & 30,623 & 0,01 \\
\hline
\end{tabular}

\begin{tabular}{crrrrrrrrr}
\hline Equações de Perda de Carga nos Circuitos & & & & & \\
\hline Circuitos & 1 & 2 & 3 & 4 & 5 & 6 & 7 & 8 & Soma Perda \\
& & & & & & & & \\
1 & $-0,313$ & & & & 1,432 & 0,507 & $-1,626$ & 0,0001 \\
2 & & $-0,853$ & 0,346 & 1,013 & & $-0,507$ & & 0,0001 \\
\hline
\end{tabular}

Tabela da Função Objetivo

\begin{tabular}{|c|c|c|c|c|c|c|c|c|c|c|c|c|c|c|}
\hline \multirow{2}{*}{ Trecho } & \multicolumn{2}{|c|}{ Nó Montante } & \multicolumn{2}{|c|}{ No Jusante } & \multirow{2}{*}{$\begin{array}{r}\begin{array}{r}\text { Extensão } \\
\text { do Trecho }\end{array} \\
(\mathrm{m})\end{array}$} & \multirow{2}{*}{$\begin{array}{c}\begin{array}{c}\text { Vazão do } \\
\text { Trecho }\end{array} \\
\text { l/s }\end{array}$} & \multirow{2}{*}{$\begin{array}{c}\begin{array}{c}\text { Diâmetro } \\
\text { Nominal } \\
\text { Comercial }\end{array} \\
(\mathrm{mm})\end{array}$} & \multirow{2}{*}{$\begin{array}{c}\begin{array}{c}\text { Diâmetro } \\
\text { Ótimo }\end{array} \\
(\mathrm{mm})\end{array}$} & \multirow{2}{*}{$\begin{array}{c}\text { Velocidade } \\
(\mathrm{m} / \mathrm{s})\end{array}$} & \multirow[t]{2}{*}{$\begin{array}{l}\text { Fator de } \\
\text { Atrito } f\end{array}$} & \multirow{2}{*}{$\begin{array}{c}\begin{array}{c}\text { Perda de } \\
\text { Carga }\end{array} \\
(\mathrm{m})\end{array}$} & \multirow{2}{*}{$\begin{array}{c}\begin{array}{c}\text { Carga } \\
\text { Montante }\end{array} \\
(\mathrm{m})\end{array}$} & \multirow{2}{*}{$\begin{array}{c}\text { Carga Jusante } \\
(\mathrm{m})\end{array}$} & \multirow{2}{*}{$\begin{array}{c}\text { Potência Dissipada } \\
\mathrm{kW}\end{array}$} \\
\hline & Nome & Cota & Nome & Cota & & & & & & & & & & \\
\hline $\mathrm{T} 1$ & $\mathrm{~N} 1$ & 4,56 & N2 & 3,50 & 258,48 & 179,4 & 400 & 400 & 1,42 & 0,0082 & 0,55 & 11,64 & 12,15 & 1,37 \\
\hline T3 & $\mathrm{N} 4$ & 1,50 & N5 & 0,49 & 657,53 & 24,8 & 200 & 200 & 0,79 & 0,0082 & 0,85 & 12,21 & 12,37 & 0,30 \\
\hline T4 & N5 & 0,49 & N6 & 0,50 & 253,28 & 12,4 & 150 & 149 & 0,70 & 0,0082 & 0,35 & 12,37 & 12,01 & 0,06 \\
\hline T5 & N6 & 0,50 & N7 & 1,50 & 660,47 & 47,2 & 250 & 249 & 0,96 & 0,0082 & 1,01 & 12,01 & 10,00 & 0,67 \\
\hline T6 & N2 & 3,50 & N7 & 1,50 & 644,10 & 131,7 & 350 & 350 & 1,36 & 0,0082 & 1,43 & 12,15 & 12,72 & 2,64 \\
\hline
\end{tabular}

4) Resumo do Dimensionamento Otimizado

\begin{tabular}{|c|c|c|c|}
\hline & Potê & a Dissipada & Pressurização Inicial \\
\hline Soma & & 5,61 & 29,22 \\
\hline Energia & & $36.843,21$ & $192.006,96$ \\
\hline FA & & 7,25 & 7,25 \\
\hline Sub-Total & $\mathbf{R} \$$ & $44.344,62$ & $231.100,30$ \\
\hline
\end{tabular}

\begin{tabular}{|c|c|c|}
\hline Custos & & Porcentagem \\
\hline Custo de Tubulação $R \$$ & $934.801,82$ & $69,87 \%$ \\
\hline Custo de Movimento de Terra $R \$$ & $65.168,87$ & $4,87 \%$ \\
\hline Custo de Assentamento $\mathrm{R} \$$ & $10.608,37$ & $0,79 \%$ \\
\hline Custo de Pavimentação $\mathrm{R} \$$ & $51.833,19$ & $3,87 \%$ \\
\hline Custo da Pressurização Inicial $\mathrm{R} \$$ & $231.100,30$ & $17,27 \%$ \\
\hline Custo da Potência Dissipada $R \$$ & $44.344,62$ & $3,31 \%$ \\
\hline Total Global (Funçäo Objetivo) R\$ & $1.337 .857,17$ & $100,00 \%$ \\
\hline Total Referencial Unitário $\mathbf{R} \$$ & 367,54 & por metro de rede \\
\hline
\end{tabular}


5) Quantitativos e Custos de Implantação das Redes de Abastecimento

\begin{tabular}{|c|c|c|c|c|c|c|c|c|c|}
\hline Trecho & $\begin{array}{l}\text { Locação da } \\
\text { Tubulação }\end{array}$ & $\begin{array}{c}\text { Tipo de } \\
\text { Superfície }\end{array}$ & Tipo de Tráfego & & & & & & \\
\hline $\mathrm{T} 1$ & viario pavimentado & paralelepipedos & - & & & & & & \\
\hline $\mathrm{T} 2$ & viario pavimentado & paralelepipedos & - & & & & & & \\
\hline T3 & vario pavimentado & paralelepipedos & - & & & & & & \\
\hline T4 & vario pavimentado & paralelepipedos & - & & & & & & \\
\hline $\mathrm{T5}$ & viario pavimentado & paralelepipedos & - & & & & & & \\
\hline T6 & viario pavimentado & paralelepipedos & - & & & & & & \\
\hline 77 & viario pavimentado & paralelepipedos & - & & & & & & \\
\hline \multirow[t]{2}{*}{ T8 } & viario pavimentado & paralelepipedos & - & & & & & & \\
\hline & \multicolumn{6}{|c|}{ Vala } & \multicolumn{3}{|c|}{ Tubulação } \\
\hline \multirow[t]{2}{*}{ Trecho } & Largura & $\begin{array}{l}\text { Profundidade } \\
\end{array}$ & Escavação & Reaterro & Bota-Fora & TOTAL & Assentamento & Material & TOTAL \\
\hline & $\mathrm{m}$ & $\mathrm{m}$ & $\mathrm{m}^{3}$ & $\mathrm{~m}^{3}$ & $\mathrm{~m}^{3}$ & $\mathrm{R} \$$ & $\mathrm{R} \$$ & $\mathrm{R} \$$ & $\mathrm{R} \$$ \\
\hline $\mathrm{T} 1$ & 0,75 & 1,40 & 271,40 & 238,92 & 32,48 & $6.481,67$ & $1.330,32$ & $117.523,27$ & $118.853,60$ \\
\hline $\mathrm{T} 2$ & 0,55 & 1,20 & 168,91 & 160,87 & 8,04 & $4.155,87$ & 635,06 & $56.118,96$ & $56.754,03$ \\
\hline T3 & 0,55 & 1,20 & 433,97 & 413,31 & 20,66 & $10.677,19$ & $1.631,59$ & $144.179,67$ & $145.811,26$ \\
\hline T4 & 0,50 & 1,15 & 145,64 & 141,16 & 4,48 & $3.607,75$ & 499,61 & $43.671,97$ & \begin{tabular}{|l|l|}
$44.171,58$ \\
\end{tabular} \\
\hline T5 & 0,60 & 1,25 & 495,35 & 462,93 & 32,42 & $12.098,91$ & $2.016,56$ & $178.936,95$ & $180.953,51$ \\
\hline T6 & 0,70 & 1,35 & 608,67 & 546,70 & 61,97 & $14.645,24$ & $2.824,95$ & $250.311,21$ & $253.136,16$ \\
\hline 77 & 0,60 & 1,25 & 189,77 & 177,34 & 12,42 & $4.634,98$ & 772,53 & $68.549,10$ & $69.321,63$ \\
\hline \multirow[t]{2}{*}{ T8 } & 0,50 & 1,08 & 354,88 & 351,57 & 3,30 & $8.867,25$ & 897,74 & $75.510,68$ & $76.408,42$ \\
\hline & & & & & Soma & $65.168,87$ & $\begin{array}{ll}R \$ 10.608,37 \\
\end{array}$ & $\mathrm{R} \$ 934.801,82 \quad \mathrm{R} \$$ & $945.410,19$ \\
\hline \multirow{2}{*}{\multicolumn{10}{|c|}{$\frac{\text { Pavimentação }}{\text { Vala }}$}} \\
\hline & & & & & & & & & \\
\hline \multirow[t]{2}{*}{ Trecho } & Área & $\begin{array}{l}\text { Área de } \\
\text { Concreto }\end{array}$ & $\begin{array}{c}\text { Área de } \\
\text { Paralelepipedos }\end{array}$ & $\begin{array}{l}\text { Área de } \\
\text { Asfalto }\end{array}$ & Área de Binder & $\begin{array}{l}\text { Area de Concreto Astático } \\
\text { Usinado a Quente }\end{array}$ & & & \\
\hline & $\mathrm{m}^{2}$ & $\mathrm{~m}^{2}$ & $\mathrm{~m}^{2}$ & $\mathrm{~m}^{2}$ & $\mathrm{~m}^{2}$ & $\mathrm{~m}^{2}$ & & & \\
\hline $\mathrm{T} 1$ & 193,86 & 0,00 & 193,86 & 0,00 & 0,00 & 0,00 & & & \\
\hline $\mathrm{T} 2$ & 140,76 & 0,00 & 140,76 & 0,00 & 0,00 & 0,00 & & & \\
\hline T3 & 361,64 & 0,00 & 361,64 & 0,00 & 0,00 & 0,00 & & & \\
\hline T4 & 126,64 & 0,00 & 126,64 & 0,00 & 0,00 & 0,00 & & & \\
\hline T5 & 396,28 & 0,00 & 396,28 & 0,00 & 0,00 & 0,00 & & & \\
\hline T6 & 450,87 & 0,00 & 450,87 & 0,00 & 0,00 & 0,00 & & & \\
\hline 77 & 151,81 & 0,00 & 151,81 & 0,00 & 0,00 & 0,00 & & & \\
\hline T8 & 328,59 & 0,00 & 328,59 & 0,00 & 0,00 & 0,00 & & & \\
\hline
\end{tabular}

\begin{tabular}{|c|c|c|c|c|c|c|c|c|c|}
\hline \multirow{4}{*}{ Trecho } & \multicolumn{9}{|c|}{ Pavimentação } \\
\hline & \multicolumn{3}{|c|}{ Volume } & \multicolumn{2}{|c|}{ Área } & \multicolumn{4}{|c|}{ Custos } \\
\hline & Macadame Hidáulico & Binder & $\begin{array}{l}\text { Concreto } \\
\text { Astáltico Usinado } \\
\text { a Quente }\end{array}$ & $\begin{array}{l}\text { Imprimação } \\
\text { Betuminosa } \\
\text { Ligante }\end{array}$ & $\begin{array}{l}\text { Imprimação } \\
\text { Betuminosa } \\
\text { Impermeabiliza } \\
\text { nte }\end{array}$ & Remoção & Recomposição & Transporte & TOTAL \\
\hline & $\mathrm{m}^{3}$ & $\mathrm{~m}^{3}$ & $\mathrm{~m}^{3}$ & $\mathrm{~m}^{2}$ & $\mathrm{~m}^{2}$ & $\mathrm{R} \$$ & $\mathrm{R} \$$ & $\mathrm{R} \$$ & $\mathrm{R} \$$ \\
\hline $\mathrm{T} 1$ & 0,00 & 0,00 & 0,00 & 0,00 & 0,00 & 993,09 & $3.679,58$ & 0,00 & $4.672,67$ \\
\hline $\mathrm{T} 2$ & 0,00 & 0,00 & 0,00 & 0,00 & 0,00 & 721,08 & $2.671,74$ & 0,00 & $3.392,82$ \\
\hline T3 & 0,00 & 0,00 & 0,00 & 0,00 & 0,00 & $1.852,59$ & $6.864,18$ & 0,00 & $8.716,77$ \\
\hline T4 & 0,00 & 0,00 & 0,00 & 0,00 & 0,00 & 648,74 & $2.403,70$ & 0,00 & $3.052,45$ \\
\hline T5 & 0,00 & 0,00 & 0,00 & 0,00 & 0,00 & $2.030,04$ & $7.521,67$ & 0,00 & $9.551,72$ \\
\hline T6 & 0,00 & 0,00 & 0,00 & 0,00 & 0,00 & $2.309,68$ & $8.557,79$ & 0,00 & $10.867,47$ \\
\hline 77 & 0,00 & 0,00 & 0,00 & 0,00 & 0,00 & 777,69 & $2.881,48$ & 0,00 & $3.659,18$ \\
\hline T8 & 0,00 & 0,00 & 0,00 & 0,00 & 0,00 & $1.683,28$ & $6.236,84$ & 0,00 & $7.920,12$ \\
\hline
\end{tabular}




\section{APÊNDICE D6 - Planilha de Dimensionamento para Vida Útil de 20 anos e Viário em Paralelepípedo - FoFo}

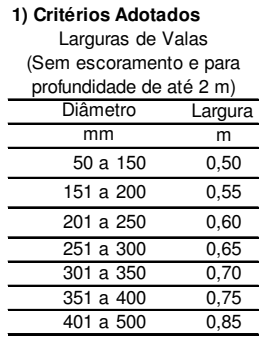

Locação das Redes

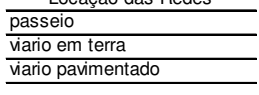

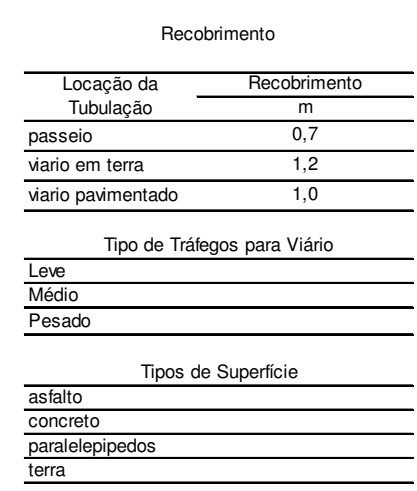

2) Dados Adotados Tubulação

Material

Rugosidade Equivalente $(\mathrm{m}) \quad 0,0001$

Fator entre Diâmetro Hidráulico e Comercial
Pressurização Inicial

\begin{tabular}{lr}
\hline Carga Inicial & 11,64 \\
\hline Rendimento Global & 0,70
\end{tabular}

Vida Útil

1,05
Largura Adotadas para Reposição de Pavimentos Devido Abertura de Valas (m)

\begin{tabular}{ll}
\hline Concreto Asfáltico Usinado a Quente & 3 \\
\hline Imprimacão Betuminosa Ligante & 3
\end{tabular} \begin{tabular}{lc}
\hline Imprimação Betuminosa Ligante & 3 \\
\hline Binder & Larguravala $+0,2$
\end{tabular}

\begin{tabular}{ll}
\hline Binder & Larguravala $+0,2$ \\
\hline Imprimação Betuminosa Impermeabilizante & Largura \\
\hline
\end{tabular}

\begin{tabular}{ll}
\hline Macadame Hidáulico & Larguravala \\
\hline
\end{tabular}

Espessuras Adotadas para Reposição de Pavimentos Devido Abertura de Valas (m) Tráfego Leve Médio $\quad$ Pesado Binder

\begin{tabular}{llll}
\hline Concreto Asfáltico Usinado a Quente & 0,04 & 0,05 & 0,10 \\
\hline
\end{tabular}

\begin{tabular}{lll}
\hline Macadame Hidáulico & 0,10 & 0,12
\end{tabular}

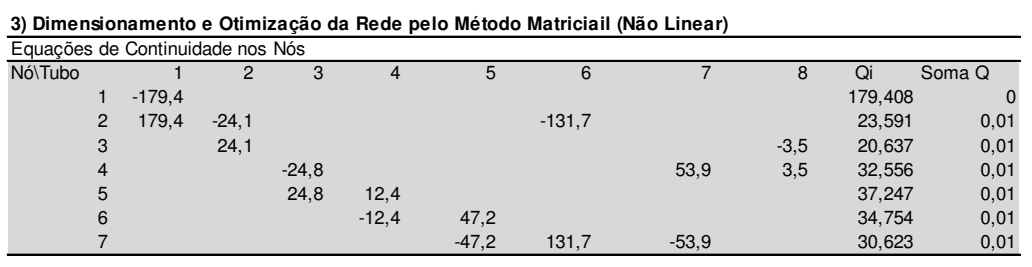

\begin{tabular}{cccccccccr}
\hline Equações de Perda de Carga nos Circuitos & & & & & & \\
\hline Circuitos & 1 & 2 & 3 & 4 & 5 & 6 & 7 & 8 & Soma Perda \\
& & & & & & & & \\
1 & $-0,313$ & & & & 1,432 & 0,507 & $-1,626$ & $1 \mathrm{E}-04$ \\
2 & & $-0,853$ & 0,346 & 1,013 & & $-0,507$ & & $1 \mathrm{E}-04$ \\
\hline
\end{tabular}

Tabela da Função Objetivo

\begin{tabular}{|c|c|c|c|c|c|c|c|c|c|c|c|c|c|c|}
\hline \multirow{2}{*}{ Trecho } & \multicolumn{2}{|c|}{ Nó Montante } & \multicolumn{2}{|c|}{ No Jusante } & \multirow{2}{*}{$\begin{array}{r}\begin{array}{r}\text { Extensão } \\
\text { do Trecho }\end{array} \\
(\mathrm{m})\end{array}$} & \multirow{2}{*}{$\begin{array}{c}\begin{array}{c}\text { Vazão do } \\
\text { Trecho }\end{array} \\
\text { l/s }\end{array}$} & \multirow{2}{*}{$\begin{array}{c}\begin{array}{c}\text { Diâmetro } \\
\text { Nominal } \\
\text { Comercial }\end{array} \\
(\mathrm{mm})\end{array}$} & \multirow{2}{*}{$\begin{array}{c}\begin{array}{c}\text { Diâmetro } \\
\text { Ótimo }\end{array} \\
(\mathrm{mm})\end{array}$} & \multirow{2}{*}{$\begin{array}{c}\text { Velocidade } \\
(\mathrm{m} / \mathrm{s})\end{array}$} & \multirow[t]{2}{*}{$\begin{array}{l}\text { Fator de } \\
\text { Atrito } f\end{array}$} & \multirow{2}{*}{$\begin{array}{c}\begin{array}{c}\text { Perda de } \\
\text { Carga }\end{array} \\
(\mathrm{m})\end{array}$} & \multirow{2}{*}{$\begin{array}{c}\begin{array}{c}\text { Carga } \\
\text { Montante }\end{array} \\
(\mathrm{m})\end{array}$} & \multirow{2}{*}{$\begin{array}{c}\text { Carga Jusante } \\
(\mathrm{m})\end{array}$} & \multirow{2}{*}{$\begin{array}{c}\text { Potência Dissipada } \\
\mathrm{kW}\end{array}$} \\
\hline & Nome & Cota & Nome & Cota & & & & & & & & & & \\
\hline T1 & N1 & 4,56 & N2 & 3,50 & 258,48 & 179,4 & 400 & 400 & 1,42 & 0,0082 & 0,55 & 11,64 & 12,15 & 1,37 \\
\hline T3 & $\mathrm{N} 4$ & 1,50 & N5 & 0,49 & 657,53 & 24,8 & 200 & 200 & 0,79 & 0,0082 & 0,85 & 12,21 & 12,37 & 0,30 \\
\hline T4 & N5 & 0,49 & N6 & 0,50 & 253,28 & 12,4 & 150 & 149 & 0,70 & 0,0082 & 0,35 & 12,37 & 12,01 & 0,06 \\
\hline T5 & N6 & 0,50 & N7 & 1,50 & 660,47 & 47,2 & 250 & 249 & 0,96 & 0,0082 & 1,01 & 12,01 & 10,00 & 0,67 \\
\hline T6 & N2 & 3,50 & N7 & 1,50 & 644,10 & 131,7 & 350 & 350 & 1,36 & 0,0082 & 1,43 & 12,15 & 12,72 & 2,64 \\
\hline
\end{tabular}

4) Resumo do Dimensionamento Otimizado

\begin{tabular}{|c|c|c|c|}
\hline & Potê & Dissipada & Pressurização Inicial \\
\hline Soma & & 5,61 & 29,22 \\
\hline Energia & & $36.843,21$ & $192.006,96$ \\
\hline FA & & 10,60 & 10,60 \\
\hline Sub-Total & $\mathbf{R} \$$ & $64.884,76$ & $338.144,46$ \\
\hline
\end{tabular}

\begin{tabular}{|c|c|c|}
\hline Custos & & Porcentagem \\
\hline Custo de Tubulação $R \$$ & $934.801,82$ & $63,79 \%$ \\
\hline Custo de Movimento de Terra $R \$$ & $65.168,87$ & $4,45 \%$ \\
\hline Custo de Assentamento $\mathrm{R} \$$ & $10.608,37$ & $0,72 \%$ \\
\hline Custo de Pavimentação $\mathrm{R} \$$ & $51.833,19$ & $3,54 \%$ \\
\hline Custo da Pressurização Inicial $\mathrm{R} \$$ & $338.144,46$ & $23,07 \%$ \\
\hline Custo da Potência Dissipada $R \$$ & $64.884,76$ & $4,43 \%$ \\
\hline Total Global (Funçäo Objetivo) R\$ & $1.465 .441,46$ & $100,00 \%$ \\
\hline Total Referencial Unitário $\mathbf{R} \$$ & 402,59 & por metro de rede \\
\hline
\end{tabular}


5) Quantitativos e Custos de Implantação das Redes de Abastecimento

\begin{tabular}{|c|c|c|c|c|c|c|c|c|c|}
\hline Trecho & $\begin{array}{l}\text { Locação da } \\
\text { Tubulação }\end{array}$ & $\begin{array}{c}\text { Tipo de } \\
\text { Superfície }\end{array}$ & Tipo de Tráfego & & & & & & \\
\hline $\mathrm{T} 1$ & viario pavimentado & paralelepipedos & - & & & & & & \\
\hline $\mathrm{T} 2$ & viario pavimentado & paralelepipedos & - & & & & & & \\
\hline T3 & vario pavimentado & paralelepipedos & - & & & & & & \\
\hline T4 & vario pavimentado & paralelepipedos & - & & & & & & \\
\hline $\mathrm{T5}$ & viario pavimentado & paralelepipedos & - & & & & & & \\
\hline T6 & viario pavimentado & paralelepipedos & - & & & & & & \\
\hline 77 & viario pavimentado & paralelepipedos & - & & & & & & \\
\hline \multirow[t]{2}{*}{ T8 } & viario pavimentado & paralelepipedos & - & & & & & & \\
\hline & \multicolumn{6}{|c|}{ Vala } & \multicolumn{3}{|c|}{ Tubulação } \\
\hline \multirow[t]{2}{*}{ Trecho } & Largura & $\begin{array}{l}\text { Profundidade } \\
\end{array}$ & Escavação & Reaterro & Bota-Fora & TOTAL & Assentamento & Material & TOTAL \\
\hline & $\mathrm{m}$ & $\mathrm{m}$ & $\mathrm{m}^{3}$ & $\mathrm{~m}^{3}$ & $\mathrm{~m}^{3}$ & $\mathrm{R} \$$ & $\mathrm{R} \$$ & $\mathrm{R} \$$ & $\mathrm{R} \$$ \\
\hline $\mathrm{T} 1$ & 0,75 & 1,40 & 271,40 & 238,92 & 32,48 & $6.481,67$ & $1.330,32$ & $117.523,27$ & $118.853,60$ \\
\hline $\mathrm{T} 2$ & 0,55 & 1,20 & 168,91 & 160,87 & 8,04 & $4.155,87$ & 635,06 & $56.118,96$ & $56.754,03$ \\
\hline T3 & 0,55 & 1,20 & 433,97 & 413,31 & 20,66 & $10.677,19$ & $1.631,59$ & $144.179,67$ & $145.811,26$ \\
\hline T4 & 0,50 & 1,15 & 145,64 & 141,16 & 4,48 & $3.607,75$ & 499,61 & $43.671,97$ & \begin{tabular}{|l|l|}
$44.171,58$ \\
\end{tabular} \\
\hline T5 & 0,60 & 1,25 & 495,35 & 462,93 & 32,42 & $12.098,91$ & $2.016,56$ & $178.936,95$ & $180.953,51$ \\
\hline T6 & 0,70 & 1,35 & 608,67 & 546,70 & 61,97 & $14.645,24$ & $2.824,95$ & $250.311,21$ & $253.136,16$ \\
\hline 77 & 0,60 & 1,25 & 189,77 & 177,34 & 12,42 & $4.634,98$ & 772,53 & $68.549,10$ & $69.321,63$ \\
\hline \multirow[t]{2}{*}{ T8 } & 0,50 & 1,08 & 354,88 & 351,57 & 3,30 & $8.867,25$ & 897,74 & $75.510,68$ & $76.408,42$ \\
\hline & & & & & Soma & $65.168,87$ & $\begin{array}{ll}R \$ 10.608,37 \\
\end{array}$ & $\mathrm{R} \$ 934.801,82 \quad \mathrm{R} \$$ & $945.410,19$ \\
\hline \multirow{2}{*}{\multicolumn{10}{|c|}{$\frac{\text { Pavimentação }}{\text { Vala }}$}} \\
\hline & & & & & & & & & \\
\hline \multirow[t]{2}{*}{ Trecho } & Área & $\begin{array}{l}\text { Área de } \\
\text { Concreto }\end{array}$ & $\begin{array}{c}\text { Área de } \\
\text { Paralelepipedos }\end{array}$ & $\begin{array}{l}\text { Área de } \\
\text { Asfalto }\end{array}$ & Área de Binder & $\begin{array}{l}\text { Area de Concreto Astático } \\
\text { Usinado a Quente }\end{array}$ & & & \\
\hline & $\mathrm{m}^{2}$ & $\mathrm{~m}^{2}$ & $\mathrm{~m}^{2}$ & $\mathrm{~m}^{2}$ & $\mathrm{~m}^{2}$ & $\mathrm{~m}^{2}$ & & & \\
\hline $\mathrm{T} 1$ & 193,86 & 0,00 & 193,86 & 0,00 & 0,00 & 0,00 & & & \\
\hline $\mathrm{T} 2$ & 140,76 & 0,00 & 140,76 & 0,00 & 0,00 & 0,00 & & & \\
\hline T3 & 361,64 & 0,00 & 361,64 & 0,00 & 0,00 & 0,00 & & & \\
\hline T4 & 126,64 & 0,00 & 126,64 & 0,00 & 0,00 & 0,00 & & & \\
\hline T5 & 396,28 & 0,00 & 396,28 & 0,00 & 0,00 & 0,00 & & & \\
\hline T6 & 450,87 & 0,00 & 450,87 & 0,00 & 0,00 & 0,00 & & & \\
\hline 77 & 151,81 & 0,00 & 151,81 & 0,00 & 0,00 & 0,00 & & & \\
\hline T8 & 328,59 & 0,00 & 328,59 & 0,00 & 0,00 & 0,00 & & & \\
\hline
\end{tabular}

\begin{tabular}{|c|c|c|c|c|c|c|c|c|c|}
\hline \multirow{4}{*}{ Trecho } & \multicolumn{9}{|c|}{ Pavimentação } \\
\hline & \multicolumn{3}{|c|}{ Volume } & \multicolumn{2}{|c|}{ Área } & \multicolumn{4}{|c|}{ Custos } \\
\hline & Macadame Hidáulico & Binder & $\begin{array}{l}\text { Concreto } \\
\text { Astáltico Usinado } \\
\text { a Quente }\end{array}$ & $\begin{array}{l}\text { Imprimação } \\
\text { Betuminosa } \\
\text { Ligante }\end{array}$ & $\begin{array}{l}\text { Imprimação } \\
\text { Betuminosa } \\
\text { Impermeabiliza } \\
\text { nte }\end{array}$ & Remoção & Recomposição & Transporte & TOTAL \\
\hline & $\mathrm{m}^{3}$ & $\mathrm{~m}^{3}$ & $\mathrm{~m}^{3}$ & $\mathrm{~m}^{2}$ & $\mathrm{~m}^{2}$ & $\mathrm{R} \$$ & $\mathrm{R} \$$ & $\mathrm{R} \$$ & $\mathrm{R} \$$ \\
\hline $\mathrm{T} 1$ & 0,00 & 0,00 & 0,00 & 0,00 & 0,00 & 993,09 & $3.679,58$ & 0,00 & $4.672,67$ \\
\hline $\mathrm{T} 2$ & 0,00 & 0,00 & 0,00 & 0,00 & 0,00 & 721,08 & $2.671,74$ & 0,00 & $3.392,82$ \\
\hline T3 & 0,00 & 0,00 & 0,00 & 0,00 & 0,00 & $1.852,59$ & $6.864,18$ & 0,00 & $8.716,77$ \\
\hline T4 & 0,00 & 0,00 & 0,00 & 0,00 & 0,00 & 648,74 & $2.403,70$ & 0,00 & $3.052,45$ \\
\hline T5 & 0,00 & 0,00 & 0,00 & 0,00 & 0,00 & $2.030,04$ & $7.521,67$ & 0,00 & $9.551,72$ \\
\hline T6 & 0,00 & 0,00 & 0,00 & 0,00 & 0,00 & $2.309,68$ & $8.557,79$ & 0,00 & $10.867,47$ \\
\hline 77 & 0,00 & 0,00 & 0,00 & 0,00 & 0,00 & 777,69 & $2.881,48$ & 0,00 & $3.659,18$ \\
\hline T8 & 0,00 & 0,00 & 0,00 & 0,00 & 0,00 & $1.683,28$ & $6.236,84$ & 0,00 & $7.920,12$ \\
\hline
\end{tabular}




\section{APÊNDICE D7 - Planilha de Dimensionamento para Vida Útil de 30 anos e Viário em Paralelepípedo - FoFo}

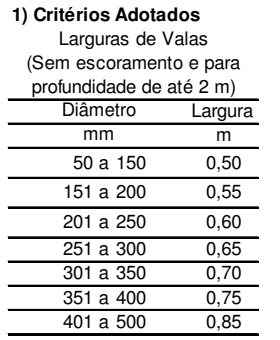

Locação das Redes

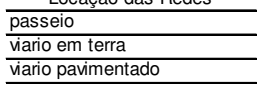

Recobrimento

\begin{tabular}{lc}
\hline Locação da & Recobrimento \\
\cline { 2 - 2 } Tubulação & $\mathrm{m}$ \\
\hline passeio & 0,7 \\
\hline viario em terra & 1,2 \\
\hline viario pavimentado & 1,0 \\
\hline
\end{tabular}

\begin{tabular}{l}
\hline \multicolumn{1}{c}{ Tipo de Tráfegos para Viário } \\
\hline Leve \\
\hline Médio \\
\hline Pesado \\
\hline \multicolumn{1}{c}{ Tipos de Superfície } \\
\hline asfalto \\
\hline poncreto \\
\hline terra
\end{tabular}

Pressurização Inicial Carga Inicial Rendimento Global Vida Útil
2) Dados Adotados Tubulação

Material

Classe de Pressão $\quad 6,4 \mathrm{Mp}$ Rugosidade Equivalente $(\mathrm{m}) \quad 0,0001$

Fator entre Diâmetro Hidráulico e Comercial

1,05

Largura Adotadas para Reposição de Pavimentos Devido Abertura de Valas (m)

\begin{tabular}{lc}
\hline Concreto Asfáltico Usinado a Quente & 3 \\
\hline Imprimação Betuminosa Ligante & 3 \\
\hline Binder & Larguravala $+0,2$ \\
\hline Imprimação Betuminosa Impermeabilizante & Larguravala $+0,2^{-}$
\end{tabular}

\begin{tabular}{ll}
\hline Macadame Hidáulico & Larguravala \\
\hline
\end{tabular}

Espessuras Adotadas para Reposição de Pavimentos Devido Abertura de Valas (m) Tráfego

Binder

\begin{tabular}{lll} 
& 0,04 & 0,07 \\
\hline Concreto Asfáltico Usinado a Quente & 0,04 & 0,05
\end{tabular}

\begin{tabular}{lll}
\hline Concreto Asfáltico Usinado a Quente & 0,04 & 0,05 \\
\hline Macadame Hidáulico & 0,10 & 0,12
\end{tabular}

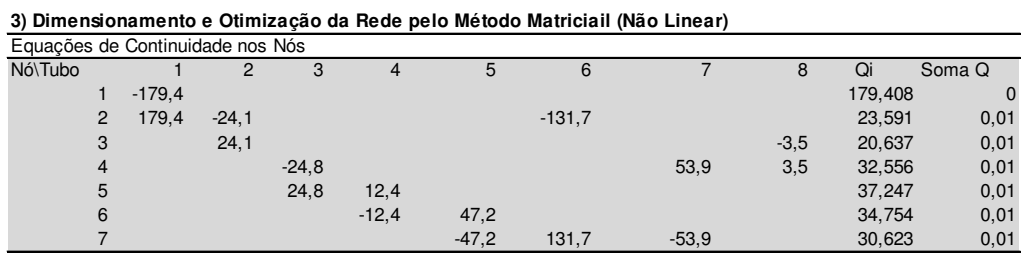

\begin{tabular}{crrrrrrrrr}
\hline Equações de Perda de Carga nos Circuitos & & & & & \\
\hline Circuitos & 1 & 2 & 3 & 4 & 5 & 6 & 7 & 8 & Soma Perda \\
& & & & & & & & \\
1 & $-0,313$ & & & & 1,432 & 0,507 & $-1,626$ & 0,0001 \\
2 & & $-0,853$ & 0,346 & 1,013 & & $-0,507$ & & 0,0001 \\
\hline
\end{tabular}

Tabela da Função Objetivo

\begin{tabular}{|c|c|c|c|c|c|c|c|c|c|c|c|c|c|c|}
\hline \multirow{2}{*}{ Trecho } & \multicolumn{2}{|c|}{ Nó Montante } & \multicolumn{2}{|c|}{ No Jusante } & \multirow{2}{*}{$\begin{array}{r}\begin{array}{r}\text { Extensão } \\
\text { do Trecho }\end{array} \\
(\mathrm{m})\end{array}$} & \multirow{2}{*}{$\begin{array}{c}\begin{array}{c}\text { Vazão do } \\
\text { Trecho }\end{array} \\
\text { l/s }\end{array}$} & \multirow{2}{*}{$\begin{array}{c}\begin{array}{c}\text { Diâmetro } \\
\text { Nominal } \\
\text { Comercial }\end{array} \\
(\mathrm{mm})\end{array}$} & \multirow{2}{*}{$\begin{array}{c}\begin{array}{c}\text { Diâmetro } \\
\text { Ótimo }\end{array} \\
(\mathrm{mm})\end{array}$} & \multirow{2}{*}{$\begin{array}{c}\text { Velocidade } \\
(\mathrm{m} / \mathrm{s})\end{array}$} & \multirow[t]{2}{*}{$\begin{array}{l}\text { Fator de } \\
\text { Atrito } f\end{array}$} & \multirow{2}{*}{$\begin{array}{c}\begin{array}{c}\text { Perda de } \\
\text { Carga }\end{array} \\
(\mathrm{m})\end{array}$} & \multirow{2}{*}{$\begin{array}{c}\begin{array}{c}\text { Carga } \\
\text { Montante }\end{array} \\
(\mathrm{m})\end{array}$} & \multirow{2}{*}{$\begin{array}{c}\text { Carga Jusante } \\
(\mathrm{m})\end{array}$} & \multirow{2}{*}{$\begin{array}{c}\text { Potência Dissipada } \\
\mathrm{kW}\end{array}$} \\
\hline & Nome & Cota & Nome & Cota & & & & & & & & & & \\
\hline T1 & N1 & 4,56 & N2 & 3,50 & 258,48 & 179,4 & 400 & 400 & 1,42 & 0,0082 & 0,55 & 11,64 & 12,15 & 1,37 \\
\hline T3 & $\mathrm{N} 4$ & 1,50 & N5 & 0,49 & 657,53 & 24,8 & 200 & 200 & 0,79 & 0,0082 & 0,85 & 12,21 & 12,37 & 0,30 \\
\hline T4 & N5 & 0,49 & N6 & 0,50 & 253,28 & 12,4 & 150 & 149 & 0,70 & 0,0082 & 0,35 & 12,37 & 12,01 & 0,06 \\
\hline T5 & N6 & 0,50 & N7 & 1,50 & 660,47 & 47,2 & 250 & 249 & 0,96 & 0,0082 & 1,01 & 12,01 & 10,00 & 0,67 \\
\hline T6 & N2 & 3,50 & N7 & 1,50 & 644,10 & 131,7 & 350 & 350 & 1,36 & 0,0082 & 1,43 & 12,15 & 12,72 & 2,64 \\
\hline
\end{tabular}

4) Resumo do Dimensionamento Otimizado

\begin{tabular}{|c|c|c|c|}
\hline & Potê & a Dissipada & Pressurização Inicial \\
\hline Soma & & 5,61 & 29,22 \\
\hline Energia & & $36.843,21$ & $192.006,96$ \\
\hline FA & & 12,16 & 12,16 \\
\hline Sub-Total & $\mathbf{R} \$$ & $74.398,82$ & $387.726,61$ \\
\hline
\end{tabular}

\begin{tabular}{|c|c|c|}
\hline Custos & & Porcentagem \\
\hline Custo de Tubulação $R \$$ & $934.801,82$ & $61,32 \%$ \\
\hline Custo de Movimento de Terra $R \$$ & $65.168,87$ & $4,27 \%$ \\
\hline Custo de Assentamento $\mathrm{R} \$$ & $10.608,37$ & $0,70 \%$ \\
\hline Custo de Pavimentação $\mathrm{R} \$$ & $51.833,19$ & $3,40 \%$ \\
\hline Custo da Pressurização Inicial $\mathrm{R} \$$ & $387.726,61$ & $25,43 \%$ \\
\hline Custo da Potência Dissipada $R \$$ & $74.398,82$ & $4,88 \%$ \\
\hline Total Global (Funçäo Objetivo) R\$ & $1.524 .537,67$ & $100,00 \%$ \\
\hline Total Referencial Unitário $\mathbf{R} \$$ & 418,83 & por metro de rede \\
\hline
\end{tabular}


5) Quantitativos e Custos de Implantação das Redes de Abastecimento

\begin{tabular}{|c|c|c|c|c|c|c|c|c|c|}
\hline Trecho & $\begin{array}{l}\text { Locação da } \\
\text { Tubulação }\end{array}$ & $\begin{array}{c}\text { Tipo de } \\
\text { Superfície }\end{array}$ & Tipo de Tráfego & & & & & & \\
\hline $\mathrm{T} 1$ & viario pavimentado & paralelepipedos & - & & & & & & \\
\hline $\mathrm{T} 2$ & viario pavimentado & paralelepipedos & - & & & & & & \\
\hline T3 & vario pavimentado & paralelepipedos & - & & & & & & \\
\hline T4 & vario pavimentado & paralelepipedos & - & & & & & & \\
\hline $\mathrm{T5}$ & viario pavimentado & paralelepipedos & - & & & & & & \\
\hline T6 & viario pavimentado & paralelepipedos & - & & & & & & \\
\hline 77 & viario pavimentado & paralelepipedos & - & & & & & & \\
\hline \multirow[t]{2}{*}{ T8 } & viario pavimentado & paralelepipedos & - & & & & & & \\
\hline & \multicolumn{6}{|c|}{ Vala } & \multicolumn{3}{|c|}{ Tubulação } \\
\hline \multirow[t]{2}{*}{ Trecho } & Largura & $\begin{array}{l}\text { Profundidade } \\
\end{array}$ & Escavação & Reaterro & Bota-Fora & TOTAL & Assentamento & Material & TOTAL \\
\hline & $\mathrm{m}$ & $\mathrm{m}$ & $\mathrm{m}^{3}$ & $\mathrm{~m}^{3}$ & $\mathrm{~m}^{3}$ & $\mathrm{R} \$$ & $\mathrm{R} \$$ & $\mathrm{R} \$$ & $\mathrm{R} \$$ \\
\hline $\mathrm{T} 1$ & 0,75 & 1,40 & 271,40 & 238,92 & 32,48 & $6.481,67$ & $1.330,32$ & $117.523,27$ & $118.853,60$ \\
\hline $\mathrm{T} 2$ & 0,55 & 1,20 & 168,91 & 160,87 & 8,04 & $4.155,87$ & 635,06 & $56.118,96$ & $56.754,03$ \\
\hline T3 & 0,55 & 1,20 & 433,97 & 413,31 & 20,66 & $10.677,19$ & $1.631,59$ & $144.179,67$ & $145.811,26$ \\
\hline T4 & 0,50 & 1,15 & 145,64 & 141,16 & 4,48 & $3.607,75$ & 499,61 & $43.671,97$ & \begin{tabular}{|l|l|}
$44.171,58$ \\
\end{tabular} \\
\hline T5 & 0,60 & 1,25 & 495,35 & 462,93 & 32,42 & $12.098,91$ & $2.016,56$ & $178.936,95$ & $180.953,51$ \\
\hline T6 & 0,70 & 1,35 & 608,67 & 546,70 & 61,97 & $14.645,24$ & $2.824,95$ & $250.311,21$ & $253.136,16$ \\
\hline 77 & 0,60 & 1,25 & 189,77 & 177,34 & 12,42 & $4.634,98$ & 772,53 & $68.549,10$ & $69.321,63$ \\
\hline \multirow[t]{2}{*}{ T8 } & 0,50 & 1,08 & 354,88 & 351,57 & 3,30 & $8.867,25$ & 897,74 & $75.510,68$ & $76.408,42$ \\
\hline & & & & & Soma & $65.168,87$ & $\begin{array}{ll}R \$ 10.608,37 \\
\end{array}$ & $\mathrm{R} \$ 934.801,82 \quad \mathrm{R} \$$ & $945.410,19$ \\
\hline \multirow{2}{*}{\multicolumn{10}{|c|}{$\frac{\text { Pavimentação }}{\text { Vala }}$}} \\
\hline & & & & & & & & & \\
\hline \multirow[t]{2}{*}{ Trecho } & Área & $\begin{array}{l}\text { Área de } \\
\text { Concreto }\end{array}$ & $\begin{array}{c}\text { Área de } \\
\text { Paralelepipedos }\end{array}$ & $\begin{array}{l}\text { Área de } \\
\text { Asfalto }\end{array}$ & Área de Binder & $\begin{array}{l}\text { Area de Concreto Astático } \\
\text { Usinado a Quente }\end{array}$ & & & \\
\hline & $\mathrm{m}^{2}$ & $\mathrm{~m}^{2}$ & $\mathrm{~m}^{2}$ & $\mathrm{~m}^{2}$ & $\mathrm{~m}^{2}$ & $\mathrm{~m}^{2}$ & & & \\
\hline $\mathrm{T} 1$ & 193,86 & 0,00 & 193,86 & 0,00 & 0,00 & 0,00 & & & \\
\hline $\mathrm{T} 2$ & 140,76 & 0,00 & 140,76 & 0,00 & 0,00 & 0,00 & & & \\
\hline T3 & 361,64 & 0,00 & 361,64 & 0,00 & 0,00 & 0,00 & & & \\
\hline T4 & 126,64 & 0,00 & 126,64 & 0,00 & 0,00 & 0,00 & & & \\
\hline T5 & 396,28 & 0,00 & 396,28 & 0,00 & 0,00 & 0,00 & & & \\
\hline T6 & 450,87 & 0,00 & 450,87 & 0,00 & 0,00 & 0,00 & & & \\
\hline 77 & 151,81 & 0,00 & 151,81 & 0,00 & 0,00 & 0,00 & & & \\
\hline T8 & 328,59 & 0,00 & 328,59 & 0,00 & 0,00 & 0,00 & & & \\
\hline
\end{tabular}

\begin{tabular}{|c|c|c|c|c|c|c|c|c|c|}
\hline \multirow{4}{*}{ Trecho } & \multicolumn{9}{|c|}{ Pavimentação } \\
\hline & \multicolumn{3}{|c|}{ Volume } & \multicolumn{2}{|c|}{ Área } & \multicolumn{4}{|c|}{ Custos } \\
\hline & Macadame Hidáulico & Binder & $\begin{array}{l}\text { Concreto } \\
\text { Astáltico Usinado } \\
\text { a Quente }\end{array}$ & $\begin{array}{l}\text { Imprimação } \\
\text { Betuminosa } \\
\text { Ligante }\end{array}$ & $\begin{array}{l}\text { Imprimação } \\
\text { Betuminosa } \\
\text { Impermeabiliza } \\
\text { nte }\end{array}$ & Remoção & Recomposição & Transporte & TOTAL \\
\hline & $\mathrm{m}^{3}$ & $\mathrm{~m}^{3}$ & $\mathrm{~m}^{3}$ & $\mathrm{~m}^{2}$ & $\mathrm{~m}^{2}$ & $\mathrm{R} \$$ & $\mathrm{R} \$$ & $\mathrm{R} \$$ & $\mathrm{R} \$$ \\
\hline $\mathrm{T} 1$ & 0,00 & 0,00 & 0,00 & 0,00 & 0,00 & 993,09 & $3.679,58$ & 0,00 & $4.672,67$ \\
\hline $\mathrm{T} 2$ & 0,00 & 0,00 & 0,00 & 0,00 & 0,00 & 721,08 & $2.671,74$ & 0,00 & $3.392,82$ \\
\hline T3 & 0,00 & 0,00 & 0,00 & 0,00 & 0,00 & $1.852,59$ & $6.864,18$ & 0,00 & $8.716,77$ \\
\hline T4 & 0,00 & 0,00 & 0,00 & 0,00 & 0,00 & 648,74 & $2.403,70$ & 0,00 & $3.052,45$ \\
\hline T5 & 0,00 & 0,00 & 0,00 & 0,00 & 0,00 & $2.030,04$ & $7.521,67$ & 0,00 & $9.551,72$ \\
\hline T6 & 0,00 & 0,00 & 0,00 & 0,00 & 0,00 & $2.309,68$ & $8.557,79$ & 0,00 & $10.867,47$ \\
\hline 77 & 0,00 & 0,00 & 0,00 & 0,00 & 0,00 & 777,69 & $2.881,48$ & 0,00 & $3.659,18$ \\
\hline T8 & 0,00 & 0,00 & 0,00 & 0,00 & 0,00 & $1.683,28$ & $6.236,84$ & 0,00 & $7.920,12$ \\
\hline
\end{tabular}




\section{APÊNDICE D8 - Planilha de Dimensionamento para Vida Útil de 40 anos e Viário em Paralelepípedo - FoFo}

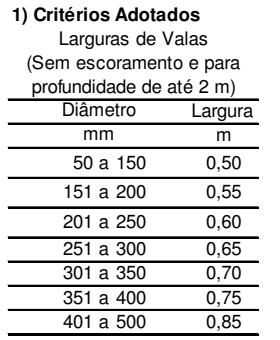

Locação das Redes

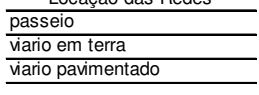

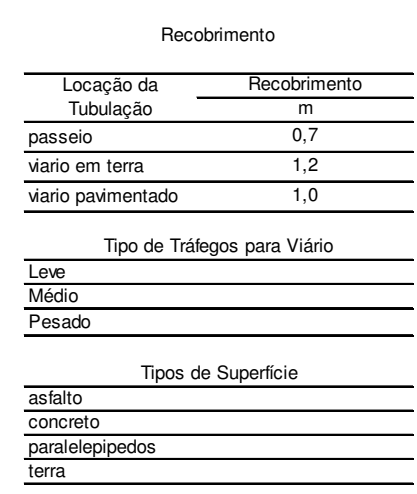

2) Dados Adotados Tubulação

Materia \begin{tabular}{lr} 
Rugosidade Equivalente $(\mathrm{m}) \quad 0,0001$ \\
\hline
\end{tabular}

Fator entre Diâmetro Hidráulico e Comercial
Pressurização Inicial \begin{tabular}{lr}
\hline Carga Inicial & 11,64 \\
\hline Rendimento Global & 0,70 \\
\hline
\end{tabular}

\begin{tabular}{ll}
\hline Horas de Funcionamer & 6,70 \\
\hline Vidano
\end{tabular} Vida Útil

1,05
Largura Adotadas para Reposição de Pavimentos Devido Abertura de Valas (m)

\begin{tabular}{ll}
\hline Concreto Asfáltico Usinado a Quente & 3 \\
\hline Imprimacão Betuminosa Ligante & 3
\end{tabular} \begin{tabular}{lc}
\hline Imprimação Betuminosa Ligante & 3 \\
\hline Binder & Larguravala $+0,2$
\end{tabular} \begin{tabular}{ll}
\hline Binder & Larguravala $+0,2$ \\
\hline Imprimação Betuminosa Impermeabilizante & Largura
\end{tabular} \begin{tabular}{ll}
\hline Macadame Hidáulico & Larguravala \\
\hline
\end{tabular}

Espessuras Adotadas para Reposição de Pavimentos Devido Abertura de Valas (m) Tráfego Leve Médio Pesado \begin{tabular}{lll}
\hline Binder & 0,04 & 0,07 \\
\hline Concreto Asfáltico Usinado a Quente & 0,04 & 0,05
\end{tabular}

\begin{tabular}{lll}
\hline Macadame Hidáulico & 0,10 & 0,12
\end{tabular}

0,05

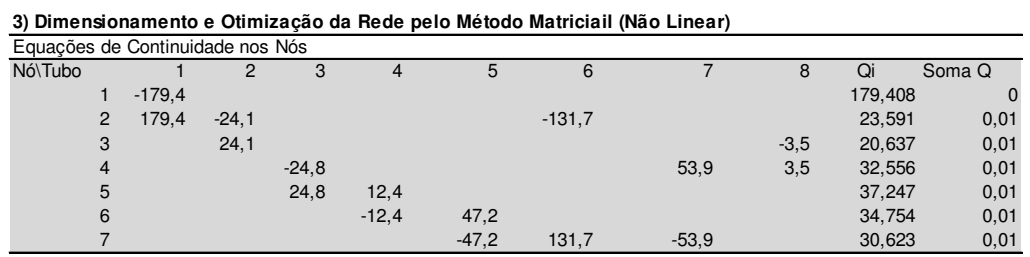

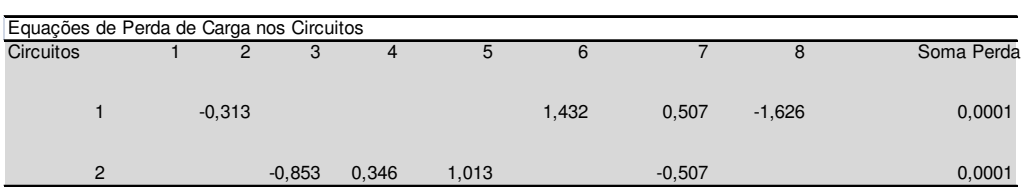

Tabela da Função Objetivo

\begin{tabular}{|c|c|c|c|c|c|c|c|c|c|c|c|c|c|c|}
\hline \multirow{2}{*}{ Trecho } & \multicolumn{2}{|c|}{ Nó Montante } & \multicolumn{2}{|c|}{ No Jusante } & \multirow{2}{*}{$\begin{array}{r}\begin{array}{r}\text { Extensão } \\
\text { do Trecho }\end{array} \\
(\mathrm{m})\end{array}$} & \multirow{2}{*}{$\begin{array}{c}\begin{array}{c}\text { Vazão do } \\
\text { Trecho }\end{array} \\
\text { l/s }\end{array}$} & \multirow{2}{*}{$\begin{array}{c}\begin{array}{c}\text { Diâmetro } \\
\text { Nominal } \\
\text { Comercial }\end{array} \\
(\mathrm{mm})\end{array}$} & \multirow{2}{*}{$\begin{array}{c}\begin{array}{c}\text { Diâmetro } \\
\text { Ótimo }\end{array} \\
(\mathrm{mm})\end{array}$} & \multirow{2}{*}{$\begin{array}{c}\text { Velocidade } \\
(\mathrm{m} / \mathrm{s})\end{array}$} & \multirow[t]{2}{*}{$\begin{array}{l}\text { Fator de } \\
\text { Atrito } f\end{array}$} & \multirow{2}{*}{$\begin{array}{c}\begin{array}{c}\text { Perda de } \\
\text { Carga }\end{array} \\
(\mathrm{m})\end{array}$} & \multirow{2}{*}{$\begin{array}{c}\begin{array}{c}\text { Carga } \\
\text { Montante }\end{array} \\
(\mathrm{m})\end{array}$} & \multirow{2}{*}{$\begin{array}{c}\text { Carga Jusante } \\
(\mathrm{m})\end{array}$} & \multirow{2}{*}{$\begin{array}{c}\text { Potência Dissipada } \\
\mathrm{kW}\end{array}$} \\
\hline & Nome & Cota & Nome & Cota & & & & & & & & & & \\
\hline T1 & N1 & 4,56 & N2 & 3,50 & 258,48 & 179,4 & 400 & 400 & 1,42 & 0,0082 & 0,55 & 11,64 & 12,15 & 1,37 \\
\hline T3 & $\mathrm{N} 4$ & 1,50 & N5 & 0,49 & 657,53 & 24,8 & 200 & 200 & 0,79 & 0,0082 & 0,85 & 12,21 & 12,37 & 0,30 \\
\hline T4 & N5 & 0,49 & N6 & 0,50 & 253,28 & 12,4 & 150 & 149 & 0,70 & 0,0082 & 0,35 & 12,37 & 12,01 & 0,06 \\
\hline T5 & N6 & 0,50 & N7 & 1,50 & 660,47 & 47,2 & 250 & 249 & 0,96 & 0,0082 & 1,01 & 12,01 & 10,00 & 0,67 \\
\hline T6 & N2 & 3,50 & N7 & 1,50 & 644,10 & 131,7 & 350 & 350 & 1,36 & 0,0082 & 1,43 & 12,15 & 12,72 & 2,64 \\
\hline
\end{tabular}

4) Resumo do Dimensionamento Otimizado

\begin{tabular}{|c|c|c|c|}
\hline & Potê & a Dissipada & Pressurização Inicial \\
\hline Soma & & 5,61 & 29,22 \\
\hline Energia & & $36.843,21$ & $192.006,96$ \\
\hline FA & & 12,88 & 12,88 \\
\hline Sub-Total & $\mathbf{R} \$$ & $78.805,67$ & $410.692,75$ \\
\hline
\end{tabular}

\begin{tabular}{|c|c|c|}
\hline Custos & & Porcentagem \\
\hline Custo de Tubulação $R \$$ & $934.801,82$ & $60,24 \%$ \\
\hline Custo de Movimento de Terra $R \$$ & $65.168,87$ & $4,20 \%$ \\
\hline Custo de Assentamento $\mathrm{R} \$$ & $10.608,37$ & $0,68 \%$ \\
\hline Custo de Pavimentação $\mathrm{R} \$$ & $51.833,19$ & $3,34 \%$ \\
\hline Custo da Pressurização Inicial $\mathrm{R} \$$ & $410.692,75$ & $26,46 \%$ \\
\hline Custo da Potência Dissipada $\mathrm{R} \$$ & $78.805,67$ & $5,08 \%$ \\
\hline Total Global (Funçäo Objetivo) R\$ & $1.551 .910,66$ & $100,00 \%$ \\
\hline Total Referencial Unitário $\mathbf{R} \$$ & 426,35 & por metro de rede \\
\hline
\end{tabular}


5) Quantitativos e Custos de Implantação das Redes de Abastecimento

\begin{tabular}{|c|c|c|c|c|c|c|c|c|c|}
\hline Trecho & $\begin{array}{l}\text { Locação da } \\
\text { Tubulação }\end{array}$ & $\begin{array}{c}\text { Tipo de } \\
\text { Superfície }\end{array}$ & Tipo de Tráfego & & & & & & \\
\hline $\mathrm{T} 1$ & viario pavimentado & paralelepipedos & - & & & & & & \\
\hline $\mathrm{T} 2$ & viario pavimentado & paralelepipedos & - & & & & & & \\
\hline T3 & vario pavimentado & paralelepipedos & - & & & & & & \\
\hline T4 & vario pavimentado & paralelepipedos & - & & & & & & \\
\hline $\mathrm{T5}$ & viario pavimentado & paralelepipedos & - & & & & & & \\
\hline T6 & viario pavimentado & paralelepipedos & - & & & & & & \\
\hline 77 & viario pavimentado & paralelepipedos & - & & & & & & \\
\hline \multirow[t]{2}{*}{ T8 } & viario pavimentado & paralelepipedos & - & & & & & & \\
\hline & \multicolumn{6}{|c|}{ Vala } & \multicolumn{3}{|c|}{ Tubulação } \\
\hline \multirow[t]{2}{*}{ Trecho } & Largura & $\begin{array}{l}\text { Profundidade } \\
\end{array}$ & Escavação & Reaterro & Bota-Fora & TOTAL & Assentamento & Material & TOTAL \\
\hline & $\mathrm{m}$ & $\mathrm{m}$ & $\mathrm{m}^{3}$ & $\mathrm{~m}^{3}$ & $\mathrm{~m}^{3}$ & $\mathrm{R} \$$ & $\mathrm{R} \$$ & $\mathrm{R} \$$ & $\mathrm{R} \$$ \\
\hline $\mathrm{T} 1$ & 0,75 & 1,40 & 271,40 & 238,92 & 32,48 & $6.481,67$ & $1.330,32$ & $117.523,27$ & $118.853,60$ \\
\hline $\mathrm{T} 2$ & 0,55 & 1,20 & 168,91 & 160,87 & 8,04 & $4.155,87$ & 635,06 & $56.118,96$ & $56.754,03$ \\
\hline T3 & 0,55 & 1,20 & 433,97 & 413,31 & 20,66 & $10.677,19$ & $1.631,59$ & $144.179,67$ & $145.811,26$ \\
\hline T4 & 0,50 & 1,15 & 145,64 & 141,16 & 4,48 & $3.607,75$ & 499,61 & $43.671,97$ & \begin{tabular}{|l|l|}
$44.171,58$ \\
\end{tabular} \\
\hline T5 & 0,60 & 1,25 & 495,35 & 462,93 & 32,42 & $12.098,91$ & $2.016,56$ & $178.936,95$ & $180.953,51$ \\
\hline T6 & 0,70 & 1,35 & 608,67 & 546,70 & 61,97 & $14.645,24$ & $2.824,95$ & $250.311,21$ & $253.136,16$ \\
\hline 77 & 0,60 & 1,25 & 189,77 & 177,34 & 12,42 & $4.634,98$ & 772,53 & $68.549,10$ & $69.321,63$ \\
\hline \multirow[t]{2}{*}{ T8 } & 0,50 & 1,08 & 354,88 & 351,57 & 3,30 & $8.867,25$ & 897,74 & $75.510,68$ & $76.408,42$ \\
\hline & & & & & Soma & $65.168,87$ & $\begin{array}{ll}R \$ 10.608,37 \\
\end{array}$ & $\mathrm{R} \$ 934.801,82 \quad \mathrm{R} \$$ & $945.410,19$ \\
\hline \multirow{2}{*}{\multicolumn{10}{|c|}{$\frac{\text { Pavimentação }}{\text { Vala }}$}} \\
\hline & & & & & & & & & \\
\hline \multirow[t]{2}{*}{ Trecho } & Área & $\begin{array}{l}\text { Área de } \\
\text { Concreto }\end{array}$ & $\begin{array}{c}\text { Área de } \\
\text { Paralelepipedos }\end{array}$ & $\begin{array}{l}\text { Área de } \\
\text { Asfalto }\end{array}$ & Área de Binder & $\begin{array}{l}\text { Area de Concreto Astático } \\
\text { Usinado a Quente }\end{array}$ & & & \\
\hline & $\mathrm{m}^{2}$ & $\mathrm{~m}^{2}$ & $\mathrm{~m}^{2}$ & $\mathrm{~m}^{2}$ & $\mathrm{~m}^{2}$ & $\mathrm{~m}^{2}$ & & & \\
\hline $\mathrm{T} 1$ & 193,86 & 0,00 & 193,86 & 0,00 & 0,00 & 0,00 & & & \\
\hline $\mathrm{T} 2$ & 140,76 & 0,00 & 140,76 & 0,00 & 0,00 & 0,00 & & & \\
\hline T3 & 361,64 & 0,00 & 361,64 & 0,00 & 0,00 & 0,00 & & & \\
\hline T4 & 126,64 & 0,00 & 126,64 & 0,00 & 0,00 & 0,00 & & & \\
\hline T5 & 396,28 & 0,00 & 396,28 & 0,00 & 0,00 & 0,00 & & & \\
\hline T6 & 450,87 & 0,00 & 450,87 & 0,00 & 0,00 & 0,00 & & & \\
\hline 77 & 151,81 & 0,00 & 151,81 & 0,00 & 0,00 & 0,00 & & & \\
\hline T8 & 328,59 & 0,00 & 328,59 & 0,00 & 0,00 & 0,00 & & & \\
\hline
\end{tabular}

\begin{tabular}{|c|c|c|c|c|c|c|c|c|c|}
\hline \multirow{4}{*}{ Trecho } & \multicolumn{9}{|c|}{ Pavimentação } \\
\hline & \multicolumn{3}{|c|}{ Volume } & \multicolumn{2}{|c|}{ Área } & \multicolumn{4}{|c|}{ Custos } \\
\hline & Macadame Hidáulico & Binder & $\begin{array}{l}\text { Concreto } \\
\text { Astáltico Usinado } \\
\text { a Quente }\end{array}$ & $\begin{array}{l}\text { Imprimação } \\
\text { Betuminosa } \\
\text { Ligante }\end{array}$ & $\begin{array}{l}\text { Imprimação } \\
\text { Betuminosa } \\
\text { Impermeabiliza } \\
\text { nte }\end{array}$ & Remoção & Recomposição & Transporte & TOTAL \\
\hline & $\mathrm{m}^{3}$ & $\mathrm{~m}^{3}$ & $\mathrm{~m}^{3}$ & $\mathrm{~m}^{2}$ & $\mathrm{~m}^{2}$ & $\mathrm{R} \$$ & $\mathrm{R} \$$ & $\mathrm{R} \$$ & $\mathrm{R} \$$ \\
\hline $\mathrm{T} 1$ & 0,00 & 0,00 & 0,00 & 0,00 & 0,00 & 993,09 & $3.679,58$ & 0,00 & $4.672,67$ \\
\hline $\mathrm{T} 2$ & 0,00 & 0,00 & 0,00 & 0,00 & 0,00 & 721,08 & $2.671,74$ & 0,00 & $3.392,82$ \\
\hline T3 & 0,00 & 0,00 & 0,00 & 0,00 & 0,00 & $1.852,59$ & $6.864,18$ & 0,00 & $8.716,77$ \\
\hline T4 & 0,00 & 0,00 & 0,00 & 0,00 & 0,00 & 648,74 & $2.403,70$ & 0,00 & $3.052,45$ \\
\hline T5 & 0,00 & 0,00 & 0,00 & 0,00 & 0,00 & $2.030,04$ & $7.521,67$ & 0,00 & $9.551,72$ \\
\hline T6 & 0,00 & 0,00 & 0,00 & 0,00 & 0,00 & $2.309,68$ & $8.557,79$ & 0,00 & $10.867,47$ \\
\hline 77 & 0,00 & 0,00 & 0,00 & 0,00 & 0,00 & 777,69 & $2.881,48$ & 0,00 & $3.659,18$ \\
\hline T8 & 0,00 & 0,00 & 0,00 & 0,00 & 0,00 & $1.683,28$ & $6.236,84$ & 0,00 & $7.920,12$ \\
\hline
\end{tabular}




\section{APÊNDICE E1 - Planilha de Dimensionamento para aumento de $100 \%$ na tubulação de PVC e Viário em Paralelepípedo}

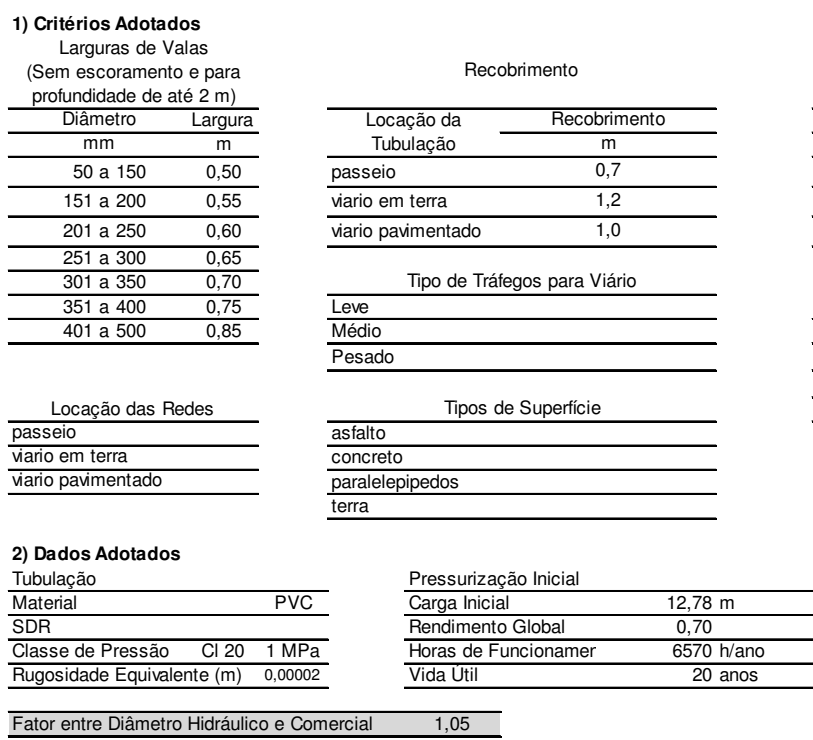

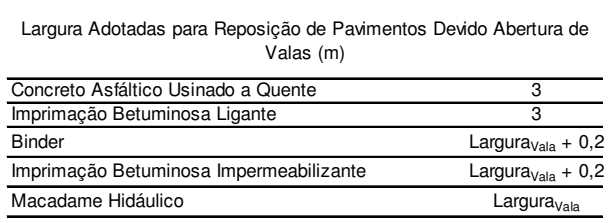

Espessuras Adotadas para Reposição de Pavimentos Devido Abertura de Valas (m)

\begin{tabular}{|c|c|c|c|}
\hline Tráfego & Leve & Médio & Pesado \\
\hline Binder & 0,04 & 0,07 & 0,10 \\
\hline Concreto Asfáltico Usinado a Quente & 0,04 & 0,05 & 0,05 \\
\hline $\begin{array}{l}\text { Macadame Hidáulico } \\
\end{array}$ & 0,10 & 0,12 & 0,15 \\
\hline
\end{tabular}

Energia
\begin{tabular}{ll}
\hline Grupo A (Alta e Média Tensão) \\
\hline Sub-Grupo A4 (2,3 KV a 25 KV) \\
\hline Custo de Energia por Demanda & $31,31 \mathrm{R} \$ / \mathrm{KW}$ \\
\hline Custo de Energia por Consumo & $0,16132 \mathrm{R} \$ / \mathrm{KWh}$ \\
\hline Taxa de Juros & $8,00 \% \mathrm{aa}$ \\
\hline Fator de Atualização & 10,60 \\
\hline
\end{tabular}

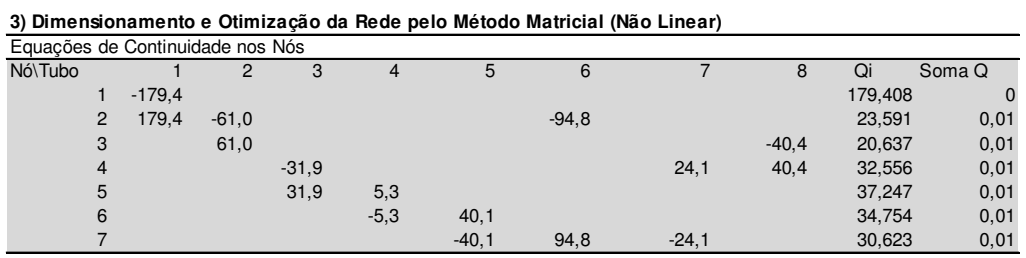

\begin{tabular}{|c|c|c|c|c|c|c|c|c|c|}
\hline \multicolumn{10}{|c|}{ Equações de Perda de Carga nos Circuitos } \\
\hline Circuitos & 1 & 2 & 3 & 4 & 5 & 6 & 7 & 8 & Soma Perda \\
\hline 1 & & $-0,506$ & & & & 1,237 & 1,006 & $-1,737$ & 0,0001 \\
\hline 2 & & & $-1,087$ & 0,372 & 1,720 & & $-1,006$ & & $1 \mathrm{E}-04$ \\
\hline
\end{tabular}

Tabela da Função Objetivo

\begin{tabular}{|c|c|c|c|c|c|c|c|c|c|c|c|c|c|c|}
\hline \multirow{2}{*}{ Trecho } & \multicolumn{2}{|c|}{ Nó Montante } & \multicolumn{2}{|c|}{ No Jusante } & \multirow{2}{*}{$\begin{array}{c}\begin{array}{c}\text { Extensão } \\
\text { do Trecho }\end{array} \\
\text { (m) } \\
\end{array}$} & \multirow{2}{*}{$\begin{array}{c}\text { Vazão do } \\
\text { Trecho }\end{array}$} & \multirow{2}{*}{$\begin{array}{c}\begin{array}{c}\text { Diâmetro } \\
\text { Nominal } \\
\text { Comercial }\end{array} \\
(\mathrm{mm})\end{array}$} & \multirow{2}{*}{$\begin{array}{c}\text { Diâmetro } \\
\text { Ótimo }\end{array}$} & \multirow{2}{*}{$\begin{array}{c}\text { Velocidade } \\
(\mathrm{m} / \mathrm{s})\end{array}$} & \multirow[t]{2}{*}{$\begin{array}{l}\text { Fator de } \\
\text { Atrito } f\end{array}$} & \multirow{2}{*}{$\begin{array}{c}\text { Perda de Carga } \\
(\mathrm{m})\end{array}$} & \multirow{2}{*}{$\begin{array}{c}\begin{array}{c}\text { Carga } \\
\text { Montante }\end{array} \\
(\mathrm{m})\end{array}$} & \multirow{2}{*}{$\begin{array}{c}\text { Carga Jusante } \\
(\mathrm{m})\end{array}$} & \multirow{2}{*}{$\begin{array}{c}\text { Potência Dissipada } \\
\text { kW }\end{array}$} \\
\hline & Nome & Cota & Nome & Cota & & & & & & & & & & \\
\hline T1 & $\mathrm{N} 1$ & 4,56 & N2 & 3,50 & 258,48 & 179,4 & 400 & 400 & 1,42 & 0,0063 & 0,42 & 12,78 & 13,42 & 1,06 \\
\hline T2 & N2 & 3,50 & N3 & 3,50 & 255,93 & 61,0 & 250 & 250 & 1,24 & 0,0063 & 0,51 & 13,42 & 12,92 & 0,43 \\
\hline T3 & $\mathrm{N} 4$ & 1,50 & N5 & 0,49 & 657,53 & 31,9 & 200 & 200 & 1,01 & 0,0063 & 1,09 & 13,18 & 13,10 & 0,49 \\
\hline T4 & N5 & 0,49 & N6 & 0,50 & 253,28 & 5,3 & 100 & 100 & 0,68 & 0,0063 & 0,37 & 13,10 & 12,72 & 0,03 \\
\hline T5 & N6 & 0,50 & N7 & 1,50 & 660,47 & 40,1 & 200 & 200 & 1,27 & 0,0063 & 1,72 & 12,72 & 10,00 & 0,96 \\
\hline T6 & N2 & 3,50 & N7 & 1,50 & 644,10 & 94,8 & 300 & 300 & 1,34 & 0,0063 & 1,24 & 13,42 & 14,19 & 1,64 \\
\hline 77 & N7 & 1,50 & $\mathrm{~N} 4$ & 1,50 & 253,02 & 24,1 & 150 & 150 & 1,36 & 0,0063 & 1,01 & 14,19 & 13,18 & 0,34 \\
\hline T8 & N3 & 3,50 & $\mathrm{~N} 4$ & 1,50 & 657,18 & 40,4 & 200 & 200 & 1,28 & 0,0063 & 1,74 & 13,42 & 13,69 & 0,98 \\
\hline
\end{tabular}

4) Resumo do Dimensionamento Otimizado

\begin{tabular}{|c|c|c|}
\hline & Potência Dissipada & Pressurização Inicial \\
\hline Soma & 5,93 & 32,10 \\
\hline Energia & $38.982,80$ & $210.921,98$ \\
\hline $\mathrm{FA}$ & 10,60 & 10,60 \\
\hline Sub-Total & $68.652,82$ & $371.455,80$ \\
\hline
\end{tabular}

\begin{tabular}{|c|c|c|}
\hline Custos & & Porcentagem \\
\hline Custo de Tubulação $R \$$ & $718.646,48$ & $56,00 \%$ \\
\hline Custo de Movimento de Terra $\mathrm{R} \$$ & $63.515,87$ & $4,95 \%$ \\
\hline Custo de Assentamento $\mathrm{R} \$$ & $10.274,21$ & $0,80 \%$ \\
\hline Custo de Pavimentação $R \$$ & $50.751,55$ & $3,95 \%$ \\
\hline Custo da Pressurização Inicial $R \$$ & $371.455,80$ & $28,95 \%$ \\
\hline Custo da Potência Dissipada $\mathrm{R} \$$ & $68.652,82$ & $5,35 \%$ \\
\hline Total Global (Função Objetivo) R\$ & $1.283 .296,72$ & $100,00 \%$ \\
\hline Total Referencial Unitário R\$ & 352,56 & por metro de rede \\
\hline
\end{tabular}


5) Quantitativos e Custos de Implantação das Redes de Abastecimento

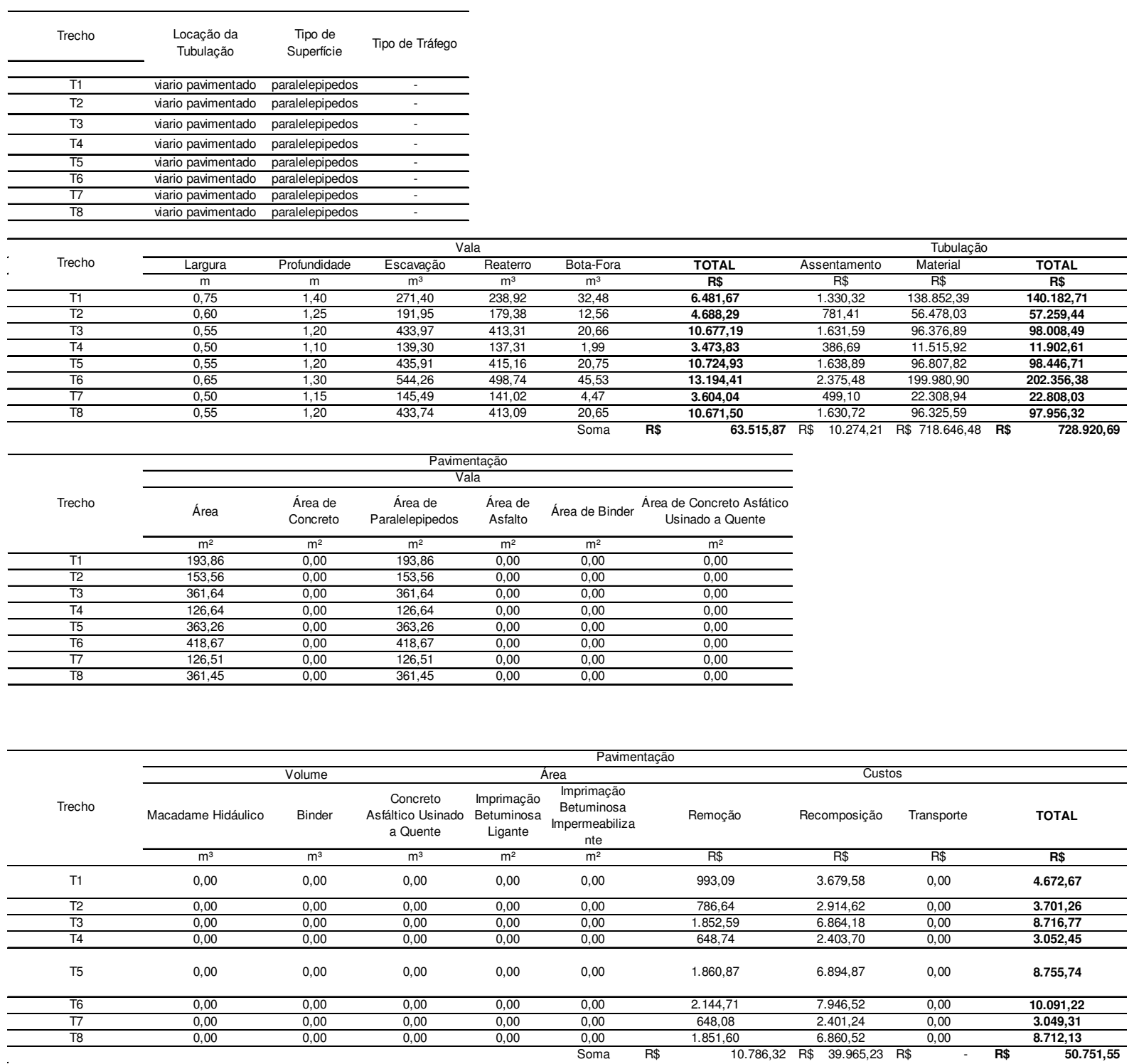




\section{APÊNDICE E2 - Planilha de Dimensionamento para aumento de 125\% na tubulação de PVC e Viário em Paralelepípedo}

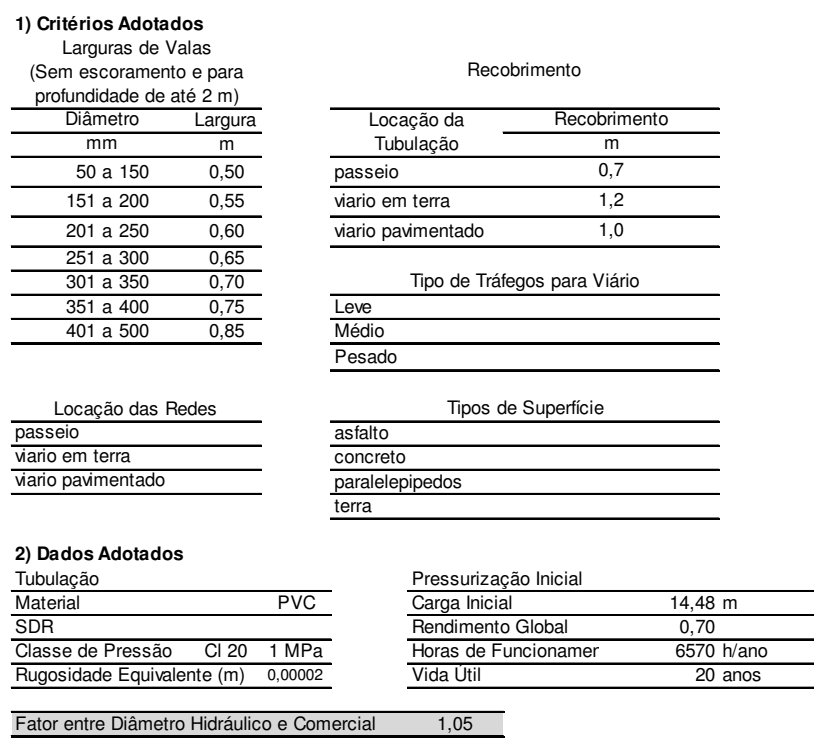

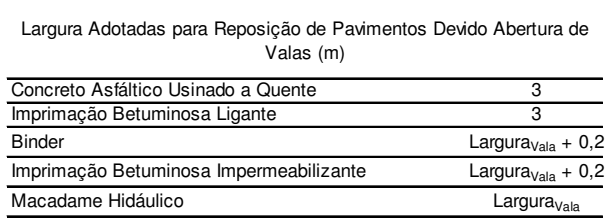

Espessuras Adotadas para Reposição de Pavimentos Devido Abertura de Valas (m)

\begin{tabular}{|c|c|c|c|}
\hline Tráfego & Leve & Médio & Pesado \\
\hline Binder & 0,04 & 0,07 & 0,10 \\
\hline Concreto Asfáltico Usinado a Quente & 0,04 & 0,05 & 0,05 \\
\hline $\begin{array}{l}\text { Macadame Hidáulico } \\
\end{array}$ & 0,10 & 0,12 & 0,15 \\
\hline
\end{tabular}
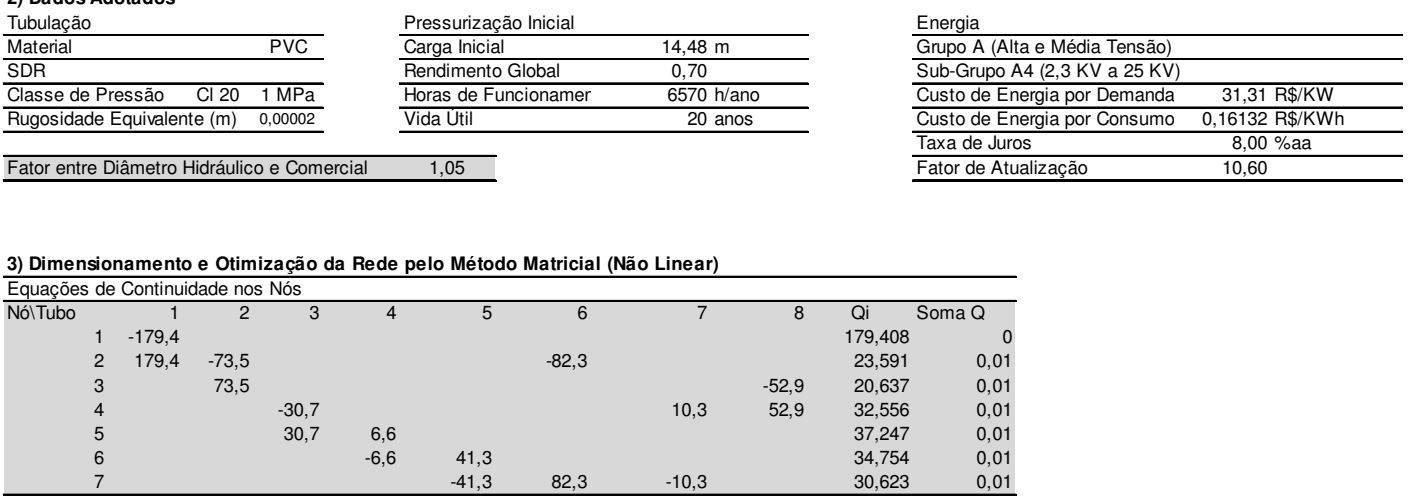

\begin{tabular}{|c|c|c|c|c|c|c|c|c|c|}
\hline \multicolumn{10}{|c|}{ Equações de Perda de Carga nos Circuitos } \\
\hline Circuitos & 1 & 2 & 3 & 4 & 5 & 6 & 7 & 8 & Soma Perda \\
\hline 1 & & $-0,736$ & & & & 2,319 & 1,399 & $-2,982$ & 0,0001 \\
\hline 2 & & & $-1,003$ & 0,570 & 1,831 & & $-1,399$ & & 0,0001 \\
\hline
\end{tabular}

Tabela da Função Objetivo

\begin{tabular}{|c|c|c|c|c|c|c|c|c|c|c|c|c|c|c|}
\hline \multirow{2}{*}{ Trecho } & \multicolumn{2}{|c|}{ Nó Montante } & \multicolumn{2}{|c|}{ No Jusante } & \multirow{2}{*}{$\begin{array}{c}\begin{array}{c}\text { Extensão } \\
\text { do Trecho }\end{array} \\
\text { (m) }\end{array}$} & \multirow{2}{*}{$\begin{array}{c}\begin{array}{c}\text { Vazão do } \\
\text { Trecho }\end{array} \\
\text { 1/s }\end{array}$} & \multirow{2}{*}{$\begin{array}{c}\text { Diâmetro } \\
\text { Nominal } \\
\text { Comercial }\end{array}$} & \multirow{2}{*}{$\begin{array}{c}\begin{array}{c}\text { Diâmetro } \\
\text { Ótimo }\end{array} \\
(\mathrm{mm})\end{array}$} & \multirow{2}{*}{$\begin{array}{c}\text { Velocidade } \\
(\mathrm{m} / \mathrm{s})\end{array}$} & \multirow{2}{*}{$\begin{array}{l}\text { Fator de } \\
\text { Atrito } f\end{array}$} & \multirow{2}{*}{$\begin{array}{c}\text { Perda de Carga } \\
(\mathrm{m})\end{array}$} & \multirow{2}{*}{$\begin{array}{c}\begin{array}{c}\text { Carga } \\
\text { Montante }\end{array} \\
(\mathrm{m})\end{array}$} & \multirow{2}{*}{$\begin{array}{c}\text { Carga Jusante } \\
(\mathrm{m})\end{array}$} & \multirow{2}{*}{$\begin{array}{c}\text { Potência Dissipada } \\
\text { kW }\end{array}$} \\
\hline & Nome & Cota & Nome & Cota & & & & & & & & & & \\
\hline $\mathrm{T} 1$ & $\mathrm{~N} 1$ & 4,56 & N2 & 3,50 & 258,48 & 179,4 & 400 & 401 & 1,42 & 0,0063 & 0,42 & 14,48 & 15,12 & 1,06 \\
\hline T2 & N2 & 3,50 & N3 & 3,50 & 255,93 & 73,5 & 250 & 250 & 1,49 & 0,0063 & 0,74 & 15,12 & 14,39 & 0,76 \\
\hline T3 & $\mathrm{N} 4$ & 1,50 & N5 & 0,49 & 657,53 & 30,7 & 200 & 200 & 0,97 & 0,0063 & 1,00 & 13,40 & 13,41 & 0,43 \\
\hline T4 & N5 & 0,49 & N6 & 0,50 & 253,28 & 6,6 & 100 & 100 & 0,84 & 0,0063 & 0,57 & 13,41 & 12,83 & 0,05 \\
\hline T5 & N6 & 0,50 & N7 & 1,50 & 660,47 & 41,3 & 200 & 200 & 1,31 & 0,0063 & 1,83 & 12,83 & 10,00 & 1,06 \\
\hline T6 & N2 & 3,50 & N7 & 1,50 & 644,10 & 82,3 & 250 & 250 & 1,67 & 0,0063 & 2,32 & 15,12 & 14,80 & 2,67 \\
\hline 77 & N7 & 1,50 & N4 & 1,50 & 253,02 & 10,3 & 100 & 100 & 1,31 & 0,0063 & 1,40 & 14,80 & 13,40 & 0,20 \\
\hline T8 & N3 & 3,50 & $\mathrm{~N} 4$ & 1,50 & 657,18 & 52,9 & 200 & 200 & 1,68 & 0,0063 & 2,98 & 15,12 & 14,14 & 2,21 \\
\hline & & & & Soma & 3639,99 & & & & & & & & & 8,44 \\
\hline
\end{tabular}

4) Resumo do Dimensionamento Otimizado

\begin{tabular}{|c|c|c|c|}
\hline \multicolumn{3}{|c|}{ Potência Dissipada } & Pressurização Inicial \\
\hline Soma & & 8,44 & 36,37 \\
\hline Energia & & $55.452,29$ & $238.957,16$ \\
\hline FA & & 10,60 & 10,60 \\
\hline Sub-Total & $\mathbf{R} \$$ & $97.657,33$ & $420.828,69$ \\
\hline
\end{tabular}

\begin{tabular}{|c|c|c|}
\hline Custos & & Porcentagem \\
\hline Custo de Tubulação $\mathrm{R} \$$ & $732.616,51$ & $53,37 \%$ \\
\hline Custo de Movimento de Terra $R \$$ & $61.986,71$ & $4,52 \%$ \\
\hline Custo de Assentamento $\mathrm{R} \$$ & $9.752,51$ & $0,71 \%$ \\
\hline Custo de Pavimentação $\mathrm{R} \$$ & $49.975,30$ & $3,64 \%$ \\
\hline Custo da Pressurização Inicial $\mathrm{R} \$$ & $420.828,69$ & $30,65 \%$ \\
\hline Custo da Potência Dissipada $\mathrm{R} \$$ & $97.657,33$ & $7,11 \%$ \\
\hline Total Global (Função Objetivo) R\$ & $1.372 .817,06$ & $100,00 \%$ \\
\hline Total Referencial Unitário $\mathbf{R} \$$ & 377,15 & por metro de rede \\
\hline
\end{tabular}


5) Quantitativos e Custos de Implantação das Redes de Abastecimento

\begin{tabular}{|c|c|c|c|c|c|c|c|c|c|}
\hline Trecho & $\begin{array}{l}\text { Locação da } \\
\text { Tubulação }\end{array}$ & $\begin{array}{l}\text { Tipo de } \\
\text { Superfície }\end{array}$ & Tipo de Tráfego & & & & & & \\
\hline $\mathrm{T} 1$ & viario pavimentado & paralelepipedos & - & & & & & & \\
\hline $\mathrm{T} 2$ & viario pavimentado & paralelepipedos & - & & & & & & \\
\hline T3 & viario pavimentado & paralelepipedos & - & & & & & & \\
\hline $\mathrm{T} 4$ & viario pavimentado & paralelepipedos & - & & & & & & \\
\hline T5 & viario pavimentado & paralelepipedos & - & & & & & & \\
\hline T6 & viario pavimentado & paralelepipedos & - & & & & & & \\
\hline 77 & viario pavimentado & paralelepipedos & - & & & & & & \\
\hline T8 & viario pavimentado & paralelepipedos & - & & & & & & \\
\hline \multirow{3}{*}{ Trecho } & \multicolumn{6}{|c|}{ Vala } & \multicolumn{3}{|c|}{ Tubulação } \\
\hline & Largura & $\begin{array}{l}\text { Profundidade } \\
\end{array}$ & Escavação & Reaterro & Bota-Fora & TOTAL & Assentamento & Material & TOTAL \\
\hline & $\mathrm{m}$ & $\mathrm{m}$ & $\mathrm{m}^{3}$ & $\mathrm{~m}^{3}$ & $\mathrm{~m}^{3}$ & $\mathbf{R} \$$ & $\mathrm{R} \$$ & $\mathrm{R} \$$ & $\mathbf{R} \$$ \\
\hline $\mathrm{T} 1$ & 0,75 & 1,40 & 271,40 & 238,92 & 32,48 & $6.481,67$ & $1.330,32$ & $156.519,76$ & $157.850,08$ \\
\hline $\mathrm{T} 2$ & 0,60 & 1,25 & 191,95 & 179,38 & 12,56 & $4.688,29$ & 781,41 & $63.658,15$ & $\begin{array}{l}64.439,56 \\
\end{array}$ \\
\hline T3 & 0,55 & 1,20 & 433,97 & 413,31 & 20,66 & $10.677,19$ & $1.631,59$ & $108.622,08$ & $110.253,67$ \\
\hline $\mathrm{T} 4$ & 0,50 & 1,10 & 139,30 & 137,31 & 1,99 & $3.473,83$ & 386,69 & $12.974,56$ & $13.361,25$ \\
\hline T5 & 0,55 & 1,20 & 435,91 & 415,16 & 20,75 & $10.724,93$ & $1.638,89$ & $109.107,76$ & $110.746,65$ \\
\hline T6 & 0,60 & 1,25 & 483,08 & 451,46 & 31,62 & $11.799,03$ & $1.966,58$ & $160.208,70$ & $162.175,28$ \\
\hline$\pi 7$ & 0,50 & 1,10 & 139,16 & 137,17 & 1,99 & $3.470,27$ & 386,29 & $12.961,24$ & $13.347,54$ \\
\hline \multirow[t]{2}{*}{ T8 } & 0,55 & 1,20 & 433,74 & 413,09 & 20,65 & $10.671,50$ & $1.630,72$ & $108.564,26$ & $110.194,99$ \\
\hline & & & & & Soma & $61.986,71$ & $\begin{array}{ll}\mathrm{R} \$ \quad 9.752,51 \\
\end{array}$ & $\mathrm{R} \$ 732.616,51 \quad \mathrm{R} \$$ & $742.369,02$ \\
\hline \multicolumn{10}{|c|}{ Pavimentação } \\
\hline \multirow{3}{*}{ Trecho } & & & $\mathrm{Va}$ & la & & & & & \\
\hline & Área & $\begin{array}{l}\text { Área de } \\
\text { Concreto }\end{array}$ & $\begin{array}{c}\text { Área de } \\
\text { Paralelepipedos }\end{array}$ & $\begin{array}{l}\text { Área de } \\
\text { Asfalto }\end{array}$ & Área de Binder & $\begin{array}{l}\text { Área de Concreto Astático } \\
\text { Usinado a Quente }\end{array}$ & & & \\
\hline & $\mathrm{m}^{2}$ & $\mathrm{~m}^{2}$ & $\mathrm{~m}^{2}$ & $\mathrm{~m}^{2}$ & $\mathrm{~m}^{2}$ & $\mathrm{~m}^{2}$ & & & \\
\hline $\mathrm{T} 1$ & 193,86 & 0,00 & 193,86 & 0,00 & 0,00 & 0,00 & & & \\
\hline $\mathrm{T} 2$ & 153,56 & 0,00 & 153,56 & 0,00 & 0,00 & 0,00 & & & \\
\hline T3 & 361,64 & 0,00 & 361,64 & 0,00 & 0,00 & 0,00 & & & \\
\hline T4 & 126,64 & 0,00 & 126,64 & 0,00 & 0,00 & 0,00 & & & \\
\hline T5 & 363,26 & 0,00 & 363,26 & 0,00 & 0,00 & 0,00 & & & \\
\hline T6 & 386,46 & 0,00 & 386,46 & 0,00 & 0,00 & 0,00 & & & \\
\hline 77 & 126,51 & 0,00 & 126,51 & 0,00 & 0,00 & 0,00 & & & \\
\hline $\mathrm{T} 8$ & 361,45 & 0,00 & 361,45 & 0,00 & 0,00 & 0,00 & & & \\
\hline \multirow{4}{*}{ Trecho } & \multicolumn{9}{|c|}{ Pavimentação } \\
\hline & \multicolumn{3}{|c|}{ Volume } & \multicolumn{2}{|c|}{ Area } & \multicolumn{4}{|c|}{ Custos } \\
\hline & Macadame Hidáulico & Binder & $\begin{array}{l}\text { Concreto } \\
\text { Asfáltico Usinado } \\
\text { a Quente }\end{array}$ & $\begin{array}{c}\text { Imprimação } \\
\text { Betuminosa } \\
\text { Ligante }\end{array}$ & $\begin{array}{c}\text { Imprimação } \\
\text { Betuminosa } \\
\text { Impermeabiliza } \\
\text { nte }\end{array}$ & Remoção & Recomposição & Transporte & TOTAL \\
\hline & $\mathrm{m}^{3}$ & $\mathrm{~m}^{3}$ & $\mathrm{~m}^{3}$ & $\mathrm{~m}^{2}$ & $\mathrm{~m}^{2}$ & $\mathrm{R} \$$ & $\mathrm{R} \$$ & $\mathrm{R} \$$ & $\mathbf{R} \$$ \\
\hline $\mathrm{T} 1$ & 0,00 & 0,00 & 0,00 & 0,00 & 0,00 & 993,09 & $3.679,58$ & 0,00 & $4.672,67$ \\
\hline $\mathrm{T} 2$ & 0,00 & 0,00 & 0,00 & 0,00 & 0,00 & 786,64 & $2.914,62$ & 0,00 & $3.701,26$ \\
\hline T3 & 0,00 & 0,00 & 0,00 & 0,00 & 0,00 & $1.852,59$ & $6.864,18$ & 0,00 & $8.716,77$ \\
\hline T4 & 0,00 & 0,00 & 0,00 & 0,00 & 0,00 & 648,74 & $2.403,70$ & 0,00 & $3.052,45$ \\
\hline T5 & 0,00 & 0,00 & 0,00 & 0,00 & 0,00 & $1.860,87$ & $6.894,87$ & 0,00 & $8.755,74$ \\
\hline T6 & 0,00 & 0,00 & 0,00 & 0,00 & 0,00 & $1.979,73$ & $7.335,25$ & 0,00 & $9.314,98$ \\
\hline 77 & 0,00 & 0,00 & 0,00 & 0,00 & 0,00 & 648,08 & $2.401,24$ & 0,00 & $3.049,31$ \\
\hline T8 & 0,00 & 0,00 & 0,00 & 0,00 & 0,00 & $1.851,60$ & $6.860,52$ & 0,00 & $8.712,13$ \\
\hline & & & & & Soma & $10.621,34$ & $\mathrm{R} \$ \quad 39.353,96$ & $\mathbf{R} \$$ & $49.975,30$ \\
\hline
\end{tabular}




\section{APÊNDICE E3 - Planilha de Dimensionamento para aumento de $150 \%$ na tubulação de PVC e Viário em Paralelepípedo}

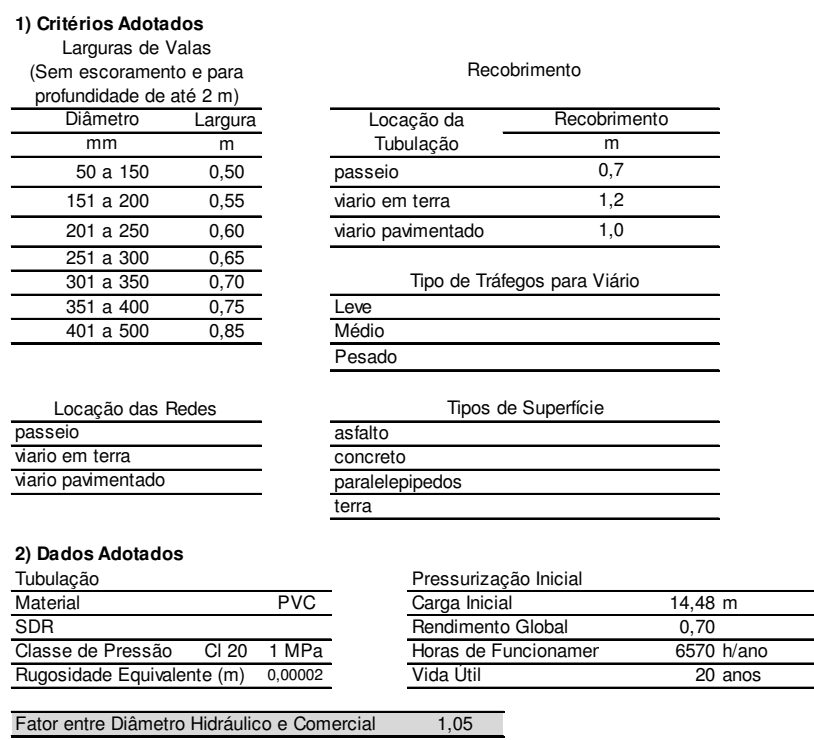

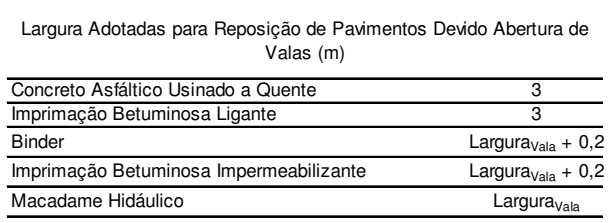

Espessuras Adotadas para Reposição de Pavimentos Devido Abertura de Valas (m)

\begin{tabular}{|c|c|c|c|}
\hline Tráfego & Leve & Médio & Pesado \\
\hline Binder & 0,04 & 0,07 & 0,10 \\
\hline Concreto Asfáltico Usinado a Quente & 0,04 & 0,05 & 0,05 \\
\hline $\begin{array}{l}\text { Macadame Hidáulico } \\
\end{array}$ & 0,10 & 0,12 & 0,15 \\
\hline
\end{tabular}

Energia
\begin{tabular}{ll}
\hline Grupo A (Alta e Média Tensão) \\
\hline Sub-Grupo A4 (2,3 KV a 25 KV) \\
\hline Custo de Energia por Demanda & $31,31 \mathrm{R} \$ / \mathrm{KW}$ \\
\hline Custo de Energia por Consumo & $0,16132 \mathrm{R} \$ / \mathrm{KWh}$ \\
\hline Taxa de Juros & $8,00 \%$ aa \\
\hline Fator de Atualização & 10,60 \\
\hline
\end{tabular}

\begin{tabular}{|c|c|c|c|c|c|c|c|c|c|c|}
\hline \multicolumn{11}{|c|}{ Equações de Continuidade nos Nós } \\
\hline NólTubo & 1 & 2 & 3 & 4 & 5 & 6 & 7 & 8 & Qi & Soma Q \\
\hline & $-179,4$ & & & & & & & & 179,408 & \\
\hline & 179,4 & $-73,5$ & & & & $-82,3$ & & & 23,591 & 0,01 \\
\hline & & 73,5 & & & & & & $-52,9$ & 20,637 & 0,01 \\
\hline & & & $-30,7$ & & & & 10,3 & 52,9 & 32,556 & 0,01 \\
\hline & & & 30,7 & 6,6 & & & & & 37,247 & 0,01 \\
\hline & & & & $-6,6$ & 41,3 & & & & 34,754 & 0,01 \\
\hline & & & & & $-41,3$ & 82,3 & $-10,3$ & & 30,623 & 0,01 \\
\hline
\end{tabular}

\begin{tabular}{|c|c|c|c|c|c|c|c|c|c|}
\hline \multicolumn{10}{|c|}{ Equações de Perda de Carga nos Circuitos } \\
\hline Circuitos & 1 & $\frac{2}{2}$ & 3 & 4 & 5 & 6 & 7 & 8 & Soma Perda \\
\hline 1 & & $-0,736$ & & & & 2,319 & 1,399 & $-2,982$ & 0,0001 \\
\hline 2 & & & $-1,003$ & 0,570 & 1,831 & & $-1,399$ & & $1 \mathrm{E}-04$ \\
\hline
\end{tabular}

Tabela da Função Objetivo

\begin{tabular}{|c|c|c|c|c|c|c|c|c|c|c|c|c|c|c|}
\hline \multirow{2}{*}{ Trecho } & \multicolumn{2}{|c|}{ Nó Montante } & \multicolumn{2}{|c|}{ No Jusante } & \multirow{2}{*}{$\begin{array}{l}\begin{array}{l}\text { Extensão } \\
\text { do Trecho }\end{array} \\
\text { (m) }\end{array}$} & \multirow{2}{*}{$\begin{array}{c}\begin{array}{c}\text { Vazão do } \\
\text { Trecho }\end{array} \\
\text { I/s } \\
\end{array}$} & \multirow{2}{*}{$\begin{array}{c}\begin{array}{c}\text { Diâmetro } \\
\text { Nominal } \\
\text { Comercial }\end{array} \\
(\mathrm{mm})\end{array}$} & \multirow{2}{*}{$\begin{array}{c}\text { Diâmetro } \\
\text { Ótimo }\end{array}$} & \multirow{2}{*}{$\begin{array}{c}\text { Velocidade } \\
(\mathrm{m} / \mathrm{s})\end{array}$} & \multirow{2}{*}{$\begin{array}{l}\text { Fator de } \\
\text { Atrito } f\end{array}$} & \multirow{2}{*}{$\begin{array}{c}\text { Perda de Carga } \\
(\mathrm{m})\end{array}$} & \multirow{2}{*}{$\begin{array}{c}\begin{array}{c}\text { Carga } \\
\text { Montante }\end{array} \\
(\mathrm{m})\end{array}$} & \multirow{2}{*}{$\begin{array}{c}\text { Carga Jusante } \\
(\mathrm{m})\end{array}$} & \multirow{2}{*}{$\begin{array}{c}\text { Potência Dissipada } \\
\mathrm{kW}\end{array}$} \\
\hline & Nome & Cota & Nome & Cota & & & & & & & & & & \\
\hline $\mathrm{T1}$ & $\mathrm{N} 1$ & 4,56 & N2 & 3,50 & 258,48 & 179,4 & 400 & 401 & 1,42 & 0,0063 & 0,42 & 14,48 & 15,12 & 1,06 \\
\hline T2 & N2 & 3,50 & N3 & 3,50 & 255,93 & 73,5 & 250 & 250 & 1,49 & 0,0063 & 0,74 & 15,12 & 14,39 & 0,76 \\
\hline T3 & N4 & 1,50 & N5 & 0,49 & 657,53 & 30,7 & 200 & 200 & 0,97 & 0,0063 & 1,00 & 13,40 & 13,41 & 0,43 \\
\hline T4 & N5 & 0,49 & N6 & 0,50 & 253,28 & 6,6 & 100 & 100 & 0,84 & 0,0063 & 0,57 & 13,41 & 12,83 & 0,05 \\
\hline T5 & N6 & 0,50 & N7 & 1,50 & 660,47 & 41,3 & 200 & 200 & 1,31 & 0,0063 & 1,83 & 12,83 & 10,00 & 1,06 \\
\hline T6 & N2 & 3,50 & N7 & 1,50 & 644,10 & 82,3 & 250 & 250 & 1,67 & 0,0063 & 2,32 & 15,12 & 14,80 & 2,67 \\
\hline 77 & N7 & 1,50 & $\mathrm{~N} 4$ & 1,50 & 253,02 & 10,3 & 100 & 100 & 1,31 & 0,0063 & 1,40 & 14,80 & 13,40 & 0,20 \\
\hline T8 & N3 & 3,50 & N4 & 1,50 & 657,18 & 52,9 & 200 & 200 & 1,68 & 0,0063 & 2,98 & 15,12 & 14,14 & 2,21 \\
\hline
\end{tabular}

4) Resumo do Dimensionamento Otimizado

\begin{tabular}{|c|c|c|c|}
\hline \multicolumn{3}{|c|}{ Potência Dissipada } & Pressurização Inicial \\
\hline Soma & & 8,44 & 36,37 \\
\hline Energia & & $55.452,29$ & $238.957,16$ \\
\hline FA & & 10,60 & 10,60 \\
\hline Sub-Total & $\mathbf{R} \$$ & $97.657,33$ & $420.828,69$ \\
\hline
\end{tabular}

\begin{tabular}{|c|c|c|}
\hline Custos & & Porcentagem \\
\hline Custo de Tubulação $\mathrm{R} \$$ & $813.409,32$ & $55,96 \%$ \\
\hline Custo de Movimento de Terra $R \$$ & $61.986,71$ & $4,26 \%$ \\
\hline Custo de Assentamento $\mathrm{R} \$$ & $9.752,51$ & $0,67 \%$ \\
\hline Custo de Pavimentação $\mathrm{R} \$$ & $49.975,30$ & $3,44 \%$ \\
\hline Custo da Pressurização Inicial $\mathrm{R} \$$ & $420.828,69$ & $28,95 \%$ \\
\hline Custo da Potência Dissipada $\mathrm{R} \$$ & $97.657,33$ & $6,72 \%$ \\
\hline Total Global (Função Objetivo) R\$ & $\mathbf{1 . 4 5 3 . 6 0 9 , 8 7}$ & $100,00 \%$ \\
\hline Total Referencial Unitário $\mathbf{R} \$$ & 399,34 & por metro de rede \\
\hline
\end{tabular}


5) Quantitativos e Custos de Implantação das Redes de Abastecimento

\begin{tabular}{|c|c|c|c|c|c|c|c|c|c|}
\hline Trecho & $\begin{array}{l}\text { Locação da } \\
\text { Tubulação }\end{array}$ & $\begin{array}{c}\text { Tipo de } \\
\text { Superfície }\end{array}$ & Tipo de Tráfego & & & & & & \\
\hline $\mathrm{T} 1$ & viario pavimentado & paralelepipedos & - & & & & & & \\
\hline $\mathrm{T} 2$ & viario pavimentado & paralelepipedos & - & & & & & & \\
\hline T3 & viario pavimentado & paralelepipedos & - & & & & & & \\
\hline T4 & viario pavimentado & paralelepipedos & - & & & & & & \\
\hline T5 & viario pavimentado & paralelepipedos & - & & & & & & \\
\hline T6 & viario pavimentado & paralelepipedos & - & & & & & & \\
\hline 77 & viario pavimentado & paralelepipedos & - & & & & & & \\
\hline \multirow[t]{2}{*}{ T8 } & viario pavimentado & paralelepipedos & - & & & & & & \\
\hline & \multicolumn{6}{|c|}{ Vala } & \multicolumn{3}{|c|}{ Tubulação } \\
\hline \multirow[t]{2}{*}{ Trecho } & Largura & Profundidade & Escavação & Reaterro & Bota-Fora & TOTAL & Assentamento & Material & TOTAL \\
\hline & $\mathrm{m}$ & $\mathrm{m}$ & $\mathrm{m}^{3}$ & $\mathrm{~m}^{3}$ & $\mathrm{~m}^{3}$ & $\mathrm{R} \$$ & $\mathrm{R} \$$ & $\mathrm{R} \$$ & $\mathrm{R} \$$ \\
\hline $\mathrm{T} 1$ & 0,75 & 1,40 & 271,40 & 238,92 & 32,48 & $6.481,67$ & $1.330,32$ & $173.772,53$ & $175.102,85$ \\
\hline $\mathrm{T} 2$ & 0,60 & 1,25 & 191,95 & 179,38 & 12,56 & $4.688,29$ & 781,41 & $70.677,67$ & $71.459,08$ \\
\hline T3 & 0,55 & 1,20 & 433,97 & 413,31 & 20,66 & $10.677,19$ & $1.631,59$ & $120.602,95$ & $122.234,54$ \\
\hline T4 & 0,50 & 1,10 & 139,30 & 137,31 & 1,99 & $3.473,83$ & 386,69 & $14.407,62$ & $14.794,31$ \\
\hline T5 & 0,55 & 1,20 & 435,91 & 415,16 & 20,75 & $10.724,93$ & $1.638,89$ & $121.142,20$ & $122.781,09$ \\
\hline T6 & 0,60 & 1,25 & 483,08 & 451,46 & 31,62 & $11.799,03$ & $1.966,58$ & $177.874,77$ & $179.841,35$ \\
\hline 77 & 0,50 & 1,10 & 139,16 & 137,17 & 1,99 & $3.470,27$ & 386,29 & $14.392,83$ & $14.779,13$ \\
\hline \multirow[t]{4}{*}{$\mathrm{T} 8$} & 0,55 & 1,20 & 433,74 & 413,09 & 20,65 & $10.671,50$ & $1.630,72$ & $120.538,75$ & $122.169,48$ \\
\hline & & & & & Soma & $61.986,71$ & $9.752,51$ & $\mathrm{R} \$ 813.409,32 \quad \mathrm{R} \$$ & $823.161,83$ \\
\hline & \multirow{2}{*}{\multicolumn{6}{|c|}{$\begin{array}{l}\text { Pavimentação } \\
\text { Vala }\end{array}$}} & & & \\
\hline & & & & & & & & & \\
\hline \multirow[t]{2}{*}{ Trecho } & Área & $\begin{array}{l}\text { Área de } \\
\text { Concreto }\end{array}$ & $\begin{array}{c}\text { Área de } \\
\text { Paralelepipedos }\end{array}$ & $\begin{array}{l}\text { Área de } \\
\text { Asfalto }\end{array}$ & Área de Binder & $\begin{array}{l}\text { Area de Concreto Asfático } \\
\text { Usinado a Quente }\end{array}$ & & & \\
\hline & $\mathrm{m}^{2}$ & $\mathrm{~m}^{2}$ & $\mathrm{~m}^{2}$ & $\mathrm{~m}^{2}$ & $\mathrm{~m}^{2}$ & $\mathrm{~m}^{2}$ & & & \\
\hline $\mathrm{T} 1$ & 193,86 & 0,00 & 193,86 & 0,00 & 0,00 & 0,00 & & & \\
\hline $\mathrm{T} 2$ & 153,56 & 0,00 & 153,56 & 0,00 & 0,00 & 0,00 & & & \\
\hline T3 & 361,64 & 0,00 & 361,64 & 0,00 & 0,00 & 0,00 & & & \\
\hline T4 & 126,64 & 0,00 & 126,64 & 0,00 & 0,00 & 0,00 & & & \\
\hline T5 & 363,26 & 0,00 & 363,26 & 0,00 & 0,00 & 0,00 & & & \\
\hline T6 & 386,46 & 0,00 & 386,46 & 0,00 & 0,00 & 0,00 & & & \\
\hline 77 & 126,51 & 0,00 & 126,51 & 0,00 & 0,00 & 0,00 & & & \\
\hline T8 & 361,45 & 0,00 & 361,45 & 0,00 & 0,00 & 0,00 & & & \\
\hline
\end{tabular}

\begin{tabular}{|c|c|c|c|c|c|c|c|c|c|}
\hline \multirow{4}{*}{ Trecho } & \multicolumn{9}{|c|}{ Pavimentação } \\
\hline & \multicolumn{3}{|c|}{ Volume } & \multicolumn{2}{|c|}{ Área } & \multicolumn{4}{|c|}{ Custos } \\
\hline & Macadame Hidáulico & Binder & $\begin{array}{l}\text { Concreto } \\
\text { Astáltico Usinado } \\
\text { a Quente }\end{array}$ & $\begin{array}{l}\text { Imprimação } \\
\text { Betuminosa } \\
\text { Ligante }\end{array}$ & $\begin{array}{l}\text { Imprimação } \\
\text { Betuminosa } \\
\text { Impermeabiliza } \\
\text { nte }\end{array}$ & Remoção & Recomposição & Transporte & TOTAL \\
\hline & $\mathrm{m}^{3}$ & $\mathrm{~m}^{3}$ & $\mathrm{~m}^{3}$ & $\mathrm{~m}^{2}$ & $\mathrm{~m}^{2}$ & $\mathrm{R} \$$ & $\mathrm{R} \$$ & $\mathrm{R} \$$ & $\mathrm{R} \$$ \\
\hline $\mathrm{T} 1$ & 0,00 & 0,00 & 0,00 & 0,00 & 0,00 & 993,09 & $3.679,58$ & 0,00 & $4.672,67$ \\
\hline $\mathrm{T} 2$ & 0,00 & 0,00 & 0,00 & 0,00 & 0,00 & 786,64 & $2.914,62$ & 0,00 & $3.701,26$ \\
\hline T3 & 0,00 & 0,00 & 0,00 & 0,00 & 0,00 & $1.852,59$ & $6.864,18$ & 0,00 & $8.716,77$ \\
\hline T4 & 0,00 & 0,00 & 0,00 & 0,00 & 0,00 & 648,74 & $2.403,70$ & 0,00 & $3.052,45$ \\
\hline T5 & 0,00 & 0,00 & 0,00 & 0,00 & 0,00 & $1.860,87$ & $6.894,87$ & 0,00 & $8.755,74$ \\
\hline T6 & 0,00 & 0,00 & 0,00 & 0,00 & 0,00 & $1.979,73$ & $7.335,25$ & 0,00 & $9.314,98$ \\
\hline 77 & 0,00 & 0,00 & 0,00 & 0,00 & 0,00 & 648,08 & $2.401,24$ & 0,00 & $3.049,31$ \\
\hline T8 & 0,00 & 0,00 & 0,00 & 0,00 & 0,00 & $1.851,60$ & $6.860,52$ & 0,00 & $8.712,13$ \\
\hline
\end{tabular}




\section{APÊNDICE E4 - Planilha de Dimensionamento para aumento de $175 \%$ na tubulação de PVC e Viário em Paralelepípedo}

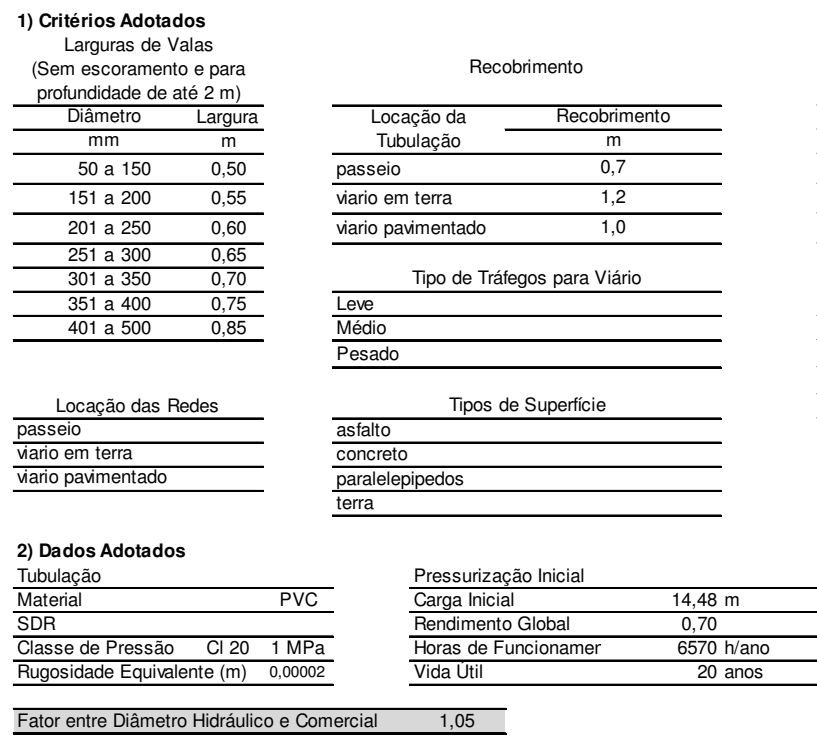

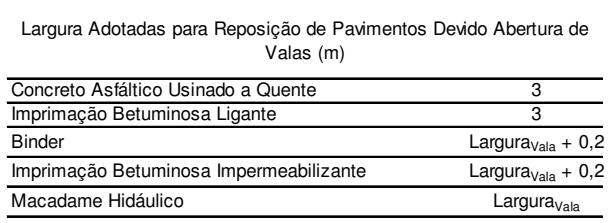

Espessuras Adotadas para Reposição de Pavimentos Devido Abertura de Valas (m)

\begin{tabular}{|c|c|c|c|}
\hline Tráfego & Leve & Médio & Pesado \\
\hline Binder & 0,04 & 0,07 & 0,10 \\
\hline Concreto Asfáltico Usinado a Quente & 0,04 & 0,05 & 0,05 \\
\hline $\begin{array}{l}\text { Macadame Hidáulico } \\
\end{array}$ & 0,10 & 0,12 & 0,15 \\
\hline
\end{tabular}
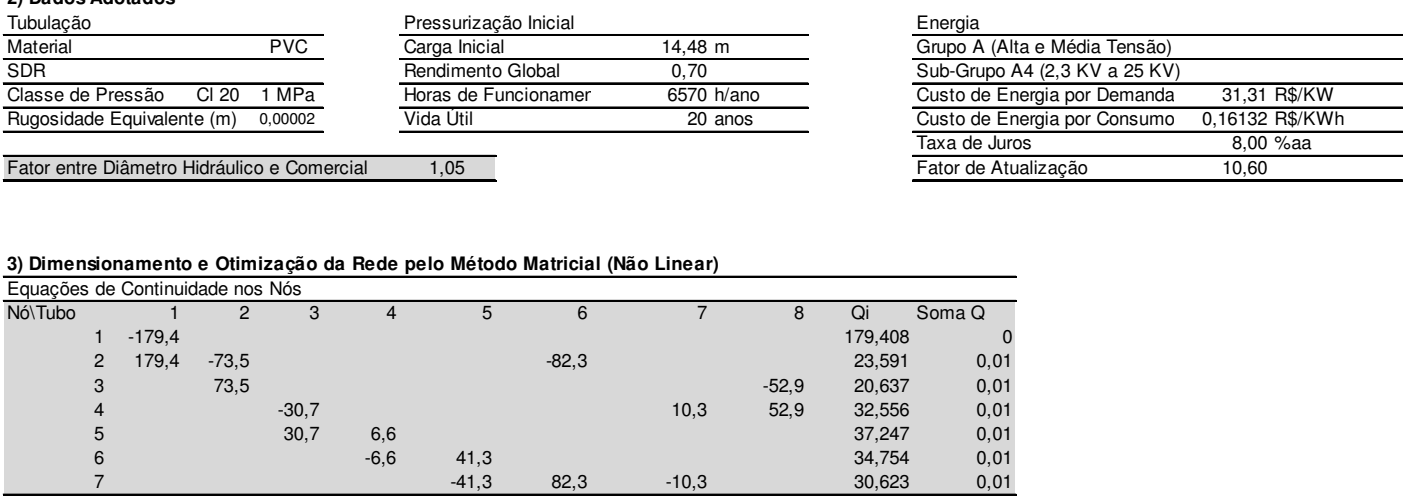

\begin{tabular}{cccccccccr}
\hline Equações de Perda de Carga nos Circuitos & & & & & & \\
\hline & 1 & 2 & 3 & 4 & 5 & 6 & 7 & 8 & Soma Perda \\
1 & $-0,736$ & & & & 2,319 & 1,399 & $-2,982$ & 0,0001 \\
2 & & & & & & & & \\
2 & & $-1,003$ & 0,570 & 1,831 & & $-1,399$ & & 1 E- 04 \\
\hline
\end{tabular}

Tabela da Função Objetivo

\begin{tabular}{|c|c|c|c|c|c|c|c|c|c|c|c|c|c|c|}
\hline \multirow{2}{*}{ Trecho } & \multicolumn{2}{|c|}{ Nó Montante } & \multicolumn{2}{|c|}{ No Jusante } & \multirow{2}{*}{$\begin{array}{c}\begin{array}{c}\text { Extensão } \\
\text { do Trecho }\end{array} \\
\text { (m) }\end{array}$} & \multirow{2}{*}{$\begin{array}{c}\begin{array}{c}\text { Vazão do } \\
\text { Trecho }\end{array} \\
\text { I/s } \\
\end{array}$} & \multirow{2}{*}{$\begin{array}{c}\begin{array}{c}\text { Diâmetro } \\
\text { Nominal } \\
\text { Comercial }\end{array} \\
(\mathrm{mm})\end{array}$} & \multirow{2}{*}{$\begin{array}{c}\begin{array}{c}\text { Diâmetro } \\
\text { Ótimo }\end{array} \\
(\mathrm{mm}) \\
\end{array}$} & \multirow{2}{*}{$\begin{array}{l}\text { Velocidade } \\
(\mathrm{m} / \mathrm{s})\end{array}$} & \multirow{2}{*}{$\begin{array}{l}\text { Fator de } \\
\text { Atrito } f\end{array}$} & \multirow{2}{*}{$\begin{array}{c}\text { Perda de Carga } \\
(\mathrm{m})\end{array}$} & \multirow{2}{*}{$\begin{array}{c}\begin{array}{c}\text { Carga } \\
\text { Montante }\end{array} \\
(\mathrm{m})\end{array}$} & \multirow{2}{*}{$\begin{array}{c}\text { Carga Jusante } \\
(\mathrm{m})\end{array}$} & \multirow{2}{*}{$\begin{array}{c}\text { Potência Dissipada } \\
\text { kW }\end{array}$} \\
\hline & Nome & Cota & Nome & Cota & & & & & & & & & & \\
\hline T1 & $\mathrm{N} 1$ & 4,56 & N2 & 3,50 & 258,48 & 179,4 & 400 & 400 & 1,42 & 0,0063 & 0,42 & 14,48 & 15,12 & 1,06 \\
\hline T2 & N2 & 3,50 & N3 & 3,50 & 255,93 & 73,5 & 250 & 250 & 1,49 & 0,0063 & 0,74 & 15,12 & 14,39 & 0,76 \\
\hline T3 & $\mathrm{N} 4$ & 1,50 & N5 & 0,49 & 657,53 & 30,7 & 200 & 200 & 0,97 & 0,0063 & 1,00 & 13,40 & 13,41 & 0,43 \\
\hline T4 & N5 & 0,49 & N6 & 0,50 & 253,28 & 6,6 & 100 & 80 & 0,84 & 0,0063 & 0,57 & 13,41 & 12,83 & 0,05 \\
\hline T5 & N6 & 0,50 & N7 & 1,50 & 660,47 & 41,3 & 200 & 200 & 1,31 & 0,0063 & 1,83 & 12,83 & 10,00 & 1,06 \\
\hline T6 & N2 & 3,50 & N7 & 1,50 & 644,10 & 82,3 & 250 & 250 & 1,67 & 0,0063 & 2,32 & 15,12 & 14,80 & 2,67 \\
\hline 77 & N7 & 1,50 & $\mathrm{~N} 4$ & 1,50 & 253,02 & 10,3 & 100 & 100 & 1,31 & 0,0063 & 1,40 & 14,80 & 13,40 & 0,20 \\
\hline T8 & N3 & 3,50 & $\mathrm{~N} 4$ & 1,50 & 657,18 & 52,9 & 200 & 200 & 1,68 & 0,0063 & 2,98 & 15,12 & 14,14 & 2,21 \\
\hline
\end{tabular}

4) Resumo do Dimensionamento Otimizado

\begin{tabular}{|c|c|c|c|}
\hline \multicolumn{3}{|c|}{ Potência Dissipada } & Pressurização Inicial \\
\hline Soma & & 8,44 & 36,37 \\
\hline Energia & & $55.452,29$ & $238.957,16$ \\
\hline FA & & 10,60 & 10,60 \\
\hline Sub-Total & $\mathbf{R} \$$ & $97.657,33$ & $420.828,69$ \\
\hline
\end{tabular}

\begin{tabular}{|c|c|c|}
\hline Custos & & Porcentagem \\
\hline Custo de Tubulação $\mathrm{R} \$$ & $894.209,87$ & $58,28 \%$ \\
\hline Custo de Movimento de Terra $R \$$ & $61.986,71$ & $4,04 \%$ \\
\hline Custo de Assentamento $\mathrm{R} \$$ & $9.752,51$ & $0,64 \%$ \\
\hline Custo de Pavimentação $\mathrm{R} \$$ & $49.975,30$ & $3,26 \%$ \\
\hline Custo da Pressurização Inicial $\mathrm{R} \$$ & $420.828,69$ & $27,43 \%$ \\
\hline Custo da Potência Dissipada $\mathrm{R} \$$ & $97.657,33$ & $6,36 \%$ \\
\hline Total Global (Função Objetivo) R\$ & $1.534 .410,42$ & $100,00 \%$ \\
\hline Total Referencial Unitário $\mathbf{R} \$$ & 421,54 & por metro de rede \\
\hline
\end{tabular}


5) Quantitativos e Custos de Implantação das Redes de Abastecimento

\begin{tabular}{|c|c|c|c|c|c|c|c|c|c|}
\hline Trecho & $\begin{array}{l}\text { Locação da } \\
\text { Tubulação }\end{array}$ & $\begin{array}{l}\text { Tipo de } \\
\text { Superfície }\end{array}$ & Tipo de Tráfego & & & & & & \\
\hline $\mathrm{T} 1$ & viario pavimentado & paralelepipedos & - & & & & & & \\
\hline $\mathrm{T} 2$ & viario pavimentado & paralelepipedos & - & & & & & & \\
\hline T3 & vario pavimentado & paralelepipedos & - & & & & & & \\
\hline T4 & vario pavimentado & paralelepipedos & - & & & & & & \\
\hline $\mathrm{T5}$ & viario pavimentado & paralelepipedos & - & & & & & & \\
\hline T6 & viario pavimentado & paralelepipedos & - & & & & & & \\
\hline 77 & viario pavimentado & paralelepipedos & - & & & & & & \\
\hline \multirow[t]{2}{*}{ T8 } & viario pavimentado & paralelepipedos & - & & & & & & \\
\hline & \multicolumn{6}{|c|}{ Vala } & \multicolumn{3}{|c|}{ Tubulação } \\
\hline \multirow[t]{2}{*}{ Trecho } & Largura & $\begin{array}{l}\text { Profundidade } \\
\end{array}$ & Escavação & Reaterro & Bota-Fora & TOTAL & Assentamento & Material & TOTAL \\
\hline & $\mathrm{m}$ & $\mathrm{m}$ & $\mathrm{m}^{3}$ & $\mathrm{~m}^{3}$ & $\mathrm{~m}^{3}$ & $\mathbf{R} \$$ & $\mathrm{R} \$$ & $\mathrm{R} \$$ & $\mathbf{R} \$$ \\
\hline $\mathrm{T} 1$ & 0,75 & 1,40 & 271,40 & 238,92 & 32,48 & $6.481,67$ & $1.330,32$ & $191.026,33$ & $192.356,66$ \\
\hline $\mathrm{T} 2$ & 0,60 & 1,25 & 191,95 & 179,38 & 12,56 & $4.688,29$ & 781,41 & $77.697,84$ & $78.479,25$ \\
\hline T3 & 0,55 & 1,20 & 433,97 & 413,31 & 20,66 & $10.677,19$ & $1.631,59$ & $132.585,13$ & $134.216,72$ \\
\hline T4 & 0,50 & 1,10 & 139,30 & 137,31 & 1,99 & $3.473,83$ & 386,69 & $15.840,94$ & $16.227,63$ \\
\hline T5 & 0,55 & 1,20 & 435,91 & 415,16 & 20,75 & $10.724,93$ & $1.638,89$ & $133.177,96$ & $134.816,84$ \\
\hline T6 & 0,60 & 1,25 & 483,08 & 451,46 & 31,62 & $11.799,03$ & $1.966,58$ & $195.542,44$ & $197.509,02$ \\
\hline 77 & 0,50 & 1,10 & 139,16 & 137,17 & 1,99 & $3.470,27$ & 386,29 & $15.824,68$ & $16.210,97$ \\
\hline \multirow[t]{2}{*}{$\mathrm{T} 8$} & 0,55 & 1,20 & 433,74 & 413,09 & 20,65 & $10.671,50$ & $1.630,72$ & $132.514,56$ & $134.145,28$ \\
\hline & & & & & Soma & $61.986,71$ & $9.752,51$ & $\mathrm{R} \$ 894.209,87 \quad \mathrm{R} \$$ & $903.962,39$ \\
\hline \multicolumn{10}{|c|}{$\frac{\text { Pavimentação }}{\text { Vala }}$} \\
\hline & & & $\mathrm{V}$ & & & & & & \\
\hline \multirow[t]{2}{*}{ Trecho } & Área & $\begin{array}{l}\text { Área de } \\
\text { Concreto }\end{array}$ & $\begin{array}{c}\text { Área de } \\
\text { Paralelepipedos }\end{array}$ & $\begin{array}{l}\text { Área de } \\
\text { Asfalto }\end{array}$ & Área de Binder & $\begin{array}{l}\text { Area de Concreto Astático } \\
\text { Usinado a Quente }\end{array}$ & & & \\
\hline & $\mathrm{m}^{2}$ & $\mathrm{~m}^{2}$ & $\mathrm{~m}^{2}$ & $\mathrm{~m}^{2}$ & $\mathrm{~m}^{2}$ & $\mathrm{~m}^{2}$ & & & \\
\hline $\mathrm{T} 1$ & 193,86 & 0,00 & 193,86 & 0,00 & 0,00 & 0,00 & & & \\
\hline $\mathrm{T} 2$ & 153,56 & 0,00 & 153,56 & 0,00 & 0,00 & 0,00 & & & \\
\hline T3 & 361,64 & 0,00 & 361,64 & 0,00 & 0,00 & 0,00 & & & \\
\hline T4 & 126,64 & 0,00 & 126,64 & 0,00 & 0,00 & 0,00 & & & \\
\hline T5 & 363,26 & 0,00 & 363,26 & 0,00 & 0,00 & 0,00 & & & \\
\hline T6 & 386,46 & 0,00 & 386,46 & 0,00 & 0,00 & 0,00 & & & \\
\hline 77 & 126,51 & 0,00 & 126,51 & 0,00 & 0,00 & 0,00 & & & \\
\hline T8 & 361,45 & 0,00 & 361,45 & 0,00 & 0,00 & 0,00 & & & \\
\hline
\end{tabular}

\begin{tabular}{|c|c|c|c|c|c|c|c|c|c|}
\hline \multirow{4}{*}{ Trecho } & \multicolumn{9}{|c|}{ Pavimentação } \\
\hline & \multicolumn{3}{|c|}{ Volume } & \multicolumn{2}{|c|}{ Área } & \multicolumn{4}{|c|}{ Custos } \\
\hline & Macadame Hidáulico & Binder & $\begin{array}{l}\text { Concreto } \\
\text { Astáltico Usinado } \\
\text { a Quente }\end{array}$ & $\begin{array}{l}\text { Imprimação } \\
\text { Betuminosa } \\
\text { Ligante }\end{array}$ & $\begin{array}{l}\text { Imprimação } \\
\text { Betuminosa } \\
\text { Impermeabiliza } \\
\text { nte }\end{array}$ & Remoção & Recomposição & Transporte & TOTAL \\
\hline & $\mathrm{m}^{3}$ & $\mathrm{~m}^{3}$ & $\mathrm{~m}^{3}$ & $\mathrm{~m}^{2}$ & $\mathrm{~m}^{2}$ & $\mathrm{R} \$$ & $\mathrm{R} \$$ & $\mathrm{R} \$$ & $\mathrm{R} \$$ \\
\hline $\mathrm{T} 1$ & 0,00 & 0,00 & 0,00 & 0,00 & 0,00 & 993,09 & $3.679,58$ & 0,00 & $4.672,67$ \\
\hline $\mathrm{T} 2$ & 0,00 & 0,00 & 0,00 & 0,00 & 0,00 & 786,64 & $2.914,62$ & 0,00 & $3.701,26$ \\
\hline T3 & 0,00 & 0,00 & 0,00 & 0,00 & 0,00 & $1.852,59$ & $6.864,18$ & 0,00 & $8.716,77$ \\
\hline T4 & 0,00 & 0,00 & 0,00 & 0,00 & 0,00 & 648,74 & $2.403,70$ & 0,00 & $3.052,45$ \\
\hline T5 & 0,00 & 0,00 & 0,00 & 0,00 & 0,00 & $1.860,87$ & $6.894,87$ & 0,00 & $8.755,74$ \\
\hline T6 & 0,00 & 0,00 & 0,00 & 0,00 & 0,00 & $1.979,73$ & $7.335,25$ & 0,00 & $9.314,98$ \\
\hline 77 & 0,00 & 0,00 & 0,00 & 0,00 & 0,00 & 648,08 & $2.401,24$ & 0,00 & $3.049,31$ \\
\hline T8 & 0,00 & 0,00 & 0,00 & 0,00 & 0,00 & $1.851,60$ & $6.860,52$ & 0,00 & $8.712,13$ \\
\hline
\end{tabular}

